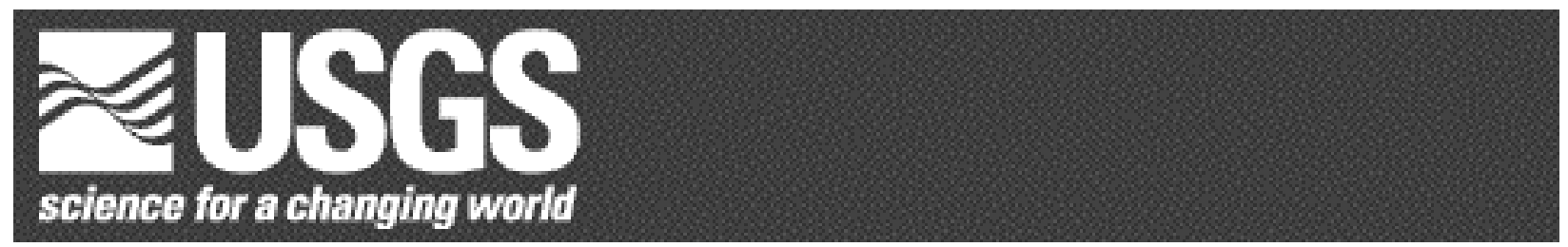

\title{
Earthquake Probabilities in the San Francisco Bay Region: 2002-2031
}

By Working Group On California Earthquake Probabilities

Open-File Report 03-214

2003

This report is preliminary and has not been reviewed for conformity with U.S. Geological Survey editorial standards or with the North American Stratigraphic Code. Any use of trade, firm, or product names is for descriptive purposes only and does not imply endorsement by the U.S. Government. 


\section{Table of Contents}

Executive Summary

Participants in the Working Group process

Chapter 1: Introduction

Chapter 2: $\quad$ Models, methods, and things that matter

Chapter 3: Characterization of the SFBR earthquake sources

Chapter 4: The SFBR earthquake source model: Magnitudes and long-term rates

Chapter 5: Calculating earthquake probabilities for the SFBR

Chapter 6. Earthquake probabilities for the SFBR 2002-2031: Results and discussion

Chapter 7: Implications for earthquake hazard in the SFBR

Chapter 8: $\quad$ Reflections and future directions

References

Appendix A: Implications of the depth of seismicity for the rupture extent of future earthquakes in the SFBA

Appendix B: The seismogenic scaling factor, $\mathrm{R}$

Appendix C: R-factors inferred from geodetic modeling

Appendix D: Magnitude and area data for strike slip earthquakes

Appendix E: Moment released in aftershocks

Appendix F: Estimated changes in state on SFBR faults resulting from the 1906 and 1989 earthquakes

Appendix G: Moment-balancing procedure 


\section{EXECUTIVE SUMMARY}

Drawing on new data and new methodologies, we have concluded that there is a 0.62 probability (i.e., a $62 \%$ probability) of a major, damaging earthquake striking the greater San Francisco Bay Region (SFBR) over the next 30 years (2002-2031). Such earthquakes are most likely to occur on seven main fault systems identified in this study, but may also occur on faults that were not characterized as part of the study (i.e., in the "background") (Figure ES.1). Our results come from a comprehensive analysis lead by the USGS and involving input from a broad group of geologists, seismologists, and other earth scientists representing government, academia and the private sector. The results of this study are appropriate for use in estimating seismic hazard in the SFBR, and estimating the intensity of ground shaking expected for specified "scenario" earthquakes. In addition, they provide a basis for calculating earthquake insurance premiums, planning and prioritizing expenditures for seismic upgrades of structures, and developing building codes.

\section{Introduction}

Earthquakes in the San Francisco Bay Region result from strain energy constantly accumulating across the region because of the northwestward motion of the Pacific Plate relative to the North American Plate (Figure ES.2). The region experienced large and destructive earthquakes in 1838, 1868, 1906, and 1989, and future large earthquakes to relieve this continually accumulating strain are a certainty. For our study we define the SFBR as extending from Healdsburg on the northwest to Salinas on the southeast. It encloses the entire metropolitan area, including its most rapidly expanding urban and suburban areas. We have used the term "major" earthquake as one with $\mathbf{M} \geq 6.7$ (where $\mathbf{M}$ is moment magnitude). As experience from recent earthquakes in Northridge, California (M6.7, 1994, 20 killed, \$20B in direct losses) and Kobe, Japan (M6.9, 1995, 5500 killed, \$147B in direct losses), earthquakes of this size can have a profound impact on the social and economic fabric of densely urbanized areas.

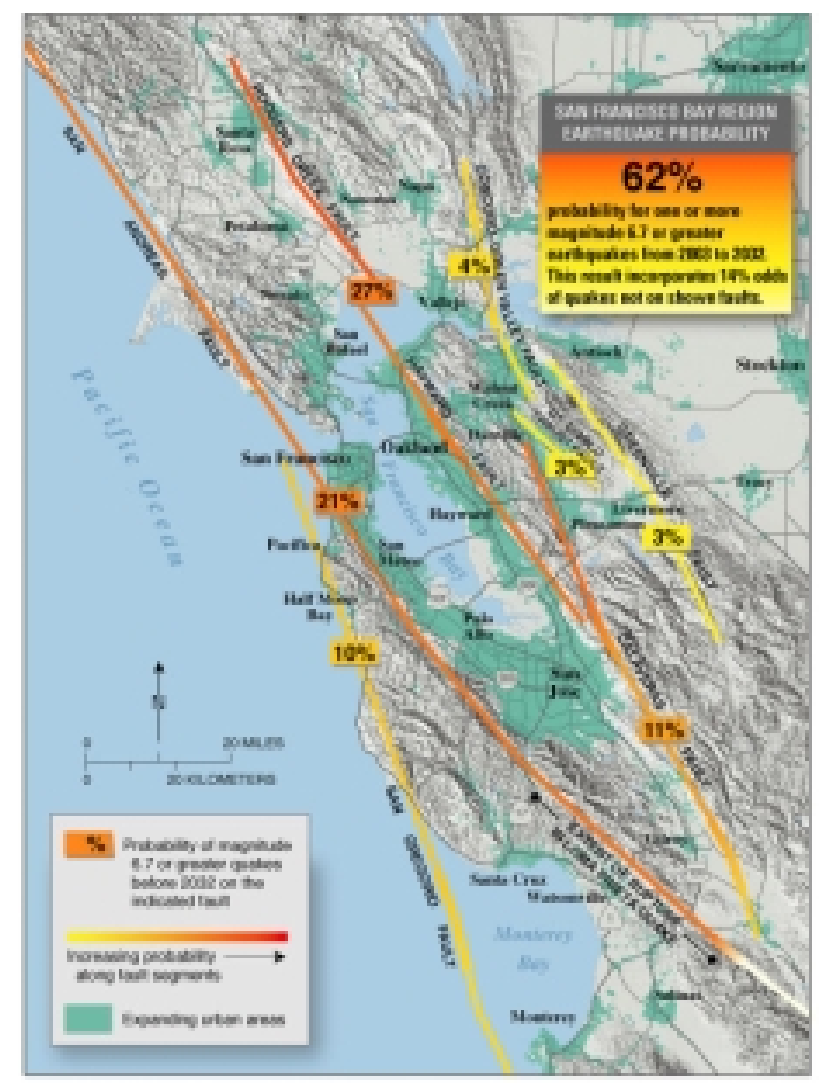

Figure ES.1. Probabilities of one or more major $(M \geq 6.7)$ earthquakes on faults in the San Francisco Bay Region during the coming 30 years. Color indicates the probability that each fault segment will rupture in such a quake. 


\section{Working Group probability study}

To evaluate the probability of future large earthquakes in the San Francisco Bay Region, the U.S. Geological Survey has established a series of Working Groups on California Earthquake Probabilities (hereafter referred to as WG88, WG90, WG99). Each of these Working Groups has expanded on the work of its predecessors, applying, in turn, the data and methodology available at the time and drawing on input from broad cross-sections of the earth science community.

WG88 and WG90 established a framework for estimating earthquake probabilities based on simple physical models for the San Andreas and Hayward faults in the Bay Area, and on the San Andreas, San Jacinto, and Imperial Faults in southern California. WG99 extended this framework into a more comprehensive, regional one for the SFBR based on a greatly expanded set of geological and geophysical observations. In its calculations, WG99 combined the results of multiple viable models when a single consensus model did not exist. Summaries of WG99 methods and results were published in 1999 on the tenth anniversary of the Loma Prieta earthquake, as U.S. Geological Survey Open-File Report 99-517, and USGS Fact Sheet 151-99.

The present study (hereafter referred to as WG02) is a continuation and extension of WG99 and updates the results of that study. WG02 adopts the basic framework used by WG99 and expands on it by:

- incorporating additional data;

- more fully analyzing the possible effects of the 1906 earthquake (the "stress-shadow" effect) on the current earthquake potential in the SFBR;

- more fully developing the uncertainties associated with the calculated probabilities;

- exploring some of the implications for earthquake hazard in SFBR;
- making available a full documentation of the methods and computer codes used ${ }^{1}$.

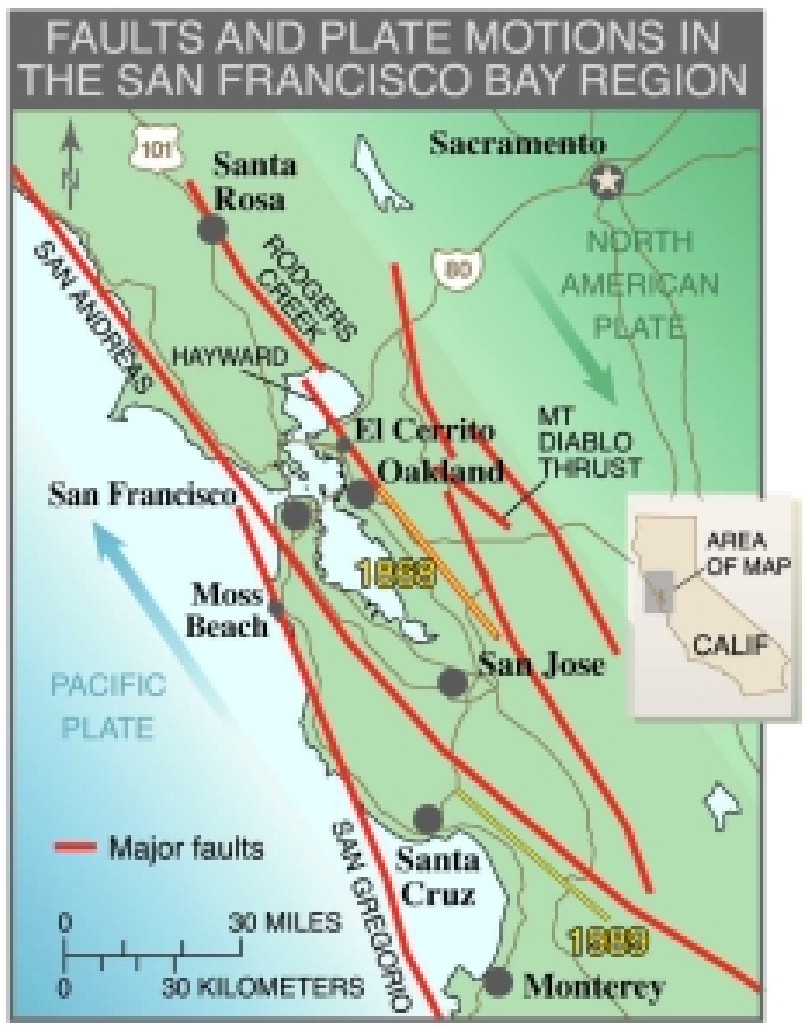

Figure ES.2. Faults and plate motions in the San Francisco Bay Region. Faults in the region, principally the seven faults shown here and characterized in this report, accommodate about $40 \mathrm{~mm} / \mathrm{yr}$ of mostly strike-slip motion between the Pacific and North American tectonic plates. Yellow lines show the locations of the 1868 M6.8 earthquake on the southern portion of the Hayward Fault and the 1989 M6.9 Loma Prieta earthquake near the San Andreas fault northeast of Monterey Bay.

\section{Broadened modeling approach}

This WG02 report builds on previous analyses of earthquake likelihood, modifying some of the methodologies used in those studies and introducing new ones. The earthquake probabilities presented here are the product of model calculations consisting of three basic elements. The first element is the SFBR earthquake model, which determines the average magnitudes and long-term rates of occurrence

\footnotetext{
${ }^{1}$ Computer codes will be released in a separate USGS publication.
} 
of earthquakes on the principal faults and for the region as a whole. These average long-term rates of earthquakes lead to average, timeindependent probabilities of earthquakes at or above a particular magnitude level of interest (e.g., $\mathbf{M} \geq 6.7$ ).

The second element consists of a suite of time-dependent earthquake probability models, which incorporate physical aspects of the causes and effects of earthquakes that vary with time. The two most important of these are the progression of faults through the "earthquake cycle" and the interactions of faults, through which the stress released by an earthquake on one fault is transferred in part to other faults or adjacent fault segments. The most significant interaction effect - that produced by the 1906 earthquake-figures prominently in the modeling. There is no consensus within the earth science community, or within this Working Group, as to whether the SFBR remains within the 1906 stress shadow (as suggested by seismicity data for the past 96 years), is now emerging from it (as suggested by the occurrence of the Loma Prieta earthquake and by calculations based on models of viscous flow in the lower crust and mantle), or has emerged from it (as suggested by simple elastic fault interaction models). The addition of a suite of probability models to represent this range of thinking represents the most substantial difference between the analysis reported by WG99 and that reported here.

The third new element introduced in our calculations is the characterization of the rate of occurrence of "background" earth-

quakes - earthquakes in the Bay region that do not occur on the principal faults. The probability for these events is based on seismicity rates known since 1836, extrapolated to $\mathbf{M} \geq 6.7$ events. Background earthquakes include events such as the September 2001 M5.1 Napa earthquake, and the 1989 M6.9 Loma Prieta earthquake.

WG02 has devoted considerable effort to defining and quantifying uncertainties in all data, models, and parameters used in the analysis. In the calculations, estimates of uncertainty from all parts of the model are carried through to the end, providing an objective basis for assessing the reliability of the model calculation results and pointing to critical research needed to increase the precision and reliability of future assessments.

\section{Summary of main results}

1. Regional earthquake probability. There is a $0.62^{2}$ probability (i.e., a $62 \%$ probability) of at least one magnitude 6.7 or greater earthquake in the 3-decade interval 2002-2031 within the SFBR. Such earthquakes are most likely to occur on the seven fault systems characterized in the analysis, but may also occur on faults that were not characterized in this study (i.e., in the "background"). This result is consistent with regional 30-year probability estimates made by WG88 (0.5), WG90 (0.67), and WG99 (0.70), given the differences among these studies and their uncertainty ranges.

Table ES.1. Probabilities of one or more $\mathbf{M} \geq 6.7$ earthquakes in the SFBR, 2002-2031.

\begin{tabular}{lcc}
\multicolumn{1}{c}{ Source fault } & Probability & $\begin{array}{c}\text { 95\% Confi- } \\
\text { dence Bounds }\end{array}$ \\
\hline SFBR region & 0.62 & {$[0.37$ to 0.87$]$} \\
San Andreas & 0.21 & {$[0.02$ to 0.45$]$} \\
Hayward/Rodgers Crk & 0.27 & {$[0.10$ to 0.58$]$} \\
Calaveras & 0.11 & {$[0.03$ to 0.27$]$} \\
Concord/Green Valley & 0.04 & {$[0.00$ to 0.12$]$} \\
San Gregorio & 0.10 & {$[0.02$ to 0.29$]$} \\
Greenville & 0.03 & {$[0.00$ to 0.08$]$} \\
Mt. Diablo thrust & 0.03 & {$[0.00$ to 0.08$]$} \\
Background & 0.14 & {$[0.07$ to 0.37$]$}
\end{tabular}

\footnotetext{
${ }^{2}$ This result, like virtually every other result in this report, is associated with a confidence range that reflects uncertainties in the analysis. The $95 \%$ confidence bounds for the regional probability is [0.37 to 0.87] (Table ES.1).
} 


\section{Geographic distribution of probability.}

The earthquake likelihood is distributed broadly across the SFBR, from the San Gregorio fault on the west to the Green Valley and Greenville faults on the east (Figure ES.1). The easternmost faults along the rapidly developing Interstate 680 corridor in central and eastern Contra Costa and Alameda Counties have a mean combined probability for $\mathbf{M} \geq 6.7$ earthquakes of $0.19^{3}$. Combining this with the contributions from the Hayward-Rodgers Creek fault, the central and southern parts of the $\mathrm{Ca}$ laveras fault, and half the background earthquake likelihood, the probability for $\mathbf{M} \geq 6.7$ earthquakes east of San Francisco Bay is 0.46 [0.17 to 0.64]. West of San Francisco Bay, the San Andreas and San Gregorio faults have a mean combined probability for a $\mathbf{M} \geq 6.7$ earthquake of 0.32 . With half of the background probability included, this part of the SFBR has a probability of 0.34 [0.05 to 0.57 ] for one or more $\mathbf{M} \geq 6.7$ earthquakes in 2002-2031.

\section{Highest-probability faults. Consistent} with previous probability estimates, the Hayward-Rodgers Creek and San Andreas fault systems have the highest probabilities of generating a $\mathbf{M} \geq 6.7$ earthquake before 2032 . The Hayward fault is of particular concern because of the dense urban development along and directly adjacent to it and the major infrastructure lines (water, electricity, gas, transportation) that cross it.

4. Background earthquakes. The probability of a sizeable earthquake on a fault not characterized by WG02 (i.e., an earthquake in the "background") is substantial. For events $\mathbf{M} \geq$ 6.7, the likelihood is 0.14 [ 0.07 to 0.37 ], greater than that on any individual fault system other than the Hayward-Rodgers Creek and San Andreas faults. Many of the significant recent earthquakes in California, including the 1989 Loma Prieta event, have occurred on faults that

\footnotetext{
${ }^{3}$ Probabilities are combined according to Equation (5.9) of this report.
}

were not recognized at the time of their occurrence.

5. Larger earthquakes $(\boldsymbol{M}>7.0, \boldsymbol{M}>7.5)$. The magnitude of an earthquake is directly related to the size of the fault rupture. Our analysis suggests a 30 year probability of an earthquake M7.5 or larger striking the region is only 0.10 (0.02 to 0.20). Only the San Andreas and San Gregorio faults, both lying west of San Francisco Bay, have sufficient length to generate such a large event. When the magnitude threshold is dropped to M7, the probability is considerably larger, 0.36 (0.17 to 0.60$)$ and is concentrated on faults adjacent to the most developed parts of the region, the San Andreas, Hayward-Rodgers Creek, and San Gregorio fault systems.

6. Smaller earthquakes $(\boldsymbol{M}>6.0)$. We estimated the probability of a moderate earthquake (M6.0 to M6.7) over the next 30 years to be at least 0.80 (at least four times as likely to happen as not). As the recent past has demonstrated, earthquakes of this magnitude and smaller can produce significant damage over localized areas. For example, the 1984 M6.2 Morgan Hill earthquake on the southern Calaveras fault caused $\$ 10$ million damage, while a M5.1 earthquake that occurred in September 2000 in a rural area 10 miles northwest of Napa caused $\$ 70$ million damage to that community.

7. Stress shadow. Probability estimates for the next 30-year interval depend critically on the degree to which the SFBR has emerged from the seismic quiescence that followed the great 1906 San Francisco earthquake. The quiescence is thought to be caused by a regionwide drop in stress produced by that earthquake. Regional seismicity rates from the last few decades of the 20th century (Figure ES.3) suggest that the SFBR has been emerging from this quiescence, but has not returned to the high rate of earthquakes experienced in the 1800's. Until a better understanding of the evolution of the 1906 "stress shadow" is developed, this fundamental uncertainty will continue to ham- 
per the accuracy of time-dependent probability estimations in the SFBR.

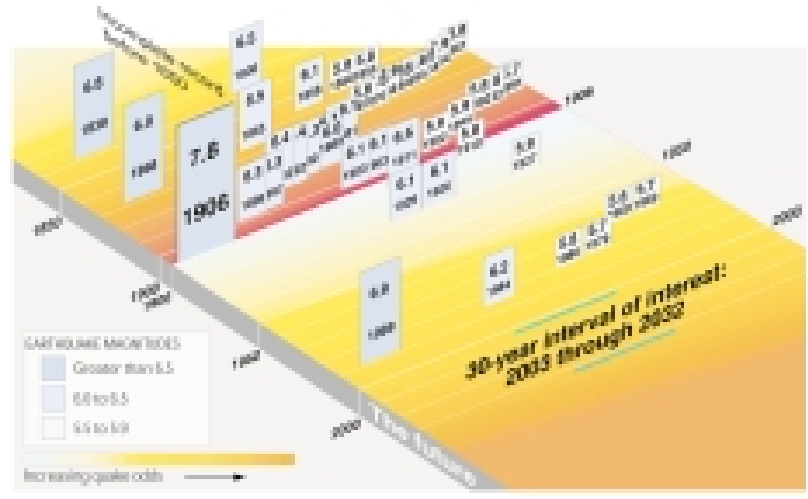

Figure ES.3. Earthquakes $\mathbf{M} \geq 5.5$ in the SFBR since 1850 . The decrease in rate of large earthquakes in the 20th century has been attributed to a region-wide drop in stress due to the 1906 M7.8 earthquake, the "stress shadow" hypothesis.

8. Reliability of results. Generally speaking, the larger the spatial and temporal scales, the more reliable the results. The earthquake probabilities for the SFBR as a whole, for example, are more reliable than those for any individual fault. Similarly, earthquake probabilities for several decades are more reliable than those for the next year.

\section{Implications for earthquake hazard}

Earthquake probabilities are one key component in estimating the seismic hazard in a region, but not the only one. Most earthquake damage is caused by strong, sustained ground shaking. The strength and duration of shaking at a particular location depends on the earthquake's size, its distance from the location, soil conditions at the location, and details about the rupture itself and the propagation of the seismic waves from it.

WG02 has identified 35 potential earthquake rupture sources on the seven faults characterized in this study. For each potential source, a "scenario" map of the expected shaking intensity was constructed, using existing knowledge about the expected propagation and site effects in the SFBR. Figure ES.4 shows the expected shaking intensity distribution related to a M6.9 event on the southern Hayward fault, a likely repeat of the 1868 earthquake. This particular event has a likelihood of occurrence of 0.11 over the next 30 years.

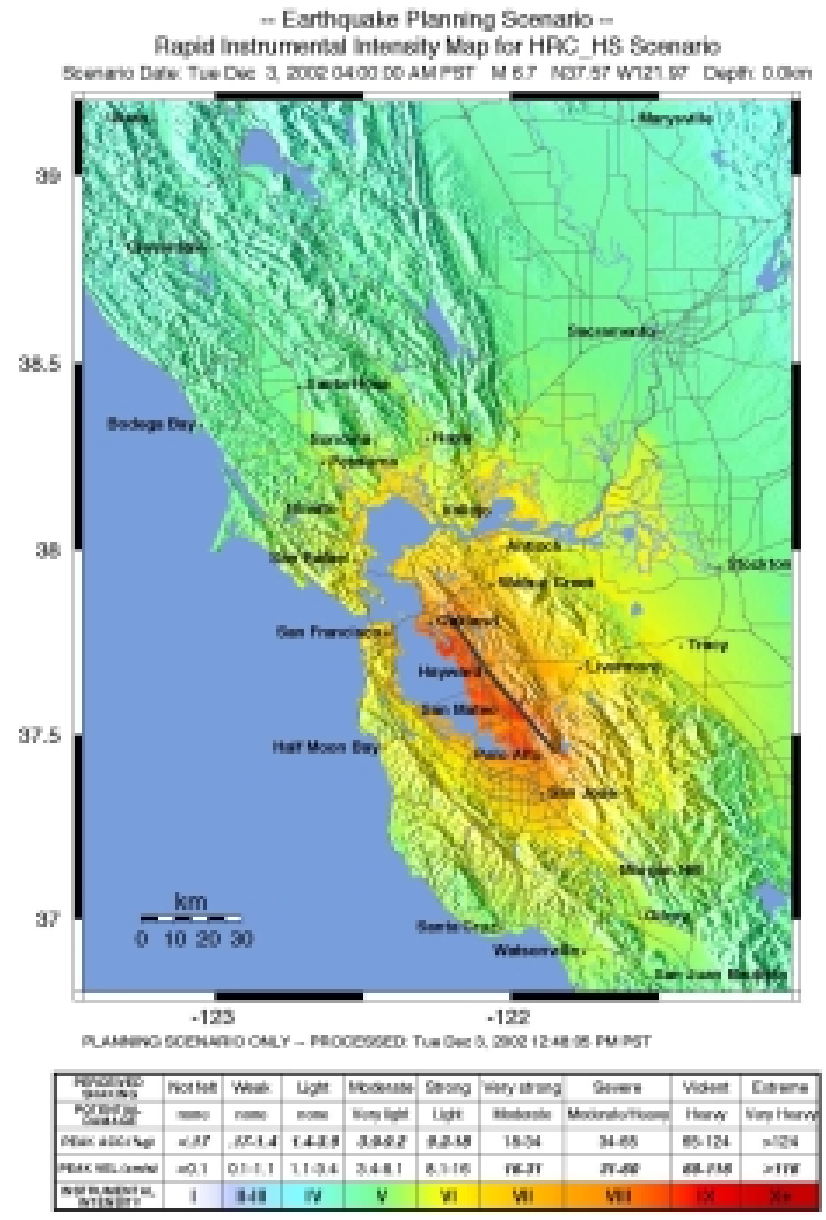

Figure ES.4. Scenario ShakeMap illustrating the strength and regional extent of shaking that can be expected from a future M6.7 earthquake on the southern Hayward fault.

The full suite of 35 potential earthquake sources (and their probabilities) have been combined with the likelihood of background earthquakes to produce regional shaking hazard maps (Figure ES.5). These shaking hazard maps quantify the expected shaking in terms of modified Mercalli intensity (MMI), a scale that is related to damage. These maps represent average expectations and do not attempt to characterize details of the distribution of ground shaking and damage expected in any individual earthquake. The hazard map shown in Figure 
ES.5 depicts the MMI shaking level ${ }^{4}$ at a given site with a $50 \%$ chance of being exceeded in 30 years. This type of information is used as the input into the seismic design criteria in building codes.

Both the scenario shaking intensity maps and regional shaking hazard maps show that future earthquakes, regardless of where they occur in the San Francisco Bay region, are expected to produce damaging ground motions over broad areas and at substantial distances from their locations. Furthermore, the hazard maps show that sites located on rock have even odds in 30 years of experiencing up to MMI VII shaking, which is likely to damage only weak structures. In contrast, most sites on soft soils surrounding San Francisco Bay and the Sacramento River Delta generally have even odds in 30 years of experiencing MMI VIII or stronger shaking, which is expected to cause significant damage in engineered structures.

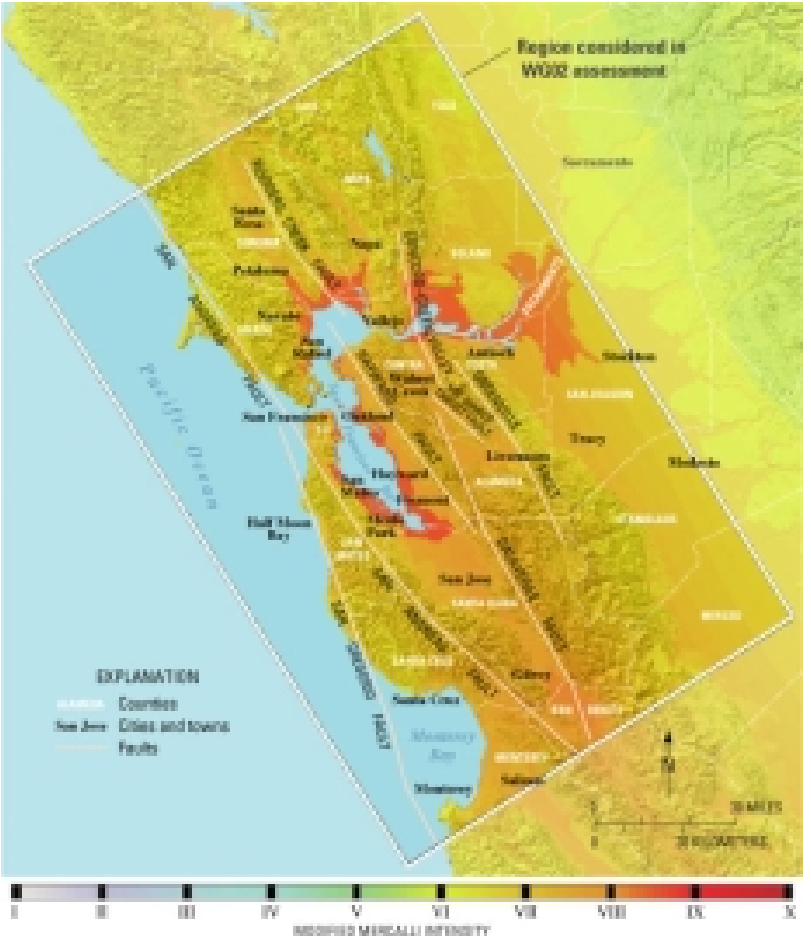

Figure ES.5. Shaking hazard of the SFBR, expressed as the modified Mercalli Intensity (MMI) having even odds of being exceeded in 30 years. Shaking hazard is high throughout the region, and especially pronounced on the soft-soil areas surrounding the bay.

\footnotetext{
${ }^{4}$ The MMI scale is described and tabulated at http://neic.usgs.gov/neis/general/handouts/mercalli.html.
} 


\section{Working Group Participants}

The '99 and '02 incarnations of the Working Group on California Earthquake Probabilities solicited the participation and open discussion of the earthquake research community. Participants included scientists from Federal and State governments, private industry, consulting firms, and academia. Thirteen people were voting members of the WG02 Overview Group, which had responsibility for guiding the study and completing this report:

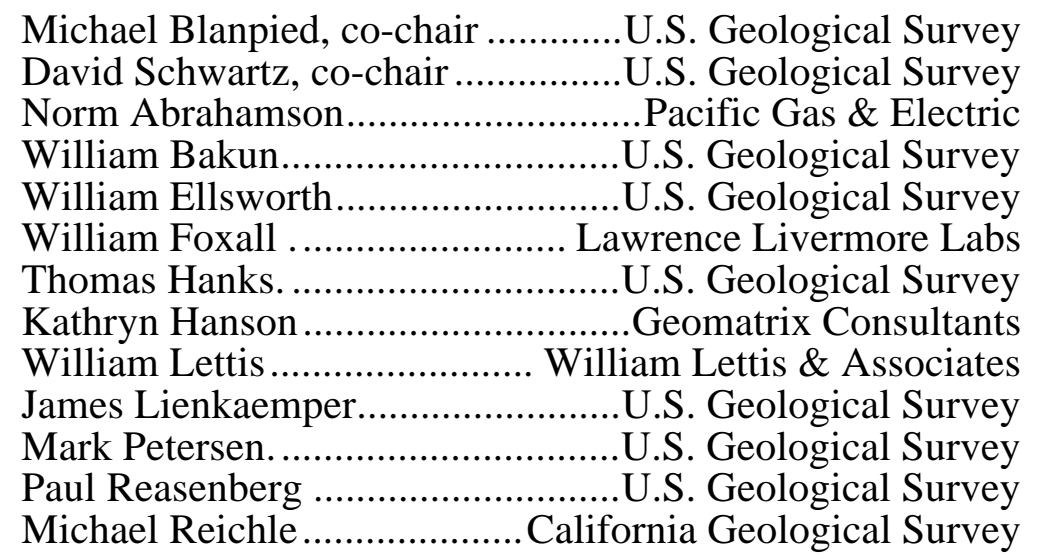

The following persons also participated in the WG99 and/or WG02 studies:

Joe Andrews, U.S. Geological Survey

Michael Angell, Geomatrix

John Baldwin, Wm. Lettis \& Assoc.

Roger Bilham, University of Colorado

Jack Boatwright, U.S. Geological Survey

Glenn Borchardt, Soil Tectonics

William Bryant, CA Div. Mines \& Geo.

Roland Bürgmann, UC Berkeley

Ken Campbell, EQE

John Caskey, San Francisco State Univ.

Chris Cramer, CA Div. Mines \& Geo.

Timothy Dawson, U.S. Geological Survey

James Dieterich, U.S. Geological Survey

Trevor Dumitru, Stanford University

Clark Fenton, URS Greiner Wood. Clyde

Jacob Fink, Univ. California Berkeley

Sean Ford, Univ. California Berkeley

Tom Fumal, U.S. Geological Survey

Eric Geist, U.S. Geological Survey

Joan Gomberg, U.S. Geological Survey

Russell Graymer, U.S. Geological Survey

Tim Hall, Geomatrix

Ruth Harris, U.S. Geological Survey

Suzanne Hecker, U.S. Geological Survey

James Hengesh, Dames \& Moore

Thomas Henyey, Univ. of Southern Calif.

Tom Hildenbrand, U.S. Geological Survey

George Hilley, Arizona State U.

Christopher Hitchcock, Wm. Lettis Assoc.
Robert Jachens, U.S. Geological Survey Angela Jayko, U.S. Geological Survey Keith Kelson, Wm. Lettis \& Assoc. Shelley Kenner, Univ. of Kentucky Steve Kirby, U.S. Geological Survey Keith Knudsen, Wm. Lettis \& Assoc. Allan Lindh, U.S. Geological Survey David Manaker, U.S. Geological Survey Mark Matthews, Walden Consulting Andy Michael, U.S. Geological Survey Tom McEvilly, Univ. California Berkeley Robert McLaughlin, U.S. Geological Survey Robert Nadeau, Lawrence Berkeley Labs Tina Niemi, University of Missouri Stuart Nishenko, FEMA David Oppenheimer, U.S. Geol. Survey Tom Parsons, U.S. Geological Survey Fred Pollitz, U.S. Geological Survey David Ponce, U.S. Geological Survey Will Prescott, U.S. Geological Survey Stephanie Ross, U.S. Geological Survey Doug Schmidt, UC Berkeley Paul Segall, Stanford University Gary D. Simpson, Wm. Lettis \& Assoc. Robert Simpson, U.S. Geological Survey Ross Stein, U.S. Geological Survey Wayne Thatcher, U.S. Geological Survey Tousson Toppozada, CA Div. Mines \& Geo. Robert Uhrhammer, UC Berkeley 
Jeffery Unruh, Wm. Lettis \& Assoc.

John Wakabayashi, Independent Consultant Felix Waldhauser, U.S. Geological Survey

Steve Ward, UC Santa Cruz

Janine Weber-Band, Failure Analysis

Donald Wells, Geomatrix

John R. Wesling, Geomatrix

Steve Wesnousky, Univ. Nevada Reno
Robert Wesson, U.S. Geological Survey

Colin Williams, U.S. Geological Survey

Patrick Williams, UC Berkeley

Chris Wills, CA Div. Mines \& Geo.

Ivan Wong, URS Greiner Woodward Clyde

Robert Wright, Harlan Tait Associates

Mary Lou Zoback, U.S. Geological Survey 


\title{
CHAPTER 1: INTRODUCTION
}

\author{
In Earth, as in all Nature's vast domain, \\ A cycle rules events as night and day, \\ And powerful quakes like those that struck before, \\ Will soon again shake San Francisco Bay. \\ When joined in sum the region's numerous faults \\ Portend disastrous earthquakes yet to be, \\ With strength enough to shake foundations loose, \\ Disrupting all in our society. \\ While science can't predict when earthquakes strike, \\ We know enough to know we'd best prepare. \\ For in the end, the future looks toward us \\ To heed those facts of which we are aware. \\ - Paul Reasenberg
}

This report presents probabilities for the occurrence of one or more $\mathbf{M} \geq 6.7$ earthquakes, where M denotes moment magnitude, in the San Francisco Bay Region (SFBR) for the 30-year period 2002-2031. The models and inputs presented here revise and update those given in Working Group on California Earthquake Probabilities (1999) (hereafter WG99) as U.S. Geological Survey Open-File Report 99-517 in October 1999. The results presented here supersede those of WG99. The Working Group on California Earthquake Probabilities (2002) (hereafter WG02) has taken into account new geologic, seismologic, and geodetic information developed since 1999, and extends the previous analysis through a keener appreciation of the "stress shadow" cast by the 1906 earthquake and the influence it has likely had on SFBR seismicity from 1906 to the present - and may continue to have on SFBR seismicity for the next 30 years. This study, like WG99's, has involved a broad spectrum of the earthquake-science community in its analysis, including government, university and private-sector scientists.

This report

- Documents the data, methods, and assumptions used to calculate SFBR earthquake probabilities.

- Presents a long-term model for the occurrence of earthquakes in the SFBR (a modification of the WG99 model) based on the currently available geologic information.

- Quantifies the likelihood of damaging earthquakes occurring on major faults, on segments of these faults, and throughout the entire SFBR.

- Quantifies and discusses the uncertainty in these probability estimates.

- Estimates the intensity of ground shaking expected for some of the most likely anticipated earthquakes in the SFBR. 
- Estimates the earthquake hazard for the SFBR in terms of the expected intensity of ground shaking.

WG02 is the latest in a series of analyses of earthquake probabilities for California. Each of these studies has advanced the modeling of earthquake generation. The first Working Group on California Earthquake Probabilities (1988) (hereafter WG88) produced the initial report on earthquake probabilities for the San Andreas Fault system. WG88 developed a faultsegmentation model for the San Andreas, Hayward, San Jacinto, and Imperial Faults; used slip rates to calculate average earthquake recurrence intervals; and employed the time-predictable model to estimate fault segment probability. WG88 concluded that the probability of one or more large (M 7) earthquakes in the SFBR during the next 30 years (1988-2017) was at least 0.5 $(50 \%)$. This was based on an analysis of information about the earthquake history and behavior of only two SFBR faults, the San Andreas and Hayward Faults.

Following the damaging $\mathbf{M}=6.91989$ Loma Prieta earthquake, the Working Group on California Earthquake Probabilities (1990) (hereafter WG90) was convened and charged with re-evaluating SFBR earthquake probabilities in light of that event. Using new slip-rate information from the Rodgers Creek Fault, and adding this fault to the estimate, WG90 found the 30-year earthquake probability to be $0.67(67 \%)$. WG90 noted that other earthquake sources pose a threat to the region, including the Calaveras, San Gregorio, Concord-Green Valley, and Greenville Faults. However, these were not included in the analysis at that time because of insufficient information, particularly slip-rate data. WG90 added sophistication to the probability calculations by considering alternative rupture scenarios for the Peninsula segment of the San Andreas Fault and the effects of stress changes associated with the Loma Pieta earthquake. A principal limitation of the WG88 and WG90 models, however, was in the limited number and variety of the ruptures it characterized.

A major effort to re-evaluate earthquake probabilities in southern California was completed in 1995 by the Southern California Earthquake Center (SCEC Phase II report, 1994; Jackson and others, 1995). That study attempted to include the earthquake contributions from all faults in the region, added geodetic estimates of fault slip rates to the geologic estimates, and developed a method for calculating recurrence intervals for multiple-segment ruptures on the southern San Andreas Fault (the Cascade model). WG95 raised issues about the need to carefully compare regional seismic moment release and earthquake recurrence rates based on historical seismicity, geodesy, and the geological observations.

The WG99 report built on many of the concepts pioneered in these earlier California probability studies. In particular, WG99 expanded the use of multiple-segment ruptures in its long-term model for the occurrence of earthquakes in the SFBR by including 18 segments on the San Andreas, Hayward-Rodgers Creek, San Gregorio, Calaveras, Concord-Green Valley, Greenville and Mt. Diablo Faults and providing for 35 different possible ruptures of them. Their model balanced the long-term earthquake activity with observations of historical seismicity and the observed rate of tectonic plate motion. WG99 also expanded the use of formalized expert opinion and logic-trees to account for uncertainty in each stage of the probability calculations. And whereas WG88 and WG90 exclusively used the time-predictable model for calculating 
earthquake probabilities, WG99 employed a weighted combination of several alternative probability models. Using this approach, WG99 found a $0.70(70 \%)$ likelihood of at least one M>6.7 earthquake in the SFBR from 2002 through 2031.

The present report (WG02) adopts, with minor modifications, WG99's methods, including multiple-segment-based long-term earthquake model and multiple probability models. Key differences include a more fully developed model for the "stress-shadow" effect of the 1906 earthquake in calculating the current probabilities of earthquakes. We also expand the results to include the probability of earthquakes for a range of magnitudes and time intervals; and explore implications for earthquake hazard in the SFBR.

Since the 1989 Loma Prieta earthquake, much new geologic, geodetic, and seismologic information has been obtained for SFBR faults. Some of this information was reviewed and summarized in 1996 by the Working Group on Northern California Earthquake Potential (WGNCEP 96) as input to the California seismic hazard map (Petersen and others, 1996) and US National Seismic Hazard map (Frankel and others, 1996), and both WG99 and WG02 built on these efforts. Specifically:

- Geologic slip rates and information on earthquake recurrence are now available for the northern Calaveras Fault, San Gregorio Fault, Concord-Green Valley Fault, and Greenville Fault.

- Understanding of the San Andreas Fault has improved with reevaluation of the distribution of slip in the 1906 earthquake coupled with paleoseismic slip rate and recurrence studies in Marin County, on the San Francisco peninsula, and in the Santa Cruz Mountains.

- Interpretation of the earthquake history of the Hayward Fault has significantly changed with recognition that a large earthquake in 1836 was not on the northern segment of the fault, but likely occurred southeast of San Francisco Bay.

- Knowledge of contractional deformation across the region has greatly improved, particularly the locations of reverse, thrust, and blind thrust faults and their associated slip rates.

- The effect of the 1906 earthquake, which relaxed the major faults in the SFBR and lowered the rate of seismicity for much of the $20^{\text {th }}$ century, can now be estimated in several ways and incorporated into probability calculations.

- Several of the SFBR strike-slip faults exhibit aseismic slip or creep. The role played by fault creep in determining the seismogenic behavior of these faults is recognized here and incorporated into estimates of potential earthquake magnitude and recurrence rate.

- New analytical approaches to estimate the size and improve the location of historical earthquakes have resulted in a more complete catalog of SFBR $\mathbf{M} \geq 5.5$ earthquakes back to 1850. Furthermore, the likelihood that specific historical earthquakes are associated with specific faults has been estimated. 
- Global Positioning System (GPS) measurements of crustal deformation now provide a more precise estimate of the present day rate of deformation across the region, which is an important constraint on earthquake recurrence calculations.

An overview of the WG02 model is presented in Chapter 2. Chapter 3 summarizes on a faultby-fault basis much of the geologic and geophysical data utilized in this study, and additional data and models are contained in the Appendices. Chapter 4 describes and constructs the SFBR earthquake model, which determines the average rate of earthquake occurrence for the faults characterized herein and for the region as a whole. Chapter $\mathbf{5}$ describes the five probability models used to determine earthquake probabilities in the SFBR for the coming decades. Chapter 6 presents the results of these calculations and discusses their uncertainties and sensitivity to key modeling assumptions. Chapter 7 explores some of the implications of these calculations for probabilistic seismic hazard as well as strong ground motion from probable future earthquakes in the SFBR. Finally, Chapter 8 summarizes the issues that matter most to the results presented here in the form of directions for future research. 


\section{ChAPTER 2: OVERVIEW OF MOdels AND METHODOLOGY}

The San Francisco Bay region (SFBR) sits within the Pacific-North American plate boundary (Figures 2.1, 2.4). About 80 percent of the total plate boundary slip occurs across a $150 \mathrm{~km}$ wide zone extending from the Farallon Islands to the west edge of the Central Valley, with most of this deformation occurring in an even narrower (50 km-wide) zone spanning the San Andreas and Calaveras Fault zones. The SFBR has the highest density of active faults and the highest rate of seismic moment release per $\mathrm{km}^{2}$ of any urban area in the United States. The SFBR has experienced many sizeable and damaging earthquakes, including six magnitude $\mathbf{M} \geq 6.5$ events in 1836, 1838, 1865, 1868, 1906, and 1989 (Figure 2.2) with magnitudes of 6.5, 6.8, 6.5, 6.8, 7.8, and 6.9 , respectively.

The earthquake history of the SFBR has been documented in detail by Bakun (1999) and is believed to be complete for $M \geq 5.5$ events since 1850 (Figure 2.2), when the population of the SFBR increased greatly due to the discovery of gold in the Sierra foothills east of Sacramento. In the context of this study, three important observations can be made of this earthquake history. First, four $\mathbf{M} \geq 6.7$ earthquakes have occurred in the historical record. Four events since 1838 corresponds to a rate of occurrence for $\mathbf{M} \geq 6.7$ events in the SFBR of between $0.020 / \mathrm{yr}$ and 0.024/yr. Second, Bakun (1999) has shown that the size distribution of earthquakes in the SFBR corresponds to $b=0.9$ in the Gutenberg-Richter representation, both for the larger events since 1850 and for smaller events in the $20^{\text {th }}$ Century.

Finally, the rate of earthquakes in the SFBR was considerably higher before 1906 than after (Figure 2.2). For the 70 years before 1906, $17 \mathbf{M} \geq 6$ earthquakes occurred in the SFBR while in the 95 years after 1906 there have been only five (Ellsworth and others, 1981; Bakun, 1999). We estimate the chance of this change in rate being due to random fluctuations to be less than $5 \%$. The post-1906 seismic quiescence is thought to be due to a "stress shadow" cast by the 1906 earthquake over much if not all of the SFBR (Harris and Simpson, 1998). Both large and small earthquakes can be suppressed by the occurrence of a nearby earthquake, and can remain suppressed until the faults in the region are sufficiently reloaded (e.g., Harris and Simpson, 1998). In the SFBR, reloading occurs as the Pacific Plate moves northwestward past the North American Plate. In the SFBR, most of the major faults were relaxed to some degree by the 1906 earthquake, owing to the great length of its rupture and the sub-parallel, strike-slip geometry of these faults (R.W. Simpson, Appendix F).

There is no consensus within WG02, however, as to whether the SFBR remains within the 1906 stress shadow, as suggested by seismicity data for the past 96 years; is now emerging from it, as suggested by calculations based on rheological models of the crust and uppermost mantle; or has emerged from 1906 effects, as suggested by the simplest elastic interaction models. This area of uncertainty has led to substantial differences between the analysis reported by WG99 and that reported here. Put another way, the stress shadow cast over the SFBR by the 1906 San Francisco earthquake has, in turn, cast a considerable cloud of uncertainty over the deliberations and findings of Working Group 2002. 
Uncertainty is no stranger to assessments and projections in the Earth Sciences, but it has rarely been an honored guest at these functions. WG02 has devoted considerable effort to defining uncertainties in the data, models, and parameters exercised here; quantifying these uncertainties; and tracking them throughout the calculations. In any model, there may be two types of uncertainty: aleatory uncertainty and epistemic uncertainty. Aleatory uncertainty refers to the random variability that occurs in the natural world. The throwing of dice is the classic example, perhaps because the word aleatory has its etymological origins in the Latin word for dice. Epistemic uncertainty refers to what we don't know about the natural world, our ignorance of how the Earth works to manufacture earthquakes of a certain size at a certain place and time, for example. The differing opinions on the present-day effects of the 1906 stress shadow are a measure of epistemic uncertainty about this matter. To the extent a process is knowable, its epistemic uncertainty is reducible. Aleatory uncertainty, on the other hand, while quantifiable through direct observation of the phenomena of interest, is irreducible. WG02 uses models (sometimes more than one) to calculate quantities, and these models are defined by parameters that must be estimated. Both the choice of models and estimation of their parameters have uncertainty associated with them. These model uncertainties and parameter uncertainties are, in general, of both the aleatory and epistemic types. Finally, WG02 uses expert opinion to decide a number of matters in this report. Differing expert opinion also represents uncertainty. Insofar as such differences arise from differing evaluations or perceptions of available but incomplete knowledge (for example, the varying interpretations of the present-day effects of the 1906 stress shadow), this uncertainty is of the epistemic type.

Almost all of the uncertainty considered in this report, including that arising from diverse expert opinion, is treated as epistemic uncertainty. (The only exceptions are the event-to-event variability that we associate with magnitude distributions, natural variability in which fault segments combine to create earthquakes, and the aleatory component of the uncertainty in our time-dependent probability models.) Confronted with a range of possibilities for a parameter (for example, the length of a fault segment) or a relation (for example, the relation between segment area and earthquake magnitude) or a probability model, WG02 uses multiple choices with weights assigned to reflect the uncertainty. To sample systematically among the vast number of combinations of the weighted choices for input data and models, WG02 employs a Monte Carlo technique (also described as a logic-tree approach) in which thousands of complete calculations for SFBR earthquakes and their probability are made. From the distribution of the calculation results, we obtain various mean values (for example, long-term rupture rates or 30-year earthquake probabilities) and their $90 \%$ and $95 \%$ confidence bands.

An example of how weighted choices are used to represent uncertainty is shown in Figure 2.3 for the case of estimating the seismogenic area and seismic moment rate (and their uncertainties) for the North Hayward Fault segment, given sets of weighted choices for segment length $L$, segment width $W$, seismic slip factor $R$ and slip rate $v$. (This calculation is described more fully in Chapter 4.) The result calculated using the preferred values is near or at the maximum of the distribution function for all possible results, as we would expect. Uncertainties in the calculated results can be large, however, if high confidence levels are imposed on the results. Every result presented in Chapter 6 is stated as a mean value and its 95\% confidence band, as inferred from the Monte Carlo sampling. 
The earthquake probabilities reported here are the results of a set of model calculations consisting of three basic elements. The first element is the SFBR earthquake model (described more fully in Chapter 4) which determines the average, long-term rate of earthquakes on the principal faults. The second element is the set of "background" earthquakes, those earthquakes that occur in the SFBR on faults either uncharacterized or unrecognized by this study, the probability for which is based on historical seismicity rates extrapolated to $\mathbf{M} \geq 6.7$ events. The third element of these calculations is a suite of probability models, which are described in Chapter 5. The probability models range from the simplest (a time-independent Poisson model) to those that incorporate certain time-dependent physical aspects of the causes and effects of earthquakes, such as the progression of faults through an "earthquake cycle" and the interactions of faults through their stress fields.

Because of the inclusive approach taken by WG02 toward all forms of uncertainty and differing expert opinion, the model used by WG02 to calculate earthquake probability is complex. This complexity notwithstanding, certain assumptions and parts of the model play critical roles in the calculation and strongly affect the results, while others affect the results only a little. In the remainder of this chapter, we introduce the key elements of the WG02 model, paying particular attention to those things that matter most in calculating the earthquake probabilities in the SFBR.

\section{SFBR Earthquake Model}

For the purposes of this study, the San Francisco Bay Region (SFBR) is a rectangular region, extending from Santa Rosa on the north to Monterey on the south, which trends parallel to the northwesterly strike of the principal faults of the San Andreas system and which includes them all (Figure 2.4). From west to east, they are the San Gregorio, San Andreas, Hayward-Rodgers Creek, Calaveras, Concord-Green Valley, and Greenville Faults, plus the Mt Diablo Thrust, a blind thrust lying between the northern end of the Calaveras Fault and the southern end of the Concord-Green Valley Fault. These seven faults are referred to as the characterized faults in this study.

Attached to the SFBR is a panhandle extending along the San Andreas Fault to Cape Mendocino. This extension is needed to mechanically accommodate in our model long ruptures of the San Andreas Fault, such as that which occurred in 1906. However, when we report results for the SFBR herein, they reflect only earthquakes occurring in or extending into the rectangular SFBR region.

The SFBR earthquake model is fundamentally a geologic model in that both its geometry and long-term behavior are defined and constrained by geologic observation. The model incorporates complexity that leads to a wide spectrum of earthquake sizes, and includes both fault-by-fault and regional constraints on the frequency of occurrence of these earthquakes based on geologic and geodetic observations of slip rate. The basic elements of the SFBR earthquake model are introduced in the box below, and more fully discussed in Chapters 3 and 4. 


\section{The SFBR Earthquake Model}

\section{Fault segments}

The SFBR model is built upon the seven characterized faults mentioned above. Each fault is divided into as many as four, non-overlapping segments -18 segments in all. These segments are the basic building blocks for earthquake ruptures on each fault. Each fault segment has length $L$, width $W$, geologic slip velocity $v$, and seismogenic scaling factor $R$, which accounts for any part of the geologic slip that is aseismic (Figure 2.5, Table 3.8).

\section{Rupture sources}

Unlike WG90, which considered only single-segment ruptures, the present study allows for the simultaneous rupture of two or more adjacent segments of a fault. Each possible combination of segments is a rupture source. These rupture sources-35 in all-are listed in Table 4.8. A mean magnitude is computed for each rupture source based on its seismogenic area $A$ (determined by $L, W$ and $R$ on each of its segments) through "M-log $A$ " relations, as described in Chapter 4.

\section{Floating earthquakes}

Each fault (except Mt. Diablo) is host to floating earthquakes-earthquakes of a specified magnitude but without a fixed location. Floating earthquakes, which allow for the fact that some earthquakes are not represented by the prescribed segmentation, are also classified and treated as rupture sources and are listed in Table $\mathbf{4 . 3}$.

\section{Rupture scenarios}

A rupture scenario is a combination of rupture sources that describes a possible mode of failure of the entire fault during one earthquake cycle. For example, in one rupture scenario the Hayward-Rodgers Creek Fault fails only in 3-segment ruptures, in another it fails only in singlesegment ruptures, and in a third scenario it fails in combinations of 1-segment and 2-segment ruptures (Table 3.4).

\section{Fault rupture models}

A fault rupture model us a weighted combinations of the rupture scenarios for a fault, each combination representing one possibility for the long-term behavior of the fault. The weights are determined by expert opinion. The fault rupture models serve the same function as the "earthquake-cascade" models employed in WG95 (SCEC, 1995). For most faults, multiple fault rupture models are considered.

\section{Regional model}

A viable regional model is an aggregate of seven rupture models (one for each fault) and a background earthquake model (described below) that satisfies a plate-motion slip rate constraint across the entire SFBR defined by geodetic observations. A regional model provides a complete description of the long-term earthquake activity in the SFBR. 


\section{Background Earthquakes}

Earthquakes that have occurred (and will occur) within the SFBR on structures other than the seven characterized faults are termed background earthquakes. Numerous known faults and structures in the SFBR not characterized here are considered capable of producing $\mathbf{M} \geq 6.7$ earthquakes, as are, presumably, some yet-unrecognized faults and structures at depth in the SFBR (for example, prior to 1989, the source of the Loma Prieta earthquake).

Like the characterized earthquakes, background earthquakes have their origins in the elastic strain accumulation driven by the relative motions of the North American and Pacific plates. As described more fully in Chapter 4, the SFBR accommodates about $40 \mathrm{~mm} / \mathrm{yr}$ of strike-slip plate motion (De Mets and Dixon, 1999; Prescott et al., 2001) and about $4 \mathrm{~mm} / \mathrm{yr}$ of convergent plate motion (Prescott et al., 2001. Almost all of the strike-slip plate motion occurs on the characterized faults (excluding the Mt. Diablo thrust) but some also occurs in background earthquakes. The accommodation of plate tectonic motion by earthquakes of various types is schematically illustrated in Figure 2.6.

WG02 characterizes only one geologic structure that can accommodate appreciable convergent plate motion - the Mt. Diablo Thrust. Given the small dimension of this structure compared to the 220-km along-strike length of the SFBR, the Mt. Diablo Thrust can account for only a small fraction of the convergent plate motion. Convergent background earthquakes also accommodate convergent plate motion. These may occur in other regions of local uplift associated with thrust faults, along the eastern edge of the Great Valley, for example, or the west side of the Santa Clara Valley (Figure 2.7).

Background earthquakes of both the strike-slip and convergent types are considered here in terms of a Gutenberg-Richter distribution with $b=0.9, \mathbf{M}_{\max }=7.25 \pm 0.25$, and a constant rate of occurrence defined by the rates in the historical and instrumental records. WG02 does not apply a strain accumulation/release (moment-balance) constraint to the background earthquakes, as we do for earthquakes on characterized faults.

\section{Probability Models}

An earthquake probability model describes the time-dependence of earthquake occurrence. After the mean rupture rates and magnitudes are calculated for rupture sources in the SFBR, they become input for the several probability models used in this study and described more fully in Chapter 5. Different probability models incorporate different physical attributes of the earthquake process.

In calculating earthquake probabilities in the SFBR, WG02 recognizes two essential, timedependent aspects of the causes and effects of earthquakes, the first relating to the earthquake cycle and the second to fault interactions. The concept of the earthquake cycle has its origins in the elastic-rebound hypothesis, first formulated for the 1906 earthquake and its likely successor on the San Andreas Fault (Reid, 1908). It holds that after a major earthquake and its immediate aftershocks, another major earthquake on the same reach of fault is not possible until elastic strain has re-accumulated in an amount comparable to that released in the previous major 
earthquake. As time goes on and more and more elastic strain accumulates, the next large earthquake becomes increasingly likely. If the SFBR had only the San Andreas Fault and 1906type earthquakes to account for, quantifying these effects would be far simpler (although not necessarily accurate with available data). But this is not the case. Smaller-magnitude but still large earthquakes, perhaps with their own "earthquake cycles," have occurred on or near the reach of the San Andreas Fault that ruptured during the 1906 earthquake, both before (in 1838) and after (in 1989) this event.

With respect to fault interactions, it is necessary to estimate the effects of the 1906 earthquake on the other SFBR faults, as well as similar (but smaller and more localized) effects of the Loma Prieta earthquake (Oct. 17, 1989; $\mathbf{M}=6.9$ ). Both model calculations and known seismicity rates since 1836 (Figure 2.2) suggest that the 1906 earthquake cast a deep and long-lasting "stress shadow" across the entire SFBR (see, for example, Harris and Simpson, 1998). As noted previously, however, there is no consensus as to whether the SFBR remains within the 1906 stress shadow, is now emerging from it, or is well removed from 1906-related effects.

All of this lends considerable uncertainty to the probability estimates reported here-uncertainty in addition to that contained in the SFBR earthquake model. This uncertainty is expressed both in the range of probability models described below and in the expert opinion applied to them in the form of relative weights.

The first of the five probability models used to determine earthquake probabilities in the SFBR is the Poisson model. Poisson probabilities do not vary with time and are fully determined by the mean rates of earthquakes in the SFBR regional model.

The Empirical model is a variation of the Poisson model. It incorporates time-dependence by modulating the average rates of rupture sources with the current regional rate of seismicity, which is currently lower than its long-term average. The Empirical model thus uses modern seismicity rates as a proxy for stress shadow calculations that rely on poorly known rheological/mechanical properties of the crust and uppermost mantle under the SFBR. Inclusion of the Empirical model is a significant departure from the approaches toward probability modeling taken by WG90 and WG99.

The Brownian Passage Time (BPT) and Time-Predictable (TP) models used in this study are both time-dependent probability models. In BPT model, the failure condition of a fault or fault segment is specified by a state variable, which rises from a ground state to the failure state in the course of the earthquake cycle. Evolution of this model toward failure is governed by a deterministic parameter reflecting the reloading rate of the fault or fault segment and a stochastic parameter $\alpha$, or "aperiodicity", that allows for random variations in the process. The "stress shadow" effects of nearby earthquakes are admitted in the BPT model through steps in the state variable calculated with elastic interaction models. The TP model requires that both the date and the amount of slip of the most recent earthquake be known. In this model, the expected time of the next characterized earthquake is equal to the time required for the strain accumulation process to provide for the same amount of faulting displacement as occurred in the previous event. The TP model is applied here only to segments of the San Andreas Fault that ruptured in 
the 1906 earthquake; this is the only SFBR earthquake for which detailed slip measurements are available.

How the inherent randomness of the earthquake process is modeled affects the probability calculations for all of the rupture sources. We estimated $\alpha$ from 37 sequences of repeating earthquakes to be in the range $0.3-0.7$, similar to the the cov of $0.5 \pm 0.2$ used by WG95. This is in contrast to smaller values used by WG88 and WG90 based on the work of Buland and Nishenko (1987), and it is fair to say that the estimation of $\alpha$ remains a significant scientific challenge and a significant source of uncertainty in time-dependent earthquake forecasting. The effect of $\alpha$ on WG02's probability calculations depends on the time since the most recent rupture. For the 30-year period 2002-2031, assuming greater randomness decreases the probability on most of the faults, but increases the probability of earthquakes on the San Andreas Fault.

\section{Expert Opinion}

Expert opinion has been used in seismic hazard and risk analyses for more than two decades. For most earth scientists, the theory and practice of expert opinion will come as new developments, but WG02 believes that the basic principles are consonant with the philosophy of multiple working hypotheses (multiple working models, in the case of this report). Earth scientists have long embraced the use of multiple working hypotheses when knowledge is insufficient to eliminate any of them (Gilbert, 1886; Chamberlin, 1890). In this approach, experts are convened to define and portray the body and range of informed opinion on the matter at hand (SSHAC, 1997; Hanks, 1997). The process should be inclusive: that is, any other group of experts should express the same range of knowledge and models. The " truth" or "right answer" is assumed to lie somewhere among or between the various opinions. In this context it is not useful to try to decide which experts are "right" and which experts are "wrong" because there is no way of knowing. If there were, there would be no need for all the experts in the first place. Finally, all should recognize that experts are not convened to reduce uncertainty; indeed, in their differing opinions, they are the source of much of it.

This report is not a consensus report, at least not in the sense that previous reports on California earthquake probabilities $(1988,1990,1995)$ were consensus reports. In particular, WG02 does not arrive at final probability numbers by agreeing in advance on a single model or method for calculating them. Rather, this report proceeds on the basis of a consensus process, which admits a variety of models that are significantly different from one another, for one reason or another. The final result is determined by the aggregated expert opinion expressed individually by the 13 members of the Overview Group of WG02, which had responsibility for contents and conclusions of this report. The members of that group are listed at the beginning of this report.

The SFBR earthquake model is a consensus feature of this study. WG02 uses only this model to estimate earthquake rates as a function of size on a fault-by-fault and segment-by-segment basis, even though other models, such as the cascade model of WG95 or the models of Ward (2000) and Andrews and Schwerer (2001), do similar things. Surely, therefore, there is some uncertainty associated with the adoption of this single model that is left unquantified here. Perhaps the segmentation basis of the analysis here is incorrect, or perhaps the choices of segments are 
incorrect, or perhaps the proscription against ruptures of only a part of a segment (apart from floating earthquakes) is incorrect. If so, WG02 has no way of knowing by how much. What we can do is compare the SFBR model predictions of average earthquake occurrence rates to what is known to us through the historical and prehistoric records of earthquakes. The SFBR earthquake model passes these tests, but so do other models.

\section{The Strain Accumulation/Release Constraint}

Earthquakes in the San Francisco Bay Region have their origins in the elastic strain energy accumulating in the region due to the steady motion of the Pacific plate relative to the North American plate. Most of this relative motion is in the form of horizontal shear of $36-43 \mathrm{~mm} / \mathrm{yr}$ across the SFBR and is released on faults in strike-slip earthquakes.

Both the accumulation and release of strain energy are measurable quantities for the San Francisco Bay Region (Bakun, 1999; Prescott and others, 2001). There are long-term and shortterm estimates for each (Figure 2.8). In terms of slip velocity across the region, the long-term accumulation inferred from global plate motion models is $41 \pm 1 \mathrm{~mm} / \mathrm{yr}$ (De Mets and Dixon, 1999). This value is an average over the past five million years, and has been corrected for the San Francisco Bay by subtracting contributions of Great Basin extension and motion of the Sierra Nevada-Great Valley block from the full relative motion of the Pacific and North American plates. The short-term accumulation rate measured using GPS data for the past seven years is in good agreement at 39.8 $\pm 1.2 \mathrm{~mm} / \mathrm{yr}$ (Prescott and others, 2001).

Long-term release of strain energy on individual faults is measured by the faults' geologic slip rates averaged over thousands - often many thousands - of years. Sums of the slip velocity measured on strike-slip faults in the SFBR can be compared to the plate-motion rate (Figure 2.9). Finally, the short-term release of strain energy can be estimated from the historical record of earthquakes in the SFBR. The seismic moment sum for the period 1850 to present corresponds to a mean slip velocity of roughly $31 \mathrm{~mm} / \mathrm{yr}$. A large uncertainty-approximately $50 \%$ of this value - arises primarily from uncertainty in the seismic moment of the 1906 earthquake, which alone has contributed about two thirds of SFBR seismic moment sum since 1850 (Bakun, 1999).

The coincidence of these four very different measures of slip velocity reveals that what goes into the SFBR in the way of plate motion strain energy accumulation comes out as strain energy release, whether this is measured by geologic fault slip rates or by the seismic moment sum of the historical record of earthquakes. These estimates of strain energy accumulation and release are in remarkably good agreement on both the long term and, even more surprisingly, on the short term.

\section{From Segments to Earthquakes}

WG02's method for estimating the size of earthquakes on the characterized faults (including both single-segment and multiple-segment ruptues) uses the fault area A to estimate moment magnitude $\mathbf{M}$. Seismic moment $\mathbf{M}_{0}$ for each event is then determined from the inverse of the moment magnitude relation (Hanks and Kanamori, 1979) 


$$
\log \mathrm{M}_{0}=3 / 2 \mathbf{M}+16.05 .
$$

To put the strain accumulation/release constraint of the last section into play, the seismic moment sum for each characterized fault is computed. These sums are balanced against the total moment rate defined by areas and geologic slip velocities determined for segments involved.

We use three sets of $\mathbf{M}-\log$ A relations in this analysis: that of Wells and Coppersmith (1994); those developed originally by W.L. Ellsworth for WG99 and reproduced here in Appendix D; and those of Hanks and Bakun (2002) invoking L-model scaling of fault slip at $\mathbf{M} \geq 7$. The differences between these relations make for the principal source of uncertainty in the SFBR earthquake model. Even modest differences (or uncertainties) among these relations (say 0.2 units in $\mathbf{M}$ ) provide for a factor of 2 difference (or uncertainty) in $\mathbf{M}_{0}$ and therefore in the rates of such earthquakes, given the moment-balanced format of our calculations.

In addition to the $\mathbf{M}-\log$ A relations, several other considerations play key roles in determining the long-term average rate of earthquakes and their size distribution. Aseismic slip, or fault creep, comes into play through the seismogenic factor $R$, the ratio of seismogenic fault slip to total fault slip, by reducing the effective area of the rupture sources in the model (Appendix B). Generally, where the $R$ factor reduces the rupture area, it reduces the earthquake magnitude. For some of the shorter fault segments having significant amounts of aseismic slip, such as those on the Hayward, Calaveras, and Concord-Green Valley Faults, magnitudes associated with singlesegment ruptures can be and often are $\mathbf{M}<6.7$. Thus, it is important to distinguish between the rates of $\mathbf{M} \geq 6.7$ earthquakes, which is our principal concern in this analysis, and segment-rupture rates, which include all of the rupture sources involving a given segment, including those with $\mathbf{M}<6.7$. Segment-rupture rates may be more useful than $\mathbf{M} \geq 6.7$ earthquake rates for interpreting geologic, site-rupture data for paleo-earthquakes with $\mathbf{M} \sim 6.7$.

A third factor controlling the rates of earthquakes in the SFBR model are the various rupture scenarios and rupture models. These are important features in moment-balanced calculations such as these, because the seismic moments of just a few large earthquakes will typically dominate the total moment for a segment, for a fault, or for the SFBR as a whole. Finally, the choice of $\mathbf{M}$ for the floating earthquakes may or may not be an important contributor to the total moment for that segment, depending on the floating earthquake's size relative to the size of the segment-rupturing earthquakes on that fault.

\section{The Calculation Sequence}

The Calculation Sequence (CS), described more fully in Chapter 4, is the computational apparatus that embodies the SFBR earthquake model, the background earthquake model, and the probability models, and calculates the earthquake probabilities. The CS first calculates average rates of rupture sources on the characterized faults. These rates, in turn, are the input to each of the five probability models. The rates of background earthquakes are calculated with a Gutenberg-Richter model for the SFBR as a whole; probabilities for the background earthquakes are calculated only for the Poisson probability model. 
The CS is illustrated schematically in Figures 2.10 and 2.11. Calculation of the rates of rupture sources is shown in Figure 2.10, beginning with the segment geometry and creep rates on the left and concluding with rupture rates on the right. Along the way, we calculate $\mathbf{M}$ and $\mathbf{M}_{0}$ for each rupture source in the bottom path of Figure 2.10. In the top path we calculate seismic moment rates for each segment and each rupture model through their $\Sigma \mathrm{M}_{0}$ 's, constraining them both locally and regionally according to individual fault slip rates and the plate-motion rate, respectively. The resulting rupture source rates are then input to the probability models (Figure 2.11).

Implicit in these schematic diagrams are the multiple choices of numerous parameters and models involved in these calculations and their assigned weights. For example, as illustrated in Figure 2.3, the seismogenic area A of a fault segment is calculated from the product of its length $L$, width $W$, and seismogenic scaling factor $R$. Its length, in turn, is calculated from the geographic coordinates of the segment's endpoints. The uncertainty in each of these parameters (each $L$ endpoint location, $W$, and $R$ ) is represented by three branches. Thus, there are $81\left(3^{4}\right)$ paths through this part of the CS, yielding 81 measures of the seismogenic area. The most likely measure is that found for the highest-weighted branch choices, but the less likely paths are also followed in the Monte Carlo sampling of the CS. Put another way, each choice of these parameters, together with the weight assigned to it by WG02, occupies a branch of the logic tree. WG02 often assumes that the uncertainty in a parameter is normally distributed, and represents the mean and width of the distribution with three branches (or occasionally five) and their respective weights (corresponding to either the $90 \%$ and $95 \%$ uncertainty bounds), as given in Table 2.2.

Table 2.2: Branch weights corresponding to mean and $90 \%$ and $95 \%$ bounds for parameter estimates.

\begin{tabular}{|c|c|c|c|c|c|}
\hline Uncertainty bound & \multicolumn{5}{|c|}{ Branch weights } \\
\hline $90 \%( \pm 1.64$ sigma $)$ & 0.185 & & 0.63 & & .185 \\
\hline \multirow{2}{*}{$95 \%$ ( \pm 1.96 sigma $)$} & 0.13 & & 0.74 & & 0.13 \\
\hline & 0.09 & 0.16 & 0.50 & 0.16 & 0.09 \\
\hline
\end{tabular}

Similarly, alternate models for a calculation - for example, the several $\mathbf{M}-\log A$ models-are also represented by multiple branches in the logic tree, but with weights assigned by expert opinion. The number of possible paths through the whole CS is huge. WG02 explores the range of possible behaviors with a random sampling or Monte Carlo technique. The results of the CS - the calculated probabilities of earthquakes - are described in Chapter 6. For each result we report the mean and $95 \%$ confidence range for a suite of 10,000 model realizations. Through repeated testing of the code we have determined this number to be more than sufficient to ensure that mean and uncertainty bounds are well determined. The CS is carried out in a Fortran 77 program that is described in Appendix G. 


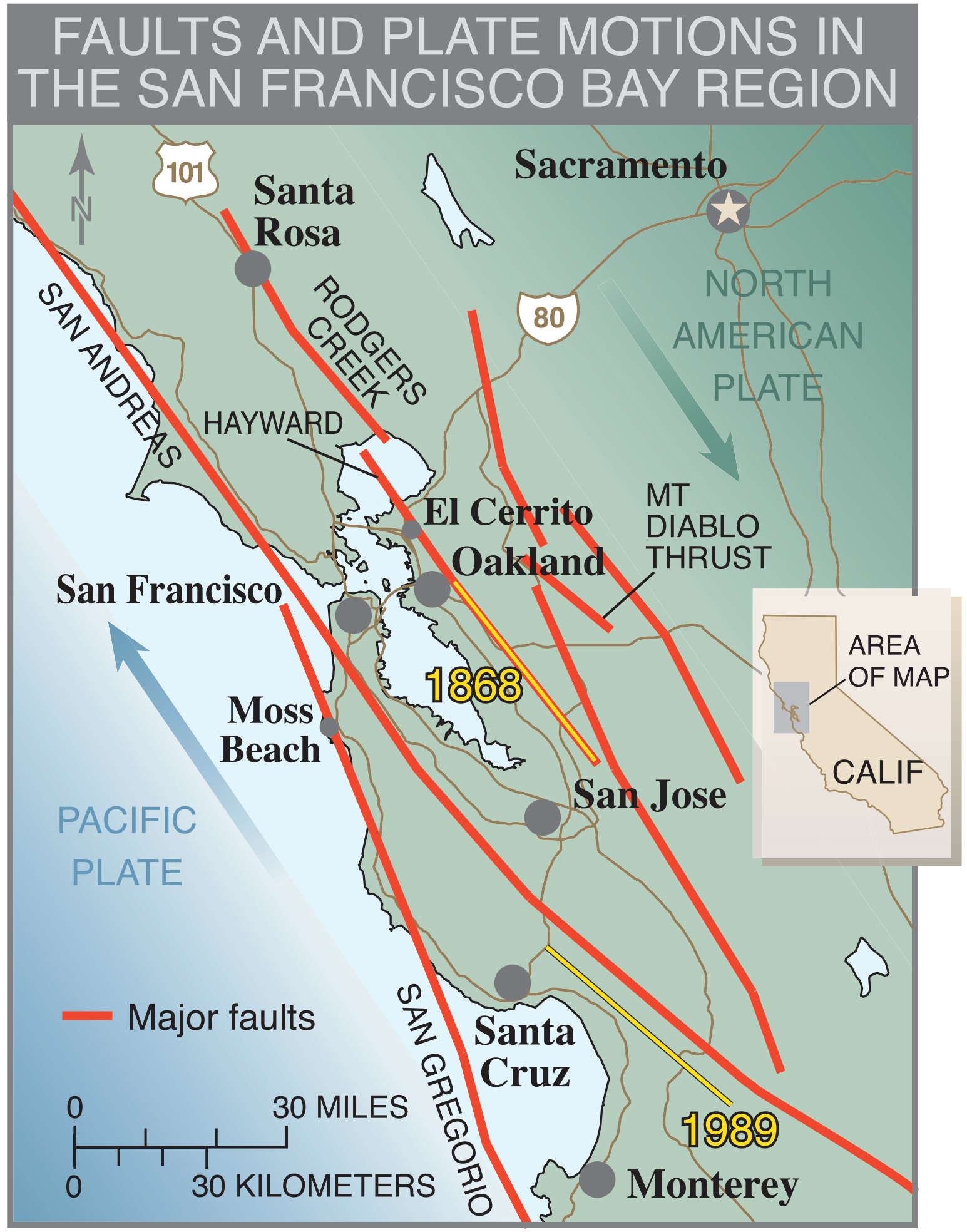

Figure 2.1. Major faults of the San Francisco Bay Region. Arrows show the mostly strike-slip sense of tectonic plate motion accommodated by earthquakes and aseismic creep on SFBR faults. Yellow lines indicate extent of rupture in the 1868 M 6.8 earthquake on the southern Hayward faults and that in the 1989 M6.9 Loma Prieta earthquake near the San Andreas fault northeast of Monterey Bay. 


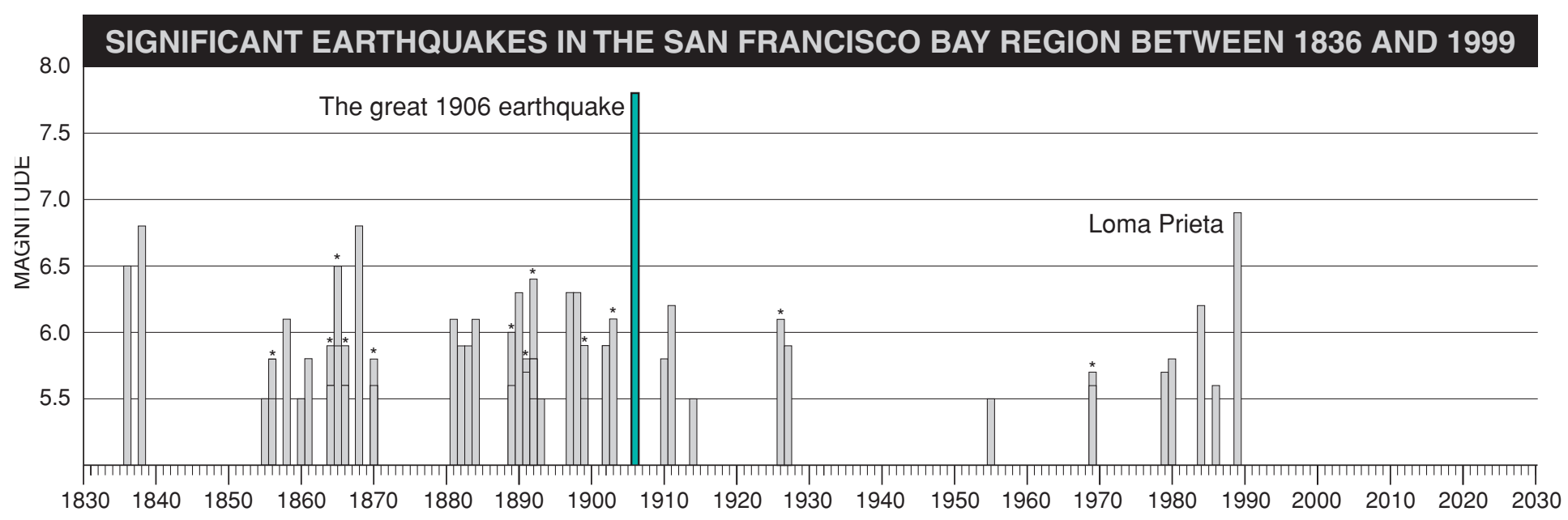

Figure 2.2. Time sequence of earthquakes $M>=5.5$ in the SFBR since the early 19th century, from the catalog of Bakun (1999) The catalog is believed to be complete for such magnitude earthquakes since 1850. A high rate of earthquake activity in the late 1800's was followed by relatively little activity after 1906. Asterisk indicates more than one earthquake occurred that year. 

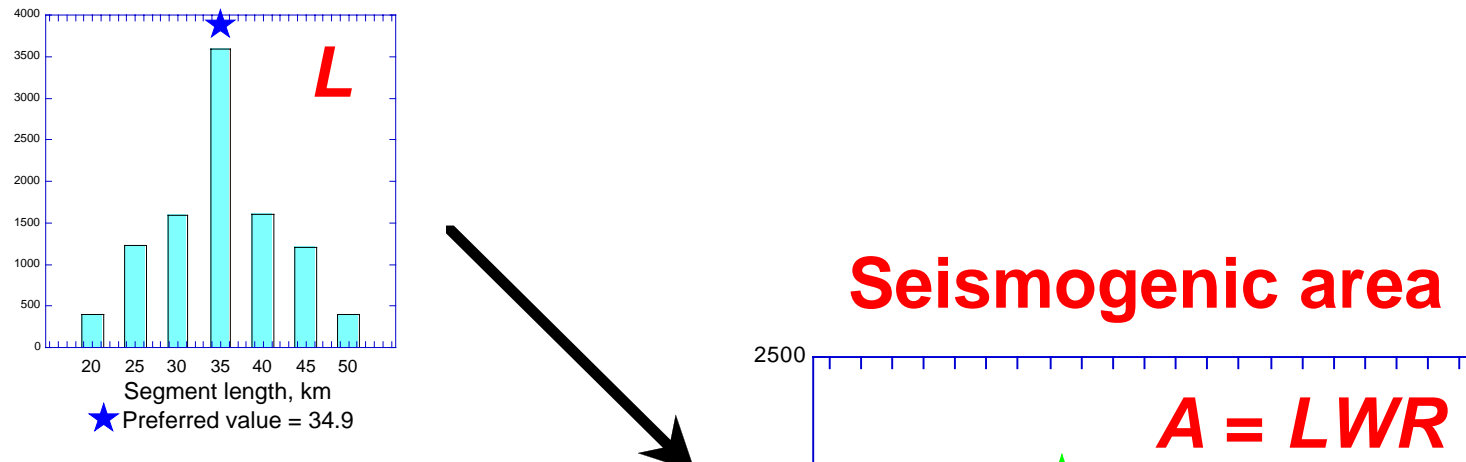

\section{Segment moment rate}
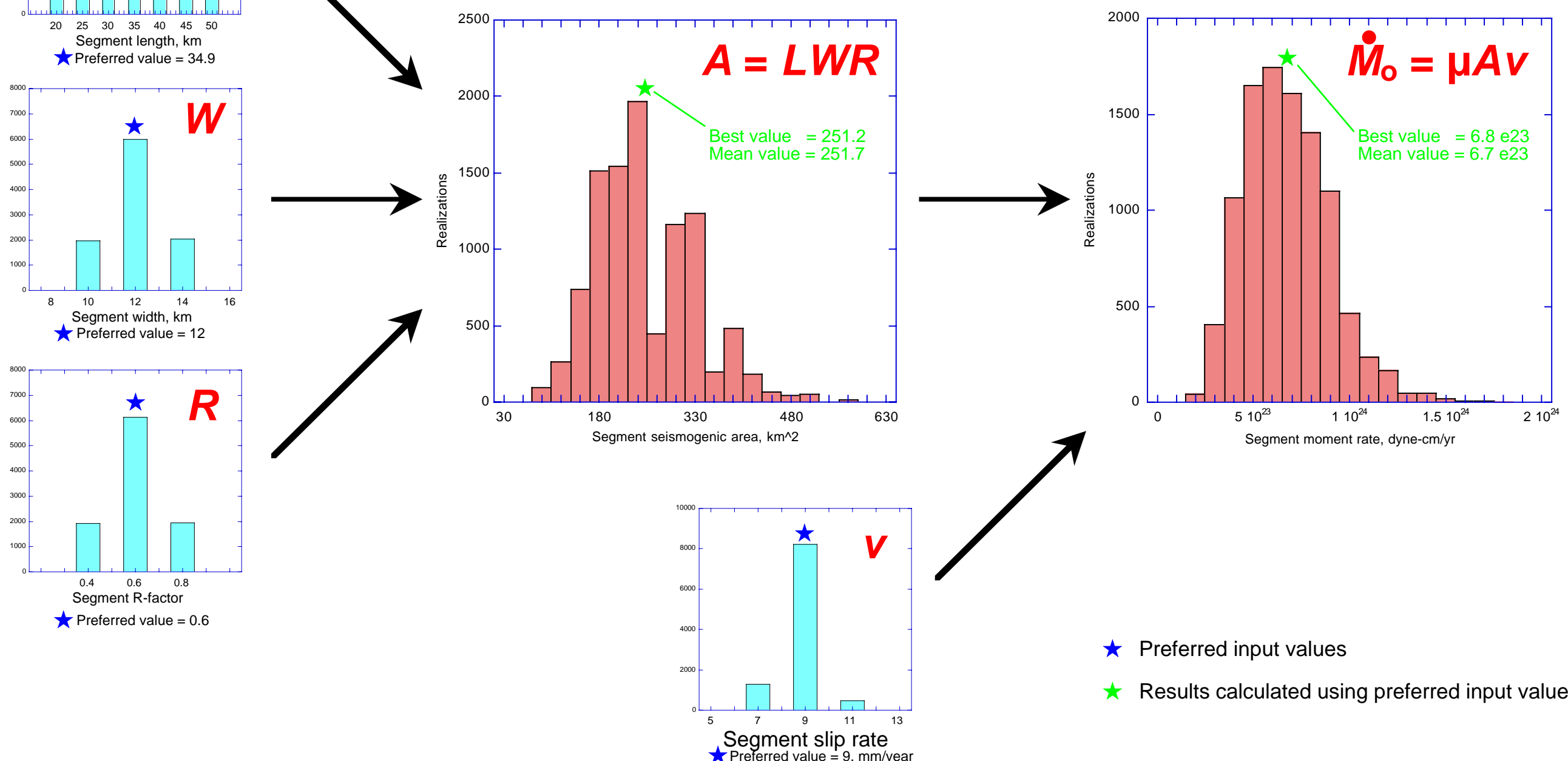

Segment moment rate, dyne-cm/yr

^ Preferred input values

$\star$ Results calculated using preferred input values

Figure 2.3. Illustration of WG02's approach to model calculations. Blue histograms show values and frequencies of fault segment length $\mathrm{L}$, width $\mathrm{W}$, seismogenic scaling factor $\mathrm{R}$, and slip rate $\mathrm{v}$. Red histograms show resulting calculations of seismogenic area $A$ and segment moment rate. This example is for the northern Hayward (HN) segment and the results are from 10,000 realizations of the calculation sequence. 


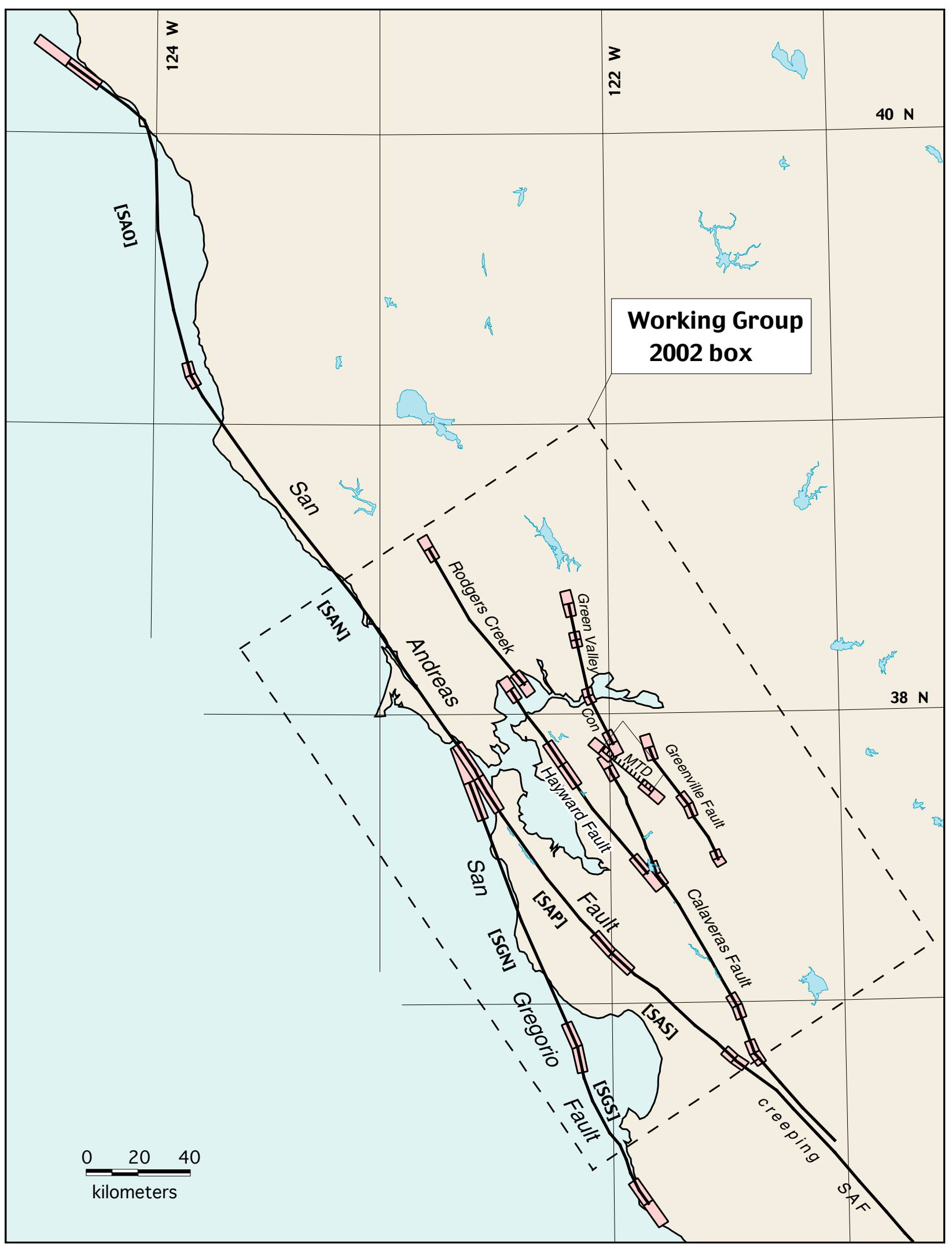

Figure 2.4, Dashed rectangle (Working Group 2002 box) shows the region included for calculation of earthquake probability and seismic moment. Bold solid lines indicate major faults for which probabilities were calculated. MTD, Mount Diablo Thrust; Con, Concord Fault. San Andreas Fault segments: SAN, North Coast; SAO, Offshore; SAP, Peninsula; SAS, Santa Cruz Mountains. San Gregorio Fault segments: SGN, North; SGS, South. 


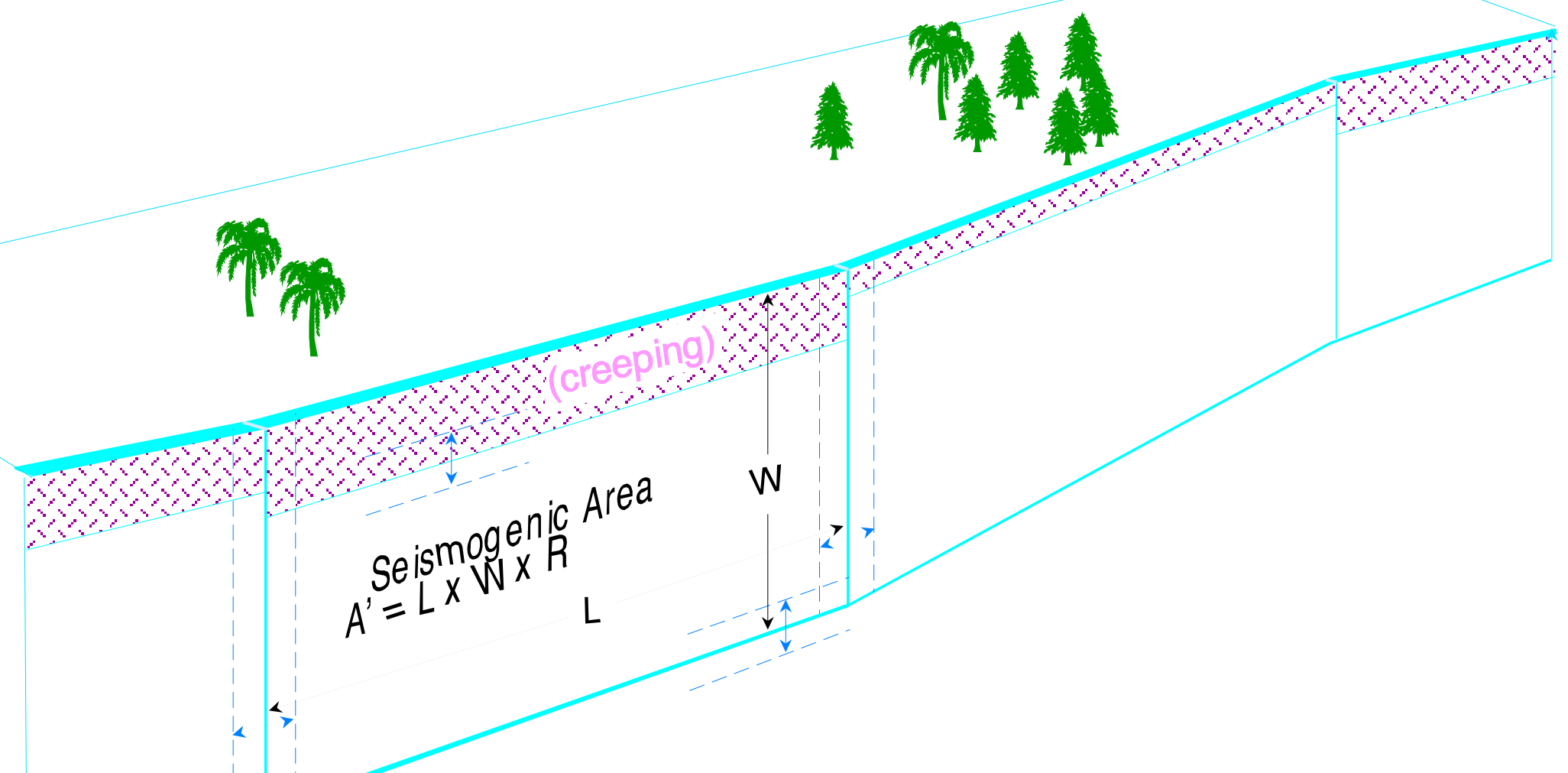

Figure 2.5. Conceptual illustration of a segmented vertical fault. Also shown are measures of length $L$, down-dip width $\mathrm{W}$ and reduction of seismogenic area due to near-surface creep.

Dashed lines illustrate uncertainties in segment endpoint position and other quantities. 


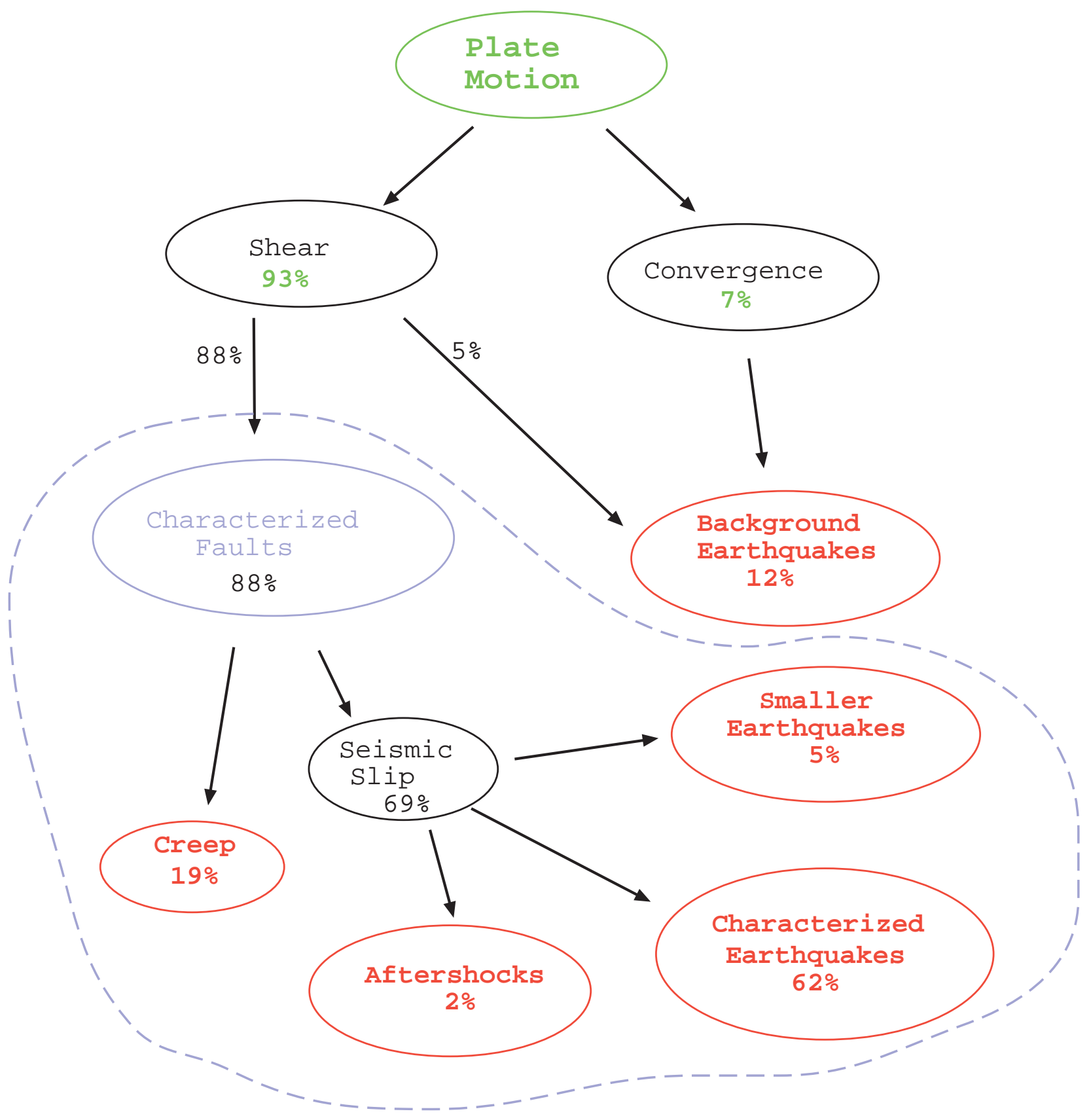

Figure 2.6. Schematic of the SFBR Earthquake Machine. The input (green) plate rate is ouput (red) as characteristic earthquakes, aftershocks, smaller earthquakes in the exponential tail, background earthquakes, and as creep. The approximate part of the total relative plate motion across the SFBR (about $2 \times 10^{\wedge} 18$ N.m/yr of potential seismic moment) are expressed as percents. For example, the earthquake sources characterized in this report account for about $62 \%$ of the total plate motion across the SFBR. 


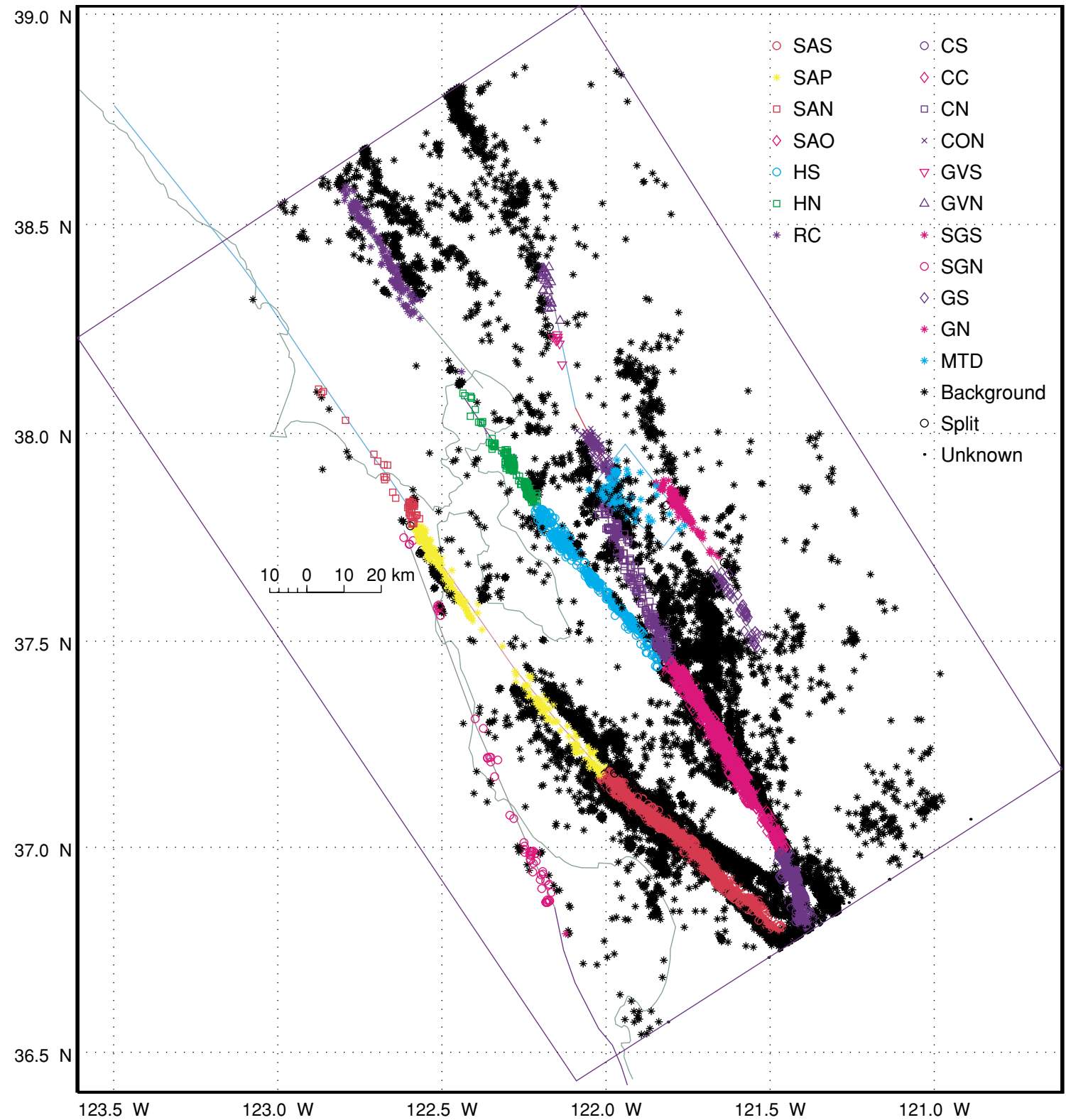

Figure 2.7. Earthquakes from the Northern California Seismic Network catalog in the SFBR. Color and symbol show the dominant probability of association with the WG02 fault segments. (Figure 9 of Wesson, et al., 2003.) 


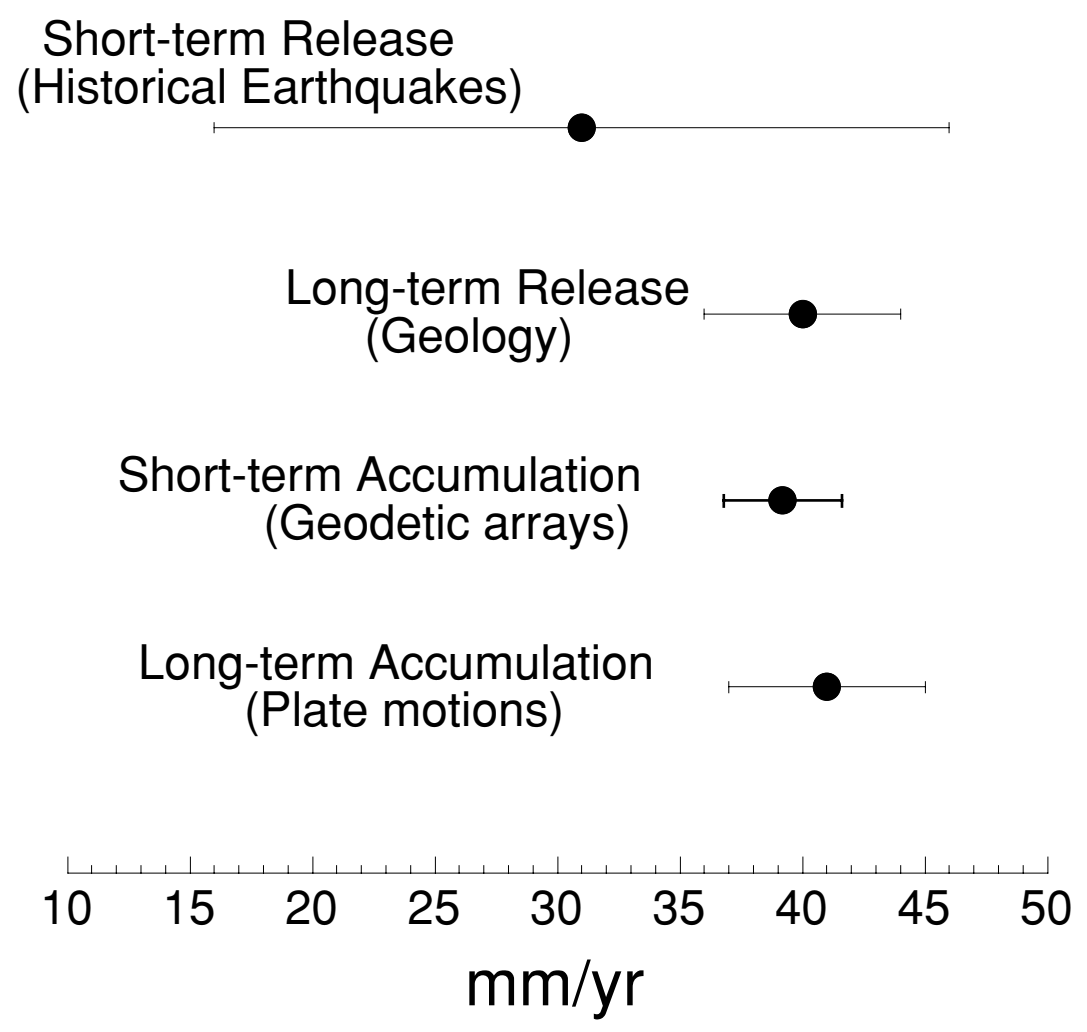

Figure 2.8. Input and output rates of slip for the SFBR earthquake machine. Error bars represent $\pm 2 \sigma$. The long-term and short-term accumulation rates (input to the machine) are obtained from plate-motion rates and geodetic measurements over the past few years respectively. The long-term and short-term release rates (output to the machine) are obtained from geologic slip rates and historical seismicity respectively. 


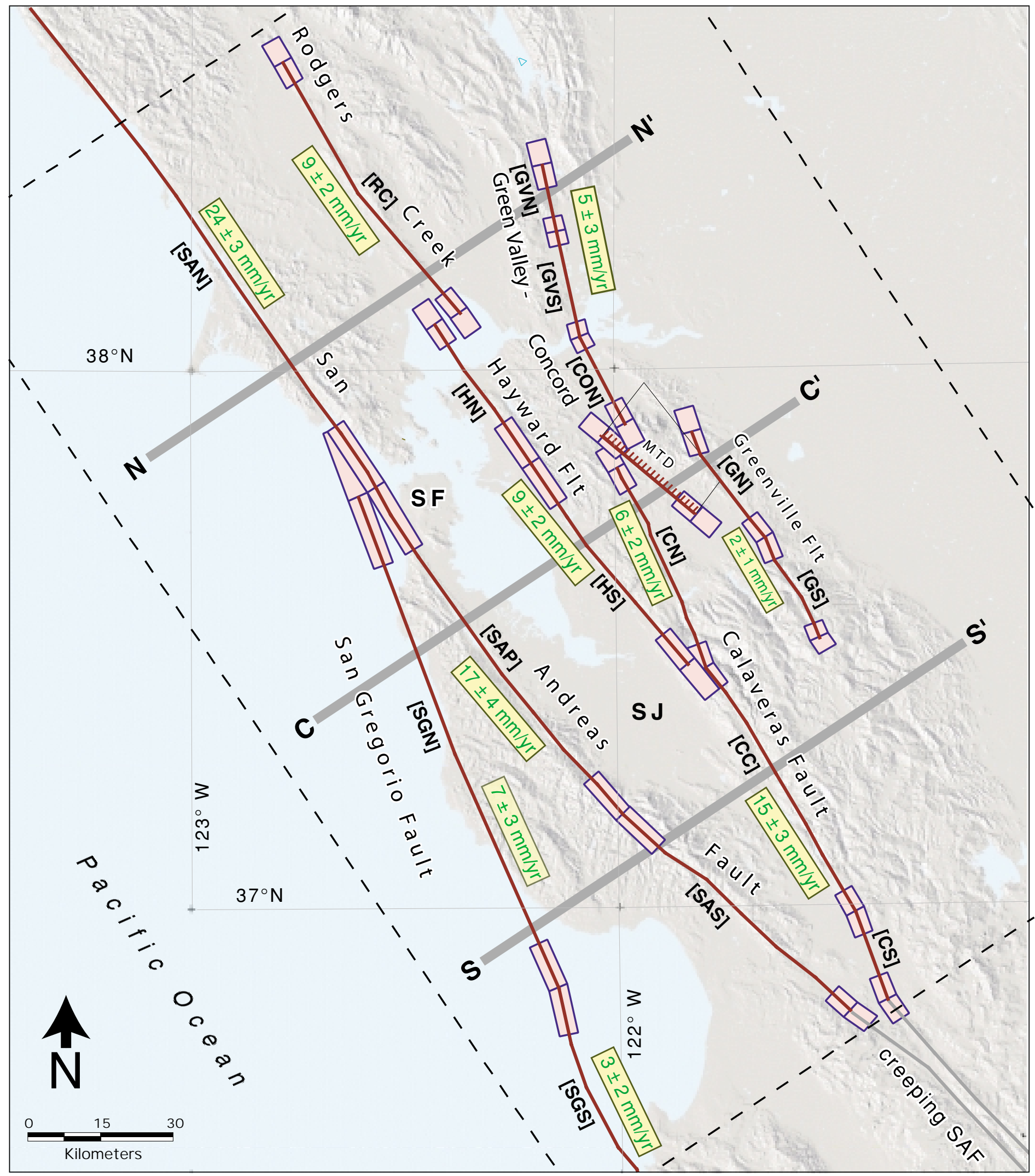

Figure 2.9, WG02 segments and slip rate. Solid gray lines tranverse to the major faults are the three transects used to sum slip rates across the region. 


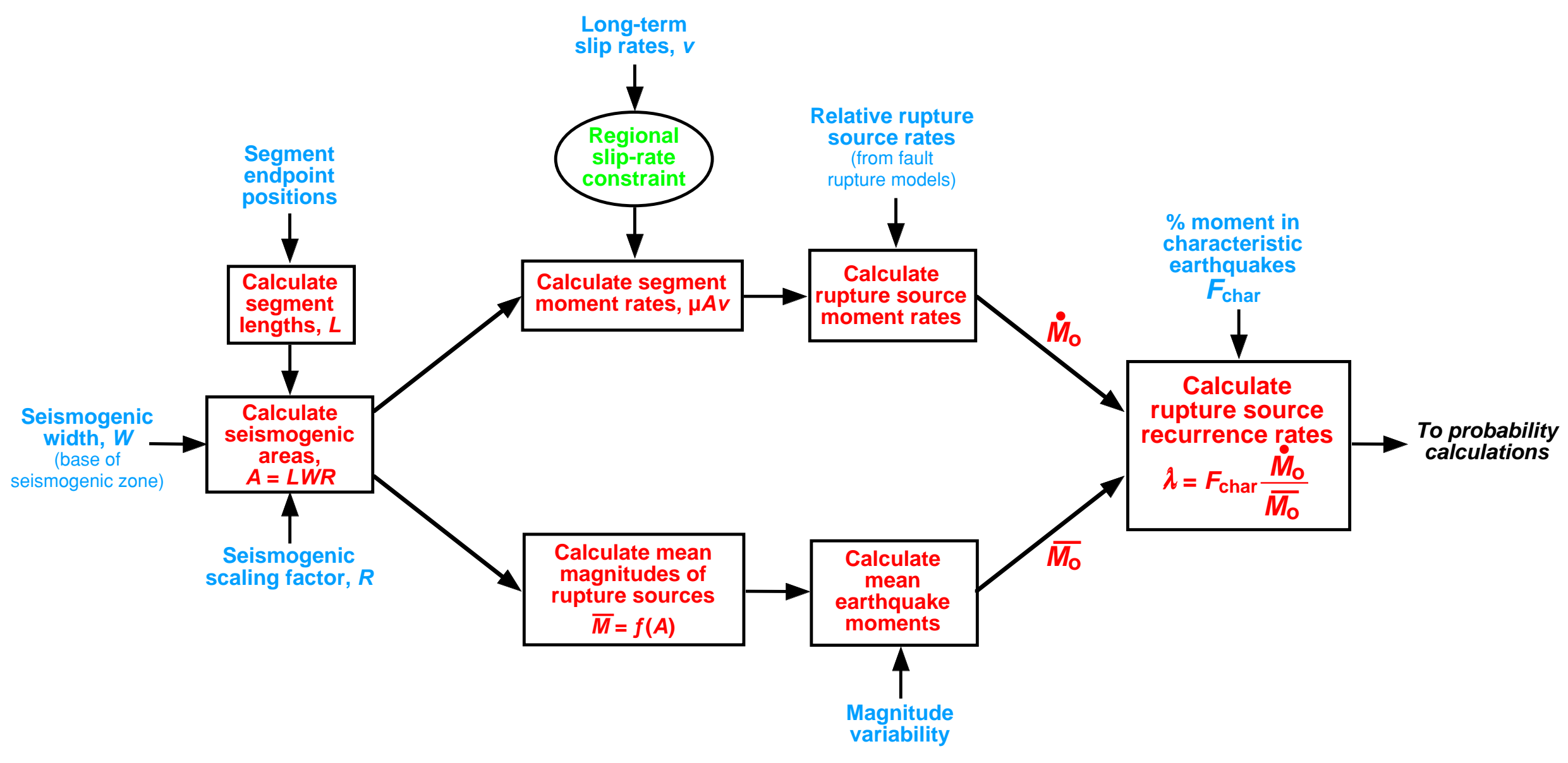

Figure 2.10. Schematic flow-chart illustrating the steps taken to calculate long-term average rupture source rates in the SFBR earthquake model. Blue text shows inputs. Boxes indicate calculation steps. The top path shows steps taken to calculate the moment rate of each rupture source. The bottom path shows the calculation of mean moment per event for those sources. The calculation in the right-most box yields the rupture source rates, which are the primary inputs to the calculation of 30-year probabilities. Not shown are the steps taken to calculate the rate of smaller earthquakes in the exponential tail, and those taken to calculate the rate of background earthquakes. 


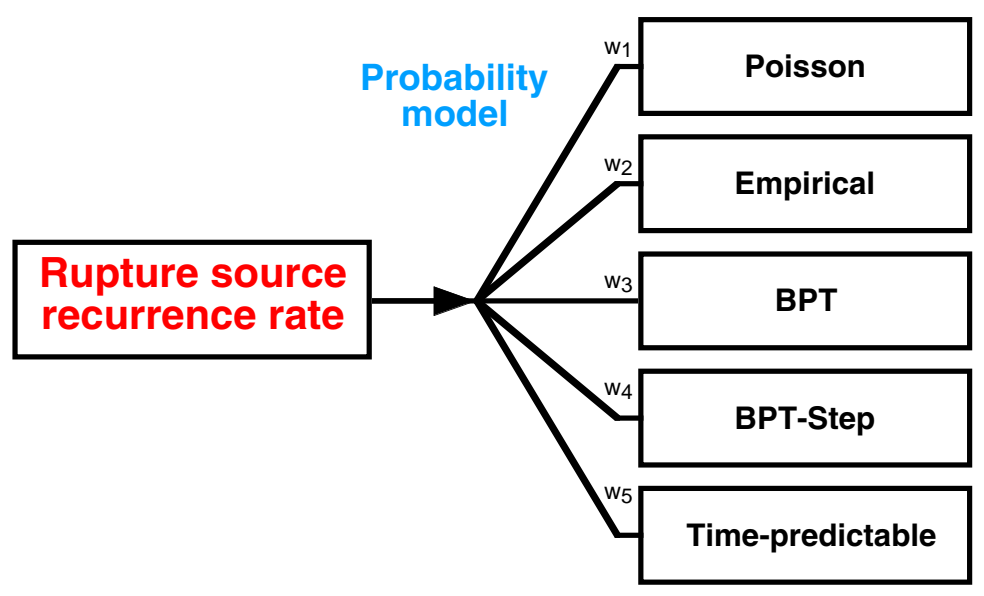

Figure 2.11. WG02 uses five alternative models for calculating probability of earthquakes in a given time interval (e.g., 2002-2031), given the long-term rate of occurrence of rupture sources. Each model requires a different set of additional information, as described in the text. Branch weights $w_{1}-w_{5}$ were determined by expert opinion. 


\section{Chapter 3: Characterization OF THE SFBR EARTHQUAKE SOURCES}

\section{Introduction}

This chapter summarizes the geologic data for the characterized sources of SFBR: the San Gregorio, San Andreas, Hayward-Rodgers Creek, Calaveras, Greenville, Concord-Green Valley faults and the Mt. Diablo thrust (Figure 3.1). These data, to be used as input in the Calculation Sequence of the following chapter, include:

1) Fault Segmentation. The 18 fault segments defined in this study are the basic building blocks of the SFBR earthquake model. Segments and the uncertainty in segment end points are shown in Figure 3.1. Segment names and their acronyms are listed in Table 3.1.

2) Geologic Slip Rates. These determine the average rates of earthquakes as given by the SFBR earthquake model. Geologic slip rates are typically averaged over time periods of hundreds to several tens of thousands of years.

3) Previous Earthquakes: Recurrence and Slip per Event. Recurrence interval data obtained from the paleoseismic record provide important checks on recurrence intervals resulting from the SFBR earthquake model, but such data are sparse for SFBR faults. Timing of the most recent event (MRE) is essential for all of the time-dependent probability models; the MRE displacements are needed in addition for the time-predictable model.

4) Rupture Sources, Rupture Scenarios, and Fault-Rupture Models. These are new concepts developed for this analysis to allow for all possible combinations of earthquake rupture along faults comprised of two or more segments.

5) Data for Determining Fault Area (A). Estimates are summarized for segment or fault width (W), the length of the down-dip extent of the fault from the surface to the base of the seismogenic crust (Appendix A), and the seismogenic slip factor $\mathrm{R}$ for each segment (Appendices B and C). Together with segment lengths (L), these quantities determine segment areas A.

Much of these data can be assembled from the available literature, but the fault segmentation and fault-rupture models presented here are the products of three source-characterization groups (SCG) convened for this purpose. The first of these groups (San Andreas SCG) dealt with the San Andreas and San Gregorio faults, the second (East Bay SCG) with the four East Bay strikeslip faults, and the third (Thrust and Reverse SCG) with regional thrust and reverse faults. These groups were also charged with evaluating newly available data in the context of the existing literature. Each group was composed of geologists, geodecists, seismologists, and geophysicists with expert knowledge of the specific faults and/or the general earthquakesprocess. Each group met in a series of workshops, which led to development of the source characterization inputs presented here. Participants in these groups are listed in Appendix A 
Table 3.1 SFBR segments names and acronyms.

\begin{tabular}{|l|l|l|}
\hline Fault & Seg. & Segment Name \\
\hline \hline \multirow{5}{*}{ San Andreas } & SA0 & Offshore \\
\cline { 2 - 3 } & SAN & North Coast \\
\cline { 2 - 3 } & SAP & Peninsula \\
\cline { 2 - 3 } & SAS & Santa Cruz Mountains \\
\hline Hayward/Rodgers Creek & RC & Rodgers Creek \\
\cline { 2 - 3 } & HN & Northern Hayward \\
\cline { 2 - 3 } & HS & Southern Hayward \\
\hline Conaveras & CN & Northern Calaveras \\
\cline { 2 - 3 } & CC & Central Calaveras \\
\cline { 2 - 3 } & CS & Southern Calaveras \\
\hline San Gregorio & GVN & Northern Green Valley \\
\cline { 2 - 3 } & GVS & Southern Green Valley \\
\cline { 2 - 3 } & CON & Concord \\
\hline Greenville & SGN & Northern San Gregorio \\
\cline { 2 - 3 } & SGS & Southern San Gregorio \\
\hline Mount Diablo Thrust & GN & Northern Greenville \\
\cline { 2 - 3 } & GS & Southern Greenville \\
\hline
\end{tabular}

\section{FAULT SEGMENTATION}

\section{Fault Segments, Rupture Sources, Rupture Scenarios, and Rupture Models}

A fault segment is the basic building block for each fault, the shortest section considered capable of repeatedly rupturing to produce the large earthquakes of interest here. Fault segments are identified according to two criteria: kinematic considerations, such as geometry and structure, and dynamic considerations, such as timing, rupture length, and displacements of previous earthquakes Kinematic considerations include changes in strike, the occurrence of restraining bends or extensional steps, branching or intersection points, changes in fault complexity, and major changes in lithology along the fault. Because earthquakes may respect none of these features, kinematic segmentation alone can be uncertain. Most important of the dynamic considerations are differences in timing of events on adjacent parts of a fault based on paleoseismic dates and/or historical ruptures. Changes in fault slip rate, the distribution and nature of microearthquake activity, and the transition to or changes in the rate of creep along a fault are also indicators of potential segmentation points. Within the limits of the available data all of these indicators were utilized to identify the fault segments presented here. The floating earthquake is also introduced as part of the fault characterization. This is an earthquake, with magnitude and length fixed by the historical record, that can occur on a fault at locations other than the segments defined in the current characterization.

If SFBR earthquakes arose only from single-segment ruptures, making and counting earthquakes in the slip-rate balanced format of the SFBR earthquake model would be a straightforward calculation. Indeed, this was the basis for the WG90 report, calculating single-segment rupture 
rates and probabilities for the three segments of the Hayward-Rodgers Creek fault and three segments of the San Andreas fault. The geologic evidence is clear, however, that multiplesegment ruptures can and do occur in the SFBR, most recently during the 1906 earthquake in which all three of the WG90 segments, and all four of the segments that comprise the San Andreas fault in this study, ruptured.

WG02 differs from WG 90 not only in the definition and characterization of the fault segments, but in allowing multiple segment ruptures. To accommodate multiple segment ruptures WG 99 introduced the concepts of rupture source, rupture scenario, and rupture model. The HaywardRodgers Creek fault serves as an example for these (Figure 3.2). A rupture source is a single fault segment, or a combination of two or more adjacent segments, that produces an earthquake. For the Hayward- Rodgers Creek fault there are three rupture segments: southern Hayward (HS), northern Hayward ( HN), and Rodgers-Creek (RC) (Figure 3.2a). The Hayward-Rodgers Creek fault, then, has six possible, rupture sources: three single-segment rupture sources (HS, HN, and $\mathrm{RC}$ ), two two-segment rupture sources (HS+HN and $\mathrm{HN}+\mathrm{RC}$ ) and one three-segment rupture source (HS+HN+RC) (Figure 3.2b). Slip in multiple segment ruptures is larger than in the corresponding set of single-segment ruptures. An important consequence of allowing for multiple-segment ruptures, then, is that larger their larger slip reduces the rates of single-segment ruptures. In addition to these characterized rupture sources, floating earthquakes of $\mathbf{M}=6.9$ can occur anywhere along the Hayward-Rodgers Creek fault.

A rupture scenario is a combination of rupture sources that describes a possible mode of failure of the entire fault during one earthquake cycle. For the Hayward-Rodgers fault, there are four characterized fault-rupture scenarios: 1) HS, HN, and RC as single-segment ruptures; 2) SH as a single-segment rupture and $\mathrm{HN}+\mathrm{RC}$ as a two-segment rupture; 3) $\mathrm{RC}$ as a single-segment rupture and $\mathrm{SH}+\mathrm{HN}$ as a two-segment rupture; and 4) $\mathrm{HS}+\mathrm{HN}+\mathrm{RC}$ as a three-segment rupture (Figure 3.2c). A fifth fault-rupture scenario is the entire Hayward-Rodgers Creek fault failing only as a result of the floating earthquakes.

Fault-rupture models are weighted combinations, expressing the expert opinion of the appropriate source-characterization group, of the fault-rupture scenarios. Each rupture model is a proposed representation of the long-term behavior of the fault. Specifically, group members were asked the following question: If the entire length of a fault failed completely 100 times, what would be the frequency (percentage) of each rupture scenario? Fault rupture models for the Hayward-Rodgers Creek fault, with weights assigned to each scenario and to each model, are illustrated in Figure 3.2d. These models reflect the considered opinion of the source characterization groups about the strength and persistence of segmentation points. For example, if dates of historical and paleoearthquakes indicated that different parts of the fault had ruptured at distinctly different times, and if there were geometric changes associated with these locations, then a rupture model would likely contain a higher percentage of rupture scenarios with individual segments. If dates of paleoearthquakes along the fault overlapped, or if geometric changes were minor, this would be reflected by a rupture model that allowed for a larger percentage of multi-segment ruptures.

The product of rupture scenario and model weights provides a general estimate of the mean rate of occurrence of each rupture source (different size earthquakes) for each of the characterized 
SFBR faults. However, both earthquake size and fault slip rate affect the straightforward calculation of recurrence in this way. For example, Hayward-Rodgers Creek rupture scenario 3 contains two ruptures sources--a single segment source (RC) and a multi-segment source (HN+HS) (Figure 3.2b). Because the $\mathrm{HN}+\mathrm{HS}$ source is longer it produces a larger earthquake with more slip, and the RC segment must fail more frequently given that the slip rate is constant along the fault length. To account for this, slip rates must be applied to the rupture scenarios for the purpose of recalculating frequency of rupture, a process referred to as moment balancing (Chapter 4). Complexity is added for faults that have variable slip rates along their length such as the San Andreas and the Calaveras, and by including a floating earthquake.

The moment balancing used in the rupture frequency calculations was developed and applied after the source characterization groups had completed their efforts. Because of this, the SCG's did not have the opportunity to review and compare the moment-balanced results. Rather than reconstitute the SCG's for this purpose, a subset of the Overview Group compared the rupture frequencies from the weighted source characterization models to those calculated after the moment-balancing step (Appendix G). While there are small differences, the overall intent of the characterization groups with regard to the behavior of each fault has been maintained through this process.

\section{SOURCE CHARACTERIZATION OF THE SFBR FAULTS}

\section{San Andreas Fault}

The San Andreas fault alone accounts for more than half of the geologic slip rate across SFBR and more than $90 \%$ of the SFBR seismic moment sum in the historical record. Three of the four historical SFBR $M \geq 6.7$ earthquakes (1838, 1906, and 1989) have occurred on or near the San Andreas fault. The 470-km rupture length of the 1906 earthquake is, by far, the longest known surface rupture for strike-slip earthquakes in continental crust.

\section{$\underline{\text { Segmentation }}$}

WG 90 divided the San Andreas fault into three segments: the North Coast, Peninsula, and southern Santa Cruz Mountains segments. The basis for this was a combination of data from the 1838, 1906, and1989 earthquakes, variability in the distribution of geodetically determined slip in the 1906 earthquake (Thatcher and Lisowski, 1987), and changes in the strike of the fault. The North Coast segment was considered to fail only in 1906-type ruptures. The likely occurrence of the 1838 earthquake along the fault on the San Francisco peninsula suggested the existence of the Peninsula segment, with a southern boundary at the north end of the Loma Prieta aftershock zone and a northern boundary at Lower Crystal Springs Reservoir. The latter location is the site of a $5^{\circ}$ releasing bend and is also where slip in 1906 was geodetically inferred to decrease from $4 \mathrm{~m}$ to $2.5 \mathrm{~m}$. WGNCEP 96 and Petersen and others (1996) concluded that the north end of the Peninsula segment should be near the Golden Gate to reflect the revised 1906 geodetic slip distribution (Thatcher and others, 1997) which moved the major decrease in displacement from Lower Crystal Springs Reservoir to a point offshore of the Golden Gate. 
Consistent with WGNCEP 96 segmentation, the San Andreas SCG divided the San Andreas fault into four major segments: Offshore (SAO), North Coast (SAN), Peninsula (SAP), and Santa Cruz Mountains (SAS). The segments and their boundaries are shown in Figure 3.1 and Figure 3.3.

SAO. The 135-km long SAO segment subdivides the 1906 rupture north of the Golden Gate. Little is known about this part of the fault because it is largely offshore. The northern boundary is at the geodetically-determined end of the 1906 rupture (Thatcher and others,1997), and the southern boundary is placed in a $\pm 5 \mathrm{~km}$ long zone offshore of Pt. Arena, where a $10-15^{\circ}$ change in the strike of the fault occurs. The 1898 earthquake $(\mathbf{M}=6.8)$ produced extensive damage along the Mendocino County coast and may have occurred on the southern part of SAO (Bakun, 2000). Thatcher and others (1997) inferred a step in 1906 displacements near Pt. Arena and increasing fault slip to the northwest.

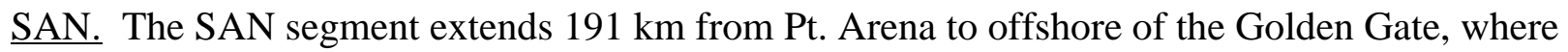
a structurally complex intersection between the San Andreas and San Gregorio faults is located. Here, a 3-km right-releasing step along the San Andreas fault is inferred from aeromagnetic, seismic-reflection, and seismicity data (Jachens and Zoback, 1999; Zoback et.al., 1999). Slip in the 1906 earthquake decreases from an average of $5.3 \pm 0.3 \mathrm{~m}$ north of the Golden Gate to $3.3 \pm$ $0.3 \mathrm{~m}$ on the Peninsula (Thatcher, 1999) (Figure 3.4). There is also a change in the geologic slip rate, with the late-Holocene rate decreasing southward across the Golden Gate from $24 \mathrm{~mm} / \mathrm{yr}$ to $17 \mathrm{~mm} / \mathrm{yr}$ (Schwartz and others, 1998; Hall and others, 1999). The 1906 event is thought to have nucleated in this area. An uncertainty of $\pm 15 \mathrm{~km}$ is assigned to the south end of this segment (Figure 3.1).

SAP. The Peninsula segment extends $85 \mathrm{~km}$ from the Golden Gate southeast to Los Gatos. The southern end lies in a broad zone $( \pm 10 \mathrm{~km})$ coincident with a restraining bend in the fault, the north end of the Loma Prieta aftershock zone, and a major lithologic change defined by the north end of the Logan Gabbro. The 1838 earthquake has been located on this part of the San Andreas fault (Louderback, 1947; WG 88, WG 90). Toppozada and Borchardt (1998) concluded that the 1838 event occurred on the Peninsula and Santa Cruz Mountains segments with a magnitude of 7.5. They based this on intensity data at Monterey (MMI VI) only and interpreted this intensity as requiring a rupture form Golden Gate to San Jaun Bautista. Using the same intensity reports, Bakun (1999) interpreted the Peninsula segment as a high probability location, but estimated the $\mathrm{M}$ to be 6.8. Paleoseismic studies at the Filoli site allow the possibility that $1.6 \mathrm{~m}$ of offset occurred during an earthquake that post-dates 1650, which could be 1838 slip (Hall and others, 1999). While it seems reasonable that the 1838 earthquake occurred on the Peninsula segment, there are no unequivocal observations placing the 1838 event on the San Andreas fault.

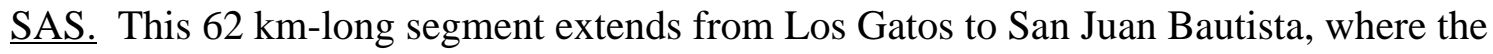
transition to aseismic slip occurs. SAN is similar in length to that delineated by WG90, WGNCEP96, and Petersen and others (1996). Independent behavior of this segment is indicated by the timing of past events, evidently different from the Peninsula segment to the north. Evidence from Grizzly Flat (Schwartz and others, 1998) and Arano Flat (Heingartner and Schwartz,1996; Fumal, and others,1999) indicates that rupture of the 1838 earthquake did not extend into the Santa Cruz Mountains as suggested by Toppozada and Borchardt (1998). 
Schwartz and others (1998) concluded that only one surface rupture, that in 1906, has broken this segment of the fault since AD 1640-1659. WG02 considers this section of the San Andreas fault to be distinct from the reverse-oblique source of the 1989 Loma Prieta earthquake.

Other potential segments. The San Andreas SCG also discussed other possible San Andreas segments, most notably one between Pt. Arena and Ft. Ross. Here, a 50-km-long low in1906 slip has been determined from geodetic data (Thatcher et al, 1997), which is coincident with a similar low in the 1906 surface offsets (Lawson, 1908). Noller and Lightfoot (1997) obtained a minimum late-Holocene slip rate of 16-18 mm/yr based on the displacement of an archaeological site at Fort Ross. Just to the south of Fort Ross, Prentice and others (2001) suggest a preliminary slip of $18 \pm 3 \mathrm{~mm} / \mathrm{yr}$ for the past $\sim 5000$ years. If the $24 \mathrm{~mm} / \mathrm{yr}$ slip rate assigned to the North Coast is uniform across this reach of the fault, the slip low could fill in with an earthquake of about M 7, a magnitude consistent with this length of fault. Having no information on slip in the pre-1906 earthquake and given the slip rate uncertainties, a distinct Ft. Ross segment is not presently defined. The potential for this type of rupture is treated with the use of a floating $\mathrm{M}$ 6.9 earthquake.

\section{$\underline{\text { Slip Rate }}$}

WG 90 used a uniform slip rate of $19 \pm 4 \mathrm{~mm} / \mathrm{yr}$ along the length of the 1906 rupture, which was based on geologic rates, geodetic rates, and estimates of slip from the 1906, and1989 earthquakes. Paleoseismic data developed since1990, however, indicate the San Andreas slip rate decreases south of the Golden Gate (WGNCEP, 1996; Schwartz and others, 1998; Hall and others, 1999). At Point Arena, Prentice (1989) estimates a slip rate of $\leq 25 \pm 2.5 \mathrm{~mm} / \mathrm{yr}$ and a preferred rate of $23 \pm 3 \mathrm{~mm} / \mathrm{yr}$ for the past 2350-2700 years based on offset of a buried channel. Niemi and Hall (1992) conclude that the slip rate at the Vedanta site near Olema is $24 \pm 3 \mathrm{~mm} / \mathrm{yr}$ for the past $1800 \pm 78$ years. Trenches at the Filoli site on the San Francisco Peninsula exposed an offset paleochannel that yields a slip rate of $17 \pm 4 \mathrm{~mm} / \mathrm{yr}$ for the past 2000 years (Hall and others, 1999). WGNCEP 96 used the Point Arena and Olema results to estimate a slip rate of 24 $\pm 3 \mathrm{~mm} / \mathrm{yr}$ for the San Andreas north of the Golden Gate and used the Filoli results of $17 \pm 4$ $\mathrm{mm} / \mathrm{yr}$ for the SAP slip rate south of the Golden Gate. WG99 uses the $24 \pm 3 \mathrm{~mm} / \mathrm{yr}$ slip rate for the SAO and SAN segments and uses the $17 \pm 4 \mathrm{~mm} / \mathrm{yr}$ slip rate for the SAP segment and also for the SAS segment, for which there is no measured geologic rate. In the Santa Cruz Mountains, active deformation occurs across a broad volume of crust adjacent to the San Andreas fault, as indicated by the Loma Prieta rupture and the Sargent fault. The partitioning of slip onto these faults could reduce the long-term rate of the SAS.

\section{Previous Earthquakes: Recurrence and Slip per Event}

Prentice (1989) found evidence near Pt. Arena for at least five surface-faulting earthquakes during the past 2000 years. Although the dating of individual earthquakes was poorly constrained, Prentice (1989) concludes that the recurrence of ruptures along this part of the fault range from 188 to 340 years, averaging about 260 years. At the Vedanta site, Niemi (1992) and Niemi and Hall (1992) identify two pre-1906 surface faulting earthquakes in trenches across marsh deposits. The third event back was estimated to have occurred between AD 1276 and 1450; the penultimate event occurred after AD 1427-1629. In more recent work at Vedanta, Niemi and others (2002) have identified the occurrence of a least seven surface rupturing events during the past 2000 to 2500 years. Of these, at least four have occurred since $850 \mathrm{AD}$, and three 
since $1250 \mathrm{AD}$, suggesting average recurrences of about 300 years for earthquakes rupturing this SAN location. South of the Santa Cruz mountains at Arano Flat, preliminary analysis of offset fluvial deposits suggests as many as six surface-rupturing events since 1100 AD (Fumal and others, 1999). This implies a recurrence interval shorter that than the North Coast and may reflect higher activity near the transition between the locked and creeping section of the fault.

Schwartz and others (1998) compared dates of the penultimate earthquake(s) at sites along the 1906 rupture north of San Francisco and in the Santa Cruz mountains. They concluded that the similarity of ages indicated the San Andreas fault may have failed either as a sequence of closely timed earthquakes on adjacent segments or as a single long rupture similar to the 1906 earthquake near the mid 1600s, the latter interpretation being preferred. They estimated the penultimate event dates to AD 1600 to 1670, yielding an interval of 235 to 300 years between it and the 1906 earthquake, although a narrower range of AD 1630 to 1660 was also permitted by the radiocarbon dating. At Bolinas Lagoon and Bodega Harbor on SAN, Knudsen and others (2001) found buried peats at two levels. In view of the coseismic subsidence that occurred at Bolinas in 1906, Knudsen and others (2001) interpret their buried peats as an expression of coseismic subsidence from earlier events. Dating of the lower peat indicates subsidence between $\mathrm{AD} 1290$ and 1340. If this dates a large earthquake, the interval between it and the penultimate event on the SAN is 260 to 380 years. The date of the older submerged peat at Bolinas lagoon is similar to the third event back at Vedanta and consistent with preliminary dates for an event at Arano flat near Watsonville (Fumal and others, 1999). While the uncertainties are considerable, these data together are consistent with the occurrence of a long rupture, similar to 1906, in the early 1300s. Overall, the paleoseismic observations indicate recurrence intervals for large earthquakes on the San Andreas fault, and particularly on SAN, to be several hundred years (ranging from 180 to 370 years).

Slip per event is diagnostic of rupture length of past earthquakes; large-earthquake slip is associated with long earthquake ruptures. Unfortunately, along the $470 \mathrm{~km}$ length of the 1906 rupture, only one location has been found where paleoseismic slip has been measured. At Pt. Arena, Baldwin and others (2001) found a paleochannel margin offset $4 \mathrm{~m}$ during the penultimate event, which is comparable to the $4.9 \mathrm{~m}$ measured near the site in 1906 . This paleoseismic evidence for repeating long ruptures, of which the 1906 earthquake is just the most recent example, has played an important role in the source- characterization group's decisions regarding long-term rupture models of the San Andreas fault.

\section{Rupture Sources and Scenarios}

For the four-segment representation of the San Andreas fault, there are ten rupture sources and nine possible rupture scenarios, including the floating-earthquake scenario. The rupture scenarios are illustrated in Figure 3.4.

(1) $\mathrm{SAO}+\mathrm{SAN}+\mathrm{SAP}+\mathrm{SAS}$ : This scenario provides for simultaneous rupture of all four segments, our 1906 facsimile earthquake rupture. A similar may have occurred in the early to mid 1600s (Schwartz and others, 1998) and in the early 1300s (Knudsen and others, 1999). 
(2) SAO+SAN, SAP+SAS: This is a two source scenario with a segmentation point at the Golden Gate. Toppozada and Borchardt (1998) interpret the 1838 earthquake as a combined SAP + SAS rupture.

(3) SAO+SAN, SAP, SAS: This scenario treats the two northern segments as one and the two southern segments as separate earthquake sources. Bakun (1999) interprets the 1838 earthquake as confined to the SAP.

(3A) SAO+SAN+SAP, SAS: This scenario has the three northern segments rupturing as one, almost but not quite the 1906 earthquake facsimile (Scenario (1)), and the southern segment as an independent source.

(4) SAO, SAN, SAP, SAS: This scenario represents independent rupture of each segment.

(4A) SAO, SAN, SAP+SAS: This scenario permits independent rupture of the two northern segments and simultaneous rupture of the two southern segments.

(4B) SAO, SAN+SAP, SAS: This scenario provides for independent rupture of the northern and southern segments and simultaneous rupture of the two middle segments..

(4C) SAO, SAN+SAP+SAS: This scenario has the northern segment rupturing by itself, with the other three segments rupturing together.

(5) Floating $\mathbf{M}=6.9$ earthquakes: This scenario provides for strain release to be achieved by randomly placed floating earthquakes. The historical record indicates M 7 earthquakes near or along various segments of the northern San Andreas fault in 1838 (M 6.8), 1898 (M 6.8), and 1989 (M 6.9). The magnitudes of these events are the basis for the $M$ of the floating earthquake used here.

\section{Fault Rupture Models}

The rupture scenarios presented above form a set of the possible ways in which the San Andreas fault can rupture in the course of an earthquake cycle, given our four-segment/floating earthquake representation of it. No one scenario is likely to be the only way the San Andreas fault works. The San Andreas SCG combined these rupture scenarios in different ways to define, in the end, five fault-rupture models that represents its best collective judgment about the alternative ways in which the fault can rupture in earthquakes. These models (A to E) are presented as columns in Table 3.2, with the nine rupture scenarios appearing as rows. Models are defined by the scenario weights entered as elements of the matrix. The model weights are given at the bottom of Table 3.2.

What is apparent from Table 3.2 is that the San Andreas SCG is that four of the models (excepting model D) contain a high percentage of scenario 1. The strong preference for scenario 1 reflects the consensus view of SA/SA SCG that the fundamental behavior of the San Andreas fault is expressed as full-length, 1906-type earthquakes, which is suggested by both the historical and paleoseismic records. Scenarios 2 and 3 have in common the Golden Gate segmentation point's being a significant feature of the mechanics of the San Andreas fault. It defines the 
intersection of the San Gregorio and San Andreas faults and is the locus of the slip-velocity change along the San Andreas fault. The only difference between these two scenarios is whether the southern two segments SAP and SAS rupture in unison or separately, with San Andreas SCG opinion favoring the former interpretation in the model weightings by more than $2: 1$. Toppozada and Borchardt (1998) interpret the 1838 earthquake as rupturing both SAP and SAS, but Bakun (1999) does not. Neither does the paleoseismic evidence at Grizzly Flat (Schwartz et al, 1998) show evidence of rupture of the 1838 earthquake through the Santa Cruz Mountains. Finally, the floating-earthquake scenario reflects SCG opinion, based on the historical seismic record, that considerable opportunity exists for the occurrence of $\mathbf{M}=6.9$ earthquakes without regard to the four-segment characterization of the San Andreas fault.

As discussed later, these fault-rupture models and the weighting applied to them by the San Andreas SCG will lead to a relatively large number of large magnitude events $(\mathbf{M} \geq 7.5)$ on the San Andreas fault, given the mean magnitudes of earthquakes arising from $\mathrm{SAO}+\mathrm{SAN}+\mathrm{SAP}+\mathrm{SAS}$ and $\mathrm{SAO}+\mathrm{SAN}$.

Table 3.2. San Andreas Fault Rupture Models and Weights

\begin{tabular}{|c|c|c|c|c|c|}
\hline Rupture Scenario & Model A & Model B & Model C & Model D & Model E \\
\hline 1 SAO+SAN+SAP+SAS & $76 \%$ & $45 \%$ & $56 \%$ & $24 \%$ & $49 \%$ \\
\hline $2 \mathrm{SAO}+\mathrm{SAN}, \mathrm{SAP}+\mathrm{SAS}$ & $5 \%$ & $45 \%$ & $4 \%$ & $36 \%$ & $8 \%$ \\
\hline 3 SAO+SAN, SAP, SAS & $14 \%$ & $0 \%$ & $12 \%$ & $16 \%$ & $4 \%$ \\
\hline $3_{\mathrm{A}} \mathrm{SAO}+\mathrm{SAN}+\mathrm{SAP}, \mathrm{SAS}$ & $0 \%$ & $0 \%$ & $8 \%$ & $0 \%$ & $0 \%$ \\
\hline 4 SAO, SAN, SAP, SAS & $0 \%$ & $0 \%$ & $0 \%$ & $0 \%$ & $8 \%$ \\
\hline $4_{\mathrm{A}} \mathrm{SAO}, \mathrm{SAN}, \mathrm{SAP}+\mathrm{SAS}$ & $0 \%$ & $0 \%$ & $0 \%$ & $2 \%$ & $3 \%$ \\
\hline $4_{\mathrm{B}} \mathrm{SAO}, \mathrm{SAN}-\mathrm{SAP}, \mathrm{SAS}$ & $0 \%$ & $0 \%$ & $0 \%$ & $0 \%$ & $0 \%$ \\
\hline $4_{C} \mathrm{SAO}, \mathrm{SAN}+\mathrm{SAP}+\mathrm{SAS}$ & $0 \%$ & $0 \%$ & $0 \%$ & $2 \%$ & $3 \%$ \\
\hline \multirow[t]{2}{*}{ 5. Floating $\mathbf{M}=6.9$} & $5 \%$ & $10 \%$ & $20 \%$ & $20 \%$ & $25 \%$ \\
\hline & $100 \%$ & $100 \%$ & $100 \%$ & $100 \%$ & $100 \%$ \\
\hline Model Weights & $15 \%$ & $23 \%$ & $31 \%$ & $8 \%$ & $23 \%$ \\
\hline
\end{tabular}

\section{San Gregorio Fault}

The San Gregorio fault, the westernmost member of the San Andreas Fault system in SFBR, courses southeastward $175 \mathrm{~km}$ from the Golden Gate segmentation point along the western edge of the San Francisco Peninsula into and through Monterey Bay (Figure 3.1). Much of the San 
Gregorio fault is offshore; all of the southern segment (SGS) is offshore and more than one active trace is believed to exist beneath Monterey Bay. The behavior of the San Gregorio fault is known only from its northern segment (SGN) along the San Mateo County coast where paleoseismic investigations show the occurrence of large slip events (Simpson and others, 1998). Although the most recent large-slip earthquake probably predates the historical era, there is a small probability that the 1838 earthquake occurred on SGN (Bakun,1999).

\section{Segmentation}

SA/SG SCG identified two major segments of the San Gregorio fault, the northern (SGN) and southern (SGS) segments (Figure 3.1).

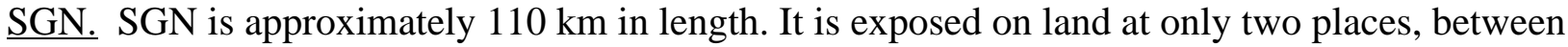
Seal Cove and Half moon Bay and at Pt. Ano Nuevo. Its northern boundary is near the Golden Gate (Figure 3.3). Jachens and Zoback (1999) interpret high-resolution aeromagnetic data to indicate a right-stepping en-echelon pattern of faulting for the San Gregorio fault as it appears to merge with the San Andreas fault across a 4-km-wide zone south of Bolinas Lagoon. The southern segment boundary is placed in the central part of Monterey Bay. This $\sim 20-\mathrm{km}$ long zone is co-located with the intersection of southeast-splaying, Pleistocene and Holocene oblique right-lateral and thrust faults observed from seafloor observations (D. Stakes, personal communication, 1999) and on shore south of Monterey Bay (Rosenberg and Clark, 1994). Northern Monterey Bay is also marked by a cluster of seismicity, (McNally and Stakes, 1998; Ross and others, 1998), as well as two $\mathbf{M}=6.1$ earthquakes in 1926.

SGS. The southern boundary of the $\sim 66-\mathrm{km}$-long SGS is located $20 \mathrm{~km}$ south of Pt. Sur,with an uncertainty of $\pm 10 \mathrm{~km}$ (Figure 3.5). Geologic mapping suggests a distributed zone of shear on several faults south of Pt. Sur but no clear geomorphic connection between the San Gregorio fault and the San Simeon-Hosgri fault system $75 \mathrm{~km}$ to the southeast. The southern boundary adopted here coincides with WGNCEP 96's and Peterson and others (1996) south endpoint of the San Gregorio fault.

\section{Slip Rate}

Holocene slip rates on the San Gregorio fault have been difficult to obtain due to the relatively short on-land strands available for study. Multiple faulot strands increase the difficulty of obtaining full rates across the entire fault zone. WGNCEP 96 assumed a slip rate of $5 \pm 2 \mathrm{~mm} / \mathrm{yr}$ for SGN based on preliminary paleoseismic rates at Seal Cove and Pt. Año Nuevo. It also developed a rate of $3 \pm 1.5 \mathrm{~mm} / \mathrm{yr}$ for SGS, basing this largely on possible continuity with the San Simeon-Hosgri fault system and accounting for partitioning of minor slip onto structures such as the Monterey Bay-Tularcitos fault fault onshore south of Monterey Bay. WGNCEP 96 noted that these estimates were poorly constrained.

Mapping and trenching of a San Vicente Creek paleochannel offset 300-360 m at Seal Cove suggests a slip rate of $3.5 \mathrm{~mm} / \mathrm{yr}$ to $4.5 \mathrm{~mm} / \mathrm{yr}$ over the past 80,000-85,000 years for the eastern trace of the fault (the Seal Cove strand) (Simpson and others, 1998). This slip rate is a minimum estimate because there is an unknown amount of slip on the offshore western strand of the San Gregorio fault zone, well expressed topographically on the seafloor. Farther south, Weber and Cotton (1981), Weber (1994), and Weber and others (1997) have reported slip rates of 4-11 
$\mathrm{mm} / \mathrm{yr}$ across the entire zone at Pt. Año Nuevo. These rates are based on cumulative right-lateral offset of marine shoreline angles across the Coastways, Frijoles and related faults and also on right-lateral offsets of Año Nuevo Creek and Cascade Creek, as averaged over the past 100,000 years. There are no late-Holocene slip rates available. A possible constraint on the lateHolocene rate is derived from the change in the San Andreas slip rate north and south of the Golden Gate, where the San Gregorio fault intersects the San Andreas. Here, the San Andreas slip rate decreases from 24 to $17 \mathrm{~mm} / \mathrm{yr}$. This $7 \mathrm{~mm} / \mathrm{yr}$ slip-rate difference does not appear to be transmitted eastward to the Hayward fault and is likely partitioned onto the San Gregorio fault. From these observations, the San Andreas SCG adopted a slip rate for SGN of $7 \pm 3 \mathrm{~mm} / \mathrm{yr}$.

The slip rate for SGS is even more problematic because no part of the fault is exposed on shore. On the southern shores of Monterey Bay, the Monterey Bay - Tularcitos - Navy - Chupines (MBNTC) fault system forms a broad zone of deformation that may carry some SGS slip to the southeast. Simila and others (1998) concluded that the two $M_{L} 6.1$ earthquakes in 1926 were located on the MBNTC fault system. However, slip rates on individual faults are not well constrained. Vaughn and others (1991) report that a segment of the Chupines fault is associated with dextrally deflected drainages and may have a slip rate as high as $2 \mathrm{~mm} / \mathrm{yr}$. If correct, this would be a minimum rate for the MBNTC zone, reducing the $7 \mathrm{~mm} / \mathrm{yr}$ SGN slip rate to less than $5 \mathrm{~mm} / \mathrm{yr}$ on SGS. At this time, there are no new data that warrant a change from the WGNCEP 96 report. Aware that some slip is being transferred onshore and that the slip rate on the San Simeon-Hosgri fault system may reflect that of the San Gregorio, the San Andreas SCG assigned SGN a slip rate of $3 \pm 2 \mathrm{~mm} / \mathrm{yr}$.

\section{Previous Earthquakes: Recurrence and Slip per Event}

Paleoseismic data are sparse for the San Gregorio fault because of limited on-land exposure. Trench excavations at Seal Cove (Simpson and others, 1998) exposed evidence of the past two surface-faulting earthquakes. The most recent event occurred after the deposition of a native Californian cooking hearth dated AD 1270-1400 but before the arrival of the Spanish missionaries in 1776. The penultimate event at the Seal Cove site occurred between AD 620 and 1400. Given the dating uncertainties, intervals between these events could have been 300 to 690 years. Thornburg and Weber (1998) found evidence for three or four events in deposits interpreted to be as old as 6000-8000 years on the Frijoles fault strand at Cascade Ranch, near Pt. Año Nuevo, ,indicating a minimum recurrence interval of 1500-2000 years. No comparable data exist for the Coastways fault strand, although Weber, Nolan and Zinn (1993) report evidence of Holocene right-lateral slip on the Coastways fault strand.

Individual events on the San Gregorio fault appear to be large. Based on reconstruction of trench stratigraphy, Simpson and others (1998) estimated lateral slip of $5(-2,+6) \mathrm{m}$ for the most recent event and $3( \pm 0.2) \mathrm{m}$ for the penultimate event at Seal Cove.

\section{$\underline{\text { Rupture Sources and Scenarios }}$}

For the two-segment representation of the San Gregorio fault, there are three rupture sources, and three rupture scenarios, including the floating-earthquake $(\mathbf{M}=6.9)$ scenario, presented below and illustrated in Figure 3.6:

(1) SGN, SGS: Independent rupture of both segments. 
(2) SGN+SGS: Simultaneous slip of both segments.

(3) Floating $\mathbf{M}=6.9$ earthquakes: Given the large uncertainties about San Gregorio segmentation, the San Andreas SCG also permitted a $\mathbf{M}=6.9$ event to occur anywhere along the fault. The magnitude assigned to the floating source is the same as for the San Andreas fault.

SA/SG SCG also considered, and rejected, the possibility that the San Gregorio fault might rupture together with the two northern segments of the San Andreas fault (SAN and SAO) in a single large $\mathbf{M} \sim 8$ event, because there was no evidence supporting this scenario.

\section{Fault Rupture Models}

All that is known about large earthquakes on the San Gregorio fault is that such events have occurred on the Seal Cove strand of SGN. Without other paleoseismic data, it is difficult to assign meaningful differences in the relative frequencies of occurrence of the rupture scenarios. As such, the San Andreas SCG defined three rupture models that cover this broad uncertainty and weighted them equally (Table 3.3 ).

Table 3.3 San Gregorio Fault Rupture Models and Weights

\begin{tabular}{|l|l|l|l|l|}
\hline & Rupture Scenario & Model A & Model B & Model C \\
\hline \hline & & & & \\
\hline 1 & SGN, SGS & $70 \%$ & $35 \%$ & $0 \%$ \\
\hline 2 & SGN+SGS & $0 \%$ & $35 \%$ & $70 \%$ \\
\hline 3 & Floating M =6.9 & $30 \%$ & $30 \%$ & $30 \%$ \\
\hline & & & & \\
\hline & Model Weights & $33.3 \%$ & $33.3 \%$ & $33.3 \%$ \\
\hline
\end{tabular}

\section{Hayward-Rodgers Creek Fault}

The Hayward-Rodgers Creek fault system is $140 \mathrm{~km}$ long, extending from near Healdsburg on the north to the Warm Springs district of Fremont on the south (Figure 3.7). South of San Pablo Bay, the fault passes through areas heavily urbanized area where much evidence of the fault is obscured. The southern part of the fault produced the regionally damaging $1868 \mathrm{M} 6.8$ earthquake. The East Bay SCG considers the Hayward-Rodgers Creek fault to be a threesegment system, as did WG90 and WGNCEP96; significant new information is available to this study, however, which has led to some changes in the details. The discussions and conclusions of the East Bay SCG presented below have been summarized by Lettis (2001).

\section{Segmentation}

In the WG 90 and WGNCEP 96 reports, this fault system was characterized with the southern Hayward, northern Hayward, and Rodgers Creek segments. The bases for this division were differences in both timing of the most recent earthquake along the fault and major changes in fault geometry and structure along the strike of the fault. The timing differences are: 1) the occurrence of the 1868 earthquake on the southern Hayward fault; 2) the belief that a large 
earthquake occurred on the northern Hayward fault in 1836 (WG90); and 3) the historical seismic record, which indicated no large magnitude earthquakes on the Rodgers Creek fault since at leas the early 1800s. The 6-km-wide releasing stepover between the Hayward and Rodgers Creek faults beneath San Pablo Bay was considered wide a stepover for ruptures to propagate through, and an additional reason to separate the northern Hayward fault from the Rodgers Creek fault.

As in the earlier reports, the East Bay SCG defines three segments for the Hayward-Rodgers Creek fault: the south Hayward (HS), north Hayward (HN), and Rodgers Creek (RC) segments (Figure 3.7). The East Bay SCG considered the following important new information: a) relocation of the 1836 earthquake from the Hayward fault to south of San Francisco Bay (Toppozada and Borchardt, 1998; Bakun, 1999); b) paleoseismic data showing that the most recent large event (MRE) on the HN occurred between 1640-1776 (HFWG, 1999)and the MRE on the RC occurred between 1670-1776 (Hecker, written communication, 1999; Schwartz and others, 2001)); and c) an increase in the estimated length of the 1868 rupture using geodetic data (Yu and Segall, 1997). This new information removed a major timing constraint on segmentation relied on in previous working group reports.

RC. The Rodgers Creek fault segment is essentially unchanged from the WG90 characterization. The northern boundary is a $\pm 5 \mathrm{~km}$-wide zone south of Healdsburg in which the Holocene trace of the fault appears to die out (Hart, 1992). The southern boundary is a $\pm 5 \mathrm{~km}$ zone offshore beneath San Pablo Bay. The $6 \mathrm{~km}$ stepover from the RC to the $\mathrm{HN}$ is coincident the western edge of a prominent gravity low that extends approximately $20 \mathrm{~km}$ to the east of the step-over. There are no geophysical data that indicate the presence of a structural depression or extensional faulting within the stepover. It is also not known whether $\mathrm{RC}$ and $\mathrm{HN}$ join at depth beneath this structure or remain individual faults through the seismogenic crust. Based on modeling of rupture propagation across steps in faults (Harris, 1995), the San Pablo Bay stepover continues to be viewed as a major structural and geometric barrier for ruptures propagating into it. That is, the SCG viewed the San Pablo Bay stepover as a particularly strong segmentation point.

HN. This northern segment of the Hayward fault extends from the San Pablo Bay stepover to near Montclair in Oakland. With the timing constraint of the most recent event (formerly the 1836 earthquake) removed, the primary basis for defining $\mathrm{HN}$ is that it is the section of the Hayward fault that did not rupture in 1868 . An uncertainty of $\pm 5 \mathrm{~km}$ is assigned to the northern boundary in San Pablo Bay. The southern endpoint is less certain. The possible north end of the 1868 rupture near Rocky Mound (Yu and Segall, 1997) is $20 \mathrm{~km}$ north of the segment boundary near San Leandro adopted by WG 90, where the evidence for 1868 surface rupture was distinct (Lawson, 1908). Trenching evidence suggests the 1868 surface rupture extended at least to Montclair (Lienkaemper and Williams, 1999). There are no obvious geometric or lithologic changes along this reach of the fault that provide a physical basis for proposing a segment boundary. Therefore, a southern endpoint is possible anywhere between Mira Vista on the north, which did not rupture at the surface in 1868 (HFWG, 1998) and San Leandro. The segment endpoint selected by the East Bay SCG lies at Montclair, about midway between Mira Vista and San Leandro, with an uncertainty of $\pm 10 \mathrm{~km}$. This new endpoint shortens the HN length considerably from that used in the WG88 and WG90 reports. 
HS. The East Bay SCG takes HS to be the extent of the 1868 rupture. Nothing is known about the slip distribution of the 1868 earthquake or of the variability in rupture lengths and/or slip distributions of pre-historic HS events. It is it possible that HN and HS ruptures could overlap10 to $20 \mathrm{~km}$ in the broad boundary between the two segments. The southern endpoint of HS is midway between the south end of known 1868 surface rupture at Agua Caliente Creek (Lawson, 1908 ) and the Alum Rock seismicity trend. Uncertainty in the location of this boundary is \pm 10 $\mathrm{km}$.

\section{$\underline{\text { Slip Rate }}$}

Slip rates for the Hayward-Rodgers Creek fault have not changed since the WG90 report. WG90 used a rate of $9 \pm 2 \mathrm{~mm} / \mathrm{yr}$ for each of the three fault segments based on paleoseismic and faultcreep data. WGNCEP 96 also used these rates, consistent with new paleoseismic observations of a minimum rate of 7-10 mm/yr for the past 8,400 years on HS at Union City (Lienkaemper and Borchardt, 1996) and 8.4 $2 \mathrm{~mm} / \mathrm{yr}$ for the past 900 years on RC (Schwartz and others, 1992). Measurements of surface creep (Lienkaemper and others, 2001) show that the Hayward fault has an average creep rate of about 4 to $6 \mathrm{~mm} / \mathrm{yr}$ with a high of $9 \mathrm{~mm} / \mathrm{yr}$ near Fremont, a significant fraction of the overall geologic slip rate. Williams (1999) reports a long-term (35 ka) slip rate of $10 \pm 1 \mathrm{~mm} / \mathrm{yr}$ on HN from offset of Strawberry Canyon. The East Bay SCG continues the use of $9 \pm 2 \mathrm{~mm} / \mathrm{yr}$ for $\mathrm{HS}, \mathrm{HN}$, and RC.

\section{Previous Earthquakes: Recurrence and Slip per Event.}

On the RC segment, trenching at the Triangle $\mathrm{G}$ site indicates the most recent surface faulting earthquake occurred after AD 1640 and before 1776 (Hecker, written communication; Schwartz et al, 2001)). At least two other events have occurred during the past 1100 years at this location, and individual recurrence intervals range from 235 to 387 years (Schwartz et al, 1992). From an offset channel at the nearby Beebe Ranch, Budding et al (1990) have estimated slip for the most recent event (MRE) event to be $2.0(+0.3,-0.2) \mathrm{m}$. Total slip for the past three events is 5.1 to $7.2 \mathrm{~m}$, giving an average slip of $1.9(+0.4,-0.3) \mathrm{m}$ for these paleoearthquakes. The trench-based recurrence intervals have large uncertainties but, along with the mean calculated RI of 230 years dervived from the slip rate and slip per event, suggest intervals of 200-300 years for large surface ruptures.

At the Mira Vista site on HN, the MRE is bracketed between AD 1640 and 1776. The trenches reveal that a minimum of four to seven surface-faulting events have occurred during the past 1630 to 2130 years, providing maximum average recurrence intervals from 270 to 710 years (HFWG, 1998). Because the event history recorded at this site appears to be incomplete (HFWG, 1998) the actual rupture rate on the northern Hayward is likely to be shorter than the 270 to 710 year trench recurrence interval. Surface rupture associated with the 1868 earthquake is not evident at the Mira Vista site, thereby constraining the northern extent of the 1868 rupture. There are no data for $\mathrm{HN}$ on the amount of horizontal slip during past earthquakes.

The MRE on HS is the 1868 rupture. Paleoseismic investigations by Williams (1992) at the north end of Tule pond suggest six or seven earthquakes during the past 1500-2000 years, with an average repeat time of 150 to 250 years; timing of individual events, however, is not well constrained. At the south end of Tule pond, Lienkaemper et al (2002) find that four surfacefaulting earthquakes have occurred between AD 1470 and 1868 for an average recurrence during 
this period of $130 \pm 40$ years. The only information on the amount of slip during past earthquakes is the average geodetic offset of $1.9 \mathrm{~m}$ for the 1868 earthquake (Yu and Segal, 1998).

\section{$\underline{\text { Rupture Sources and Scenarios }}$}

For the three-segment representation of the Hayward-Rodgers Creek fault, there six rupture sources and five possible rupture scenarios (Figure 3.2), including the floating-earthquake $(\mathbf{M}=$ 6.9), described below.

(1) $\mathrm{RC}+\mathrm{HN}+\mathrm{HS}$ : Simultaneous rupture of all three segments, extending from the northern end of the Rodgers Creek fault to the southern end of the Hayward fault. . This scenario is permitted by the overlapping dates of the most recent event on $\mathrm{RC}$ and $\mathrm{HN}$ with the penultimate event on HS.

(2) RC+HN, HS: Simultaneous rupture of the Rodgers Creek fault with HN and independent rupture of HS. In this scenario, the San Pablo Bay step-over is considered to be the nucleation point for a bilateral rupture. The overlapping dates of the most recent large earthquakes on the HN and RC, coupled with observations that the 1995 Kobe earthquake nucleated in a 4-km-wide extensional step and ruptured bilaterally, provide the basis for the this $\mathrm{RC}+\mathrm{NH}$ source in this scenario.

(3) RC, HN+HS: Independent rupture of the Rodgers Creek fault and simultaneous rupture of the two Hayward fault segments. In this scenario the San Pablo Bay step-over is a strong barrier to rupture and the $\mathrm{HS} / \mathrm{HN}$ segmentation point is not a barrier to through-going rupture. The combined $\mathrm{HN}+\mathrm{HS}$ source reflects the absence of a well-defined geometric or dynamic segmentation point along the Hayward fault plus the observation that rupture in 1868 occurred along more than 60 percent of the mapped surface trace of the Hayward fault.

(4) RC, HN, HS: Independent rupture of all three fault segments. The San Pablo Bay step-over plus the division of the Hayward fault into two segments based on partial rupture in 1868 form the basis for this scenario.

(5) Floating $\mathbf{M}=6.9$ earthquakes. This scenario allows the fault to fail in $\mathbf{M}=6.9(\sigma=0.12)$ events that are spatially unconstrained along the length of the fault. The size of the floating earthquake is close to the magnitude estimated for the 1868 earthquake.

\section{Fault Rupture Models}

The fault rupture models considered by the East Bay SCG for the Hayward-Rodgers Creek fault are shown in Table 3.4, A to D. The models are quite similar, with a relatively small range in model weights. This reflects, in part, the relatively large amount of information available for the fault, which results in a narrowing of the differences that are proposed for alternative rupture models. EBay SCG has placed considerable weight on rupture scenarios 3 and 4 above in all four fault rupture models. These scenarios have $\mathrm{RC}$ as an independent rupture source, based on the East Bay SCG's assessment that the San Pablo Bay step-over is a strong segmentation point. The SCG gave high weights to independent rupture of all three segments (scenario 4) in each model. However, as indicated by the model weights, the East Bay SCG also favors HS and HN failing 
simultaneously (models A and B), not independently, placing little confidence in the efficacy of the HS/HN segmentation point. Low weights are given to both the floating earthquake source and the rupture of the entire fault in a single event.

Table 3.4 Hayward-Rodgers Creek Fault System Rupture Models and Weights

\begin{tabular}{|lcccc|}
\hline \multicolumn{1}{|c}{ Rupture Scenario } & Model A & Model B & Model C & Model D \\
\hline \hline 1 RC+HN+HS & $9 \%$ & $5 \%$ & $7 \%$ & $3 \%$ \\
2 RC+HN, HS & $6 \%$ & $10 \%$ & $20 \%$ & $7 \%$ \\
3 RC, HN+HS & $55 \%$ & $40 \%$ & $10 \%$ & $15 \%$ \\
5 Floating M $=6.9$ & $25 \%$ & $40 \%$ & $55 \%$ & $70 \%$ \\
& $5 \%$ & $5 \%$ & $8 \%$ & $5 \%$ \\
\cline { 2 - 5 } & $100 \%$ & $100 \%$ & $100 \%$ & $100 \%$ \\
Model Weights & $22 \%$ & $36 \%$ & $11 \%$ & $31 \%$ \\
\hline
\end{tabular}

\section{Calaveras Fault}

To the east of the Hayward-Rodgers Creek fault, the Calaveras fault extends $123 \mathrm{~km}$, splaying from the San Andreas fault near Hollister and terminating at Danville at its northern end (Figure 3.8). The Calaveras fault is one of the most geologically active and complex faults in SFBR. Since the WG90 report, slip rates and recurrence estimates have been obtained at Leyden Creek, Welch Creek, and San Ysidro Creek (Figure 3. 8), and monitoring of surface fault creep has continued at several localities. These data provide a better understanding of slip rates along the fault, but many questions remain about its potential to produce large earthquakes, particularly along the rapidly creeping sections south of Calaveras Reservoir. Much of the discussion of the East Bay SCG with respect to the Calaveras fault is summarized by Kelson (2002).

\section{$\underline{\text { Segmentation }}$}

Previous studies have divided the fault into two segments based on their seismic behavior: (1) a southern segment extending from south of Hollister to Calaveras Reservoir (Bakun, 1980; Oppenheimer et al., 1990) and (2) a northern segment extending from Calaveras Reservoir to near the town of Danville (WGNCEP, 1996). Kelson et al. (1998) further divided the southern segment into a central segment from San Felipe Lake to Calaveras Reservoir and a southern segment from the Paicines fault south of Hollister to San Felipe Lake. The East Bay SCG adopted the three-segment model for the Calaveras fault of Kelson et al. (1998): northern CN, central CC, and southern CS segments (Figure 3.8). 
CN. This segment extends $45 \pm 5 \mathrm{~km}$ from Calaveras reservoir to Danville, the northernmost extent of identifiable Holocene faulting. An uncertainty of $\pm 5 \mathrm{~km}$ allows for the possibility that ruptures terminate at structures defined by either the 1970 Danville or 1990 Alamo earthquake swarms. The south end of $\mathrm{CN}$ is placed at the south end of Calaveras Reservoir, which occupies a 7-km-long releasing stepover associated with a $15^{\circ}$ change in strike of the fault. An uncertainty of $\pm 5 \mathrm{~km}$ for this boundary captures the entire stepover. This southern boundry of $\mathrm{CN}$ also coincides with the complex, poorly understood zone of intersection of the Calaveras and Hayward faults.

The absence of microseismicity on CN (Ellsworth and others, 1982; Oppenheimer and Lindh, 1992; Oppenheimer and MacGregor-Scott, 1992), negligible to low amounts of fault creep, a lower geologic slip rate, and clear evidence of large paleoseismic surface offsets distinguish $\mathrm{CN}$ from CC and CS. There is evidence for only one historical earthquake on $\mathrm{CN}$, the $1861 \mathbf{M}=5.8$ San Ramon Valley earthquake, for which Jennings (1994) shows a 4-km-long rupture on the Calaveras fault. However, it is uncertain whether this was a coseismic surface rupture or shaking induced. Creep rates are significantly lower along $\mathrm{CN}$ than they are to the south. The historical creep rate on $\mathrm{CN}$ in the Pleasanton-Sunol area is 2.5 to $3.5 \mathrm{~mm} / \mathrm{yr}$ (Mosier, 1977; Prescott et al., 1981; Burford and Sharp, 1982; Prescott and Lisowski, 1983). Farther north in San Ramon, Galehouse and Lienkaemper (2002, BSSA) and colleagues measured a rate of $1.7 \mathrm{~mm} / \mathrm{yr}$ between 1981 and 1999. This contrasts with creep rates of $6 \mathrm{~mm} / \mathrm{yr}$ at Calaveras reservoir (Prescott et al., 1981) and rates as high as 13.5-16.3 mm/yr on CS at Coyote Ranch (Galehouse and Lienkaemper, 2002). Paleoseismic investigations just north of Calaveras Reservoir at Leyden Creek and Welch Creek sites (Figure 3.8)) provide Holocene slip rates of $5(+2,-1)$ $\mathrm{mm} / \mathrm{yr}$ (Kelson et al., 1996) and $6 \pm 1 \mathrm{~mm} / \mathrm{yr}$ (Simpson et al., 1999), respectively. This contrasts with a rate of $14 \pm 5 \mathrm{~mm} / \mathrm{yr}$ for the past 4000 years (Kelson and others, 1998) on CC at San Ysidro Creek. In addition, the Leyden Creek and Welch Creek sites provide evidence, distinct from creep, for the occurrence of surface-faulting earthquakes.

CC. This segment extends $59 \pm 10 \mathrm{~km}$ from Calaveras Reservoir to San Felipe Lake to Calaveras Reservoir where the fault strike changes $7^{\circ}$. The location uncertainty associated with the south boundary is assigned a value of $\pm 5 \mathrm{~km}$ to include the possibility of a rupture extending to the intersection between the Calaveras and the Busch Ranch faults $4 \mathrm{~km}$ south of San Felipe Lake. San Felipe Lake also marks the south end of the 1979 Coyote Creek earthquake rupture at depth.

CC is characterized by abundant microseismicity (Bakun, 1980, 1984; Bakun and others, 1986: 1985; Oppenheimer et al., 1990), which may reflect the high rate of creep. The simple average creep rate from 1968 to 1999 is $16.3 \mathrm{~mm} / \mathrm{yr}$ (Galehouse and Lienkaemper, 2002), although this value includes slip possibly triggered by the 1989 Loma Prieta earthquake (Galehouse, 1997). At a site about $5 \mathrm{~km}$ southeast of the Coyote Ranch array, Kelson et al. (1998) obtain an average slip rate of $14 \pm 5 \mathrm{~mm} / \mathrm{yr}$ since the middle Holocene. Within the uncertainty of the geologic data, the long-term slip rate on the central Calaveras is consistent with the short-term slip rate derived from aseismic slip data and geodetic modeling.

In addition to abundant microseismicity, $\mathrm{CC}$ has also been the source of moderate-magnitude earthquakes (1949 Gilroy, M 5.2; 1979 Coyote Lake, M 5.9; 1984 Morgan Hill, M 6.2; 1988 
Alum Rock, M 5.1). A similar sequence of comparably-sized earthquakes occurred between 1897 and 1911. Recent syntheses characterize the central Calaveras fault as capable of producing earthquakes no larger than M 6.2 (Peterson et al., 1996; WGNCEP, 1996). Agreement between the geodetic/creep rates and the geologic slip-rates (Kelson and others, 1992a) suggests that there is little or no strain accumulation along the fault that would result in a large earthquake. Based on these relations, the WGNCEP (1996) assumed that the 1984 Morgan Hill earthquake (M 6.2) is the maximum magnitude event to occur on the central Calaveras fault and calculated a repeat time of 60 years for an earthquake of this size. On the other hand, evidence from trenches at San Ysidro Creek can be interpreted as support for more than $2 \mathrm{~m}$-displacement surfacerupturing earthquakes along the central Calaveras fault, with three events occurring in the past 3 ka (Kelson et al., 1998).

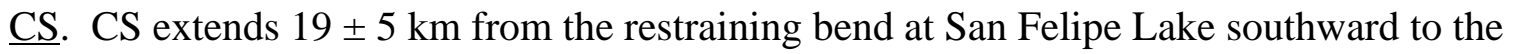
intersection with the Paicines fault, about $7 \mathrm{~km}$ south of Hollister. The southern boundary is a complex intersection, with the two faults merging in a series of subparallel fault strands, and this endpoint is assigned an uncertainty of $\pm 5 \mathrm{~km}$. CS has experienced a low level of microseismicity from1963 to 1997 (Walters and Oppenheimer, in press).

\section{Slip Rate}

The slip rate on the Calaveras changes significantly where the Hayward fault splays northwest from it. WGNCEP 96 assigned a rate of $6 \pm 2 \mathrm{~mm} / \mathrm{yr}$ to the northern Calaveras and $15 \pm 2 \mathrm{~mm} / \mathrm{yr}$ to the southern Calaveras (CC and CS in the present report). The rates for $\mathrm{CN}$ were based on offsets of channel margins at Leyden Creek that yielded a slip rate of $5 \pm 2 \mathrm{~mm} / \mathrm{yr}$ for the past 2300 years (Kelson et. al, 1996) and a $6 \mathrm{~mm} / \mathrm{yr}$ creep rate on a small-aperture geodetic net at Calaveras Reservoir (Prescott and Lisowski, 1983). Since 1996, Simpson et al. (1999) have developed a late-Holocene slip rate at Welch Creek of $6 \pm 2 \mathrm{~mm} / \mathrm{yr}$. The East Bay SCG thus retains the rate of $6 \pm 2 \mathrm{~mm} / \mathrm{yr}$ for $\mathrm{CN}$.

Creep rates used here for the new CC segment are best documented at the Coyote Ranch alignment array near Coyote Lake, which was measured intermittently by the USGS between 1968 and 1988. Measurements resumed at this site in early 1997. As of mid-May 1999, the average creep rate for 1968 to 1999 was $16.3 \mathrm{~mm} / \mathrm{yr}$ (Galehouse and Lienkaemper, 2002), although this value includes slip possibly triggered by the 1989 Loma Prieta earthquake (Galehouse, 1990). Measurements made since 1997 provide an average rate of $13.5 \mathrm{~mm} / \mathrm{yr}$ (J. Galehouse, written comm., 1999). Similar rates are observed at San Ysidro Creek, $5 \mathrm{~km}$ southeast of the Coyote Lake array, where dating of offset buried stream channels provides a preliminary geologic slip rate of $14 \pm 5 \mathrm{~mm} / \mathrm{yr}$ for the past 4000 years (Kelson et al., 1998). With these new observations, the East Bay SCG assigns a slip rate of $15 \pm 3 \mathrm{~mm} / \mathrm{yr}$ to both the CC and CS segments.

\section{Previous Earthquakes: Recurrence and Slip per Event}

There are no data to constrain well the timing of the MRE on CN. Observations at Leyden Creek (Kelson et al.,1996) and Welch Creek (Simpson et. al., 1999), indicate that the MRE occurred between AD 1160 and 1425. Five or six scarp-forming surface faulting events have occurred during the past 2,500 years, suggesting a geologically based recurrence interval of $550 \pm 300$ years (Kelson et al., 1996). At the Welch Creek site in Sunol, trenching by Simpson et al.(1999) 
allows an interpretation of three surface ruptures during approximately the same time interval. Neither of the sites yielded well-constrained timing of the MRE. No measurement of horizontal silp per event is available at either of these sites.

There is also uncertainty regarding the nature of earthquake recurrence on CC and CS. Trench exposures at San Ysidro Creek suggest that surface-rupturing earthquakes may have along CC (Kelson et al.,1998). They interpret offset paleochannels as evidence of large coseismic slip events on the fault and suggest a minimum of three discrete surface-rupturing earthquakes between about $4 \mathrm{ka}$ and $2 \mathrm{ka}$. As such, the East Bay SCG allows the possibility of largemagnitude ruptures on $\mathrm{CC}$. Although the weight of seismologic and geodetic evidence supports the interpretation that $\mathrm{CC}$ and $\mathrm{CS}$ are capable of producing only moderate-magnitude earthquakes, the geologic interpretations at San Ysidro are the reason for the East Bay SCG's including rupture models that produce large events on these rapidly creeping segments.

\section{$\underline{\text { Rupture Sources and Scenarios }}$}

Like the Hayward- Rodgers Creek fault, the three-segment representation of the Calaveras fault has six possible rupture sources and five possible rupture scenarios. The East Bay SCG constructed the six rupture scenarios given below, using two possibilities for the floating earthquake scenario.

(1) $\mathrm{CN}+\mathrm{CC}+\mathrm{CS}$ ): Simultaneous rupture of all three segments extending from Danville to Hollister.

(2) $\mathrm{CN}+\mathrm{CC}, \mathrm{CS}$ : Simultaneous rupture of the northern and central segments, and independent rupture of the southern Calaveras. Kelson and others (1996) note that the trenches at the Leyden Creek site may contain evidence for overlapping ruptures from the northern and central Calaveras segments.

(3) $\mathrm{CN}, \mathrm{CC}+\mathrm{CS}$ : Independent rupture of the northern segment and simultaneous rupture of the central and southern segments.

(4) $\mathrm{CN}, \mathrm{CC}, \mathrm{CS}$ : Independent ruptures of the three segments.

(5) $\mathrm{CN}$ and floating $\mathbf{M}=6.2$ earthquake: Independent rupture of the northern Calaveras fault coupled with floating earthquakes along the central and southern fault segments. $\mathbf{M}=6.2$ is the magnitude of the 1984 Morgan Hill earthquake.

(6) Floating $\mathbf{M}=6.2$ earthquakes: $\mathbf{M}=6.2$ earthquakes spatially unconstrained along the entire fault sytstem.

\section{Fault Rupture Models}

EBay SCG developed four rupture models for the Calaveras fault, with a clear preference for rupture models that have the boundary between the northern and central Calaveras as a strong segmentation point. This preference reflects the collective judgment that the changes in creep rate, slip rate, seismicity, and geometry that occur near the Calaveras reservoir express a basic change in the rupture behavior of the Calaveras fault. Uncertainties in the behavior of the rapidly creeping central and southern segments are clearly reflected in the high weighting of 
models B and C. These have moderate (model C) to high (Model B) weights on scenarios that contain the floating earthquake as the dominant rupture mode; each also allows the possibility of large events. Model B, which rules out multi-segment ruptures and places high weight on an independent $\mathrm{CN}$ and floating earthquakes elsewhere, received the highest weighting of any of these models. While long ruptures involving multiple segments are permitted, the East Bay SCG considered these to be very infrequent events.

Table 3.5 Calaveras Fault Rupture Models and Weights

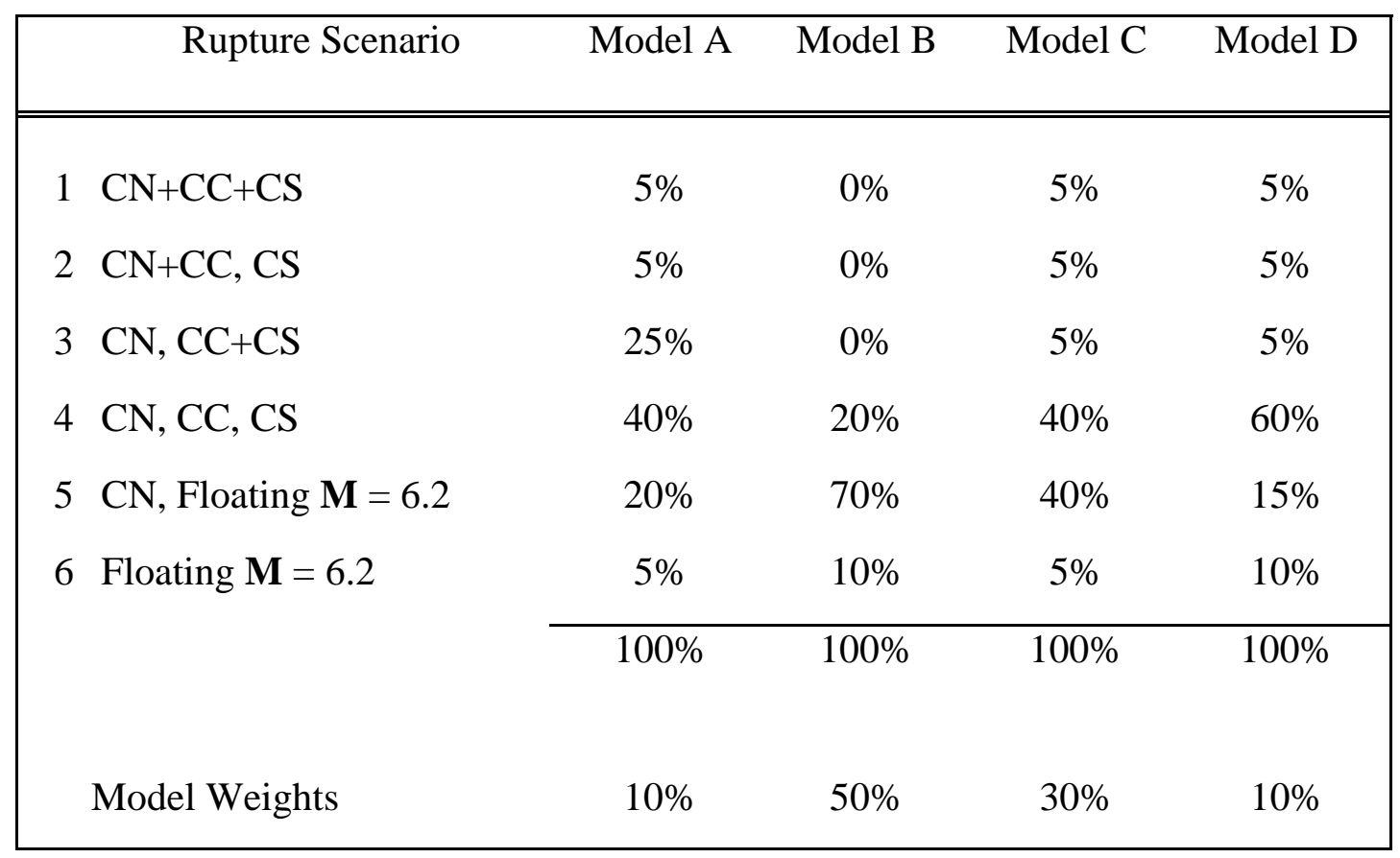

\section{Concord-Green Valley Fault System}

The Concord-Green Valley fault extends from the vicinity of Walnut Creek north to Wooden Valley, a distance of approximately $56 \mathrm{~km}$ ( Figure 3.9). Large earthquakes have not occurred on the Concord-Green Valley fault during the historical period, although a Ms 5.4 earthquake occurred on the central part of the Concord fault in 1955. Aseismic slip occurs locally along sections of the Concord-Green Valley fault, with rates increasing from about $4 \mathrm{~mm} / \mathrm{yr}$ for the past 18.5 years in Concord to $5 \mathrm{~mm} / \mathrm{yr}$ near Cordelia (Galehouse, 1998). The deliberations of the East Bay SCG on the Concord-Green Valley fault are summarized by Borchardt and Baldwin (2001) and are discussed below.

\section{Segmentation}

WGNCEP 96 considered the Concord-Green Valley fault to consist of two segments, the Concord and Green Valley segments based on a minor $\left(5^{\circ}\right)$ change in strike of the fault beneath Suisun Bay. The East Bay SCG defines the northern Green Valley (GVN), the southern Green Valley (GVS), and the Concord (CON) segments for this fault, as described below and shown in Figure 3.9. 


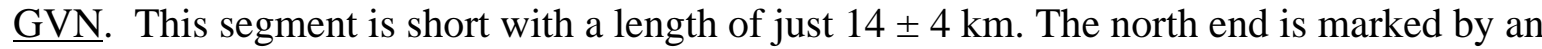
abrupt termination of the fault as a prominent geomorphic feature, although slip may be transferred northwest across a series of west-vergent folds and thrust faults (Baldwin and others, 1998). The south boundary is a minor bend or stepover to the southern Green Valley fault near the Green Valley Golf Course. An additional structural complexity occurs near this location where the Cordelia fault, which has a slip rate about $0.5 \mathrm{~mm} / \mathrm{yr}$, may branch at depth from or form a right step over from the Green Valley fault. The uncertainty in the location of the south end of the segment boundary $\pm 5 \mathrm{~km}$.

GVS. This segment extends for $22 \mathrm{~km}$ from the Green Valley Golf Course on the north to Suisun Bay on the south. On its south end, a $7^{\circ}$ releasing bend occurs where the fault crosses joins the Concord segment. This bend is the largest geometric change along the fault. A small increase in the creep rate on the southern Green Valley segment is coincident with this bend (Galehouse, 2001)

CON. The southern termination of the Concord fault is mapped as several discontinuous fault strands along the base of Lime Ridge, a northwest-trending extension of the Mt. Diablo anticlinorium (Wills and Hart, 1992). This part of the fault is poorly defined geomorphically and the SCG extended it south to its intersection with the Mt. Diablo thrust fault in the southern Walnut Creek area (Unruh and Lettis, 1998).

\section{$\underline{\text { Slip Rate }}$}

WGNCEP 96 assigned a geologic slip rate of $6 \pm 2 \mathrm{~mm} / \mathrm{yr}$ for the entire fault zone. The primary basis was the assumption that slip on the northern Calaveras fault $(6 \mathrm{~mm} / \mathrm{yr})$ steps to the Concord fault and that creep rates as high as $8 \mathrm{~mm} / \mathrm{yr}$ have been observed on this fault system north of SFBR. Given the slip rate of $3.4 \pm 0.3 \mathrm{~mm} / \mathrm{yr}$ over the past 6,000 years at Galindo Creek (Borchardt et al., 1999), the minimum slip rate of 3.8 to $4.8 \mathrm{~mm} / \mathrm{yr}$ over the past 350 years at Lopes Ranch (Baldwin and Lienkaemper, 1999), and creep rates averaging $4.9 \mathrm{~mm} / \mathrm{yr}$ for the past 18 years on the Green Valley fault at Red Top Road, the East Bay SCG assigns rates of $4 \pm 2$ $\mathrm{mm} / \mathrm{yr}$ and $5 \pm 3 \mathrm{~mm} / \mathrm{yr}$ to the Concord and Green Valley segments, respectively.

\section{Previous Earthquakes: Recurrence and Slip per Event}

At present there is no direct information on the timing of individual earthquakes along the Concord-Green Valley fault. Trenches on the northern part of the Concord fault show discrete offsets in alluvium (Hart and Bryant, 1997) indicative of multiple episodes of surface fault rupture, although paleoearthquake dates are not available. At the the Lopes Ranch site, trenches exposed evidence of discrete surface-faulting events on the Green Valley fault during the past 2,700 years, but the number and timing of these events are poorly known.

\section{Rupture Sources and Scenarios}

For the three-segment representation of the Concord-Green Valley fault, there are six rupture sources and five possible rupture scenarios described below. 
(1) $\mathrm{CON}+\mathrm{GVS}+\mathrm{GVN}$ : Simultaneous rupture of all three segments, extending from the northern end of the Green Valley fault to the southern end of the Concord fault.

(2) CON+GVS, GVN: Simultaneous rupture of the Concord fault with the southern Green Valley fault and independent rupture of the northern Green Valley fault.

(3) CON, GVS+GVN: Independent rupture of the Concord fault and simultaneous rupture of the northern and southern Green Valley segments.

(4) CON, GVS, GVN: Independent rupture of all three segments.

(5) Floating $\mathbf{M}=6.2$ earthquakes: Rupture of the Concord-Green Valley fault in $\mathbf{M}=6.2$ events spatially unconstrained along the fault. The East Bay SCG considered this $\mathbf{M}$ to be representative of moderate size events on a creeping fault.

\section{Fault Rupture Models}

Ebay SCG developed three fault rupture models that reflect a broad range of opinion and much uncertainty about the seismogenic behavior of the Concord-Green Valley fault. This uncertainty derives mainly from the lack of paleoearthquake datesto distinguish rupture segments. The highest weight is given to Model A, which acknowledges segmentation and the occurrence of moderate-to-large earthquakes, but has no preferred rupture scenario. Model B, which strongly favors rupture of the entire fault system in a single event, also received a relatively high weighting. Model C places a very high weight on the floating-earthquake scenario; the low weight for this model reflects the trench observations of repeated surface ruptures, which are commonly associated with earthquakes larger than $\mathbf{M}=6.2$.

Table 3.6. Concord-Green Valley Fault Rupture Models and Weights

\begin{tabular}{|rccc|}
\hline Rupture Scenario & Model A & Model B & Model C \\
\hline \hline 1 CON+GVS+GVN & $20 \%$ & $80 \%$ & $5 \%$ \\
2 CON+GVS, GVN & $20 \%$ & $5 \%$ & $5 \%$ \\
3 CON, GVS+GVN & $20 \%$ & $5 \%$ & $5 \%$ \\
4 CON, GVS, GVN & $20 \%$ & $5 \%$ & $5 \%$ \\
5 Floating M =6.2 & $20 \%$ & $5 \%$ & $80 \%$ \\
\cline { 2 - 4 } & $100 \%$ & $100 \%$ & $100 \%$ \\
& & & \\
Model Weights & $48 \%$ & $33 \%$ & $19 \%$ \\
\hline
\end{tabular}




\section{Greenville Fault}

The Greenville fault is the easternmost strand of the San Andreas strike-slip fault system in SFBR (Figure 3.1, Figure 3.10). It extends from the eastern flank of Mt. Diablo south to San Antonio Valley, a length of $43 \pm 20 \mathrm{~km}$. The Greenville fault is the least studied and most poorly known of the strike-slip faults considered in this study. The central Greenville fault produced $\mathbf{M}=5.8$ and 5.4 earthquakes in 1980 (Bolt et al.,1981). Microseismicity displays a subvertical alignment of epicenters extending to depths of approximately $17 \mathrm{~km}$ at the latitude of Livermore Valley (Hill et al., 1990). For the Greenville fault, WCNCEP 96 assigned a slip rate of $2 \pm 1 \mathrm{~mm} / \mathrm{yr}$; a length and width of $73 \mathrm{~km}$ and $11 \mathrm{~km}$, respectively; and a maximum earthquake of $\mathbf{M}=6.9$ with recurrence interval of 550 years. WGNCEP 96 did not segment the Greenville fault.

\section{$\underline{\text { Segmentation }}$}

The segmentation proposed by the East Bay SCG, the northern Greenville (GN) and southern Greenville (GS) segments, is based largely on differences in geomorphic expression of Holocene faulting and the location of the 1980 earthquakes. WG 02 currently proposes two segments (Figure 3.11), although three were used three segments in our earlier model (WG 99). This change was made to reflect shortening of the northern extent of Holocene displacement along the Greenville fault based on re-evaluation of geologic mapping.

GN. The north segment boundary is chosen to coincide with the northern end of the aftershock zone of the $1980 \mathbf{M}=5.8$ earthquake. Most of GN is geomorphically well expressed with clear evidence of Holocene activity. Minor right lateral surface offset occurred on the GN during the 1980 Livermore earthquake (Hart, 1981). The southern termination of GN is the structural intersection with the left-lateral Las Positas fault near the southern margin of the Livermore Basin. The length of GN is $27 \mathrm{~km}$.

GS. GS extends southward from GN to San Antonio Valley, and is clearly identified by its geomorphic expression of Holocene fault activity, including linear valleys, deflected and beheaded drainages, and uphill-facing scarps. The southern boundary of GS is not well defined. Unruh and Sawyer (1999) suggest that the fault forms a left-restraining step-over to the Ortigalita fault across the Mt. Oso anticline. The East Bay SCG places the southern end of GS at the Mt. Oso anticline with an uncertainty of $\pm 10 \mathrm{~km}$. The length of GS is estimated at $24 \mathrm{~km}$.

\section{$\underline{\text { Slip Rate }}$}

The Greenville fault has traditionally been viewed as having a low slip rate. Wright and others (1982) estimated a late-Quaternary rate of 0.5 to $0.7 \mathrm{~mm} / \mathrm{yr}$ based on $90 \mathrm{~m}$ of dextral offset on stream terraces during the past 125 to $180 \mathrm{ka}$. Ages of these terraces, based on soil-profile development, are highly uncertain. Paleoseismic trench investigations across one strand of the Greenville fault documented Holocene surface-rupturing events. Assuming a 1:3 ratio of vertical-to-horizontal separation, Wright and others (1982) estimated a horizontal slip rate of approximately 0.1 to $0.3 \mathrm{~mm} / \mathrm{yr}$.

Unruh and Sawyer (1997) proposed that contractional deformation in the Mt. Diablo-Livermore area is primarily the result of a restraining stepover between the Greenville and Concord faults. 
If this model is correct, then the late-Cenozoic shortening rate across Mt. Diablo can be used to estimate a long-term average slip rate for the Greenville fault. Including the uncertainties in these data, the average rate of horizontal motion parallel to the Greenville fault due to shortening in the Mt. Diablo fold-and-thrust belt is about $1.4 \mathrm{~mm} / \mathrm{yr}$ (7 $\mathrm{km}$ in 5 million years) to about 3.5 $\mathrm{mm} / \mathrm{yr}(12 \mathrm{~km}$ in 3.4 million years).

EBay SCG opted for the better determined, but longer-term averaged slip rate of $2 \pm 1 \mathrm{~mm} / \mathrm{yr}$ on the Greenville fault to satisfy the kinematic model for growth of the Mt. Diablo anticline and related contractional structures in the Livermore area. The clear geomorphic expression of the Greenville fault does not seem consistent with slip rates of just fractions a mm/yr

\section{Previous Earthquakes: Recurrence and Slip per Event}

These data do not presently exist for either segment of the Greenville fault.

\section{$\underline{\text { Rupture Sources and Scenarios }}$}

The two-segment representation of the Greenville fault, there are three rupture sources and three rupture scenarios, including the floating-earthquake $(\mathbf{M}=6.0)$ scenario:

(1) GN+GS: Simultaneous rupture of both segments.

(2) GN, GS: Independent rupture of the two segments.

(3) Floating $\mathbf{M}=6.2$ earthquakes: The Greenville fault fails in spatially unconstrained $\mathbf{M}=$ 6.02 earthquakes, approximately the size of the larger of the1980 earthquakes.

\section{Fault Rupture Models}

In the absence of paleoseismic data, the East Bay SCG constructed the three rupture models shown in Table 3.7, weighting equally at $1 / 3$ each.

Table 3.7. Greenville Fault Rupture Models and Weights

\begin{tabular}{|l|l|l|l|l|}
\hline & Rupture Source & Model A & Model B & Model C \\
\hline & & & & \\
\hline 1 & GN+GS & $70 \%$ & $35 \%$ & $0 \%$ \\
\hline 2 & GN, GS & $0 \%$ & $35 \%$ & $70 \%$ \\
\hline 3 & Floating M 6.2 & $30 \%$ & $30 \%$ & $30 \%$ \\
\hline & & & & \\
\hline & Model Weights & $33.3 \%$ & $33.3 \%$ & $33.3 \%$ \\
\hline
\end{tabular}

\section{Thrust and Reverse Faults}

The Thrust and Reverse Fault Source Characterization Group (Thrust and Reverse SCG) met four times in 1998 to review the state of knowledge regarding thrust faults as seismic sources in SFBR. The Thrust and Reverse SCG reviewed geodetic data, geologic data, and global plate 
motion models that provide constraints on rates of deformation across the boundary between the Pacific plate and the Sierra Nevada-Great Valley microplate. Considered together, these data do not support large shortening rates ( $>3$ to $6 \mathrm{~mm} / \mathrm{yr}$ ) directed at a high angle to the plate boundary. GPS data in SFBR indicate that the maximum rate of boundary-normal shortening is about 3-4 $\mathrm{mm} / \mathrm{yr}$. The group discussed two end-member models for accommodating boundary-normal shortening: (1) the shortening may be uniformly distributed among many structures across the entire plate boundary; or (2) the shortening may be accommodated by a single fault or localized within a discrete contractional domain (e.g., the "Coast Range-Sierra Block boundary zone"). In the former case, it is unlikely that any single thrust fault would have a slip rate in excess of 1 to 2 $\mathrm{mm} / \mathrm{yr}$. In the latter case, we would expect to observe geologic, seismic and geodetic evidence for locally high contractional strain rates; i.e. a contractional "hot spot". It was also noted that contractional "hot spots" may be associated with restraining geometries of strike-slip faults, where local contractional strain rates are more directly related to the slip rate on the specific strike-slip fault than a component of boundary-normal shortening.

Following the assessment of regional shortening rates in the Bay Area, the group developed the following list of potential "hot spots" where significant contractional deformation may be occurring:
1) Northeastern Santa Cruz Mountains
2) East Bay Hills
3) Mt. Diablo-Livermore Region
4) Sacramento-San Joaquin Delta
5) Coast Ranges-Sierra Block Boundary Zone
6) Howell Mountains
7) Miyacamas Mountains
8) Northern SFBR (Marin, Bodega)
9) Mare Island

Specific thrust-fault sources, or evidence for distributed late-Cenozoic contractional deformation within an areal source zone, were discussed for each of these areas. These discussions, summarized by Unruh (2001), singled out the Mt. Diablo thrust as having a slip rate $>1 \mathrm{~mm} / \mathrm{yr}$. On this basis it was included as an SFBR earthquake source.

\section{Mt. Diablo blind thrust fault}

The Mt. Diablo thrust is a blind thrust fault, one not observable at the Earth's surface (Figure 3.1, Figure3.10). The fault itself, its geometry, and rates of slip are inferred from structural and kinematic models of Mt. Diablo. Mt. Diablo is an antiicline associated with a belt of lateCenozoic folds and thrust faults (the "Mt. Diablo fold-and-thrust belt" of Crane (1995) and Unruh and Sawyer (1997)) that can be traced continuously for $70 \mathrm{~km}$ from the northern Diablo Range to the western Sacramento-San Joaquin Delta. Compressional structures within this belt are oriented WNW-ESE; exhibit a well-defined, right-stepping, en-echelon pattern; and are bounded by the Greenville fault to the southeast and the Concord fault to the northwest. Crustal shortening within this belt appears to be driven a restraining transfer of slip from the Greenville fault to the Concord fault (Unruh and Sawyer, 1997). The Mt. Diablo thrust fault is thought to 
underlie the asymmetric, southwest-vergent Mt. Diablo and Tassajara anticlines for a total length of $25 \pm 5 \mathrm{~km}$ (Crane, 1995; Unruh and Sawyer, 1997).

Considerable debate surrounded the inclusion of the Mt. Diablo thrust as an SFBR source because it is an inferred structure. Even so, this fault is required to explain the structure, topography, and youthful tectonic geomorphology of Mt. Diablo. In its review of Bay Area contractional structures, the Thrust and Reverse SCG identified the Mt. Diablo thrust as the reverse fault with the highest slip rate in SFBR, $3 \pm 2 \mathrm{~mm} / \mathrm{yr}$. The geometry of the fault and its potential rupture area are estimated from balanced cross-sections, as well as comparisons of the dimensions of the Mt. Diablo anticline to folds overlying the 1983 Coalinga and 1994 Northridge earthquakes (Unruh and Sawyer, 1997). The subsurface rupture length and its uncertainty are shown in Figure 3.11. There is no basis for segmenting the fault, and it is treated as a single earthquake source. Geometric relations between the Mt. Diablo thrust and the Greenville fault suggest that the Mt. Diablo thrust is truncated by the Greenville fault.

\section{$\underline{\text { Slip Rate }}$}

Available slip-rate estimates for the Mt. Diablo thrust fault are long-term average rates derived from balanced cross-sections and analysis of stratigraphic relations to determine when shortening began.

For the range of values in horizontal shortening, fault-dip orientation, and timing of deformation summarized in Unruh and Sawyer (1997), the minimum slip rate on the Mt. Diablo thrust fault is about $1.3 \mathrm{~mm} / \mathrm{yr}\left(10 \mathrm{~km}\right.$ total shortening; $30^{\circ}$ fault dip; $9 \mathrm{Ma}$ onset of shortening). The maximum slip rate permitted is $7 \mathrm{~mm} / \mathrm{yr}\left(17 \mathrm{~km}\right.$ total shortening; $45^{\circ}$ fault dip; $3.4 \mathrm{Ma}$ onset of shortening). The SCG considered the $7 \mathrm{~mm} / \mathrm{yr}$ rate to be too high: if the kinematic model of Unruh and Sawyer (1997) is correct, a slip rate of $7 \mathrm{~mm} / \mathrm{yr}$ on the Mt. Diablo thrust fault would require relatively high slip rates $(>3 \mathrm{~mm} / \mathrm{yr}$ ) on the Greenville fault, for which there no observational support. The SCG slip-rate range for the Mt. Diablo thrust is $3 \pm 2 \mathrm{~mm} / \mathrm{yr}$.

\section{Summary of Geologic Data for Fault Segments}

\section{$\underline{\text { Segment Lengths }}$}

Fault segment length is calculated from the segment endpoints identified for each fault segment. Each segment endpoint is represented by three weighted options, a preferred location and two bounding locations. These represent $\sim 90 \%$ confidence bounds on endpoint position. The length of each segment is calculated as the along-strike distance between its endpoints (Figure 1.3), accounting for any internal bends. Given three positions of each endpoint, a fault segment may have up to nine possible lengths. The preferred (median) length computed from the preferred endpoint positions and the minimum and maximum lengths are listed in Table 3.8.

\section{$\underline{\text { Segment Widths }}$}

Fault width refers to the down-dip depth range over which seismic faulting is possible. Widths are determined by the distribution of regional seismicity and heat flow data, with the depths of microearthquakes being the primary consideration. The base of the seismogenic zone is defined by the depth extent of small-magnitude seismicity associated with each fault, which varies across 
SFBR; heat flow data and models were also used to constrain fault width (Appendix A). The fault-parallel seismicity cross-sections used in these estimates are shown in Figure 3.12. The average depth of seismicity in SFBR is $11-12 \mathrm{~km}$, although locally it extends to $14-16 \mathrm{~km}$. The areas of deepest seismicity, which include the Santa Cruz Mountains and the Mt. Diablo region, are regions of transpression in the strike-slip system where crustal shortening locally thickens the brittle crust.

\section{Seismogenic Scaling Factor, $R$}

Faults that creep are common in SFBR but otherwise rare among active faults in continental crust. Aseismic slip at depth occurs in lieu of slip during earthquakes so that an accurate accounting of the extent and amount of aseismic slip at depth is essential. While aseismic slip is a clear surface feature of the Hayward, Calaveras, and Concord-Green Valley faults, its depth extent and role in seismogenesis is poorly understood. Creep can be viewed as a vehicle for reducing the rate of strain accumulation (effectively reducing the slip rate accounted for in earthquake slip), or for reducing the fault area over which seismic slip occurs (or some combination of the two). In this analysis, fault creep is accommodated by reduction of fault area available for earthquake production.

Fault creep is represented in the SFBR earthquake model as the seismogenic scaling factor $R$, which varies from $R=0$ (all slip occurs aseismically) to $R=1$ (all slip occurs in earthquakes). $R$ then represents the percentage of the fault plane area that is locked between coseismic events, in the same manner that Oppenheimer et al., (1990) represented the central segment of the Calaveras fault. The Calculation Sequence scales the area of the fault segment that slips in earthquakes (Section 4 ). Thus, $R$ affects the size of segment-rupturing earthquakes and thus their mean rate: the smaller the value of $R$, the smaller the seismogenic area. The smaller the area, the smaller the magnitude and seismic slip of earthquakes, and the more frequent those earthquakes must occur to balance the long-term slip rate.

An expert group convened by WG02 considered methods for constraining values of $R$. The group concluded that regional models based on geodetic observations collected in the past few decades should be the primary basis for the $R$ values used in the calculations. Discussion of the appropriate models for estimating $R$ for each fault segment from geodetic observations is contained in Appendices B and C. Table 3.8 lists the values and weights used in the present report. The range of $R$ varies from a high of $0.9-1.0$ for the faults that either lack microearthquake activity that indicates creep or show no evidence of surface creep, to a low value of 0.0-0.4 for the southern Calaveras, which is creeping near or at its long-term slip rate. The Mt. Diablo thrust is assigned $R=1.0$ (all seismogenic) because the Working Group is unaware of documented creep on near-surface thrust faults in the Bay region and because uncertainty in the seismogenic area of this fault is incorporated into the endpoint and width values. The distribution of weights for all but the Concord-Green Valley fault and the Central Calaveras (CC) fault segment represents $90 \%$ confidence bounds. The weights for the ConcordGreen Valley reflect the higher degree of uncertainty in the large-earthquake behavior this fault.

Historical seismicity and deformation data are consistent with a creeping $\mathrm{CC}$ segment failing in M6.2 earthquakes every 50-100 years. Geologic evidence suggests, however, that the CC fault segment might fail in M7 events every 2000 years or so. Our preliminary model results (those 
adopted by WG99) were characterized by frequent M6.5 events, rather than frequent M6.2 events and infrequent $\mathbf{M} 7$ events. We found that this model mismatch could be eliminated by adjustments in $R$ that did not violate available geodetic information. The Working Group voted to adopt branches with $R=0.1,0.3$, and 0.5 rather than the initial values of $0.3,0.5$, and 0.7 .

\section{Implications of $R$ factor treatment to hazard modeling}

WG02 used $R$ factors to account for the effects of creep in its long-term model. As described in Appendix B, WG02 used $R$ to reduce the seismogenic area of a fault segment, consistent with Oppenheimer et al.'s (1990) descriptions of the behavior of the creeping fault segments CC and CS. Oppenheimer et al. (1990) identified six aseismic zones at depths of about 5 to 10 kilometers as the locations of future $5<\mathbf{M}<\sim 6$ earthquakes. WG02's reduction of the seismogenic area reduces the magnitude of segment-rupturing events. WG02 specifies neither the location of these reduced area events on the fault nor the distributions of slip on the areas, as this level of model detail is not relevant to estimation of earthquake recurrence rates and probabilities. However, this level of detail may be important to hazard estimates at near-fault sites where ground motions of $\mathbf{M}<6$ events may contribute significantly to the hazard estimate. The distributions of slip during the 1979 M5.7 Coyote Lake and 1984 M6.2 Morgan Hill earthquakes on CC are illustrative of the range of source models that must be considered in hazard models. Whereas slip in the Coyote Lake event apparently was concentrated in a circular zone at 5-to-10 depth (Liu and Helmberger, 1983), slip in the Morgan Hill event was concentrated at the ends of the 15 -to- $20 \mathrm{~km}$ long rupture, with little slip near the center of the rupture length (Hartzell and Heaton, 1986). Nearly all of the strong ground motions were generated in the 1-meter slip at the end of the rupture (Bakun et al, 1984). Hazard models should encompass these examples and conform, in a statistical sense, to the distribution of nearly-constant 30-bar stress drops documented for crustal strike-slip earthquakes in numerous publications (e.g., Thatcher and Hanks, 1973; Hanks and Bakun, 2002).

\section{Fault segment slip rate, $v$}

Fault segment slip rates were estimated primarily from observations of offset geological or cultural features, and thus are average values over some time interval, typically hundreds to several tens of thousands of years. Preferred and 95\%-bounding values were prescribed for each fault segment as described in this chapter. Values are summarized in Table 3.8. 
Table 3.8 Length, width, $R$ (seismogenic scaling factor), and slip rate for each fault segment

\begin{tabular}{|c|c|c|c|c|c|c|c|c|c|c|}
\hline \multirow[b]{2}{*}{ Fault } & \multirow[b]{2}{*}{ Seg. } & \multicolumn{3}{|c|}{ Length, km } & \multicolumn{2}{|c|}{ Width, km } & \multicolumn{2}{|c|}{$\mathrm{R}$ (seis. scaling factor) } & \multicolumn{2}{|c|}{ Slip rate, $\mathrm{mm} / \mathrm{yr}$} \\
\hline & & Preferred & Min & Max & Preferred & $90 \%$ bounds & Values & Weights* & Preferred & $95 \%$ bounds \\
\hline \multirow[t]{4}{*}{ San Andreas } & SAS & 62 & 47 & 77 & 15 & $13-17$ & $0.8 / 0.9 / 1.0$ & (a) & 17 & $13-21$ \\
\hline & SAP & 85 & 60 & 110 & 13 & $11-15$ & $0.9 / 1.0$ & (b) & 17 & $13-21$ \\
\hline & SAN & 191 & 171 & 211 & 11 & $9-13$ & $0.9 / 1.0$ & (b) & 24 & $21-27$ \\
\hline & SAO & 135 & 115 & 155 & 11 & $9-13$ & $0.9 / 1.0$ & (b) & 24 & $21-27$ \\
\hline \multirow[t]{3}{*}{ Hayward/RC } & $\mathrm{HS}$ & 53 & 34 & 71 & 12 & $10-14$ & $0.4 / 0.6 / 0.8$ & (a) & 9 & $7-11$ \\
\hline & $\mathrm{HN}$ & 35 & 20 & 50 & 12 & $10-14$ & $0.4 / 0.6 / 0.8$ & (a) & 9 & $7-11$ \\
\hline & $\mathrm{RC}$ & 63 & 53 & 73 & 12 & $10-14$ & $0.9 / 1.0$ & (b) & 9 & $7-11$ \\
\hline \multirow[t]{3}{*}{ Calaveras } & CS & 19 & 9 & 29 & 11 & $9-13$ & $0.0 / 0.2 / 0.4$ & (a) & 15 & $12-18$ \\
\hline & $\infty$ & 59 & 49 & 69 & 11 & $9-13$ & $0.1 / 0.3 / 0.5$ & (c) & 15 & $12-18$ \\
\hline & $C N$ & 45 & 35 & 55 & 13 & $11-15$ & $0.7 / 0.8 / 0.9$ & (a) & 6 & 4-8 \\
\hline \multirow[t]{3}{*}{ Concord/GV } & $\mathrm{CON}$ & 20 & 12 & 28 & 16 & $14-18$ & $0.2 / 0.5 / 0.8$ & (d) & 4 & $2-6$ \\
\hline & GVS & 22 & 16 & 28 & 14 & $12-16$ & $0.2 / 0.5 / 0.8$ & (d) & 5 & $2-8$ \\
\hline & GVN & 14 & 6 & 22 & 14 & $12-16$ & $0.2 / 0.5 / 0.8$ & (d) & 5 & $2-8$ \\
\hline \multirow[t]{2}{*}{ San Gregorio } & SGS & 66 & 46 & 86 & 12 & $10-14$ & $0.8 / 0.9 / 1.0$ & (a) & 3 & $1-5$ \\
\hline & SGN & 110 & 85 & 134 & 13 & $11-15$ & $0.8 / 0.9 / 1.0$ & (a) & 7 & $4-10$ \\
\hline \multirow[t]{2}{*}{ Greenville } & GS & 24 & 15 & 31 & 15 & $12-18$ & $0.8 / 0.9 / 1.0$ & (a) & 2 & $1-3$ \\
\hline & GN & 27 & 17 & 37 & 15 & 12-18 & $0.8 / 0.9 / 1.0$ & (a) & 2 & $1-3$ \\
\hline Mt Diablo & MTD & 25 & 15 & 35 & 14 & $12.2-16.2$ & 1.0 & 1.0 & 2 & $1-3$ \\
\hline
\end{tabular}

* Weights: (a) Mean and 90\% bounds: 0.185/0.63/0.185. (b) Only lower $90 \%$ bound set: $0.185 / 0.815$.

(c) Weights determined by WG02: $0.4 / 0.5 / 0.1$ (see text). (d) Equal weighting of 1/3 on each branch.

\section{Summary of Time of Most Recent Rupture of SFBR Fault Segments}

The elapsed time since the most recent, segment-rupturing earthquake (MRE) is an important input for the time-dependent probability models, because the "segment clock" is set at this time (Chapter 5). The available data for the dates of large earthquakes on SFBR fault segments is summarized in Table 3.9. For many of these segments there is no paleoseismic information. The assumptions used to estimate the reset times on the segments for which there are no direct data, and the weights on the distribution of all reset dates, are found in Chapter 5. 
Table 3.9. Time of most recent rupture on SFBR fault segments

\begin{tabular}{|c|c|c|}
\hline Fault & Seg. & MRE date \\
\hline \multirow[t]{4}{*}{ San Andreas } & SAS & 1906 \\
\hline & SAP & 1906 \\
\hline & SAN & 1906 \\
\hline & SAO & 1906 \\
\hline \multirow[t]{3}{*}{ Hayward/Rodgers Creek } & HS & 1868 \\
\hline & $\mathrm{HN}$ & $1635-1776$ \\
\hline & $\mathrm{RC}$ & $1670-1776$ \\
\hline \multirow[t]{3}{*}{ Calaveras } & CS & No direct data \\
\hline & $\mathrm{CC}$ & No direct data \\
\hline & $\mathrm{CN}$ & $1670-1830$ \\
\hline \multirow[t]{3}{*}{ Concord/Green Valley } & $\mathrm{CON}$ & No direct data \\
\hline & GVS & No direct data \\
\hline & GVN & No data \\
\hline \multirow[t]{2}{*}{ San Gregorio } & SGS & No direct data \\
\hline & SGN & $\mid 1270-1776$ \\
\hline \multirow[t]{2}{*}{ Greenville } & $\overline{G S}$ & No direct data \\
\hline & GN & No direct data \\
\hline Mount Diablo Thrust & MTD & No direct data \\
\hline
\end{tabular}




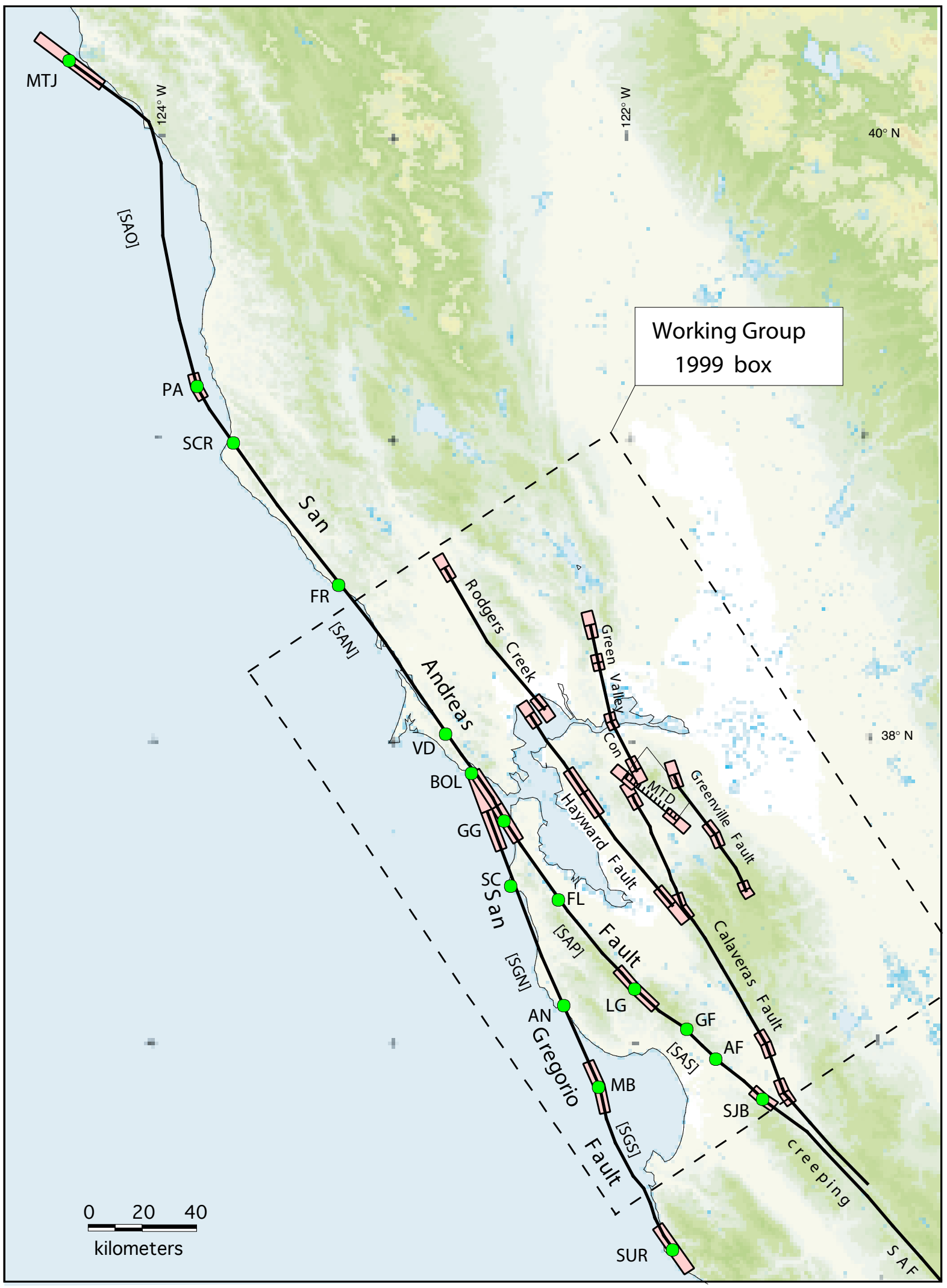

Figure 3.1. Segmentation of SFBR faults. Bold solid lines indicate major faults for which probabilities were calculated. Light rectangles are segment boundaries. MTD, Mount Diablo Thrust; Con, Concord Fault. San Andreas Fault segments: SAN, North Coast; SAO, Offshore; SAP, Peninsula; SAS, Santa Cruz Mountains. San Gregorio Fault segments: SGN,North; SGS, South. Localities (circles): AF, Arano Flat; AN, Ano Nuevo; BOL, Bolinas, FL, Filoli; FR, Fort Ross; GF, Grizzly Flat; GG, Golden Gate stepover zone in SAF and SGF; LG, Los Gatos bend in SAF; MB, Monterey bend in SGF; MTJ, Mendocino triple junction; PA, Point Arena; SC, Seal Cove; SCR, Scaramella Ranch; SJB, San Juan Bautista; SUR, Point Sur; VD, Vedanta. 


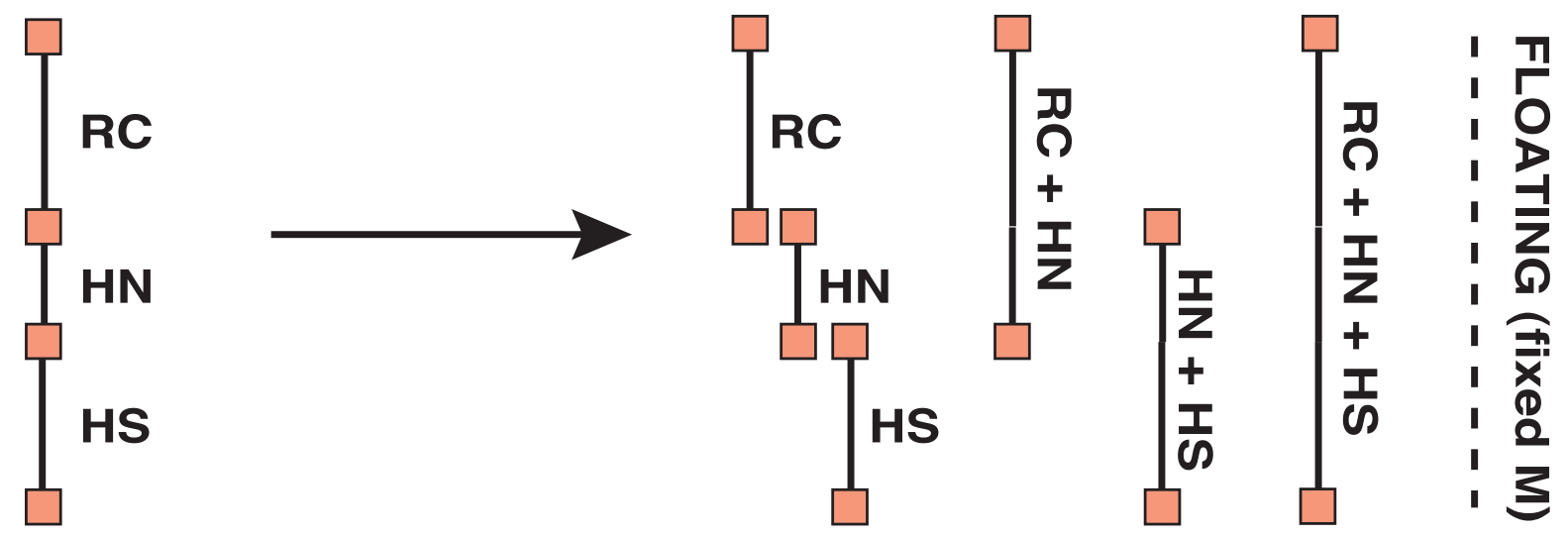

3.2a Fault Segments

3.2b Rupture Sources

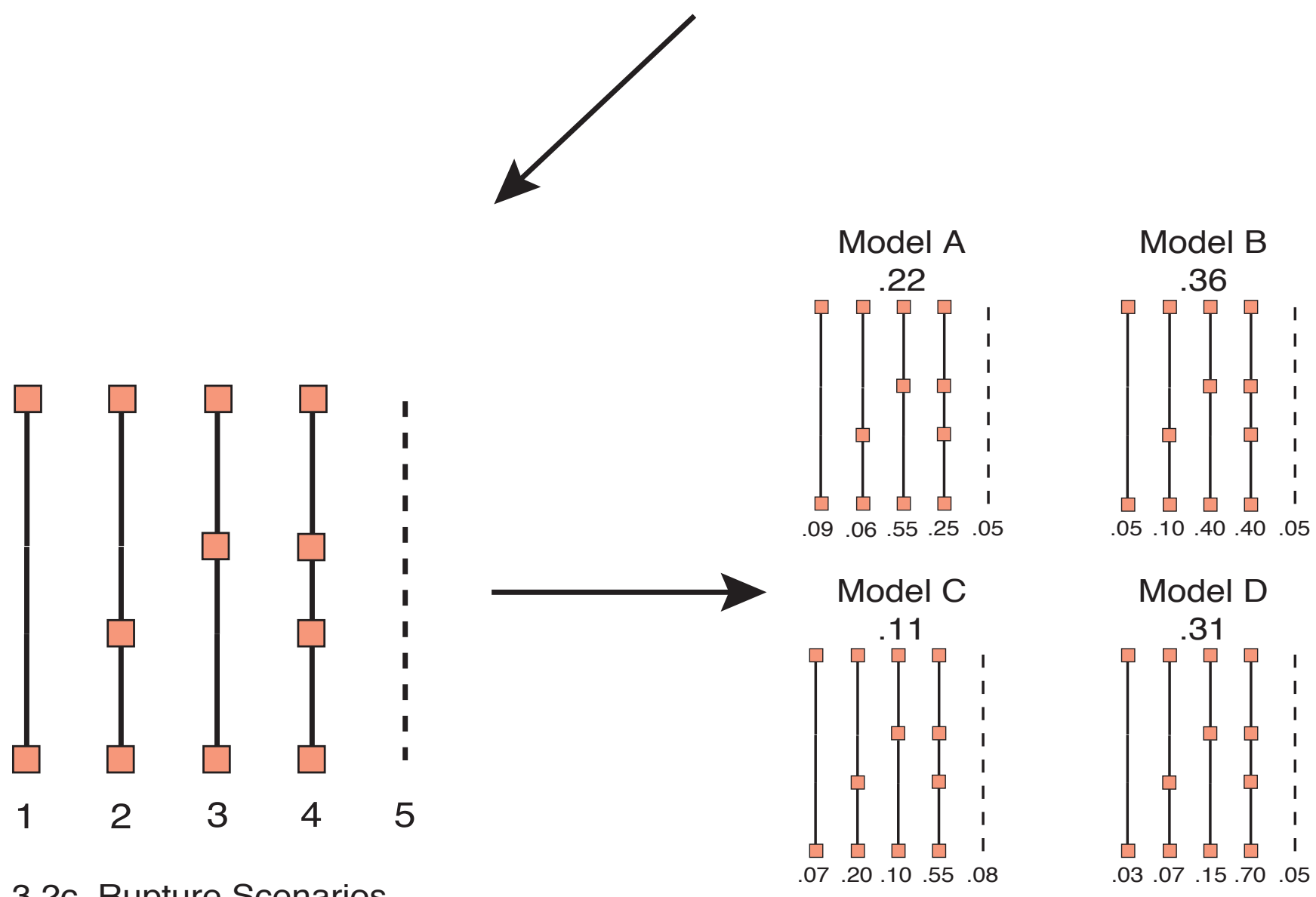

3.2d Rupture Models

Figure 3.2 Diagram illustrating construction of rupture models from fault segments using the Hayward - Rodgers Creek fault as an example. Orange boxes are segment boudaries. a) initial 3-segment fault; b) 6 rupture sources (+ floating earthquake) derived from segments; c) rupture scenarios built from sources; d) rupture models with weights for each model and rupture scenario. 


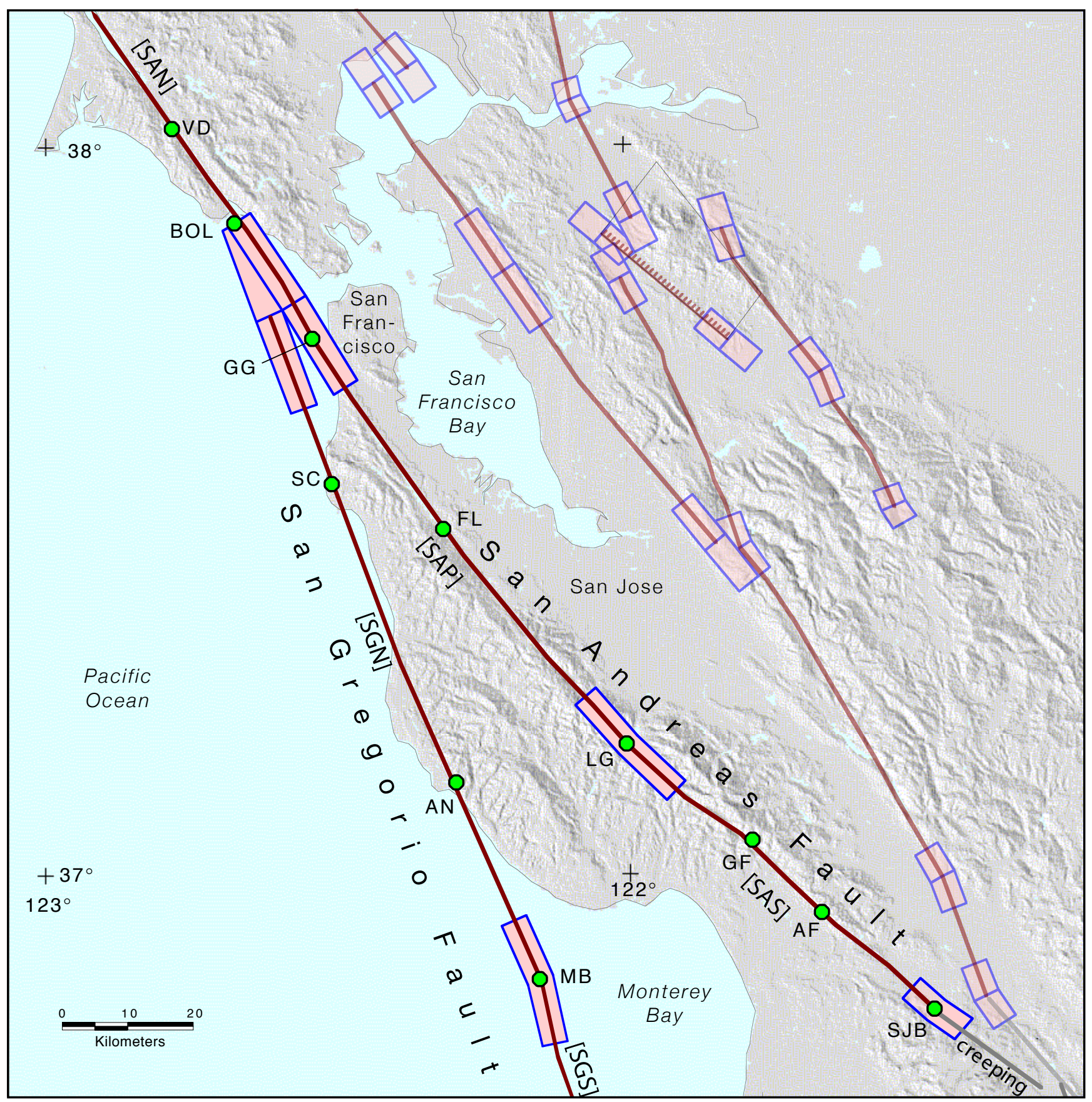

Figure 3.3. Segment boundaries for the San Andreas and San Gregorio faults. San Andreas Fault segments: SAN, North Coast; SAP, Peninsula; SAS, Santa Cruz Mountains. San Gregorio Fault segments: SGN, North; SGS, South. Localities (circles): AF, Arano Flat; AN, Ano Nuevo; BOL, Bolinas, FL, Filoli; GF, Grizzly Flat; GG, Golden Gate stepover zone in SAF and SGF; LG, Los Gatos bend in SAF; MB, Monterey bend in SGF; SC, Seal Cove; SJB, San Juan Bautista; VD, Vedanta. 


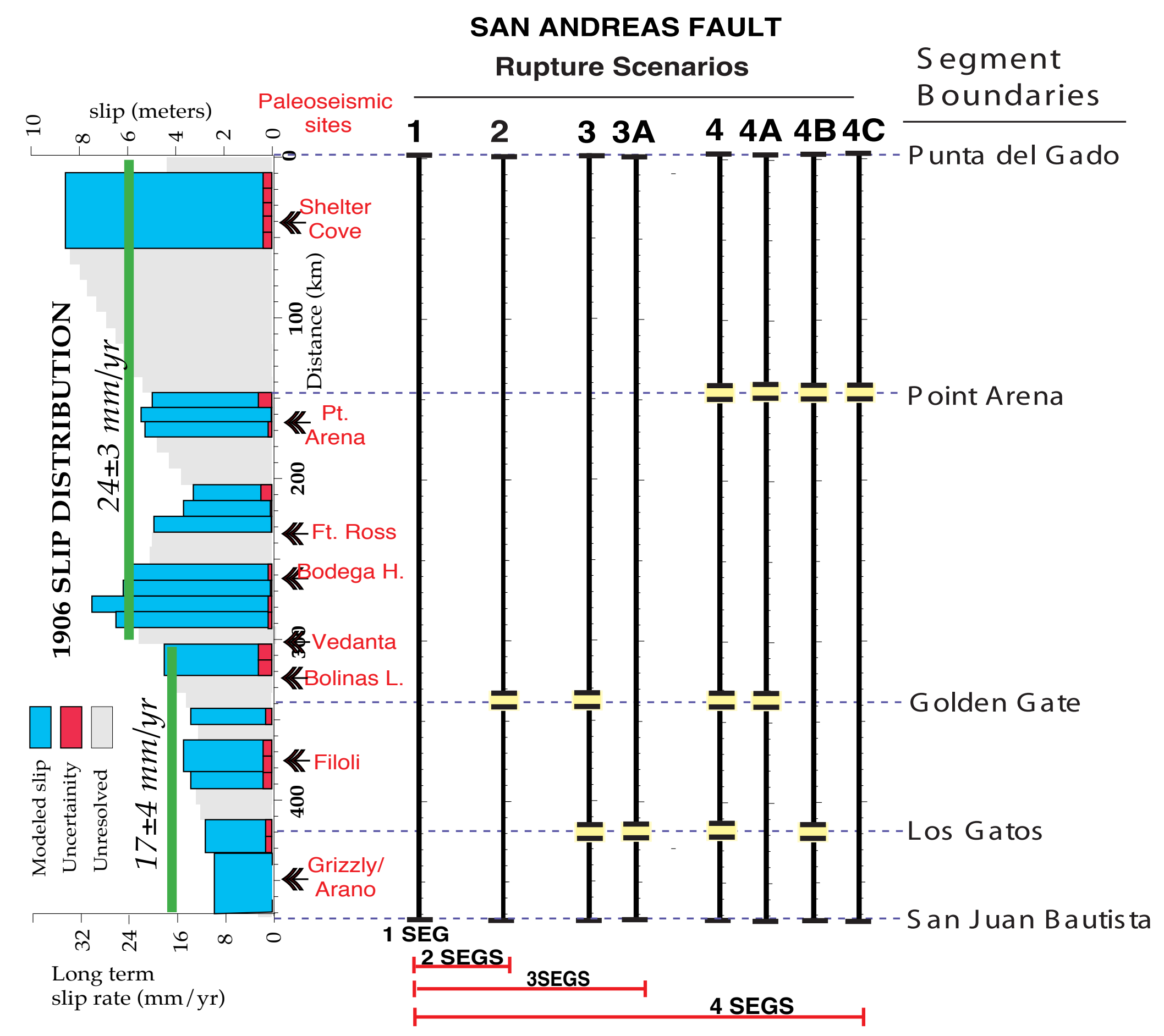

Figure 3.4 San Andreas rupture scenarios. Graph on left shows geodetic slip from 1906 earthquake. Green bands are geologic slip rates. Arrows show locations of paleoseismic sites described in text. 


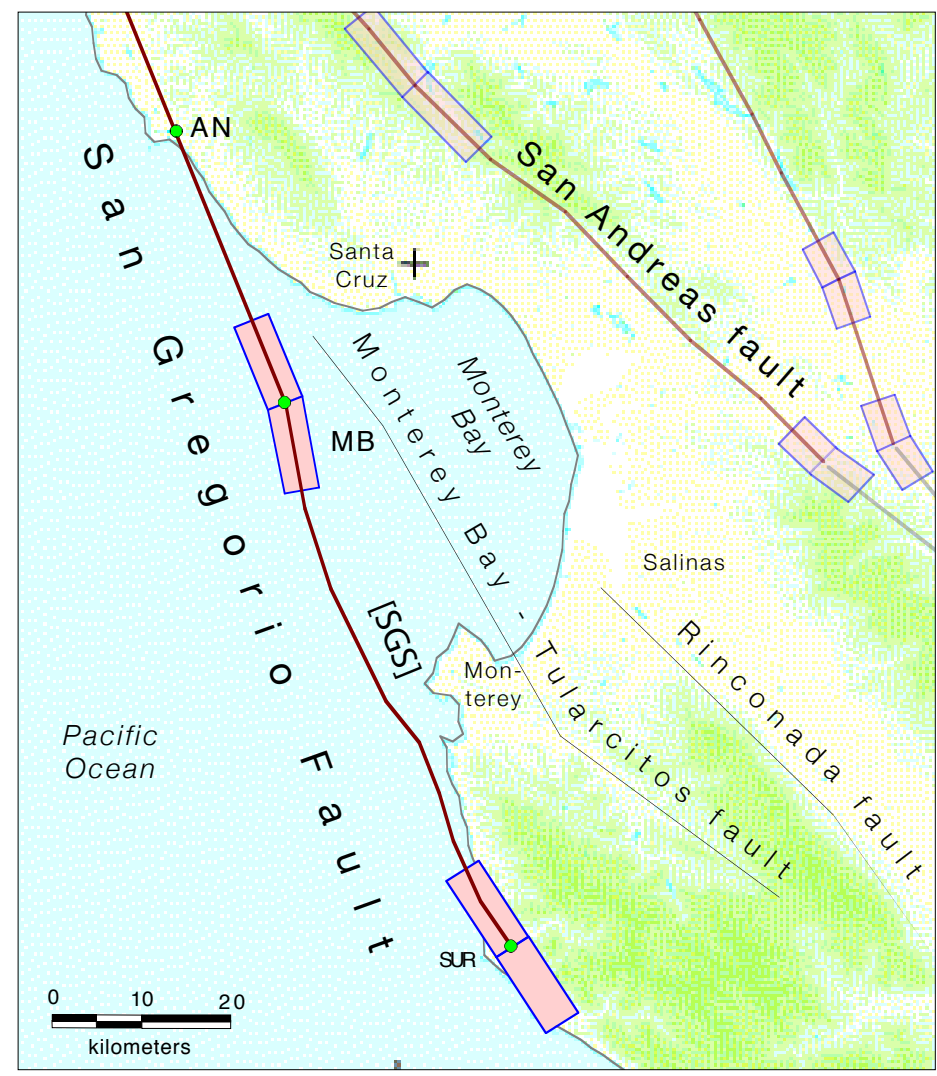

Figure 3.5. Segment boundaries for the southern segment of the San Gregorio fault [SGS]. Localities (circles): AN, Ano Nuevo; MB, Monterey bend in SGF; SUR, Point Sur. 


\section{A. San Gregorio fault}

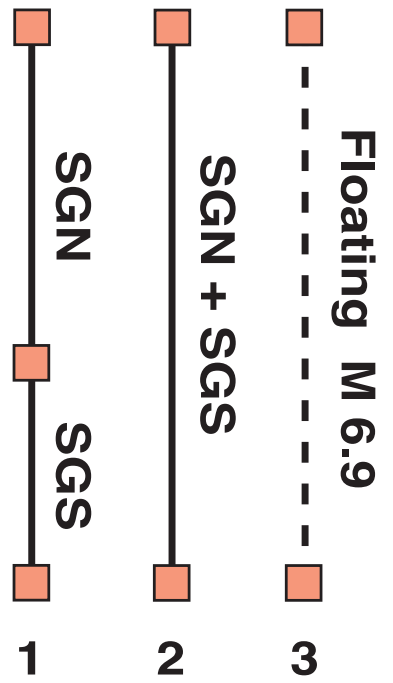

\section{B. Calaveras fault}

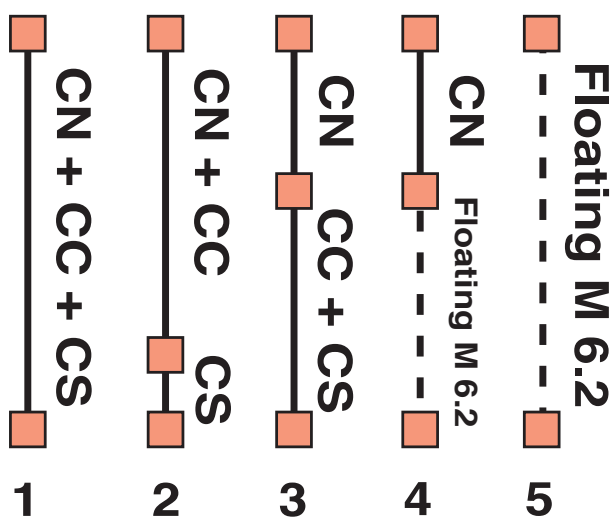

C. Concord - Green Valley

D. Greenville fault fault
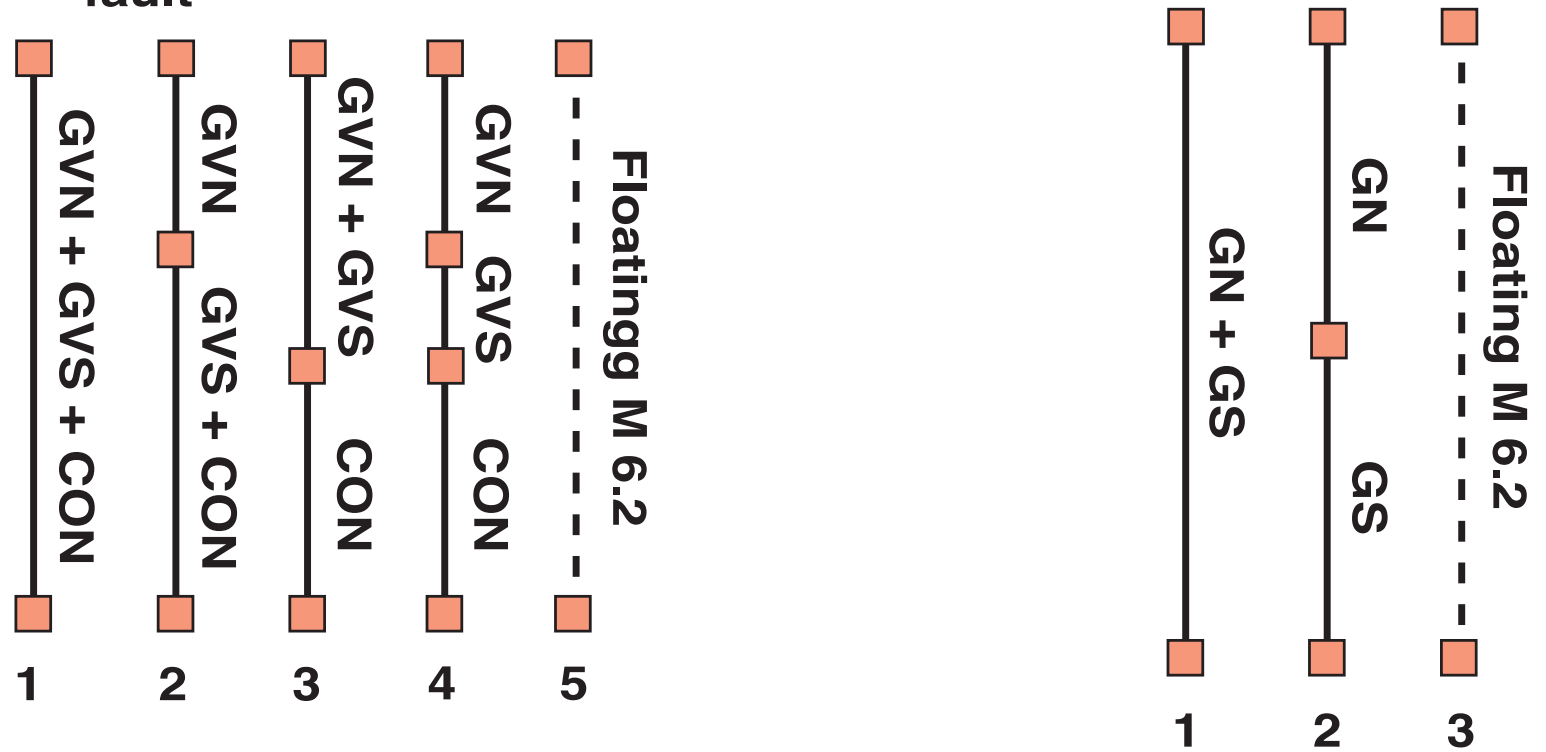

Figure 3.6 Schematic fault rupture scenarios for the San Gregorio (A), Calaveras (B), Concord - Green Valley (C), and Greenville (D) faults. Orange boxes are segment boundaries. Scenarios are described in text. 


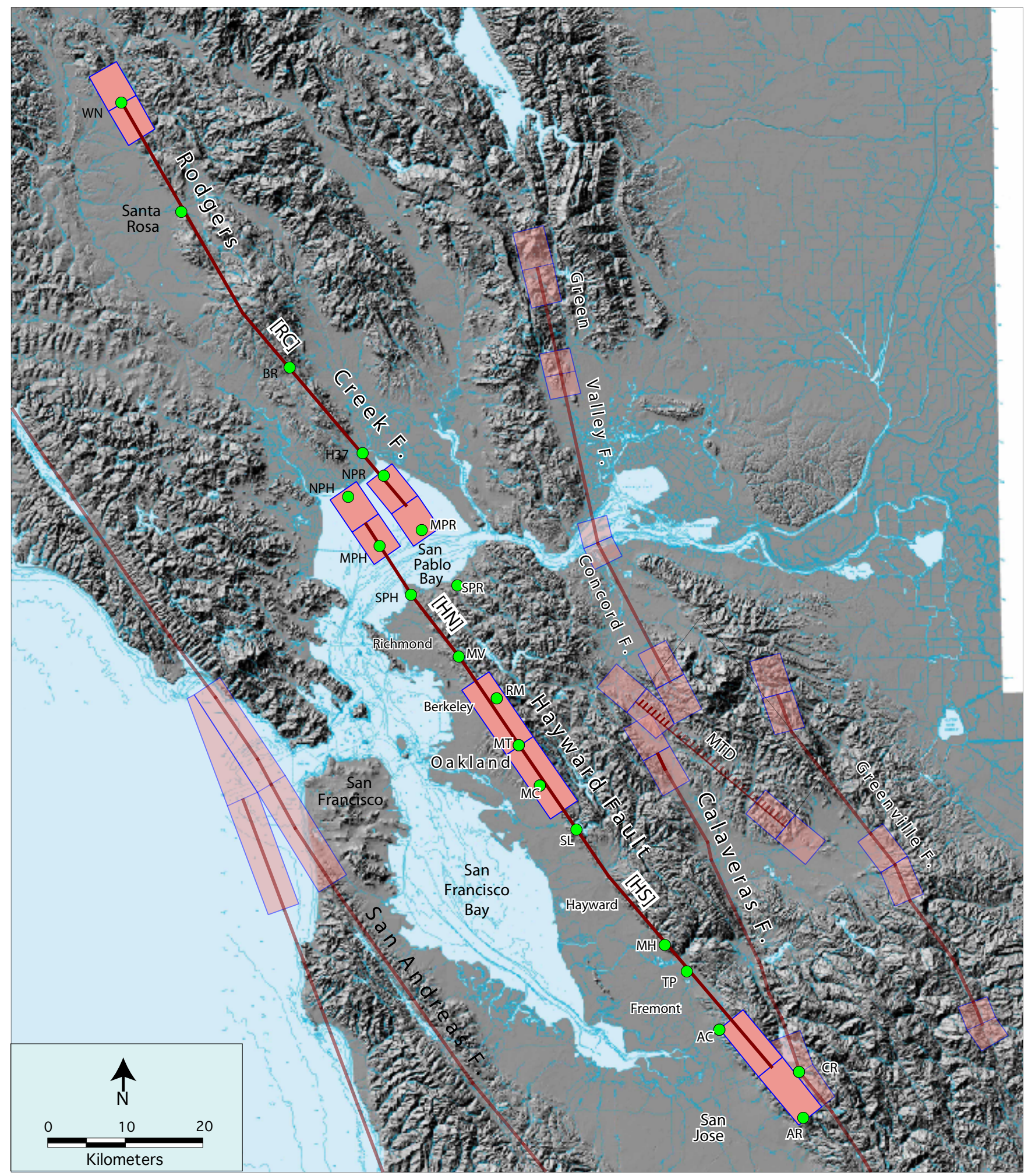

Figure 3.7. Hayward-Rogers Creek segments: HN, Hayward North; HS, Hayward South; RC, Rodgers Creek. AC, Agua Caliente Creek; AR, Alum Rock; BR, Beebe Ranch, CR; Calaveras Reservoir; H37, Highway 37; MC, Mills College; MH, Masonic Home; MPH, middle San Pablo Bay on Hayward fault; MPR, middle San Pablo Bay on Rodgers Creek fault; MT; Montclair; MV, Mira Vista Golf Course; NPH, north end San Pablo Bay on Hayward Fault; NPH, north end San Pablo Bay on Rodgers Creek Fault; RM, Rocky Mound; SL, San Leandro; SPH, south end San Pablo Bay on Hayward Fault; SPH, south end San Pablo Bay on Rodgers Creek Fault; TP, Tule Pond; WN, Windsor. 


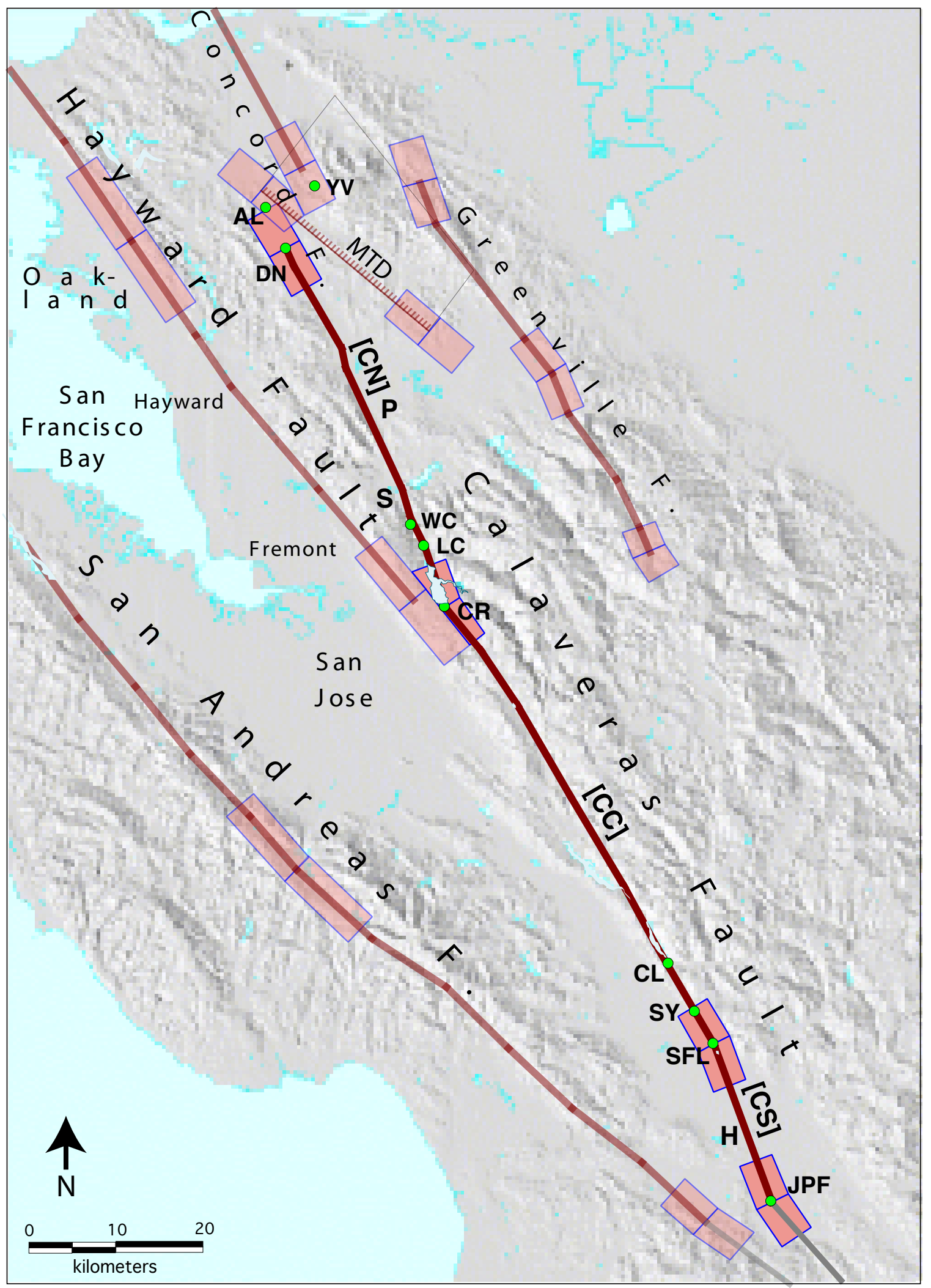

Figure 3.8. Calaveras Fault segments: CC, Central; CN, North; CS, South. Localities: AL, Alamo; CL, Coyote Lake; DN, Danville; H, Hollister; JPF, Junction Paicines Fault; LC, Leyden Creek; P, Pleasanton; S, Sunol; SFL, San Felipe Lake; SY, San Ysidro Creek; WC, Welch Creek; YV, Ygnacio Valley 


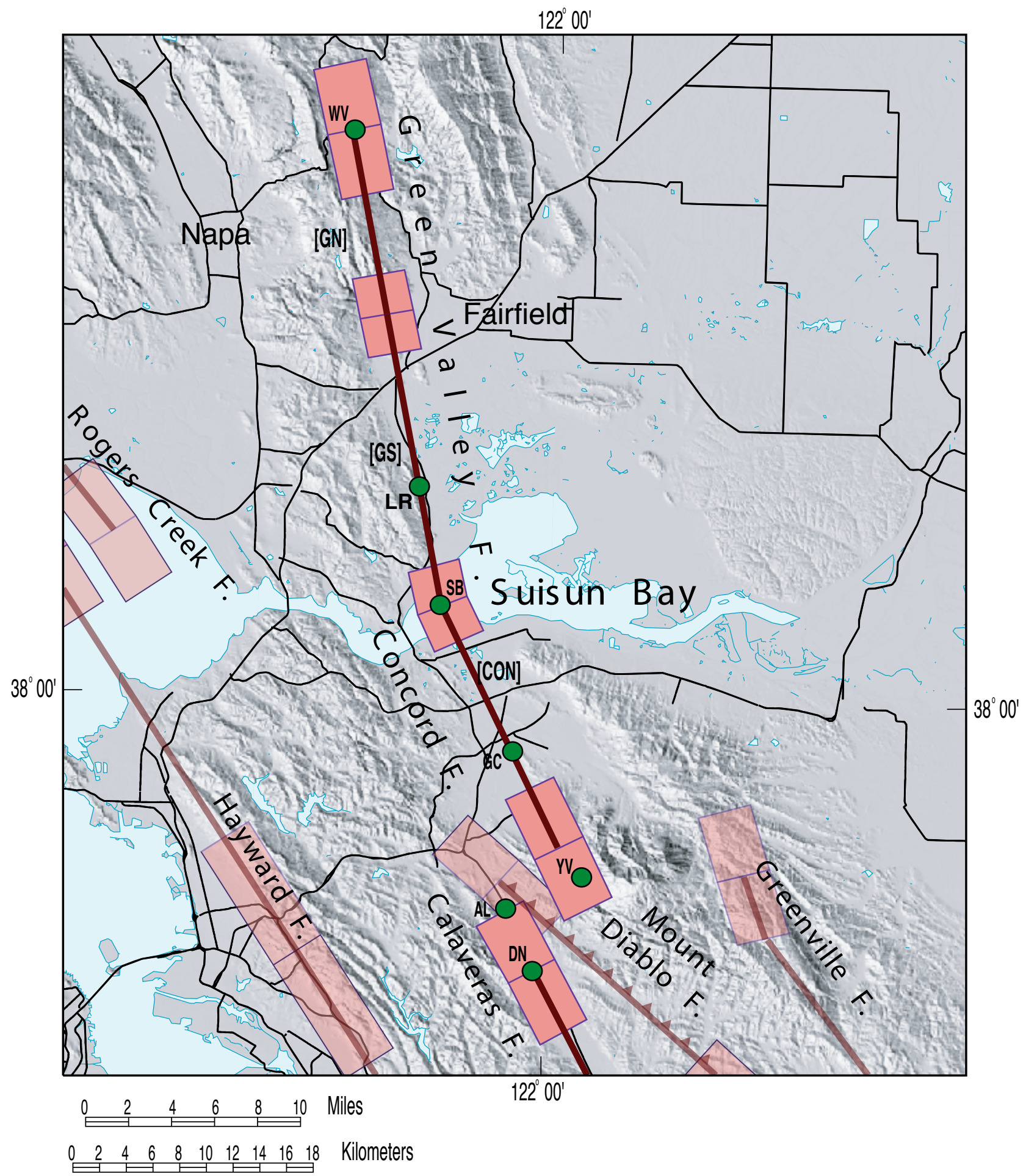

Figure 3.9. Segments of the Green Valley and Concord Faults. Segments: CON, Concord; GVN, Green Valley Fault North; GVS, Green Valley Fault South. Localities: GC, Gallindo Creek; LR, Lopes Ranch; SB, Suisun Bay; WV, Wooden Valley; Ygnacio Valley; others same as previous figures. 


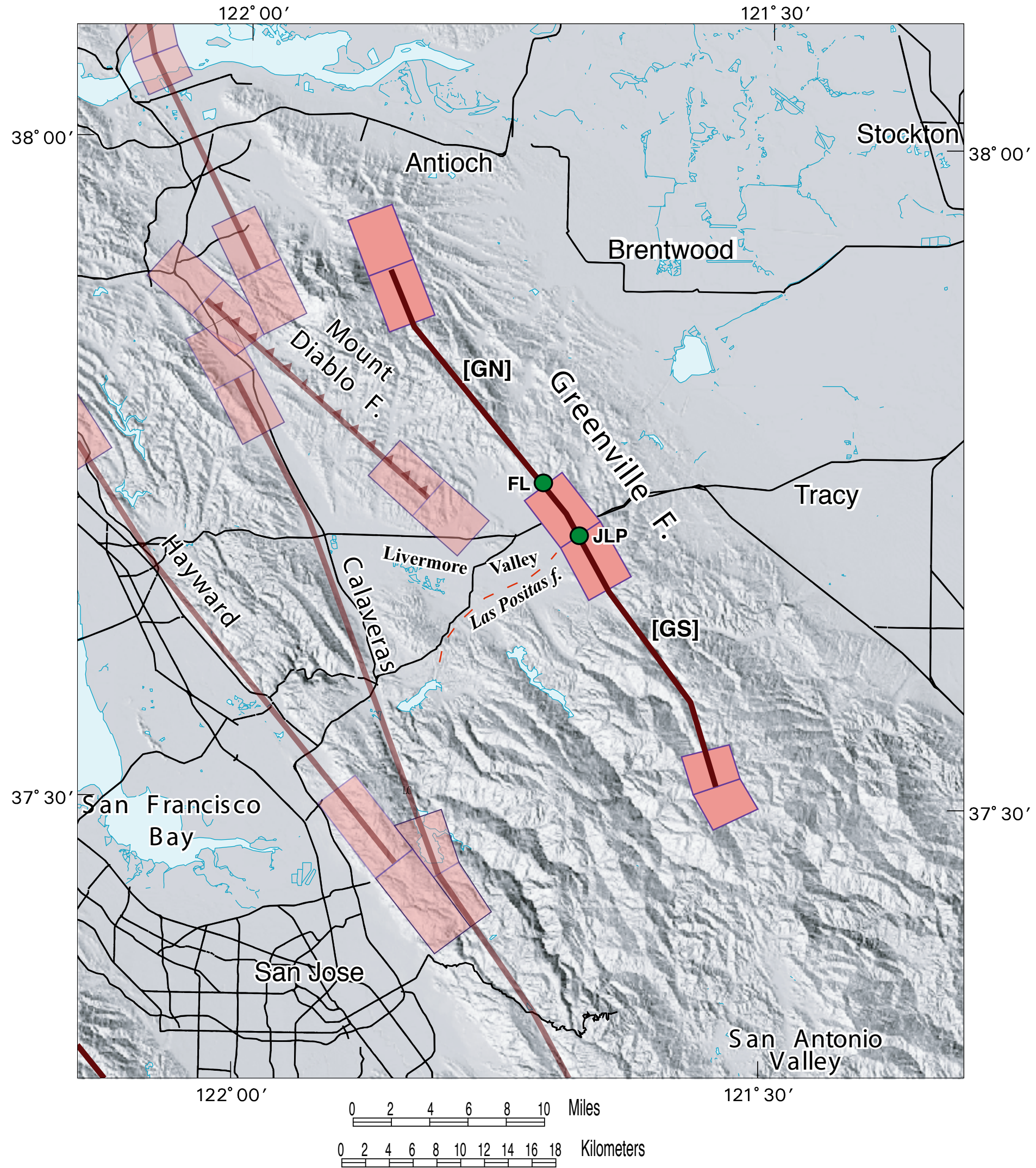

Figure 3.10. Segments of the Greenville fault: GN, North; GS, South. Localities: FL, Frick Lake; JLP, Junction Las Positas Fault. 


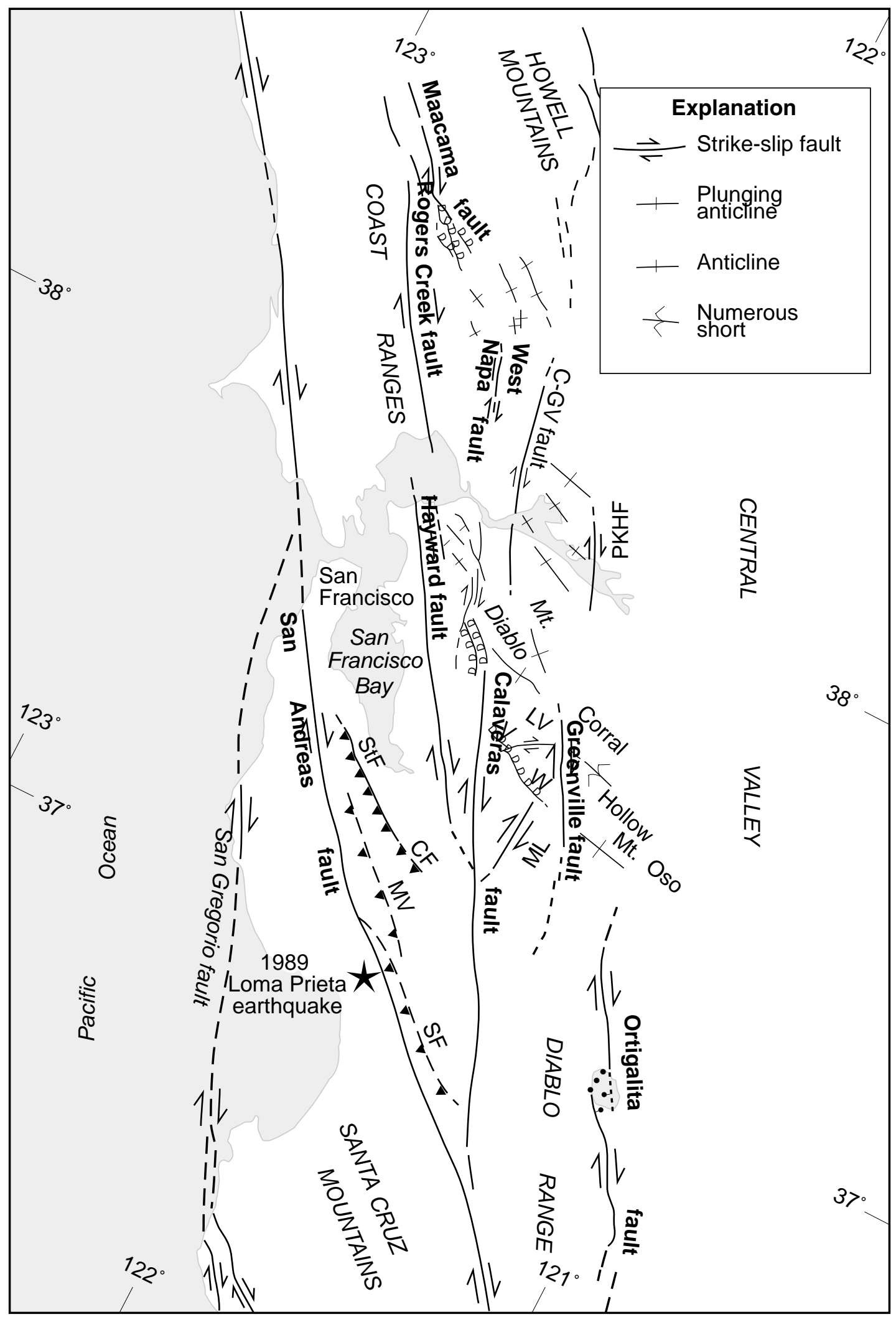

Figure 3.11. Major late Cenozoic strike-slip faults, folds and thrust faults in the greater San Francisco Bay area. Note that the thrust faults and folds typically are oriented about $45^{\circ}$ to the strike-slip faults of the San Andreas system, and locally exhibit a right-stepping en echelon geometry typical of dextral wrench structures. Collectively, the strike-slip faults, thrust faults and folds accommodate about $40 \mathrm{~mm} / \mathrm{yr}$ of NW dextral shear between the Pacific plate on the west and the Sierra Nevada-Great Valley microplate on the east. Abbreviations: StF $=$ Stanford fault; $\mathrm{CF}=$ Cascade fault; $\mathrm{MV}=$ Monte Vista fault; $\mathrm{SF}=$ Sargent fault; $\mathrm{LV}=$ Livermore Valley; $\mathrm{ML}=\mathrm{Mt}$. Lewis fault; $\mathrm{V}=$ Verona fault $; \mathrm{W}=$ Williams fault; PKHF = Pittsburg-Kirby Hills fault. 


\section{NORTHWEST}

Greenville Fault

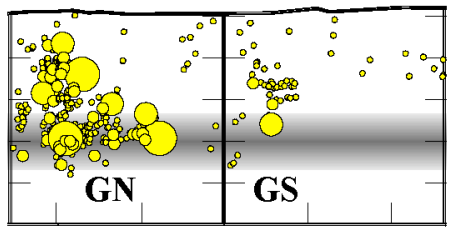

C a I a veras Fault
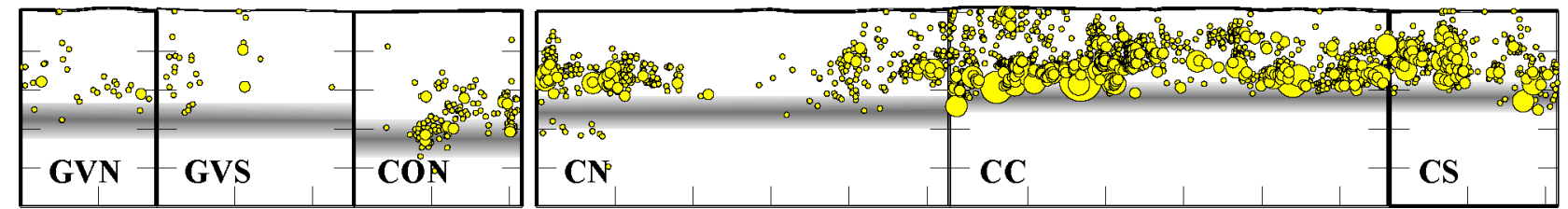

Rogers Creek Fault

Hay ward Fault

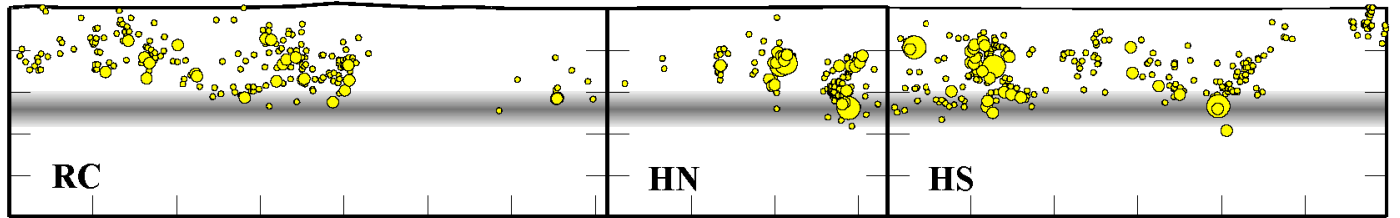

San Andreas Fault

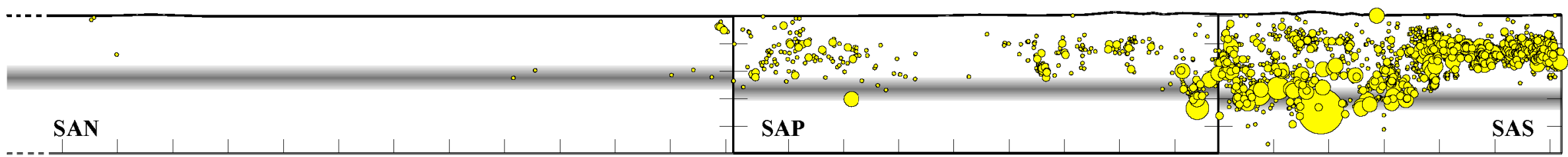

Figure 3.12. Cross-section diagrams of the characterized SFBR fault systems, illustrating the segmentation framework adopted in the WG99 earthquake source model. The Mt.

Diablo thrust is not shown. Yellow circles show seismicity

$\mathrm{M} \geq 2$ recorded on and near the faults. Fault segment boundaries (vertical lines) were chosen on the basis of surface expression, variations in the density or depth of seismicity, the extent of rupture in previous large earthquakes, and other evidence (see Appendix A). Uncertainty in segment boundary position is not shown (cf. Figure 0.1). Fault segment width (depth extent) and its uncertainty is shown as gray bars; width was chosen on the basis of recorded seismicity and heat flow (see Appendix A). No vertical exaggeration.
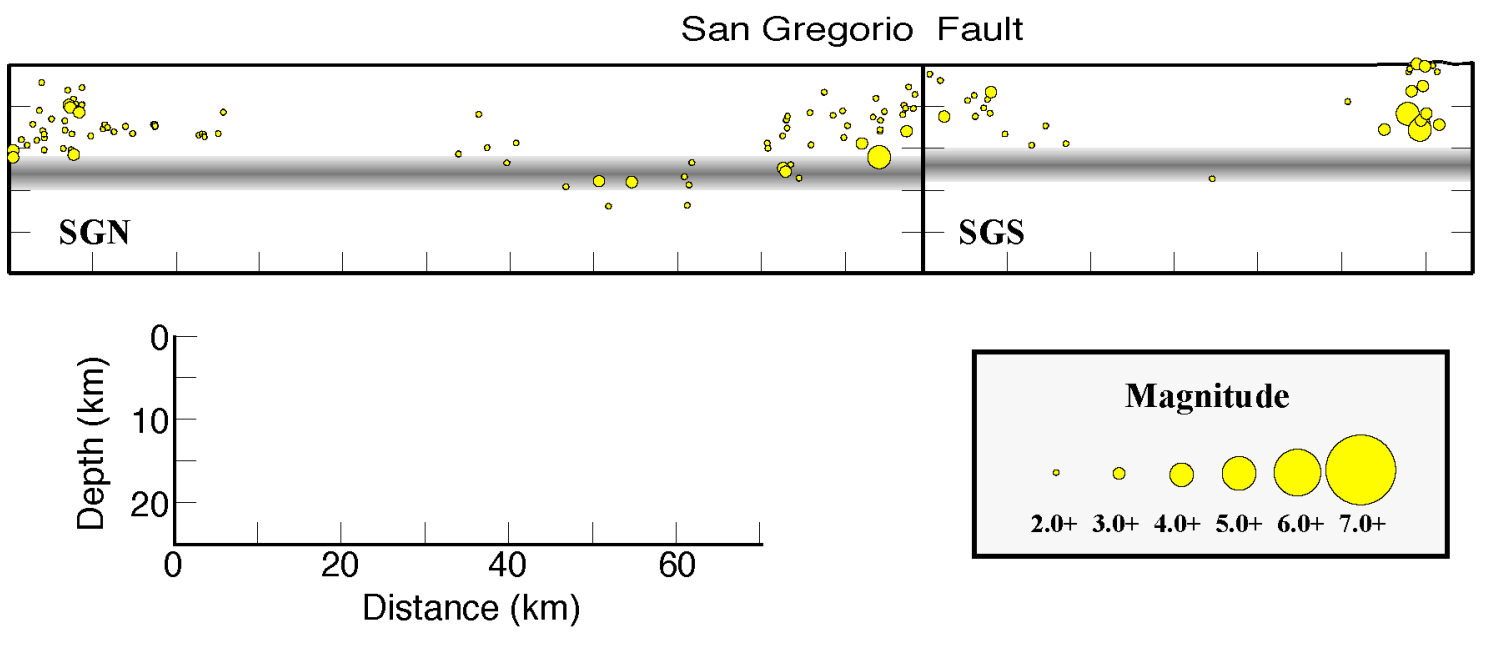

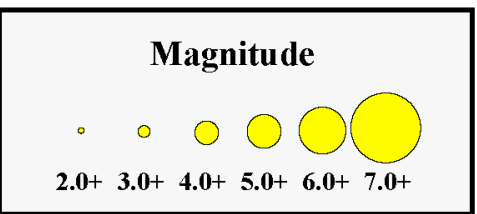




\title{
ChaPTer 4: The SFBR EARThQUAKe SOURCE MODEL: MAgNitUdeS AND LONG-TERM RATES
}

\author{
Introduction: Calculating Rupture Source Rates in a Complex Model
}

The tectonically complex San Francisco Bay Region (SFBR) contains both known and unidentified faults that produce a broad range of earthquake sizes at different rates of occurrence. In this chapter we use fault zone information developed in the previous chapter to construct an earthquake source model that describes long-term rates of earthquake production in the SFBR. Specifically, this SFBR earthquake model defines the sizes and locations of earthquake rupture sources in the region, the magnitudes of the earthquakes produced by those sources, and the long-term recurrence rates of those earthquakes. The earthquakes described by the model include large segment-breaking and floating events on the seven characterized faults, and background events on uncharacterized or unknown faults. The SFBR earthquake model is constructed using the variety of geologic, geodetic, and seismic data summarized in the previous chapter, and is faithful to what is currently known about the rates of seismic moment accumulation and release across the region.

Mean rates of earthquake occurrence are primary inputs into the calculations of earthquake probability presented in the following chapters. Information on earthquake recurrence times is limited because of the shortness of the historical and paleoseismic records. However, estimates of geologic slip rates allow us to estimate rates of seismic moment release on each of the characterized faults. There is also information on segment lengths, widths, and seismogenic scaling factors $R$, which provide an estimate of the seismogenic areas $A$ of each rupture source (Figure 2.3). These area estimates are the basis for estimating the magnitude $\mathbf{M}$ of earthquakes that occur on them, through $\mathbf{M}-\log A$ relations. The main focus of this chapter is the estimation of earthquake rates, which is obtained from the moment release rate and the size of earthquakes that release the moment.

If each fault segment in the SFBR acted as an independent rupture source, the calculation of earthquake rates would be straightforward: the long-term slip rate for each segment would be achieved by a repeating sequence of similar-sized earthquakes. Given the long-term moment release rate of the segment, $\dot{M}_{0}$ (obtained from its seismogenic area and slip rate) and the mean moment of those repeating earthquakes, $\bar{M}_{0}$ (obtained from its seismogenic area), their ratio would define the rate of earthquakes, or rupture source rate, $\gamma$.

$$
\gamma=\frac{\dot{M}_{0}}{\bar{M}_{0}}
$$

However, our model allows segments to fail in combination, such that the long-term earthquake history of a fault segment may involve failure in a number of different rupture scenarios involving combinations with its neighbors or failure of portions of the fault system in floating earthquakes. Also, we specify that a small fraction of the fault system's moment budget, $F_{\text {small }}$, goes toward the production of smaller (sub-segment sized) earthquakes. Because each fault may pro- 
duce such a variety of earthquakes, we modify equation (4.1) to define a system of equations, one for each characterized rupture source, that together satisfy the long-term slip rates of all the fault segments:

$$
\gamma_{\text {char }_{i}}=\frac{\dot{M}_{0_{i}} F_{\text {char }}}{\bar{M}_{0 \text { char } r_{i}}}
$$

where subscript char refers to characterized (fixed and floating) rupture sources, $\dot{M}_{0_{i}}$ is the moment rate of rupture source $i, \bar{M}_{0 c h a r_{i}}$ is the mean moment of earthquakes produced by rupture source $i$, and $F_{\text {char }}$ is the fraction of seismogenic moment rate expended in characterized earthquakes. Equation (4.2a) corresponds to the right-most box in the calculation flow diagram Figure 2.10. In the first three major sections that follow, we summarize the approach taken by WG02 to calculate the three quantities on the right side of (4.2a).

For the purpose of calculating large-earthquake rates - the primary purpose of this chapter-we need only discover the moment rate fraction $F_{\text {char }}$ and other quantities in (4.2a). However, estimating $F_{\text {char }}$ will require us to also estimate the moment rate fraction expended in aftershocks, $F_{\text {aftershock }}$, and that expended in other small earthquakes on the fault system, $F_{\text {small }}$, such that $F_{\text {char }}+$ $F_{\text {aftershock }}+F_{\text {small }}=1$. It turns out to be useful in some applications to specify the rate and magnitude distribution of those smaller events. For that purpose one may employ an expression analogous to (4.2a) for the rate of smaller earthquakes within a specified magnitude range:

$$
\gamma_{\text {small }_{i}}=\frac{\dot{M}_{0_{i}} F_{\text {small }}}{\bar{M}_{0 \text { small }_{i}}}
$$

where $\bar{M}_{0 \text { small }}$ is the mean moment of smaller earthquakes (within that magnitude range), and $F_{\text {small }}$ is the fraction of seismogenic moment rate expended in smaller earthquakes. We expand briefly upon this application later in the chapter (see box later in this chapter).

Calculations are carried out independently for each of the seven characterized fault systems. We also estimate the rate of background earthquakes (those which occur elsewhere than on the seven characterized ones). Finally, the rates of earthquakes on the fault systems and the background are combined to find the long-term earthquake rate (as a function of magnitude) for the SFBR as a whole. Calculations were performed using a computer program that is released with this report; interested readers are directed to Appendix G.

Readers who wish to skip directly to the results of this analysis may turn to the section entitled "Results: Long-term earthquake rates in the SFBR" later in this chapter. There, the results of the WG02 earthquake source model calculations are presented in two tables: Table 4.8 presents long-term rates of rupture and mean magnitudes for each fixed and floating rupture source. Table 4.9 contains calculated earthquake occurrence rates and recurrence intervals for each fault segment. In the final sections of this chapter, the modeled values for regional, fault, and segment recurrence are evaluated by comparison to historical seismicity and paleoseismic recurrence observations in the SFBR, and to the results from other earthquake models. 


\section{Steps in the Calculation Sequence}

The SFBR model is developed using the calculation steps summarized in the following chart. The first four steps collect the information needed to calculate rupture source rates from equation (4.2a). The remaining three steps complete the description of the SFBR earthquake model.

Table 4.1. Steps in the calculation sequence for the SFBR earthquake model:

\begin{tabular}{|c|c|c|}
\hline Calculation step: & Strategy and equations: & Outputs: \\
\hline $\begin{array}{l}\text { Calculate the mean mo- } \\
\text { ments of characterized } \\
\text { rupture sources, } \bar{M}_{0 \text { char }} \text { in } \\
(4.2 \mathrm{a}) \text {. }\end{array}$ & $\begin{array}{l}\text { a. Calculate the mean magnitude } \overline{\mathbf{M}}_{\text {char }} \text { as } \\
\text { a function of seismogenic area } A \text { using } \\
\text { M-log } A \text { relations, (4.4)-(4.6). } \\
\text { b. Define variability of M as Gaussian, and } \\
\text { determine the degree of variability, } \sigma_{\mathrm{m}} \\
\text { c. Calculate } \bar{M}_{\text {Ochar } r_{i}} \text { as a function of } \overline{\mathbf{M}}_{c h a r} \\
\text { and } \sigma_{\mathrm{m}},(4.7) \text {. }\end{array}$ & $\begin{array}{l}\text { Values of } A \text { and } M \text { are } \\
\text { listed in Table 4.4. }\end{array}$ \\
\hline $\begin{array}{l}\text { 2. Calculate rupture } \\
\text { source moment rates, } \\
\dot{M}_{0_{i}} \text { in }(4.2 \mathrm{a})\end{array}$ & $\begin{array}{l}\text { a. Calculate the fault segment moment } \\
\text { rates as a function of } A \text { and } v(4.8) \text {. } \\
\text { b. Adjust parameters in fault rupture model } \\
\text { (Chapter 3) to balance the long-term mo- } \\
\text { ment rate of each fault segment, Appendix } \\
\text { G. } \\
\text { c. Use fault rupture models to calculate } \\
\text { relative rupture source rates. } \\
\text { d. Combine results to obtain } \dot{M}_{0_{i}} \text {. }\end{array}$ & $\begin{array}{l}\text { Values of } \dot{M}_{0_{i}} \text { are } \\
\text { computed for each } \\
\text { rupture source. }\end{array}$ \\
\hline $\begin{array}{l}\text { 3. Determine moment rate } \\
\text { fractions, } F_{\text {char }} \text { and } F_{\text {small }} \text {. }\end{array}$ & $\begin{array}{l}\text { a. Analyze historical seismicity on SFBR } \\
\text { faults (Table 4.6) to determine } F_{\text {small }} \text {. } \\
\text { b. Determine fraction of fault moment rate } \\
\text { expended in aftershocks, } F_{\text {affershock }} \\
\text { c. Calculate } F_{\text {char }}=1-F_{\text {small }}-F_{\text {affershock }} \text {. }\end{array}$ & $\begin{array}{l}F_{\text {small }} \text { determined to be } \\
0.06[0.04 \text { to } 0.08, \\
95 \%] . F_{\text {affershock }} \text { deter- } \\
\text { mined to be small and } \\
\text { set to zero. }\end{array}$ \\
\hline $\begin{array}{l}\text { 4. Calculate mean rate of } \\
\text { characterized earth- } \\
\text { quakes, } \gamma_{\text {char }} \text { on each rup- } \\
\text { ture source and on each } \\
\text { fault segment. }\end{array}$ & $\begin{array}{l}\text { a. Apply equation ( } 4.2 \mathrm{a}) \text { to obtain the fail- } \\
\text { ure rate of each rupture source. } \\
\text { b. For each fault segment, sum the rates of } \\
\text { all rupture sources that involve the seg- } \\
\text { ment. }\end{array}$ & $\begin{array}{l}\text { Rupture source rates } \\
\text { are shown in Table } \\
\text { 4.8. Fault segment oc- } \\
\text { currence rates are } \\
\text { shown in Table 4.9. }\end{array}$ \\
\hline $\begin{array}{l}\text { 5. Calculate the long- } \\
\text { term frequency- } \\
\text { magnitude relation for } \\
\text { each fault. }\end{array}$ & $\begin{array}{l}\text { For each magnitude increment within the } \\
\text { range of interest, sum the rates of each } \\
\text { rupture source }(4.9),(4.10) \text {. }\end{array}$ & $\begin{array}{l}\text { Results are plotted in } \\
\text { Figures } 4.6 \text { and } 4.8 .\end{array}$ \\
\hline $\begin{array}{l}\text { 6. Estimate the fre- } \\
\text { quency-magnitude distri- } \\
\text { bution of background } \\
\text { earthquakes. }\end{array}$ & $\begin{array}{l}\text { For each magnitude increment within the } \\
\text { range of interest, calculate background rate } \\
(4.13) \text {. }\end{array}$ & $\begin{array}{l}\text { Results are plotted in } \\
\text { Figures } 4.6 \text { and } 4.8 \text {. }\end{array}$ \\
\hline
\end{tabular}




\section{Estimating the magnitudes and moments of earthquakes}

The goal of this part of the calculation sequence is to determine the mean moment of characteristic earthquakes, $\bar{M}_{0 \text { char }}$ for each rupture source. We first determine the mean earthquake magnitude, $\overline{\mathbf{M}}_{\text {char }}$ and define the natural variability of magnitude as a distribution around that mean. Then we calculate the mean moment from that distribution.

For earthquakes on fixed rupture sources, a mean earthquake magnitude is calculated from the seismogenic area of its rupture source. For floating earthquakes, the mean magnitude was set $a$ priori (Chapter 3). For both types of earthquakes, we allow for natural variability in earthquake magnitude (for a given rupture area) by describing the magnitude as a probability density function with truncated normal distribution (Figure 4.1). Once the mean magnitude and distribution function are in hand, it will be straightforward to calculate the mean moment of repeated earthquakes on each rupture source from equation (4.7).

\section{Seismogenic area}

The seismogenic area is the effective portion of fault surface that produces earthquakes

$$
A=L W R
$$

$L$ is segment length, the distance between two segmentation points (Figure 2.5). $W$ is down-dip segment width, corresponding to the thickness of the brittle upper crust in which strain energy available to be released as earthquakes is stored. $R$ is a seismogenic scaling factor (ranging from 0 to 1 ) that accounts for the role of fault creep in reducing the fault surface area available for earthquake rupture. These quantities are further described in Chapter 3, and tabulated for each fault segment in Table 3.8 .

The seismogenic area of a rupture source is sum of seismogenic areas of the fault segments which comprise it. Rupture source areas are listed in Table 4.4, along with the mean magnitudes calculated in the following section.

\section{Mean characteristic magnitude.}

Following the findings of Wells and Coppersmith (1994), we utilize $\mathbf{M}-\log A$ relations to obtain mean magnitude of characteristic earthquakes, where $A$ is seismogenic area. From regression of data for 83 continental strike-slip earthquakes, Wells and Coppersmith (1994) found (their Table 2A and Figure 16a):

$$
\mathbf{M}=(3.98 \pm 0.07)+(1.02 \pm 0.03) \log _{10} A,
$$

where $A$ has units of $\mathrm{km}^{2}$. The regression is well determined, as indicated by the small standard errors ( \pm one sigma) for the regression coefficients. However, WG99 noted that equation (4.5) significantly underestimates $\mathbf{M}$ for large $(\mathbf{M} \geq 7)$ strike-slip earthquakes in California, Figure 4.2a. For their report, WG99 assembled from several sources larger data sets for global strike slip earthquakes. Those data appear in Appendix D, accompanied by a brief analysis of likely 
measurement uncertainties in $\mathbf{M}$ and $A$. There is considerable uncertainty in the data available for the correlation analysis that we rely upon for our estimates of $\mathbf{M}$. Therefore, two different approaches were followed to develop new relations consistent with available data in the magnitude range of primary interest in this report.

In the first approach, the data $A>500 \mathrm{~km}^{2}$ were fitted with simple, one-parameter equations:

$$
\begin{aligned}
& \mathbf{M}=4.1+\log _{10} A \\
& \mathbf{M}=4.2+\log _{10} A \\
& \mathbf{M}=4.3+\log _{10} A
\end{aligned}
$$

The preferred equation (4.6b) is obtained from maximum likelihood fitting of the data with coefficient on the logarithm held fixed at 1.0. For $\mathbf{M} \geq 6.7$, (4.5b) fits the data well, with an r.m.s. error of 0.19 for $A>500 \mathrm{~km}^{2}$ (Figure 4.2e). Although this relation over-predicts $\mathbf{M}$ for $A<500$ $\mathrm{km}^{2}$, the measured rupture areas of those earthquakes may be biased, particularly by the use of aftershock area as a measure of rupture area by Wells and Coppersmith (1994). (See Mendoza and Hartzell (1987) for a discussion of the systematics of aftershock areas and rupture areas.) Equations (4.5a) and (4.5c) represent approximately 95\% bounds on the fit (Figures $\mathbf{4 . 2 d}$ and 4.2f).

Hanks and Bakun (2001) took a different approach. For $\mathbf{M}<7$, where the Wells and Coppersmith (1994) relations work well, Hanks and Bakun (2001) noted that they could be reproduced theoretically using constant stress drop $(\Delta \sigma)$ source scaling, with $\Delta \sigma=30$ bars. For $\mathbf{M} \geq 7$, they invoked $L$-model (length) scaling of average fault slip $U=\alpha L$, where $\alpha=2 \times 10^{-5}$, found elsewhere in Wells and Coppersmith (1994). The Hanks and Bakun (2001) model for converting segment and multi-segment areas to $\mathbf{M}$ comes in the form of two pairs of equations (Figure 4.2b,c), each expressing a bilinear relation between $\mathbf{M}$ and $A$ above and below some area threshold:

and

$$
\mathbf{M}=4.03+\log _{10} A\left(A \leq 1000 \mathrm{~km}^{2}\right), \quad \mathbf{M}=3.03+4 / 3 \log _{10} A\left(A>1000 \mathrm{~km}^{2}\right)
$$

$$
\mathbf{M}=3.98+\log _{10} A\left(A \leq 468 \mathrm{~km}^{2}\right), \quad \mathbf{M}=3.09+4 / 3 \log _{10} A\left(A>468 \mathrm{~km}^{2}\right) .
$$

Equations (4.6a) are purely a model construct, based on $\Delta \sigma=30$ bars and $\alpha=2 \times 10^{-5}$. Equations (4.6b) result from least-squares adjustments of the intercept values (but not the slopes), yielding a best-fitting $\Delta \sigma=26$ bars and $\alpha=2.3 \times 10^{-5}$. The r.m.s. error is 0.21 for $\mathrm{A}>500 \mathrm{~km}^{2}$.

Branch weights for the six candidate $\mathbf{M}-\log A$ models, above, were obtained through a vote of the WG02 Overview Group (OG), following extensive discussion of the relative merits of each of the six equations above. Consideration was given to the magnitude, slip, and recurrence interval implied by each equation, particularly for the San Andreas and Hayward/Rodgers Creek fault systems for which paleoseismic and historical data are available. Opinions varied considerably on the importance to be place on matching the observed magnitude and slip of the 1906 San Andreas earthquake. There emerged two, very different views on this issue: (1) that the 1906 earthquake is one instance in a global dataset, in which it sits near the bottom in $\mathbf{M}-\log A$ space for $\mathbf{M}$ $\geq 7.5$ continental strike-slip earthquakes, or (2) that the 1906 earthquake is a dataset of one-but the one such earthquake we know to be relevant to SFBR. In the latter way of looking at the 
1906 earthquake, the 1906 earthquake is indeed in a league of its own, with considerably longer rupture than even its southern California cousin, the 1857 Fort Tejon event, of comparable $\mathbf{M}$ but far shorter fault length.

For some perspective on where the 1906 event sits with regard to $\mathbf{M}$ vs $L$, a short table of data for large continental strike-slip earthquake follows.

Table 4.2. Magnitudes and rupture lengths for selected continental strike-slip earthquakes.

\begin{tabular}{clcc}
\hline Year & Earthquake & Magnitude & Length $(\mathrm{km})$ \\
\hline 1857 & Fort Tejon & M7.9 & 300 \\
1905 & Bulnay, Mongolia & M8.0-8.1 & $300-350$ \\
1906 & San Francisco & M7.8 & 480 \\
1920 & Kansu, China & M8.0 & 220 \\
1939 & Erzihcan, Turkey & M7.9 & $330-360$ \\
1957 & Gobi-Altay, Mongolia & M7.8-8.1 & 260 \\
\hline
\end{tabular}

Opinion was nearly evenly divided within the OG on these two ways at looking at the 1906 earthquake.

Members of the WG02 Oversight Group were polled on the relative likelihood of each relation. Resulting weights were rounded to increments of 0.05 , and equation (4.5c), which received little support, was abandoned. Results are shown in Table 4.3. These models and model weights supersede those developed by WG99.

Table 4.3: Expert-opinion weights of $\mathbf{M}-\log A$ models.

\begin{tabular}{ccc}
\hline Equation \# & Mean voted weight & Adopted weight \\
\hline \hline$(4.4)$ & 0.138 & 0.15 \\
\hline$(4.5 \mathrm{a})$ & 0.229 & 0.25 \\
$(4.5 \mathrm{~b})$ & 0.377 & 0.40 \\
$(4.5 \mathrm{c})$ & 0.033 & 0 \\
\hline$(4.6 \mathrm{a})$ & 0.150 & 0.15 \\
$(4.6 \mathrm{~b})$ & 0.073 & 0.05 \\
\hline
\end{tabular}


Table 4.4. Areas, mean magnitudes of SFBR rupture sources.

\begin{tabular}{|c|c|c|c|c|c|c|c|}
\hline \multirow[b]{2}{*}{ Fault Name } & \multirow[b]{2}{*}{ Rupture Source } & \multicolumn{3}{|c|}{$\begin{array}{l}\text { Seismogenic area }\left(\mathrm{km}^{\wedge} 2\right) \\
\left(\mathrm{km}^{\wedge} 2\right)\end{array}$} & \multicolumn{3}{|c|}{ Mean magnitude } \\
\hline & & Mean & $2.5 \%$ & $97.5 \%$ & Mean & $2.5 \%$ & $97.5 \%$ \\
\hline \multirow{11}{*}{ San Andreas } & SAS & 829 & 606 & 1141 & 7.03 & 6.84 & 7.22 \\
\hline & SAP & 1066 & 765 & 1483 & 7.15 & 6.95 & 7.32 \\
\hline & SAN & 2042 & 1545 & 2678 & 7.45 & 7.28 & 7.61 \\
\hline & SAO & 1434 & 1093 & 1817 & 7.29 & 7.12 & 7.44 \\
\hline & SAS+SAP & 1907 & 1483 & 2412 & 7.42 & 7.26 & 7.56 \\
\hline & SAP+SAN & 3121 & 2478 & 3815 & 7.65 & 7.48 & 7.79 \\
\hline & $\mathrm{SAN}+\mathrm{SAO}$ & 3482 & 2755 & 4432 & 7.70 & 7.53 & 7.86 \\
\hline & SAS+SAP+SAN & 3958 & 3187 & 4779 & 7.76 & 7.59 & 7.92 \\
\hline & $\mathrm{SAP}+\mathrm{SAN}+\mathrm{SAO}$ & 4559 & 3621 & 5537 & 7.83 & 7.65 & 8.01 \\
\hline & $\mathrm{SAS}+\mathrm{SAP}+\mathrm{SAN}+\mathrm{SAO}$ & 5397 & 4341 & 6531 & 7.90 & 7.72 & 8.10 \\
\hline & floating & - & - & - & 6.90 & 6.90 & 6.90 \\
\hline \multirow[t]{7}{*}{ Hayward/RC } & HS & 367 & 210 & 599 & 6.67 & 6.36 & 6.93 \\
\hline & $\mathrm{HN}$ & 235 & 119 & 391 & 6.49 & 6.18 & 6.78 \\
\hline & $\mathrm{HS}+\mathrm{HN}$ & 616 & 400 & 882 & 6.91 & 6.68 & 7.12 \\
\hline & $\mathrm{RC}$ & 736 & 563 & 949 & 6.98 & 6.81 & 7.14 \\
\hline & $\mathrm{HN}+\mathrm{RC}$ & 981 & 756 & 1267 & 7.11 & 6.94 & 7.28 \\
\hline & $\mathrm{HS}+\mathrm{HN}+\mathrm{RC}$ & 1359 & 1044 & 1737 & 7.26 & 7.09 & 7.42 \\
\hline & floating & - & - & - & 6.90 & 6.90 & 6.90 \\
\hline \multirow[t]{8}{*}{ Calaveras } & CS & 48 & 1 & 107 & 5.79 & 0.00 & 6.14 \\
\hline & $\propto$ & 132 & 53 & 353 & 6.23 & 5.75 & 6.68 \\
\hline & $\mathrm{CS}+\mathrm{CC}$ & 176 & 59 & 395 & 6.36 & 5.87 & 6.75 \\
\hline & CN & 465 & 348 & 610 & 6.78 & 6.58 & 6.97 \\
\hline & $\mathrm{CC}+\mathrm{CN}$ & 616 & 433 & 861 & 6.90 & 6.68 & 7.11 \\
\hline & $\mathrm{CS}+\mathrm{CC}+\mathrm{CN}$ & 657 & 464 & 921 & 6.93 & 6.72 & 7.14 \\
\hline & floating & - & - & - & 6.20 & 6.20 & 6.20 \\
\hline & floating $\mathrm{CS}+\mathrm{CC}$ & - & - & - & 6.20 & 6.20 & 6.20 \\
\hline \multirow[t]{7}{*}{ Concord/GV } & $\mathrm{CON}$ & 137 & 44 & 323 & 6.25 & 5.75 & 6.67 \\
\hline & GVS & 131 & 46 & 285 & 6.24 & 5.75 & 6.65 \\
\hline & $\mathrm{CON}+\mathrm{GVS}$ & 291 & 111 & 541 & 6.58 & 6.13 & 6.91 \\
\hline & GVN & 85 & 25 & 213 & 6.02 & 5.45 & 6.49 \\
\hline & GVS+GVN & 235 & 93 & 439 & 6.48 & 6.03 & 6.81 \\
\hline & $\mathrm{CON}+\mathrm{GVS}+\mathrm{GVN}$ & 395 & 182 & 668 & 6.71 & 6.34 & 7.00 \\
\hline & floating & - & - & - & 6.20 & 6.20 & 6.20 \\
\hline \multirow[t]{4}{*}{ San Gregorio } & SGS & 701 & 504 & 958 & 6.96 & 6.75 & 7.17 \\
\hline & SGN & 1272 & 966 & 1683 & 7.23 & 7.04 & 7.41 \\
\hline & SGS+SGN & 1983 & 1556 & 2513 & 7.44 & 7.27 & 7.58 \\
\hline & floating & - & - & - & 6.90 & 6.90 & 6.90 \\
\hline \multirow[t]{4}{*}{ Greenville } & GS & 311 & 199 & 460 & 6.60 & 6.37 & 6.83 \\
\hline & GN & 351 & 225 & 512 & 6.66 & 6.41 & 6.88 \\
\hline & GS+GN & 670 & 488 & 892 & 6.94 & 6.74 & 7.13 \\
\hline & floating & - & - & - & 6.20 & 6.20 & 6.20 \\
\hline Mt Diablo & MTD & 350 & 210 & 489 & 6.65 & 6.42 & 6.89 \\
\hline
\end{tabular}




\section{Natural variability in magnitude about its mean}

For repeated ruptures of a fault of given area, one expects some variation in magnitude about its mean due to variations in factors such as earthquake stress drop. WG99 considered various distributions; this is an area rich in controversy but poor in constraining data. Lacking a firm precedent, we chose a truncated Gaussian distribution in moment magnitude, $\mathbf{M}$ (over, say, a truncated Gaussian distribution in moment), Figure 4.1. The variability in magnitude is approximately Gaussian when variations in magnitude arise from Gaussian variations in the length, width and mean slip, all with comparable coefficients of variation (ratio of standard deviation to the mean). Under this assumption, the corresponding variability in moment is approximately lognormal.

The aleatory (natural) variability in $\mathbf{M}$ of $\sigma_{\mathrm{m}}=0.12$ magnitude units was derived by considering the influence of errors in the measurement of both $\mathbf{M}$ and rupture area, $A$, on $\mathbf{M}-\log A$ relationships. Independent estimates of $\mathbf{M}$ and $A$ for 16 strike slip earthquakes were used to estimate their epistemic uncertainty (Appendix D). The measurement error of $\mathbf{M}$ corresponds to a standard deviation of approximately 0.08 magnitude units. Similarly, the measurement error for $\log (A)$ is $0.15 \log$-units (a factor of 1.4). Taking the observational errors into account in plots of $\mathbf{M}$ versus $\log A$ (Figure 4.2), we find that an aleatory variation of 0.12 for $\mathbf{M}$ is consistent with available data, whereas larger values, such as 0.25 based on ignoring measurement errors, are not.

We truncate the normal distribution of $\mathbf{M}$ at \pm 2 standard deviations $= \pm 0.24$. In other words, we assume that a rupture source of a given area will produce earthquakes that vary in magnitude over a range of 0.48 magnitude units. This truncation prevents there from being rare earthquakes that deviate greatly from a "reasonable" magnitude for a given area and those with slips and implied stress drops far greater than those observed in nature. Again, this is consistent with the available data, but those data are insufficient to test the correctness of this treatment. (The magnitude variability implied by this truncation is illustrated graphically in several figures in Appendix D.)

\section{Calculating mean moment}

The mean moment of the characteristic earthquake is a function of its mean magnitude $\overline{\mathbf{M}}_{\text {char }}$ and the shape and truncation limits of the magnitude pdf. For magnitude described by a Gaussian truncated at $\pm 2 \sigma_{\mathrm{m}}$, the moment is approximately log-normally distributed. The mean moment is

$$
\bar{M}_{0 \text { char }}=\frac{1}{\sqrt{2 \pi}} \int_{-2}^{2} 10^{1.5\left(\mathbf{M}+\sigma_{m} x\right)+16.05} e^{-\frac{x^{2}}{2}} d x
$$

which can be approximated by the following expression:

$$
\bar{M}_{0 \text { char }}=10^{1.5 \overline{\mathbf{M}}_{\text {char }}+16.05-0.0481 \sigma_{m}+1.775 \sigma_{m}{ }^{2}}
$$

To determine the constants in (4.7b), the mean moment was estimated numerically for a range of $\sigma_{\mathrm{m}}$. The ratio of the mean moment to the moment for the mean magnitude was computed for each 
$\sigma_{\mathrm{m}}$, then the resulting ratios were fitted to the form of equation (4.7b) using ordinary leastsquares. This avoids having to compute the integral in (4.7a).

\section{Estimating rupture source moment rates}

The following calculations define the long-term rate of seismic moment release on each rupture source, $\dot{M}_{0_{i}}$ in equations (4.2a,b). The moment release rate for each rupture source is found by summing contributions from its component fault segments. Quantifying those contributions is not straightforward, because a given fault segment may fail in one-segment, multi-segment, and/or floating earthquakes. We must ask: How much of a fault segment's long-term moment rate is expended in each type of earthquake? For example, on a two-segment fault such as the San Gregorio, how much of each segment's moment rate is expended in one-segment, twosegment, and floating earthquakes? The slip (or moment) from those various earthquakes must balance the long-term slip rate (or moment rate) for each segment.

Three steps are taken to define the rupture source moment rates:

1) Query panels of experts for fault rupture models that define the relative likelihood for fault failure in various modes (this was done by WG99 as described in Chapter 3),

2) Calculate the available moment rate from the seismogenic area and slip rate of the fault segments, and

3) Combine a fault rupture model and fault segment moment rates to obtain a set of relative rupture source moment rates that balance the long-term slip rate.

\section{Fault segment moment rate}

Each segment is represented as a rectangular fault patch with uniform long-term slip rate (Figure 2.5). The moment rate of each fault segment is obtained from its seismogenic area $A$ from equation (4.3) and its long-term slip rate $v$ :

$$
\dot{M}_{0}=\mu A v
$$

where $\mu$ is shear modulus (taken here as $3 \times 10^{11} \mathrm{dyne} / \mathrm{cm}^{2}$ ). Values of $v$ for each fault segment were developed in the previous chapter and are listed in Table 3.8.

Regional slip-rate (plate rate) constraint

Global Positioning System (GPS) data collected between 1992 and 2000 in central California (Prescott and others, 2001) document the deformation across the Pacific-North America plate boundary that drives the earthquake activity in the SFBR (Figure 1.1). Prescott and others (2001) model most of the deformation as $39.8 \pm 1.2 \mathrm{~mm} / \mathrm{yr}( \pm 1 \sigma)$ of shear on planes parallel to the San Andreas fault system, in agreement with $39 \pm 2 \mathrm{~mm} / \mathrm{yr}$ obtained by Argus and Gordon (2001) using GPS and VBLI data. A longer-term estimate, $41 \pm 1 \mathrm{~mm} / \mathrm{yr}( \pm 1 \sigma)$, was obtained by DeMets and Dixon (1999), and Prescott and others (2001) using global plate-motion models. The shear deformation is distributed across a $120-\mathrm{km}$ wide zone in the SFBR that corresponds to the width of the study region. Because there are uncertainties on the long-term slip rate of each fault segment, it is possible for a SFBR source model to contain combinations of segment slip rates 
that violate the region-wide geodetic constraint. Therefore, we check the viability of each candidate model by summing the chosen slip rates across three transects (Figure 1.3), and rejecting those models for which the sum lies outside the range 36 to $43 \mathrm{~mm} /$ year (Table 4.5). The 36 to $43 \mathrm{~mm} / \mathrm{yr}$ range reflects the greatest upper $2 \sigma$ limit and least lower $2 \sigma$ limit of the short-term GPS and longer-term plate-motion estimates of deformation. The transects cross known faults not characterized in our model (e.g., the Zayante, Sargent, Coyote Creek, Madrone Springs, and Ortigalita faults); we account for these faults by adding a small, additional slip rate (see Table 4.5) to the fault-segment sums before comparing to the geodetic range.

Table 4.5: Plate-motion constraint transects.

\begin{tabular}{c|cccc}
\hline Transect & Fault segments & $\begin{array}{c}\text { Added slip } \\
\text { Rate increment }\end{array}$ & $\begin{array}{c}\text { Range of } \\
\text { possible slip rate }\end{array}$ & $\begin{array}{c}\text { Percent of } \\
\text { trials rejected }^{*}\end{array}$ \\
\hline Northern & SAN+RC+GVN & $3 \mathrm{~mm} / \mathrm{yr}$ & 33 to 49 & $18 \%$ \\
Central & SGN+SAP+HS+CN+GN & $1 \mathrm{~mm} / \mathrm{yr}$ & 30 to 54 & $33 \%$ \\
Southern & SGN+SAS+CC & $2 \mathrm{~mm} / \mathrm{yr}$ & 31 to 51 & $19 \%$ \\
\hline
\end{tabular}

* Candidate model is rejected if any (at least one) transect lies outside the range $36-43 \mathrm{~mm} / \mathrm{year}$.

The plate-motion constraint rejects $18 \%, 33 \%$, and $19 \%$ of the candidate aggregate models for the northern, central, and southern transects respectively. $42 \%$ of the aggregate models are rejected on the basis of at least one transect. Thus, 17,120 trials were required in order to obtain the 10,000 viable models used to obtain the results of this report.

\section{Defining relative likelihoods of rupture}

This step defines the suite of rupture sources for which earthquake magnitudes and rates will be calculated, and employs expert opinion to assign a relative likelihood of rupture to each source. Two types of rupture sources are considered: 1) fixed rupture sources that consist of one or more contiguous fault segments that fail together in an earthquake. 2) floating rupture sources that can occur anywhere along the fault.

As described in the previous chapter, the fault characterization sub-groups assigned preliminary relative likelihood to the various rupture sources by assembling fault rupture models for each system. A fault rupture model consists of combinations of rupture scenarios that define the complete rupture of the fault system (e.g., Figure 3.2). Each scenario is assigned a weight, or relative frequency, which specifies the amount that that mode of failure contributes to the long-term seismic behavior of the fault. Recall that the sub-groups used a combination of available evidence and expert opinion to develop alternative fault rupture models, i.e., alternative combinations of scenario frequencies. The fault rupture models were weighted collectively by expert opinion. The variation in scenario frequencies between models (e.g., across a row of Table 3.4) reflects the degree of certainty that exists in the community about the strength and persistence of segmentation points on each fault. In each realization of the model, a single fault rupture model (a set of relative scenario rates, e.g., a column of Table 3.4) is selected for each of the seven fault systems.

In general, the relative scenario frequencies within a given fault rupture model will not result in a moment-rate-balanced model (i.e., will not satisfy $\dot{M}_{0}$ on each fault segment) because the rupture sources within each segmentation scenario have different moments, and those moments vary 
with the choices of $L, W$ and $R$ made in a given realization of the SFBR model. The problem of moment-rate balancing the model is over-determined because there are generally more rupture source rates determined from the relative scenario frequencies than segment moment rates (or slip rates) to constrain them. Therefore, we use least-squares regression to obtain a set of revised relative rates that are the best fit to the relative rates supplied by the subgroups. Details of this procedure and comments on its effectiveness are given in Appendix G.

\section{Rupture source moment rate}

The moment rate for each rupture source, $\dot{M}_{0_{i}}$ (numerator of (4.2a)) is calculated as product of the available moment rate (sum of segment moment rates (4.8)) times the moment-balanced partition factors (above), summed across all rupture scenarios that include the given rupture source.

\section{Partitioning moment rate across earthquake types}

Fault segments in our model are typically tens of kilometers in length. Because fault segments are the smallest units of the characterized faults that can rupture in the model, the set of characteristic rupture sources does not provide a complete description of independent earthquakes in the SFBR. The lower size limit on characterized earthquakes varies from fault to fault; for the region as a whole the model is incomplete below about M6.7. Small earthquakes on characterized faults fall into two classes: aftershocks, the occurrence of which is dependent on an earlier main shock, and those that occur on a fault system but are not part of an aftershock sequence. It is necessary to account for the fraction of fault system moment expended in such events, lest the rate of characterized earthquakes be overestimated. In the following sections we calculate the moment rate fraction expended in these two classes of earthquakes. The moment rate expended in aftershocks will be shown to be small, and will be ignored in our analysis (i.e., $F_{\text {aftershock }} \approx 0$ ). The moment rate fraction in small earthquakes, $F_{\text {small }}$, will be shown to be a few percent.

\section{Seismic moment rate in aftershocks}

Aftershocks occurring on the characterized fault plane contribute to the long-term moment budget. Their occurrence is contingent upon the recent occurrence of a main shock, and therefore cannot be considered to be independent earthquakes as are those of the other three types. However, to the extent that their occurrence contributes to the long-term moment rate of the fault, the moment due to aftershocks should be accounted for, and our model allows a fraction of the moment rate for each source to be removed. Analysis of main shock/aftershock sequences in California (Appendix E) demonstrates that the summed moment of aftershocks equals, on average, $10 \%$ of the main shock moment. That is a considerable fraction of the moment budget; however, that average value is held high by the occasional occurrence of a very large aftershock, typically on a fault plane other than that which hosted the main shock. Restricting the analysis to aftershocks occurring on or near the main shock plane, $F_{\text {aftershock }}$ is roughly $3 \pm 2 \%$. The WG99 Overview Group had substantial disagreement among OG members on the relationship between aftershocks and the seismic moment rate on the parts of faults responsible for the generation of large earthquakes, in particular whether the spatial distribution of aftershock moment release on the fault plane is similar to, or complementary to, the pattern of moment release in mainshocks. Due

to this lack of consensus, and because $F_{\text {aftershock }}$ is small compared to uncertainties in other parts of 
the calculation sequence, we chose not to remove aftershock moment in our calculations ${ }^{1}$. All else being equal, removing this small moment-rate increment would have slightly lowered earthquake rates and 30-year earthquake probabilities.

\section{Seismic moment rate in smaller earthquakes}

Previous studies have examined fault and regional seismicity to determine the ratio of moment expended in characteristic events versus smaller ones. Youngs and Coppersmith (1985)separated fault seismicity into characteristic events with magnitudes distributed around a central value, and smaller earthquakes with an Gutenberg-Richter (G-R) magnitude-size distribution, or "exponential tail" (see Figure 4.1) Based on examination of data from several faults, they specified distribution parameters that corresponded to placing $94 \%$ of the moment in the characteristic events and $6 \%$ in the exponential tail. Similarly, Field et al. (1999) examined the moment rates in characteristic and smaller earthquakes in southern California. They found that roughly $15 \%$ moment rate in a G-R distribution of earthquakes capped at $\mathbf{M}=6.7$ enabled the observed rates of intermediate-magnitude seismicity to be matched; this percentage was shown to be sensitive to the number of seismogenic faults contained in the model, as their model combined our "background" seismicity and small (sub-segment-sized) earthquakes on the characterized faults.

We used Wesson et al.'s (2003) analysis of 150 years of historical seismicity (Bakun, 1999) to estimate the value of $F_{\text {small }}$ appropriate for the SFBR. The probabilities for each historical earthquake associated with each of the characterized faults and with the background are listed in Table 3 of Wesson et al. (2003). Table 4.6 is Wesson et al's Table 3 reordered so that the earthquakes are listed in order of increasing $\mathbf{M}$ and the probabilities are multiplied by the moment for that M. The moment listed for the 1906 earthquake is for that part of the 1906 rupture within the SFBR (Bakun, 1999). The summed moment for all earthquakes on a fault with M less than some magnitude threshold $M_{T}$ is easily obtained from the list.

The threshold $M_{T}$ for each fault system is our minimum mean characteristic M less 0.24 (i.e., $2 \sigma_{\mathrm{m}}$ ): $M_{T}=6.65$ for the San Andreas fault, etc. (See $M_{T}$ at bottom of table.) The seismic moment rate for small earthquakes for each fault is the summed moment for events with $\mathbf{M}<M_{T}$ divided by 150 years. Whereas 150 years is not long enough to sample many characteristic earthquakes, it may be long enough to establish the character of smaller events on each fault. If $M_{T}$ is much larger than 5.5 on a fault, then the moment for missing $\mathbf{M}<5.5$ events can be ignored. The Calaveras fault, with $M_{T}=5.56$, does not meet this criteria, so we omit that fault from the mean estimate below. $\mathbf{M}_{0} / \mathbf{y r}$ is the moment rate in the exponential tail for each fault.

The line "Model Moment/yr" in Table 4.6 is the moment rate for the characterized segments on that fault using approximate values of fault lengths, widths, geologic slip rates, and $\mathrm{R}$ values. The line "\% of model" is the $\%$ of seismic moment in the exponential tail $=\mathrm{M}_{0} / \mathrm{yr}$ divided by "Model Moment/yr". For example, according to this analysis, $8.93 \%$ of the model moment rate for the SAF has been released in earthquakes $\mathbf{M}<6.65$. Lacking a longer catalog, we assume that this percentage is typical for the fault.

\footnotetext{
${ }^{1}$ The WG02 computer code allows the removal of aftershock moment rate by specifying $F_{\text {aftershock }}>0$. This moment is removed entirely from the model, thereby lowering the moment rate available for making characteristic earthquakes.
} 
The mean $\%$ of model $\pm 1 \sigma$ is $0.062 \pm 0.010$, close to the value of 0.06 obtained by Youngs and Coppersmith (1985) for the San Francisco Bay area. From this analysis, we adopt the mean $\pm 2 \sigma$ to define branch values for $F_{\text {small }}$ of $0.04,0.06$, and 0.08 with appropriate weights.

\section{Note on occurrence rate of smaller earthquakes}

This probability report is not concerned with the probability of small earthquakes in the region, and we do not report either the rate of small earthquakes nor the probability of their occurrence within specified time intervals. However, certain applications of our results may require that the frequency of earthquakes be specified over a broad range of magnitude. The WG02 computer code includes the provision to compute the time-independent rate of earthquakes over a specified magnitude interval. In designing this feature of the code, we follow the lead of previous authors (e.g., Youngs and Coppersmith, 1985, and Field et al., 1999) and specify that smaller earthquakes obey a Gutenberg-Richter (G-R) distribution of rates on a given fault system. The upper end of this G-R distribution is defined here as $2 \sigma_{\mathrm{m}}$ below the smallest mean magnitude of any rupture source on the fault system of interest; this ensures that the exponential-tail and characteristic parts of the frequency-magnitude distribution remain distinct. We note that evidence is scant at best that small earthquakes on individual faults obey G-R statistics, and urge interested users to consider a range of treatments before employing this feature of the code. 
Table 4.6. Historical Seismicity and the calculation of $F_{\text {small }}$ (see text for explanation).

\begin{tabular}{|c|c|c|c|c|c|c|c|c|c|c|}
\hline \multirow[b]{2}{*}{ Date } & \multirow[b]{2}{*}{ M } & \multirow[b]{2}{*}{ Moment } & & \multirow[b]{2}{*}{ Background } \\
\hline & & & SAF & Hay/RC & Calav. & Con/GV & San $\mathbf{G}$ & Greenville & Mt Diablo & \\
\hline 27 Aug 1855 & 5.50 & $1.995 E+24$ & $2.62 E+22$ & $6.08 \mathrm{E}+23$ & $1.71 \mathrm{E}+22$ & $4.41 \mathrm{E}+23$ & $1.11 \mathrm{E}+22$ & $8.99 \mathrm{E}+21$ & $1.86 \mathrm{E}+22$ & $6.512 E+23$ \\
\hline 2 Jan 1856 & 5.50 & $1.995 E+24$ & $3.31 E+23$ & $9.98 \mathrm{E}+22$ & $2.36 \mathrm{E}+23$ & $2.32 \mathrm{E}+22$ & $4.22 \mathrm{E}+23$ & $2.68 \mathrm{E}+22$ & $1.54 \mathrm{E}+22$ & $8.086 \mathrm{E}+23$ \\
\hline 17 Apr 1860 & 5.50 & $1.995 E+24$ & $2.24 \mathrm{E}+23$ & $3.41 \mathrm{E}+20$ & $5.81 \mathrm{E}+23$ & $1.01 \mathrm{E}+18$ & $4.59 \mathrm{E}+23$ & $1.22 \mathrm{E}+21$ & $1.59 \mathrm{E}+19$ & $7.298 \mathrm{E}+23$ \\
\hline 30 Apr 1892 & .50 & $1.995 \mathrm{E}+24$ & $2.21 \mathrm{E}+14$ & $4.71 \mathrm{E}+20$ & $1.31 \mathrm{E}+18$ & $2.92 \mathrm{E}+23$ & $2.70 \mathrm{E}+13$ & $1.61 \mathrm{E}+19$ & $1.73 \mathrm{E}+20$ & $1.703 \mathrm{E}+24$ \\
\hline 9 Aug 1893 & 5.50 & $1.995 E+24$ & $1.16 \mathrm{E}+22$ & $9.20 \mathrm{E}+23$ & $6.05 \mathrm{E}+20$ & $7.93 E+22$ & $4.23 E+21$ & $9.62 \mathrm{E}+19$ & $6.43 \mathrm{E}+20$ & $5.836 \mathrm{E}+23$ \\
\hline 2 June 1899 & 5.50 & $1.995 E+24$ & $3.10 \mathrm{E}+23$ & $8.45 \mathrm{E}+23$ & $4.65 \mathrm{E}+22$ & $1.17 \mathrm{E}+23$ & $9.99 \mathrm{E}+22$ & & & $3.025 \mathrm{E}+23$ \\
\hline November 9, 1914 & 5.50 & $1.995 \mathrm{E}+24$ & $8.92 \mathrm{E}+23$ & $7.59 \mathrm{E}+21$ & $3.70 \mathrm{E}+23$ & $9.84 \mathrm{E}+17$ & $2.75 E+23$ & $1.19 \mathrm{E}+21$ & $2.49 \mathrm{E}+19$ & $4.487 \mathrm{E}+23$ \\
\hline September 5, 1955 & 5.50 & $1.995 E+24$ & $0.00 \mathrm{E}+00$ & $2.52 \mathrm{E}+14$ & $9.76 \mathrm{E}+23$ & $0.00 \mathrm{E}+00$ & $0.00 \mathrm{E}+00$ & $0.00 \mathrm{E}+00$ & $0.00 \mathrm{E}+00$ & $1.019 E+24$ \\
\hline 21 May 1864 & 5.60 & $2.818 \mathrm{E}+24$ & $4.85 E+23$ & $1.52 \mathrm{E}+23$ & $7.73 E+23$ & $1.88 \mathrm{E}+22$ & $2.16 \mathrm{E}+23$ & $1.34 \mathrm{E}+23$ & $3.21 \mathrm{E}+22$ & $9.805 E+23$ \\
\hline 26 Mar 1866 & 5.60 & $2.818 \mathrm{E}+24$ & $5.78 \mathrm{E}+23$ & $9.21 \mathrm{E}+20$ & $1.28 \mathrm{E}+24$ & $4.85 \mathrm{E}+17$ & $3.08 E+23$ & $4 \mathrm{E}+20$ & $4.38 \mathrm{E}+18$ & $.539 E+23$ \\
\hline 2 Apr 1870 & 5.60 & $2.818 \mathrm{E}+24$ & $2.59 \mathrm{E}+23$ & $1.24 \mathrm{E}+24$ & $2.56 \mathrm{E}+23$ & $3.56 \mathrm{E}+23$ & & & & $3.479 \mathrm{E}+23$ \\
\hline 31 July 1889 & 5.60 & $2.818 \mathrm{E}+24$ & $2.91 \mathrm{E}+23$ & $1.62 \mathrm{E}+24$ & $2.14 \mathrm{E}+23$ & $1.35 \mathrm{E}+23$ & & & & $3.394 \mathrm{E}+23$ \\
\hline March 31, 1986 & 5.60 & $2.818 \mathrm{E}+24$ & $0.00 \mathrm{E}+00$ & $0.00 \mathrm{E}+00$ & $0.00 \mathrm{E}+00$ & $0.00 \mathrm{E}+00$ & & & & $2.818 \mathrm{E}+24$ \\
\hline October 2, 1969 & 5.60 & $2.818 \mathrm{E}+24$ & $0.00 \mathrm{E}+00$ & $1.76 \mathrm{E}+21$ & $0.00 \mathrm{E}+00$ & $0.00 \mathrm{E}+00$ & $0.00 \mathrm{E}+00$ & $0 \mathrm{E}+00$ & & $2.817 \mathrm{E}+24$ \\
\hline 2 Jan 1891 & 5.70 & $3.981 E+24$ & & $2.56 \mathrm{E}+23$ & $1.64 \mathrm{E}+24$ & $4.05 E+20$ & $9.07 \mathrm{E}+22$ & $9 \mathrm{E}+22$ & $E+21$ & $5.150 \mathrm{E}+23$ \\
\hline August 6,1979 & 5.70 & $3.981 E+24$ & & & $7.59 \mathrm{E}+23$ & & & & & \\
\hline October 2, 1969 & 5.70 & $3.981 E+24$ & $0.00 \mathrm{E}+00$ & & $0.00 \mathrm{E}+00$ & $0.00 \mathrm{E}+00$ & $0.00 \mathrm{E}+00$ & & & $3.896 \mathrm{E}+24$ \\
\hline 15 Feb 1856 & 5.80 & $5.623 E+24$ & $1.50 \mathrm{E}+24$ & $1.41 \mathrm{E}+24$ & $3.63 E+23$ & $1.27 \mathrm{E}+23$ & $5.83 E+23$ & & & $1.290 \mathrm{E}+24$ \\
\hline 4 July 1861 & 5.80 & $5.623 E+24$ & & & $E+24$ & $E+23$ & & & & $E+23$ \\
\hline 17 Feb 1870 & 5.80 & $5.623 E+24$ & 2.6 & & $E+24$ & $E+19$ & $E+23$ & $E+21$ & $E+20$ & $E+24$ \\
\hline 12 Oct 1891 & 5.80 & $5.623 E+24$ & & & $E+20$ & $1.89 \mathrm{E}+24$ & & & & $E+23$ \\
\hline 13 Nov 1892 & 5.80 & $5.623 E+24$ & & & $1.71 \mathrm{E}+24$ & & & & & \\
\hline March 11, 1910 & 5.80 & $5.623 \mathrm{E}+24$ & 1.55 & $1.27 \mathrm{E}+22$ & $1.32 \mathrm{E}+24$ & $1.28 \mathrm{E}+19$ & $1.17 \mathrm{E}+24$ & & & $5 \mathrm{E}+24$ \\
\hline January 24,15 & 5.80 & $5.623 E+24$ & & & & & & & & \\
\hline 26 Feb 1864 & 5.90 & +24 & & & +24 & +20 & & & & \\
\hline 5 Mar 1864 & 5.90 & +24 & & & +24 & +22 & & & & $E+24$ \\
\hline 24 May 1865 & 5.90 & $7.943 E+24$ & & & $E+24$ & & & & & $E+24$ \\
\hline 15 July 1866 & 5.90 & $7.943 \mathrm{E}+24$ & $E+23$ & $1.29 \mathrm{E}+22$ & $1.50 \mathrm{E}+24$ & $7.84 \mathrm{E}+21$ & $\mathrm{E}+22$ & $E+23$ & $E+22$ & $2 E+24$ \\
\hline 28 June 18 & 5.90 & $E+24$ & & & & & & & & $E+24$ \\
\hline 30 Mar 1883 & 5.90 & +24 & & & +24 & $E+12$ & & & & $E+24$ \\
\hline 30 Apr 1899 & 5.90 & +24 & & & +24 & $E+14$ & & & & $E+24$ \\
\hline 6 July 1899 & 5.90 & $7.943 E+24$ & & & $E+24$ & $6.02 E+14$ & & & & $E+24$ \\
\hline 19 May 1902 & 5.90 & $7.943 \mathrm{E}+24$ & $2.24 \mathrm{E}+14$ & $4.94 \mathrm{E}+20$ & $6.09 \mathrm{E}+19$ & $1.87 \mathrm{E}+24$ & $1.80 \mathrm{E}+13$ & & $7.52 \mathrm{E}+21$ & $E+24$ \\
\hline February 15 & 5.90 & $7.943 E+24$ & $1.24 \mathrm{E}+24$ & $1.39 \mathrm{E}+20$ & $3.06 \mathrm{E}+24$ & $1.82 \mathrm{E}+14$ & $1.20 \mathrm{E}+24$ & +20 & $E+16$ & $E+24$ \\
\hline 19 May $18 \varepsilon$ & 6.00 & +25 & & & & & & & & \\
\hline 26 Nov 185 & .10 & +25 & & & +24 & +22 & & & & +24 \\
\hline 10 Apr 1881 & 6.10 & $1.585 E+25$ & & & $2.05 \mathrm{E}+24$ & $1.13 \mathrm{E}+22$ & & & & $E+25$ \\
\hline 26 Mar 1884 & 6.10 & $1.585 E+25$ & & & $2.27 \mathrm{E}+24$ & $1.21 \mathrm{E}+19$ & & & $\mathrm{E}+20$ & $1 \mathrm{E}+24$ \\
\hline 11 June 1903 & 6.10 & $1.585 \mathrm{E}+25$ & +24 & $E+23$ & $4.49 \mathrm{E}+24$ & $1.37 \mathrm{E}+18$ & & $E+21$ & $E+20$ & $5 E+24$ \\
\hline 3 Aug 1903 & 6.10 & & & & & & & & & +24 \\
\hline October 22 & 10 & +25 & & & & & & & & \\
\hline July 1, 1911 & .20 & $2.239 E+25$ & & & $52 E+25$ & +20 & $8.97 \mathrm{E}+21$ & & $E+22$ & $E+24$ \\
\hline April 24,1984 & 6.20 & $2.239 \mathrm{E}+25$ & & $0.00 \mathrm{E}+00$ & $2.22 \mathrm{E}+25$ & $0.00 \mathrm{E}+00$ & $0.00 \mathrm{E}+00$ & $0.00 \mathrm{E}+00$ & $0.00 \mathrm{E}+00$ & $1.478 \mathrm{E}+23$ \\
\hline 24 Apr 1890 & 6.30 & $3.162 \mathrm{E}+25$ & & & $E+25$ & $1.36 \mathrm{E}+11$ & & & & $\mathrm{E}+24$ \\
\hline 20 June 1897 & 6.30 & & & & & & & & & +24 \\
\hline 31 Mar 1898 & .30 & +25 & & & +22 & +25 & & & & +24 \\
\hline 19 Apr 1892 & .40 & +25 & & & & +24 & & & & +25 \\
\hline 21 Apr 1892 & 6.40 & $4.467 E+25$ & & $2.73 E+18$ & $7.35 \mathrm{E}+13$ & $1.51 \mathrm{E}+24$ & $7.36 \mathrm{E}+04$ & $4.26 \mathrm{E}+15$ & $8.16 \mathrm{E}+17$ & $4.316 \mathrm{E}+25$ \\
\hline 10 June 1836 & 6.50 & $6.310 \mathrm{E}+25$ & $1.41 \mathrm{E}+25$ & $2.01 \mathrm{E}+23$ & $2.45 \mathrm{E}+25$ & $6.99 \mathrm{E}+20$ & $8.42 \mathrm{E}+24$ & $1.03 E+23$ & $4.89 \mathrm{E}+21$ & $1.578 \mathrm{E}+25$ \\
\hline 8 Oct 1865 & 6.50 & $6.310 E+25$ & & $3.50 \mathrm{E}+24$ & $1.37 \mathrm{E}+25$ & $2.51 \mathrm{E}+19$ & $9.24 \mathrm{E}+23$ & $4.48 \mathrm{E}+21$ & $1.39 \mathrm{E}+21$ & $9.377 \mathrm{E}+24$ \\
\hline June 1838 & 6.80 & $778 E+26$ & & & & & & & & $E+25$ \\
\hline & 6.80 & +26 & & & & +00 & & & & $E+00$ \\
\hline October 18 & 6.90 & & & & & & & & & $E+26$ \\
\hline March 21, 1906 & 7.85 & $2.85 E+27$ & $2.85 E+27$ & $0.00 \mathrm{E}+00$ & $0.00 \mathrm{E}+00$ & $0.00 \mathrm{E}+00$ & $0.00 \mathrm{E}+00$ & $0.00 \mathrm{E}+00$ & $0.00 \mathrm{E}+00$ & $0.000 \mathrm{E}+00$ \\
\hline Total moment & & $4.082 \mathrm{E}+27$ & & & & & & & & \\
\hline Threshold M & & & 6.65 & 6.19 & 5.56 & 5.95 & 6.65 & 5.95 & 6.4 & \\
\hline $\mathrm{MO} / \mathrm{yr} \quad(\mathbf{M}<\mathrm{MT})$ & & & $8.77 E+23$ & $1.24 \mathrm{E}+23$ & $1.48 \mathrm{E}+22$ & $3.80 \mathrm{E}+22$ & $1.91 \mathrm{E}+23$ & $3.01 \mathrm{E}+22$ & $2.86 \mathrm{E}+22$ & $4.93 E+26$ \\
\hline Model Moment & & & $9.815 \mathrm{E}+24$ & $3.7325 \mathrm{E}+24$ & $2.49 E+24$ & $5.7 E+23$ & $3.69 \mathrm{E}+24$ & $6.57 \mathrm{E}+23$ & $3.195 E+23$ & $2.65915 \mathrm{E}+24$ \\
\hline & & & $8.93 \%$ & $\mathbf{3 . 3 2} \%$ & $0.60 \%$ & $6.66 \%$ & $5.18 \%$ & $4.59 \%$ & $8.95 \%$ & \\
\hline
\end{tabular}




\section{Magnitude-frequency distributions for faults}

In order to illustrate the long-term seismic behavior of the modeled faults, we calculate the rate of earthquakes as a function of earthquake magnitude. For each realization of the SFBR model, the frequency of earthquake occurrence is calculated at tenth-magnitude increments for each fault, for the background, and for the region as a whole.

The magnitude of each fixed and floating rupture source is described by a pdf, defined above as a truncated normal distribution (Figure 4.1). Therefore, we must take into account the probability that each given rupture will or will not contribute to the long-term rate at a given magnitude threshold value $M_{T}$ :

$$
\gamma_{\text {char }_{i}}\left(\mathbf{M}>M_{T}\right)=\sum_{i=1}^{\text {Nrup }} \gamma_{\text {char }_{i}} P_{i}\left(\mathbf{M}>M_{T}\right)
$$

where $P_{i}\left(\mathbf{M}>M_{T}\right)$ is the probability that the magnitude of rupture $i$ is greater than the threshold value, and the summation is made over the suite of Nrup fixed and floating rupture sources on the fault of interest. This quantity is evaluated by integrating the pdf from $M_{T}$ upwards:

$$
P_{i}\left(\mathbf{M}>M_{T}\right)=\int_{M_{T}}^{\infty} f_{m_{i}}(m) d m
$$

where $f_{\text {mi }}(m)$ is the magnitude probability density function (pdf) for the $i^{\text {th }}$ rupture source. This procedure is illustrated schematically in Figure 4.3. In that figure, the pdf for Rupture 1 lies entirely below the threshold magnitude $M_{T}$, so $P_{I}\left(\mathbf{M}>M_{T}\right)=0$ and its rate does not contribute to the fault rate at or above this magnitude. The pdf for Rupture 2 lies entirely above $M_{T}$, so $P_{2}\left(\mathbf{M}>M_{T}\right)=1$ and its entire rate contributes to the fault rate. The pdf for Rupture 3 straddles $M_{T}$, so $P_{3}\left(\mathbf{M}>M_{T}\right)$, the ratio of the shaded area to the entire area under the pdf, is found from (4.10).

\section{Earthquake rate for fault segments}

It is useful, for comparison with available geologic data, to calculate the rate at which a segment is ruptured by a characterized earthquake. The segment rupture rate is computed by summing the rate of the rupture sources (fixed and floating) that affect the given segment.

The rate of floating earthquakes are distributed uniformly along the rupture (pro-rated to the segments according to length).

The rate at which a fault segment ruptures in earthquakes greater than some threshold level of interest (e.g. $M_{T} \geq 6.7$ ) is given by (4.9), where the summation is restricted to those ruptures that involve that fault segment.

\section{Background earthquakes}

We use the Gutenberg-Richter form, truncated at high magnitude, to describe the frequency of occurrence of background earthquakes. Historical rates of earthquake occurrence were drawn 
from the analysis of Wesson and others [in prep.]. Two G-R relations, $\log \mathrm{N} / \mathrm{yr}=a-b \mathrm{M}$, that describe the magnitude-frequency distributions of background earthquakes were developed: one for the 1951-1998 period ( $\mathbf{M} \geq 3$ ) with $a=3.67$ [3.60 to 3.74 at $95 \%$ confidence] and $b=0.89$; and the other for the 1836-2001 period ( $\mathbf{M} \geq 5.5$ ) with $a=3.94$ [3.62 to 4.31 at 95\% confidence] and $b=0.89$.

The 1951-1998 relation provides a rate based on recent activity, and the 1836-2001 relation provides a rate based on longer-term activity. We use both rates to estimate the 30 -year conditional probability of $\mathbf{M} \geq 6.7$ earthquakes in the background. That is, we define 2 models, one based on the recent rate of $\mathbf{M} \geq 6.7$ earthquakes and the other on the longer-term rate. Each model is then split into 3 branches, based on the mean rate, the $+2 \sigma$ rate and the $-2 \sigma$ rate. The WG steering committee voted on the relative weights of the 2 models (weights of 0.483 and 0.517 , respectively), which were then apportioned across the 6 resulting branches in the calculation sequence (Table 4.7).

For this study the maximum magnitude for background earthquakes is $7.25 \pm 0.25$. For $\mathbf{M}=4.1+\log \mathrm{A}, \mathbf{M} 7.5$ implies $\mathrm{A}=2500 \mathrm{~km} 2$, or a fault patch $180 \times 14 \mathrm{~km}$. M7.25 implies $\mathrm{A}=1400 \mathrm{~km} 2$, or a fault patch $100 \times 14 \mathrm{~km}$. While thrust fault events on blind faults are likely sources of large background events they, will most likely not exceed M 6 1/2-M6 3/4, and larger strike-slip events on uncharacterized faults are possible. WG02 has not characterized the strikeslip Bartlett Springs fault, judged capable of producing an M7.1 segment-rupturing event (WGNCEP, 1996). If the 85-km-long Bartlett Springs segment ruptured with adjoining segments to the north, an M7.25 or perhaps M 7.5 might result. Therefore, a strike-slip "background" events as large as M7 .5 might occur in the in the northeast part of the study region. Because the truncated G-R distribution falls off sharply as the maximum magnitude is approached, the rate of background earthquakes above $\mathbf{M} 7$ is low and their probability extremely small.

Table 4.7. Background earthquake distribution parameters $a$ and $b$, and branch weights.

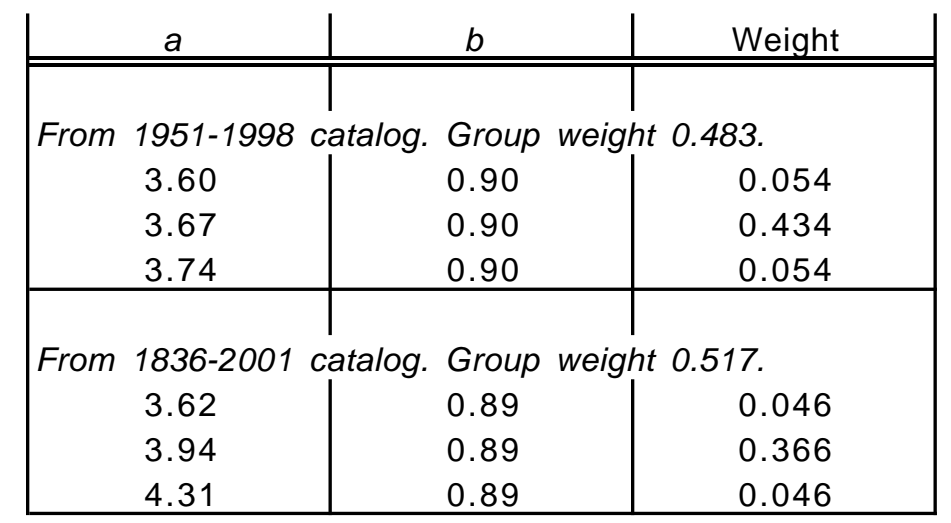




\section{Results: Long-term earthquake rates in the SFBR}

Each realization of the SFBR model yields one complete characterization of each of the seven fault systems and the rate of background earthquakes. For the results presented herein, we compiled 10,000 realizations, a number sufficient to adequately sample the range of weighted branch choices. For each realization we retained mean values of the rate of failure of each fault segment in characterized (fixed or floating) earthquakes, the mean magnitude and mean rate of failure of each characteristic and floating earthquake source, and the rate and maximum magnitude of background earthquakes. We then noted the mean, median and $95 \%$ bounds on the resulting distribution of 10,000 values. Those statistical measures are summarized for the rupture sources and fault segments, respectively, in Tables 4.8 and 4.9. For each rupture source listed in Table 4.8, the mean magnitude and its rate of occurrence represent rupture of that source by itself. The recurrence intervals for the rupture sources are displayed graphically in Figure 4.4. For each fault segment listed in Table 4.9, the mean rate represents the rate at which a rupture occurs on that segment, whether or not the rupture initiated in that segment. (In other words, the segment rates are the sum of rates of the rupture sources that affect the segment.) 
Table 4.8. Long-term magnitudes and occurrence rates of rupture sources. For reference, recurrence intervals are also listed; these are simply calculated as the inverse of the occurrence rate statistics listed in the center columns.

\begin{tabular}{|c|c|c|c|c|c|c|c|c|c|c|}
\hline \multirow[b]{2}{*}{ Fault Name } & \multirow[b]{2}{*}{ Rupture Source } & \multicolumn{3}{|c|}{ Mean magnitude } & \multicolumn{3}{|c|}{ Occurrence rate $(/ y r)$} & \multicolumn{3}{|c|}{ Recurrence interval (yr) } \\
\hline & & Mean & $2.5 \%$ & $97.5 \%$ & Mean & $2.5 \%$ & $97.5 \%$ & Mean & $2.5 \%$ & $97.5 \%$ \\
\hline \multirow[t]{11}{*}{ San Andreas } & SAS & 7.03 & 6.84 & 7.22 & 0.0007 & 0 & 0.0015 & 1402 & 646 & ${ }_{\infty}$ \\
\hline & SAP & 7.15 & 6.95 & 7.32 & 0.0005 & 0 & 0.0010 & 2017 & 967 & $\infty$ \\
\hline & SAN & 7.45 & 7.28 & 7.61 & 0.0001 & 0 & 0.0008 & 7180 & 1316 & $\infty$ \\
\hline & SAO & 7.29 & 7.12 & 7.44 & 0.0002 & 0 & 0.0011 & 4540 & 897 & $\infty$ \\
\hline & SAS+SAP & 7.42 & 7.26 & 7.56 & 0.0010 & 0.0002 & 0.0029 & 1037 & 343 & 4863 \\
\hline & SAP+SAN & 7.65 & 7.48 & 7.79 & 0 & 0 & 0 & $\infty$ & $\infty$ & $\infty$ \\
\hline & $\mathrm{SAN}+\mathrm{SAO}$ & 7.70 & 7.53 & 7.86 & 0.0012 & 0.0004 & 0.0035 & 809 & 282 & 2772 \\
\hline & $\mathrm{SAS}+\mathrm{SAP}+\mathrm{SAN}$ & 7.76 & 7.59 & 7.92 & 0.00002 & 0 & 0.0001 & 42489 & 8240 & $\infty$ \\
\hline & SAP+SAN+SAO & 7.83 & 7.65 & 8.01 & 0.0001 & 0 & 0.0004 & 13046 & 2676 & $\infty$ \\
\hline & $\mathrm{SAS}+\mathrm{SAP}+\mathrm{SAN}+\mathrm{SAO}$ & 7.90 & 7.72 & 8.10 & 0.0026 & 0.0012 & 0.0042 & 378 & 239 & 808 \\
\hline & floating & 6.90 & 6.90 & 6.90 & 0.0009 & 0.0001 & 0.0019 & 1104 & 536 & 7723 \\
\hline \multirow[t]{7}{*}{ Hayward/RC } & $\mathrm{HS}$ & 6.67 & 6.36 & 6.93 & 0.0034 & 0.0012 & 0.0069 & 292 & 144 & 830 \\
\hline & $\mathrm{HN}$ & 6.49 & 6.18 & 6.78 & 0.0032 & 0.0011 & 0.0069 & 312 & 146 & 907 \\
\hline & $\mathrm{HS}+\mathrm{HN}$ & 6.91 & 6.68 & 7.12 & 0.0024 & 0.0009 & 0.0047 & 413 & 211 & 1100 \\
\hline & $\mathrm{RC}$ & 6.98 & 6.81 & 7.14 & 0.0040 & 0.0023 & 0.0063 & 250 & 159 & 438 \\
\hline & $\mathrm{HN}+\mathrm{RC}$ & 7.11 & 6.94 & 7.28 & 0.0005 & 0 & 0.0013 & 2086 & 766 & $\infty$ \\
\hline & $\mathrm{HS}+\mathrm{HN}+\mathrm{RC}$ & 7.26 & 7.09 & 7.42 & 0.0003 & 0.0001 & 0.0007 & 3524 & 1511 & 19158 \\
\hline & floating & 6.90 & 6.90 & 6.90 & 0.0003 & 0.0001 & 0.0006 & 3524 & 1706 & 7294 \\
\hline \multirow[t]{8}{*}{ Calaveras } & CS & 5.79 & 0.00 & 6.14 & 0.0075 & 0 & 0.0158 & 134 & 63 & $\infty$ \\
\hline & $\propto$ & 6.23 & 5.75 & 6.68 & 0.0054 & 0.0025 & 0.0097 & 184 & 103 & 397 \\
\hline & $\mathrm{CS}+\mathrm{CC}$ & 6.36 & 5.87 & 6.75 & 0.0018 & 0 & 0.0065 & 541 & 155 & $\infty$ \\
\hline & CN & 6.78 & 6.58 & 6.97 & 0.0035 & 0.0015 & 0.0065 & 284 & 154 & 685 \\
\hline & $\mathrm{CC}+\mathrm{CN}$ & 6.90 & 6.68 & 7.11 & 0.0001 & 0 & 0.0011 & 10958 & 924 & $\infty$ \\
\hline & $\mathrm{CS}+\mathrm{CC}+\mathrm{CN}$ & 6.93 & 6.72 & 7.14 & 0.0006 & 0 & 0.0018 & 1555 & 543 & $\infty$ \\
\hline & floating & 6.20 & 6.20 & 6.20 & 0.0030 & 0.0009 & 0.0077 & 331 & 130 & 1158 \\
\hline & floating $\mathrm{CS}+\mathrm{CC}$ & 6.20 & 6.20 & 6.20 & 0.0120 & 0.0025 & 0.0285 & 83 & 35 & 405 \\
\hline \multirow[t]{7}{*}{ Concord/GV } & $\mathrm{CON}$ & 6.25 & 5.75 & 6.67 & 0.0014 & 0.0002 & 0.0038 & 690 & 264 & 5374 \\
\hline & GVS & 6.24 & 5.75 & 6.65 & 0.0007 & 0.0001 & 0.0018 & 1527 & 551 & 12725 \\
\hline & $\mathrm{CON}+\mathrm{GVS}$ & 6.58 & 6.13 & 6.91 & 0.0005 & 0.00003 & 0.0016 & 2158 & 640 & 40002 \\
\hline & GVN & 6.02 & 5.45 & 6.49 & 0.0017 & 0.0002 & 0.0043 & 582 & 231 & 4474 \\
\hline & GVS+GVN & 6.48 & 6.03 & 6.81 & 0.0009 & 0.0001 & 0.0024 & 1125 & 411 & 10866 \\
\hline & $\mathrm{CON}+\mathrm{GVS}+\mathrm{GVN}$ & 6.71 & 6.34 & 7.00 & 0.0017 & 0.0003 & 0.0050 & 580 & 199 & 2888 \\
\hline & floating & 6.20 & 6.20 & 6.20 & 0.0026 & 0.0001 & 0.0126 & 386 & 80 & 9327 \\
\hline \multirow[t]{4}{*}{ San Gregorio } & SGS & 6.96 & 6.75 & 7.17 & 0.0007 & 0 & 0.0023 & 1403 & 444 & $\infty$ \\
\hline & SGN & 7.23 & 7.04 & 7.41 & 0.0012 & 0 & 0.0034 & 828 & 295 & $\infty$ \\
\hline & SGS+SGN & 7.44 & 7.27 & 7.58 & 0.0008 & 0 & 0.0021 & 1202 & 483 & $\infty$ \\
\hline & floating & 6.90 & 6.90 & 6.90 & 0.0008 & 0.0004 & 0.0014 & 1220 & 733 & 2833 \\
\hline \multirow[t]{4}{*}{ Greenville } & GS & 6.60 & 6.37 & 6.83 & 0.0010 & 0.0004 & 0.0019 & 976 & 515 & 2622 \\
\hline & $\mathrm{GN}$ & 6.66 & 6.41 & 6.88 & 0.0010 & 0.0004 & 0.0018 & 1040 & 550 & 2824 \\
\hline & $\mathrm{GS}+\mathrm{GN}$ & 6.94 & 6.74 & 7.13 & 0.0005 & 0.0002 & 0.0009 & 1994 & 1063 & 5393 \\
\hline & floating & 6.20 & 6.20 & 6.20 & 0.0002 & 0.0001 & 0.0003 & 5897 & 3131 & 15835 \\
\hline Mt Diablo & MTD & 6.65 & 6.42 & 6.89 & 0.0026 & 0.0006 & 0.0053 & 389 & 189 & 1609 \\
\hline
\end{tabular}


Table 4.9. Long-term earthquake recurrence rates and recurrence intervals for SFBR fault segments. Rates include earthquakes on all fixed and floating rupture sources that affect a given segment. For reference, recurrence intervals are also listed; these are simply calculated as the inverse of the occurrence rate statistics listed in the center columns.

\begin{tabular}{|lc|ccc|ccc|}
\multirow{2}{*}{ Fault Name } & \multicolumn{4}{|c}{ Recurrence rate (/yr) } & \multicolumn{3}{c|}{ Recurrence Interval (yr) } \\
\cline { 3 - 8 } & Segment & Mean & $2.5 \%$ & $97.5 \%$ & Mean & $2.5 \%$ & $97.5 \%$ \\
\hline \hline San Andreas & SAS & 0.0045 & 0.0028 & 0.0064 & 224 & 156 & 363 \\
& SAP & 0.0044 & 0.0027 & 0.0063 & 229 & 160 & 377 \\
& SAN & 0.0045 & 0.0025 & 0.0065 & 223 & 153 & 397 \\
& SAO & 0.0044 & 0.0025 & 0.0065 & 225 & 154 & 405 \\
\hline Hayward/RC & HS & 0.0062 & 0.0035 & 0.0101 & 161 & 99 & 283 \\
& HN & 0.0065 & 0.0037 & 0.0105 & 155 & 95 & 273 \\
& RC & 0.0049 & 0.0029 & 0.0073 & 205 & 136 & 345 \\
\hline Calaveras & CS & 0.0134 & 0.0026 & 0.0245 & 75 & 41 & 390 \\
& C & 0.0185 & 0.0094 & 0.0326 & 54 & 31 & 106 \\
& GN & 0.0054 & 0.0030 & 0.0085 & 187 & 117 & 339 \\
\hline Concord/GV & CON & 0.0046 & 0.0015 & 0.0084 & 219 & 118 & 646 \\
& GVS & 0.0048 & 0.0015 & 0.0089 & 210 & 112 & 665 \\
& GVN & 0.0050 & 0.0016 & 0.0094 & 201 & 106 & 622 \\
\hline San Gregorio & SGS & 0.0019 & 0.0007 & 0.0031 & 540 & 319 & 1441 \\
& SGN & 0.0026 & 0.0011 & 0.0043 & 392 & 232 & 926 \\
\hline Greenville & GS & 0.0016 & 0.0006 & 0.0030 & 623 & 330 & 1677 \\
& GN & 0.0016 & 0.0006 & 0.0029 & 644 & 343 & 1748 \\
\hline Mt Diablo & MTD & 0.0026 & 0.0006 & 0.0053 & 389 & 189 & 1609 \\
\hline
\end{tabular}

\section{Evaluating the SFBR Model}

The products of the calculation sequence are a) the mean occurrence rate for earthquakes on 18 fault segments and the 7 characterized faults and b) the mean magnitude and recurrence rate of each rupture source. Adding the mean rupture rate of the background yields a rate for the entire SFBR. While the resulting SFBR model accounts for all $\mathbf{M} \geq 6.7$ events, it does not include all of the $\mathbf{M}<6.7$ events in the region. How well does the SFBR model work as a physically realistic earthquake machine? There are a number of consistency checks available to evaluate whether the numerical operations in the WG02 calculation sequence produce reasonable results. First, we compare the predicted rate of $\mathbf{M} \geq 6.7$ earthquakes with the historical record back to 1836 and paleoseismic earthquake records back to about 1600. Second, the recurrence rate of $\mathbf{M} \geq 6.7$ events for each fault segment is compared to paleoseismic recurrence rates obtained from trenches excavated across the fault trace within that segment. Finally, regional results from the SFBR model are compared to other regional models.

These model earthquake rates are determined by factors we can loosely describe as "absolute", factors that more or less raise (or lower) the rates uniformly, and "relative", factors that change the rates of earthquakes by changing the distribution of earthquakes with respect to size. The "relative" factors operate differently on different faults, but the sum of the earthquake rates on the faults is the principal determinant of the regional rates. 
For the region as a whole, such "absolute" factors include the regional slip rate across SFBR (36 - $43 \mathrm{~mm} / \mathrm{yr}$ ), the weighted $\mathbf{M}-\log A$ relations, and the background earthquake rate. For individual faults, the fault-specific slip velocity and the weighted $\mathbf{M}-\log A$ relations are also "absolute" factors. Significant "relative" factors operating on individual faults include the weighted fault-rupture models which express the fault's seismogenic character; $\mathbf{M}$ for the floating earthquake (the larger the floating earthquake, the more seismic moment it releases and the less frequently it occurs); and the seismic slip factor $R$. In this analysis, $R<1$ reduces fault area $A$ for all affected fault segments and rupture sources, thereby reducing the mean magnitudes and increasing the rates of these earthquakes.

\section{Checks on the SFBR model}

\section{Regional comparisons}

The mean rate of occurrence and magnitude distribution of $\mathbf{M} \geq 6.7$ earthquakes are the two most important model results for evaluating the SFBR model since observations of these quantities were not a part of the model construction. The SFBR model produces $0.031 \mathbf{M} \geq 6.7$ earthquakes/yr (0.024 to 0.041 at the $95 \%$ confidence level), and $b=1.02 \pm 0.03(1 \sigma)$ for $6.7 \leq \mathbf{M} \leq$ 7.7 (Figure 4.5). The 1.02 slope of the magnitude frequency distribution is greater than the bvalue of 0.90 obtained by Bakun (1999) for the SFBR but Bakun's (1999) b-value for the $\mathbf{M} \geq$ 5.5 earthquakes since 1850 was $0.99 \pm 0.11$. The modeled mean rate of $0.031 \mathbf{M} \geq 6.7$ earthquakes/yr is consistent with that observed since 1836. The observed rate, $0.024 \mathbf{M} \geq 6.7$ earthquakes/yr, includes only four events; assuming a Poisson model, regional rates of $\mathbf{M} \geq 6.7$ earthquakes lower than 0.007 and greater than 0.047 respectively can be rejected with $95 \%$ confidence (Reasenberg et al, 2003). Finally, the $\mathbf{M} \geq 5.5$ historical/instrumental rate of seismicity connects with the SFBR model, both in the vicinity of $\mathbf{M}=6.7$ and at larger magnitudes (Figure 4.5).

Another regional check is the comparison between the SFBR long-term rates and the regional paleoseismic record. The timing of the most recent rupture associated with a large magnitude earthquake on each of the characterized faults is described in Chapter $\mathbf{3}$ and summarized in Fig-

ure 4.6. The most robust observations of recent rupture are on the San Andreas, northern and southern Hayward, and Rodgers Creek faults, each occurring after 1600 AD. The timing of the most recent event on the northern Calaveras is less certain and its size is also not as well constrained. The most recent event on the San Gregorio fault has large uncertainties but is permissively post-1600. If each of the 10 events shown on Figure 4.6 is an independent $\mathbf{M} \geq 6.7$ earthquake, then a rate of $\mathrm{N}(\mathbf{M} \geq 6.7)$ of 0.024 events/yr have occurred over the past 400 years. This is the same rate as obtained above for the historical record since 1836. If the San Gregorio event occurred earlier than 1600 and two of the Hayward-Rodgers Creek events represent a combined rupture source, the region would have experienced 8 events during the past 400 years for a rate $\mathrm{N}(\mathbf{M} \geq 6.7)$ of 0.020 events/yr. In either case the paleoseismic record, as presently understood, is in good agreement with both the historical regional seismicity rate and the earthquake production rate of the long-term SFBR model, excluding background earthquakes not yet seen in the paleoseismic record. 
Although the San Andreas and Hayward-Rodgers Creek faults are the two principal faults that contribute most significantly to the regional $\mathbf{M} \geq 6.7$ seismicity of SFBR, these faults generate earthquakes in very different ways from each other and from SFBR as a whole. The HaywardRodgers Creek fault is composed of three segments, the southern Hayward (HS), northern Hayward (HN) and Rodgers Creek (RC) segments. More than 95\% of the model ruptures of the Hayward-Rodgers Creek fault occur either as single-segment ruptures or in the HS + HN combination, all with mean $\mathbf{M} \leq 7.0$ (Table 4.8). More than $60 \%$ of the ruptures of the San Andreas fault, on the other hand, occur as the 2-segment SAN+SAO or 4-segment SAS+SAP+SAN+SAO ruptures, both with mean $\mathbf{M} \geq 7.75$. These two, very different modes of rupture, with a small contribution from the San Gregorio fault at intermediate magnitudes ( $7.0 \leq \mathbf{M} \leq 7.4)$, add up to a G-R regional distribution for $6.7 \leq \mathbf{M} \leq 7.85$. That is, another consequence of the SFBR model is the strong asymmetry in the production of more-frequent $\mathbf{M} \leq 7.0$ earthquakes on the East Bay faults, principally the Hayward-Rodgers Creek fault, with respect to the production of less frequent, ( $\mathbf{M} \geq 7.2$ earthquakes on the West Bay faults, principally the San Andreas fault.

This East Bay-West Bay asymmetry is due to two features of the model, the shorter segment lengths of the East Bay faults relative to the San Andreas and San Gregorio faults and the expertopinion assignments of the relative frequency of occurrence of multi-segment ruptures, based on the perceived strength of segment boundaries and site-rupture chronologies. It does not seem likely, for example, that the four known co-seismic ruptures inferred from the paleoseismic record for the southern Hayward segment between AD 1470 and 1868 (Lienkaemper and others, 2002) could involve more than one multi-segment rupture, given the rate at which these events occurred; The first known event, ca. AD 1470, may have been multi-segment rupture and may have followed a long quiescence. Andrews and Schwerer (2000) found the same East Bay-West Bay asymmetry in the production of small and large earthquakes without recourse to expert opinion. Their Figure 4a shows not only this East Bay-West Bay asymmetry, but also nearly the same transition magnitude (at $\mathbf{M}=7.0$ ) produced by the SFBR model.

Figure 4.5 also reveals that the background sources contribute significantly to the SFBR model in the magnitude range $6.7 \leq \mathbf{M} \leq 7.0$. The background is based on Wesson el al.'s (2003) analysis of historical seismicity relative to known faults and WG02's expert-opinion assignments of weighted maximum magnitudes for the magnitude-frequency distribution. The uncharacterized faults in SFBR that contribute to the background, with the exception of the Bartlett Springs fault, are not likely capable of producing $\mathbf{M}>7.0$ earthquakes. The rate of background earthquakes accounts for $6 \%$ of the potential seismic moment in the SFBR (Figure 4.5).

\section{Fault-specific comparisons}

The SFBR model is next compared on a fault-by-fault basis to the seismicity of that fault for the past 165 years and to the paleoseismic record of significant earthquakes on that fault, as expressed in trenches excavated across them.

\section{Historical/Instrumental Seismicity Data}

The seismicity of the seven characterized faults, the background, and the SFBR as a whole, together with their associated 5\% and 95\% ranges, are shown in Figure 4.7. Seismicity in the 
SFBR, even since 1836, is sparse, and sparser still when partitioned onto seven faults and the background. Three general features of the SFBR seismicity are apparent. First, there is general concordance of the $\mathbf{M} \geq 5.5$ seismicity since 1836 (open squares) with the SFBR model rates of $\mathbf{M} \geq 6.7$ earthquakes, at least for the more active San Andreas, Hayward-Rodgers Creek, and Calaveras faults. (There is less agreement for the lower slip-rate faults; the agreement between the model and observed seismicity for the background is predetermined, the model background seismicity being the observed background seismicity.) Second, with the exception of the Greenville fault, the pronounced drop in the regional seismicity rate following the 1906 earthquake is expressed by every source (compare N/yr of pre-1906 open diamonds to post-1906 solid squares in Figure 4.7). Third, the 1951 to 1998 seismicity, mostly at $\mathbf{M} \leq 5.5$, is generally disconnected from the SFBR model rates of $\mathbf{M} \geq 6.7$ earthquakes. This discrepant rate for the last several decades is pronounced for the San Andreas and Hayward-Rodgers Creek faults, the two faults that contribute the most to seismicity rates for the SFBR model and for the historical record since 1836 .

The Mt. Diablo thrust has no surface expression; its geometry, a 25-kilometer-long WNW-ESE zone dipping to the northeast, is inferred from structural and kinematic models of Mt. Diablo. Although modeled by WGCEP (1996) as an unsegmented plane, the Mt. Diablo thrust likely contains tear faults. Most, if not all, of the recent events that are associated with the Mt. Diablo thrust on Figure 4.7g are known by their focal mechanisms to be associated with vertical, eastwest striking strike-slip faults (Walter and others, 1998; Wesson and others, 2003) that crosscut the Mt. Diablo thrust.

\section{Paleoseismic Data}

Paleoseismic recurrence interval data (Chapter 3) are in short supply for SFBR faults, but those values that are available (Table 4.10) can be compared to recurrence intervals calculated by the SFBR model. The column "WG02 mean RI" in Table 4.10 is the frequency of occurrence of all segment-rupturing characteristic earthquakes for that segment (i.e., no M6.7 threshold). The 95\% confidence range of the model RI are given in parentheses. These recurrence intervals are directly comparable to the trench data (RI Trench), which provide frequency of occurrence of ruptures at a site regardless of whether they represent single or multiple-segment events. The values in the "RI Trench" column are estimates of mean rupture rate based on the number of events and intervals defined in a trench during a measured period of time (Chapter 3). The column "RI Calculated" gives average repeat time derived from slip/event divided by the slip rate for those faults for which these data are available. 
Table 4.10. Comparing Paleoseismic and SFBR Model Mean Recurrence Intervals (RI) (years)

\begin{tabular}{lcll}
\hline Fault Segment & $\begin{array}{l}\text { SFBR Model Mean } \\
\text { RI }\end{array}$ & RI Trench & RI Calculated \\
\hline San Andreas (SAN) & $223(153$ to 397$)$ & 180 to 370 & $218(181$ to 262$))$ \\
Southern Hayward & $161(99$ to 283$)$ & 110 to 170 & $211(136$ to 328$)$ \\
Northern Hayward & $155(95$ to 273$)$ & 270 to 710 & -- \\
Rodgers Creek & $205(136$ to 345$)$ & 235 to 387 & $230(131$ to 370$)$ \\
Northern Calaveras & $187(117$ to 339$)$ & 250 to 850 & -- \\
San Gregorio North & $392(232$ to 926$)$ & 300 to 690 & $571(300$ to 1250$)$ \\
\hline
\end{tabular}

Geologic information for the Hayward-Rodgers Creek fault system is the most robust for SFBR faults. Paleoseismic observations on the Rodgers Creek fault (Budding and others, 1991; Schwartz and others, 1992) show the occurrence of three surface-rupturing earthquakes between about AD 1000 and 1776. These three events produced 5.1 to $7.2 \mathrm{~m}$ of offset, with slip during the most recent event of 1.8 to 2.3 meters. The trench-based recurrence intervals have large uncertainties but, along with the mean calculated RI of 230 years, are reasonably close to the mean SFBR model rupture rate. On the southern Hayward fault there is evidence for four coseismic ruptures (3 intervals) between AD 1470 and 1868 (Lienkaemper and others, 2002). An average slip of 1.9 meters was estimated from geodetic data for the 1868 earthquake, which ruptured this segment (Yu and Segall, 1998). The horizontal offset for older events is not known. Both the paleoseismic (trench) recurrence and the calculated recurrence intervals (average slip in 1868 divided by the $9 \pm 2 \mathrm{~mm} / \mathrm{yr}$ slip rate) are shorter than, but within the uncertainties of, the recurrence intervals predicted by the SFBR model.

The geologic recurrence interval of 270 to 710 years for the northern Hayward fault is based on observations at the Mira Vista site (Chapter 3, Figure 3.1) of at least four to seven surfacefaulting events that occurred during the past 1630 to 2130 years). The event history is likely incomplete at the Mira Vista site because slip can occur here along the main creeping trace without producing brittle deformation in the associated sag pond deposits and short depositional hiatuses in the pond stratigraphic section can also mask event occurrence. The actual rupture rate on the northern Hayward, therefore, is likely to be shorter than the 270 to 710 year trench RI shown in Table 4.10. Note that the mean $\mathrm{M}$ of $\mathrm{HN}$ segment rupturing events is 6.18 , too small to be reliably detected in trench excavations. The NH model RI, therefore, cannot meaningfully be compared with the trench results. No horizontal offset data/event are available at the Mira Vista site for use in calculating a slip-based recurrence interval.

Recurrence data for the North Coast segment of the San Andreas fault are sparse but are also in general agreement with WG02 mean rupture rates. Schwartz and others (1998) suggest the penultimate event dates from AD 1630 to 1660. A broader age range, AD 1600 to 1670, is permissive and 235 to 300 years between it and 1906 is reasonable. Based on buried peats at Bolinas lagoon, Knudsen and others (1999) have interpreted the third event back on this segment of the fault to have occurred between AD 1290 to 1340, providing an interval of 390 to 370 years between it and the penultimate event. The intervals for the two surface rupturing events on the SAN segment before 1906 average 298 years. Noller and others (1993) calculate a recurrence 
interval of 300 to 350 years in trenches at Ft. Ross, and Prentice (1989) concludes that intervals between large ruptures along this part of the fault range from 188 to 340 years, averaging about 260 years.

On the northern San Gregorio fault at Seal Cove (Chapter 3, Figure 3.8), Simpson and others (1998) found evidence for two large surface faulting events in the AD 600 to AD 1380 year period. They estimated lateral slip of 5 ( 3 to 11$) \mathrm{m}$ for the most recent event and $3( \pm 0.2) \mathrm{m}$ for the penultimate event. The SFBR model mean rupture interval for the northern San Gregorio segment is within the range of repeat times estimated from the limited paleoseismic data and an average recurrence interval calculated from the slip per event and a slip rate of $7 \pm 3 \mathrm{~mm} / \mathrm{yr}$.

At Leyden Creek on the northern Calaveras fault (Chapter 3, Figure 3.8) Kelson et al. (1996) identified 5 to 6 surface-rupturing earthquakes during the past 2500 years or so, yielding a recurrence interval of 250 to 850 years. No measurement of horizontal slip per event is available at the site. The SFBR model mean RI of 187 years is outside the range of observed recurrence intervals but the $95 \%$ confidence ranges of the model RI and observed RI overlap.

\section{Comparison of the SFBR model to other models}

\section{Comparison with Andrews and Schwerer (2000)}

Andrews and Schwerer (2000) found frequencies of events in Northern California by fitting to two types of truncated G-R distributions for the region as a whole. Here we compare to their cutoff model, in which the cumulative G-R distribution is cut off abruptly at a maximum magnitude. The associated differential distribution has a spike at the maximum magnitude, so there is a characteristic earthquake component (see Figure 1 in Field and others, 1999). They find that the frequency of events within or partly within the SFBR with $\mathbf{M}>6.7$ is 0.0378 /yr. They assume $b=0.9$ and use $\mathbf{M}_{\max }=7.77$, the magnitude of the 1906 event using the Wells and Coppersmith (1994) magnitude-area relationship. For given total moment release rate, the $a$ value of the distribution varies with maximum magnitude, decreasing by 0.6 for a unit increase in $\mathbf{M}_{\max }$. If $\mathbf{M}_{\max }$ in the Andrews and Schwerer (2000) model is increased by 0.14 to equal the Working Group's mean $\mathbf{M}$ for repeats of the 1906 source, then their $a$ value decreases by 0.084 , and the frequency of events with $\mathbf{M}>6.7$ becomes $0.0312 / y r$. They assumed a long-term regional slip rate of 39 $\mathrm{mm} / \mathrm{yr}$, all of which was released seismically. If only $36 \mathrm{~mm} / \mathrm{yr}$ is released seismically, then the rate for $\mathbf{M}>6.7$ becomes $0.029 / \mathrm{yr}$. This result does not depend on details of the Andrews and Schwerer model, but only on the total moment rate, the $b$ value, $\mathbf{M}_{\max }$, and the assumed shape of the distribution (the cutoff model).

The frequency of events with $\mathbf{M}>6.7$ on modeled faults in the SFBR model is $0.031 / \mathrm{yr}$. The close agreement with the result in the previous paragraph is only a coincidence, because Andrews and Schwerer used slightly different seismogenic depths, and there is ambiguity about counting events that are partly outside the SFBR. In the Andrews and Schwerer (2000) model, large events predominate on the San Andreas fault and single-segment events predominate on the East Bay faults, in qualitative agreement with the features of the SFBR model described above. 


\section{Comparison of rate with formulas for various distributions}

A different comparison can be made using the WG02 total moment rate in the following formula, which applies to the truncated incremental ("cutoff") distribution. This is equation (18) in Andrews and Schwerer (2000) and equation (9) in Molnar (1979).

$$
N=(1-B)\left[M_{0}^{\prime} / M_{0 \max }\right]\left[M_{0} / M_{0 \max }\right]^{-B}
$$

Where $N$ is the rate of occurrence of events with moment greater than $M_{0}, B=(2 / 3) b, M_{0 \max }$ is the moment of the maximum size event, and $M_{0}{ }^{\prime}$ is the total long-term moment release rate of the region. We use the following values: $B=0.6, M_{0 \max }=0.82 \times 10^{28}$ dyne-cm (corresponding to $\mathbf{M}_{\max }=7.91$ ), and $M_{0}=1.26 \times 10^{26}$ dyne-cm (corresponding to $\mathbf{M}=6.7$ ). The total moment rate is $M_{0}{ }^{\prime}=4.72 \times 10^{25} \mathrm{dyne}-\mathrm{cm} / \mathrm{yr}$. Then the formula for the truncated incremental distribution given above predicts $N(\mathbf{M}>6.7)=0.028 / y r$. Analogous formulas for the truncated cumulative ("roll-off") and gamma distributions (equations 16 and 14 of Andrews and Schwerer) predict rates of $0.043 / \mathrm{yr}$ and $0.045 / \mathrm{yr}$ respectively. The rate of the SFBR model, $N(\mathbf{M}>6.7)=0.031 / \mathrm{yr}$, is much closer to the rate predicted by the cutoff distribution than to that of the roll-off or gamma distributions. This means that the distribution of events, neglecting background, chosen by WG02 closely fits a cumulative G-R distribution with $b=0.9$ and having an abrupt cutoff at $\mathbf{M}_{\max }=7.91$.

\section{Comparison of the SFBR rate with Ward (2000)}

Ward (2000) simulated seismicity in northern California by modeling the San Andreas fault system as a system of dislocations in a thin elastic plate. His cumulative distribution of event sizes for $\mathbf{M}>6$ closely fits a G-R distribution with $b=1.1$ and with a rather abrupt cutoff near $\mathbf{M}_{\max }=7.75$. He designed his model to start with the 1906 event having $\mathbf{M}=7.9$. Subsequent modeled events on the same length of fault had smaller magnitudes, averaging 7.7. His maximum magnitude could be adjusted by changing the friction parameters. Excluding events on the Maacama fault (outside the SFBR), his rate for events with $\mathbf{M}>7$ is $0.016 / y r$. The corresponding rate from the SFBR model is $N(\mathbf{M}>7)=0.010 / y r$. The discrepancy arises from the different values of $b$ and $\mathbf{M}_{\max }$.

\section{Comparison of the WG99 rate to a truncated ("roll-off") G-R model}

WG02's fault characterization model, consisting of specified fault segments that rupture either alone or in contiguous combinations, is but one possible model for earthquakes in the SFBR. Alternate models, such as one without segmentation, or one in which non-integer segment ruptures are allowed, were not considered by WG02, but have been previously proposed for the SFBR and other regions (e.g., Jackson, 1996; Andrews and Schwerer, 2000). Here, we compare the SFBR model with a moment-balanced, truncated G-R model for earthquakes on the characterized faults. This model is similar, at least in spirit, to Jackson (1999).

To define a moment-balanced G-R model, we specify a b-value and a maximum magnitude, $\mathrm{M}_{\mathrm{Max}}$, that truncates the incremental magnitude-frequency distribution. Historical seismicity for the SFBR (Bakun, 1999) allows us to confine our exploration of G-R models to those with $\mathrm{b}=0.9$. We compare the SFBR model to truncated G-R models for each characterized fault in the SFBR with $b=0.9$ and $M_{M a x}=8.25$ (Figure 4.8). These are "roll-off" models in the terminology of 
Andrews and Schwerer (2000). On each fault, the moment release rate (and thus, the a-value) in this G-R model is determined by the fault's slip rate. The regional magnitude-frequency distributions for the G-R and SFBR models are similar, and both closely match the observed rate for $\mathbf{M} \leq 6.7$ earthquakes since 1836. Corresponding G-R models with $\mathrm{M}_{\mathrm{Max}}=8.0$ and 8.5 (not shown in Figure 4.8) lie approximately $20 \%$ above and below the $\mathrm{M}_{\mathrm{Max}}=8.25$ curve, respectively.

While this G-R model adequately matches both the observed rates, the two models differ significantly on individual faults. Because the G-R model lacks characteristic earthquakes, its rate of M 7.8 earthquakes on the San Andreas fault is about 2/3 of that for the SFBR model, which assigns significant weight to the occurrence of 1906-type rupture sources (Chapter 4). In order to balance the moment release rate on this fault, the G-R model has higher rates of $\mathbf{M} \leq 7.2$ earthquakes than the SFBR model by a factor of approximately 2 3. Observed rates on the San Andreas fault since 1836 (red triangles in Figure 4.8) are close to those in the SFBR model, but are about a factor of 3 below the rate in the G-R model. (For example, the G-R model includes the occurrence of one $\mathbf{M} \geq 6$ earthquake on the San Andreas fault per decade, on average, while approximately 5 have occurred in the past 16 decades in the SFBR. This estimate is not an integer because it derives from the Wesson et al.'s (2003) association method.)

On the Hayward-Rodgers Creek, Calaveras and Concord-Green Valley faults, the G-R model assigns more weight to $\mathbf{M} \geq 7.2$ earthquakes than does WG02, owing to the application of $\mathbf{M}_{\mathrm{Max}}=8.25$ on each fault. In order to balance the moment rate on these faults, the rate of $\mathbf{M} \leq 6.7$ earthquakes in the G-R model is lower than that in the SFBR model. Observed rates since 1836 on the Hayward-Rodgers Creek, Calaveras, and Concord-Green Valley faults are within a factor of two of the SFBR model, but are systematically under-predicted by the G-R model. For example, the G-R model includes the occurrence of one $\mathbf{M} \geq 6$ earthquake every 2 centuries on the Calaveras fault, on average, while perhaps 6 or 7 have occurred in the past 165 years. 


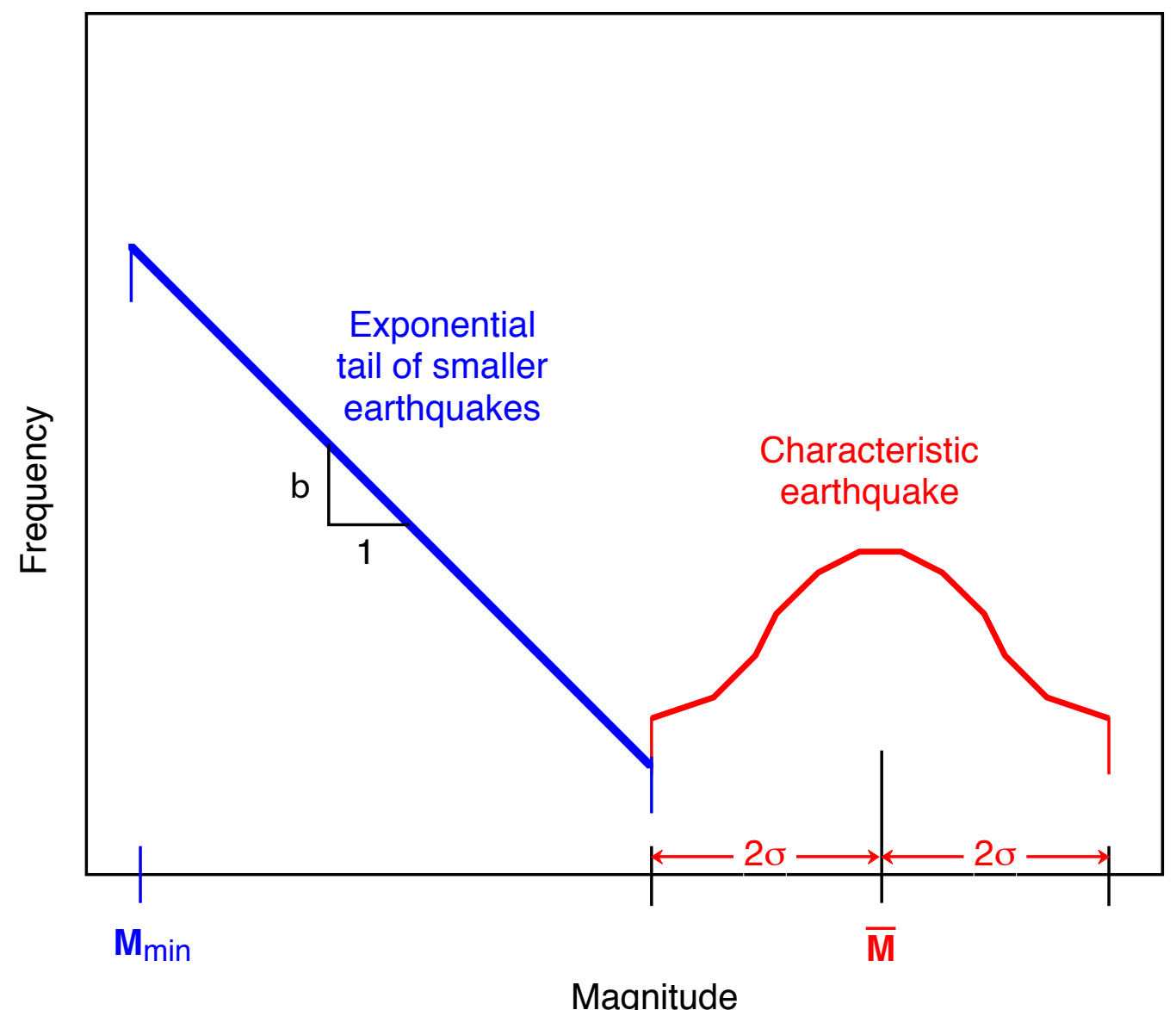

Figure 4.1. Illustration of a magnitude pdf (probability density function) for a WG99 fault containing a single rupture source. The characteristic rupture (which breaks the entire seismogenic area of the source) has a mean magnitude and a natural variability about that mean defined by +/two standard deviations (where sigma $=0.12$ ). A portion of the moment rate of the fault is expended in an exponential distribution of smaller earthquakes, where the exponential is defined by a $b$ value and magnitude bounds as shown. 
Figure 4.2. Comparison of candidate relationships between rupture area ( $\mathrm{LxW}$ in $\mathrm{km})$ and moment magnitude. Data from Tables E.1-E.4 of Appendix D. Lines correspond to numbered equations in the text, as noted.
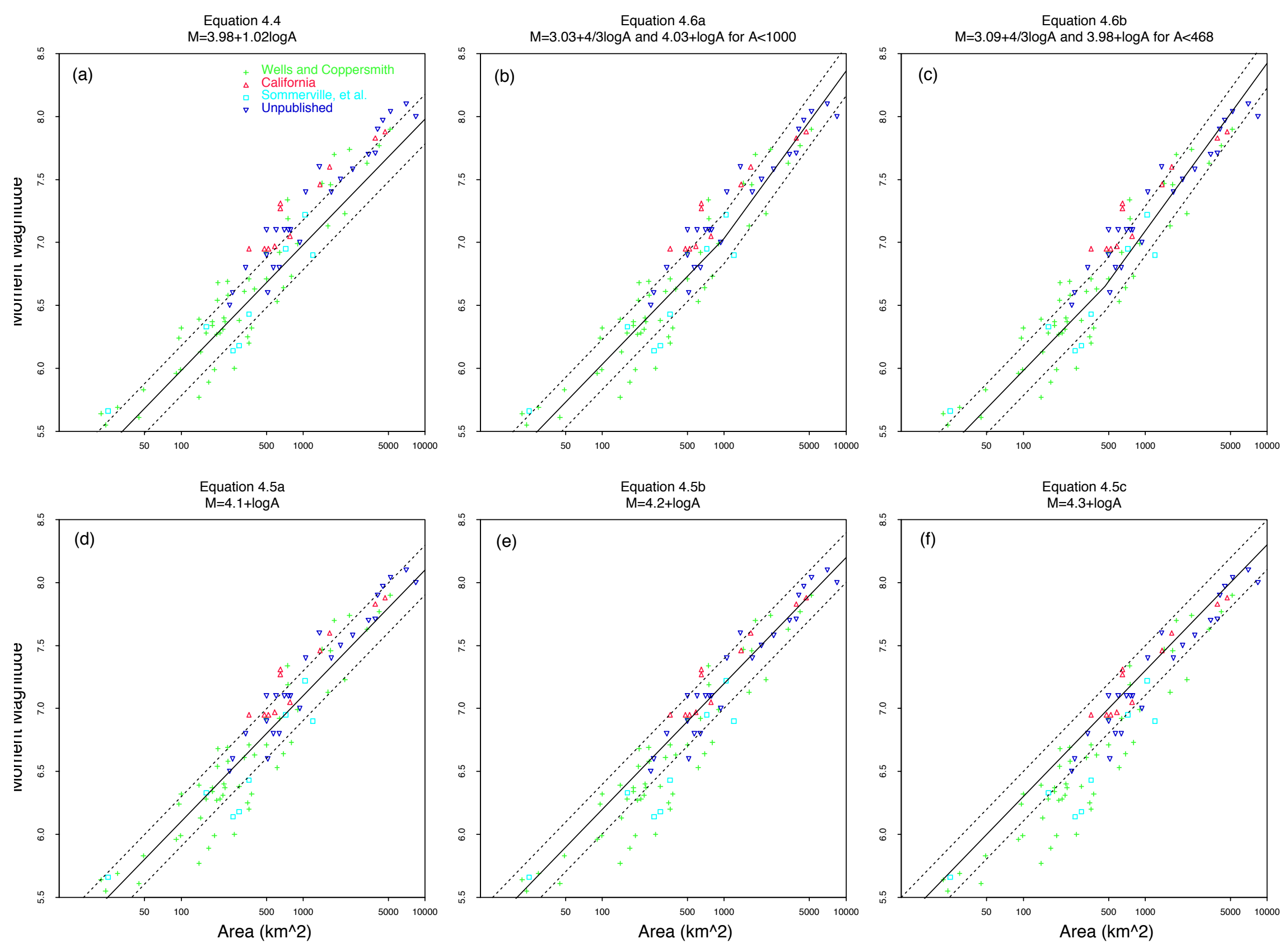


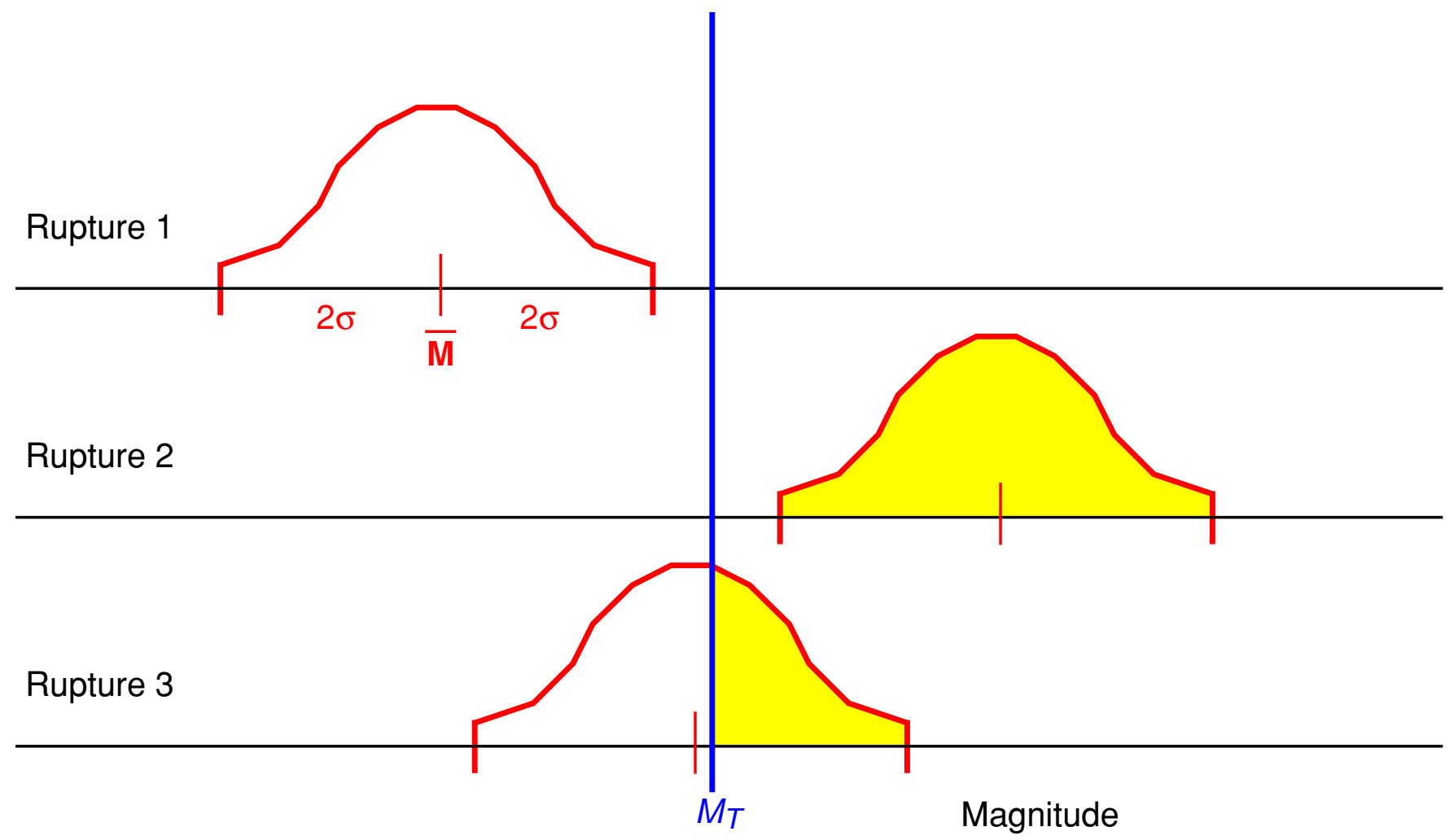

Figure 4.3. An illustrative example of how the WG99 calculation sequence applies a magnitude threshold to three rupture sources with different mean magnitudes. The probability that Rupture 3 will produce an earthquake above magnitude $M_{T}$ is the ratio of area above $M_{T}$ to the entire area under the truncated Gaussian (i.e., 0.0 in the first case, 1.0 in the second case, and 0.4 in the third case). 


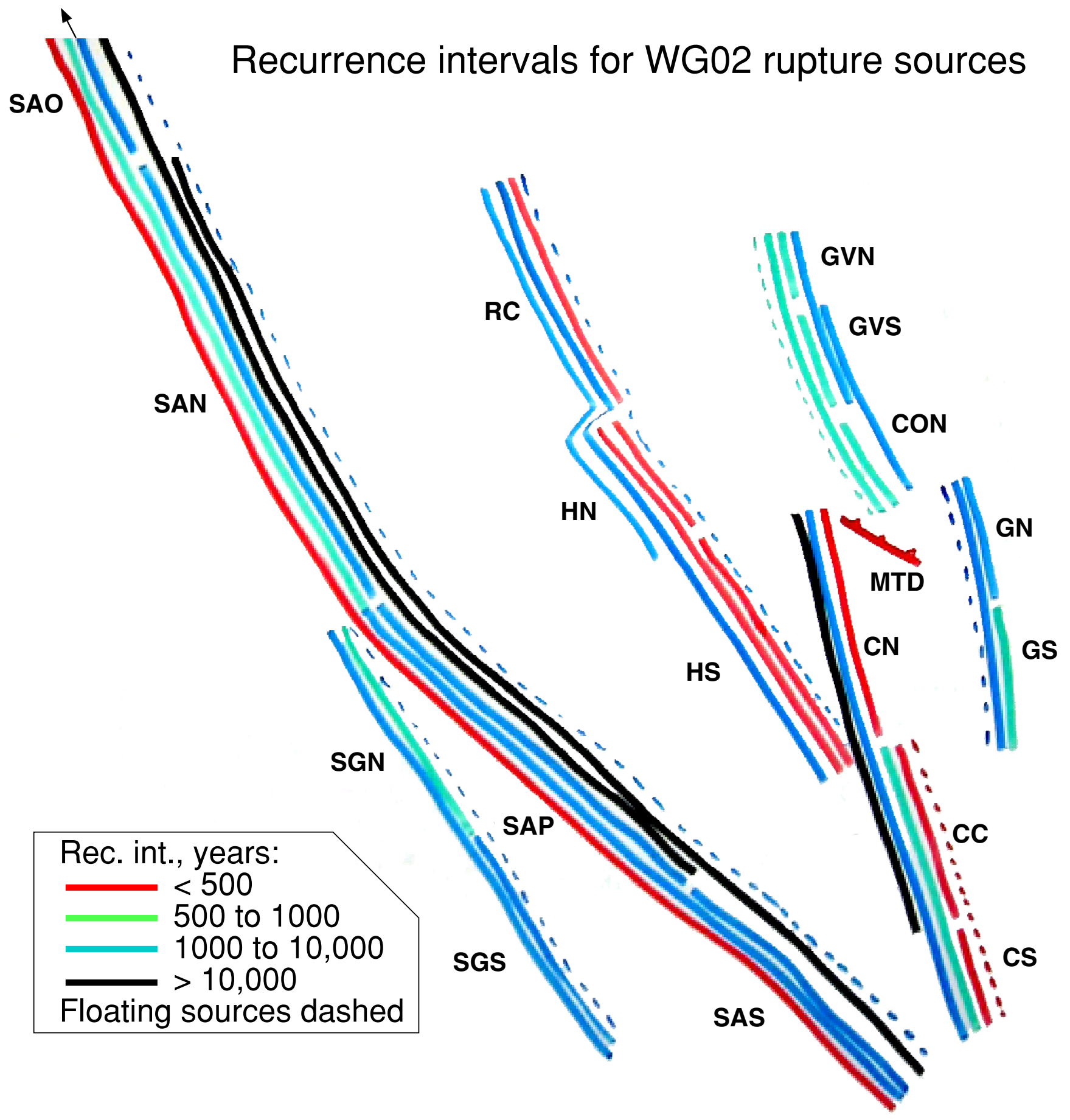

Figure 4.4. Sketch map of SFBR characterized faults, color-coded to indicate long-term recurrence interval of rupture sources. Multiple, parallel curves show the various rupture sources. Floating rupture sources may occur anywhere along the dashed curves. 


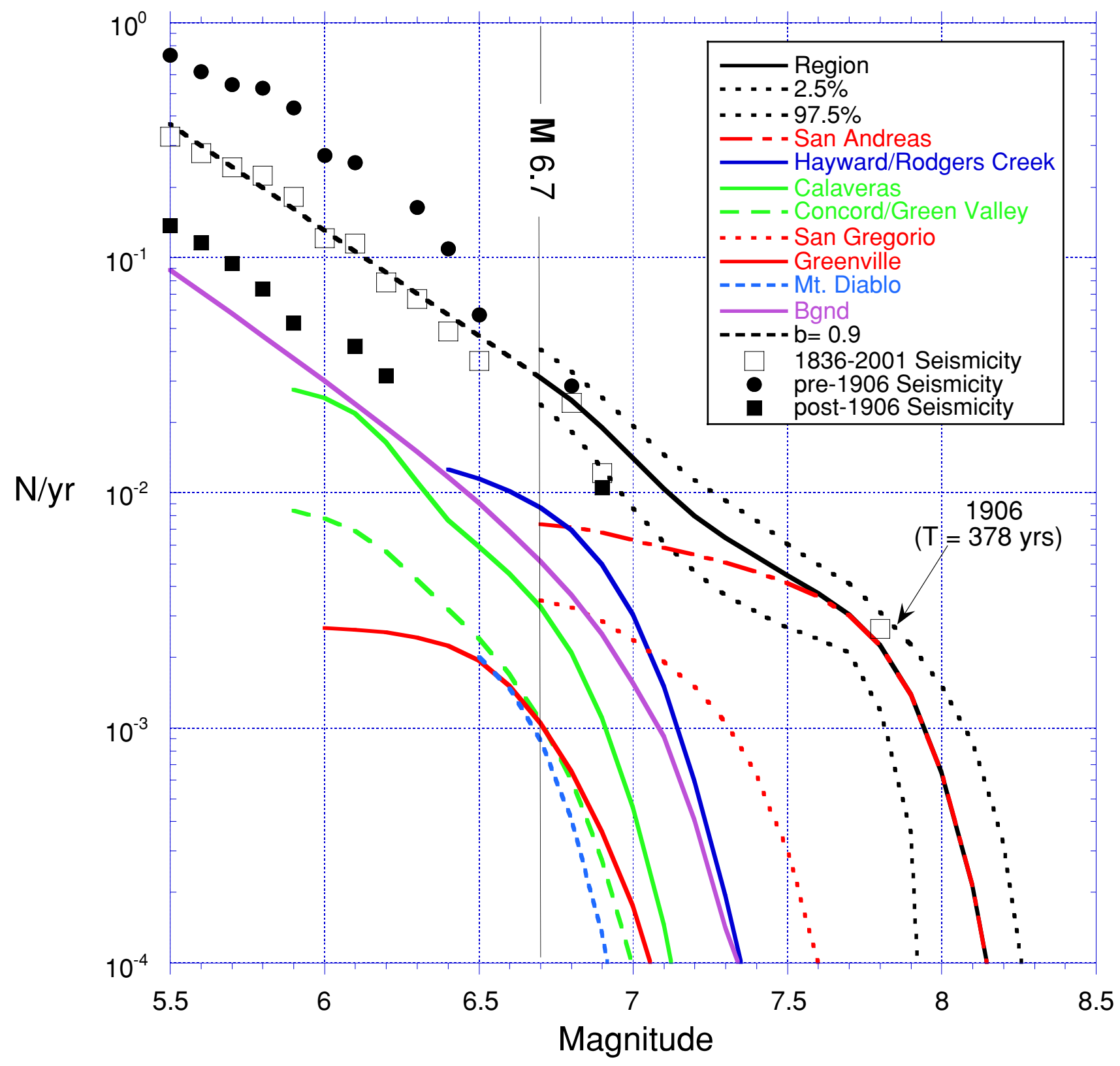

Figure 4.5. Long-term cumulative magnitude-frequency distribution for the SFBR earthquake model. The solid black curve $(\mathbf{M} \geq 6.7)$ represents the mean magnitudes for the defined rupture sources, and the dotted black lines are the 95\% confidence range. The dashed black line (slope $b=0.9$ ) defines the magnitude distribution for $\mathbf{M}<6.7$ for the region (see text). The 1836-2001 M $\geq 5.5$ historical seismicity (Bakun, 1999) is plotted as open black squares. The 1906 event is shown with the SFBR model's mean recurrence interval of 378 years for the 1906 rupture source. The pre-1906 and post-1906 seismicity are shown as solid black dots and squares respectively, illustrating the significant impact of the 1906 earthquake on the rates of historical and instrumental seismicity in the SFBR.

The colored curves represent the mean magnitudes of the rupture sources of the characterized faults and the background. The magnitude-frequency distributions of the characterized faults have been constructed with about $6 \%$ of the available seismic moment to occur as earthquakes in smaller earthquakes (the exponential tail). 


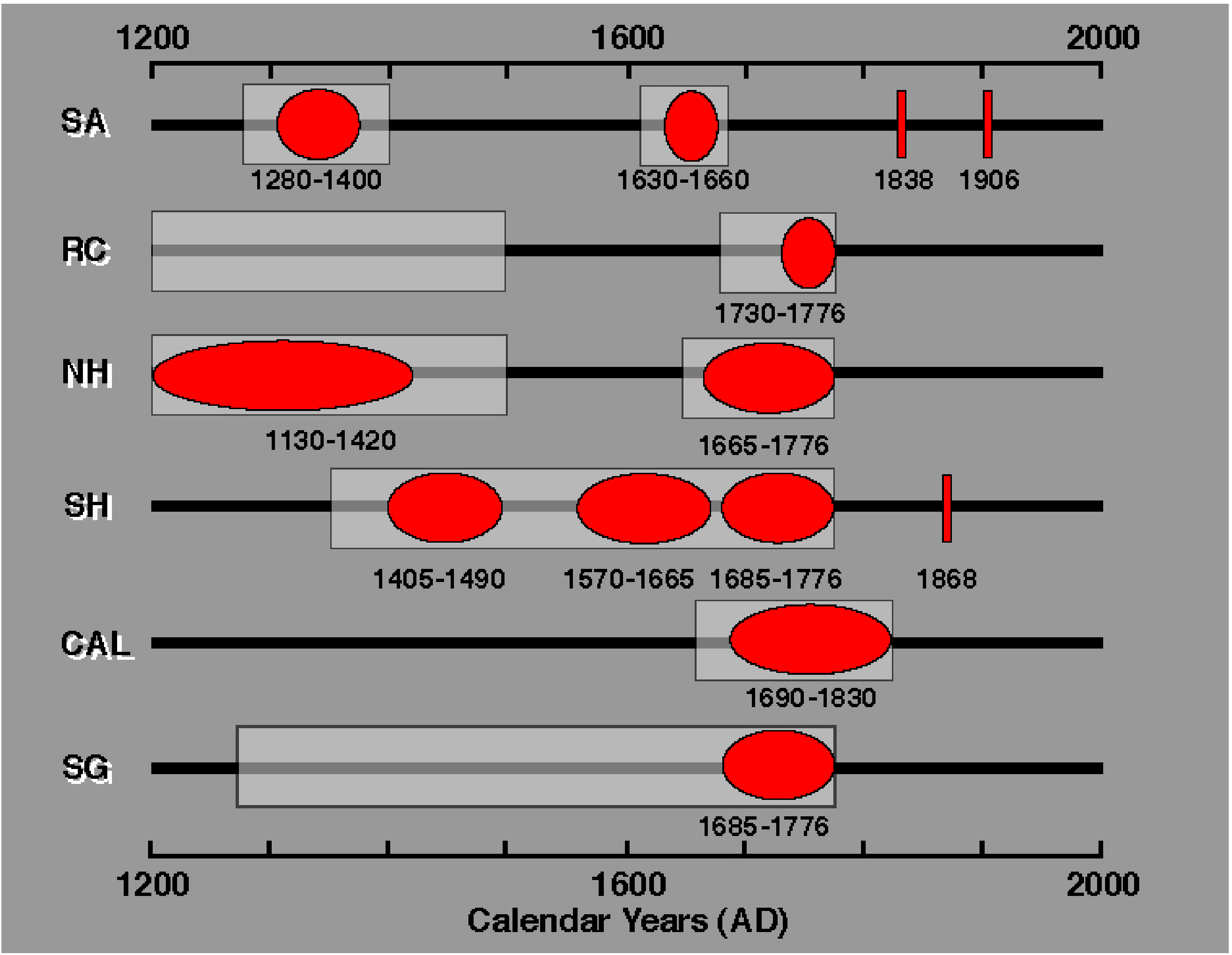

Figure 4.6. Timing of large earthquakes on SFBR faults. Historical events are shown in yellow; timing of prehistoric events as constrained by paleoseismic data and completeness of the historical record are depicted by rectangles and ovals. Rectangles show 2 -sigma (95\%) uncertainties on event age; ellipses are 1-sigma uncertainties. Data are described in Chapter 3. 
a) San Andreas

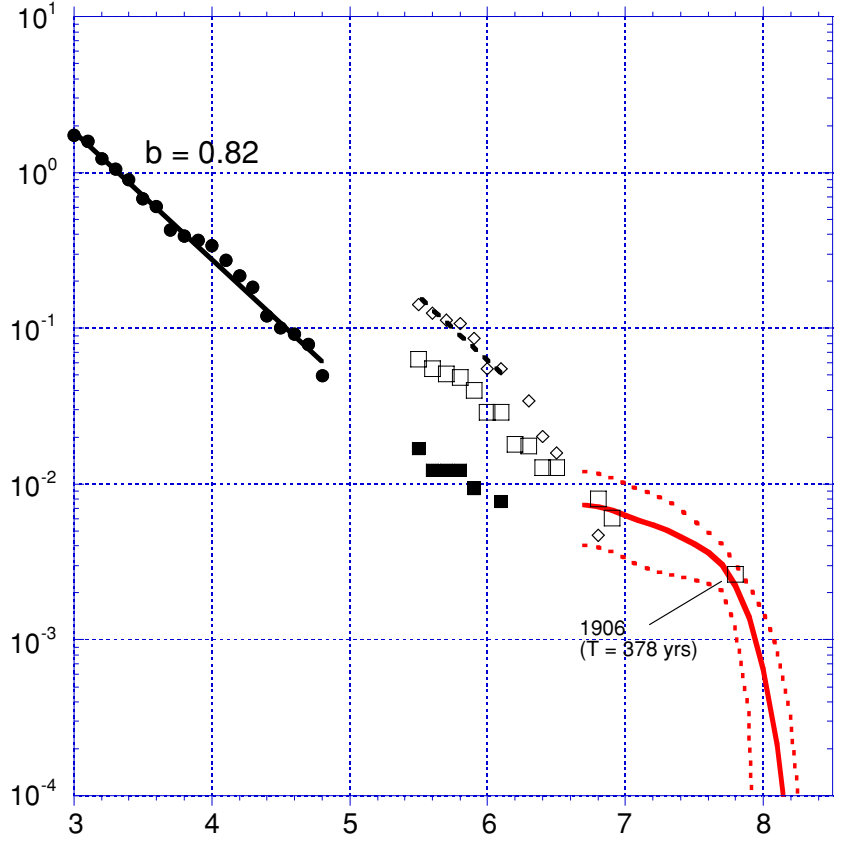

c) Calaveras

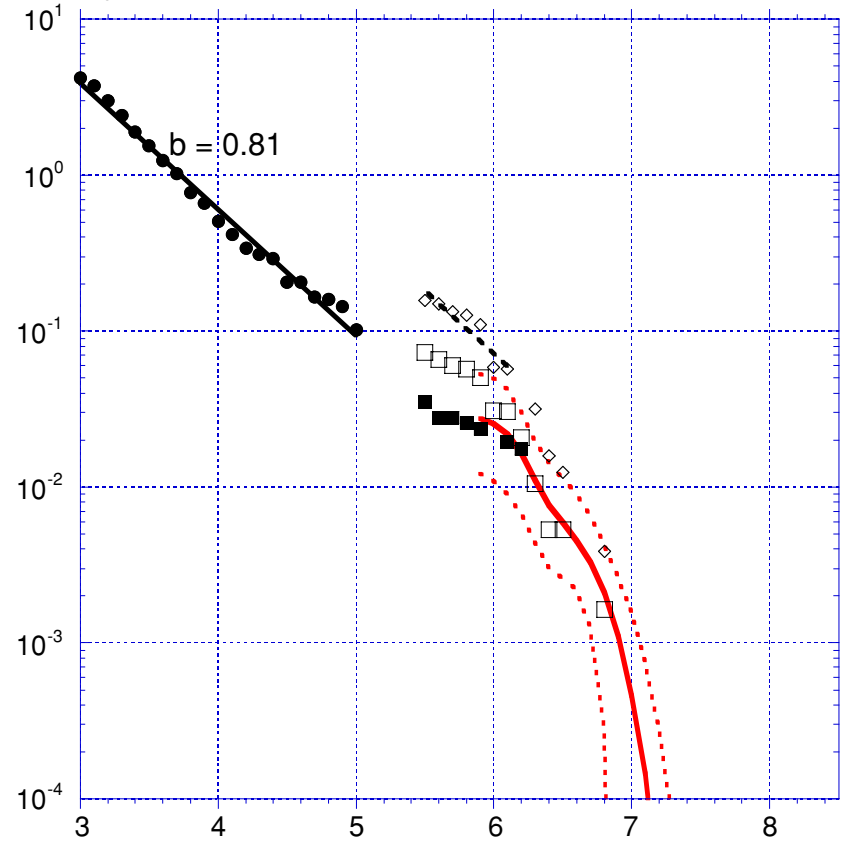

b) Hayward -Rodgers Creek

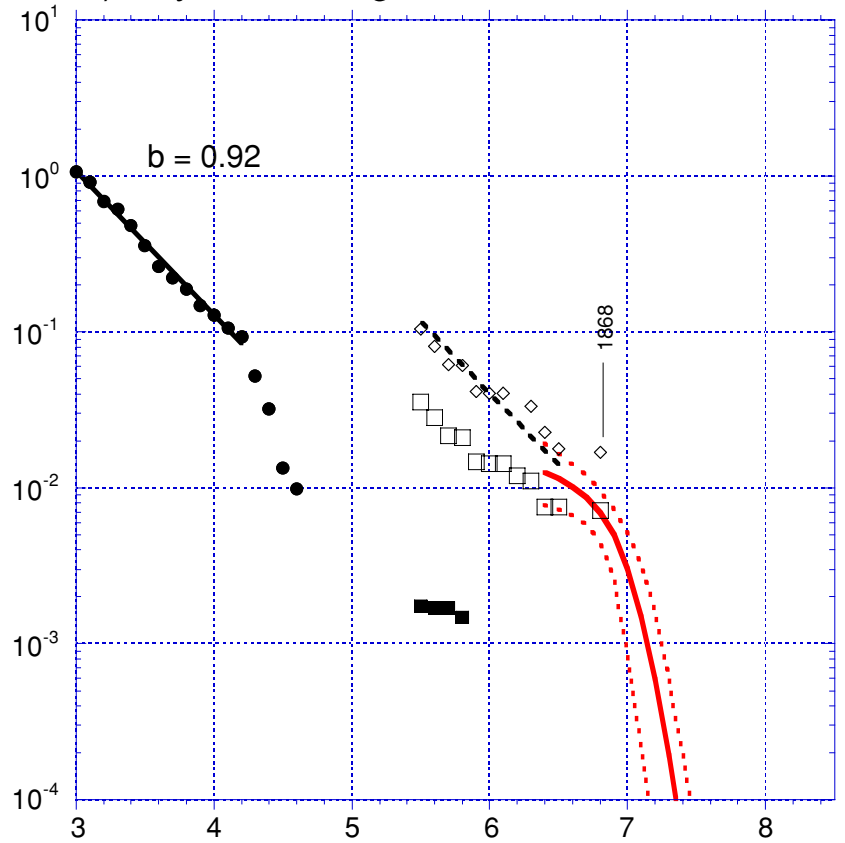

d) Concord - Green Valley

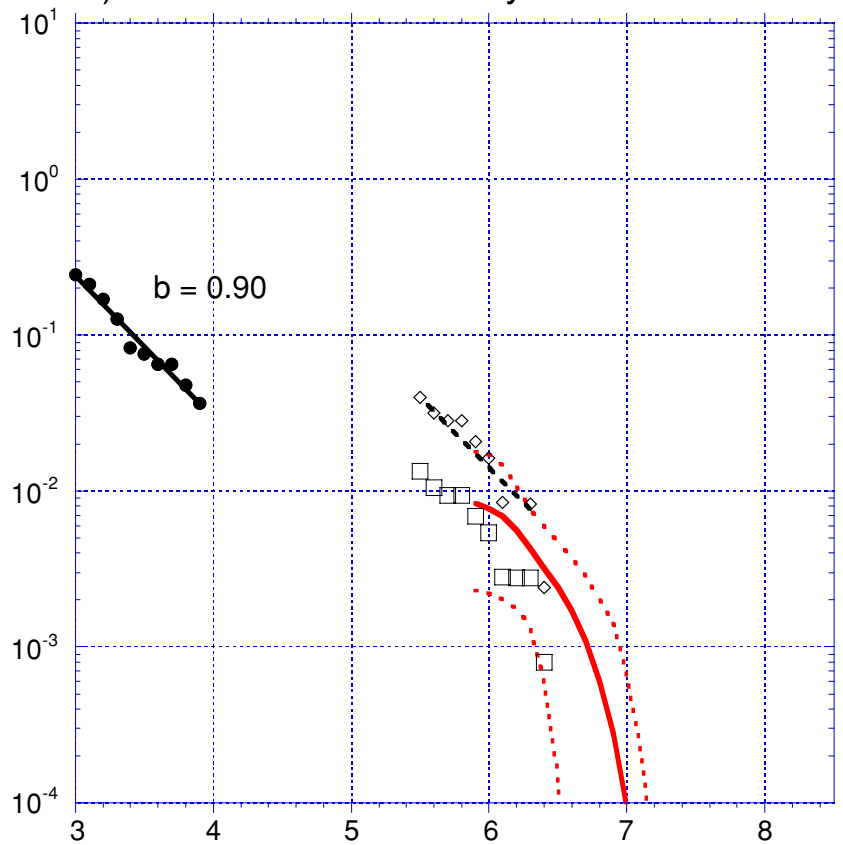

Figure 4.7. Details of the SFBR earthquake model. The solid red curves are the mean magnitudes of the rupture sources for 10,000 model realizations and the dotted red curves represent the $95 \%$ bounds. Black symbols are the historical seismicity, using Wesson et al's (2002) fault associations: $\mathbf{M} \geq 5.5$ for 1836-2001 (open squares); declustered $3 \leq \mathbf{M} \leq 5$ for 1951-1998 (solid circles); post-1906 $\mathbf{M} \geq 5.5$ (solid squares); pre-1906 $\mathbf{M} \geq 5.5$ (open diamonds).

The solid black line is the least-squares fit of selected 1951-1998 rates to log N/yr =a - b*M. For the the most active faults, the line is a reasonable fit to the post-1906 $\mathbf{M} \geq 5.5$ rates as well. The dashed black curve is a least squares fit to selected pre-1906 rates, but with b fixed for that fault. The a values apparent for the pre-1906, the post-1906, or the 1836-2001 rates do not represent the SFBR earthquake model, although the 1836-2001 rates are fortuitously about equal the long-term rate. These data suggest how the $6 \%$ of the seismic moment at smaller $\mathbf{M}$ might be distributed for hazard calculations.

For each source, the solid red curve defines the magnitude distribution for large events, while $6 \%$ of the total moment should be distributed at smaller $\mathbf{M}$ with a value of $b$ appropriate for that fault. 
e) San Gregorio

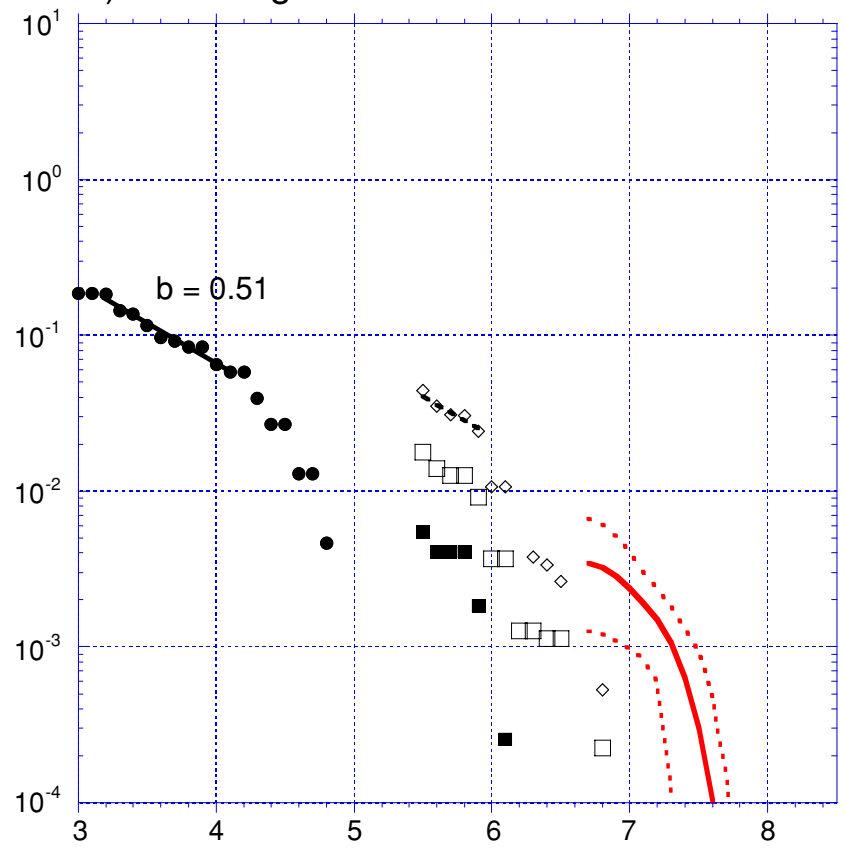

g) Mt. Diablo

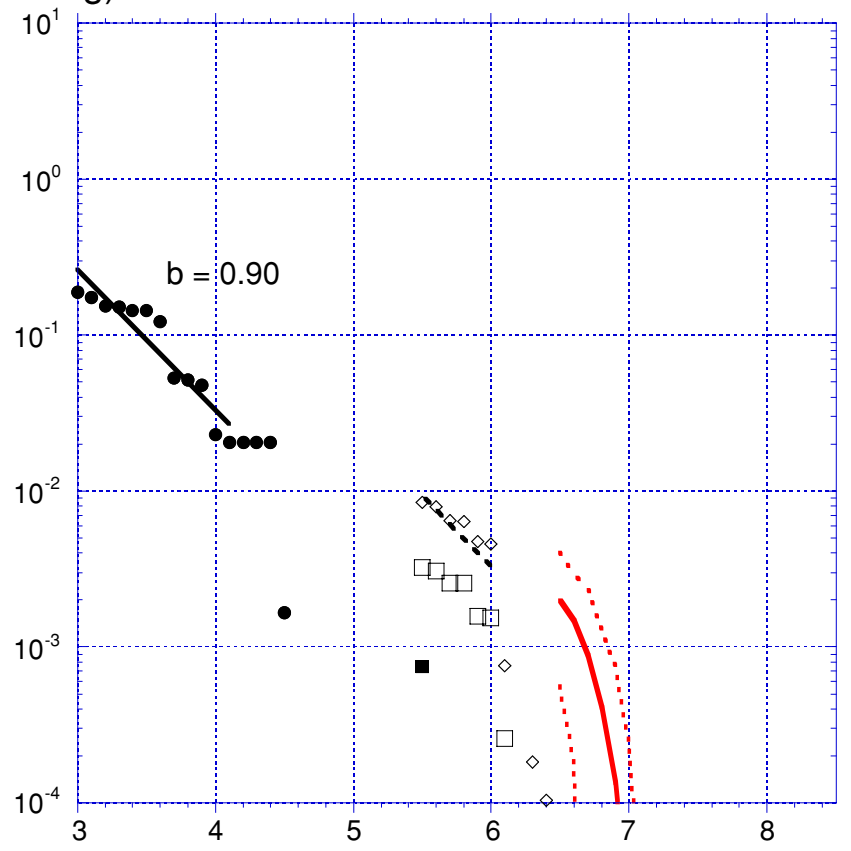

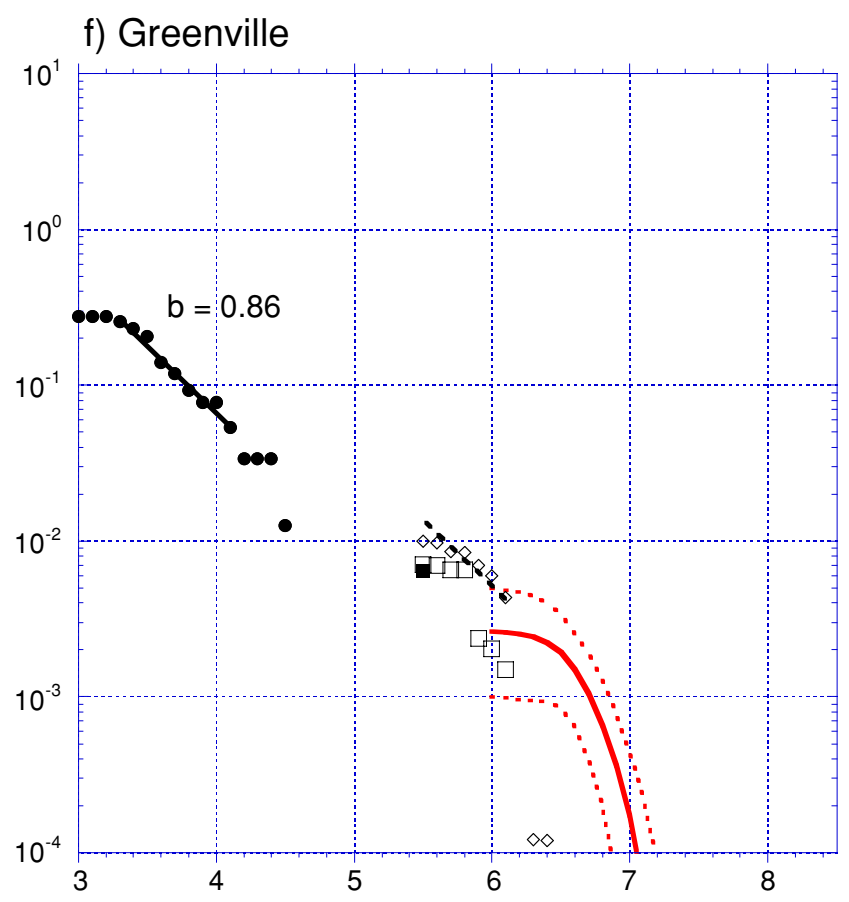

h) Background

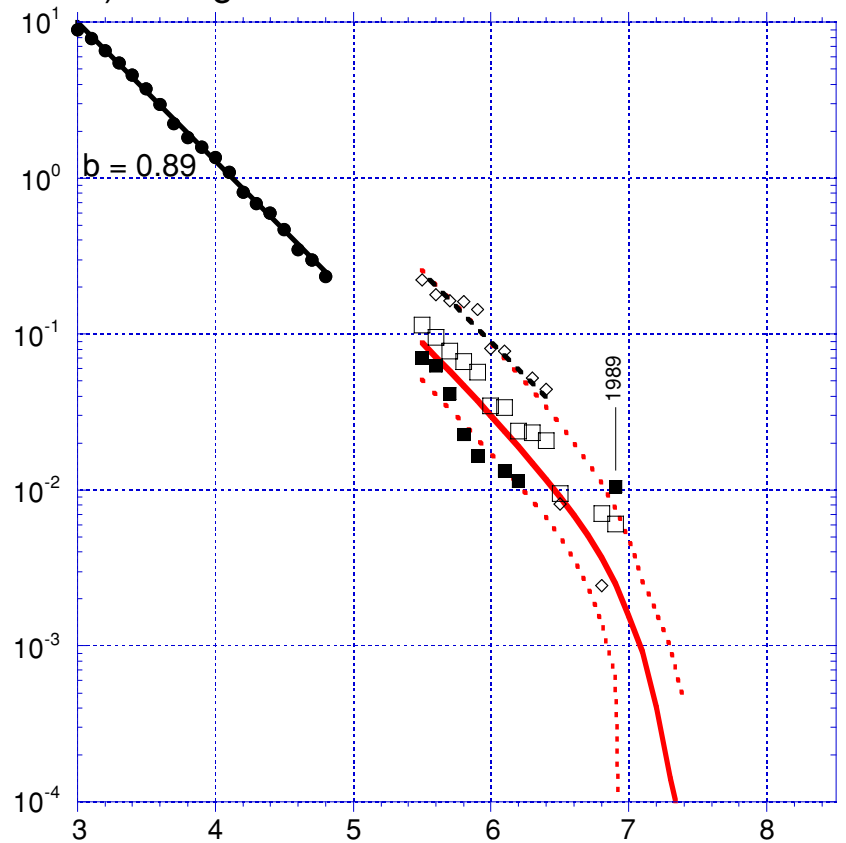

Figure 4.7. continued. 


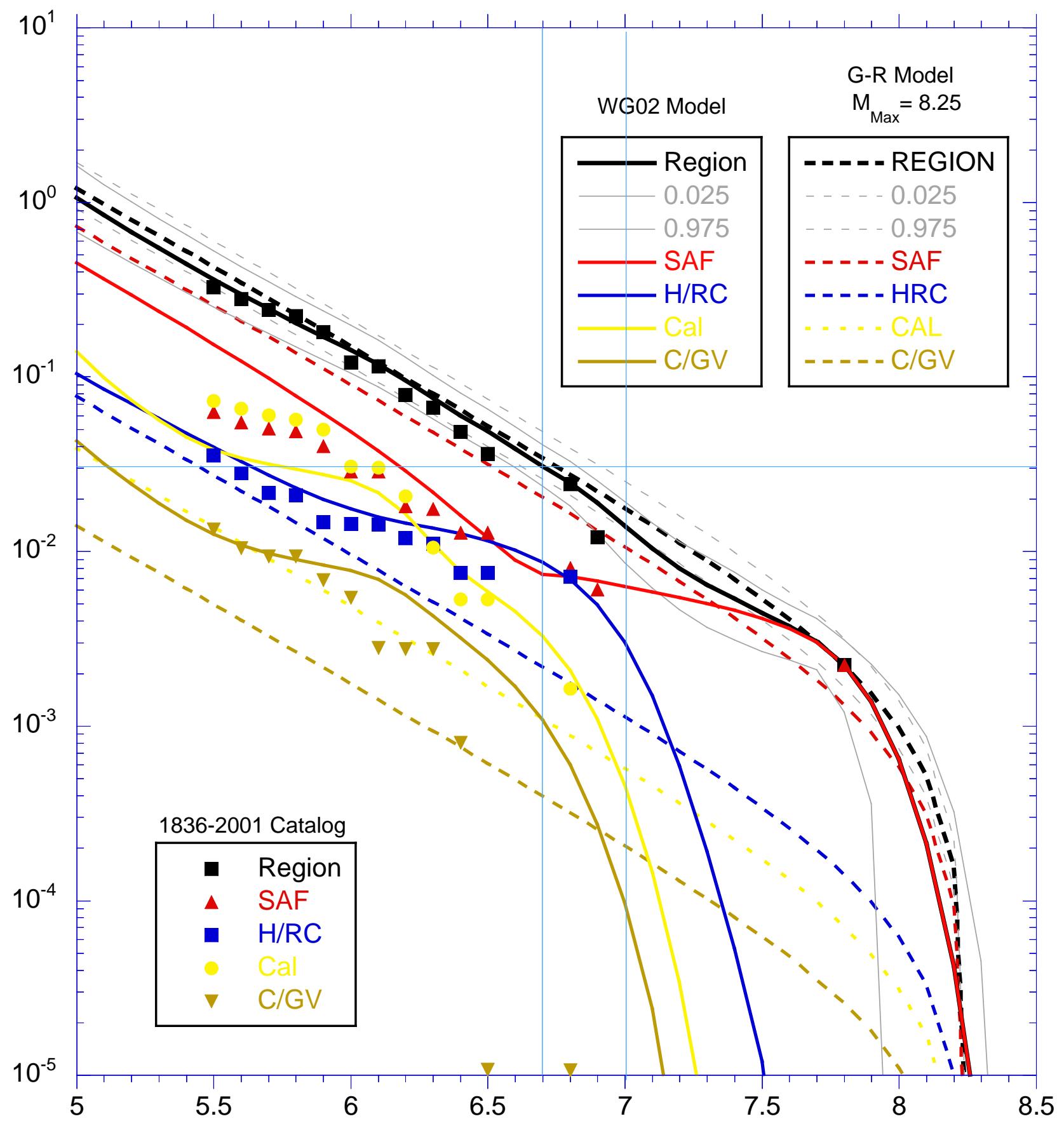

Magnitude

Figure 4.8. Comparison of Gutenberg-Richter and WG02 models to observed rates of earthquakes 1836-2001. Gutenberg-Richter model is the "roll-off" type, truncated at $\mathrm{M}_{\mathrm{Max}}=8.25$. 


\section{Chapter 5: Calculating EarthQuake PROBABILITIES FOR THE SFBR}

\section{Introduction to Probability Calculations}

The first part of the calculation sequence (Figure 2.10) defines a regional model of the long-term production rate of earthquakes in the SFBR. However, our interest here is in earthquake probabilities over time scales shorter than the several-hundred-year mean recurrence intervals of the major faults. The actual time periods over which earthquake probabilities are calculated should correspond to the time scales inherent in the principal uses and decisions to which the probabilities will be applied. Important choices involved in engineering design, retrofitting homes or major structures, and modifying building codes generally have different time-lines. Accordingly, we calculate the probability of large earthquakes for several time periods, as was done in WG88 and WG90, but focus the discussion on the period 2002-2031. The time periods for which we calculate earthquake probability are the 1-, 5-, 10-, 20-, 30- and100-year-long intervals beginning in 2002 .

The second part of the calculation sequence (Figure 5.1) is where the time-dependent effects enter into the WG02 model. In this chapter, we review what time-dependent factors are believed to be important and introduce several models for quantifying their effects. The models involve two inter-related areas: recurrence and interaction. Recurrence is concerned with the long-term rhythm of earthquake production, as controlled by the geology and plate motion. Interaction is the syncopation of this rhythm caused by recent large earthquakes on faults in the SFBR as they affect the neighboring faults.

The SFBR earthquake model allows us to portray the likelihood of occurrence of large earthquakes in several ways. This flexibility allows the various users of the information to select the expression of earthquake likelihood most applicable to their needs. We express the likelihood of occurrence of one or more $\mathbf{M} \geq 6.7$ earthquakes in the SFBR in these time periods in the following five ways.

- The probability for each characterized large earthquake rupture source.

- The probability that a particular fault segment will be ruptured by a large earthquake.

- The probability that a large earthquake will occur on any of the seven characterized fault systems.

- The probability of a background earthquake (i.e., in the SFBR, but not on one of the seven characterized fault systems).

- The probability that a large earthquake will occur somewhere in the region.

We also determine the probability of $6.0 \leq \mathrm{M}<6.7$ earthquakes in the region. 


\section{Calculating Probabilities}

To make these forecasts, a probability model for earthquake occurrence is required. The probability model describes how earthquakes are distributed in time, given a set of assumed conditions. It uses the rupture source mean occurrence rate (Table 4.8) as primary input ${ }^{1}$. We employ a suite of probability models that take into account various amounts of physics (from none to some), various views on the relative importance of certain observables (e.g., date of the last rupture; recent seismicity rates; or slip in the 1906 earthquake), and various degrees of confidence in how well we are able to model the behavior of the region and predict its future. We did not restrict ourselves to methods used by previous Working Groups, nor did we embrace all models that have been proposed. Rather, we selected five models that —in our view-represent a range of valid approaches and give quantitative results that span the range of plausibility. None in the Working Group believes that the regional 30-year probability lies outside the range $\sim 0.4$ to $\sim 0.9$ - the range resulting from the combined set of probability models used - but few in the group would reject the possibility that the answer could lie anywhere within that range. The five models used are shown in Figure $\mathbf{5 . 1}$ and described below.

Each probability model begins with an estimate of the long-term rate of either rupture sources or fault segment ruptures (Figure 5.2). We determine the probability that an earthquake will occur on the rupture source, regardless of where it initiates. The resulting probabilities are aggregated to yield the probabilities that an earthquake will occur on each fault. Finally, these are combined with the probability of background earthquakes to calculate the probability for the region as a whole (Figure 5.1). Also calculated is the probability that each fault segment experiences an earthquake (regardless of the rupture source). Probabilities are calculated relative to a threshold magnitude $M_{T}$.

We model earthquakes that rupture a fault segment as a renewal process (Cornell and Winterstein, 1988). In a renewal process, the times between successive events are considered to be independent and identically distributed random variables. This is to say that the expected time of the next event does not depend on any of the details of the last event (except the time it occurred). When a rupture occurs on the segment, it resets the renewal process to its initial state. The model is further simplified by reducing the complex physical process of the "earthquake machine" to a point process model (Cox and Lewis, 1966). That is, complexities involved in the physics of rupture initiation, propagation and stopping are ignored, and earthquakes are considered to be "events" characterized only by an occurrence time, location, and magnitude.

We employ two point process probability distributions: the Exponential distribution in the Poisson model, which yields time-independent probabilities, and the Brownian Passage Time (BPT) distribution, which is based on a new time-dependent model (Matthews et al., in press). These two probability distributions are combined with other data and assumptions to make five probability models. The simplest probability model we consider is the Poisson, which assumes

\footnotetext{
${ }^{1}$ In the past, a variety of probability distribution functions have been used as probability models, including the Lognormal (Nishenko and Buland, 1987; WGCEP, 1988; WGCEP, 1990); Weibull (Hagiwara, 1974; Sykes and Nishenko, 1984); Gamma (Utsu, 1984); Gaussian (Rikitake, 1974; Lindh, 1983); Exponential; Double Exponential (Utsu, 1972); and Brownian Passiage Time (BPT) (WG99).
} 
that the probability does not vary in time and is thus fully determined by the long-term rate of occurrence of the rupture source. We also consider an Empirical model, a variant of the Poisson, in which the constant long-term mean rate for a rupture source is modulated by an extrapolation of the recent regional rate of earthquakes. The Empirical model uses recent regional earthquake activity as a proxy for physical time-dependent processes.

We also consider time-varying probability models-the BPT, BPT-step, and TimePredictable - that take into account information about the last earthquake. The BPT model shares many features of other probability models used for earthquake forecasting, including the Lognormal model used by WG88, WG90 and WG95. In the BPT model, the failure condition of the fault is described by a state variable that rises from a ground state to the failure state during the earthquake cycle. Evolution of the point process model toward failure is governed by a deterministic parameter that pertains to the reloading rate of a specific segment, and a stochastic parameter. The model provides a statistical/mechanical description of the earthquake cycle. The use of a state variable in the BPT model permits explicit incorporation of the "stress shadow" effects of the 1906 earthquake (Harris and Simpson, 1992) and the 1989 Loma Prieta earthquake into the regional probability estimates, as the BPT-step model.

When both the time and amount of slip in the most recent event are known, we also employ the time-predictable model (Shimazaki and Nakata, 1980). In the time-predictable model, the expected time of the next event is equal to the time required to restore the fault to the same state it was in when the preceding earthquake occurred. Again, a point process model is used to represent the physics of the earthquake and loading cycle. In this report, the time-predictable model is applied only to the segments of the San Andreas Fault that ruptured in the 1906 earthquake because this is the only historical rupture for which there is a detailed model of the slip distribution along the entire fault system. While reliable estimates of slip in the 1868 M6.8 earthquake on the Hayward fault segment HS are available (Yu and Segall, 1996), neither the slip in or times of the last ruptures of the other two segments (HN, RC) of the Hayward-Rodgers Creek fault system are available.

All of the models have the same underlying mathematical model for the calculation of probabilities. The probability of rupture for each fault segment in the SFBR models is specified by a probability density function (pdf), $f(t)$, that defines the chance that failure will occur in the interval from $t$ to $t+\Delta t$, where $t$ is time measured from the date of the most recent earthquake (Figure 5.3). The area under $f(t)$ between $t=0$ and $t=\infty$ is 1 , as it is assumed that there will be a next earthquake. The area under $f(t)$ between $t=T$ and $t=\infty$ or right tail of the distribution defines the survivor function, $F(T)$, which gives the probability that at least time $T$ will elapse between successive events.

$$
F(T)=\int_{T}^{\infty} f(t) d t
$$

For any probability model, $F(0)=1$ and $F(\infty)=0$. A more useful quantity for many purposes is the hazard function, $h(t)$, defined by the ratio $h(t)=f(t) / F(t)$. It gives the instantaneous rate of failure at time $t$ conditional upon no event having occurred up to time $t$, or more plainly, the 
chance that anything surviving to time $t$ will fail immediately. The hazard function provides a convenient way to compare the properties of probability distributions.

The probability values presented in this report are conditional probabilities. These give the probability that one or more earthquakes will occur on a rupture source of interest during an interval of interest (e.g., the 30-year interval from 2002 through 2031), conditional upon it not having occurred by the year 2002. The conditional probability is determined by dividing the area under the density function in the interval of interest by the area of the density function at times equal to or greater than the start of the interval of interest (Figure 5.3). The conditional probability is defined by

$$
P(T \leq t \leq T+\Delta T \mid t>T)=\frac{F(T)-F(T+\Delta T)}{F(T)}
$$

\section{Probability Models Used in the Calculations}

Five probability models are considered, with each forming a branch (with weights assigned based on expert opinion) in the calculation sequence (Figure 5.1). Calculations for each of the five probability models are carried out independently all the way to the computation of the combined earthquake probabilities for the San Francisco Bay region. Each model and its application to calculating probabilities are described below. The assignments of weight to the probability models (and why some WG02 members chose to put weight on a given model) are described toward the end of this chapter.

\section{Poisson Model}

The Poisson model describes the distribution of times between successive events for a homogeneous Poisson process (random occurrence) and is specified by the pdf

$$
f_{\text {Exp }}(t)=\lambda e^{-\lambda t}
$$

where $\lambda$ is the mean rate of events per unit time (reciprocal to the mean interval between events). In our calculations, $\lambda$ is the mean rupture rate of each rupture source, as determined by the longterm model. The Poisson distribution has the important property that the hazard function is constant, $h_{\text {Exp }}(\mathrm{t})=\lambda$ (Figure 5.4). Thus, it has no "memory" of the time of the most recent event. An earthquake is just as likely to occur on a fault segment one day after the most recent event as it is to occur on a day two hundred years later. The conditional probability is also independent of the time of the most recent event.

The Poisson model is the standard model for probabilistic seismic hazard analyses, having been used most recently in the National Earthquake Hazard maps (for example, Frankel et al., 1997) and in the Seismic Hazard Maps of California (Petersen and others, 1996). This model is appropriate when no information other than the mean rate of earthquake production is known; it 
can be viewed as the "least-informative" or "most-conservative" model, depending on one's perspective. However, it fails to incorporate the most basic physics of the earthquake process, whereby the tectonic stress released when a fault fails must rebuild before the next earthquake can occur at that location. Evidence for this deficiency is seen in the timing of three series of paleoseismic occurrence times in central Japan, including some 29 earthquakes in all, where the Poisson model provides a significantly poorer fit to the data than do any of the Lognormal, Gamma, Weibull and Double Exponential distributions (Ogata, 1999). The Poisson model also fails to account for the observation that the level of earthquake activity in the SFBR dropped sharply after 1906 and has remained low most of the $20^{\text {th }}$ century, presumably as a result of a regional stress relaxation caused by the 1906 earthquake. Nevertheless, we include the Poisson model to provide a conservative estimate of the probability on faults for which one suspects that the time-dependent models are either too poorly constrained or missing some critical physics of the system (e.g., interactions). The model provides a "baseline" probability calculation that reflects only the long-term rates of earthquakes in the SFBR earthquake model.

\section{Application of the Poisson Model}

In the Poisson model, conditional probabilities for a specified time interval depend only on the length of the interval, $\Delta t$, and the long-term rate of rupture for each source. The conditional probability for each source is given by

$$
1-\mathrm{e}^{-\lambda \Delta \mathrm{t}}
$$

where $\Delta t$ (in this study) is $5,10,20,30$, or 100 years.

Because the expected magnitudes of earthquakes are themselves probabilistic, an additional step is needed to compute probabilities for earthquakes above a given magnitude threshold $M_{T}$ (e.g., $\mathbf{M} \geq 6.7$ events). For each source, the rate of $\mathbf{M} \geq M_{T}$ events is determined from the magnitude probability density function, as described in Chapter 4 (Figure 4.3). The rate at which the rupture source produces earthquakes exceeding $M_{T}$ is computed from equation (4.10), and assigned to $\lambda$ in the exponent of (5.4).

\section{Empirical Model}

The empirical model (Reasenberg et al., 2002) modifies the Poisson model earthquake probability (Figure 5.5) based on the rate of occurrence of moderate size earthquakes $(\mathbf{M} \geq 5.5)$ in the SFBR since 1906. It complements the other models because the record of historical $(\mathbf{M} \geq 5.5)$ earthquakes (Figure 5.6) is not used in the BPT, Poisson or time-predictable probability models. Complementing a theoretical model with an extrapolation of empirical observation is a common forecasting technique, often employed in a method of Bayesian inference. For example, a complex atmospheric model for weather prediction might be combined with regional observations of recent weather activity (e.g., looking out the window or viewing satellite imagery). Our use of an empirical model is motivated by concern (discussed below) that the effect of the regional stress change produced by the 1906 earthquake may not be adequately represented by the elastic dislocation calculations and their application in the BPT model. 
We are aware that other methods (post-seismic viscoelastic stressing and rate-and-state friction models) for calculating stress changes (and their effects) produced by the 1906 and 1989 earthquakes based on more complex physical processes are available (e.g., Kenner and Segall, 1999; Parsons, 2002a; Pollitz et al., 1998). However, these models were considered by their authors and by the WG02 Oversight Committee to be insufficiently vetted for incorporation into the current SFBR probability calculations.

Based on observations and theoretical considerations, Tocher (1959), Ellsworth and others (1981), Jaumé and Sykes (1996), and Bakun (1999), concluded that the seismicity rate in the SFBR varies throughout a regional earthquake cycle that is defined by recurrences of the largest earthquake in the region, perhaps spending little if any time near its long-term average rate (Ellsworth and others, 1981; Mogi,1982). The empirical model embodies this conception of a regional earthquake cycle.

In the empirical model, the time-dependence of earthquake activity is not described by a pdf, as it is for the fault segment-based probability models. Rather, earthquake activity is represented by a non-stationary Poisson process with varying rate $\lambda(t)$, which is estimated for the region from the historical earthquake record ( $M \geq 3.0$ since 1942 and $\mathbf{M} \geq 5.5$ since 1906) and normalized by the long-term mean rate $\lambda$ (Figure 5.6).

$$
\gamma(t)=\lambda(t) / \lambda
$$

To estimate the probability for a future period $(t, t+\Delta t), \gamma(t)$ is extrapolated forward in time using a variety of methods and the extrapolated rates are averaged. The probability $P_{i}^{E m p}$ for fault $i$ with mean rate $\lambda_{i}$ is given by

$$
P_{i}^{E m p}=1-e^{-\bar{\gamma} \lambda_{i} \Delta t}
$$

where $\bar{\gamma}$ is the average of $\gamma(t)$ over $(t, t+\Delta t)$.

In the empirical model, as in the Poisson model, the timing of individual segment ruptures is not specified. Instead, the empirical model assumes that the rates of all ruptures in the regional fault model vary in time (and in unison) about their respective long-term means (Figure 5.7). The empirical model specifies only time-dependence, preserving the magnitude distribution of the rupture sources in the fault characterization. Hence, the geological framework, paleoseismic history, fault segmentation, slip rates, aseismic slip factors and magnitude-area relations are preserved.

This model property says that there is at least some spatial coherence in the earthquake activity, but says nothing about whether this coherence is due to stress interactions, time-varying driving forces, or anything else. This is to say that $\chi(t)$, which is estimated for the region, is assumed to represent the time dependence of activity on each fault.

\footnotetext{
${ }^{2}$ There is no equation (5.5).
} 
The Empirical model is a proxy for realistic physical models of earthquake occurrence and interaction not fully represented in the analytical time-dependent models (BPT and TimePredictable) described below. The underlying, time-dependent processes controlling earthquake activity on the faults and in the region are built in to the empirical model in the sense that their effects are assumed to be reflected in the historical rate of seismicity. The empirical model is expected to provide an accurate forecast to the extent that (1) fluctuations in the rate of $\mathbf{M} \geq 3.0$ and $\mathbf{M} \geq 5.5$ earthquakes reflect fluctuations in the probability of larger events; (2) fluctuations in rate on individual faults are correlated; and (3) the rate function $\gamma(t)$ can be sensibly extrapolated forward in time $(5,10,20$, or 30 years). Assumption (2) is uncertain because the calculated effect of the 1906 earthquake stress shadow is not homogeneous in space (Harris and Simpson, 1992; Kenner and Segall, 1999). However, observations suggest that the stress shadow has affected seismicity on all major faults in the region (see Figure 8 in Reasenberg et al., 2002).

\section{Application of the Empirical model.}

Reasenberg et al. (2002) estimated $\lambda(t)$ for the SFBR from $\mathbf{M} \geq 5.5$ earthquakes since 1850 (Bakun, 1999) and from M $\geq 3.0$ earthquakes since 1942 in the CNSS catalog (Figure 5.6). They proposed a variety of methods for extrapolating $\gamma(t)$ forward in time, from which we selected six for the period 1906-2000 (Table 5.1). The mean regional annual rate (M $\geq 6.7)$ for the six branches is $0.016 \pm 0.004$, where the uncertainty corresponds to the range of extrapolated rates among the six branches. Weights of $0.1,0.5,0.4$ are assigned to these values to reflect our view that the up-trending extrapolations are more likely correct (i.e., that the region is coming out of the stress shadow). The weighted mean rate is $\bar{\gamma}=0.018$, with corresponding 30-year probability 0.42 .

Table 5.1. Empirical model extrapolated regional rate estimates.

\begin{tabular}{|c|c|c|c|c|c|}
\hline Branch & Data & Time Period & Method & $\begin{array}{c}\text { Mean rate } \\
\text { in 2002-2031 }\end{array}$ & $\begin{array}{c}\text { Mean }^{2} \text { of } \gamma(t) \\
\text { in 2002-2031 }\end{array}$ \\
\hline A & $\mathbf{M} \geq 3.0$ & $1942-1998$ & mean & 0.014 & 0.45 \\
\hline B & $\mathbf{M} \geq 3.0$ & $1984-1998$ & mean & 0.016 & 0.52 \\
\hline C & $\mathbf{M} \geq 5.5$ & $1906-2000$ & mean & 0.011 & 0.35 \\
\hline D & $\mathbf{M} \geq 5.5$ & $1979-2000$ & mean & 0.020 & 0.65 \\
\hline E & $\mathbf{M} \geq 3.0$ & $1942-1998$ & trend & 0.016 & 0.52 \\
\hline F & $\mathbf{M} \geq 3.0$ & $1970-1998$ & trend & 0.020 & 0.65 \\
\hline
\end{tabular}

${ }^{1}$ Rates are extrapolated to $\mathbf{M} \geq 6.7$ by assuming a Gutenberg-Richter relation with $b=0.9$.

${ }^{2}$ Based on a long-term regional rate $(\mathrm{M} \geq 6.7)$ of 0.031 .

To de-aggregate the empirically estimated regional probability onto the faults, we assume that the rates of all earthquake sources vary in time with $\gamma(t)$ about their respective long-term means, with each source contributing a constant proportion of the regional rate (Figure 5.7). Support for this assumption is found in Reasenberg et al. (2002), who modeled $\gamma(t)$ for each fault using the Wesson et al. (in prep.) fault associations. They found a common decrease in rate on nearly every fault in the SFBR in the $20^{\text {th }}$ century, and a common increase during the second half of the $19^{\text {th }}$ century, both relative to the respective estimated long-term mean rates. We are more confident of the empirical regional probability model than the de-aggregated probabilities for the individual faults. This situation appears to be an intrinsic aspect of regional and fault-specific earthquake probability estimates, reflecting nothing more than the relative amounts of 
information available.

\section{Brownian Passage Time Models: BPT and BPT-step}

In contrast to the Poisson model, a time-dependent renewal process model embodies the expectation that after one earthquake on a fault segment, another earthquake on that segment is unlikely until sufficient time has elapsed for stress to gradually re-accumulate (Lindh, 1983, Sykes and Nishenko, 1984, Buland and Nishenko, 1988, Ellsworth, 1995; Ogata, 1999). Such models require a minimum of two parameters, and typically include knowledge of the time of the most recent rupture. One is the mean recurrence interval, $\mu=1 / \lambda$, and the other describes the variability of recurrence intervals and can be related to the variance, $\sigma^{2}$ of the distribution. (For the Poisson distribution, $\sigma=\mu$.) We define this variability of recurrence times as the aperiodicity, $\alpha=\sigma / \mu$.

The Brownian Passage Time (BPT) model (Matthews et al., in press; Ellsworth et al., 1999; Kagan and Knopoff, 1987) is a renewal model that describes the statistical distribution of rupture times. The BPT distribution is also known as the inverse Gaussian distribution (Seshadri, 1993). The probability density is defined by

$$
f_{B P T}(t)=\sqrt{\frac{\mu}{2 \pi \alpha^{2} t^{3}}} e^{-\frac{(t-\mu)^{2}}{2 \mu t \alpha^{2}}}
$$

The hazard function (instantaneous failure rate), $h_{B P T}(t)$, is always zero at $\mathrm{t}=0$ (Figures 5.4 and 5.9). It increases to achieve a maximum value at a time greater than the mode of $f_{B P T}(t)$, and from there decreases toward an asymptotic value of $h_{B P T}(t)=1 /\left(2 \mu \alpha^{2}\right)$. Thus, a BPT process always attains a finite quasi-stationary state in which the failure rate is independent of elapsed time. When the aperiodicity $\alpha=1 / \sqrt{2}$, the asymptotic failure rate is $1 / \mu$, which equals the asymptotic failure rate for a Poisson process with the same $\mu$. In practice, the behavior of a BPT model is similar to that of a delayed Poisson process, for which the failure rate is zero up to a finite time following an event and then steps up to an approximately constant failure rate at all succeeding times.

The behavior of a BPT model depends strongly on the value of $\alpha$. For smaller values of $\alpha$, $f_{B P T}(t)$ is more strongly peaked and remains close to zero longer (Figure 5.9a). For larger values, the "delay" or "dead time" becomes shorter, $f_{B P T}(t)$ becomes increasingly Poisson-like, and its mode decreases. The hazard function in the quasi-stationary state (Figure 5.9b) increases with decreasing values of $\alpha$ and becomes Poisson-like with increasing values.

Matthews et al. (in press) derived the BPT distribution by adding Brownian perturbations to a steady tectonic loading process in which rupture occurs when a critical failure threshold is reached. The earthquake relaxes the stress to a characteristic ground level, beginning a new failure cycle. This model of a Brownian relaxation oscillator provides a connection between the time intervals separating events and a formal state variable that reflects the macroscopic mechanics of stress accumulation and release. It enables the calculation of the probabilities following the perturbation of the stress state by an external event, such as the regional effects of 
the stress release in the great 1906 earthquake. The influence of such interactions on recurrence times is transient and strongly depends on when in the loading cycle the perturbation occurs.

Earlier Working Groups used the Lognormal model (Nishenko and Buland, 1987) as a generic recurrence model for earthquake forecasting. The shape of the pdf of the Lognormal model is very close that of the BPT model. However, there are some important differences between the behaviors of the models. The hazard function of the Lognormal distribution, $h_{\mathrm{L}}(\mathrm{t})$ initially increases with $t$, beginning from $h_{\mathrm{L}}(0)=0$, but always goes to zero as $t \rightarrow \infty$ (Figure 5.4). Although the properties of $h_{\mathrm{L}}$ for $0 \leq t \leq \mu$ match our geological intuition, the long time behavior does not, and thus does not constitute a fully satisfactory model of the earthquake renewal cycle (Matthews et al., in press).

\section{BPT-step model}

The BPT model allows us to explicitly account for the effects of stress changes caused by other earthquakes on the segment under consideration, such as the effect of the 1906 "stress shadow" on the regional fault model, or the effect of the 1989 Loma Prieta earthquake on the nearby segments of the San Andreas Fault. This variation of the BPT model is referred to as the BPTstep model. Interaction in the BPT-step model occurs through the state variable. A decrease in the average stress on a segment lowers the probability of failure, while an increase in average stress causes an increase in probability or triggers a rupture. The effects on probability strongly depend on when in the loading cycle the step is applied. The effects are strongest when the segment is near failure (Figure 5.11). The probabilities evolve over time following the application of the step, and decay to the probabilities given by the simple "clock change" method of adjusting the reset time used by WG90 and WG99. The rate at which probability evolves is inversely proportional to the time elapsed since the step, or in other words, in accord with Omori's law (Matthews et al., in press).

\section{Application of the BPT model}

The BPT and BPT-step models are applied to each of the 18 segments using the mean rates of segment rupture in Table 4.6 (see Figure 5.8). Separate branches of the calculation sequence either ignore or apply stress changes from the 1906 and 1989 earthquakes when calculating the probability of an earthquake involving the segment. Segment rupture probabilities are then partitioned onto the rupture sources according to the relative rates of their occurrence in the longterm model. (An exception is made for the "floating" rupture sources. Because these rupture sources do not have reset times associated with them, the Poisson model is used to calculate probabilities for these ruptures when the BPT or BPT-step model is specified.) The additional assumption is made that the likelihood of a rupture starting on a segment (in the case of a multisegment rupture source) is proportional to the fractional length of the segment. With this assumption it is straightforward to map the segment rupture probabilities into the sources that produce them. This construction of source probabilities is needed in order to aggregate probabilities for faults and the region as a whole. The BPT model is expected to provide accurate estimates of earthquake probability to the extent that (1) the model represents the statistics of recurrence intervals for segment rupture, and (2) the time of the most recent event is known or 
constrained. The BPT-step model depends on (1) and (2), and on the assumption that (3) the effects of interactions, especially those of the 1906 earthquake, are properly characterized.

\section{Time of most recent rupture.}

A key input to the BPT and BPT-step models is the time of the most recent rupture-the time at which the renewal model is "reset". Estimates of these times come from several lines of evidence, including paleoseismic observations, dates of historical ruptures, and historical seismicity, as described in Chapter 3. On the San Andreas fault segments and on the southern Hayward fault segment (HS), these dates are known (1906 and 1868, respectively). For all other fault segments, however, these observations can only constrain the date of the last rupture to be within an interval that may range in length from 63 years (segment CS) to 666 years (segment GS) (Table 3.9 - need to add geologically-constrained ranges of dates of last ruptures to table). The calculation sequence deals with these cases by sampling the range of possible dates (Figure 5.8).

\section{Aperiodicity parameter $(\alpha)$}

The BPT distribution (5.8) is fully described by two parameters. One is the mean rate of events, $\mu$. The other, aperiodicity $(\alpha)$, is a measure of the irregularity of the length of the intervals between successive events. A perfectly regular sequence has $\alpha=0$. The aperiodicity is equal to the coefficient of variation (cov) of the distribution, defined as the standard deviation of the intervals divided by the mean rate. Because common practice has been to use cov to refer to a value of the coefficient of variation estimated from data, we use aperiodicity to refer to the BPT model parameter.

Aperiodicity was estimated by Ellsworth et al. (1999) from 37 sequences of repeating earthquakes. These sequences range in magnitude from $\mathbf{M}-0.7$ to $\mathbf{M} 9.2$, range in length from 3 to 13 events (median=6 events), include (in some cases) open intervals, and occurred in a wide variety of tectonic settings (Table 5.2). The values of $\alpha$ estimated for these sequences do not depend in any obvious way on their magnitude, length or tectonic setting (Ellsworth et al., 1999). We consider this data set sufficiently robust for inferring a representative distribution of values for $\alpha$ to use in our models.

Ellsworth et al. (1999) noted that the estimated values of $\alpha$ are biased to the low side because of the finite length of the sequences. To get around this problem, they used the actual number of intervals in each sequence to generate sets of synthetic earthquake sequences for various $\alpha$ values, and then used the same computational procedure to estimate $\alpha$ in the synthetic sequences that was used for the observed sequences. Their results show that sets of synthetic sequences generated with a fixed value of $\alpha$ produce a distribution of estimates of $\alpha$ whose shape is similar to that obtained for the observed data. Further, they showed that a "generic" aperiodicity of 0.5 was consistent with the 37 sequences.

WG02 chose sampling points for $\alpha$ (with relative weights) of $0.3(0.2), 0.5(0.5), 0.7(0.3)$. These values and weights were also used in WG99, and are similar to the cov of $0.5 \pm 0.2$ used by 
WG95. These sample points and weights define a pdf for $\alpha$ similar to the distribution observed by Ellsworth et al. (1999) for the 37 observed sequences (Figure 5.10).

\section{Earthquake Interactions}

The occurrence of an earthquake redistributes stress throughout the region. Depending on fault geometry, one earthquake may move a nearby fault segment closer to failure if the stress increases, or further from failure if the stress decreases. We consider the effect of the 1906 San Francisco earthquake (which ruptured the San Andreas fault) on segments of the other SFBR faults, and the effect of the 1989 Loma Prieta earthquake on the two nearby San Andreas fault segments (SAS and SAP). (Limitations in the Fortran program allow us to incorporate only one perturbation per segment; therefore we do not model the small effect of the 1989 earthquake on faults other than the San Andreas.) We calculate the stress changes using an elastic dislocation model. The average Coulomb stress change on a fault segment is converted into an equivalent time change by dividing stress change by estimated loading rate. For example, a drop in stress of 1 bar on a fault segment that is being loaded at a rate of 0.1 bar/year produces a "clock change" of -10 years, as 10 years will be required to bring the fault back to the same state. 


\begin{tabular}{|c|c|c|c|c|c|c|c|}
\hline Location & $\mathrm{M}$ & Last & $\mathrm{N}$ & $\mu$ & $\alpha$ & $\mu_{0.5}$ & Reference \\
\hline Copper River Delta, USA & 9.2 & 1964 & 9 & 683 & 0.23 & 753 & Plafker and Rubin, 1994. \\
\hline Willipa Bay, USA & 9.0 & 1700 & 7 & 526 & 0.53 & 530 & Atwater and Hemphill-Haley, 1997. \\
\hline Wairarapa fault, N.Z. & 8.2 & 1855 & 5 & 1551 & 0.18 & 1355 & Van Dissen and Berryman, 1996. \\
\hline Nankaido, Japan & 8.1 & 1946 & 9 & 158 & 0.40 & 166 & Ishibashi and Satake 1998. \\
\hline Tonankai, Japan & 8.1 & 1944 & 7 & 210 & 0.75 & 192 & Ishibashi and Satake 1998. \\
\hline Pallett Creek, USA & 7.8 & 1857 & 10 & 146 & 0.97 & 115 & Sieh et al., 1989. \\
\hline Wrightwood, USA & 7.8 & 1857 & 6 & 150 & 0.71 & 138 & Biasi and Weldon, 1998. \\
\hline Pitman Canyon, USA & 7.8 & 1812 & 6 & 180 & 0.96 & 144 & Seitz, Weldon and Biasi, 1997. \\
\hline Miyagi-Oki, Japan & 7.5 & 1978 & 11 & 36 & 0.27 & 40 & Utsu, 1984. \\
\hline Brigham City, USA & 7 & -130 & 6 & 1476 & 0.31 & 1645 & McCalpin and Nishenko, 1996. \\
\hline Tanna fault, Japan & 7.0 & 1930 & 7 & 972 & 0.65 & 866 & Tanna Fault Trenching Research Group, 1983 \\
\hline Irpinia fault, Italy & 6.9 & 1980 & 5 & 2058 & 0.58 & 2042 & Pantosti et al., 1993. \\
\hline Parkfield, USA & 6.4 & 1966 & 6 & 25.0 & 0.44 & 26.5 & Bakun and Lindh, 1995. \\
\hline \multicolumn{8}{|c|}{ Stone Canyon (San Andreas fault) } \\
\hline - Set 2 & 5.0 & 1995 & 4 & 14.6 & 0.40 & 18.6 & Ellsworth, 1995. \\
\hline - Set 3 & 4.7 & 1986 & 3 & 20.3 & 0.37 & 24.4 & " \\
\hline - Set 1 & 4.2 & 1995 & 5 & 14.7 & 0.29 & 16.2 & $"$ \\
\hline - Set 10 & 4.1 & 1995 & 7 & 10.2 & 0.25 & 11.3 & $"$ \\
\hline - Set 5 & 4.0 & 1990 & 6 & 10.6 & 0.32 & 12.4 & $"$ \\
\hline - Set 8 & 4.0 & 1990 & 5 & 12.3 & 0.35 & 14.7 & $"$ \\
\hline - Set 9 & 4.0 & 1990 & 5 & 13.0 & 0.42 & 14.7 & $"$ \\
\hline \multicolumn{8}{|c|}{ Parkfield (San Andreas fault) } \\
\hline - PK1 & 1.4 & 1994 & 9 & 1.12 & 0.16 & 1.25 & Ellsworth, 1995. \\
\hline$-\mathrm{S} 46$ & 0.9 & 1993 & 5 & 1.3 & 0.22 & 1.5 & Nadeau and Johnson, 1998. \\
\hline - S44 & 0.9 & 1995 & 6 & 1.7 & 0.24 & 1.9 & " \\
\hline - S40 & 0.8 & 1995 & 5 & 1.6 & 0.23 & 1.8 & $"$ \\
\hline - S39 & 0.7 & 1993 & 7 & 0.99 & 0.55 & 0.99 & $"$ \\
\hline - S35 & 0.7 & 1994 & 5 & 1.8 & 0.26 & 2.0 & $"$ \\
\hline - S34 & 0.6 & 1993 & 5 & 1.6 & 0.47 & 1.7 & $"$ \\
\hline - S33 & 0.5 & 1992 & 5 & 1.4 & 0.87 & 1.2 & $"$ \\
\hline - S27 & 0.5 & 1992 & 9 & 0.54 & 0.62 & 0.52 & $"$ \\
\hline - S25 & 0.4 & 1996 & 6 & 1.6 & 0.43 & 1.7 & $"$ \\
\hline - S22 & 0.4 & 1992 & 5 & 0.83 & 0.43 & 0.87 & $"$ \\
\hline - S21 & 0.3 & 1995 & 8 & 1.1 & 0.50 & 1.2 & $"$ \\
\hline - S20 & 0.3 & 1995 & 6 & 1.5 & 0.59 & 1.5 & $"$ \\
\hline - S18 & 0.3 & 1992 & 5 & 1.3 & 0.33 & 1.4 & $"$ \\
\hline - S07 & 0.0 & 1992 & 9 & 0.64 & 0.11 & 0.72 & $"$ \\
\hline - S05 & -0.1 & 1995 & 13 & 0.73 & 0.32 & 0.78 & $"$ \\
\hline - S01 & -0.7 & 1995 & 9 & 0.95 & 0.40 & 1.0 & $"$ \\
\hline
\end{tabular}

Notes to Table. Location - geographic placename of paleoseismic site, name of fault, or fault segment. M - magnitude of typical event. Last - calendar year of last event; negative dates for B.C. N - number of events in earthquake series. $\mu$ - estimated mean recurrence interval in years. $\alpha$ - estimated aperiodicity of earthquake series. $\mu_{0.5}$ - estimated mean recurrence interval in years for $\alpha=0.5$. Reference - primary data source for this earthquake series. [Table 2 of Ellsworth et al., 1999] 
Calculating the BPT-step perturbation requires information about the time of the perturbation producing the step in state and about the size of the state change. Although other approaches are possible, we converted the clock change to a state step using the recurrence time of the event. If, for example the mean recurrence time were 200 years, a -10 year clock change would amount to a $-5 \%$ change in state. Details of the BPT-step calculation are provided in Appendix F. Stress perturbations associated with the 1906 earthquake were large and affected faults throughout the region; the range of values shown in Appendix F (Table 6) reflect the variety of parameter choices and model geometries used in the calculation of the Coulomb stress changes. The M6.9 Loma Prieta earthquake in 1989 had a more local effect on the nearby Santa Cruz Mountains and Peninsula segments of the San Andreas fault (Appendix F, Table 6). Because of the proximity of these two segments to the earthquake, the stress effects vary considerably over the segments, yielding a broad range of clock change values within the $90 \%$ confidence bounds. However, the probability of failure on these two segments was already low given the relatively small time that has elapsed since 1906, and the perturbation from 1989 did not change this low probability by much.

The Loma Prieta earthquake is considered here to have occurred in the "background", near but not on the San Andreas fault (Shaw and Suppe, 19xx; Dietz and Ellsworth, 1990, 1997). Because this interpretation is widely but not universally accepted, we examined the probability implications of this choice by calculating probabilities (using the BPT-step model) for the case in which the Loma Prieta earthquake is on the SAS segment of the San Andreas fault. In this comparison, the reset date on the SAS segment was changed to 1989 and no state steps were applied to any of the San Andreas fault segments. The results are only slightly different in this case, as shown in Table 5.3.

Table 5.3. Comparison to the case in which the Loma Prieta earthquake is considered to have occurred on the San Andreas fault. Results of 10,000 trials using the BPT-step probability model.

\begin{tabular}{|c|c|c|}
\hline & \multicolumn{2}{|c|}{$\begin{array}{c}\text { Mean Probability of } M \geq 6.7 \text { Earthquake } \\
{[95 \% \text { uncertainty bounds] }}\end{array}$} \\
\hline & $\begin{array}{l}\text { Loma Prieta earthquake is on } \\
\text { the SAS segment }\end{array}$ & $\begin{array}{l}\text { Loma Prieta earthquake is in } \\
\text { the background }\end{array}$ \\
\hline Segment SAS & $0.078 \quad[0.025-0.163]$ & $0.099 \quad[0.004-0.272]$ \\
\hline Segment SAP & $0.091[0.005-0.190]$ & $0.101 \quad[0.005-0.233]$ \\
\hline Segment SAN & $0.106[0.008-0.220]$ & $0.110 \quad[0.009-0.230]$ \\
\hline Segment SAO & $0.105[0.006-0.220]$ & $0.109 \quad[0.007-0.232]$ \\
\hline Entire San Andreas fault & $0.146 \quad[0.015-0.314]$ & $0.235 \quad[0.029-0.524]$ \\
\hline SFBR Region & $0.673[0.534-0.855]$ & $0.682 \quad[0.538-0.864]$ \\
\hline
\end{tabular}

Other methods for calculating stress changes (and their effects) produced by the 1906 and 1989 earthquakes based on more complex physical processes were considered. These involve models 
of post-seismic viscoelastic stressing and rate-and-state friction. However, these approaches were judged to be insufficiently vetted for incorporation into the current SFBR probability calculations. These approaches are discussed in Chapter 8.

\section{Time Predictable Model}

The final probability model is the time predictable model (Shimazaki and Nakata, 1980). In this model, the next earthquake will occur when tectonic loading restores the stress released in the most recent earthquake. Typically, dividing the slip in the most recent earthquake by the fault slip rate approximates the expected time to the next earthquake. The time predictable model does not say anything about the size of the next earthquake, only when it will occur.

WG88 and WG90 used the time predictable model to make their 30-year probability calculations. They assumed that the time of the next earthquake varied about the expected time according to a lognormal distribution. In this report, we use the BPT distribution to describe the dispersion of times about the expected time. The differences between the lognormal and BPT results are small compared to uncertainty associated with other parameters that go into this model.

We determine time predictable probabilities only for the San Andreas fault, because the information available for the remainder of the SFBR faults was either lacking or judged to be too uncertain. Application of the time predictable model to the San Andreas fault also requires several extensions to the procedures employed by the earlier Working Groups:

1. We model the SFBR as a network of faults. The tectonic loading rate at a point in the model is the sum of the contributions from all of the loading processes. In general, in the loading model used (see Appendix F), the inter-seismic loading rate at any point on a fault is slightly greater than what it would be if the fault were considered in isolation. This is because there are many sub-parallel faults, and the tectonic loading of one fault by slip at depth in the model also loads the nearby faults, at least to a small degree. Other loading models may yield different results.

2. The time predictable model strictly gives the probability that a rupture will start on a segment. Earlier Working Groups did not consider multi-segment ruptures, and so for those reports the probability of rupture starting was the same as the probability of rupture. This is not the case in our model, as a segment may fail in a rupture that starts on another segment.

3. Fault segments in our model can rupture in more than one way. A segment can fail by itself, fail in combination with other segments, or produce a floating earthquake. The combination rules that give the chance that failure of one segment will propagate into its neighboring segments should depend on how close those neighboring segments are to failure, at least in the time predictable model.

4. The earlier Working Groups incorporated all of the uncertainty in the renewal time into the standard deviation of the lognormal distribution. We use Monte Carlo sampling of the parent distributions to propagate uncertainty through the model. 


\section{Application of the time-predictable model.}

The time predictable model is implemented by following a six-step calculation sequence.

Step 1: Slip in the most recent event. Determine the slip on each of the four segments of the San Andreas fault by drawing a random sample from the slip model for the 1906 earthquake by Thatcher (1997).

Step 2: Slip rate of the segment. Determine the slip rate on each segment by drawing a random sample from slip rates determined for an elastic 3-D dislocation model of the fault system. In detail, the 3-D elastic model gives a stressing rate in bars, which is converted into a slip rate by multiplying it by the amount of slip needed to produce a 1 bar stress drop on the segment (Appendix F).

Step 3: Expected time of the next rupture of the segment. Set the time predictable return time for the segment by dividing the slip from Step 1 by the slip rate from Step 2.

Step 4: Probability of a rupture starting on the segment (ignoring stress interaction neffects). Calculate the 30-year probability of an earthquake starting on the segment using the BPT model and a randomly drawn aperiodicity from the weighted values listed earlier. These are "epicentral probabilities".

For the Santa Cruz and Peninsula segments, the stress effects of the 1989 Loma Prieta earthquake are used to modify the probability. This is done by adjusting the state of the probability model, instead of by a clock change, as was done by WG90. A randomly drawn value for the average stress change on the SAS and SAP segments is first converted to a clock change by dividing it by the same factor used in Step 2. The probability is then computed using the same procedures as were used to model the stress effects of the 1906 earthquake on the rest of the faults in the BPT-step branch of the calculation sequence.

Step 5: Convert epicentral probabilities into earthquake probabilities. From Step 4 we have the probability that an earthquake will start on each of the four San Andreas Fault segments in the next 30 years. In Step 5, a probability table is created that gives the probability that an epicenter on a segment will lead to one of the 14 possible San Andreas fault sources (10 segment combinations +4 floating earthquakes). Several assumptions are required to make this table. They are 1) the long-term distribution of the epicenters for each of the sources; 2 ) the rate at which the rupture sources occur; and 3) the influence of the 1906 earthquake on multi-segment ruptures.

The distribution of epicenters is assumed to be proportional to the length of the segment. This means that if a multi-segment rupture is considered, the chance that rupture will begin on any particular segment is the length of the segment divided by the total length of the rupture source. Floating earthquakes are apportioned onto the segments in the same manner. Other possible methods would be to apportion according to segment seismogenic area or moment rate. 
Our long-term earthquake source model gives the unconditional rate of rupture sources. It is straightforward to partition these rates into the rate at which its epicenters occurs on a given segment. It is simply the fraction of the time that the epicenter is on the segment (ratio of segment length to source length) times the rate of the source. If the 1906 earthquake was believed to have no influence on these rates, then this table of rates could be normalized to give the probability that when an earthquake starts on a given segment it will become any of its possible sources. If we follow this logic, then the next San Andreas event is most likely to be a full-fault rupture, as this source is the most common in the long-term model. Perhaps this is not unreasonable, as the time predictable model does not inform us about the size of the next rupture.

However, many who have thought about the behavior of the northern San Andreas fault have come to the conclusion that the likelihood of a full-fault rupture is low (Lindh, 1983; Sykes and Nishenko, 1984; WGCEP, 1988; WGCEP, 1990). This is because the San Andreas fault slipped substantially more in the 1906 earthquake on the SAN and SAO segments, compared to the SAP and SAS segments. The question is how to implement this hypothesis in the context of our model.

We begin by examining the full four-segment rupture of the fault. In the 95 years since the 1906 earthquake, seismic moment has been accumulating at a rate of $3.7 \times 10^{23}$ dyne-cm/year on the four fault segments. The accumulated moment is equivalent to a M7.67 earthquake. This is a substantial amount of stored moment, but is it enough to produce a full-fault rupture? If the fault was "reset" by the 1906 earthquake, then we can frame this question in probabilistic terms. Specifically, we ask the probability that the stored moment is sufficient to produce a full fault rupture. According to the long-term model, the magnitude of a full fault rupture is $\mathbf{M} 7.90 \pm 0.12$. The probability of a full fault rupture being no larger than $\mathbf{M 7 . 6 7}$ is 0.03 . Under the assumption that the next earthquake will be produced by the strain energy accumulated since the last one, we would conclude that a full fault rupture is unlikely at the present time.

Consider now the likelihood that a floating earthquake (M6.9 \pm 0.12 ) could occur on the SAN. The moment stored since 1906 on any part of the SAN that is long enough to produce a floating earthquake is equivalent to M6.98, and the probability that this is sufficient moment to produce a floating earthquake is 0.75 . Thus, we might expect that if a large earthquake were to begin on the SAN, it would more likely be a floating earthquake than a full fault rupture, if these were the only two options.

The operating assumption here that the strain energy available for release is the strain energy stored since the last rupture is simply the slip predictable model (Shimazaki and Nakata, 1980). The empirical evidence provides more support for this model than it does for the time predictable model (Ellsworth, 1995). We will adopt this hypothesis for the purpose of modulating the longterm probability that an earthquake that starts on one segment will result in the failure of any of its possible rupture sources.

In these calculations, the rates from the SFBR model are the beginning point. The slip predictable assumption is used to ask the question "Has enough moment accumulated on this rupture source since 1906 to make the earthquake?" This is posed as a probability problem, and 
the answer (a number between 0 an 1 ) is used to modulate the probability of the rupture source given an epicenter on the segment.

To implement this model, we multiply the long-term rate for each rupture source by the probability that the moment stored since 1906 is sufficient to produce the earthquake. The adjusted rates are then converted into the probability that an epicenter on a segment will produce a given source.

Table 5.4 is the result of this procedure. The columns correspond to the locations of the epicenter. The rows correspond to the rupture sources. The entries in the table are the probability, given an epicenter on the segment, that it will become a particular rupture source. The individual columns must sum to unity, because the occurrence of the epicenter on the segment is a given. For example, the probability that an earthquake that starts on SAP segment will not propagate into either the SAS or SAN segments is $0.809(0.462+0.347)$. The probability that a SAP rupture will grow into a full rupture of the fault is 0.019 .

The most likely rupture to result from a earthquake initiating on the SAN or SAO segments is a floating earthquake, a result controlled by the slip-predictable assumption, the small magnitude of the floating earthquakes relative to the single-segment rupture sources SAN and SAO, and the large, unrecovered moment deficit on those segments from 1906. Conversely, earthquakes initiating on the SAS or SAP segments are less likely to be floating earthquakes (but the likelihood is still significant) because the mean magnitudes for these single-segment sources are closer to the magnitude of the floating earthquake and much of the 1906 moment deficit has been recovered.

Table 5.4. Probability that an epicenter on a given segment will become a specific rupture source.

\begin{tabular}{|l|l|l|l|l|l|}
\hline \multicolumn{2}{|c|}{ Resulting Rupture Source } & \multicolumn{4}{c|}{ Location of Epicenter } \\
\hline & $\begin{array}{l}\text { Mean } \\
\text { Mag }\end{array}$ & SAS & SAP & SAN & SAO \\
\hline SAS & 7.03 & 0.682 & 0.000 & 0.000 & 0.000 \\
\hline SAP & 7.15 & 0.000 & 0.462 & 0.000 & 0.000 \\
\hline SAN & 7.45 & 0.000 & 0.000 & 0.071 & 0.000 \\
\hline SAO & 7.28 & 0.000 & 0.000 & 0.000 & 0.227 \\
\hline SAS + SAP & 7.42 & 0.106 & 0.170 & 0.000 & 0.000 \\
\hline SAP+ SAN & 7.65 & 0.000 & 0.000 & 0.000 & 0.000 \\
\hline SAN + SA0 & 7.70 & 0.000 & 0.000 & 0.122 & 0.103 \\
\hline SAS + SAP + SAN & 7.76 & 0.000 & 0.001 & 0.001 & 0.000 \\
\hline SAP + SAN + SAO & 7.83 & 0.000 & 0.001 & 0.002 & 0.002 \\
\hline Full fault rupture & 7.90 & 0.012 & 0.019 & 0.030 & 0.026 \\
\hline SAS floating earthquake & 6.90 & 0.200 & 0.000 & 0.000 & 0.000 \\
\hline SAP floating earthquake & 6.90 & 0.000 & 0.347 & 0.000 & 0.000 \\
\hline SAN floating earthquake & 6.90 & 0.000 & 0.000 & 0.773 & 0.000 \\
\hline SAO floating earthquake & 6.90 & 0.000 & 0.000 & 0.000 & 0.643 \\
\hline
\end{tabular}

Step 6: Compute 30-year source probabilities. Step 4 gives us the probability of an epicenter on each of the four San Andreas Fault segments. To convert these epicentral probabilities into 
source probabilities it is only necessary to multiply the corresponding column of Table $\mathbf{5 . 4}$ from Step 5 by the epicentral probability. This operation apportions probability among exclusive alternatives while preserving the total probability.

Finally, the probability of a rupture of any segment is computed from the rupture source probabilities in the standard way for combining probabilities:

$$
P_{\text {total }}=1-\left(1-P_{1}\right)\left(1-P_{2}\right) \ldots\left(1-P_{N}\right)
$$

where $P_{i}$ are rupture source probabilities.

The ability of the time-predictable model to provide accurate estimates of earthquake probability depends on the accuracy of the input data on slip in 1906; of the loading rate of the faults; of the stress effects of the 1989 Loma Prieta earthquake; and of the slip-predictable assumption for rupture source probability.

\section{Final calculation steps}

\section{Probabilities for Fault Segments and Fault Systems}

The earthquake probability for a given fault segment is obtained by combining the probability that the segment will rupture in any of the fixed rupture sources that involve that segment, or in an earthquake of the exponential tail (for sufficiently small threshold magnitude $M_{T}$ ) (Figure 5.1). This probability is then combined with a probability contribution from the fault's "floating" earthquake, in proportion to the segment's relative moment rate. To calculate the probability of an earthquake occurring anywhere on the fault, the source probabilities are aggregated. Probabilities are aggregated using equation (5.9).

\section{Probabilities for Earthquakes in the Background}

We use the exponential model to describe the distribution of times between successive $\mathbf{M} \geq 6.7$ earthquakes in the background. Two G-R relations ( $\log \mathrm{N} / \mathrm{yr}=a-b \mathbf{M})$ describing the magnitude-frequency distributions of earthquakes in the background were developed in Chapter 4: one for the 1951-1998 period with $a=3.67$ (3.60 to 3.74 at $95 \%$ confidence) and $b=0.89$; and the other for the 1836-2001 period with $a=3.94$ (3.62 to 4.31 at $95 \%$ confidence) and $b=0.89$.

The 1951-1998 relation provides a rate based on recent earthquake activity, while the 1836-2001 relation represents the longer-term activity. We use both models to estimate the 30 -year conditional probability of $\mathbf{M} \geq 6.7$ earthquakes in the background. WG02 voted on the relative weights of the 2 models, assigning 0.458 to the long-term rate estimates and 0.542 to the estimate based on recent seismicity. Each model is split into 3 branches based on the mean rate, the $+2 \sigma$ rate and the $-2 \sigma$ rate, with weights of $0.74,0.13$, and 0.13 respectively. 


\section{Weighting alternative probability models}

Each of the five probability models described above offers an alternative method for calculating 30-year earthquake probabilities for the SFBR fault segments, faults, rupture sources, and region as a whole. The decision of how to weight these alternative methods represents a major source of epistemic uncertainty in the SFBR probabilities.

After considerable discussion of the pros, cons, implications, machinery, and quantitative results of each probability model, each member of WG02 was asked to divide unit weight among the four (or five, in the case of the San Andreas fault) probability models. Different weight distributions were permitted on each fault. For each model and fault the 13 fractional weights were averaged, and those mean weights were used to scale the contribution of each probability model to each fault system. Table 5.5 summarizes the mean branch weights thus determined.

The BPT, BPT-step and time-predictable models accounted for approximately half or more of the assigned weight on all faults (except on the Mt. Diablo thrust, for which the geologic data are the most limited). On the San Andreas fault, for which we know the most about past earthquake occurrence, these models account for $72 \%$ of the assigned unit weight. The Poisson and Empirical models account on average for $21 \%$ and $29 \%$ of the unit weight, respectively. In our discussions, WG02 members often cited two issues that influenced their judgement in assigning these weights: the relative amount and quality of geological data on each fault (with more and better data generally favoring more weight on recurrence models); and the modeling of the stress interaction effects of the 1906 earthquake (with lower confidence in the accuracy of the calculations for interaction effects favoring more weight on the Empirical and Poisson models).

The division of weight among the probability models is displayed graphically in Figure $\mathbf{5 . 1 2}$ for each of the seven fault systems. Because the weights assigned to any particular model differ between the fault systems and the Time Predictable model is only used for the San Andreas Fault, a mixture of probability models must occur in the random sampling of branches by the code, at least some of the time.

Table 5.5. Mean expert weights for probability models applied to the SFBR fault systems.

\begin{tabular}{lccccc} 
Fault system & Poisson & Empirical & BPT & BPT-step & $\begin{array}{c}\text { Time- } \\
\text { predictable }\end{array}$ \\
\hline \hline San Andreas & 0.100 & 0.181 & 0.154 & 0.231 & 0.335 \\
Hayward/Rodgers Creek & 0.123 & 0.285 & 0.131 & 0.462 & - \\
Calaveras & 0.227 & 0.315 & 0.142 & 0.315 & - \\
Concord/Green Valley & 0.246 & 0.277 & 0.123 & 0.354 & - \\
San Gregorio & 0.196 & 0.292 & 0.115 & 0.396 & - \\
Greenville & 0.231 & 0.288 & 0.131 & 0.350 & - \\
Mt. Diablo thrust & 0.308 & 0.396 & 0.092 & 0.204 & - \\
\hline
\end{tabular}

In order to maximize the extent to which the choice of probability model is correlated across the region, the input probafbility model weights were arranged in the order shown in Figure 5.12. (It will be seen that this is in order of increasing mean earthquake probability, except in the case of the San Andreas fault.) On each realization, the code draws a single random number (0 to 1) to select the probability model branch for each fault system. Expressed graphically, this random 
number corresponds to a horizontal position in Figure 5.12 and a vertical line drawn at that position specifies the probability model branch tip. Inspection of the figure shows that for most realizations the choice of model will be the same across the six faults, excluding the San Andreas. For example, the Empirical model weights are similar across the suite of faults, and so there are many realizations for which the probabilities for all faults are calculated using the Empirical model. When the Time Predictable model is operative on the San Andreas Fault, the BPT and/or BPT-step model is operative on most of the others.

This sampling strategy does not alter the mean probability for any fault or for the region as a whole. However, it does affect the variance of the regional probability due to the correlation of probability models between fault systems. Had independent random draws been used for each fault system, the range of regional probability values would have been smaller. Members of the working group held differing views on this question. Some of us felt that the model weights should ideally be correlated across the region, because probability models are alternative views of the physics of the earthquake generation process and as such apply to all the faults, since fault physics doesn't change from place to place. A single realization of the model should, in this view, have correlated physics across the region. (Note that we adhere to this principle of regional uniformity when it comes to fault width: our interpretation of microseismicity depth may be giving us a biased measure of width, but that bias is presumed to be regional, not different on every fault; therefore, the width branch choice is correlated over the faults.)

In contrast, some members of the working group believed that the application of a probability model should depend on particulars about each fault, such as the amount and quality of information available for the fault, their trust in the calculation of the effects of the 1906 earthquake near to and far from the San Andreas fault, their degree of faith in the characterization of the faults, etc. In the end, however, correlating the application of probability models over the faults would have required time-predictable calculations for all faults, which were not judged to be appropriate. So, as a practical matter, correlating the probability models was not possible.

\section{Probabilities for the SFBR model}

The process of computing source, segment, fault and fault system probabilities is repeated for each branch tip in the calculation sequence. Recall that each of the 10,000 computed branch tips represents a viable model for the entire fault system. The distribution of probability for any element of the model, or aggregation, captures the epistemic uncertainty in probability. In other words, the distribution of probability arises from a lack of knowledge about each of the parameters in the model or applicability of the models themselves. These distributions are summarized by their mean value and the probabilities for models at the $2.5 \%$ and $97.5 \%$ points in the range of the values.

\section{Alternative renewal models not used in this study}

As mentioned above, we had a choice of several renewal models, including the Lognormal, Normal, Weibull, Gamma, and BPT. These models all perform similarly for elapsed times near the mean recurrence time, and available data cannot distinguish between them. 
We checked this assertion directly by substituting a Lognormal calculation for the BPT model in the WG02 code. The results show that given the same input parameters and distributions with the same mean and coefficient of variation, the two distributions give nearly identical probabilities. This is true for both the case of non-interacting faults and the case in which the effect of the1906 earthquake is represented by a clock change on the other faults. Thus, we conclude that the choice of renewal model is not a significant source of epistemic uncertainty.

The observation that these two models give nearly the same results is not a reason for retaining the Lognormal model used by previous working groups. The Lognormal model, which has seen much use in the literature and been used by previous Working Groups, has not been demonstrated to be superior to other pdf's. The BPT model, however, offers the opportunity to include the stress step from the 1906 and 1989 earthquakes directly in the probability calculations, whereas the Lognormal does not. 


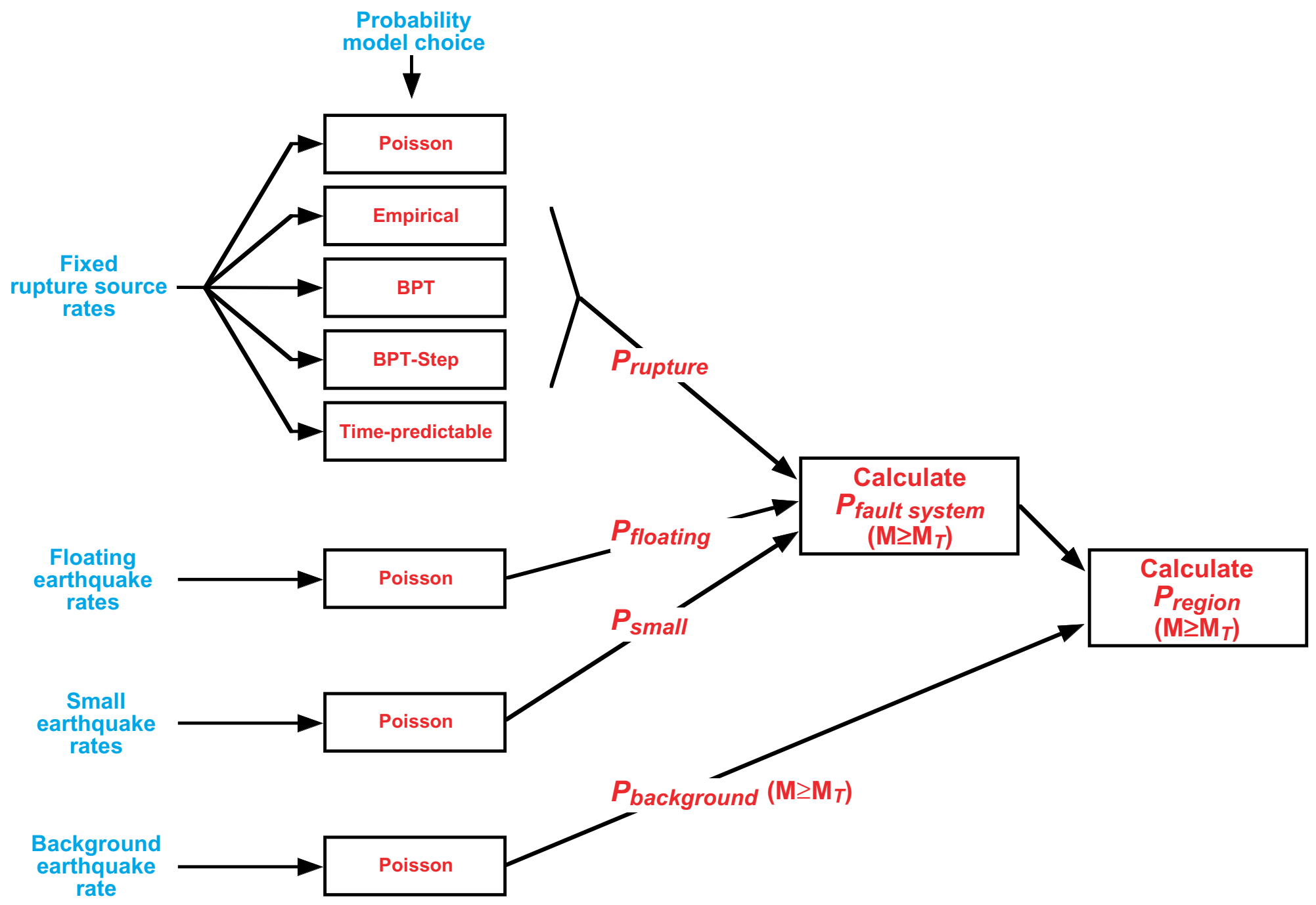

Figure 5.1. Final steps in the calculation sequence, in which time-dependent effects enter into the WG02 model. Long-term rates of fixed rupture sources, floating earthquakes, small earthquakes and background earthquakes are input to a suite of five probability models. Fixed rupture sources are input to all probability models, according weights determined by expert opinion. The other earthquake sources are input only to the Poisson model. Resulting probabilities for the fixed rupture sources, floating sources and small earthquakes are combined for each fault system, for events with magnitude $\mathbf{M} \geq \mathbf{M}_{\mathrm{T}}$. Finally, the probability of background earthquakes is combined with the probabilities for fault systems to give the regional earthquake probability. 


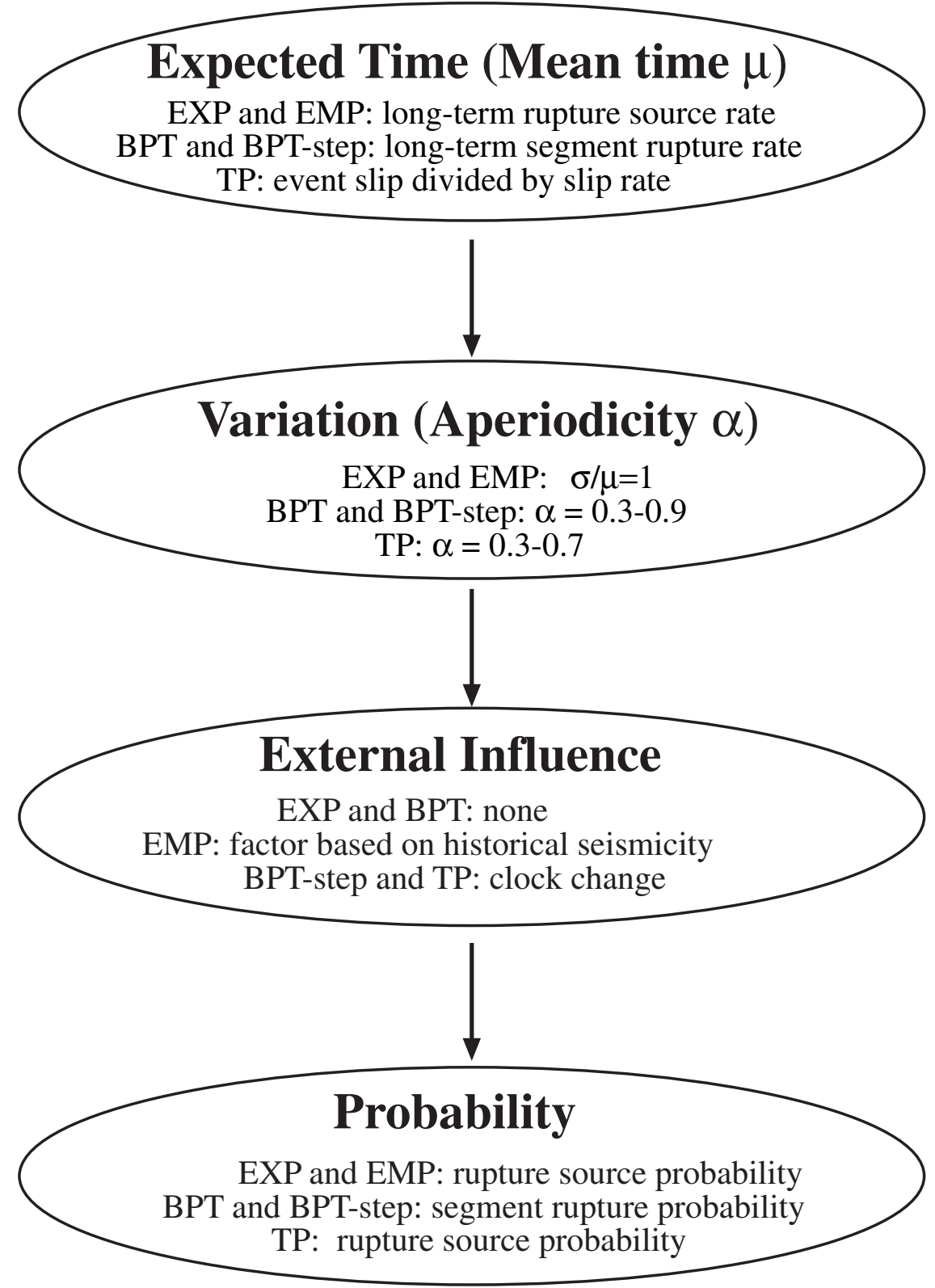

Figure 5.2. Summary of information used and assumptions made by each probability model. WG02 used five probability models: Exponential or Poisson (EXP); Empirical (EMP): Brownian Passage Time (BPT); BPT with stress-step interactions (BPT-step); and Time Predictable (TP). 


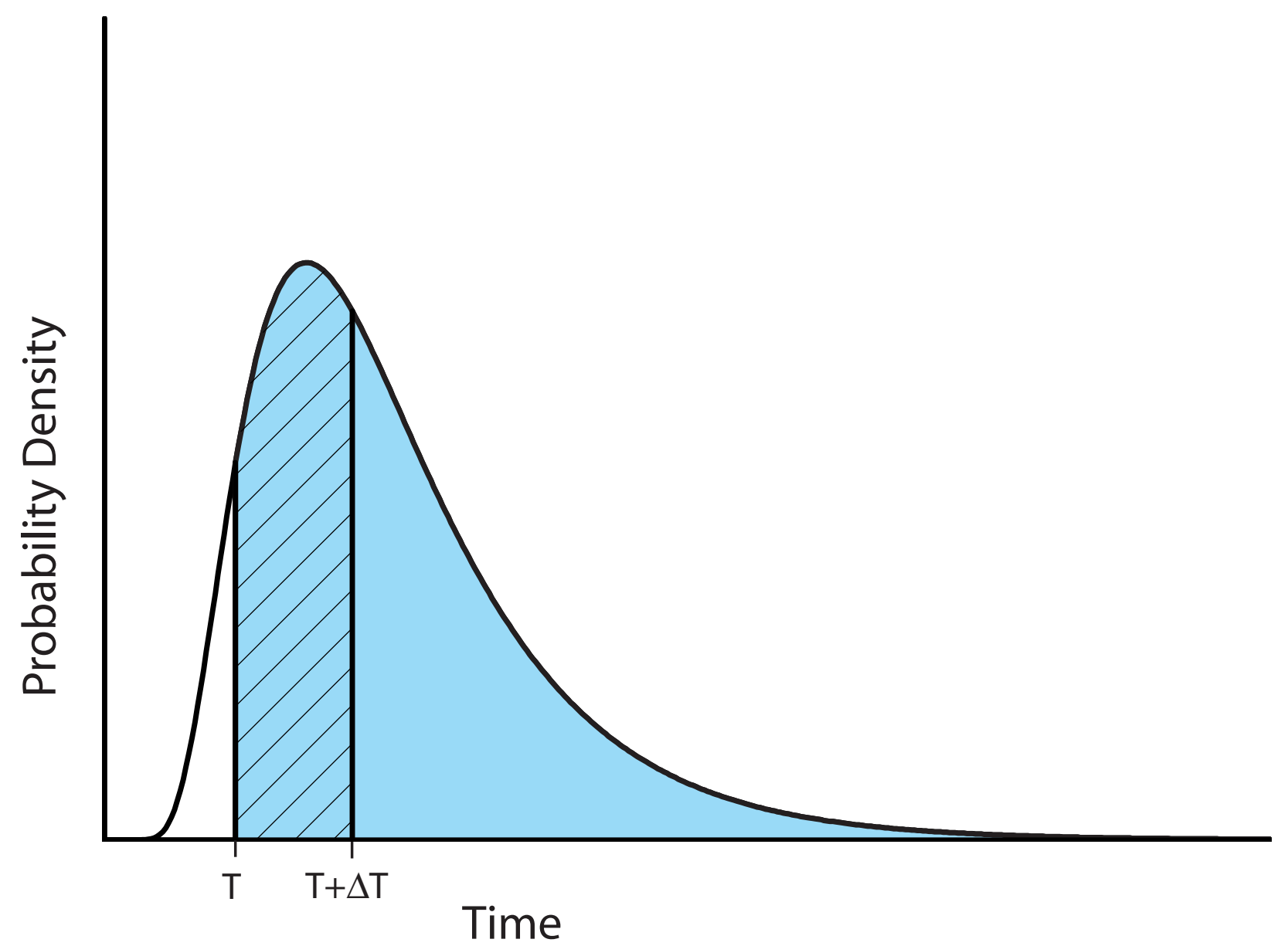

Figure 5.3. Diagram illustrating the calculation of conditional probability from a probability density function. The time interval of interest (exposure time) is from $T$ (the present time) to $T+\Delta T$ (hatchured area). The survivor function at time $\mathrm{T}$ is equal to the shaded area. The conditional probability is the ratio of these two areas. 

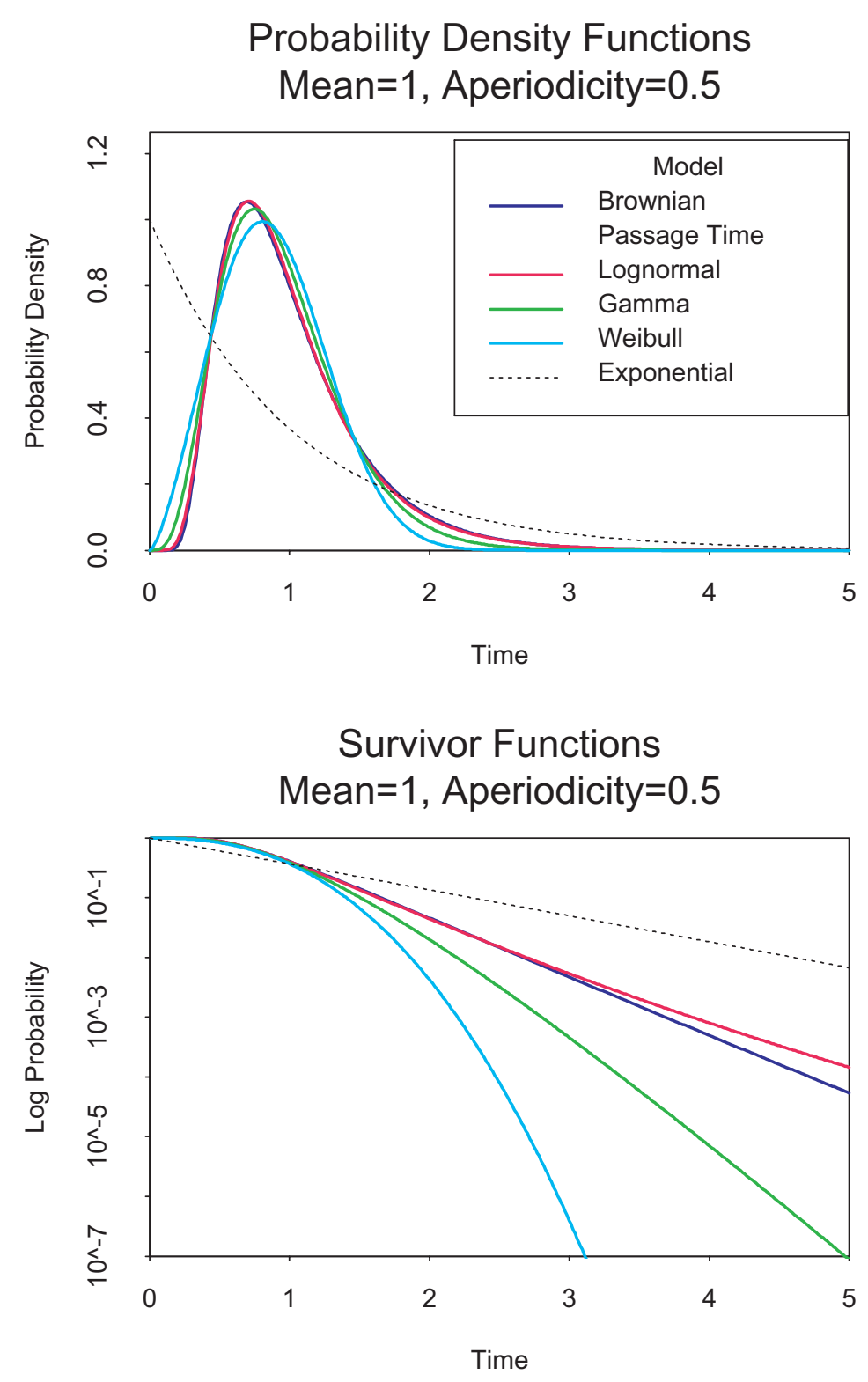

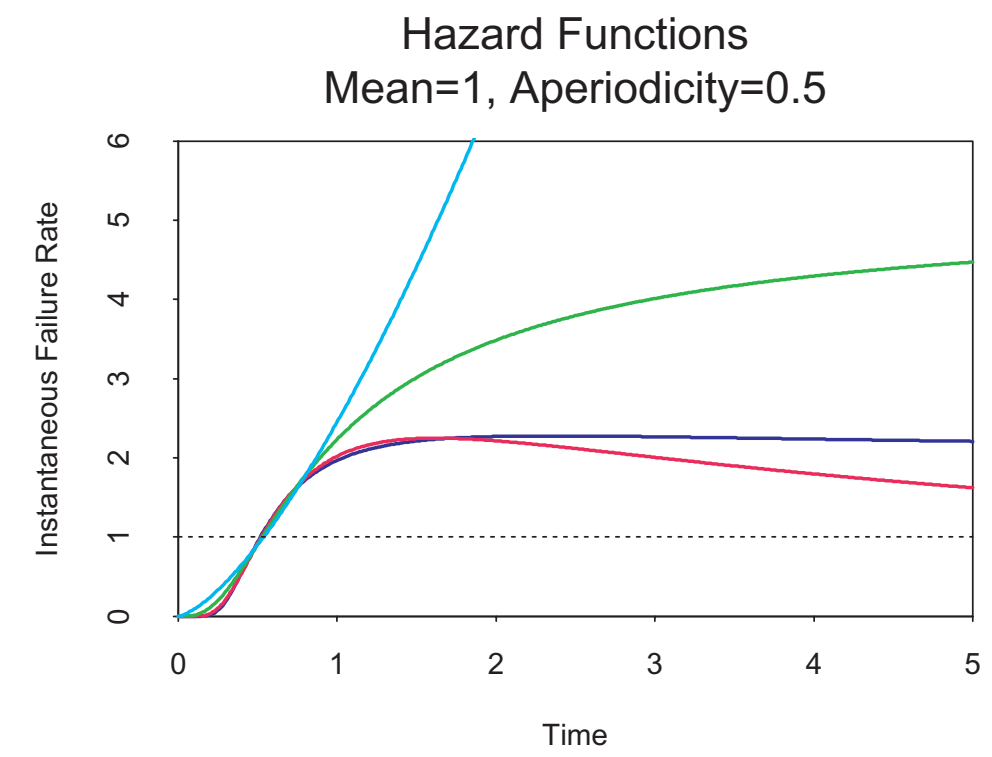

Conditional Probability for Prediction Interval of 0.3

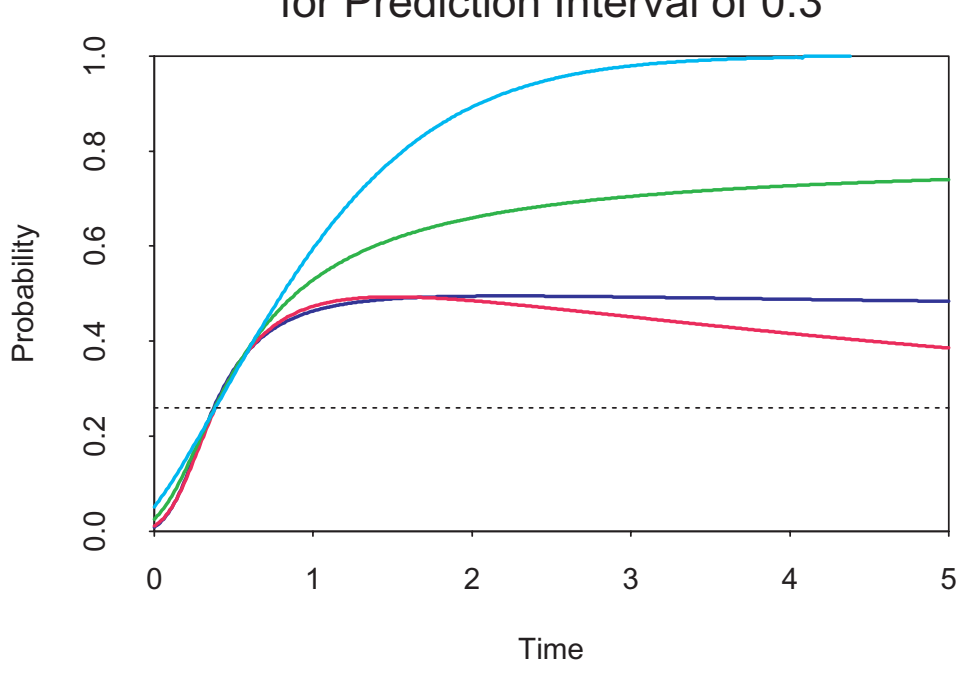

Figure 5.4. Comparison of several probability models used in long-term earthquake forecasting. All models have a mean of 1, and with the exception of the Exponential (Poisson) model, an aperiodicity (coefficient of variation) of 0.5 . Probabiity density, hazard, survivor, and conditional probability functions are shown. 


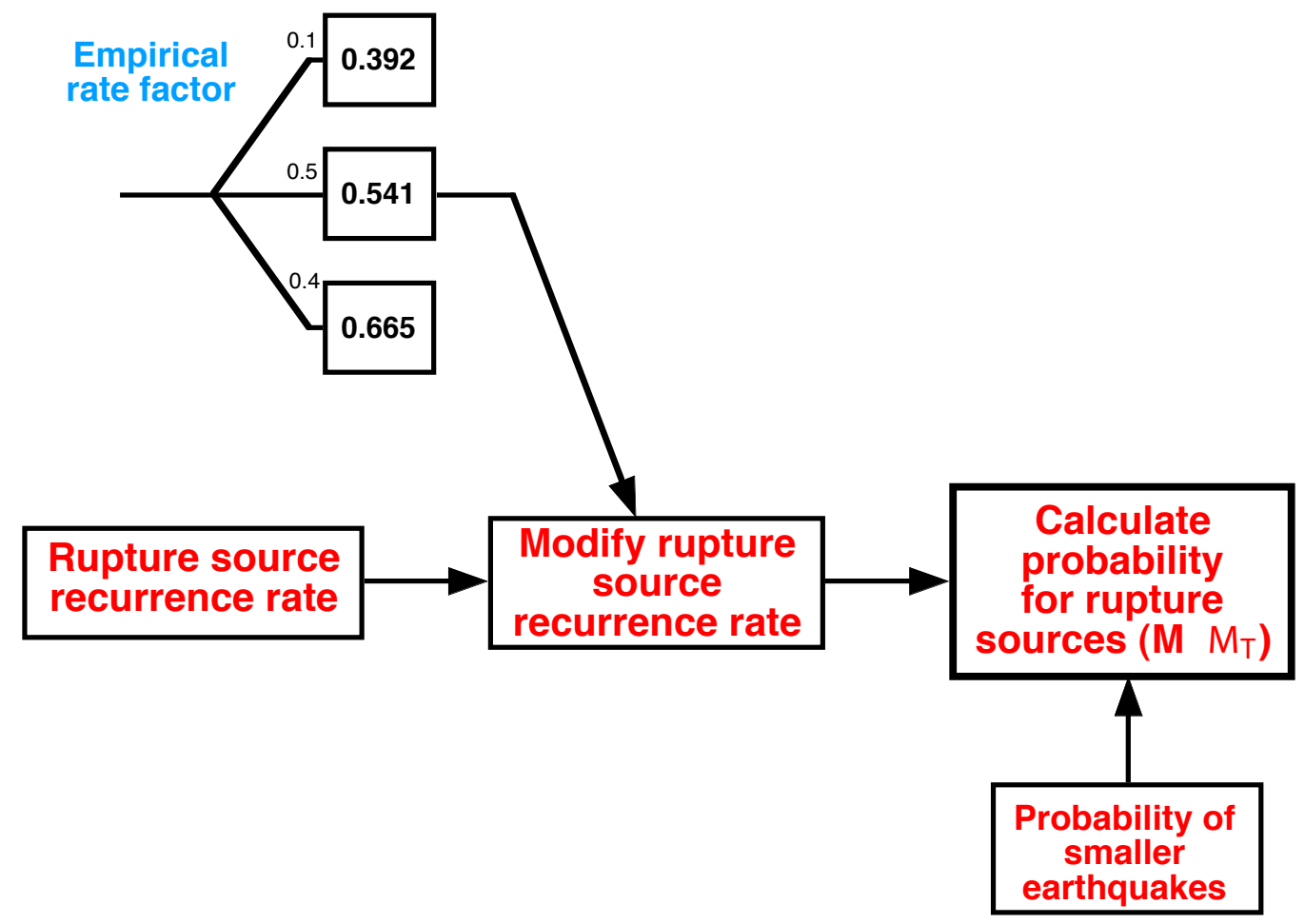

Figure 5.5. Method of calculating rupture source probabilities using the Empirical model. This model requires values for the long-term recurrence rate, plus a rate factor (derived from observations of seismicity rate) that modifies the rupture source recurrence rates. 


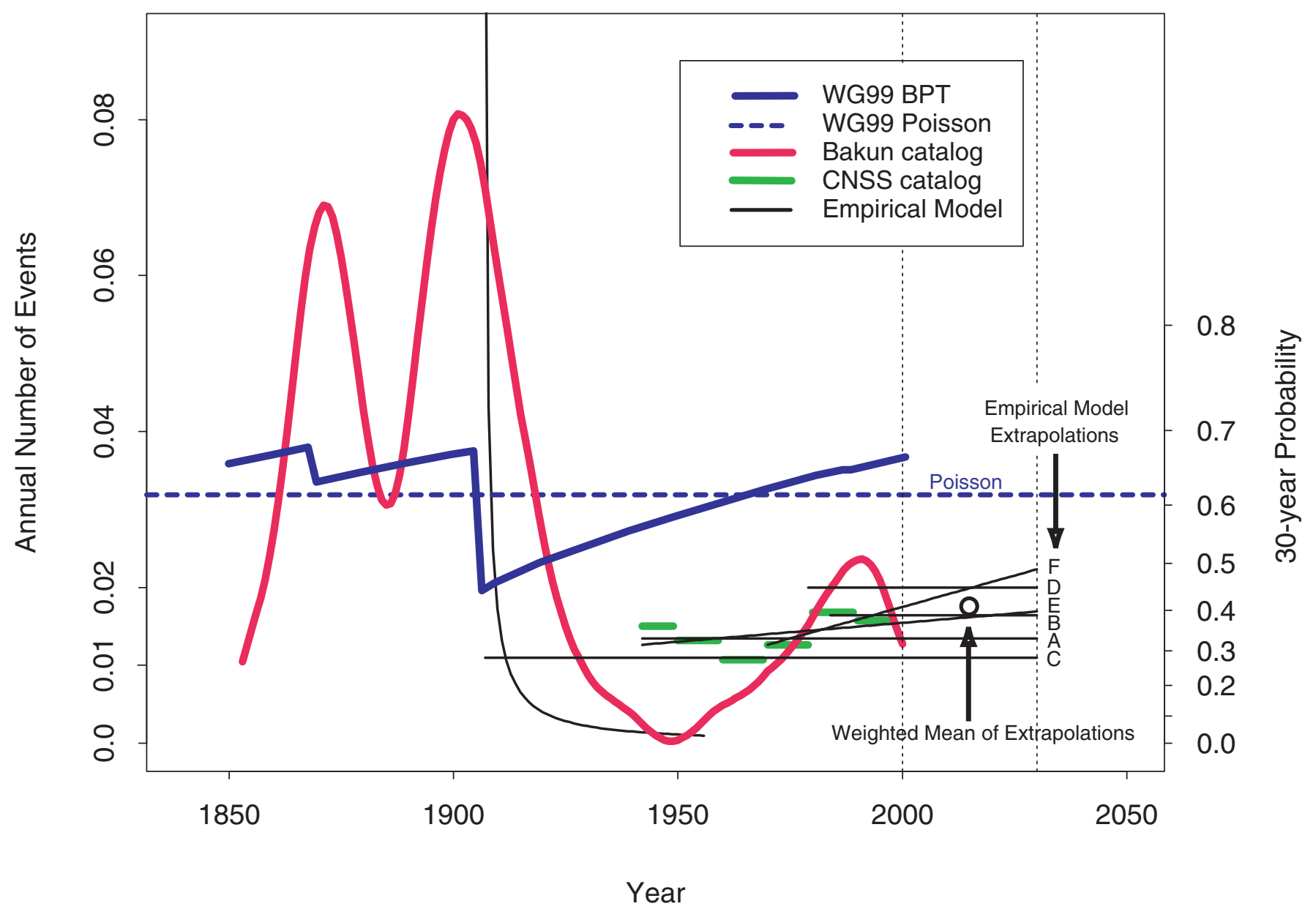

Figure 5.6. Summary of rates and 30-year probabilities of earthquakes $(M \geq 6.7)$ in SFBR calculated with various models. Dark blue line shows BPT model probability calculations (for 30 years forward) with the effects of the 1906 and 1989 stress perturbations modeled with the state-step method. Dashed blue line is long-term (Poisson) regional rate in WG02 model. Red line is a smoothed representation of the rate of $M \geq 5.5$ earthquakes (Bakun, 1999) based on a sliding 15-year-wide averaging window. Green lines are mean rates of $(M \geq 3.0)$ earthquakes in approximately 10-year periods in the CNSS catalog. Black lines are extrapolations of the $M \geq 3.0$ and $M \geq 5.5$ earthquake rates made using a variety of extrapolation methods (see text and Table 5.1). Black circle is weighted mean of extrapolated rates for 2002-2031. Curved light black line is generic aftershock sequence for 1906 earthquake. 


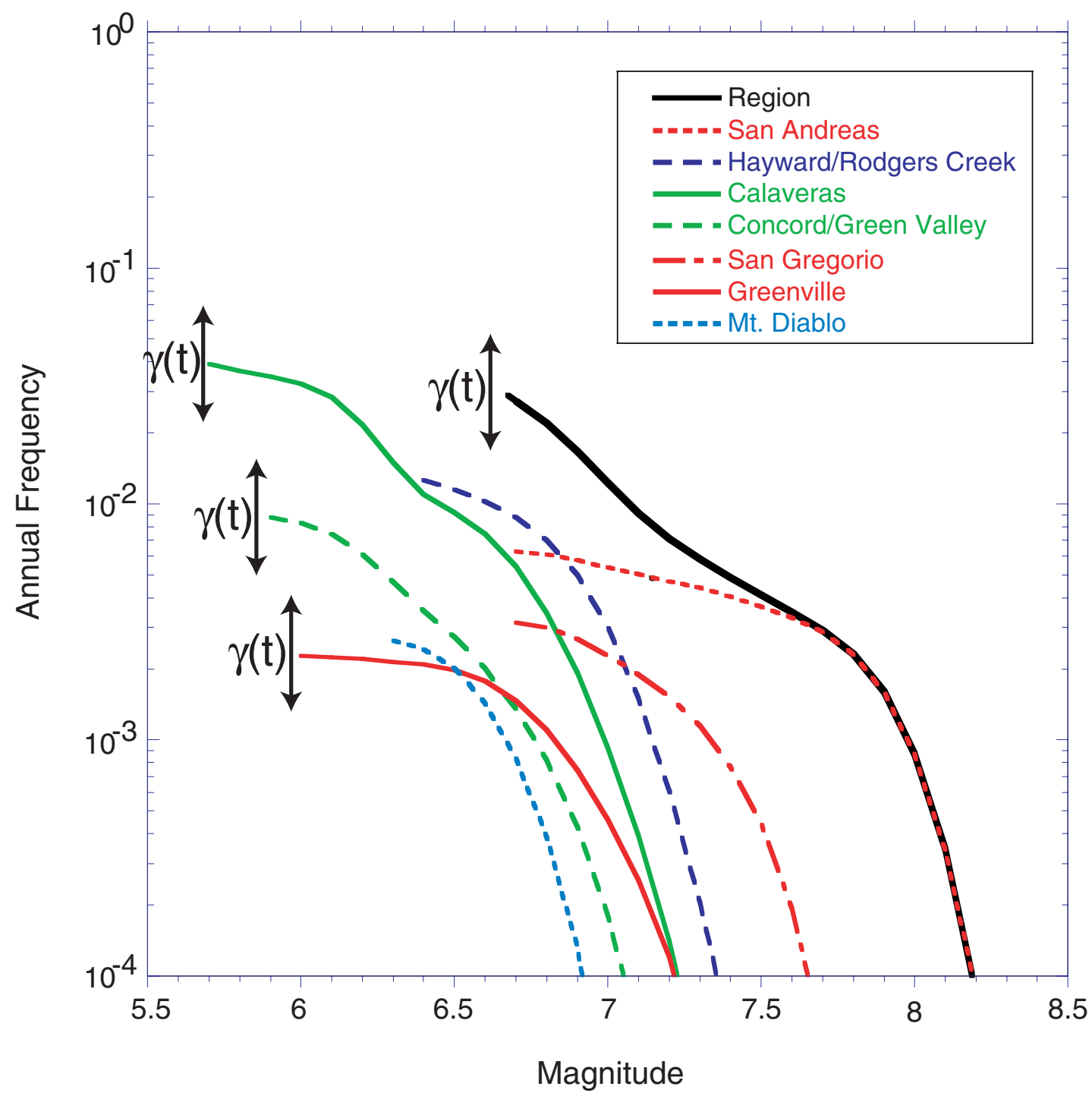

Figure 5.7. In the Empirical model, fluctuations in earthquake activity are represented by $\gamma(t)$, which modulates the rates on the faults and in the background relative to their respective long-term means (colored lines). The rates are modulated in unison. The shape of the magnitude distribution on each fault, as defined by the fault characterization model, remains unchanged; the whole distribution moves up and down in time. 


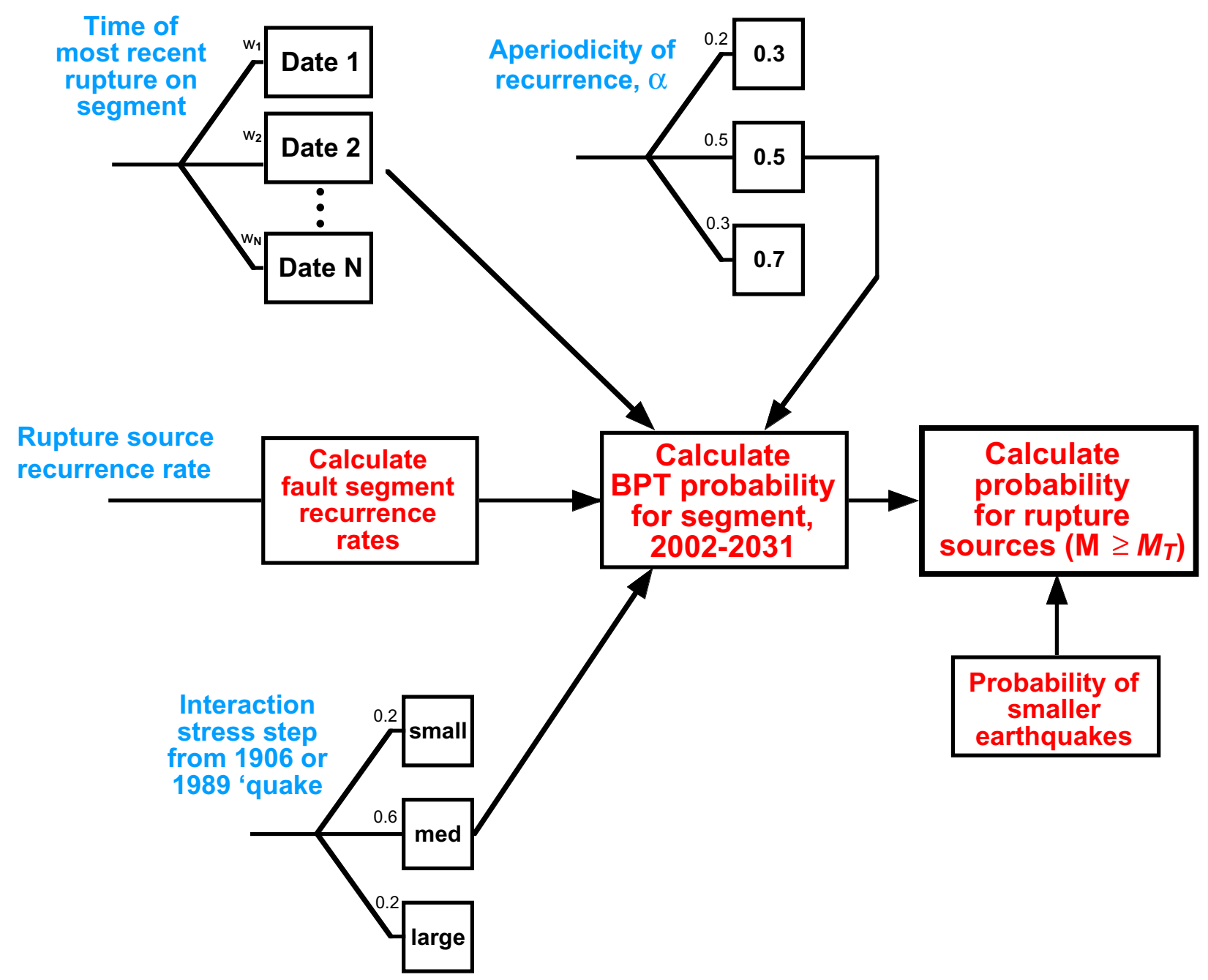

Figure 5.8. Method of calculating time-dependent probabilities using the BPT model. This model requires values for the long-term recurrence rate, the elapsed time since the last earthquake, and the aperiodicity. The modifying effect of stress steps from the 1906 and 1989 earthquakes can be accounted for.

Paleoseismic data on elapsed time are more readily available for fault segments than for rupture sources; therefore, the probability is calculated in three steps. First, the rate of failure is calculated from the rate of failure of ruptures that include it. Next, the probability of failure of each fault segment is calculated. Finally, segment probabilities are combined to determine the probability of failure of each rupture source, for earthquake magnitudes above a threshold magnitude $M_{T}$.

If $M_{T}$ is small, the rupture source probability may include that of smaller earthquakes (those of the exponential tail).

A similar procedure is used in the case of the time-predictable model. In that case additional information about the slip in the last event is required. 

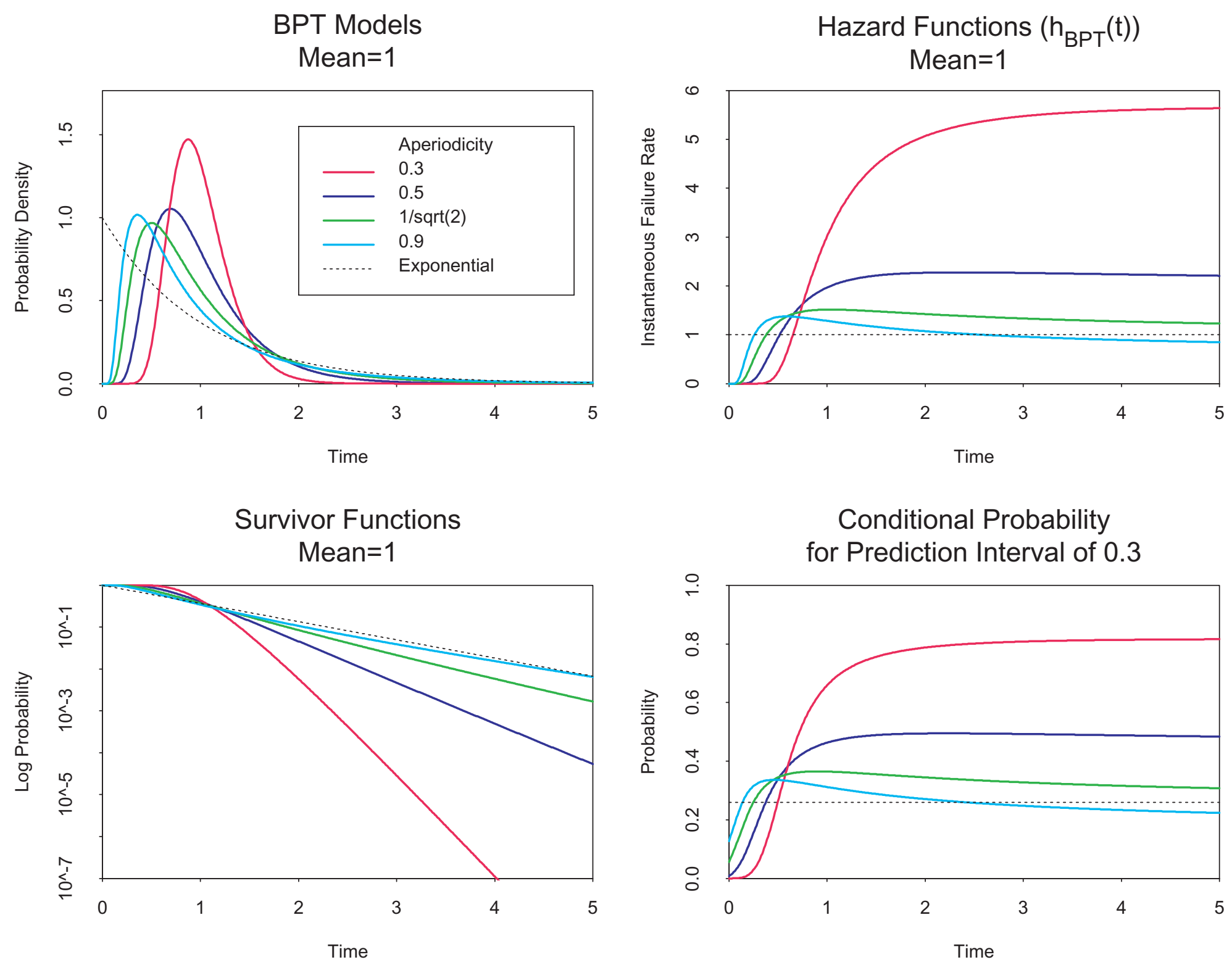

Figure 5.9. Effect of aperiodicity on the behavior of the Brownian Passage Time model. All distributions have a mean of 1. Exponential model shown for comparison. Probability density, hazard, survivor, and conditional probability functions are shown. 


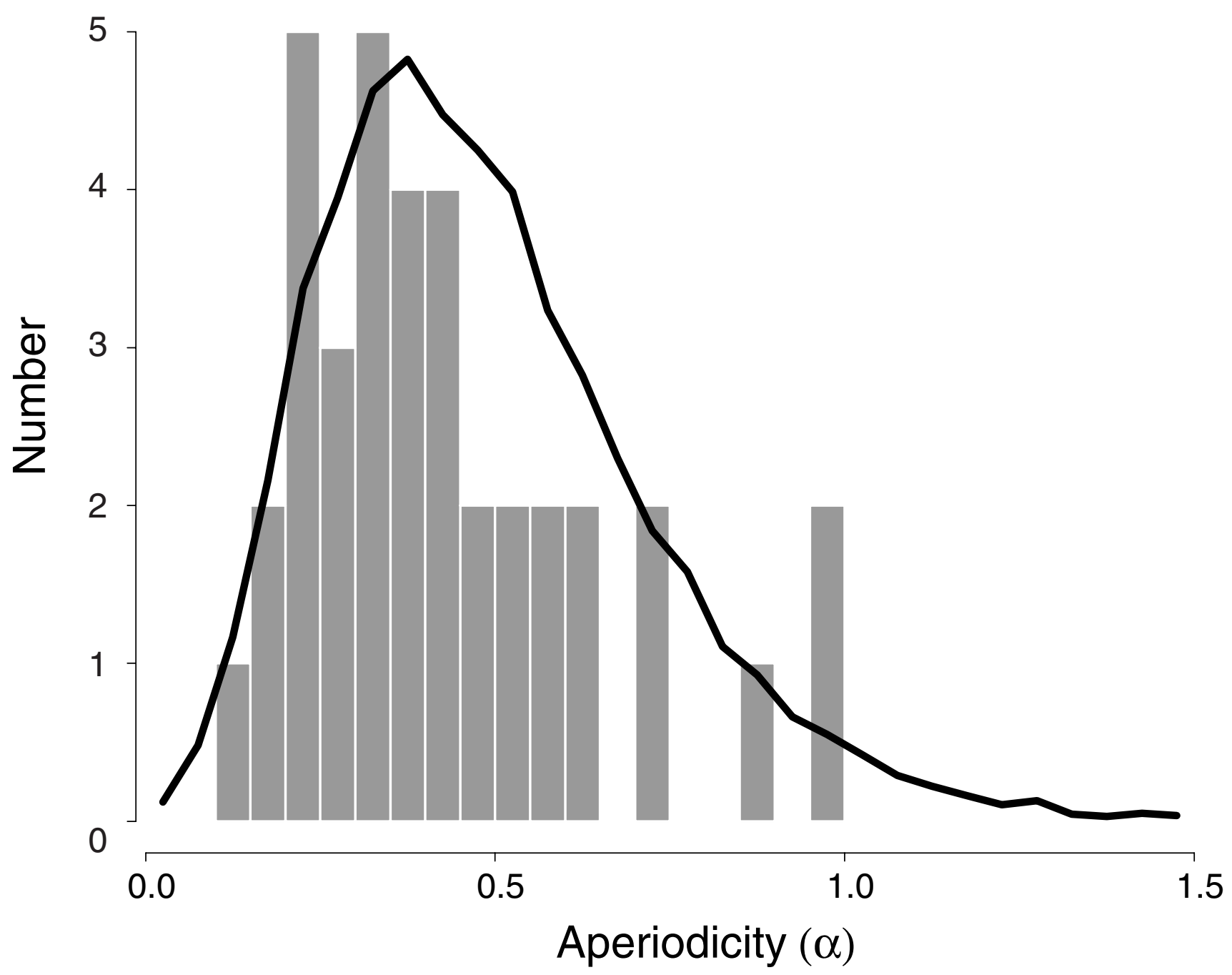

Figure 5.10. Estimates of aperiodicity ( $\alpha$ ) obtained by Ellsworth et al. (1999) for 37 earthquake sequences (histogram) and the WG02 model (solid line). The WG02 model for $\alpha$ is represented here by the distribution of estimates of $\alpha$ obtained for a set of 10,000 synthetic sequences constructed from it. The model values for $\alpha$ (and sampling weights) are $0.3(0.2), 0.5(0.5)$, and $0.7(0.3)$. 


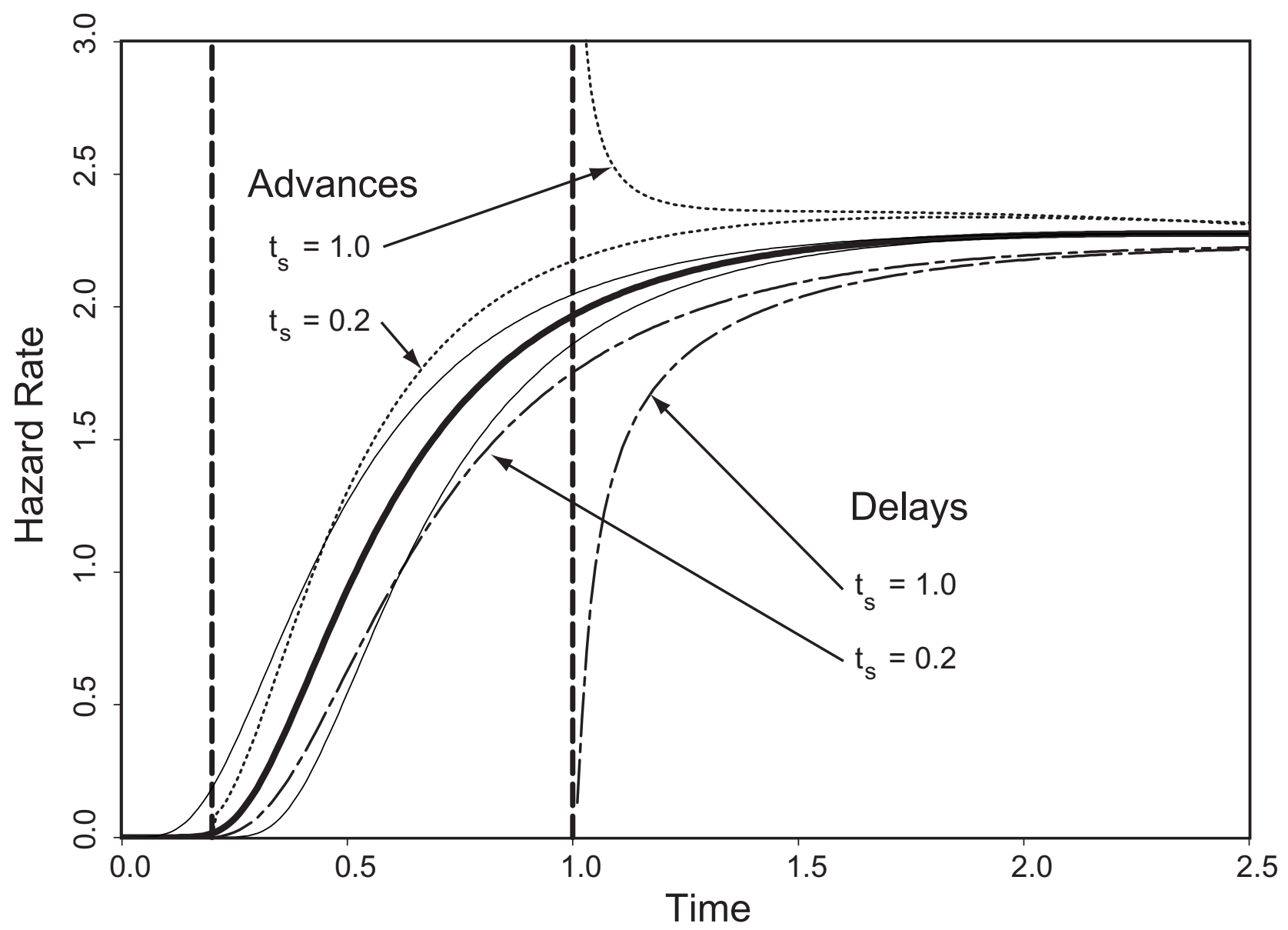

Figure 5.11. Effects on hazard rate of steps in the state of the BPT model, shown as a function of time normalized by mean recurrence time. Solid heavy curve is the hazard rate function for the unperturbed state. Dashed and dotted curves are hazard rates when an interaction step is applied early in the recurrence cycle (phase $t_{S}=0.2$ ) and at the mean recurrence time $(\mathrm{ts}=1.0)$. The absolute size of the step is $1 / 10$ the stress drop for the rupture. Dotted curves correspond to positive steps, dashed curves to negative steps. Solid light lines, shown for comparison, are hazard rates for a "clock advance" (upper) and "clock delay" (lower) of \pm 0.1 times the mean recurrence time, which are simply horizontal translations of the unperturbed hazard rate. 


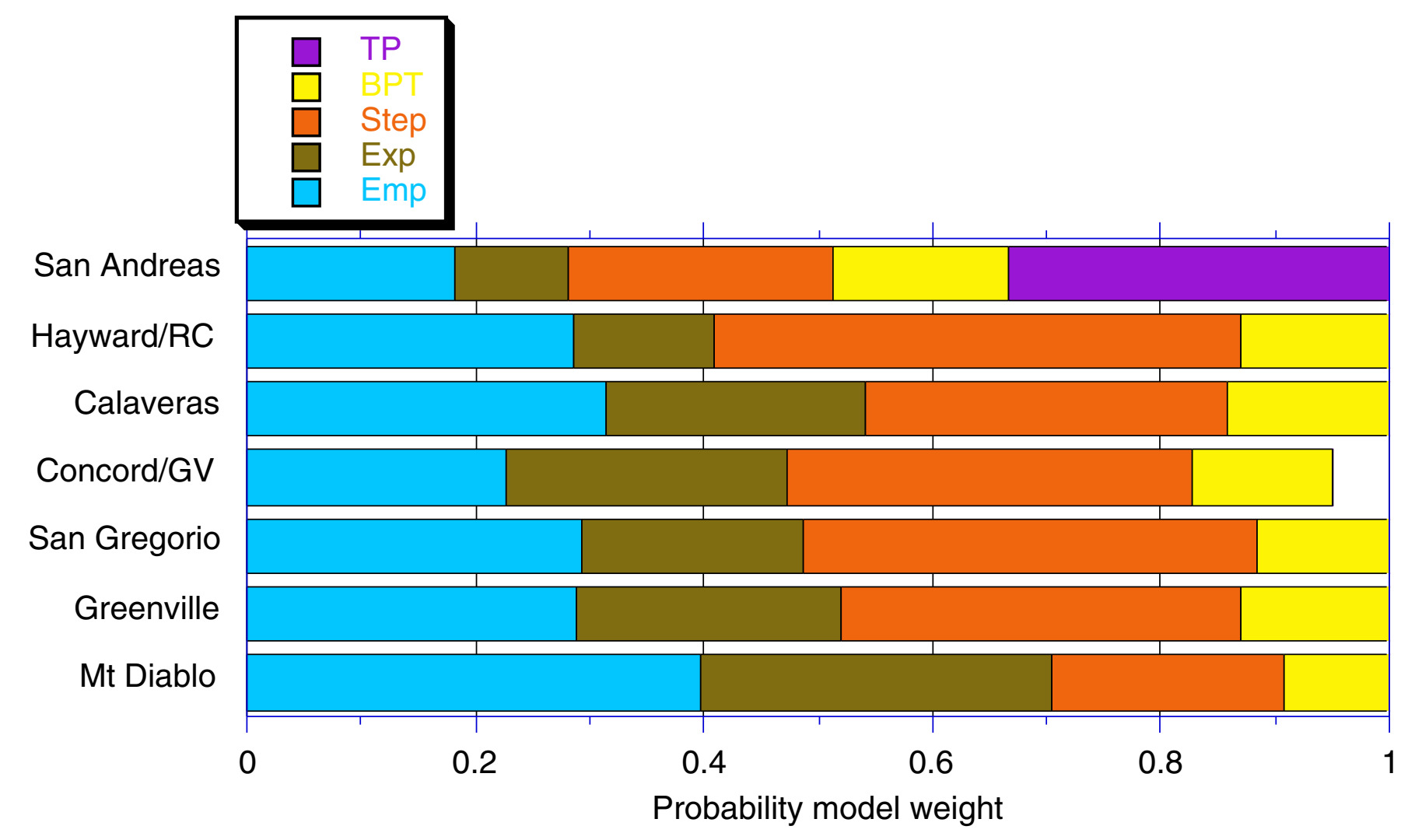

Figure 5.12. Division of weight assigned to each probability model for each fault, as determined by expert opinion and given in Table 5.5. Time predictable (TP) model was applied only to the San Andreas fault. 


\section{Chapter 6: EarthQuake Probabilities for THE SAN FRANCISCO BAY REgION 2002-2031: RESULTS AND DISCUSSION}

\section{Introduction}

Here we report and discuss earthquake probabilities calculated from the methods and inputs developed in the preceding chapters. As indicated in the adjoining box, we report probabilities for several different types of sources, and for various time periods and magnitudes of interest. A full description of the earthquake probability in the SFBR earthquake model includes estimates of the mean magnitude and probability for each rupture source (including single- and multisegment ruptures), of the probability for rupture involving a particular fault segment (which may involve earthquakes of different sizes), and of the probability of earthquakes above a specified magnitude on each fault system, in the background, and in the region. We focus on the probabilities of $\mathbf{M} \geq 6.7$ earthquakes. We also quantify and discuss rupture probabilities for earthquakes having $\mathbf{M}<6.7$. The regional probabilities reported here refer to earthquakes occurring within the geographic bounds of the SFBR. While some earthquakes in our model occur outside the SFBR (on the off-shore segment of the San Andreas fault), we include in the regional and fault system results only earthquakes that rupture one or more segments within the SFBR and floating earthquakes that occur within the region.

Because our calculations employ a Monte Carlo method, we report each probability as a mean value and the associated $95 \%$ confidence bound, the latter shown as a range printed within square brackets ${ }^{1}$. The mean values are our principal results, while the confidence bounds define the formal uncertainties in the probability calculations (as described in Chapter 5). When we refer simply to "the probability", we are referring to the mean 30-year probability. The width of the confidence bounds reflects the uncertainty in both the models and the input parameters used in the calculations.

As described in Chapter 5, we employed a suite of probability models in our calculations: Poisson, Brownian Passage Time (BPT), Time-predictable (TP) and Empirical. Our principal results reflect weighted averages of these models. To explore the implications for some of the modeling assumptions, we will from time to time refer to or compare calculations for individual probability models throughout this chapter.

We focus on the 30-year time window 2002-2031 but also report results for other intervals of interest to the community, including probabilities in 1-, 5-, 10-, and 20-year intervals calculated with our weighted (preferred) model, and in a 100-year interval (2002-2102) calculated with the time-independent, Poisson model. We also determine the probabilities for $\mathbf{M} \geq 7.0$ and $\mathbf{M} \geq 7.5$ earthquakes on each fault and in the region. Unlike WG88 and WG90. which stated

\footnotetext{
${ }^{1}$ For example, if a result is given as 0.62 [0.38-0.85], then $2.5 \%$ of the viable models in the calculation had probabilities less than 0.38 and $2.5 \%$ had probabilities greater than 0.85 .
} 
probabilities for earthquakes having magnitudes of about 7 or about 8 , this study is precise about earthquake magnitudes for each rupture source.

In what follows, the section on Regional Earthquake Probabilities presents results for the region and its major sub-regions, and for various magnitude thresholds and time periods. Next, the section on Individual Faults and the Background examines earthquake probabilities for each of the characterized fault systems and the background, and examines each fault's setting and the key factors involved in shaping the results. The section on Comparison to Earlier Probability Reports examines some of the reasons for the differences between this report and earlier ones. The section on Sensitivity of the Results examines the dependence of the results on some of the assumptions made in the model and uncertainties encountered in the data. 


\section{Probability Of What?}

Earthquake probabilities are presented in this chapter for each of the five cases defined below.

Fault segments. The 18 fault segments are the building blocks of the rupture sources. When a fault segment ruptures, the rupture may be confined to the segment, or it may involve two or more adjacent segments. Hence, ruptures of a given fault segment can involve earthquakes with a wide range of magnitudes. The probability of fault segment rupture refers to the chance the segment will rupture, regardless (unless otherwise stated) of the size of the earthquake involved. Segment rupture probabilities are shown in the left half of Table 6.3 and the middle sections of Tables 6.4-6.10. The right half of Table 6.3 shows corresponding fault segment probabilities for $\mathbf{M} \geq 6.7$ earthquakes.

Rupture sources. A rupture source comprises a specified set of (one or more) fault segments. For some faults the term also includes 'floating earthquakes'. Each rupture source generates earthquakes having a distinct mean magnitude governed by its geometry. In the SFBR, these range from M5.8 (rupture of segment CS) to M7.9 (four-segment rupture of the San Andreas fault). A rupture source probability refers to an earthquake of a specific (characteristic) magnitude occurring on that rupture source. Rupture source probabilities are shown in the lower portion of Tables 6.4-6.10. The shaking scenarios discussed in Chapter 7 are for specified rupture sources.

Fault systems. Each of the seven characterized fault systems is host to a variety of rupture sources having a variety of magnitudes (except the single-segment Mt. Diablo thrust, which has only one rupture source). Earthquake probabilities for fault systems are presented in two forms: the chance of occurrence of any earthquake on the fault system; and the chance of earthquakes above a specified magnitude threshold on the fault system. Both types of fault system probability are shown in the top sections of Tables 6.4-6.10, whereas probabilities for earthquakes above given magnitude thresholds are shown in Table 6.1.

Background. The background includes all earthquakes in the SFBR other than those occurring on the characterized faults. The probability for the background is specified for earthquakes above a specified threshold. Background probabilities for various magnitude thresholds are shown in Table 6.1 and 6.11.

Region. Probabilities of earthquakes in the entire SFBR (or in a sub-region, such as East Bay) combine the probabilities of earthquakes on all of the faults and in the portion of the background included in the region (or sub-region). These are always threshold-type probabilities. Regional probabilities are shown at the bottom of Table 6.1 and in Table 6.2. 


\section{Regional Earthquake Probabilities}

\section{0-year probabilities of $M \geq 6.7$ earthquakes}

The probability of one or more large ( $M \geq 6.7)$ earthquakes in the SFBR in the next 30 years is 0.62 [0.38 - 0.85] (Table 6.1, Figure 6.1). This regional result combines the probabilities of earthquakes on each of the seven characterized fault systems and in the background. The greatest contributors of $\mathbf{M} \geq 6.7$ earthquakes to the regional probability are the Hayward-Rodgers Creek fault system ( $\mathrm{P}=0.27)$, the San Andreas fault $(\mathrm{P}=0.21)$, and the background earthquake sources $(\mathrm{P}=0.14)$. The San Gregorio fault $(\mathrm{P}=0.10)$ and Calaveras fault $(\mathrm{P}=0.11)$ are also significant contributors to the regional probability.

Table 6.1. Probability in 2002-2031 of one or more earthquakes with magnitude M6.7 and above, M7.0 and above, and M7.5 and above, for the characterized fault systems, the background, the SFBR region, and sub-regions east and west of San Francisco Bay. (Region and sub-region values include probability for fault systems and background). The $95 \%$ confidence ranges are shown in parentheses.

\begin{tabular}{|c|c|c|c|c|c|c|c|}
\hline & \multicolumn{2}{|r|}{$M \geq 6.7$} & \multicolumn{2}{|r|}{$\mathbf{M} \geq 7.0$} & \multicolumn{3}{|c|}{$\mathbf{M} \geq 7.5$} \\
\hline Fault system & Mean & $2.5 \%-97.5 \%$ & Mean & {$[2.5 \%-97.5 \%]$} & Mean & $2.5 \%$ & $-97.5 \%$ \\
\hline San An & 0.21 & $0.01-0.58]$ & 0.17 & {$[0.01-0.33]$} & 0.09 & 0.01 & -0.18 \\
\hline & & & & $2-0.25$ & & 0.00 & \\
\hline & & $3-$ & & $0-c-c$ & & 0.00 & \\
\hline & & $0.00-0$ & $0 .(-1+x-x)$ & $0.00-0.02$ & & 0.00 & -0.00 \\
\hline & & $0.02-0$ & & $.01-0.20$ & 1 & 0.00 & -0.04 \\
\hline & & & & $0-0$ & & 0.00 & \\
\hline & & $0.00-$ & 0.0 & $0.00-0.01$ & 0.00 & 0.00 & -0.00 \\
\hline Background & 0.14 & $0.07-0.37$ & 0.04 & $0.00-0.14$ & 0.00 & 0.00 & -0.00 \\
\hline SF Bay Region & 0.62 & $0.38-0.85$ & 0.35 & $0.17-0.56$ & 0.10 & 0.02 & -0.19 \\
\hline
\end{tabular}

The probabilities for the SFBR as a whole are better constrained than those for any individual fault or for the background. This result follows directly from the average earthquake rates determined by the SFBR earthquake model in Chapter 4. Nevertheless, even the uncertainty in the regional probabilities, from 0.38 to 0.85 , is large. The uncertainty in probability reflects uncertainty in the model inputs. How the various sources of uncertainty in the model affect the results presented here is discussed in the Sensitivities Section that comes later in this chapter.

The easternmost faults, the Greenville, Concord-Green Valley and Mt. Diablo faults and the northern portion of the Calaveras fault (Figure 6.2), have a mean combined probability for $\mathbf{M} \geq 6.7$ earthquakes of 0.19 [0.16 to 0.22$].{ }^{2}$ Combining this aggregate probability with the contributions from the Hayward-Rodgers Creek fault, the remaining part of the Calaveras fault, and half the background, we find a probability for $\mathbf{M} \geq 6.7$ earthquakes east and northeast of San Francisco Bay of 0.46 [0.28 to 0.63].

West of San Francisco Bay, the San Andreas and San Gregorio faults have a mean combined probability for a $\mathbf{M} \geq 6.7$ earthquake of 0.29 [0.18 to 0.40]. (Figure 6.2). With half of the

\footnotetext{
${ }^{2}$ Estimates of uncertainty in probability for sub-regions assume that errors in probability on faults are independent and normally distributed.

${ }^{3}$ Probabilities are combined according to Equation 5.9
} 
background probability included, this part of the SFBR has a probability of 0.34 [0.20 to 0.48] for one or more $\mathbf{M} \geq 6.7$ earthquakes in 2002-2031. Thus, the mean probability for $\mathbf{M} \geq 6.7$ earthquakes is greater east of San Francisco Bay than west of it, although the respective confidence bounds substantially overlap. The reverse is the case for $\mathbf{M} \geq 7.0$ earthquakes, however (see next section).

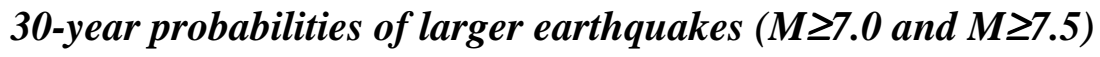

The probability of earthquakes on each fault and in the region decreases with increasing earthquake magnitude (Table 6.1, Figure 6.1). In the region, the probabilities of $M \geq 7.0$ and $\mathrm{M} \geq 7.5$ earthquakes drop to 0.35 [0.17-0.56] and 0.10 [0.02-0.19], respectively. This decrease is greatest east of San Francisco Bay, where the fault segments are relatively short (20- to 40-km in length) and full-fault ruptures were assessed to be relatively rare. East of San Francisco Bay, the aggregate mean probabilities for $\mathbf{M} \geq 7.0$ and $\mathbf{M} \geq 7.5$ earthquakes are 0.15 and $<0.01$, respectively. While the faults on this side of the bay have the highest probability of $\mathbf{M} \geq 6.7$ earthquakes, none is capable of generating $\mathbf{M}>7.5$ earthquakes, which require rupture lengths of hundreds of kilometers.

West of San Francisco Bay, the longer segments of the San Andreas and San Gregorio faults and the view of the San Andreas source characterization group that the San Andreas fault tends to fail in multi-segment ruptures (Table 6.4) result in a significant production of larger magnitude earthquakes. In this part of the region, the aggregate mean probabilities for $\mathbf{M} \geq 7.0$ and $\mathbf{M} \geq 7.5$ earthquakes are 0.25 and 0.10 , respectively.

\section{0-year probabilities of smaller earthquakes $(M<6.7)$.}

Smaller earthquakes occurring in urbanized areas may cause significant localized damage. For example, the 1987 M5.9 Whittier Narrows earthquake, which occurred in the Los Angeles area, caused \$350 million damage, while the larger 1984 M6.2 Morgan Hill earthquake, which occurred in a rural region in the southern part of the SFBR, caused $\$ 10 \mathrm{M}$ damage. However, even smaller earthquakes occurring outside urban areas can have a significant impact; a M5.2 earthquake in September 2000, in a rural area 10 miles northwest of the City of Napa resulted in $\$ 65$ million in damage to that community (California Seismic Safety Commission), 2002, http://www.seismic.ca.gov/sscearth.htm).

Recent and historical rates of seismicity in the SFBR region can provide plausible bounds on the probability of future $(6.0 \leq \mathbf{M}<6.7)$ earthquakes in the region. The most recent 30 -year period (1972-2001), in which seismicity appears to be near the minimum of the regional earthquake cycle (Figure 5.5), would suggest a 30-year probability of 0.80 for $6.0 \leq \mathbf{M}<6.7$ events (equivalently, the expected number $N_{\text {exp }}$ of such events is 1.6); this result may serve as a lower bound. In contrast, the most active historical period (1850-1906) would suggest that this probability is $0.99\left(N_{e x p}=4.6\right)$, which may serve as an upper bound for the likelihood of these smaller earthquakes.

The SFBR earthquake model can provide an estimate of the regional probability of smaller earthquakes by assuming a continuous Gutenberg-Richter cumulative magnitude distribution below M6.7 with $b=0.9$ (see Figure 4.5). This extension of the regional model suggests that, on 
average, the probability of $6.0 \leq \mathbf{M}<6.7$ earthquakes in the SFBR in a 30 -year interval is 0.96 [0.91 - 0.99] $\left(N_{e x p}=3.3\right)$, which lies within the bounds estimated from historical activity.

Which of these estimates is most applicable largely depends on what role the 1906 stress shadow plays in determining the current rate of smaller earthquakes, just as it did in the case of the larger earthquakes. While a formal probability model-weighting procedure was not applied in the calculation of probability of $6.0 \leq \mathbf{M}<6.7$ earthquakes, consideration of a stress-shadow effect for these earthquakes would reduce the model result, bringing it closer to the lower bound defined by the more recent seismicity.

\section{Earthquake probabilities at exposure times other than 30 years}

The SFBR earthquake model allows us to calculate earthquake probabilities for the region for time intervals other than 30 years (Figure 6.3). Table 6.2 lists SFBR probabilities for 1, 5, 10, 20, and 30 years for both the WG02 weighted, time-dependent model $^{4}$ and the long-term average Poisson model. With the Poisson model, we determine an extended regional probability for the next 100 years. Table 6.2 shows that there is an approximately 50-50 chance of a $\mathbf{M} \geq 6.7$ earthquake in the SFBR in the next 20 years. The similarity in the mean results calculated with the weighted model and the Poisson model over all of the different time periods reflects the distributed weights assigned to the "competing" models—-which in turn stems from our uncertainty about the effects of the stress shadow associated with the 1906 earthquake.

Table 6.2. Probability of $\mathbf{M} \geq 6.7$ earthquakes in the SFBR in various exposure times

\begin{tabular}{|c|c|c|}
\hline $\begin{array}{c}\text { Exposure Time } \\
\text { (years from 2002) }\end{array}$ & Weighted Models & $\begin{array}{c}\text { Poisson Model } \\
\text { (Time-independent) }\end{array}$ \\
\cline { 2 - 3 } 1 & $0.04[0.02-0.08]$ & $0.03[0.02-0.04]$ \\
5 & $0.16[0.07-0.32]$ & $0.14[0.11-0.18]$ \\
10 & $0.29[0.14-0.49]$ & $0.26[0.21-0.33]$ \\
20 & $0.49[0.27-0.74]$ & $0.46[0.37-0.55]$ \\
30 & $0.62[0.38-0.85]$ & $0.60[0.51-0.70]$ \\
100 & - & $0.96^{1}[0.92-0.99]$ \\
\hline
\end{tabular}

1. Equivalently, the number of $\mathbf{M} \geq 6.7$ earthquakes expected in the SFBR in 100 years is 3.1 [2.4 - 4.1]

\section{Probabilities for Individual Faults and the Background}

Earthquake probability in the SFBR is distributed among the seven characterized faults-concentrated more on some than others - as well as in the areas between these faults, which give rise to 'background' earthquakes (Table 6.1). On some characterized faults, the probability is unevenly distributed among the segments (Figure 6.5, Table 6.3). These fault-tofault and segment-to-segment variations in probability have their origins in the SFBR earthquake model (Chapter 4) and in differences among the faults in their slip rates, dates of past earthquakes and interaction effects (Chapter 5).

\footnotetext{
${ }^{4}$ Estimates for the Empirical Model rate function $\mathrm{g}(\mathrm{t})$ were made for the 30-year time interval 2002-2031 (Table 5.1). We adopt those estimates here for time intervals shorter than 30 years.
} 
Table 6.3. Probabilities of characterized earthquakes in 2002-2031 on SFBR fault segments

\begin{tabular}{|c|c|c|c|c|c|c|c|c|c|c|c|}
\hline \multirow[b]{3}{*}{ Fault system } & \multirow[b]{3}{*}{$\begin{array}{l}\text { Fault } \\
\text { seg- } \\
\text { ment }\end{array}$} & \multicolumn{10}{|c|}{ Probability } \\
\hline & & \multicolumn{4}{|c|}{ All ruptures } & \multicolumn{6}{|c|}{$\mathbf{M} \geq 6.7$ ruptures } \\
\hline & & Mean & [ $2.5 \%$ & & 97.5\% & Mean & [ & $2.5 \%$ & - & $97.5 \%$ & ] \\
\hline \multirow[t]{4}{*}{ San Andreas } & SAS & 0.113 & 0.010 & & 0.238 & 0.112 & & 0.009 & - & 0.235 & \\
\hline & SAP & 0.133 & 0.010 & & 0.295 & 0.132 & & 0.011 & - & 0.294 & \\
\hline & SAN & 0.116 & 0.014 & - & 0.235 & 0.114 & & 0.013 & - & 0.233 & \\
\hline & SAO & 0.107 & 0.011 & - & 0.220 & 0.106 & & 0.011 & - & 0.218 & \\
\hline \multirow[t]{3}{*}{ Hayward/RC } & $\mathrm{HS}$ & 0.197 & 0.063 & 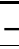 & 0.445 & 0.123 & & 0.037 & - & 0.267 & \\
\hline & $\mathrm{HN}$ & 0.218 & 0.067 & - & 0.513 & 0.114 & & 0.035 & - & 0.264 & \\
\hline & $\mathrm{RC}$ & 0.177 & 0.053 & ב & 0.460 & 0.170 & & 0.052 & - & 0.430 & \\
\hline \multirow[t]{3}{*}{ Calaveras } & CS & 0.316 & 0.050 & - & 0.640 & 0.023 & 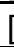 & 0.000 & - & 0.098 & \\
\hline & $\propto$ & 0.373 & 0.156 & & 0.592 & 0.029 & & 0.000 & - & 0.122 & \\
\hline & $\mathrm{CN}$ & 0.167 & 0.055 & & 0.402 & 0.099 & & 0.027 & - & 0.256 & \\
\hline \multirow[t]{3}{*}{ Concord/GV } & $\mathrm{CON}$ & 0.140 & 0.027 & & 0.359 & 0.031 & & 0.000 & - & 0.110 & \\
\hline & GVS & 0.145 & 0.027 & & 0.365 & 0.034 & & 0.000 & - & 0.118 & \\
\hline & GVN & 0.155 & 0.028 & & 0.412 & 0.031 & & 0.000 & - & 0.109 & \\
\hline \multirow[t]{2}{*}{ San Gregorio } & SGS & 0.056 & 0.009 & & 0.154 & 0.054 & & 0.008 & - & 0.140 & \\
\hline & SGN & 0.077 & 0.016 & & 0.210 & 0.076 & & 0.016 & 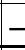 & 0.211 & \\
\hline \multirow[t]{2}{*}{ Greenville } & GS & 0.048 & 0.003 & & 0.148 & 0.021 & & 0.001 & - & 0.058 & \\
\hline & GN & 0.046 & 0.003 & & 0.142 & 0.023 & & 0.001 & & 0.065 & \\
\hline Mt Diablo & MTD & 0.075 & 0.005 & & 0.241 & 0.025 & & 0.000 & - & 0.083 & \\
\hline
\end{tabular}

In this section we present the earthquake probabilities determined for each fault and for its segments and its rupture sources. We also briefly describe the model characteristics that played a significant role in determining these probabilities. In general, these come down to the slip rate on the fault, choice of fault rupture model, times of previous earthquakes, and the amount of aseismic slip.

\section{San Andreas Fault}

The San Andreas fault is the master fault of the SFBR — and all of California — carrying about half of the $36-43 \mathrm{~mm} / \mathrm{yr}$ plate-motion velocity across the region. As modeled here, it is the only SFBR fault system capable of hosting the largest SFBR earthquakes, such as the four-segment rupture that occurred in 1906. The 470-km-long rupture of the San Andreas fault that occurred in the 1906 earthquake is, by far, the longest surface rupture of any known continental strike-slip earthquake (see Table 4.2). The occurrence of such ruptures plays a dominant role in controlling the seismic moment budget in the region. These earthquakes also cast stress shadows of yet unknown duration across the entire Bay region, as was the case following the 1906 earthquake. As noted previously, the nature and duration of this stress shadow are the sources of the greatest uncertainty in the results presented here.

The probability of one or more characterized ruptures occurring on the San Andreas fault in 2002-2031 is 0.24 (Table 6.4). Among these, the most likely (in descending order of probability) are a floating rupture (M6.90), a full (1906-type) rupture (M7.90), a rupture of 
segment SAP (M7.15), a combined rupture of segments SAS and SAP (M7.42), and a combined rupture of segments SAN and SAO (M7.70).

The relatively high probability of a floating earthquake reflects three model conditions: the weights applied to the fault-rupture models for the San Andreas fault (Table 3.2); the small magnitude (M6.9) relative to the segment ruptures, which allows for a greater frequency of occurrence, and the rate at which the Time-Predictable probability model generates earthquakes of this size. Some support for the floating-earthquake rupture scenario is found in the historical record, with the occurrence of the 1838 M6.8 earthquake, which probably, but not certainly, occurred on the San Francisco peninsula segment (SAP) (Bakun, 1999) and with the 1898 M6.8 earthquake offshore, near Point Arena, which probably occurred on the San Andreas fault (Ellsworth, 1990; Bakun 2000).

Given the geologic slip rate of the San Andreas fault (17-24 mm/yr), the probabilities for the large magnitude $\mathrm{SAS}+\mathrm{SAP}+\mathrm{SAN}+\mathrm{SAO}$ and (SAS+SAP, SAN+SAO) ruptures are primarily fixed by the weighting on the fault-rupture models. The four-segment rupture scenario is supported by the 1906 earthquake and paleoseismic data suggesting even earlier earthquakes rupturing all four segments of the San Andreas fault (Chapter 3). The 2 two-segment rupture probabilities reflect the opinion of the San Andreas SCG that the Golden Gate stepover region is an important segment boundary.

The nearly uniform probabilities for rupture of the four segments that comprise the San Andreas fault in this analysis, ranging from just 0.11 to 0.13 , reflects three things: in the BPT model, all four segments were reset in 1906 and the mean recurrence intervals of the segments are similar ranging only from 223 to $229 \mathrm{yr}$, so the respective phases in the renewal cycles are similar; in the TP model, the distribution of slip in 1906 is similar to the distribution of slip rate on the segments; and in the long-term earthquake model, the floating source, which is the largest contributor of $M \geq 6.7$ earthquakes on the fault, is uniformly distributed on the fault.

Despite its status here as a background earthquake, the Loma Prieta earthquake occurred close enough to segment SAS to reduce right-lateral shear stress on this segment, while at the same time providing a loading increment on the adjacent SAP segment. The substantially larger probability for segment SAP (0.044) relative to segment SAS (0.026) mainly reflects the state variable change in the BPT-step and time-predictable models (negative for SAS, positive for SAP) due to that event. Although the choice to treat Loma Prieta as a background earthquake seems significant, its influence on segment SAS through stress transfer is, in fact, nearly as great as it would be if treated as having occurred on that segment. We can compare the case of considering Loma Prieta as a background earthquake (wherein it reduces the failure-readiness of segment SAS through stress transfer), and the case in which Loma Prieta is a rupture of segment SAS (wherein it resets the SAS segment directly in the BPT -step probability method). The probability of an earthquake involving the SAS segment is reduced by less than $25 \%$ in the latter case (from 0.10 [0.00-0.27] to 0.08 [0.00-0.16]), a small amount relative to other uncertainties. 
Table 6.4. Probabilities for the San Andreas fault, 2002-2031.

\begin{tabular}{|l|l|}
\hline San Andreas Fault & \multicolumn{2}{|c|}{ Probability } \\
\cline { 2 - 3 } & Mean [ $2.5 \%-97.5 \%]$ \\
\hline \hline Entire Fault system & $0.238[0.029-0.531]$ \\
All ruptures & $0.235[0.029-0.524]$ \\
Ruptures M $\geq 6.7$ & $0.182[0.015-0.379]$ \\
Ruptures M $\geq 7.0$ & $0.090[0.008-0.189]$ \\
Ruptures M $\geq 7.5$ & $0.113[0.010-0.238]$ \\
\hline Fault segments - All ruptures & \\
SAS & $0.133[0.010-0.295]$ \\
SAP & $0.116[0.014-0.235]$ \\
SAN & $0.107[0.011-0.220]$ \\
SAO & \\
\hline Rupture sources (Mean & \\
magnitude) & \\
SAS (7.03) & $0.026[0.000-0.108]$ \\
SAP (7.15) & $0.044[0.000-0.172]$ \\
SAN (7.45) & $0.009[0.000-0.037]$ \\
SAO (7.29) & $0.009[0.000-0.043]$ \\
SAS+SAP (7.42) & $0.035[0.001-0.102]$ \\
SAP+SAN (7.65) & $0.000[0.000-0.000]$ \\
SAN+SAO (7.70) & $0.034[0.001-0.106]$ \\
SAS+SAP+SAN (7.76) & $0.001[0.000-0.003]$ \\
SAP+SAN+SAO (7.83) & $0.002[0.000-0.011]$ \\
SAS+SAP+SAN+SAO (7.90) & $0.047[0.003-0.138]$ \\
Floating (6.9) & $0.071[0.004-0.264]$ \\
\hline
\end{tabular}

\section{Hayward-Rodgers Creek Fault System}

The Hayward-Rodgers Creek fault system extends some $140 \mathrm{~km}$, from the Warm Springs district of Fremont, along the east side of San Francisco Bay beneath San Pablo Bay to near Healdsburg on the north. WG90 treated this system as two different and independent faults, the Hayward fault and the Rodgers Creek fault, and for all intents and purposes, so do we, given the low weight assigned to rupture scenarios that involve the Rodgers Creek fault as anything but a single-segment rupture. The geologic slip rate for the three fault segments HS, HN, and RC is 9 $\pm 2 \mathrm{~mm} / \mathrm{yr}$, but on HS and HN a large fraction of the moment rate is expended in aseismic creep.

The Hayward-Rodgers Creek fault system has the highest probability of the characterized faults in SFBR of producing $\mathbf{M} \geq 6.7$ earthquakes in the next 30 years. Its characterized ruptures range in mean magnitude from M6.5 to M7.3 (Table 6.5). The probability of one or more characterized ruptures occurring on the Hayward-Rodgers Creek fault system in 2002-2031 is 0.40 , while the corresponding probability for $\mathbf{M} \geq 6.7$ earthquakes is 0.27 (Table 6.5). Among the most likely of these (in descending order of probability) are a rupture of segment RC (M6.98); a rupture of segment HN (M6.49); and a rupture of segment HS (M6.67). The high probabilities for these single-segment ruptures reflect the expert-opinion weight placed on such ruptures 
(Table 3.2) and in the case of RC the relatively long period elapsed since the most recent earthquake. The probability of a $M \geq 7.0$ earthquake on the Hayward-Rodgers Creek fault system is relatively low because only two of its rupture sources have mean magnitudes in excess of 7.0 (Table 6.5) and both of these have been assigned low weight (Table 3.2).

The rupture probabilities for the HS and HN segments illustrate how these probabilities work above and below the $\mathbf{M} \geq 6.7$ threshold. The probability for $\mathrm{HN}$ of any type of rupture is 0.218 (Table 6.5) and for $\mathbf{M} \geq 6.7$ ruptures is 0.113 (Table 6.3), a significant reduction because the mean magnitude of the single-segment rupture is 6.49 and its upper distribution function barely crosses the M6.7 threshold (Figure 6.5). In addition to a single-segment rupture, the HN segment can rupture in four other ways: $\mathrm{HS}+\mathrm{HN}$ (0.085 probability), $\mathrm{HN}+\mathrm{RC}(0.018), \mathrm{HS}+$ $\mathrm{HN}+\mathrm{RC}(0.010)$ and in floating earthquakes apportioned according to length $(0.007 \mathrm{x}$ $35 \mathrm{~km} / 150 \mathrm{~km})$. At these small values, probabilities are additive to a first approximation, and they sum to 0.1146 , very close to the $\mathbf{M} \geq 6.7$ probability given above. For $\mathbf{M} \geq 6.7$, then, there is always a minimum rupture probability given approximately by the sum of the probabilities for high-magnitude (M>>6.7) ruptures. Such ruptures are represented, for East Bay faults, by multisegment rupture sources.

The comparable situation for HS is more complicated because the mean magnitude of the singlesegment source is $\mathbf{M}=6.67$, essentially the same as the threshold $\mathbf{M}$ of 6.7. Thus, about half of the single segment-ruptures will have $\mathbf{M}>6.7$ and half will have $\mathbf{M}<6.7$. The probability for HS of any type of rupture is 0.197 (Table 6.5) and for $\mathbf{M} \geq 6.7$ ruptures is 0.123 (Table 6.3). Clearly, the probability of earthquakes can be very sensitive to the threshold level chosen, especially in cases where there are high-probability rupture sources with magnitudes near the threshold of interest.

The principal source of uncertainty in our probability estimates for specific rupture sources on this fault system is the depth extent of aseismic creep on its segments. In our study, we used creep to reduce the source area, and hence magnitude, of potential ruptures. Some data suggest that currently the entire depth extent of the fault creeps aseismically, Another major source of uncertainty is in the position of the HS-HN segmentation point; and, even more fundamentally, in whether the northern extent of the 1868 rupture truly represents an enduring segmentation point at all (i.e., whether the entire Hayward fault always ruptures as a single segment). 
Table 6.5. Probabilities for the Hayward-Rodgers Creek fault 2002-2031.

\begin{tabular}{|l|c|}
\hline \multirow{2}{*}{$\begin{array}{l}\text { Hayward-Rodgers } \\
\text { Creek fault }\end{array}$} & \multicolumn{1}{|c|}{ Probability } \\
\cline { 2 - 3 } Entire fault system & Mean [ $2.5 \%-97.5 \%]$ \\
All ruptures & $0.397[0.137-0.787$ ] \\
Ruptures M $\geq 6.7$ & $0.272[0.096-0.578]$ \\
Ruptures $\mathrm{M} \geq 7.0$ & $0.105[0.022-0.249]$ \\
Ruptures M $\geq 7.5$ & $0.000[0.000-0.002]$ \\
\hline Fault segments - All & \\
ruptures & \\
HS & $0.197[0.063-0.445]$ \\
HN & $0.218[0.067-0.513]$ \\
RC & $0.177[0.053-0.460]$ \\
\hline Rupture sources (Mean & \\
magnitude) & \\
HS (6.67) & $0.113[0.022-0.319]$ \\
HN (6.49) & $0.123[0.023-0.360]$ \\
HS+HN (6.91) & $0.085[0.019-0.232]$ \\
RC (6.98) & $0.152[0.041-0.414]$ \\
HN+RC (7.11) & $0.018[0.000-0.066]$ \\
HS+HN+RC (7.26) & $0.010[0.001-0.033]$ \\
Floating (6.9) & $0.007[0.003-0.016]$ \\
\hline
\end{tabular}

\section{Calaveras Fault}

The Calaveras fault diverges from the San Andreas fault south of Hollister and extends $123 \mathrm{~km}$ in a northerly direction to Danville. The geologic slip rate on the southern two segments (CS and $\mathrm{CC}$ ) is $15 \pm 3 \mathrm{~mm} / \mathrm{yr}$, more than a third of the plate motion across the SFBR at these latitudes. North of CC, the Calaveras fault sheds $60 \%$ of this slip rate to the Hayward fault, leaving the northern Calaveras fault $(\mathrm{CN})$ with a slip rate of $6 \pm 2 \mathrm{~mm} / \mathrm{yr}$. Aseismic slip consumes a large fraction of the moment rate expenditure on CS and CC. Paleoseismic data indicate that surfacebreaking earthquakes have occurred on segment $\mathrm{CN}$, with the last possibly occurring between 1160 and $1425 \mathrm{AD}$, but are inconclusive for segments CC and CS. In historical time, the Calaveras fault has been the source of moderate, but not large, earthquakes. The largest of these occurred in 1911 and 1984 (both M 6.2) (Table 2.1; Bakun, 1999).

Characterized earthquakes on the Calaveras fault range in mean magnitude from M5.8 to M6.9 (Table 6.6). The probability of one of these earthquakes occurring in 2002-2031 is 0.59 [0.024 0.90]. Among these, the most likely to occur (in order of descending probability) are a floating earthquake on segment CS or CC (M6.2); a rupture of segment CS (M5.8); a rupture of segment CC (M6.2); and a rupture of segment CN (M6.8). Because the characterized ruptures on this fault are moderate in size and segments were judged to rarely link up, the probability of $\mathbf{M} \geq 6.7$ earthquakes here is much lower than it is on the San Andreas or Hayward faults, and the probability of $\mathbf{M} \geq 7.0$ earthquakes is negligible (Table 6.1). An increase (from south to north) in 
the probability of rupture of a segment of the Calaveras fault (Table 6.6) reflects the tapering of aseismic slip assigned to these segments (Table 4.1).

Characterizing the long-term earthquake production of the Calaveras fault proved to be extremely challenging. In particular, it is uncertain whether and to what the degree the predominantly creeping segments (CS and CC) are capable of producing large (M $\geq 6.7)$ earthquakes. The high creep rate and repeated historical occurrence of moderate sized earthquakes on these segments suggests that seismic moment release on the Calaveras fault might be largely accommodated by creep and moderate earthquakes. Accordingly, we have placed high weight (0.8) on fault rupture models emphasizing predominantly single-segment and floating M6.2 ruptures (Table 3.5). Geological evidence to support the existence of segments sufficiently short to host M6.2 earthquakes is lacking; therefore, high weight was placed on the floating earthquake source.

Table 6.6 Probabilities for the Calaveras fault, 2002-2031.

\begin{tabular}{|l|c|}
\hline Calaveras Fault & Probability \\
\cline { 2 - 2 } & Mean [ $2.5 \%-97.5 \%]$ \\
\hline \hline Entire fault system & \\
All ruptures & $0.592[0.243-0.895]$ \\
Ruptures $\mathrm{M} \geq 6.7$ & $0.107[0.028-0.271]$ \\
Ruptures $\mathrm{M} \geq 7.0$ & $0.015[0.000-0.061]$ \\
Ruptures M $\geq 7.5$ & $0.000[0.000-0.000]$ \\
\hline Fault segments - All & \\
ruptures & \\
CS & $0.316[0.050-0.640]$ \\
C & $0.373[0.156-0.592]$ \\
CN & $0.167[0.055-0.402]$ \\
\hline Rupture sources (Mean & \\
magnitude) & \\
CS (5.79) & $0.213[0.000-0.538]$ \\
CC (6.23) & $0.138[0.039-0.297]$ \\
CS+CC (6.36) & $0.050[0.000-0.203]$ \\
CN (6.78) & $0.124[0.030-0.356]$ \\
CC+CN (6.90) & $0.003[0.000-0.036]$ \\
CS+CC+CN (6.93) & $0.020[0.000-0.079]$ \\
Floating (6.2) & $0.074[0.017-0.195]$ \\
Floating on CS+CC (6.2) & $0.251[0.051-0.560]$ \\
\hline
\end{tabular}

\section{Concord-Green Valley Fault System}

The Concord-Green Valley fault system extends from the vicinity of Walnut Creek north to Wooden Valley, a distance of approximately $56 \mathrm{~km}$ ( Figure 3.9). The Concord-Green Valley fault is believed to carry most of the right lateral slip transferred from the northern Calaveras fault, although this is an area of active investigation. Large earthquakes have not occurred on 
either the Concord or the Green Valley faults during the historical period, although a M5.4 earthquake occurred on the central part of the Concord fault in 1955 and limited trench observations on both faults indicate the occurrence of ground-breaking ruptures in the past, although the magnitude of those earthquakes is unknown. Aseismic slip at 4-5 mm/yr occurs locally along sections of the Concord-Green Valley fault system and it is not known what portion of the fault system's moment budget is released in large earthquakes. This uncertainty is brought to bear in a large range for the seismic slip factor, $R$, and is a principle contributor the considerable uncertainty in the rupture source magnitudes, recurrence rates, and probabilities.

In our model, characterized earthquakes on the Concord-Green Valley fault range in mean magnitude from M6.0 to M6.7 (Table 4.8). The probability of one of these earthquakes occurring in 2002-2031 is 0.26 [0.04 - 0.60] (Table 6.7). Among these, the most likely are a floating earthquake (M6.2); a rupture of segment GVN (M6.0); a rupture of segment CON (M6.3); and a combined rupture of segments CON, GVS and GVN (M6.7). Because most of the characterized ruptures on the Concord-Green Valley fault are only moderate in size, the probability of $\mathbf{M} \geq 6.7$ earthquakes here is small and the probability of $\mathbf{M} \geq 7.0$ earthquakes is nil (Table 6.1).

Table 6.7 Probabilities for the Concord-Green Valley fault system, 2002-2031.

\begin{tabular}{|l|l|}
\hline \multirow{2}{*}{$\begin{array}{l}\text { Concord-Green Valley } \\
\text { Fault }\end{array}$} & \multicolumn{1}{|c|}{ Probability } \\
\cline { 2 - 3 } Entire fault system & Mean [ $2.5 \%-97.5 \%]$ \\
All ruptures & $0.258[0.044-0.601]$ \\
Ruptures M $\geq 6.7$ & $0.036[0.000-0.122]$ \\
Ruptures M $\geq 7.0$ & $0.003[0.000-0.021]$ \\
Ruptures M $\geq 7.5$ & $0.000[0.000-0.000]$ \\
\hline Fault segments - all & \\
ruptures & \\
CON & $0.140[0.027-0.359]$ \\
GVS & $0.145[0.027-0.365]$ \\
GVN & $0.155[0.028-0.412]$ \\
\hline Rupture sources (Mean & \\
magnitude) & \\
CON (6.25) & $0.050[0.003-0.182]$ \\
GVS (6.24) & $0.023[0.001-0.087]$ \\
CON+GVS (6.58) & $0.016[0.001-0.067]$ \\
GVN (6.02) & $0.061[0.004-0.219]$ \\
GVS+GVN (6.48) & $0.032[0.002-0.115]$ \\
CON+GVS+GVN (6.71) & $0.060[0.007-0.222]$ \\
Floating (6.2) & $0.062[0.002-0.296]$ \\
\hline
\end{tabular}

\section{San Gregorio Fault}

The San Gregorio fault is a major splay of the San Andreas fault and the westernmost member of the San Andreas Fault system in SFBR. It courses southeastward $175 \mathrm{~km}$ from the Golden 
Gate segmentation point along the western edge of the San Francisco Peninsula into and through Monterey Bay (Figure 3.1). Much of the San Gregorio fault is offshore; all of the southern segment of the San Gregorio Fault (SGS) is under water, and more than one active trace is believed to exist beneath Monterey Bay. The past behavior of the San Gregorio fault is known only from paleoseismic investigations on its northern segment (SGN) along the San Mateo County coast, which show the occurrence of large slip events (Simpson and others, 1998). Although the most recent major earthquake probably predates the historical era, there is a small probability that the 1838 earthquake occurred on SGN (Bakun,1999). We cannot rule out the possibility that a rupture source could be formed from the linking of SGN with the San Andreas' SAN segment north of the Golden Gate, but this permutation was not considered likely and was not included in the WG02 segmentation model.

In our model, characterized earthquakes on the San Gregorio fault range in mean magnitude from M6.9 (SGS) to M7.4 (full rupture) (Table 6.8). The probability of one of these earthquakes occurring in 2002-2031 is 0.10 [0.02 - 0.29]. Among these, the most likely is a rupture of segment SGN (M7.2). Because its characterized ruptures are relative large in magnitude, owing, in part, to the long length of segment SGN (Table 4.1), the San Gregorio fault contributes significantly to the probability of $M \geq 7.0$ earthquakes in the SFBR (Table 6.1).

Uncertainty in the probabilities estimated for the San Gregorio fault stems from uncertainty about its slip rate, segmentation, and time since the most recent earthquake, as well as our limited ability to model the interaction effects on this fault caused by the 1906 earthquake. Of all the fault segments in the SFBR, segment SGN, being closest to the San Andreas fault, is most strongly affected by the stress redistribution in 1906. It is also perhaps the most challenging segment for modeling the interaction, as the stress change varies rapidly along its length owing to its varying distance from the San Andreas.

Table 6.8 San Gregorio fault probabilities, 2002-2031.

\begin{tabular}{|l|c|}
\hline San Gregorio Fault & Probability \\
\cline { 2 - 2 } & Mean [ $2.5 \%-97.5 \%]$ \\
\hline \hline Entire fault system & $0.104[0.021-0.294]$ \\
All ruptures & $0.102[0.021-0.285]$ \\
Ruptures $\mathrm{M} \geq 6.7$ & $0.072[0.012-0.201]$ \\
Ruptures $\mathrm{M} \geq 7.0$ & $0.009[0.000-0.035]$ \\
Ruptures M $\geq 7.5$ & \\
\hline Fault segments - All & \\
ruptures & $0.056[0.009-0.154]$ \\
SGS & $0.077[0.016-0.210]$ \\
SGN & \\
\hline Rupture sources (Mean & \\
magnitude) & $0.023[0.000-0.115]$ \\
SGS (7.0) & 0.039 [ $0.000-0.175]$ \\
SGN (7.2) & $0.026[0.000-0.101]$ \\
SGS+SGN (7.4) & $0.021[0.008-0.039]$ \\
Floating (6.9) &
\end{tabular}




\section{Greenville Fault}

The Greenville fault is the easternmost strand of the San Andreas fault system in SFBR (Figure 3.1, Figure 3.10). It extends from the eastern flank of Mt. Diablo south to San Antonio Valley, for a total fault length of $43 \pm 20 \mathrm{~km}$. The central Greenville fault produced M5.8 and M5.4 earthquakes in 1980 (Bolt et al.,1981). Current paleoseismic data indicate that surface faulting earthquakes have occurred in the past, but their magnitudes are unknown.

In our model, characterized earthquakes on the Greenville fault range in mean magnitude from M6.2 (GN) to M6.9 (full rupture) (Table 6.9). The probability of one of these earthquakes occurring in 2002-2031 is 0.08 [0.01 - 0.22]. Among these, the most likely are ruptures of segment GS (M6.6) and segment GN (M6.7). The probability of a one or more $\mathbf{M} \geq 6.7$ earthquakes occurring in 2002-2031 on the Greenville fault is 0.03 (Table 6.1). The uncertainties on these numbers are large, due to the lack of information indicating whether the fault's northern and southern segments tend to rupture together or separately (Table 3.7).

Table 6.9 Greenville fault probabilities, 2002-2031.

\begin{tabular}{|l|c|}
\hline \multirow{2}{*}{ Greenville Fault } & \multicolumn{1}{|c|}{ Probability } \\
\cline { 2 - 2 } & Mean [ $2.5 \%-97.5 \%]$ \\
\hline \hline Entire fault system & $0.077[0.007-0.222]$ \\
All ruptures & $0.030[0.002-0.082]$ \\
Ruptures M $\geq 6.7$ & $0.005[0.000-0.016]$ \\
Ruptures $\mathrm{M} \geq 7.0$ & $0.000[0.000-0.000]$ \\
Ruptures M $\geq 7.5$ & \\
\hline Fault segments - All & \\
ruptures & $0.048[0.003-0.148]$ \\
GS & $0.046[0.003-0.142]$ \\
GN & \\
\hline Rupture sources (Mean & \\
magnitude) & $0.031[0.000-0.107]$ \\
GS (6.6) & $0.029[0.000-0.098]$ \\
GN (6.7) & $0.015[0.001-0.047]$ \\
GS+GN (6.9) & $0.004[0.001-0.009]$ \\
Floating (6.2) &
\end{tabular}

\section{Mount Diablo Thrust Fault}

The Mt. Diablo thrust a blind fault, one not directly observable at the Earth's surface (Figure 3.1, Figure3.10). Blind thrust faults elsewhere in California have hosted produced damaging earthquakes, including the 1983 Coalinga, 1989 Loma Prieta, and 1994 Northridge events. The fault itself, its geometry, and rates of slip are inferred from structural and kinematic models. The Unruh and Sawyer (1997) interpretation, adopted herein, is that the blind thrust is a manifestation of crustal shortening within a fold-and-thrust belt, driven by a restraining transfer of slip from the Greenville fault to the Concord fault. The Mt. Diablo thrust fault is thought to underlie the asymmetric, southwest-vergent Mt. Diablo and Tassajara anticlines for a total length of $25 \pm 5$ 
km (Crane, 1995; Unruh and Sawyer, 1997). There is no basis for segmenting the fault, and it is treated as a single earthquake source.

In our model, the single-segment Mt. Diablo fault produces earthquakes with mean magnitude M6.65. The probability of one of these earthquakes occurring in 2002-2031 is 0.08 [0.01 - 0.24] (Tables 6.1, 6.10); the corresponding probability for $\mathbf{M} \geq 6.7$ earthquakes is 0.03 .

Table 6.10 Mt. Diablo fault probabilities, 2002-2031.

\begin{tabular}{|r|c|}
\hline Mt Diablo Fault & \multicolumn{1}{|c|}{ Probability } \\
\cline { 2 - 2 } & Mean [ 2.5\%-97.5\%] \\
\hline \hline $\begin{array}{l}\text { Single-segment fault } \\
\text { (mean magnitude 6.65) } \\
\text { All ruptures }\end{array}$ & $0.075[0.005-0.241]$ \\
\hline Ruptures $\mathrm{M} \geq 6.7$ & $0.025[0.000-0.083]$ \\
\hline
\end{tabular}

\section{Background earthquakes}

While the seven faults characterized in the SFBR earthquake model are the most important and best understood faults in the region, other faults contribute to the earthquake probability in the region as well. These include faults for which we lack sufficient information for characterization in the model and faults that slip rates less than $1 \mathrm{~mm} / \mathrm{yr}$. In addition to these are (presumably) other faults in the region that are yet to be discovered. The Loma Prieta earthquake is classified as a background event. All the uncharacterized faults and unknown faults in the SFBR constitute the background.

The Thrust and Reverse SCG reviewed geodetic data, geologic data, and global plate motion models that provide constraints on rates of deformation across the boundary between the Pacific plate and the Sierra Nevada-Great Valley microplate. They identified several subregions (or "hot spots") within SFBR characterized by significant contractional strain rates accommodated by numerous thrust faults with low slip rates. Among the thrust faults currently mapped within these zones, only the Mt. Diablo thrust was assigned a slip rate exceeding $1 \mathrm{~mm} / \mathrm{yr}$ and was therefore treated as a characterized fault.

An analysis by Wesson and others [2002] of historical earthquakes in the SFBR used probabilistic methods to associate known events with either one of the 18 characterized fault segments or with an uncharacterized source fault. This analysis shows that a significant fraction of the historical events occurred on uncharacterized faults and that these earthquakes (and faults) released a significant fraction of the seismic moment within the SFBR (Figure 2.6).

As discussed in Chapter 5, we modeled the background differently from the characterized faults. We used a truncated Gutenberg-Richter model (with maximum magnitude M7.25 [7.0 7.5]) fit to historical earthquake occurrence, together with the Poisson probability model. 
The probability of a $\mathbf{M} \geq 6.7$ earthquake occurring in 2002-2031 on a fault in the background is 0.14 [0.07-0.37] (Table 6.11). This probability is a substantial part of the regional earthquake probability, exceeded only by the corresponding probabilities on the San Andreas and HaywardRodgers Creek faults (Table 6.1). Thus the uncharacterized faults contribute significantly to the regional probability in the SFBR and "fill in" the areas between the characterized faults as possible sites of large earthquakes.

Table 6.11. Probabilities for background earthquakes, 2002-2031.

\begin{tabular}{|c|c|}
\hline Magnitude & $\begin{array}{c}\text { Probability } \\
\text { Mean }[2.5 \%- \\
97.5 \%]\end{array}$ \\
\hline $\mathbf{M} \geq 6.0$ & $0.56[0.40-0.93]$ \\
\hline $\mathbf{M} \geq 6.5$ & $0.23[0.14-0.55]$ \\
\hline $\mathbf{M} \geq 6.7$ & $0.14[0.07-0.37]$ \\
\hline $\mathbf{M} \geq 7.0$ & $0.04[0.00-0.14]$ \\
\hline $\mathbf{M} \geq 7.5$ & $0.00[0.00-0.00]$ \\
\hline
\end{tabular}

\section{Comparison of Results to Earlier Probability Reports}

Previous assessments of earthquake probabilities in the SFBR were made in 1988 (WG88) and1990 (WG90). Those Working Groups focused on the most active faults, and estimated earthquake probability only for those with sufficient data for time-predictable probability calculations. Both reports used a nominal magnitude threshold of $\mathbf{M} \geq 7$. WG88 analyzed the San Andreas fault and Hayward fault, and concluded that the 30-year probability (1988 to 2018) of earthquakes on each fault was 0.5 . They also assigned an average to low level of reliability to the individual probabilities for the most important sources (which roughly correspond to our single-segment rupture sources SAS, SAP, HS, HN).

WG90 included the Rodgers Creek fault in its assessment, and introduced the use of a logic tree for the calculation sequence. Like WG88, they relied exclusively on the time-predictable probability model. Their regional probability of $\mathbf{M} \geq 7$ earthquakes (1990 to 2020) was 0.67, with the Hayward-Rodgers Creek fault system the principal contributor to the probability. On the San Andreas fault, their Peninsula segment had the highest probability.

An innovation introduced in the SCEC Phase II report-and also used by WG99 and in this study - is the inclusion of an overall moment budget, taken as the geodetically determined strain accumulation across the breadth of the region of 36 to $43 \mathrm{~mm} / \mathrm{yr}$. This constraint assured that the long-term SFBR model would agree with both geodetic and plate motion rates (Figure 6.6). Another innovation is the use of alternative probability models that differ, most importantly, in their treatment of the 1906 "stress-shadow" in the San Francisco Bay region.

Qualitatively, our results agree with these those of WG90: the fault segments most likely to rupture in $M \geq 6.7$ earthquakes in the SFBR are the Hayward-Rodgers Creek fault and the Peninsula segment of the San Andreas fault (Table 6.3). However, there are significant differences (relative to WG90) for the Hayward fault and the Peninsula segment of the San Andreas fault, where we calculate lower probabilities. These differences have origins in three 
areas: the inclusion of new and better data (specifically, a new interpretation of the 1838 earthquake by Toppozada and Borcherdt, 1998); the accounting for the effects of the 1906 and 1989 stress changes (stress shadows); and the inclusion of aseismic slip (creep) on - and the shortening of-some segments in our fault model (e.g., HN).

By extending the analysis of earthquake probability to five additional faults and including earthquake sources in the "background", we are able to present a broader regional perspective than WG90 did —one in which earthquake potential is more dispersed throughout the SFBR (Figure 6.6).

\section{Differences in fault model}

We built on (and only modified where necessary) earlier segmentation models established by the1996 Working Group on Northern California Earthquake Potential (WGNCEP96). On the San Andreas fault, we changed the segmentation of the San Andreas by moving the northern boundary of the Peninsula segment (SAP) to the Golden Gate and changed its slip rate (increasing it north of the Golden Gate from 19 to $24 \mathrm{~mm} /$ year and decreasing it to the south from 19 to $17 \mathrm{~mm} / \mathrm{yr}$ ). We increased the length of the Santa Cruz segment (SAS) to $62 \mathrm{~km}$, relative to the $35 \mathrm{~km}, 39 \mathrm{~km}$, and $37 \mathrm{~km}$ lengths defined by WG88, WG90, and WGNCEP96, respectively.

For the Hayward-Rodgers Creek fault, we adopted the slip rate used in WG90. We retained the three-segment fault system, but increased the length of HS and decreased the length of HN, based on Yu and Segall's (1996) reinterpretation of the length of the 1868 rupture.

Other important differences relative to the WG90 study include our use of alternative rupture scenarios (involving single-segment and multi-segment ruptures); assignment of earthquake magnitudes based on rupture area; and introduction of the $\mathrm{R}$ factor (used to account for aseismic slip or creep on characterized faults). These factors affect both the calculation of both magnitudes and mean recurrence intervals and therefore probability.

Some of the effects of these differences can be seen in Table 6.12, which compares the WG90 and WG02 models for segments of the San Andreas and Hayward-Rodgers Creek faults and shows the resulting estimated mean recurrence intervals for segment ruptures. On the HaywardRodgers Creek fault, model changes resulted in negligible changes in calculated mean recurrence interval. However, on the San Andreas fault these changes had a larger effect, particularly on segments SAP and SAS, where a decrease in loading rate and increase in segment length lead to significantly longer recurrence times. 
Table 6.12 Comparison of fault parameters in WG90 and WG02.

\begin{tabular}{|c|c|c|c|c|c|c|c|c|}
\hline \multirow{2}{*}{ Segment } & \multicolumn{2}{|c|}{$\begin{array}{c}\text { Slip Rate } \\
(\mathrm{mm} / \mathrm{yr})\end{array}$} & \multicolumn{2}{|c|}{$\begin{array}{c}\text { Segment } \\
\text { Length } \\
(\mathrm{km})\end{array}$} & $\begin{array}{c}\text { Mean Recurrence } \\
\text { Interval } \\
(\mathrm{yr})\end{array}$ & $\begin{array}{c}\text { Displacement } \\
(\mathrm{m})\end{array}$ & Reliability \\
\hline & WG90 & $\begin{array}{c}\text { WG0 } \\
\mathbf{2}\end{array}$ & WG90 & WG02 & WG90 & WG02 & WG90 & WG90 \\
\hline SAO & - & $\mathbf{2 4 \pm 3}$ & - & $\mathbf{1 4 5 \pm 1 1}$ & - & $\mathbf{2 2 5}$ & - & - \\
\hline SAN & $19 \pm 4$ & $\mathbf{2 4 \pm 3}$ & $340 \pm 5$ & $\mathbf{1 8 2 \pm 1 1}$ & 228 & $\mathbf{2 2 3}$ & $4.5 \pm 0.5$ & B \\
\hline SAP & $19 \pm 4$ & $\mathbf{1 7 \pm 4}$ & $61 \pm 5$ & $\mathbf{8 5 \pm 1 3}$ & 136 & $\mathbf{2 2 9}$ & 2.6 & C \\
\hline SAS & $19 \pm 4$ & $\mathbf{1 7 \pm 4}$ & $39 \pm 5$ & $\mathbf{6 1 \pm 1 5}$ & 91 & $\mathbf{2 2 4}$ & 1.8 & C \\
\hline & & & & & & & & \\
\hline RC & $9 \pm 2$ & $\mathbf{9 \pm 2}$ & $50 \pm 5$ & $\mathbf{6 3 \pm 1 0}$ & $\geq 222$ & $\mathbf{2 0 5}$ & $2.0 \pm 0.5$ & C \\
\hline HN & $9 \pm 2$ & $\mathbf{9 \pm 2}$ & $50 \pm 7.5$ & $\mathbf{3 0 \pm 1 5}$ & 167 & $\mathbf{1 5 5}$ & $1.5 \pm 0.5$ & D \\
\hline HS & $9 \pm 2$ & $\mathbf{9 \pm 2}$ & $32 \pm 7.5$ & $\mathbf{5 5 \pm 1 9}$ & 167 & $\mathbf{1 6 1}$ & $1.5 \pm 0.5$ & D \\
\hline
\end{tabular}

1. Recurrence intervals correspond to earthquakes of differing magnitude.

\section{Differences in probability modeling, including treatment of stress effects from the 1906 earthquake}

We broke the tradition of previous working groups by not adopting a single probability model for our calculations. We took this approach because no single probability model known to us appears to be fully satisfactory in representing the effect of the 1906 stress shadow - an effect that likely plays a major role in defining the probabilities. We applied the time-predictable model only to the San Andreas fault because the information available for the remainder of the SFBR faults was either lacking or judged to be too uncertain.

WG88 and WG90 used a qualitative scale (A-E, with A being the most reliable) to rate its confidence in the segment probabilities. We attempted to quantify uncertainty in all parts of our model, from basic geologic observations to modeled stress interaction effects, and explicitly carried these uncertainties through the calculation. This method provides a quantitative description of the uncertainty in the probabilities.

WG90 did not consider the effect on adjacent faults of stress changes associated with the 1906 earthquake. In our calculations, the stress changes in 1906 reduced the regional probability - in some probability models greatly, in others to a lesser degree. As we have discussed in Chapter $\mathbf{5}$, and will discuss further in the sensitivity analysis presented later in this chapter, these stress shadow effects produce the greatest single contribution to the reduction in the regional probability of earthquakes determined in this study, relative to that in WG90. The wide range of probability calculated with our probability models is indicative of our limited understanding of the fundamental physics of stress interaction processes.

The introduction of the new Brownian Passage Time probability model (BPT) allowed us to apply the stress changes produced by the 1906 earthquake directly in the probability calculation through a formal "state change", rather than through a "clock correction," as was done in WG90 and WG99. On fault segments relatively close to failure (e.g., segments RC and HS), the resulting changes in the calculated probabilities are transient and characteristically decay with 
elapse time following the stress step (Figure 5.9). On segments earlier in the recurrence cycle, the BPT and clock change methods produce probability changes that are similar to each other. Other than in their response to a sudden stress change, the BPT and Lognormal probability models produce very similar results (Table 6.13), as expected, considering the similarity of their pdf's (Figure 5.3).

Table 6.13 Comparison of probability calculations made with Lognormal and BPT models without fault interactions.

\begin{tabular}{|c|c|c|}
\hline \multirow[t]{2}{*}{ Fault } & \multicolumn{2}{|c|}{$\begin{array}{l}\text { Probability of } M \geq 6.7 \text { Earthquake in } \\
\qquad 2002-2031\end{array}$} \\
\hline & Lognormal Model & BPT Model \\
\hline San Andreas & 0.172 & 0.176 \\
\hline Hayward-Rodgers Creek & 0.381 & 0.377 \\
\hline Calaveras & 0.161 & 0.160 \\
\hline Concord Green Valley & 0.051 & 0.051 \\
\hline San Gregorio & 0.148 & 0.148 \\
\hline Greenville & 0.040 & 0.040 \\
\hline Mt. Diablo & 0.038 & 0.038 \\
\hline $\begin{array}{l}\text { Region } \\
\text { (not including background) }\end{array}$ & 0.679 & 0.678 \\
\hline
\end{tabular}

We calculated the long-term probabilities for smaller $(6 \leq \mathbf{M}<6.7)$ earthquakes (in the region (based on observed regional seismicity and the use of a truncated Gutenberg-Richter model and the Poisson probability model). WG90 did not consider earthquakes smaller than the characteristic earthquakes, which had "nominal" magnitude $\sim$ M7.

\section{Differences in presentation of results}

The interest in WG90 was in "large earthquakes," which simply meant earthquakes with expected magnitude $\mathbf{M} \sim 7$ (or, on the north coast segment of the San Andreas fault, M 8). Other than by providing a length for the Hayward-Rodgers Creek fault displacement estimates, the segment lengths measured in WG90 did not enter into the probability calculations. In contrast, our model allows for a variety of possible ruptures that span a range of magnitude from M6.2 to M7.9. This feature allows us to calculate probabilities for various magnitude thresholds. A consequence of this change is seen in the case of the northern Hayward fault (segment HN), where we model the mean magnitude for a rupture of this segment by itself to be M6.5 (Table 6.5). The probability calculated for this rupture depends on the magnitude threshold (Table 6.3). To meaningfully compare our result for segment $\mathrm{HN}$ to that of WG90, we disregard the difference in the respective magnitudes for events on this segment and use our segment probability for all ruptures (Table 6.3; Table 6.14). On the Hayward-Rodgers Creek fault, the WG90 probabilities for each segment fall approximately midway between comparable WG02 calculations made with and without considering the effect of the 1906 stress changes. 
Table 6.14. Comparison of segment rupture probabilities in WG90 and WG02

\begin{tabular}{|c|c|c|c|}
\hline $\begin{array}{c}\text { Fault } \\
\text { Segment }\end{array}$ & $\begin{array}{c}\text { WG90 } \\
\text { Probability of a } \\
\text { characteristic } \\
\text { earthquake on } \\
\text { fault segment }\end{array}$ & $\begin{array}{c}\text { Wrobability of a characterized earthquake of } \\
\text { any size on fault segment. } \\
\text { Mean [95\% confidence range] }\end{array}$ \\
\hline & & BPT (no step) & Weighted Models \\
\hline HS & 0.23 & $0.29[0.13-0.56]$ & $0.21[0.07-0.48]$ \\
\hline HN & 0.28 & $0.32[0.16-0.56]$ & $0.23[0.07-0.53]$ \\
\hline RC & 0.22 & $0.28[0.13-0.56]$ & $0.19[0.06-0.49]$ \\
\hline SAP & 0.23 & $0.12[0.06-0.25]$ & $0.14[0.02-0.29]$ \\
\hline H/RC fault & 0.57 & $0.56[0.31-0.87]$ & $0.42[0.15-0.81]$ \\
\hline
\end{tabular}

WG90's probability for SAP is significantly higher than ours, lying only barely within our 95\% confidence bound. This difference stems from differences in the fault models. We extended the northern end of SAP north to the Golden Gate, making its length $85 \mathrm{~km}$, compared to $61 \mathrm{~km}$ in the WG90 model. We modeled the single-segment rupture of SAP with mean magnitude 7.17, compared to 7 in WG90. And we used a slightly lower slip rate than did WG90. As a result of these differences, our mean recurrence interval for SAP is greater (Table 6.12) and probability lower (Table 6.14).

\section{Sensitivity of the Results to Modeling Assumptions and Parameter Uncertainties}

The calculations presented are the most complex and comprehensive analysis of earthquake hazard in the region to date, increasing (over the WG90 model) the number of characterized faults from 3 to 7 and the number of modeled fault segments from 6 to 18, and expanding the branching structure of the calculation sequence to include multiple fault rupture and earthquake probability models. The alternatives and weights defining the branching structure represent uncertainty about virtually all aspects of the model, including the geometry, slip rate, and segmentation of the faults, the relationship between source rupture area and earthquake magnitude, and the effect of aseismic slip.

From the outset, a guiding philosophy in our work has been that all sources of uncertainty about the earthquake process in the SFBR should be represented in the model. This approach acknowledges our incomplete knowledge about both the long term behavior of the earthquake machine in the SFBR and its current state as regards the probability for large earthquakes in the next 30 years. We felt that through such an approach, new information, as it became available in the future, could easily be incorporated by either eliminating branches in the calculation sequence or better constraining model parameter values. The comprehensive quantification of uncertainty about the earthquake process in the SFBR was one of the primary scientific goals of the Working Group - to be developed in parallel with the estimation of the current 30-year probabilities of earthquakes in the region.

The principal sources of uncertainty recognized in this study were introduced in Chapter 4 . Here, we explore how these uncertainties affect the estimates of the 30-year probability of 
earthquakes. While all sources of uncertainty have some influence on the probability calculations, the results are particularly sensitive to a small number of key inputs and modeling choices. The remainder of this section includes a series of sensitivity analyses for these key factors, which help put the calculations into context in two ways. First, they illustrate how well (or poorly) our knowledge constrains the estimated probabilities. Beyond that, sensitivity analyses can identify those research areas in which discovery of new information may be most valuable for sharpening future estimates of earthquake probabilities in the SFBR, which is the subject of Chapter 8.

\section{Choice of probability model and treatment of post-1906 seismic quiescence}

As discussed in Chapter 5, a major source of uncertainty in the 30-year probability estimates arises in quantifying the effects of the 1906 stress shadow. We took two approaches toward incorporating the post-1906 regional quiescence in our probability calculations. The first approach uses estimates of 1906 stress changes and long-term loading rates calculated from elastic dislocation models to adjust the state of the Brownian Passage Time model in 1906. As discussed in Chapter 5, the elastic models seem to underestimate the duration of the stress shadow and suggest that most faults are no longer in the stress shadow. As a result, the regional 30-year probability in 2002 calculated using this approach is considered to be an upper bound.

In the second approach, the Empirical model extrapolated relative rates of seismicity in the later half of the $20^{\text {th }}$ century as a proxies for the effect of fault interaction. This model suggests that most of the faults remain in the stress shadow; it produces lower 30-year probabilities, which we consider to be a likely lower bound.

We also considered two models that ignore 1906 effects altogether: a Poisson probability model, and a BPT model without fault interactions. Finally, for the San Andreas fault only, a timepredictable model used information about the amount of slip that occurred in 1906. We placed significant weight on each of these approaches in the calculation sequence (Table 5.4, Figure 5.10). The absence of a single probability model that was strongly favored among the working group members indicates the widely disparate views currently held in this crucial area and underscores the need for better physical models for fault interaction in future efforts to estimate earthquake probability.

The results in Table 6.1 for the characterized faults and the region come from our preferred model, which is a weighted combination of $i$ the 5 probability models considered. Probabilities calculated using each of the individual probability models for the occurrence of $M \geq 6.7$ earthquakes in the region and on the characterized faults are listed in Table 6.15. Corresponding probabilities for $M \geq 6.7$ earthquakes involving individual fault segments and rupture sources are listed in Tables 6.16 and 6.17, respectively. 
Table 6.15. Probabilities for the occurrence of $\mathbf{M} \geq 6.7$ earthquakes occurring on characterized faults in 2002-2031, calculated with individual probability models and with the weighted set of probability models. Probabilities for the background are always calculated with the Poisson model. Probabilities for the region combine those for the characterized faults and the background. (Note: In this table, aggregate probabilities for the SF Bay Region and the San Andreas fault include contributions from characterized earthquakes outside the SFBR "box", specifically single-segment ruptures of segment SAO and floating earthquakes on the northern extent of the San Andreas fault.)

\begin{tabular}{|c|c|c|c|c|c|c|c|c|c|c|c|c|c|c|c|c|c|c|c|c|}
\hline \multirow[b]{2}{*}{ Fault system } & \multicolumn{3}{|c|}{ Weighted results } & \multicolumn{3}{|c|}{ Poisson } & \multicolumn{3}{|c|}{ Empirical } & \multicolumn{4}{|c|}{ BPT (renewal) } & \multicolumn{4}{|c|}{ BPT + stress step } & \multicolumn{3}{|c|}{ Time-predictable } \\
\hline & Mean & \begin{tabular}{|l|l|l}
{$[2.5 \%$} & - \\
\end{tabular} & $97.5 \%$ & Mean & $2.5 \%$ & $-97.5 \%$ & Mean & {$[2.5 \%$} & $97.5 \%$ & Mean & {$[2.5 \%$} & & $97.5 \%$ & Mean & {$[2.5 \%$} & - & $97.5 \%$ & Mean & {$[2.5 \%$} & $-97.5 \%]$ \\
\hline San Andreas & 0.235 & $0.029-$ & 0.524 & 0.196 & $0.113-$ & -0.299 & 0.118 & 0.059 & -0.195 & 0.176 & 0.018 & & 0.368 & 0.166 & 0.017 & - & 0.374. & 0.385 & ][ $[0.117$ & \begin{tabular}{l|l|l|}
- & 0.562 &
\end{tabular} \\
\hline Hayward/Rodgers $\mathrm{Cr}$ & 0.272 & 0.096 & 0.578 & 0.227 & $0.161-$ & -0.304 & 0.138 & 0.084 & -0.200 & 0.377 & 0.220 & - & 0.650 & 0.342 & 0.194 & - & 0.610 & - & & \\
\hline Calaveras & 0.107 & $0.028-$ & 0.271 & 0.093 & $0.036-$ & -0.180 & 0.055 & 0.020 & -0.111 & 0.160 & 0.055 & - & 0.327 & 0.150 & 0.050 & - & 0.315 & - & & \\
\hline Concord/Green Valley & 0.036 & $0.000-$ & -0.122 & 0.032 & $0.000-$ & -0.082 & 0.018 & 0.000 & -0.050 & 0.051 & 0.000 & - & 0.151 & 0.048 & 0.000 & - & 0.145 & - & & \\
\hline San Gregorio & 0.102 & $0.021-$ & -0.285 & 0.097 & $0.036-$ & -0.181 & 0.057 & 0.020 & -0.114 & 0.148 & 0.020 & - & 0.376 & 0.124 & 0.018 & - & 0.316 & - & & \\
\hline Greenville & 0.030 & $0.002-$ & -0.082 & 0.031 & $0.011-$ & -0.055 & 0.018 & 0.006 & -0.033 & 0.040 & 0.000 & - & 0.111 & 0.036 & 0.000 & - & 0.100 & - & & \\
\hline Mt Diablo thrust & 0.025 & $0.000-$ & 0.083 & 0.026 & $0.000-$ & -0.070 & 0.015 & 0.000 & -0.040 & 0.038 & 0.000 & - & 0.129 & 0.038 & 0.000 & - & 0.127 & - & & \\
\hline $\begin{array}{l}\text { Background (other } \\
\text { sources) }\end{array}$ & 0.139 & $0.069-$ & 0.365 & 0.139 & 0.069 & 0.365 & 0.139 & 0.069 & 0.365 & 0.139 & 0.069 & - & 0.365 & 0.139 & 0.069 & - & 0.365 & - & & \\
\hline SF Bay Region & 0.633 & $0.377-$ & 0.879 & 0.600 & $0.508-$ & 0.701 & 0.445 & 0.324 & 0.579 & 0.720 & 0.584 & - & 0.893 & 0.687 & 0.544 & & 0.868 & - & & \\
\hline
\end{tabular}


Table 6.16. Probabilities that each fault segment will rupture in a $\mathbf{M} \geq 6.7$ earthquakes in 2002-2031, calculated with individual probability models and with the weighted set of probability models.

\begin{tabular}{|c|c|c|c|c|c|c|c|c|c|c|c|c|c|c|c|c|c|c|c|c|c|c|c|}
\hline \multirow[b]{2}{*}{ Fault system } & \multirow[b]{2}{*}{ Segment } & \multicolumn{3}{|c|}{ Weighted results } & \multicolumn{4}{|c|}{ Poisson } & \multicolumn{4}{|c|}{ Empirical } & \multicolumn{4}{|c|}{ BPT (renewal) } & \multicolumn{4}{|c|}{ BPT + stress step } & \multicolumn{3}{|c|}{ Time-predictable } \\
\hline & & Mean & $2.5 \%$ & $-97.5 \%$ & Mean & {$[2.5 \%$} & & $97.5 \%$ & Mean & $2.5 \%$ & & $97.5 \%$ & Mean & $2.5 \%$ & & $97.5 \%$ & Mean & $2.5 \%$ & & $97.5 \%$ & Mean & $2.5 \%$ & $-97.5 \%$ \\
\hline \multirow[t]{4}{*}{ San Andr. } & SAS & 0.112 & 0.009 & 0.234 & 0.124 & 0.078 & & 0.173 & 0.073 & 0.040 & & 0.112 & 0.110 & 0.004 & & 0.228 & 0.099 & 0.004 & & 0.272 & 0.139 & 0.037 & 0.236 \\
\hline & SAP & 0.131 & 0.010 & -0.290 & 0.121 & 0.075 & & 0.170 & 0.072 & 0.039 & & 0.110 & 0.108 & 0.004 & & 0.223 & 0.100 & 0.005 & & 0.233 & 0.198 & 0.057 & 0.327 \\
\hline & SAN & 0.116 & 0.014 & -0.235 & 0.125 & 0.072 & & 0.178 & 0.074 & 0.038 & & 0.115 & 0.114 & 0.009 & & 0.233 & 0.111 & 0.009 & & 0.231 & 0.140 & 0.026 & 0.257 \\
\hline & SAO & 0.107 & 0.011 & -0.220 & 0.124 & 0.071 & - & 0.176 & 0.073 & 0.038 & - & 0.115 & 0.112 & 0.007 & & 0.233 & 0.109 & 0.007 & & 0.232 & 0.116 & 0.020 & 0.219 \\
\hline \multirow[t]{3}{*}{ Hayward/RC } & $\mathrm{HS}$ & 0.123 & 0.036 & 0.266 & 0.107 & 0.051 & - & 0.160 & 0.063 & 0.028 & - & 0.102 & 0.171 & 0.073 & 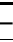 & 0.319 & 0.153 & 0.063 & & 0.284 & - & & \\
\hline & $\mathrm{HN}$ & 0.113 & 0.034 & -0.264 & 0.093 & 0.054 & - & 0.139 & 0.054 & 0.028 & - & 0.086 & 0.159 & 0.076 & 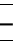 & 0.315 & 0.144 & 0.068 & & 0.282 & - & & \\
\hline & $\mathrm{RC}$ & 0.170 & 0.053 & $\begin{array}{l}-0.431 \\
\end{array}$ & 0.131 & 0.083 & - & 0.181 & 0.078 & 0.043 & - & 0.122 & 0.248 & 0.122 & & 0.512 & 0.221 & 0.102 & & 0.473 & - & & \\
\hline \multirow[t]{3}{*}{ Calaveras } & CS & 0.023 & 0.000 & 0.098 & 0.022 & 0.000 & - & 0.087 & 0.013 & 0.000 & 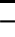 & 0.052 & 0.032 & 0.000 & 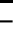 & 0.118 & 0.031 & 0.000 & & 0.115 & - & & \\
\hline & $\mathrm{CC}$ & 0.029 & 0.000 & -0.122 & 0.030 & 0.000 & - & 0.119 & 0.017 & 0.000 & - & 0.071 & 0.041 & 0.000 & & 0.144 & 0.039 & 0.000 & & 0.141 & - & & \\
\hline & $\mathrm{CN}$ & 0.099 & 0.027 & $\begin{array}{l}-0.256 \\
\end{array}$ & 0.084 & 0.036 & - & 0.128 & 0.049 & 0.020 & - & 0.080 & 0.151 & 0.054 & & 0.310 & 0.141 & 0.048 & & 0.294 & - & & \\
\hline \multirow[t]{3}{*}{ Concord/GV } & CON & 0.031 & 0.000 & 0.110 & 0.028 & 0.000 & - & 0.078 & 0.016 & 0.000 & - & 0.048 & 0.045 & 0.000 & & 0.140 & 0.042 & 0.000 & & 0.133 & - & & \\
\hline & GVS & 0.034 & 0.000 & 0.118 & 0.030 & 0.000 & - & 0.081 & 0.018 & 0.000 & - & 0.049 & 0.049 & 0.000 & 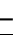 & 0.148 & 0.046 & 0.000 & & 0.142 & - & & \\
\hline & GVN & 0.031 & 0.000 & $\begin{array}{l}-0.109 \\
\end{array}$ & 0.027 & 0.000 & - & 0.078 & 0.016 & 0.000 & - & 0.047 & 0.044 & 0.000 & & 0.141 & 0.041 & 0.000 & & 0.134 & - & & \\
\hline \multirow[t]{2}{*}{ San Gregor. } & SGS & 0.050 & 0.005 & 0.136 & 0.048 & 0.015 & - & 0.074 & 0.028 & 0.009 & & 0.045 & 0.072 & 0.003 & & 0.196 & 0.063 & 0.003 & & 0.175 & - & & \\
\hline & SGN & 0.080 & 0.018 & $\begin{array}{l}-0.216 \\
\end{array}$ & 0.076 & {$[0.034$} & - & 0.127 & 0.044 & 0.019 & - & 0.078 & 0.121 & 0.017 & & 0.305 & 0.097 & 0.015 & & 0.247 & - & & \\
\hline \multirow[t]{2}{*}{ Greenville } & GS & 0.021 & 0.001 & 0.058 & 0.021 & {$[0.008$} & - & \begin{tabular}{|l|}
0.037 \\
\end{tabular} & 0.012 & 0.004 & & 0.022 & 0.028 & 0.000 & 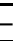 & 0.081 & 0.025 & 0.000 & & 0.073 & - & & \\
\hline & GN & 0.023 & 0.001 & $\begin{array}{l}-0.065 \\
\end{array}$ & 0.024 & 0.009 & & 0.041 & 0.014 & 0.005 & & 0.025 & 0.031 & 0.000 & & 0.091 & 0.028 & 0.000 & & 0.082 & - & & \\
\hline Mt Diablo & MTD & 0.025 & 0.000 & -0.083 & 0.026 & {$[0.000$} & - & 0.070 & 0.015 & 0.000 & - & 0.040 & 0.038 & 0.000 & & 0.129 & 0.038 & 0.000 & - & 0.127 & - & & \\
\hline
\end{tabular}


Table 6.17. Probabilities that each rupture source will fail in a $\mathbf{M} \geq 6.7$ earthquake in 2002-2031, calculated with individual probability models and with the weighted set of probability models.

\begin{tabular}{|c|c|c|c|c|c|c|c|c|c|c|c|c|c|c|c|c|c|c|c|c|c|c|c|}
\hline \multirow{2}{*}{ Fault system } & \multirow[b]{2}{*}{ Rupture source } & \multicolumn{4}{|c|}{ Weighted results } & \multicolumn{3}{|c|}{ Poisson } & \multicolumn{3}{|c|}{ Empirical } & \multicolumn{4}{|c|}{ BPT (renewal) } & \multicolumn{4}{|c|}{ BPT + stress step } & \multicolumn{4}{|c|}{ Time-predictable } \\
\hline & & Mean & $2.5 \%$ & & $97.5 \%$ & Mean & $2.5 \%-$ & $97.5 \%$ & Mean & {$[2.5 \%-$} & $-97.5 \%$ & Mean & {$[2.5 \%$} & & $97.5 \%$ & Mean & $2.5 \%$ & - & $97.5 \%$ & Mean & {$[2.5 \%$} & -9 & $97.5 \%$ \\
\hline \multirow[t]{11}{*}{ San Andr. } & SAS & 0.025 & 0.000 & $-\overline{-1}$ & 0.105 & 0.021 & $0.000-$ & -0.044 & 0.012 & $0.000-$ & 0.027 & 0.018 & 0.000 & & 0.056 & 0.013 & 0.000 & - & 0.104 & 0.047 & {$[0.002$} & -10 & 0.126 \\
\hline & SAP & 0.043 & 0.000 & - & 0.171 & 0.015 & $0.000-$ & -0.030 & 0.008 & $0.000-$ & 0.018 & 0.013 & 0.000 & & 0.037 & 0.011 & 0.000 & - & 0.038 & 0.108 & {$[0.023$} & -0 & 0.204 \\
\hline & SAN & 0.009 & 0.000 & - & 0.037 & 0.004 & $0.000-$ & -0.022 & 0.002 & $0.000-$ & -0.014 & 0.004 & 0.000 & & 0.029 & 0.004 & 0.000 & - & 0.029 & 0.020 & 0.001 & -0 & 0.046 \\
\hline & SAO & 0.009 & 0.000 & - & 0.043 & 0.007 & $0.000-$ & -0.033 & 0.004 & $0.000-$ & -0.020 & 0.006 & 0.000 & & 0.042 & 0.006 & 0.000 & - & 0.042 & 0.015 & 0.000 & -0 & 0.053 \\
\hline & SAS+SAP & 0.035 & 0.001 & - & 0.102 & 0.028 & $0.006-$ & 0.083 & 0.016 & $0.003-$ & 0.051 & 0.025 & 0.000 & & 0.108 & 0.021 & 0.000 & - & 0.116 & 0.061 & 0.015 & -0 & 0.106 \\
\hline & SAP+SAN & 0.000 & 0.000 & - & 0.000 & 0.000 & $0.000-$ & -0.000 & 0.000 & 0.000 & 0.000 & 0.000 & 0.000 & & 0.000 & 0.000 & 0.000 & - & 0.000 & 0.000 & 0.000 & -0 & 0.000 \\
\hline & $\mathrm{SAN}+\mathrm{SAO}$ & 0.034 & 0.001 & - & 0.106 & 0.035 & $0.011-$ & -0.100 & 0.021 & 0.006 & 0.058 & 0.033 & 0.000 & & 0.131 & 0.033 & 0.000 & - & 0.131 & 0.040 & 0.002 & -0 & 0.083 \\
\hline & SAS+SAP+SAN & 0.001 & 0.000 & - & 0.003 & 0.001 & $0.000-$ & -0.004 & 0.000 & $0.000-$ & $\begin{array}{l}-0.002 \\
\end{array}$ & 0.001 & 0.000 & & 0.005 & 0.001 & 0.000 & - & 0.004 & 0.001 & 0.000 & -0 & 0.001 \\
\hline & SAP+SAN+SAO & 0.002 & 0.000 & - & 0.011 & 0.002 & $0.000-$ & 0.011 & 0.001 & $0.000-$ & 0.007 & 0.002 & 0.000 & & 0.013 & 0.002 & 0.000 & - & 0.013 & 0.001 & 0.000 & -0 & 0.002 \\
\hline & SAS+SAP+SAN+SAO & 0.047 & 0.003 & - & 0.138 & 0.076 & $0.036-$ & 0.119 & 0.045 & 0.019 & 0.077 & 0.068 & 0.001 & - & 0.156 & 0.065 & 0.001 & - & 0.154 & 0.019 & 0.004 & -0 & 0.033 \\
\hline & floating M6.9 & 0.068 & 0.004 & - & 0.253 & 0.025 & $0.004-$ & -0.052 & 0.015 & $0.002-$ & $\begin{array}{l}-0.031 \\
\end{array}$ & 0.025 & 0.004 & - & 0.052 & 0.025 & 0.004 & - & 0.052 & 0.159 & 0.033 & -0 & 0.286 \\
\hline \multirow[t]{7}{*}{ Hayward/RC } & HS & 0.043 & 0.000 & - & 0.133 & 0.039 & $0.000-$ & 0.099 & 0.023 & $0.000-$ & 0.060 & 0.059 & 0.000 & & 0.166 & 0.052 & 0.000 & - & 0.151 & - & & & \\
\hline & $\mathrm{HN}$ & 0.015 & 0.000 & - & 0.089 & 0.011 & $0.000-$ & -0.057 & 0.006 & $0.000-$ & -0.032 & 0.021 & 0.000 & & 0.110 & 0.019 & 0.000 & - & 0.099 & - & & & \\
\hline & $\mathrm{HS}+\mathrm{HN}$ & 0.072 & 0.017 & - & 0.189 & 0.060 & $0.025-$ & -0.109 & 0.035 & $0.013-$ & -0.067 & 0.103 & 0.034 & 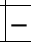 & 0.230 & 0.093 & 0.031 & - & 0.205 & - & & & \\
\hline & $\mathrm{RC}$ & 0.144 & 0.041 & - & 0.384 & \begin{tabular}{|l|}
0.107 \\
\end{tabular} & 0.065 & -0.157 & 0.063 & 0.034 & -0.102 & 0.213 & 0.099 & & 0.463 & 0.188 & 0.080 & - & 0.430 & - & & & \\
\hline & $\mathrm{HN}+\mathrm{RC}$ & 0.018 & 0.000 & - & 0.065 & 0.014 & $0.000-$ & -0.038 & 0.008 & $0.000-$ & 0.023 & 0.027 & 0.000 & & 0.079 & 0.024 & 0.000 & - & 0.072 & - & & & \\
\hline & $\mathrm{HS}+\mathrm{HN}+\mathrm{RC}$ & 0.010 & 0.001 & - & 0.033 & 0.008 & $0.002-$ & -0.020 & 0.005 & $0.001-$ & -0.012 & 0.015 & 0.002 & & 0.040 & 0.013 & 0.002 & - & 0.036 & - & & & \\
\hline & floating M6.9 & 0.007 & 0.003 & - & 0.015 & 0.008 & $0.004-$ & 0.016 & 0.005 & $0.002-$ & -0.010 & 0.008 & 0.004 & - & 0.016 & 0.008 & 0.004 & - & 0.016 & - & & & \\
\hline \multirow[t]{8}{*}{ Calaveras } & CS & 0.000 & 0.000 & - & 0.000 & 0.000 & $0.000-$ & -0.000 & 0.000 & $0.000-$ & 0.000 & 0.000 & 0.000 & - & 0.000 & 0.000 & 0.000 & - & 0.000 & - & & & \\
\hline & CC & 0.005 & 0.000 & - & 0.048 & 0.005 & $0.000-$ & -0.056 & 0.003 & $0.000-$ & -0.032 & 0.005 & 0.000 & & 0.061 & 0.005 & 0.000 & - & 0.060 & - & & & \\
\hline & $\mathrm{CS}+\mathrm{CC}$ & 0.005 & 0.000 & - & 0.049 & 0.005 & $0.000-$ & -0.053 & 0.003 & $0.000-$ & 0.031 & 0.006 & 0.000 & & 0.058 & 0.006 & 0.000 & - & 0.057 & - & & & \\
\hline & $\mathrm{CN}$ & 0.080 & 0.018 & - & 0.225 & 0.065 & $0.023-$ & -0.108 & 0.038 & $0.012-$ & -0.067 & 0.124 & 0.036 & - & 0.282 & 0.115 & 0.032 & - & 0.264 & - & & & \\
\hline & $\mathrm{CC}+\mathrm{CN}$ & 0.002 & 0.000 & - & 0.033 & 0.002 & $0.000-$ & -0.028 & 0.001 & $0.000-$ & $\begin{array}{l}-0.017 \\
\end{array}$ & 0.004 & 0.000 & - & 0.045 & 0.003 & 0.000 & - & 0.043 & - & & & \\
\hline & $\mathrm{CS}+\mathrm{CC}+\mathrm{CN}$ & 0.018 & 0.000 & - & 0.071 & 0.018 & $0.000-$ & -0.052 & 0.010 & $0.000-$ & 0.031 & 0.027 & 0.000 & - & 0.089 & 0.025 & 0.000 & - & 0.088 & - & & & \\
\hline & floating M6.2 & 0.000 & 0.000 & - & 0.000 & 0.000 & $0.000-$ & -0.000 & 0.000 & $0.000-$ & -0.000 & 0.000 & 0.000 & - & 0.000 & 0.000 & 0.000 & - & 0.000 & - & & & \\
\hline & float. M6.2 on $\mathrm{CS}+\mathrm{CC}$ & 0.000 & 0.000 & - & 0.000 & 0.000 & $0.000-$ & -0.000 & 0.000 & $0.000-$ & -0.000 & 0.000 & 0.000 & - & 0.000 & 0.000 & 0.000 & - & 0.000 & - & & & \\
\hline \multirow[t]{7}{*}{ Concord/GV } & $\mathrm{CON}$ & 0.001 & 0.000 & - & 0.014 & 0.001 & $0.000-$ & -0.013 & 0.001 & $0.000-$ & 0.007 & 0.002 & 0.000 & - & 0.019 & 0.002 & 0.000 & - & 0.017 & - & & & \\
\hline & GVS & 0.000 & 0.000 & - & 0.005 & 0.000 & $0.000-$ & 0.004 & 0.000 & $0.000-$ & 0.002 & 0.001 & {$[0.000$} & - & 0.007 & 0.001 & 0.000 & - & 0.007 & - & & & \\
\hline & CON+GVS & 0.003 & 0.000 & - & 0.017 & 0.003 & $0.000-$ & -0.013 & 0.002 & $0.000-$ & 0.008 & 0.005 & {$[0.000$} & & 0.022 & 0.004 & 0.000 & - & 0.021 & - & & & \\
\hline & GVN & 0.000 & 0.000 & - & 0.001 & 0.000 & $0.000-$ & -0.001 & 0.000 & $0.000-$ & 0.001 & 0.000 & 0.000 & & 0.001 & 0.000 & 0.000 & - & 0.001 & - & & & \\
\hline & GVS+GVN & 0.004 & 0.000 & - & 0.025 & 0.003 & $0.000-$ & -0.018 & 0.002 & $0.000-$ & 0.011 & 0.006 & 0.000 & & 0.032 & 0.005 & 0.000 & - & 0.031 & - & & & \\
\hline & CON+GVS+GVN & 0.027 & 0.000 & - & 0.103 & 0.024 & $0.000-$ & -0.076 & 0.014 & $0.000-$ & -0.046 & 0.038 & 0.000 & & 0.135 & 0.036 & 0.000 & - & 0.127 & - & & & \\
\hline & floating M6.2 & 0.000 & 0.000 & - & 0.000 & 0.000 & $0.000-$ & -0.000 & 0.000 & $0.000-$ & -0.000 & 0.000 & 0.000 & & 0.000 & 0.000 & 0.000 & - & 0.000 & - & & & \\
\hline \multirow[t]{4}{*}{ San Greg. } & SGS & 0.021 & 0.000 & - & 0.103 & \begin{tabular}{|l|}
0.019 \\
\end{tabular} & $0.000-$ & -0.059 & 0.011 & $0.000-$ & 0.037 & 0.028 & 0.000 & & 0.127 & 0.027 & 0.000 & - & 0.124 & - & & & \\
\hline & SGN & 0.039 & 0.000 & - & 0.175 & 0.034 & $0.000-$ & -0.097 & 0.020 & $0.000-$ & -0.060 & 0.065 & {$[0.000$} & & 0.281 & 0.049 & 0.000 & & 0.212 & - & & & \\
\hline & SGS+SGN & 0.026 & 0.000 & - & 0.101 & 0.025 & $0.000-$ & -0.060 & 0.015 & $0.000-$ & -0.039 & 0.041 & {$[0.000$} & & 0.144 & 0.032 & 0.000 & & 0.117 & - & & & \\
\hline & floating M6.9 & 0.020 & 0.008 & - & 0.037 & 0.023 & $0.010-$ & -0.039 & 0.013 & {$[0.006$} & 0.023 & 0.023 & {$[0.010$} & - & 0.039 & 0.023 & 0.010 & - & 0.039 & - & & & \\
\hline
\end{tabular}




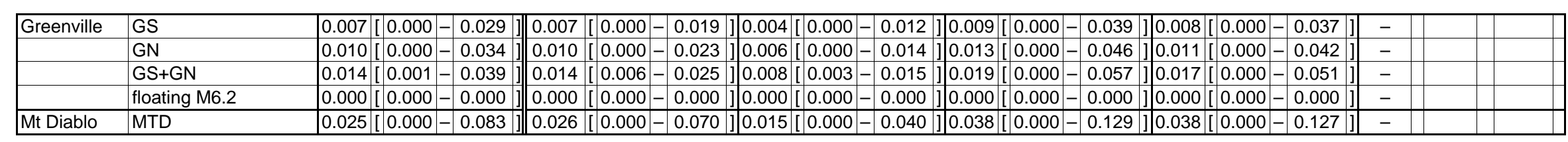


It comes as no surprise that the choice of probability model for calculating the regional earthquake probability has a significant effect on the result (Figures 6.7, 6.8). Relative to the Poisson model, with mean regional probability of a $\mathbf{M} \geq 6.7$ earthquake of 0.60 [0.51-0.70], the corresponding BPT-step model mean probability is elevated $(0.69$ [0.54 - 0.87]), while that of the Empirical model is suppressed $(0.45$ [0.32 - 0.58]), in accord with the observed low post1906 regional seismicity rate. While the difference between mean regional probability for the Poisson and BPT models is small compared to their respective spreads, the empirical calculations stand distinctly apart, with mean probability outside the $95 \%$ confidence range of both these probability models. The distribution of regional probabilities calculated with the weighted probability models reflect these differences, with the Empirical and BPT models defining, respectively, the lower and upper bounds of an approximately flat distribution (Figure 6.7b). Thus, the formidable spread in the weighted results $(\sim 0.4$ to $\sim 0.9)$ largely reflects our uncertainty about how the 1906 stress change affected the SFBR faults. If we could set aside this part of the problem (i.e., consider just one probability model, as was done in WG88 and WG90), uncertainty in the regional probability would be approximately halved.

The importance of the choice of probability model (including the choice of treatment of the interaction effects) can also be seen in results for the individual faults (Figure 6.8). On the San Andreas fault, the mean probability calculated for the Time-Predictable model is the highest. The Empirical and BPT model probabilities are both suppressed, relative to the Poisson, but for different reasons: the Empirical model result reflects the observed low seismicity rates, while the BPT model results reflect the recency of the segment-resetting 1906 earthquake on the San Andreas fault.

\section{Choice of fault rupture model}

We characterized each major fault system in the SFBR with a set of fault rupture models. Each rupture model describes a possible mode of long-term behavior of a fault in terms of the size, location and relative frequencies of the ruptures occurring on it. Each fault was described by a set of up to 5 alternate rupture models (Chapter 3), with the assignment of weights to alternate rupture models reflecting a diversity of views within the expert panels concerning the strength of the fault segment barriers and long-term rupture behavior. Here we explore the sensitivity of the 30-year probabilities to the assignment of weights to these models. For a benchmark, we use the 30-year probability of a $\mathbf{M} \geq 6.7$ earthquake calculated for a Poisson probability model using the expert-determined weights for the rupture models. We compare the benchmark to a suite of corresponding calculations in which each rupture model is, in turn, assigned a weight of 1.0 (Figure 6.9).

For $\mathbf{M} \geq 6.7$ earthquakes, the 30-year probability depends strongly on the choice of rupture model for the San Andreas and San Gregorio faults, but is relatively insensitive to the choice of rupture model for the Hayward-Rodgers Creek and Calaveras faults. On the San Andreas fault (Chapter 3), rupture model A ( $\mathrm{P}=0.21)$ favors full 1906-type ruptures, which decreases the moment available for (and, hence, rate of) smaller (M 7) earthquakes. In contrast, fault rupture model D for the San Andreas ( $\mathrm{P}=0.28)$ gives the least weight to 1906-type ruptures, and so increases the rate of the smaller-magnitude 1- and 2-segment ruptures. Model D was given the least weight 
(0.08) by the experts. On the San Gregorio fault, model C is the greatest contributor of $\mathbf{M} \geq 6.7$ earthquakes because the combined SGN-SGS rupture is not allowed in this model, so all the available moment is consumed in the production of single-segment and floating rupture sources.

\section{Choice of $M-\log$ A relation}

We estimated the mean magnitude of each rupture source from its seismogenic area. A great deal of earthquake physics is included in this step, much of it only poorly understood. Empirical models (e.g., Wells and Coppersmith, 1994) and empirically fit theoretical models (e.g., Hanks and Bakun, 2001) often are used for this purpose. We considered five alternate $\mathbf{M}-\log A$ relations in determining the mean magnitude, $\mathbf{M}$, for each rupture source, based on its area, A, and seismogenic scaling factor, R (Table 4.1). It is evident in Figure 4.2 that the available relevant observations do not clearly rule out any of these models. The uncertainty in the choice of the $\mathbf{M}-\log A$ relation is an example of epistemic uncertainty in the model, and is formally incorporated into the model through branch weights obtained via expert opinion.

For any given rupture source (except those corresponding to $\mathbf{M}>7.7$ earthquakes) the mean magnitudes given by the various $\mathbf{M}-\log A$ relations differ by at most 0.2 magnitude units (Figure 4.2). This difference corresponds to a factor of $\sim 2$ in seismic moment and has a significant impact on earthquake rates and probabilities of occurrence. Figure 6.10 shows the dependence on the choice of $\mathbf{M}-\log A$ relation of the 30-year probability (calculated with the weighted probability model) of a $\mathbf{M} \geq 6.7$ earthquake on each fault and in the region. Illustrative of the sensitivity to this modeling step is the consistent relationship between probabilities calculated with Model $1 \mathrm{~b}(\mathbf{M}=\log A+4.2)$ and Model 1a $(\mathbf{M}=\log A+4.1)$. Model 1b produces larger magnitude earthquakes and (because the fault models are slip rate-balanced) lower occurrence rates and probability, while Model 1a produces smaller magnitude earthquakes and, thus, higher rates and probability. Overall, the uncertainty associated with the choice of $\mathbf{M}-\log A$ relation contributes a significant, but not dominant, portion of the total uncertainty in probability.

\section{Accounting for aseismic slip}

We accounted for aseismic slip through the use of the seismogenic scaling factor, $R$, which varies from $R=0$ (all slip occurs aseismically) to $R=1$ (all slip occurs in earthquakes). Expert groups estimated a range of values of $R$ for each segment of the region's faults (Table 4.1, Appendix B). We considered two ways of accounting for aseismic slip in the regional earthquake model: $\mathrm{R}$ could scale the area of the fault segment that slips in earthquakes, or $\mathrm{R}$ could scale the slip rate of the segments. A combination of these approaches is permitted in the calculation sequence. We concluded that $R$ should be used solely to scale the area, and so assigned this approach a weight of 1.0 in its calculations (see discussion in appendix). Figure 6.11 compares the long-term frequency-magnitude relations for the San Andreas, HaywardRodgers Creek, Calaveras and Concord-Green Valley faults calculated using area scaling and slip rate scaling. Accounting for aseismic slip with either method lowers the earthquake potential of the fault, relative to a model that ignores creep. On the Calaveras fault, for example, slip rate scaling and area scaling for aseismic slip reduce the rate of $\mathbf{M} \geq 6.7$ earthquakes by factors of approximately 2.5 and 3, respectively (Figure 6.11). This effect is small for locked faults, larger for creeping faults. 
In addition to the choice of scaling method used, uncertainty in the value of the seismogenic area factor, $R$, also contributes to uncertainty in the calculated earthquake probabilities. Figure 6.12 shows the 30-year probability of $\mathbf{M} \geq 6.7$ earthquakes on the Hayward-Rodgers Creek and Calaveras faults calculated using, in turn, the lower, weighted, and upper value for $R$ in Table 4.1 , and $R=1.0$. Not surprisingly, the probability of characterized ruptures increases with decreasing amounts of aseismic slip.

\section{Estimate of the aperiodicity, $\alpha$, in earthquake recurrence.}

Inherent variability in the intervals between successive events (i.e., aperiodicity) introduces aleatory uncertainty in the probability calculation, which is represented in the BPT models by the parameter $\alpha$. In addition, epistemic uncertainty in the model arises from the fact that the value of $\alpha$ is not precisely known.

In Chapter 5, we considered some of the issues involved in estimating $\alpha$, and saw that pertinent paleoseismic and seismological data are sparse and require careful interpretation in order to make such estimates. Based on an analysis of available data (Ellsworth and others, 1999), we constrained $\alpha$ for the BPT model calculations to be in the range 0.3 to 0.7 and placed greater weight on the upper end of the range. The sensitivity of the 30 -year probabilities to the value of $\alpha$ over this range is illustrated in Figure 6.13, but is perhaps more fundamentally understood in terms of the hazard function for the BPT models (Figure 5.8b). The effect of $\alpha$ on earthquake probability on a fault segment depends on the segment's phase in its earthquake cycle. At times early in the cycle, the hazard increases with increasing values of $\alpha$. At these times, increasing the aperiodicity increases randomness, thus diminishing the importance of the fault's cyclic behavior and raising the probability toward its long-term level. For example, on the San Andreas fault, all of whose segments are near the beginning of their current cycle (which began in 1906), increasing $\alpha$ increases the 30-year conditional probability.

At times later in the cycle (after $\sim 1$ mean recurrence time), hazard decreases with increasing values of $\alpha$. At these times, increasing the randomness in the process diminishes the importance of the "ripeness" or "overdue" nature of the fault associated with cyclic behavior at advanced times and lowers the probability toward its long-term level. For example, on the HaywardRodgers Creek and Calaveras faults, where the time since the last resetting events is comparable to or greater than the mean recurrence time for several of their segments, increasing $\alpha$ decreases the 30-year conditional probability. Overall, the regional sensitivity to $\alpha$ is dominated by those faults that are late in their cycles, especially the Hayward-Rodgers Creek and Calaveras faults.

Because our probability calculations integrate hazard over a 30 -year period and combine the weighted contributions from five probability models, the dependence of probability on $\alpha$ seen in Figure 6.13 is diluted, relative to its dependence in a pure BPT calculation.

\section{Summary of sensitivity tests}

As discussed in Chapter 5, the greatest source of uncertainty in our probability calculations is in the choice of probability model. The distribution of regional probabilities calculated with the 
Poisson probability model includes all the sources of uncertainty arising in the fault characterization steps (Figure 6.7a). Added to this uncertainty is the uncertainty associated with the time-dependent probability models. The BPT and Empirical models each make additional assumptions and introduce additional uncertainty that broaden the distribution of the calculated regional probability (Figure 6.7a). However, the greatest source of uncertainty is in the choice among these probability models - a choice in which we found no clearly preferred candidate (Figures 5.11, 6.7b). Future efforts to estimate earthquake probability for the SFBR will benefit most from an improved understanding of the factors controlling the timing of earthquake occurrence and, in particular, the effects of fault interactions (see Chapter 8).

Within the long-term fault characterization model, the choice among the alternate fault rupture models is a major source of uncertainty for some faults. The assumptions involved in our model of fault segmentation - both in the definition of the fault segments and in the ways in which fault segment ruptures may combine in earthquakes - have a strong effect on the probabilities calculated on the San Andreas and San Gregorio faults.

Finally, on the Calaveras and Hayward faults, which sustain a significant amount of aseismic slip, the assumption of how aseismic slip affects the production of earthquakes is significant (Figure 6.11). Although we assume that aseismic slip on fault segments reduces their seismogenic area, an alternative interpretation (reduction in their long-term slip rate) can result in a significant change in the earthquake probabilities estimated for these faults. 


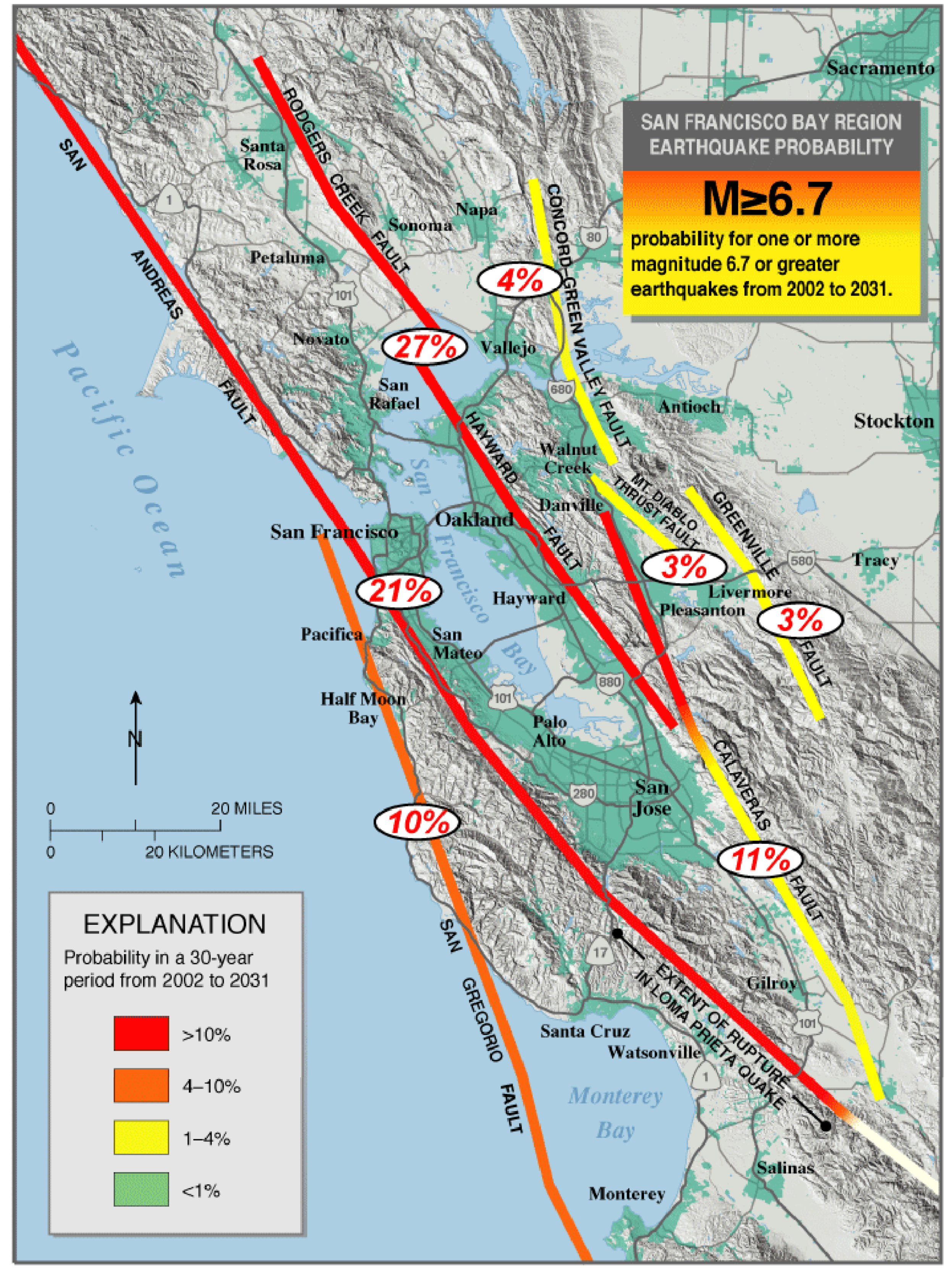

(a)

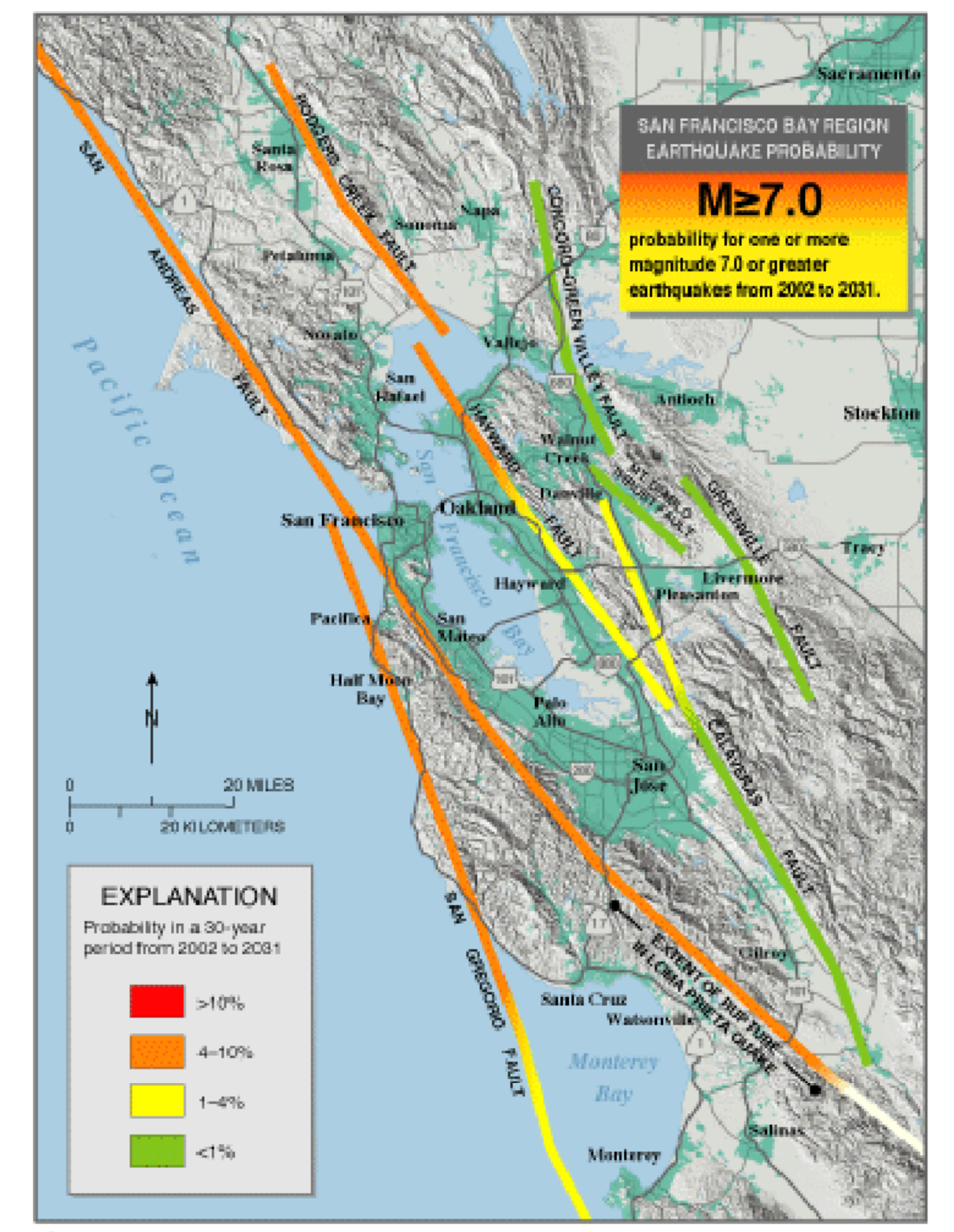

(b)

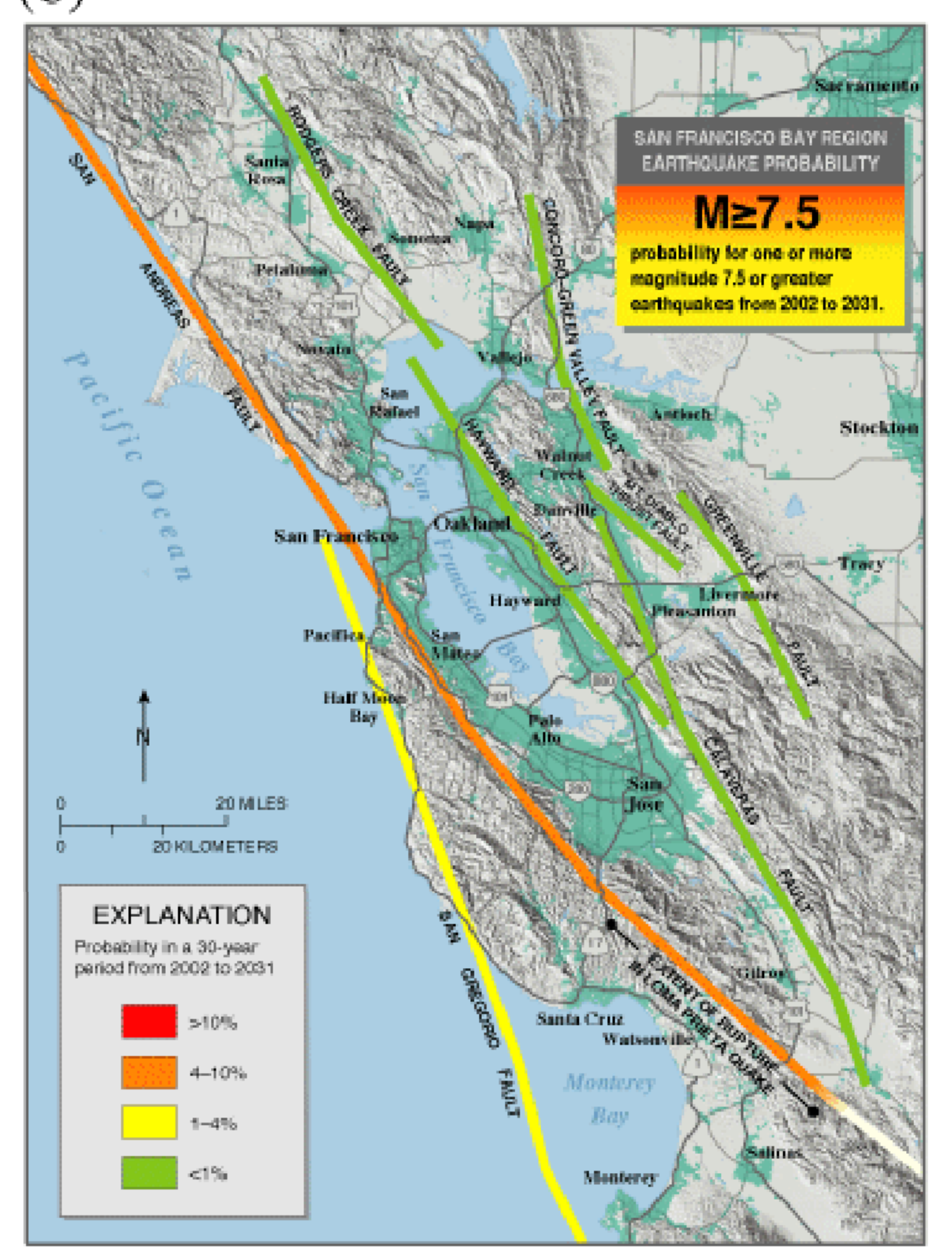

(c)

Figure 6.1. Probabilities of one or more strong earthquakes occurring on faults in the SFBR during the next 30 years. a) Earthquakes with M $\geq 6.7$. Probability of occurrence on each fault is indicated in ovals. Colors indicate the corresponding probabilities for each fault segment. b) Earthquakes with $M \geq 7.0$. c) Earthquakes with $M \geq 7.5$. The probability of earthquakes decreases with increasing earthquake magnitude (see Table 6.1). 


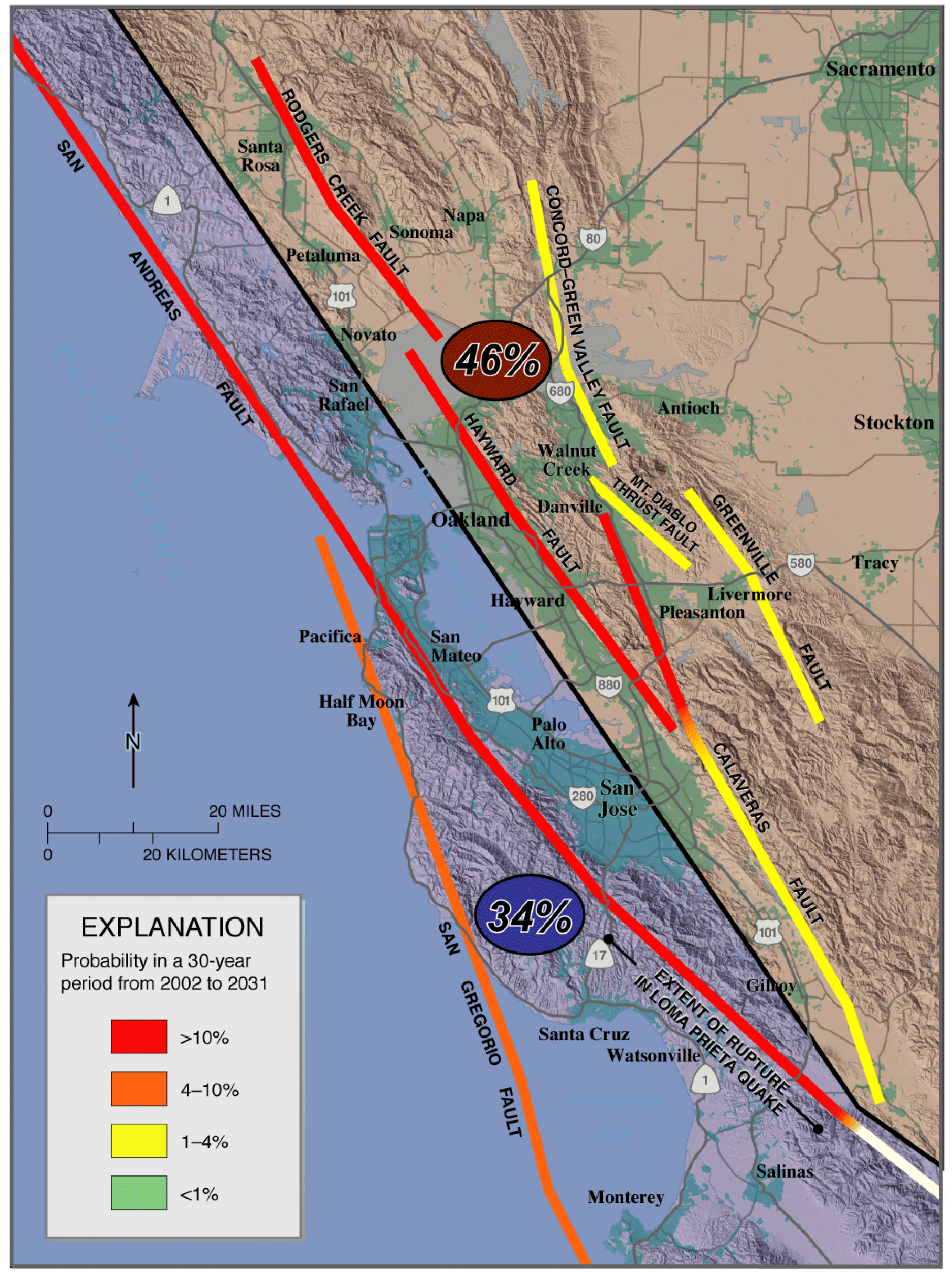

Figure 6.2. Geographic distribution of probability of $M \geq 6.7$ earthquakes in the next 30 years. Black line separates sub-regions northeast and southwest of San Francisco Bay. The combined probability in the northeast sub-region (including the faults within it and one-half the background probability) is 0.46 . In the southwest sub-region, the corresponding combined earthquake probability is 0.34 . 


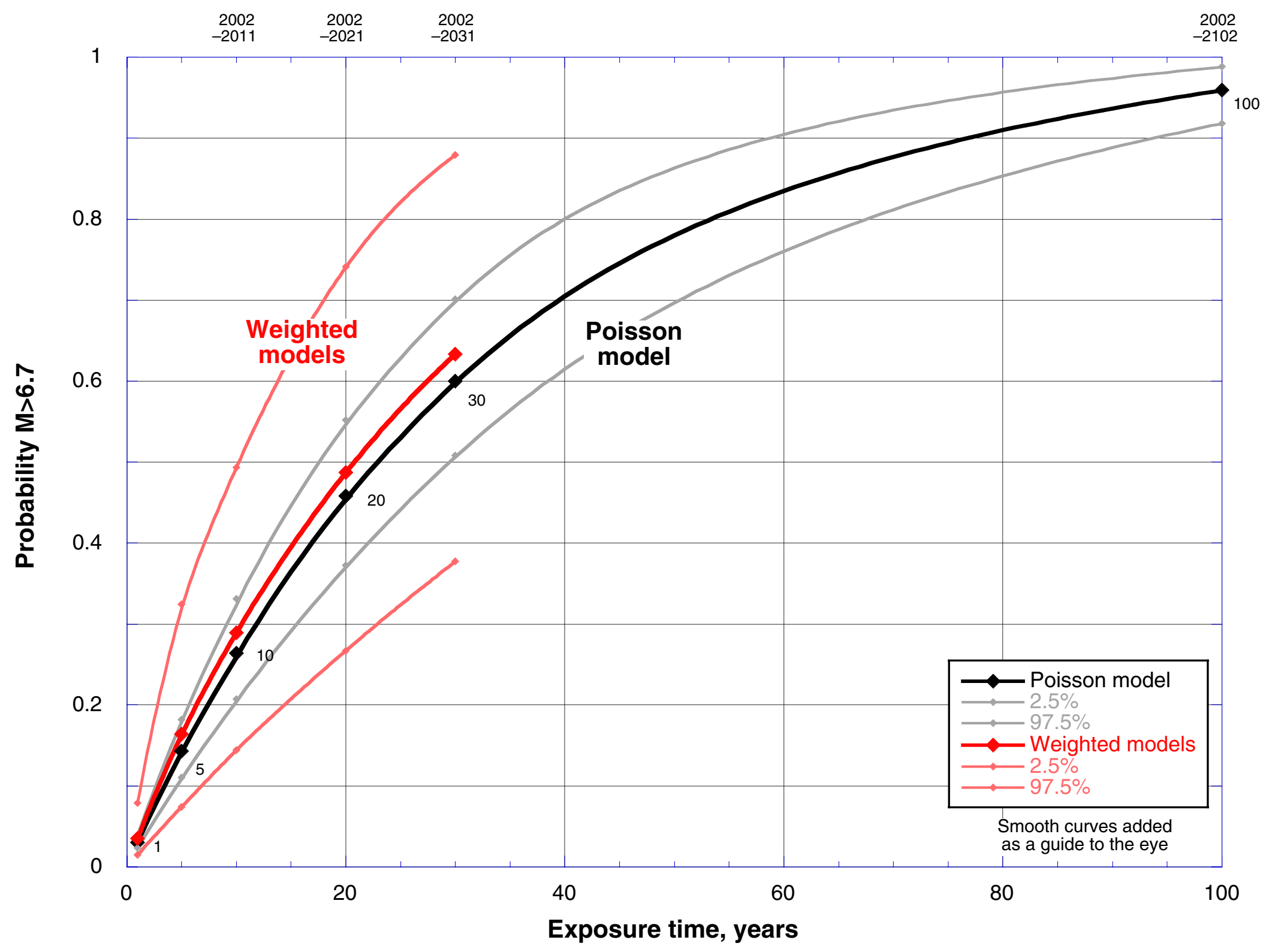

Figure 6.3. Probability of $\mathrm{M} \geq 6.7$ earthquakes in the SFBR calculated for time intervals ("exposure times") of $1,5,10,20,30$ and 100 years. All intervals begin in 2002. Calculations are shown for the weighted set of probability models (red) and for the Poisson model (black). 


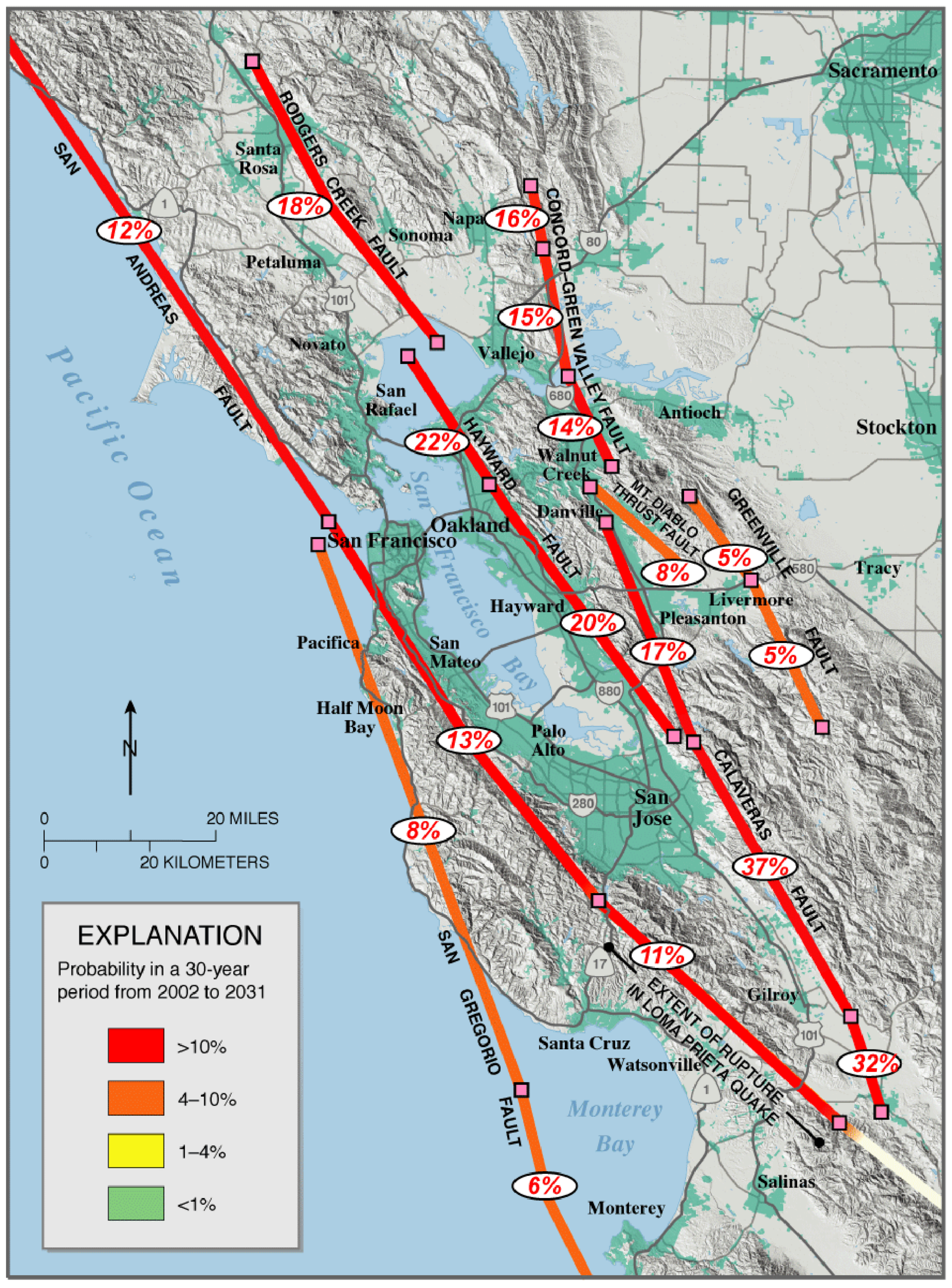

(a)

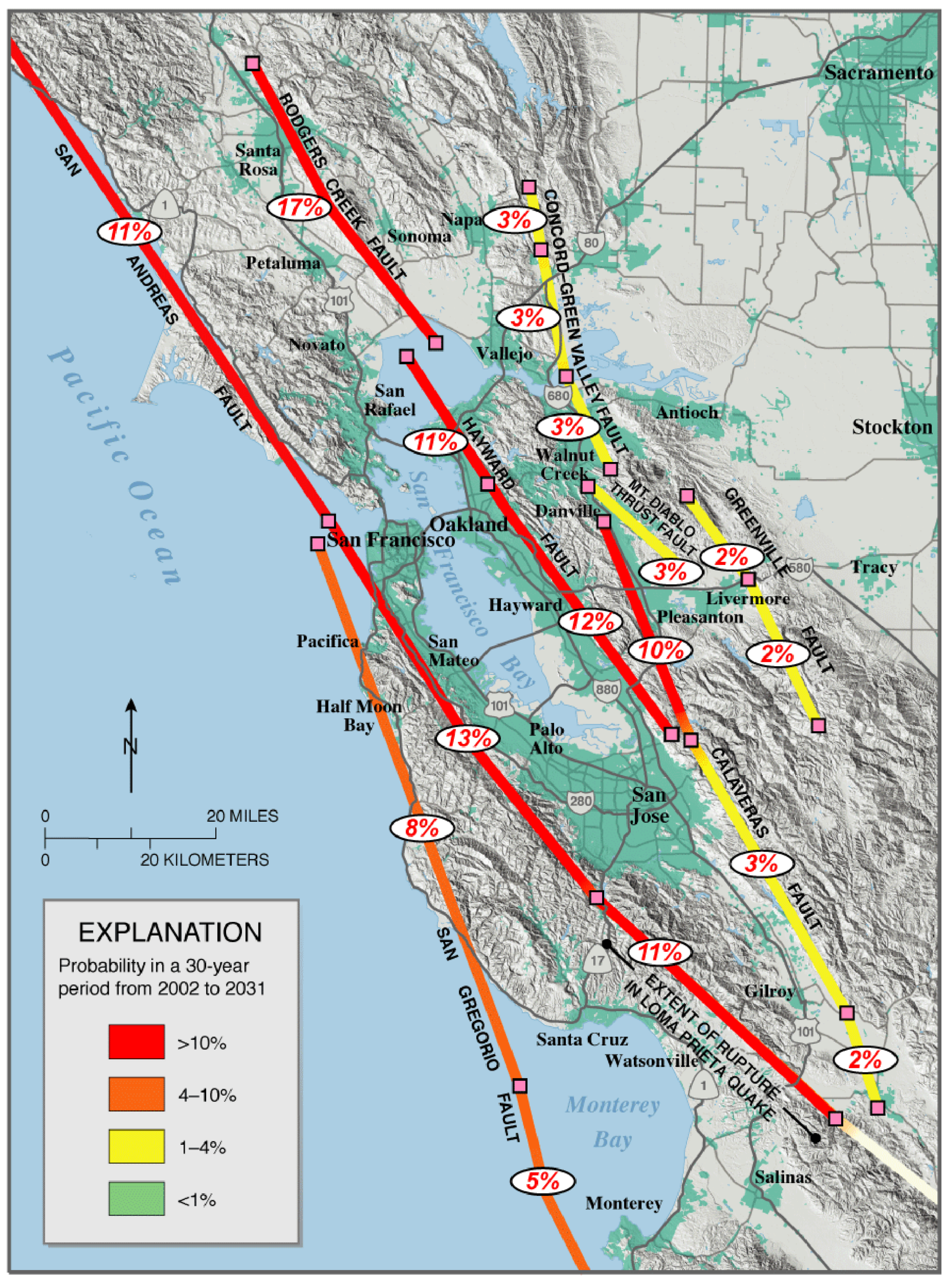

(b)

Figure 6.4. Probabilities of fault segment ruptures during the next 30 years. a) all characterized ruptures; b) M $\geq 6.7$ ruptures. Probabilites and uncertainties are listed in Table 6.3. Pink boxes are segment boundaries. 


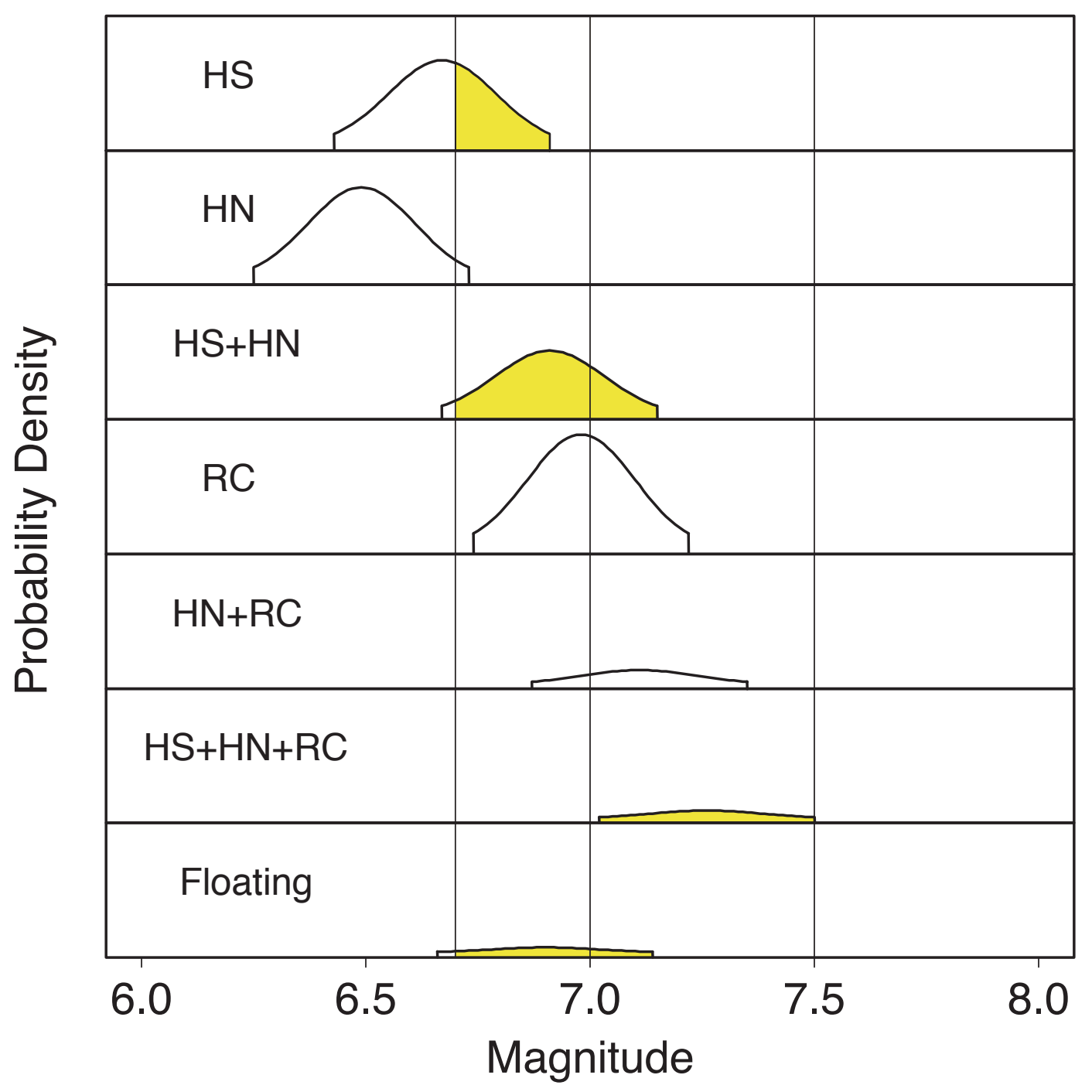

Figure 6.5. Probability density functions for rupture sources on the Hayward-Rodgers Creek Fault. The width of these truncated Gaussian distributions represents the alleatory uncertainty in magnitude of \pm 0.24 assumed for each rupture source. Mean magnitudes are listed in bottom portion of Table 6.5. The probability of rupture on a given fault segment (given in Table 6.3) is the combined area under the curves for the rupture sources involving that segment. Corresponding segment probability for ruptures above a magnitude threshold is combined areas to the right of the threshold magnitude. For example, color indicates the probability of a rupture of segment HS in M>6.7 earthquakes. (The contribution from the Floating source is a portion of the colored area proportional to the length of the segment.) Epistemic uncertainty is not included in this illustration. Vertical lines indicate $\mathrm{M}>6.7$, M>7.0 and $M>7.5$ magnitude thresholds. 


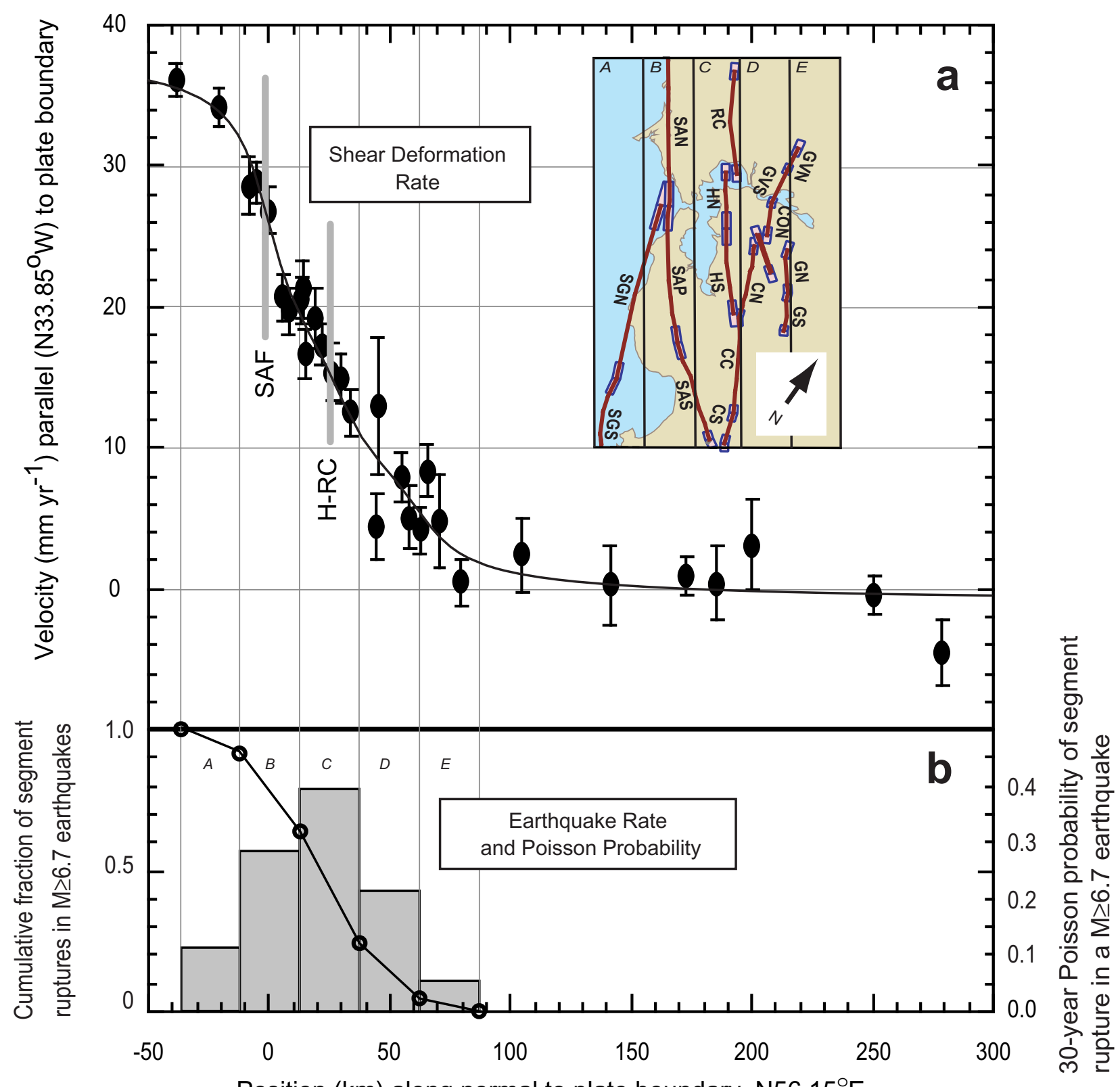

Figure 6.6. Comparison of contemporary rate of shear deformation and calculated earthquake rate and probability across the SFBR. (a) Motion of geodetic stations parallel to the Pacific-North American plate boundary (N33.85 $\mathrm{W}$ ), taken from Prescott et al. (2001) is shown by solid dots with 2-sigma error bars. Smooth curve is the deformation predicted by the best fitting model of Prescott et al. (2001). (b). Solid points and connecting lines show the cumulative fraction (scale on left) of the regional rate of segment ruptures in the WG02 long-term model occurring in 25-km-wide swaths (labeled $A$ through $E$ in inset) parallel to the San Andreas fault. One-fifth of the background rate was assigned to each swath, even though some background events (and the Mt. Diablo thrust) do not contribute to shear deformation. Gray bars show the 30-year Poisson probability (scale on right) of a segment rupture in a $M \geq 6.7$ earthquake occurring in the same 25-km-wide swaths. 

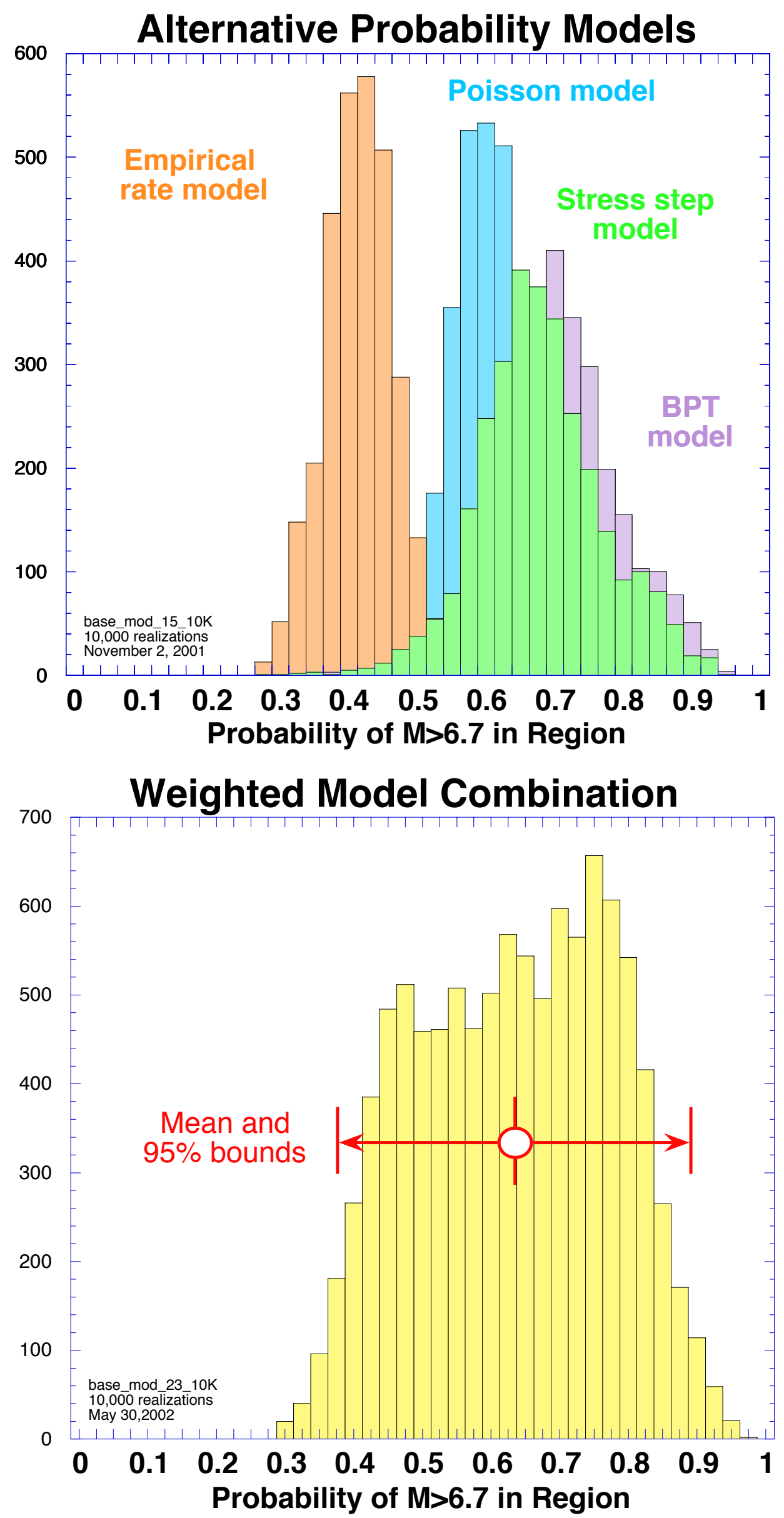

Figure 6.7. Distributions of the regional probability of a M 6.7 earthquake calculated using various probability models. a) Overlapping histograms show probability calculated in 3000 iterations using each of four models separately. The shape and width of each distribution reflects epistemic uncertainty in the choice of underlying models and parameters. b) Corresponding distribution calculated in 10,000 iterations using the weighted combination of models described in the text and shown in Figure 5.12. The broad shape of this distribution reflects the combination of distinct behaviors of he alternate models. Additional mass near $\mathrm{P}=0.8$ corresponds to realizations that employ the TimePredictable model on the San Andreas fault, not shown in (a). 

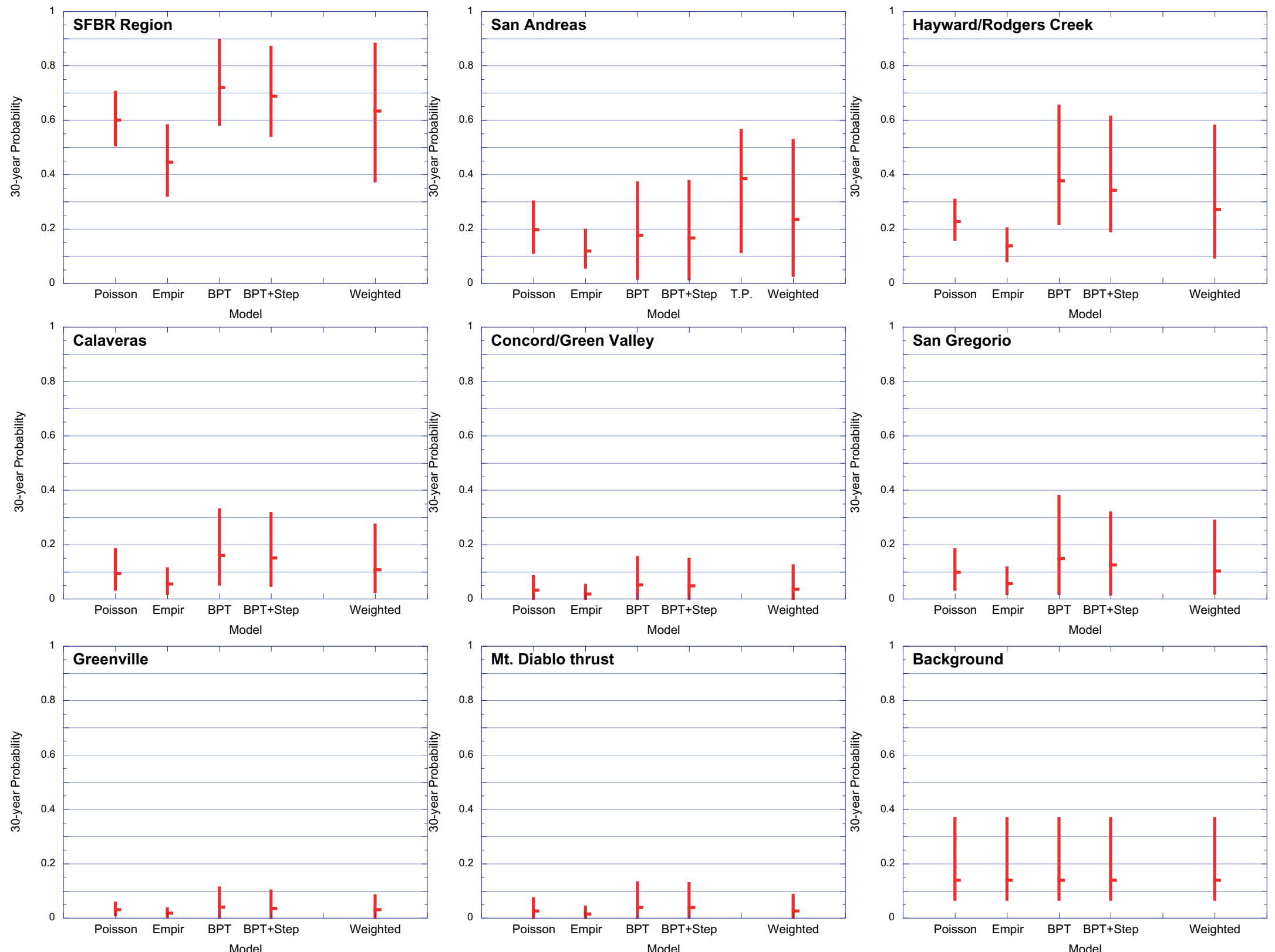

Figure 6.8. Conditional probabilities of one or more $M \geq 6.7$ earthquakes in the region, on each characterized fault, and in the background. Probabilities calculated for each probability model and for the weighted combination of models are shown (see Table 6.15). Mean probability is indicated by horizontal tick, and $95 \%$ confidence range by full length of bar. 


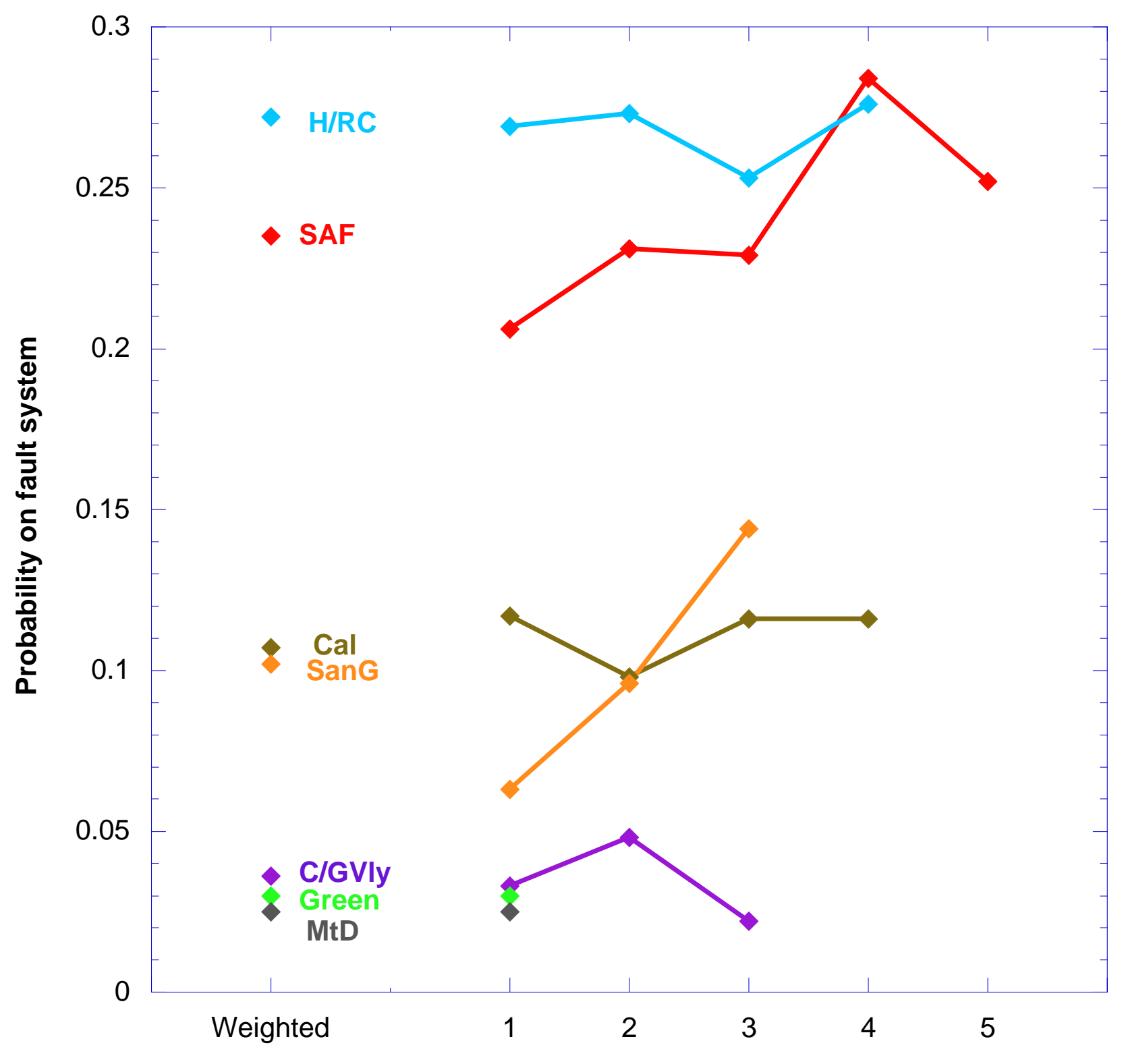

Fault rupture model

Figure 6.9. Dependence of earthquake probability on the choice of fault rupture model. See Chapter 2(?) for definitions of the fault rupture models. All calculations are for $M \geq 6.7$ earthquakes (2002-2031) on a single fault system and use the weighted probability model. Benchmark calculations (points on left) use rupture model weights adopted by WG02. Connected points are corresponding probabilities for the cases in which $100 \%$ weight is given, in turn, to each of the individual rupture models. $\mathrm{H} / \mathrm{RC}=$ Hayward-Rodgers Creek fault; $\mathrm{Cal}=$ Calaveras fault; $\mathrm{SanG}=\mathrm{San}$ Gregorio fault; $\mathrm{SAF}=\mathrm{San}$ Andreas fault; C/Gvly=Concord-Green Valley fault; Green=Greenville fault; MtD=Mount Diablo fault. 


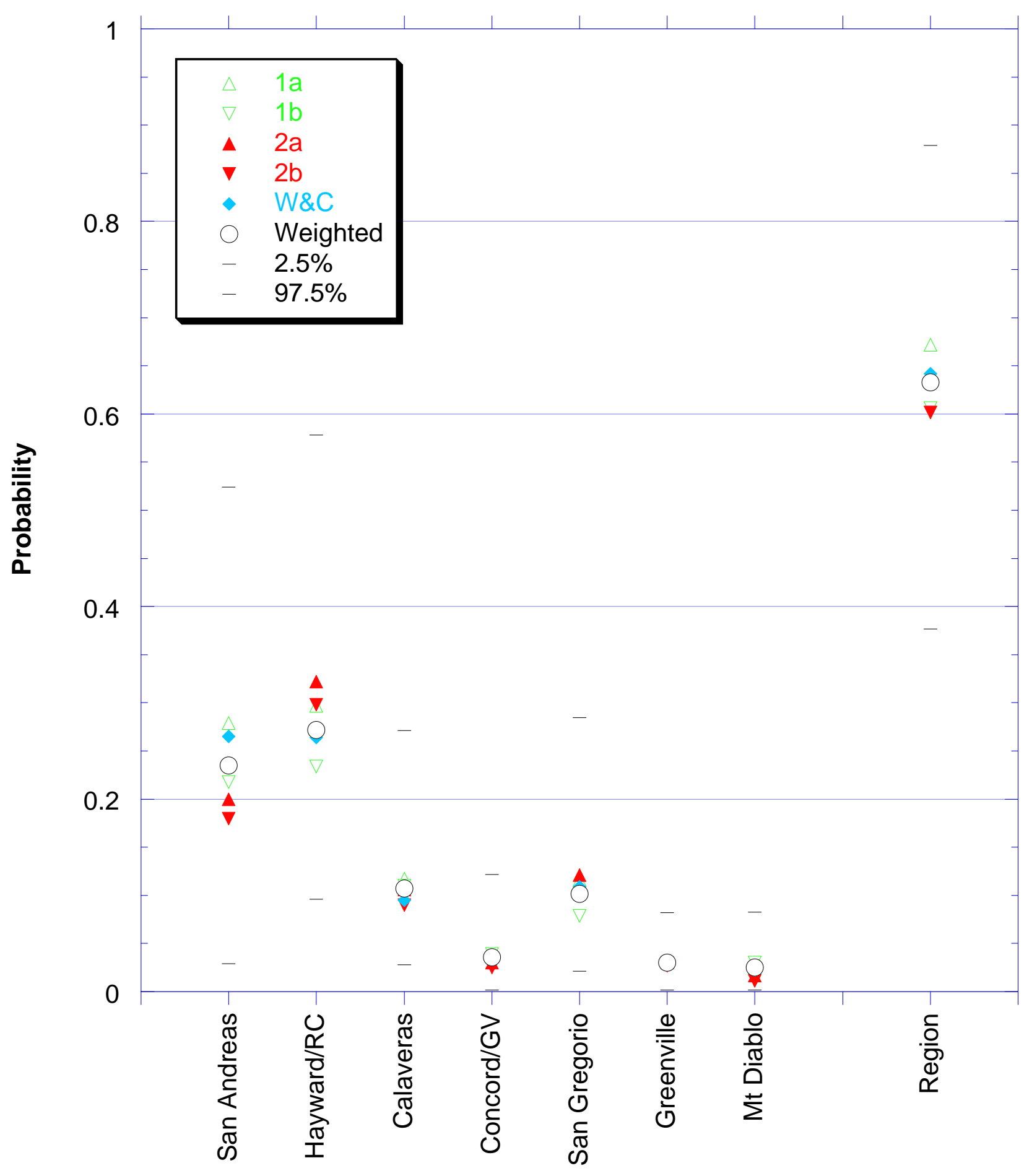

Figure 6.10. Dependence of probability on the choice of $\mathbf{M}-\log$ A relation. See Equations 4.4 to 4.6 for definitions of the $\mathbf{M}$-log $A$ relations. All calculations are for $M \geq 6.7$ earthquakes in 2002-2031.

Benchmark calculations (black circles) and their 95\% confidence range (black bars) were calculated using the weights for the $\mathbf{M}$-log A relations given in Table 4.2. Colored symbols represent the corresponding probabilities calculated with $100 \%$ weight assigned, in turn, to each $\mathbf{M}$-log $A$ relation. 


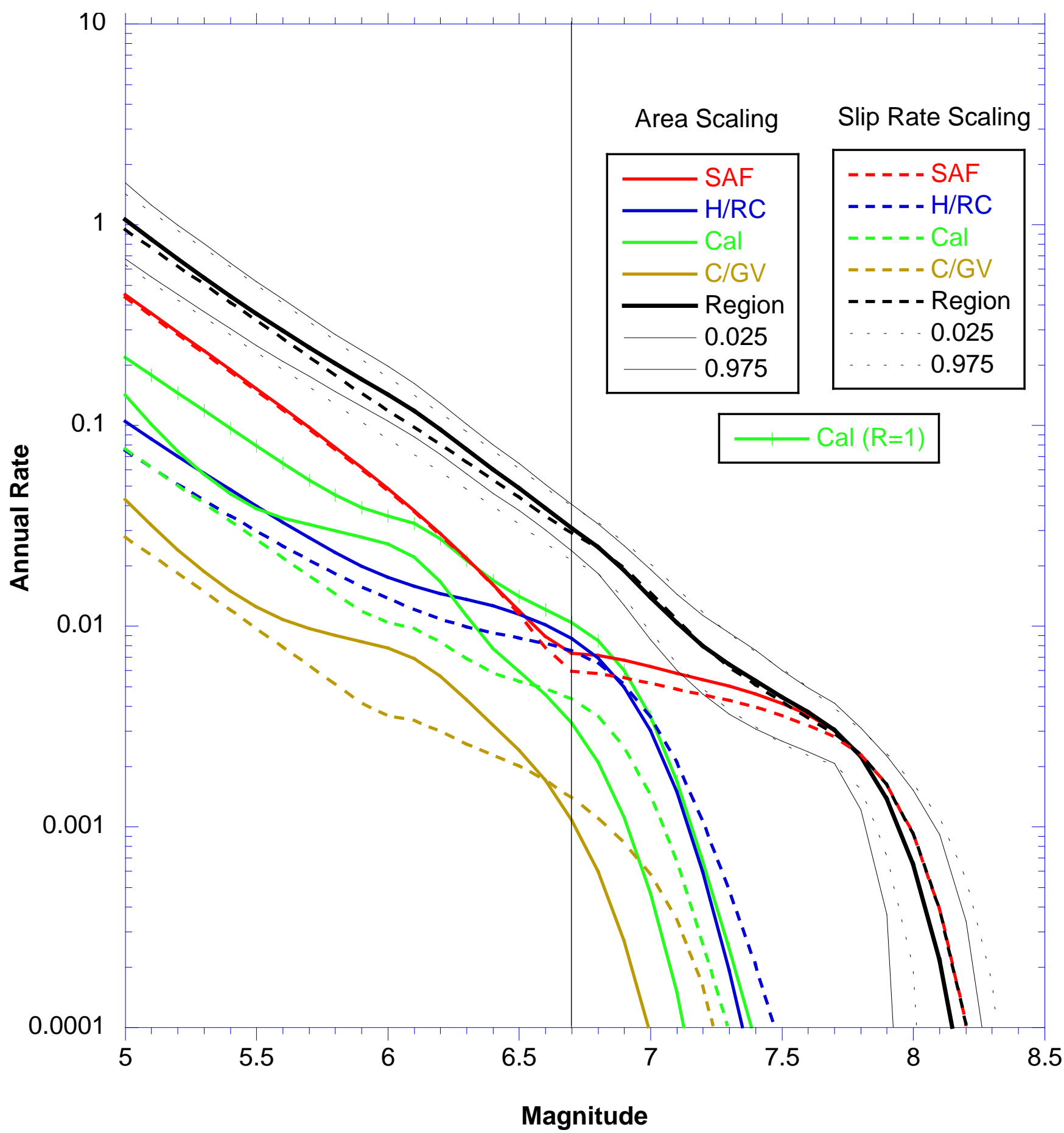

Figure 6.11. Dependence of the modeled earthquake rates on the method used in accounting for the aseismic slip (creep) on four selected faults and in the region. The frequency-magnitude relations for each fault and the region are shown for the case in which aseismic creep reduces the rupture area of each rupture source (solid lines) and the case in which aseismic creep reduces the long-term slip rate available for earthquakes (dashed lines). Hatchured green line shows frequency-magnitude distribution for the Calaveras fault without any accounting for aseismic slip (i.e., $\mathrm{R}=1.0$ ). Calculations are for $\mathrm{M}>6.7$ earthquakes in 2002-2031. 


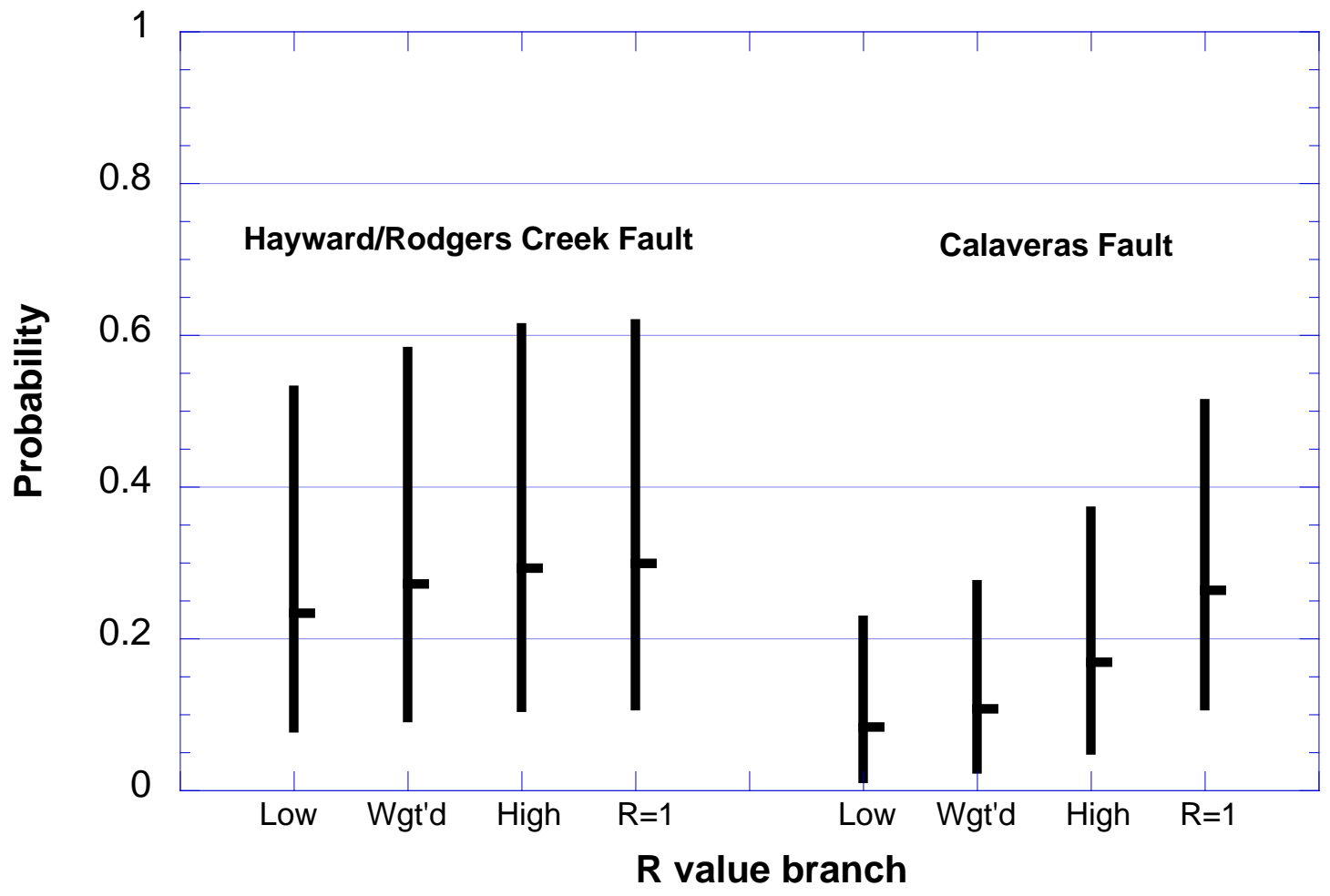

Figure 6.12. Dependence of probability on the seismogenic scaling factor, R. Calculations are for $\mathbf{M} \geq 6.7$ earthquakes (2002-2031) on the Hayward-Rodgers Creek and Calaveras faults. "Low ", "Wgt'd", High" and "R=1" correspond to the lower, weighted, and upper values of $\mathrm{R}$ given in Table 4.1 and to $\mathrm{R}=1.0$. Horizontal bars are mean values, vertical bars show the $95 \%$ confidence range. 


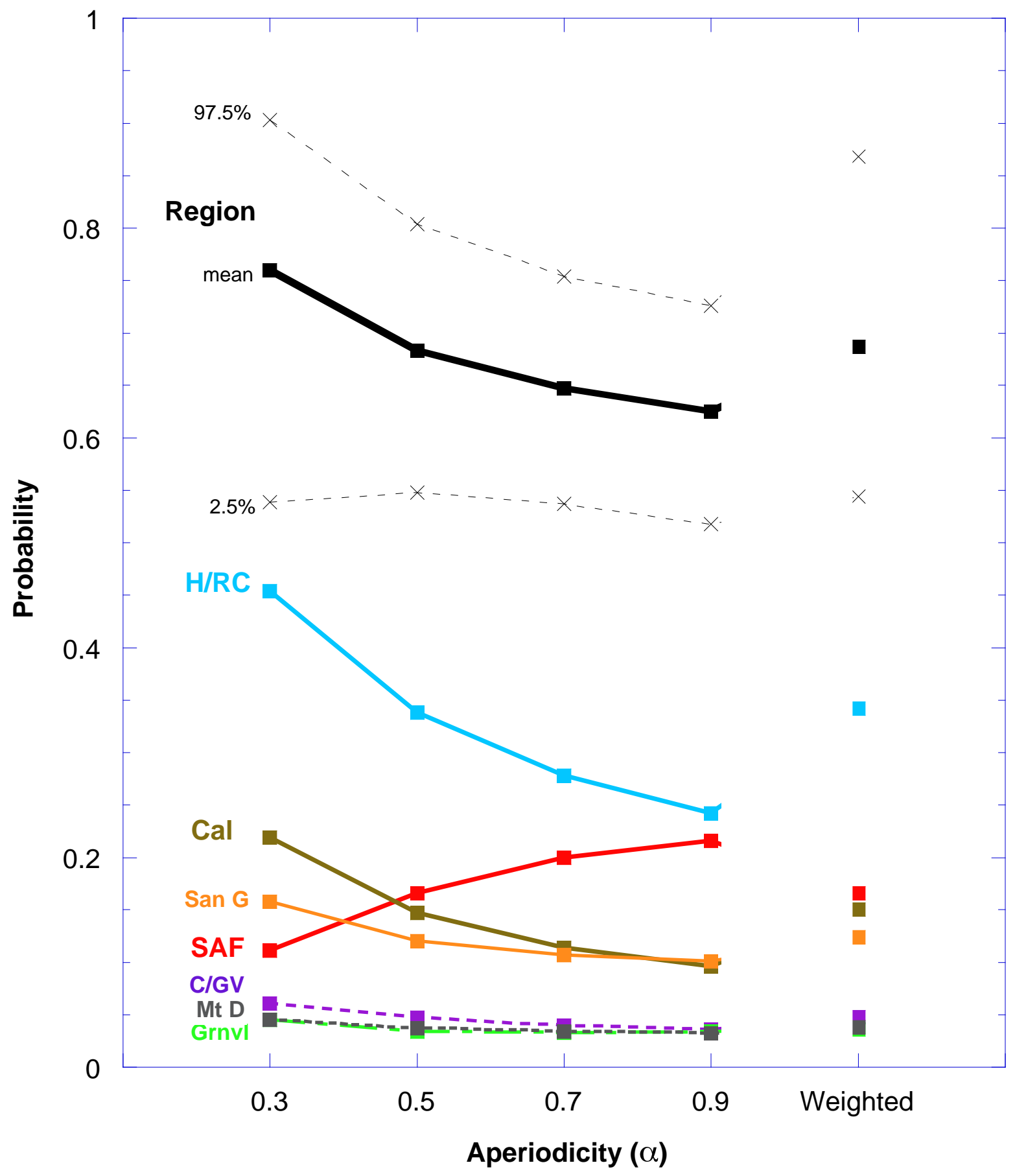

Figure 6.13. Dependence of earthquake probability on the value of the aperiodicity parameter, a, used in the BPT-step model. All calculations are for $M>6.7$ earthquakes (2002-2031) on individual fault systems and in the region. Points on right are probabilities for faults and the region calculated with the weights for $\alpha$ adopted by WG02. Connected points are the corresponding probabilities calculated with $100 \%$ weight given, in turn, to each of four values of $\alpha$. Black dashed lines and crosses show $95 \%$ confidence range for the regional probability calculations. 


\section{CHAPTER 7. IMPLICATIONS FOR EARTHQUAKE HAZARD IN THE SAN FranCisco BAY REgion}

\section{Introduction}

The foremost conclusion of our Bay Area earthquake probability study is that the likelihood of a future destructive earthquake somewhere in the region in the next 30 years is high, even though the precise probability value has a broad range of uncertainty. Relative to earlier studies, the most significant new result is that this probability is spread throughout the greater metropolitan region, not just restricted to areas surrounding San Francisco Bay. As growth and development have spread outward from the Bay margins during the past several decades, so has our recognition and definition of the earthquake hazard associated with strain accumulation and release on the 7 major fault systems that transect the region over a $75 \mathrm{~km}$ wide zone (see Figure $6.13)$.

By 2025, the population of the Bay Area is projected to exceed 8.2 million people--an increase of more than 1.4 million from the Census 2000 level (Fassinger et al., 2001). Nearly all of this growth is expected to occur in the East Bay and North Bay regions. Contra Costa, Alameda, and Santa Clara Counties are projected to experience a 15-20\% increase in population. Solano and Napa counties are anticipated to show the highest growth, each adding more than 30 percent to their respective populations. This eastward and northward growth of the region will occur in areas of significant seismic hazard. As noted in Chapter 6, the cumulative 30 year probability of an earthquake of $\mathrm{M}>=6.7$ occurring somewhere within this rapidly growing East and North Bay region alone is nearly $50 \%(\mathrm{P}=0.46[0.17-0.64]$.

Earthquake probabilities are, by themselves, only a partial description of the seismic hazard of a region. Most earthquake damage is the result of strong ground shaking, which depends on the earthquake size, distance from the causative fault, and local soil conditions as well as source to site path effects, duration of shaking, and rupture directivity. In this chapter we consider the distribution of shaking and damage that these earthquakes are likely to produce. It is important to note that these maps that do not attempt to characterize the complexity that will surely be characteristic of earthquake ground shaking and damage. These maps simply represent median ground motions and intensity levels that might occur from any of these earthquakes. Maps of expected intensity levels, as defined by the modified Mercalli intensity scale (MMI) can be created for a single earthquake, and these maps can be integrated to model the effects of a suite of future earthquakes. In general, MMI VII is characterized by damage to weak structures, MMI VIII is characterized by damage to engineered structures, and MMI IX is characterized by severe damage and partial collapse of some structures. Below, we present and discuss maps of expected shaking for the highest probability earthquakes in the WG02 study and aggregate shaking maps for the SFBR as a whole. Our goal in presenting this information is to inform policymakers and encourage mitigation and preparedness efforts to reduce the potentially devastating impacts of these future earthquakes. 


\section{Scenario Shakemaps: Anticipated Shaking Levels for High-Probability Future Earthquakes}

To examine the implications of these future earthquakes, we have produced a series of MMI intensity maps, which we describe as scenario ShakeMaps, for the potential Bay Region rupture sources. We focus discussion on maps depicting MMI intensity values for the largest and most probable WG02 rupture sources (Table 7.1). The complete set of scenario ShakeMaps for all 35 potential rupture sources defined by WG02 can be downloaded from the website http://ncwebmenlo.wr.usgs.gov/research/strongmotion/effects/shake/archive/scenario.html.

The scenario ShakeMaps graphically illustrate the strength and regional extent of shaking that can be expected from a specific earthquake source. They are particularly valuable in assessing the hazard to a particular site from the set of scenario earthquakes. The ShakeMaps are determined from the peak ground acceleration and velocity estimated using the ground motion prediction equations of Boore and others (1997) and Joyner and Boore (1981), respectively. The source parameters required for these calculations are the seismic moment and the surface projection of the rupture area. The resulting ground motions are applied to the soils map developed by the California Geological Survey (Wills et al., 2001) to account for soil amplification. The site amplifications are determined by aggregating the surface geology into NEHRP site-classes and using the non-linear amplification equations of Borcherdt (1994). The maps of peak ground acceleration and velocity are combined to estimate the Instrumental Intensity, devised by Wald and others (1999) as a quantitative approximation for the Modified Mercalli Intensity.

The maps of Instrumental Intensity are presented in this chapter as scenario ShakeMaps. Alternative measures of ground motion in the form of contour maps of peak ground acceleration, peak ground velocity, and spectral response are also given on the website for all 41 rupture sources. It is important to note that these are median estimates: when a large earthquake actually occurs, the ground motions will exceed these estimates in many places. Furthermore, the ground motion prediction equations of Boore and others (1997) and Joyner and Boore (1981) do not include explicit directivity or near-fault amplification terms, so that it is possible that the ground motion near the surface trace of these rupture sources will be stronger than the estimates on these maps. 
Table 7.1 Highest probability, large $(M \geq 6.5)$ individual rupture sources identified by WG02

\begin{tabular}{lcc} 
Rupture source & Magnitude & $\begin{array}{c}30 \text { year } \\
\text { Probability of } \\
\text { Characterized eq }\end{array}$ \\
\hline RC & 6.98 & $15.20 \%$ \\
CN & 6.78 & $12.40 \%$ \\
HN & 6.49 & $12.30 \%$ \\
HS & 6.67 & $11.30 \%$ \\
HS+HN & 6.91 & $8.50 \%$ \\
MtD & 6.65 & $7.50 \%$ \\
SAF floating M6.9 & 6.90 & $7.10 \%$ \\
CON+GVS+GVN & 6.71 & $6.00 \%$ \\
SAS+SAP+SAN+SAO & 7.90 & $4.70 \%$ \\
SAP & 7.15 & $4.40 \%$ \\
SAS & 7.03 & $2.6 \%$
\end{tabular}

Scenario ShakeMaps for the most probable strike-slip earthquake rupture sources in the SFBR are described below. We cannot calculate a scenario ShakeMap for the floating SAF event because the location is unspecified. Table 7.1 again emphasizes the high hazard WG02 has identified for the east and north Bay, with 7 of the likeliest sources located in theseareas of the SFBR. We have included an actual ShakeMap (generated by incorporating the actual strong motion data) for the 1989 M6.9 Loma Prieta earthquake to provide a "ground truth" comparison for the scenario map for the Santa Cruz Mountain segment of the San Andreas fault (SAS). Perhaps the most important message from these maps is that even though the intensities are generally higher close to the rupture source, high intensities and associated damage occur throughout the SFBR for each of these events.

\section{San Andreas fault}

The largest anticipated earthquake affecting the SFBR is a repeat of the 473-long-1906 M7.9 rupture of the San Andreas fault. The immensity of the energy released by this earthquake is obvious when scenario ShakeMaps for this and two other San Andreas rupture sources, SAP and SAS, are plotted at the same scale (Figure 7.1). As is clearly demonstrated in Figure 7.1a, a repeat of the 1906 earthquake will have devastating effects throughout much of Northern California from the Central Valley west, producing a zone of structurally damaging shaking intensities (MMI $\geq$ VIII) over a 10,000 $\mathrm{mi}^{2}$ zone (approximately 30 miles wide and over 330 miles long). Intensity VII shaking levels are anticipated to extend to the western part of the Central Valley.

A M7.2 event on the Peninsula segment of the San Andreas, possibly a repeat of the 1838 earthquake, would produce a significantly smaller region of strong shakingalong the Peninsula 
(Figure 7.1b). However, this event also produces damaging ground motions (MMI-VIII) around much of the Bay margins.

A comparison of the scenario ShakeMap for a M7.0 rupture of the Santa Cruz Mountains segment (Figure 7.1c) with the actual ShakeMap for the Loma Prieta earthquake (Figure 7.1d) illustrates some of the uncertainties in our secenarios. Although the rupture source for the for the 1989 earthquake is not identical to the SAS, there is generally good agreement in distribution and levels of shaking from the 1989 event and the predicted shaking from a similar-sized earthquake (M7.0) in the Santa Cruz mountains. While the scenario ShakeMap underestimates the intensity to the north, in Oakland, San Francisco, and San Mateo, it overestimates the intensity in Morgan Hill, Gilroy, and Watsonville. These maps also serve as a reminder that even relatively remote quakes can have a significant impact on the Bay Area, as well as on the rapidly growing communities in the Monterey Bay and along the I101 corridor south of San Jose.

\section{Hayward-Rodgers Creek fault}

The most hazardous fault system in the Bay Area identified by WG02 is the Hayward-Rogers Creek, with a likelihood of $27 \%$ for a $M \geq 6.7$ earthquake in the next 30 years. This is greater than a 1 in 4 chance of a damaging larger earthquake somewhere along its extent. Figure 7.2a shows the expected distribution of shaking intensity for the highest probability large rupture source in the WG02 model, a M6.98 rupture of the Rodgers Creek Fault ( $\mathrm{P}=0.15$, Table 7.1). Shaking for this event will be severe to violent along the length of the fault through the highly developed Santa Rosa region as far north as Healdsburg, as well as on the soft sediments along the northern margins of San Pablo Bay. Very strong to severe shaking is also expected to occur in the Vallejo-Napa area, on the south side of San Pablo Bay, and along the Bay margins west of Oakland.

Rupture of the full Hayward fault (M6.91, P=0.09) shown in Figure 7.2b, would be the most devastating East Bay event because it would occur within the highly developed Interstate 880 corridor. This earthquake would generate structurally damaging ground motions (intensities VIII-X+) from the eastern margin of the Bay through the East Bay hills, and from Milpitas in the south to as far north as Petaluma. Structurally damaging shaking levels are also expected in the financial district of San Francisco. Very strong to severe shaking would occur throughout the Santa Clara valley and eastward into the San Ramon and Livermore valleys and the western part of the Delta.

Scenario ShakeMaps for the southern $(\mathrm{P}=0.12)$ and northern $\mathrm{P}=0.11$ segments of the fault are shown on Figures 7.2c and 7.2d, respectively. The southern Hayward rupture (M6.67, Figure 7.2c) is considered similar to the 1868 Hayward earthquake. The 1868 event caused considerable damage to soft soil and landfills both in San Francisco and along the east margins of the Bay (Lawson, 1908), consistent with the strong levels of shaking predicted in the scenario ShakeMap. The area of structurally damaging shaking intensities from a northern Hayward rupture (M6.5, $\mathrm{P}=0.11$, Figure 7.2d) extends to north of San Pablo Bay, along the NE Bay margins, and eastward to the Walnut Creek area. Shaking intensities in the densely developed greater Oakland area would be in the VII to VIII range, and extensive structural damage is likely in this region. 
Note that for all the Hayward fault scenarios, severe shaking is predicted to extend westward across San Francisco Bay onto the soft soil sites on the San Francisco Peninsula and the made land/artificial fill in San Francisco. In fact, San Francisco's financial district, which is largely built on pre-1906 bay fill, is approximately equidistant from the Hayward and the San Andreas faults, making it vulnerable to large earthquakes on both sides of the Bay.

\section{Other East Bay faults}

The newly characterized East Bay faults in the WG02 study transect the regions of the fastest growth of the San Francisco Bay area. We have included scenario ShakeMaps for four of the highest probability events in the eastern part of the study area-- rupture of the northern Calaveras, the entire Concord-Green Valley, the entire Greenville fault, and the Mt. Diablo thrust--to illustrate the potential impact of such events.

Figure 7.3 shows the distribution of shaking for the East Bay faults. The ShakeMap for the highest probability event in this region, a M6.78 earthquake on the northern Calaveras fault $(\mathrm{P}=0.12)$ is given in Figure 7.3a. This earthquake would severely affect the major cites in this part of the East Bay, from Livermore north to Walnut Creek. Intensities of VIII to X would be expected along the length of the rupture and eastward into the Livermore Valley. Severe shaking would also be produced along the east side of the Bay from Oakland south to San Jose.

A rupture of the entire Concord-Green Valley fault system (M6.71, P=0.06, Figure 7.3b) would produce violent shaking along the Vallejo-Suisun Valley corridor of Interstate 80 and in the Concord-Walnut Creek area. A full rupture of the Greenville fault (M6.94) is assigned a relatively low probability $(\mathrm{P}=0.02)$, however severe shaking from this event would strongly affect the Pleasanton-Livermore Valley region along Interstate 580 as well as the ConcordWalnut Creek area to the north (Figure 7.3c).

The Mt. Diablo thrust is the only thrust fault characterized in the SFBR by WG 02 . The fault does not extend to the surface. Figure 7.3d shows the location of the modeled fault plane at depth (black rectangle) and the shaking estimated for a M 6.7 event. Very strong to severe shaking is expected to occur from the Livermore valley on the south northward to Vallejo and the western Delta. The margins of San Francisco Bay, particularly the eastern margin, is also expected to experience severe shaking.

All of these events generate strong to severe shaking in the western part of the Central Valley, particularly in the soft sediments in the Delta region south of Rio Vista. Despite their location in the eastern Bay region, large earthquakes on these faults will produce moderate to heavy shaking around the San Francisco Bay margins.

\section{Regional Shaking Levels}

Levels of shaking for a region can be calculated by combining the likelihood and magnitude of future earthquakes on specific fault segments with information on how seismic waves propagate through the region and on local soil conditions. These values are normally given in terms of the likelihood of exceeding a given level of shaking over a specific time interval. This approach, 
known as probabilistic seismic hazard assessment (PSHA) [Cornell, 1968], has been employed in developing the recent U.S. National Seismic Hazard Map .For the past several decades the U.S. Geological Survey (USGS) and the California Geological Survey (CGS) have jointly produced seismic hazard maps for California (Frankel et al., 1996; Petersen et al., 1996). These maps were used in developing the seismic design parameters for the 2000 International Building Code, setting insurance rates by the California Earthquake Authority in 1998, implementing California seismic hazard zones (1990 California Seismic Hazards Mapping Act), planning mitigation strategies (e.g., FEMA prioritization of structural retrofit following the 1994 Northridge earthquake), estimating seismic losses (FEMA-NIBS HAZUS loss estimation methodology) and calculating design ground motions for schools, hospitals, and other important structures (e.g., California Code of Regulations, Title 24, California Building Code; 1973 California Hospital Seismic Safety Act). New seismic hazard maps that use the updated WG02 SFBR earthquake sources area available at the website http://geohazards.cr.usgs.gov/eq.

Specific values of expected ground motion obtained from PSHA are of particular interest to engineers and architects. These values can be converted to earthquake intensity levels that are directly related to expected damage. We have calculated two intensity hazard maps (Figure 7.4) that depict the time-independent levels of shaking in the SFBR from the integrated earthquake sources included in the U.S. National Seismic Hazard maps (including the sources from this report) for a 30-year time window. In producing these hazard maps we have taken into account the uncertainties in the ground motions as well as the uncertainties in the damage associated with these motions. On both maps the intensity levels are color-coded using similar colors as the scenario ShakeMaps. The 10\% map (Figure 7.4a) is time-independent and corresponds to the intensity that has a 1 in 10 chance (10\%) in 30 years, or even odds $(50 \%)$ chance in 200 years, of being exceeded. The $50 \%$ map(Figure $7.4 \mathrm{~b}$ ) shows the intensity that has a $50 \%$ chance of being exceeded in 30 years or a $99 \%$ chance of being exceeded in 200 years.

The $10 \%$ map depicts high intensities across the entire Bay area that would cause significant damage to both engineered and weak structures. The 50\% probability map, which is more likely, indicates an expected intensity of about MMI VII on sites located on rock, causing damage to weak structures, and greater than MMI VIII on the soft soils surrounding the Bay and Delta, causing significant damage to engineered structures during the 30-year period. The strong shaking intensity levels on the Bay margins reflect the amplification effects of soft sediments and fill in these areas. In the past decade the Bay margins have experienced rapid commercial construction, particularly in the south Bay.

Historically, earthquake damage in the SFBR has been quite variable through the past couple of centuries. Residents of the Bay area have experienced little or no damage during decade long intervals of relative seismic quiescence and then have experienced significant damage from multiple earthquakes during long periods of seismic activity. For example, between 1830 and 1910 regional earthquake intensities were very high from at least 4 earthquakes with $M>=6.5$, culminating with the M 7.9 1906 San Francisco earthquake. However, during the subsequent 73year period between 1907-1980 almost no damaging large earthquakes occurred in the region. More recently, during the past 23 years (1980-2003) the 1989 Loma Prieta earthquake (M 6.9) ruptured near the San Andreas fault in the Santa Cruz Mountains and the 1984 Morgan Hill earthquake (M6.2) ruptured along the Calaveras fault in the south Bay area. The 1989 earthquake 
caused considerable damage at sites that are underlain by soft soils (e.g., the San Francisco Marina district and Oakland) and at sites near the earthquake rupture beneath the Santa Cruz Mountains. Therefore, during some 30-year intervals over the past 170 years the SFBR has experienced shaking intensities similar to Figure 7.4a, in other 30-year intervals the SFBR experienced intensities similar to Figure $7.4 \mathrm{~b}$, and still others it experienced relatively low levels of shaking intensity. By analyzing intensity patterns from historical earthquakes back to 1800, Toppozada et. al (1991) conclude that the SFBR has experienced MMI VII or greater on average every 30 to 50 years. The regional probabilistic intensity maps are valuable because they allow assessment of impacts of future earthquakes at a given hazard level. While a $10 \%$ likelihood may be useful for many policy decisions, even the shaking intensity expected at the $50 \%$ likelihood level over the next 30 years represents a significant hazard.

\section{Preparedness and Mitigation Now to Reduce Future Earthquake Losses}

In the section above we have used our earthquake probabilities to estimate the expected distribution of shaking intensity for the SFBR as a whole. Earthquake risk (the consequences of an earthquake in terms of probable loss of life and property) is the product of the ground shaking hazard, the exposure (buildings, infrastructure inventories), and the structural vulnerability. A detailed examination of earthquake risk for the SFBR is beyond the scope of this report. However, the earthquake rupture scenarios developed by WG02 as well as the maps of integrated regional shaking intensity derived from the national Seismic Hazard map provide fundamental inputs to a variety of risk-related analyses.

The scenario earthquake rupture sources described above can be particularly useful for loss estimation. FEMA has developed and made freely available an earthquake loss estimation software package called HAZUS .This program calculates a large number of loss parameters using ground motion inputs, including specification of the earthquake source. The required HAZUS input files for all 35 potential rupture sources in the SFBR are available on the web at: http://ncweb-menlo.wr.usgs.gov/research/strongmotion/effects/shake/archive/scenario.html . Estimates of earthquake loss for the SFBR using the most probable earthquake rupture sources as input to HAZUS have been calculated by Zoback et al (2003). The Association of Bay Area Governments (ABAG) has used the WG02 rupture sources for the scenario events to estimate the extent of liquefaction, the number of uninhabitable housing units, and impacts on the regional transportation system from future earthquakes (http://www.abag.ca.gov/bayarea/eqmaps/). To appreciate the potential scale of these effects ABAG has estimated that a southern Hayward event, for example, will result in 75,000 uninhabitable units and 170,000 displaced persons. Transportation losses include the effects of liquefaction, landslides, collapse of overpasses, and road closures due to surface fault rupture. ABAG estimates that a Northern Calaveras event (Figure 7.6) will close 363 roads, primarily in Alameda and Contra Costa Counties. A San Francisco Peninsula event is predicted to produce 879 road closures, principally in San Francisco and San Mateo counties and, for comparison, a repeat of the 1906 earthquake is expected to close more than 1330 roads throughout the region. In the SFBR the CGS has used scenario ruptures on the Hayward fault (CDMG, 1987) and Rodgers Creek fault (CDMG, 1994) to develop scenario maps and damage assessments for buildings and structures, transportation lifelines, and utility lifelines. 
In releasing these shaking data, we urge cities, counties, regional authorities, and other groups to assess their exposure and vulnerability to the effects of future earthquakes. The high probability of M 6.7 or larger earthquake in the next 30 years, and the high probability of damaging ground motion shown on Figure 7.4, place lives, housing and critical infrastructure vital to the health and functioning of the entire Bay region at significant risk. The SFBR has been at the forefront of retrofitting its infrastructure. Since the 1989 Loma Prieta earthquake more than $\$ 12$ billion spent to upgrade or replace bridges (Cal Trans); electrical substations, transmission lines, and gas pipelines (Pacific Gas and Electric Company); public transit (Bay Area Rapid Transit Authority); and water pipelines and distribution system (East Bay Municipal Utility District). And the City of San Francisco has approved a \$4 billion bond measure for the rehabilitation and retrofit of the Hetch-Hetchy water system, for which losses are estimated to be as high as $\$ 38$ billion for a repeat of the 1906 earthquake. Efforts such as these are important steps but there is much more required to prepare the region to ride through the effects of future large earthquakes. Both the high level of earthquake hazard and risk described here for the SFBR provide strong justification for accelerating retrofit programs, other mitigation strategies, and stronger preparedness measures. 
-- Earthquake Planning Scenario --

Rapid Instrumental Intensity Map for SAF_SAS+SAP+SAN+SAO Scenario Scenario Date: Thu Mar 6, 2003 04:00:00 AM PST M 7.9 N38.18 W122.92 Depth: 0.0km

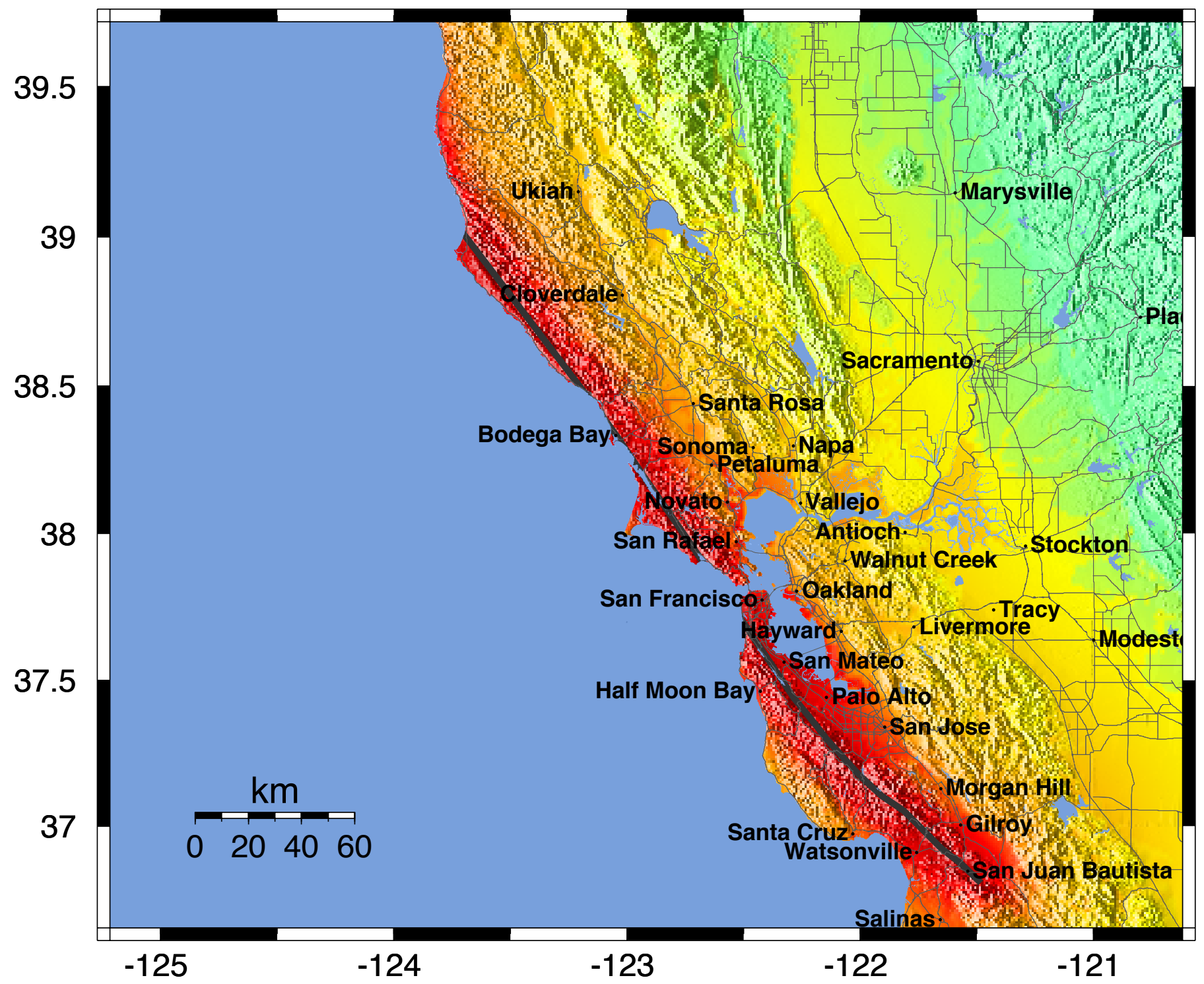

PLANNING SCENARIO ONLY -- PROCESSED: Fri Mar 7, 2003 01:59:14 PM PST

\begin{tabular}{|c|c|c|c|c|c|c|c|c|c|}
\hline $\begin{array}{c}\text { PERCEIVED } \\
\text { SHAKING }\end{array}$ & Not felt & Weak & Light & Moderate & Strong & Very strong & Severe & Violent & Extreme \\
\hline $\begin{array}{c}\text { POTENTIAL } \\
\text { DAMAGE }\end{array}$ & none & none & none & Very light & Light & Moderate & Moderate/Heavy & Heavy & Very Heavy \\
\hline PEAK ACC.(\%g) & $<.17$ & $.17-1.4$ & $1.4-3.9$ & $3.9-9.2$ & $9.2-18$ & $18-34$ & $34-65$ & $65-124$ & $>124$ \\
\hline $\begin{array}{l}\text { PEAK VEL.(cm/s) } \\
\text { PEAT }\end{array}$ & $<0.1$ & $0.1-1.1$ & $1.1-3.4$ & $3.4-8.1$ & $8.1-16$ & $16-31$ & $31-60$ & $60-116$ & $>116$ \\
\hline $\begin{array}{c}\text { INSTRUMENTAL } \\
\text { INTENSITY }\end{array}$ & $\mathbf{I}$ & $\mathbf{I I - I I I ~}$ & $\mathbf{I V}$ & $\mathbf{V}$ & $\mathbf{V I}$ & $\mathbf{V I I}$ & VIII & IX & $\mathbf{X}+$ \\
\hline
\end{tabular}

Figure 7.1a Scenario ShakeMap for rupture of all four fault segments in an event that is considered a repeat of the 1906 earthquake $(\mathrm{P}=0.05)$. 
-- Earthquake Planning Scenario --

Rapid Instrumental Intensity Map for SAF_SAP Scenario

Scenario Date: Thu Mar 6, 2003 04:00:00 AM PST M 7.2 N37.37 W122.21 Depth: 0.0km

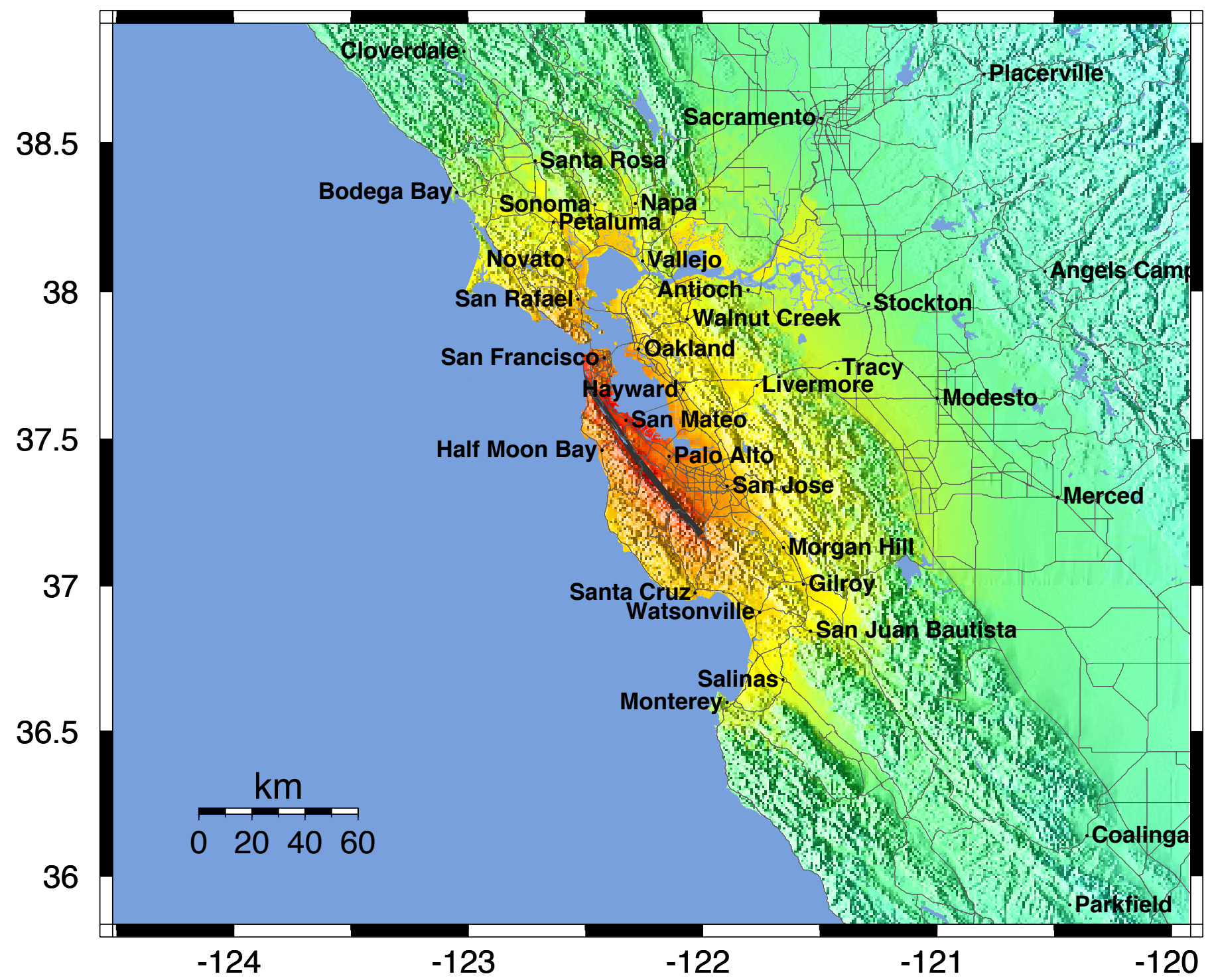

PLANNING SCENARIO ONLY -- PROCESSED: Tue Mar 11, 2003 01:58:08 PM PST

\begin{tabular}{|c|c|c|c|c|c|c|c|c|c|}
\hline $\begin{array}{l}\text { PERCEIVED } \\
\text { SHAKING } \\
\end{array}$ & Not felt & Weak & Light & Moderate & Strong & Very strong & Severe & Violent & Etreme \\
\hline $\begin{array}{l}\text { POTENTIAL } \\
\text { DAMAGE }\end{array}$ & none & none & none & Very light & Light & Moderate & Moderate/Heavy & Heavy & Very Heav \\
\hline PEAK ACC.(\%g) & $<.17$ & $.17-1.4$ & $1.4-3.9$ & $3.9-9.2$ & $9.2-18$ & $18-34$ & $34-65$ & $65-124$ & $>124$ \\
\hline PEAK VEL.(cm/s) & $<0.1$ & $0.1-1.1$ & $1.1-3.4$ & $3.4-8.1$ & $8.1-16$ & $16-31$ & $31-60$ & $60-116$ & $>116$ \\
\hline $\begin{array}{c}\text { INSTRUMENTAL } \\
\text { INTENSITY }\end{array}$ & I & ||-III & IV & V & VI & VII & VIII & IX & $X+$ \\
\hline
\end{tabular}

Figure 7.1b Scenario Shakemap for rupture of the San Francisco Peninsula segment in a $\mathrm{M} 7.2$ event $(\mathrm{P}=0.04)$, believed to be a repeat of the 1838 earthquake on the Peninsula. 
-- Earthquake Planning Scenario --

Rapid Instrumental Intensity Map for SAF_SAS Scenario

Scenario Date: Thu Mar 6, 2003 04:00:00 AM PST M 7.0 N36.93 W121.65 Depth: 0.0km

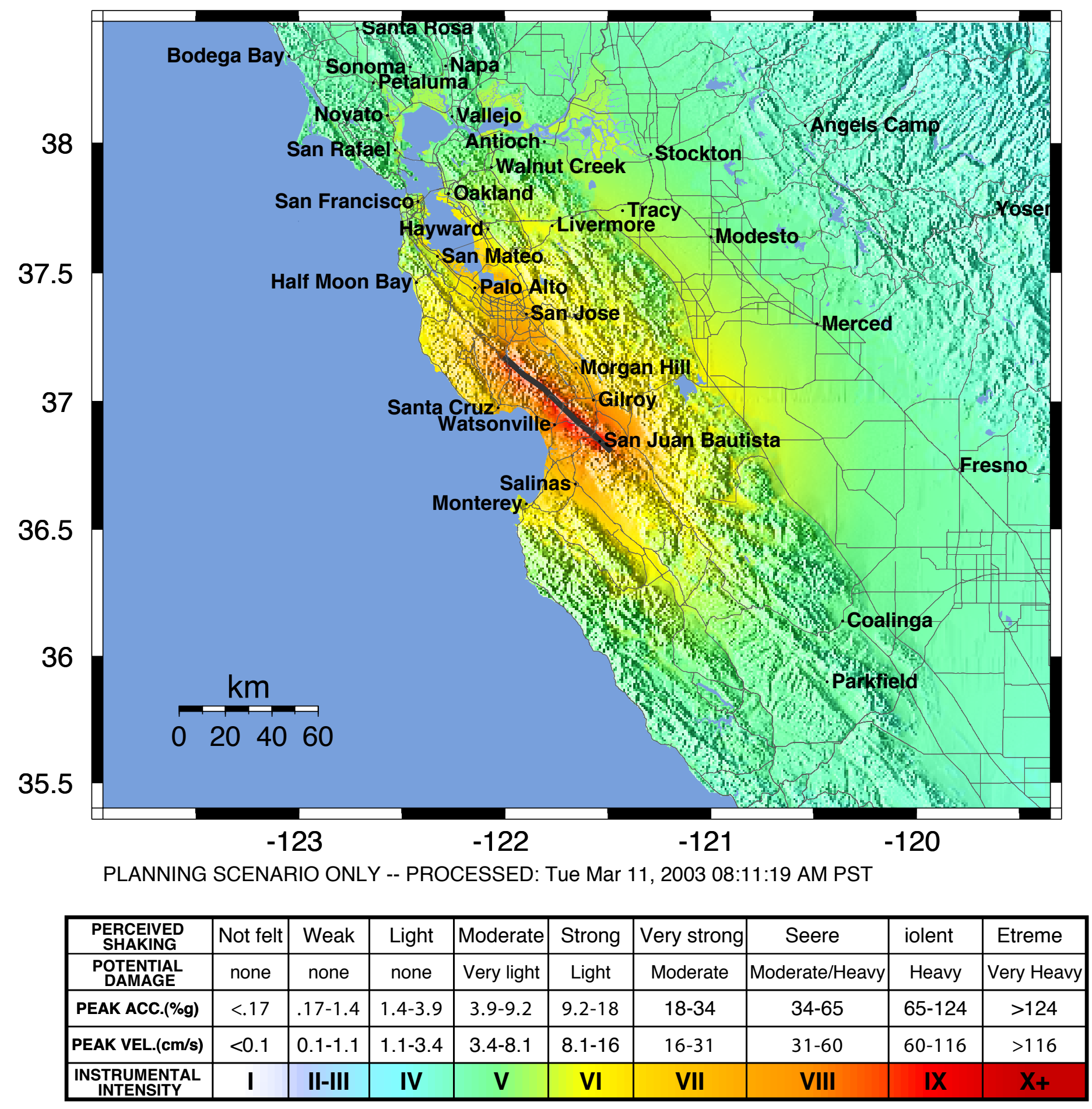

Figure 7.1c Scenario ShakeMap for rupture of the Santa Cruz Mountains segment in a M 7.0 event $(\mathrm{P}=0.03)$, similar to the 1989 M 6.9 Loma Prieta event 
USGS/UCB/CGS Rapid Instrumental Intensity Map for LP_1989 Earthquake Tue Oct 17, 1989 05:04:00 PM PDT M 6.9 N37.04 W121.88 Depth: 18.0km ID:216859

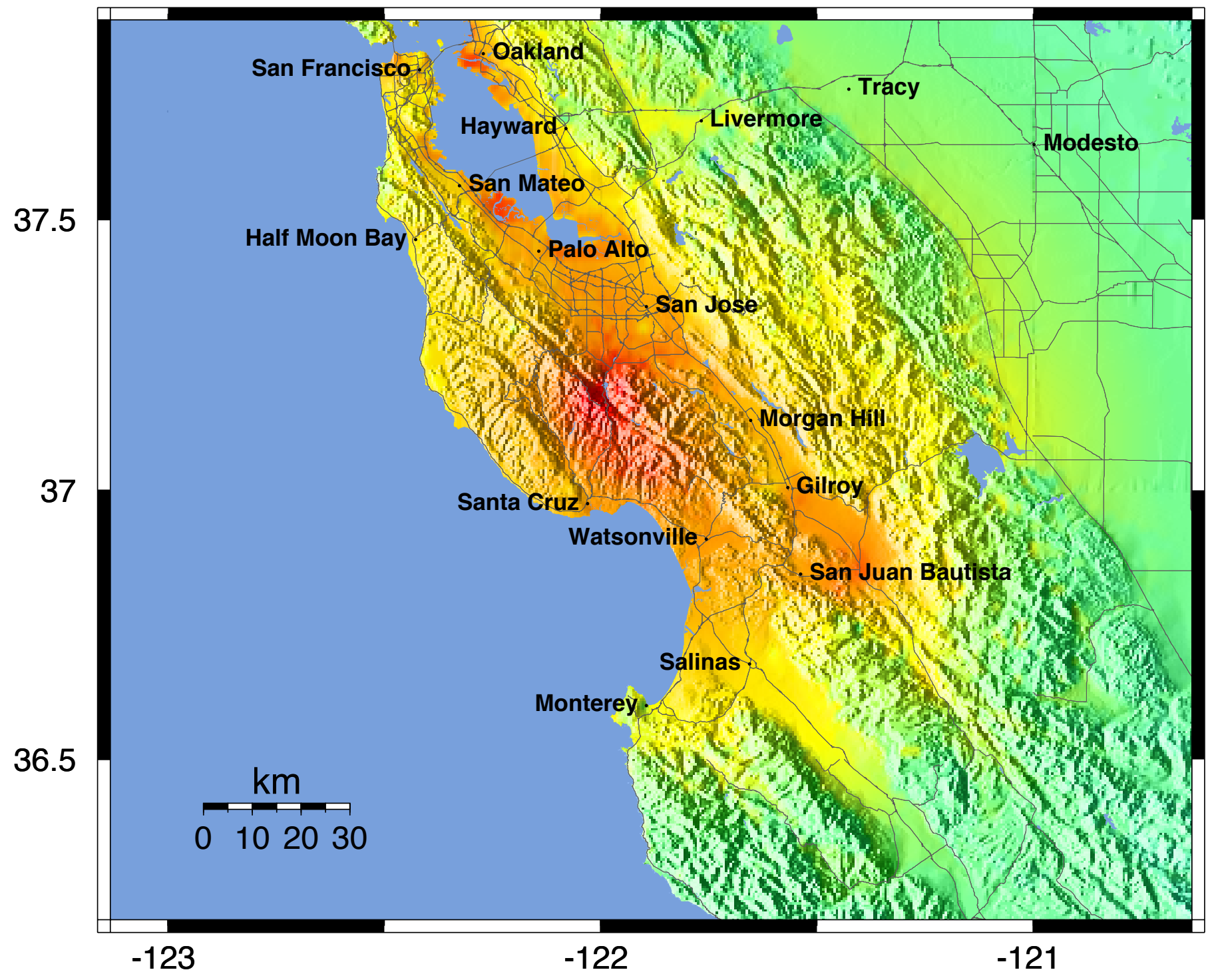

PROCESSED: Wed Mar 12, 2003 12:53:25 PM PST,

\begin{tabular}{|c|c|c|c|c|c|c|c|c|c|}
\hline $\begin{array}{c}\text { PERCEIVED } \\
\text { SHAKING }\end{array}$ & Not felt & Weak & Light & Moderate & Strong & Very strong & Severe & Violent & Extreme \\
\hline $\begin{array}{c}\text { POTENTIAL } \\
\text { DAMAGE }\end{array}$ & none & none & none & Very light & Light & Moderate & Moderate/Heavy & Heavy & Very Heavy \\
\hline PEAK ACC.(\%g) & $<.17$ & $.17-1.4$ & $1.4-3.9$ & $3.9-9.2$ & $9.2-18$ & $18-34$ & $34-65$ & $65-124$ & $>124$ \\
\hline PEAK VEL.(cm/s) & $<0.1$ & $0.1-1.1$ & $1.1-3.4$ & $3.4-8.1$ & $8.1-16$ & $16-31$ & $31-60$ & $60-116$ & $>116$ \\
\hline $\begin{array}{c}\text { INSTRUMENTAL } \\
\text { INTENSITY }\end{array}$ & $\mathbf{I}$ & $\mathbf{I I - I I I ~}$ & $\mathbf{I V}$ & $\mathbf{V}$ & $\mathbf{V I}$ & $\mathbf{V I I}$ & VIII & IX & $\mathbf{X}+$ \\
\hline
\end{tabular}

Figure 7.1d Actual ShakeMap for the 1989 M 6.9 Loma Prieta event. 


\section{-- Earthquake Planning Scenario --}

\section{Rapid Instrumental Intensity Map for HRC_RC Scenario}

Scenario Date: Thu Mar 6, 2003 04:00:00 AM PST M 7.0 N38.33 W122.61 Depth: 0.0km

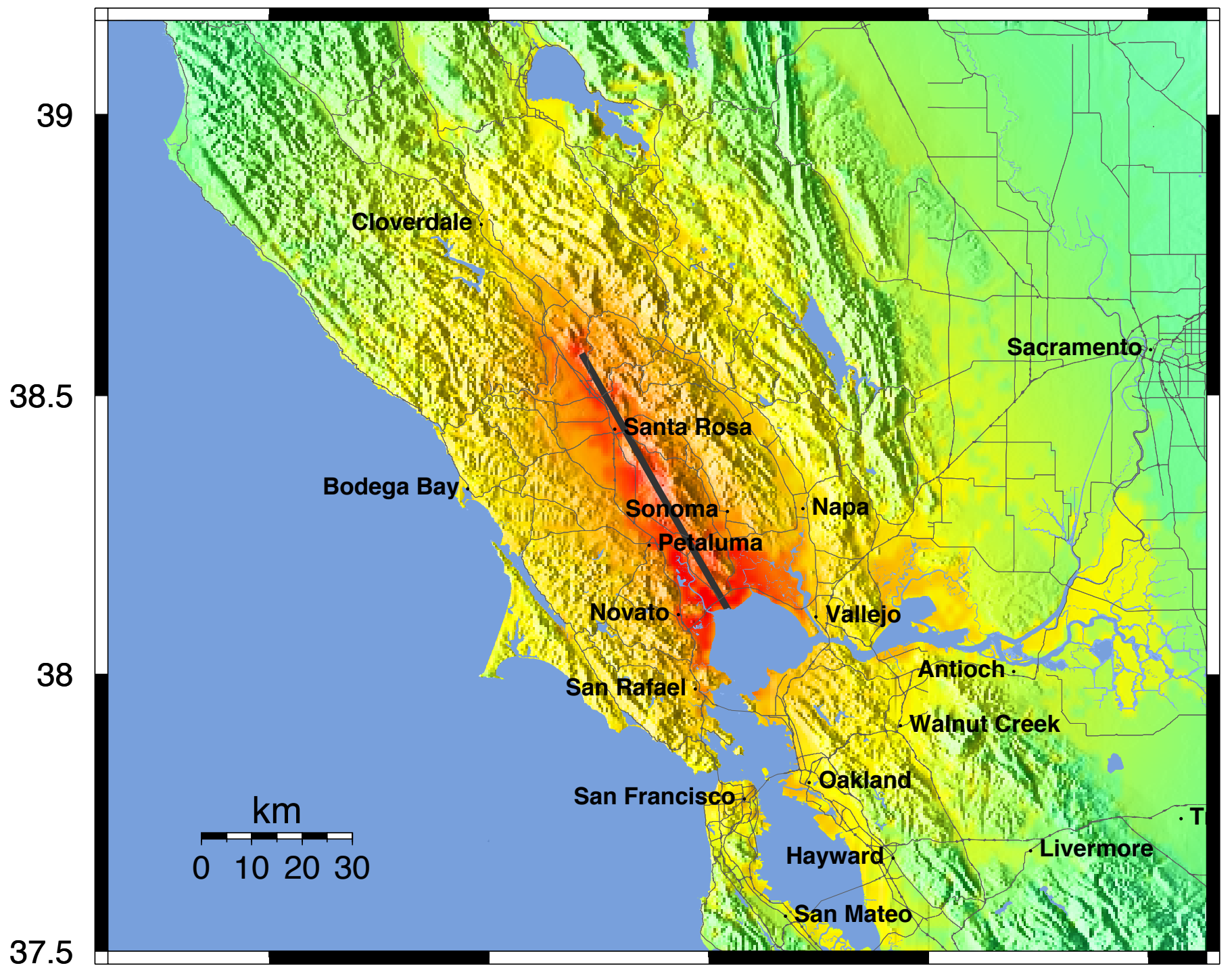

$-123$

$-122$

PLANNING SCENARIO ONLY -- PROCESSED: Tue Mar 11, 2003 01:49:05 PM PST

\begin{tabular}{|c|c|c|c|c|c|c|c|c|c|}
\hline $\begin{array}{c}\text { PERCEIVED } \\
\text { SHAKING }\end{array}$ & Not felt & Weak & Light & Moderate & Strong & Very strong & Severe & Violent & Etreme \\
\hline $\begin{array}{c}\text { POTENTIAL } \\
\text { DAMAGE }\end{array}$ & none & none & none & Very light & Light & Moderate & Moderate/Heavy & Heavy & Very Heavy \\
\hline PEAK ACC.(\%g) & $<.17$ & $.17-1.4$ & $1.4-3.9$ & $3.9-9.2$ & $9.2-18$ & $18-34$ & $34-65$ & $65-124$ & $>124$ \\
\hline PEAK VEL.(cm/s) & $<0.1$ & $0.1-1.1$ & $1.1-3.4$ & $3.4-8.1$ & $8.1-16$ & $16-31$ & $31-60$ & $60-116$ & $>116$ \\
\hline $\begin{array}{c}\text { INSTRUMENTAL } \\
\text { INTENSITY }\end{array}$ & $\mathbf{I}$ & $\mathbf{I I - I I I ~}$ & $\mathbf{I V}$ & $\mathbf{V}$ & $\mathbf{V I}$ & $\mathbf{V I I}$ & $\mathbf{V I I I}$ & $\mathbf{I X}$ & $\mathbf{X}+$ \\
\hline
\end{tabular}

Figure 7.2a Scenario ShakeMap for rupture of the Rodgers Creek segment in a M 6.98 $(\mathrm{P}=0.15)$ event. 


\section{-- Earthquake Planning Scenario --}

Rapid Instrumental Intensity Map for HRC_HS+HN Scenario

Scenario Date: Mon Mar 3, 2003 04:00:00 AM PST M 6.9 N37.68 W122.08 Depth: 0.0km

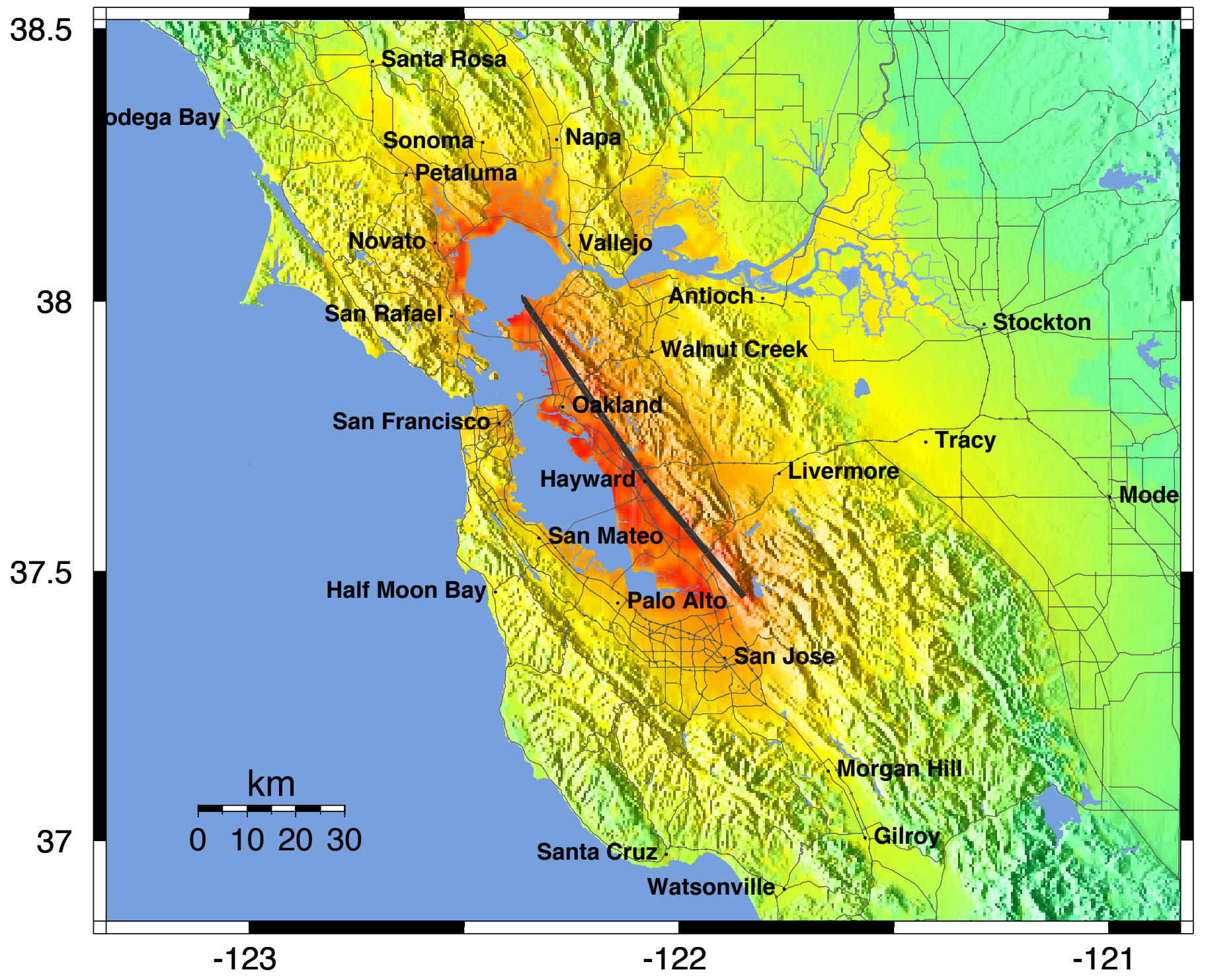

PLANNING SCENARIO ONLY -- PROCESSED: Tue Mar 11, 2003 01:41:34 PM PST

\begin{tabular}{|c|c|c|c|c|c|c|c|c|c|}
\hline $\begin{array}{c}\text { PERCEIVED } \\
\text { SHAKING }\end{array}$ & Not felt & Weak & Light & Moderate & Strong & Very strong & Severe & Violent & Extreme \\
\hline $\begin{array}{c}\text { POTENTIAL } \\
\text { DAMAGE }\end{array}$ & none & none & none & Very light & Light & Moderate & Moderate/Heavy & Heavy & Very Heavy \\
\hline PEAK ACC.(\%g) & $<.17$ & $.17-1.4$ & $1.4-3.9$ & $3.9-9.2$ & $9.2-18$ & $18-34$ & $34-65$ & $65-124$ & $>124$ \\
\hline $\begin{array}{c}\text { PEAK VEL.(cm/s) } \\
\text { PEAT }\end{array}$ & $<0.1$ & $0.1-1.1$ & $1.1-3.4$ & $3.4-8.1$ & $8.1-16$ & $16-31$ & $31-60$ & $60-116$ & $>116$ \\
\hline $\begin{array}{c}\text { INSTRUMENTAL } \\
\text { INTENSITY }\end{array}$ & $\mathbf{I}$ & $\mathbf{I I - I I I}$ & $\mathbf{I V}$ & $\mathbf{V}$ & $\mathbf{V I}$ & VII & VIII & IX & $\mathbf{X}+$ \\
\hline
\end{tabular}

Figure 7.2b Scenario ShakeMap for rupture of the entire Hayward fault in a M 6.91 $(\mathrm{P}=0.09)$ event. 


\section{-- Earthquake Planning Scenario --}

\section{Rapid Instrumental Intensity Map for HRC_HS Scenario}

Scenario Date: Thu Mar 6, 2003 04:00:00 AM PST M 6.7 N37.57 W121.97 Depth: 0.0km

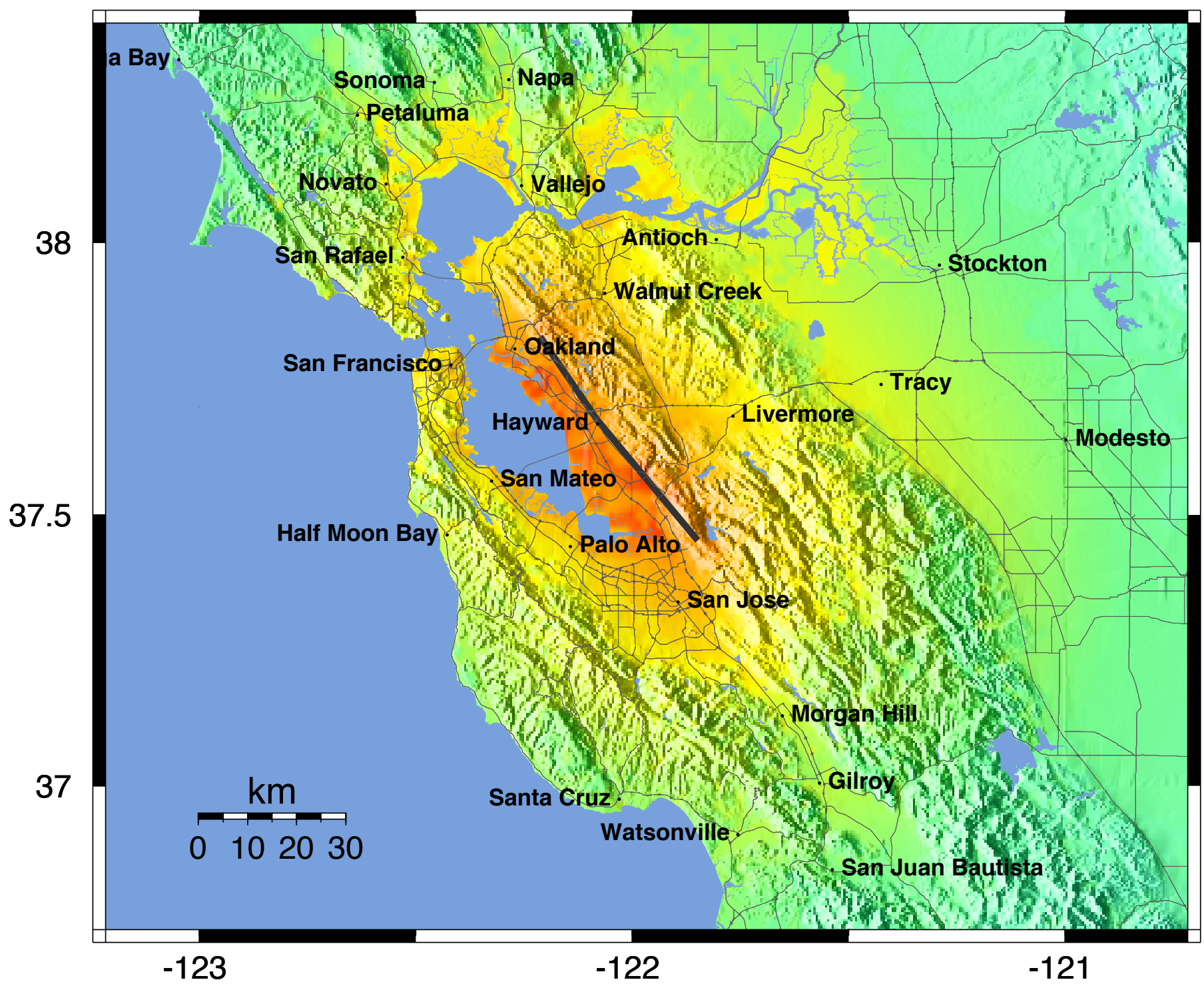

PLANNING SCENARIO ONLY -- PROCESSED: Tue Mar 11, 2003 01:26:51 PM PST

\begin{tabular}{|c|c|c|c|c|c|c|c|c|c|}
\hline $\begin{array}{c}\text { PERCEIVED } \\
\text { SHAKING }\end{array}$ & Not felt & Weak & Light & Moderate & Strong & Very strong & Severe & Violent & Extreme \\
\hline $\begin{array}{c}\text { POTENTIAL } \\
\text { DAMAGE }\end{array}$ & none & none & none & Very light & Light & Moderate & Moderate/Heavy & Heavy & Very Heavy \\
\hline PEAK ACC.(\%g) & $<.17$ & $.17-1.4$ & $1.4-3.9$ & $3.9-9.2$ & $9.2-18$ & $18-34$ & $34-65$ & $65-124$ & $>124$ \\
\hline PEAK VEL.(cm/s) & $<0.1$ & $0.1-1.1$ & $1.1-3.4$ & $3.4-8.1$ & $8.1-16$ & $16-31$ & $31-60$ & $60-116$ & $>116$ \\
\hline $\begin{array}{c}\text { INSTRUMENTAL } \\
\text { INTENSITY }\end{array}$ & $\mathbf{I}$ & $\mathbf{I I - I I I ~}$ & $\mathbf{I V}$ & $\mathbf{V}$ & $\mathbf{V I}$ & $\mathbf{V I I}$ & $\mathbf{V I I I}$ & $\mathbf{I X}$ & $\mathbf{X}+$ \\
\hline
\end{tabular}

Figure 7.2c Scenario ShakeMap for rupture of the Southern Hayward segment in a M 6.67 event, believed to be a repeat of the 1867 earthquake. 


\section{-- Earthquake Planning Scenario -- \\ Rapid Instrumental Intensity Map for HRC_HN Scenario}

Scenario Date: Thu Mar 6, 2003 04:00:00 AM PST M 6.5 N37.86 W122.24 Depth: 0.0km

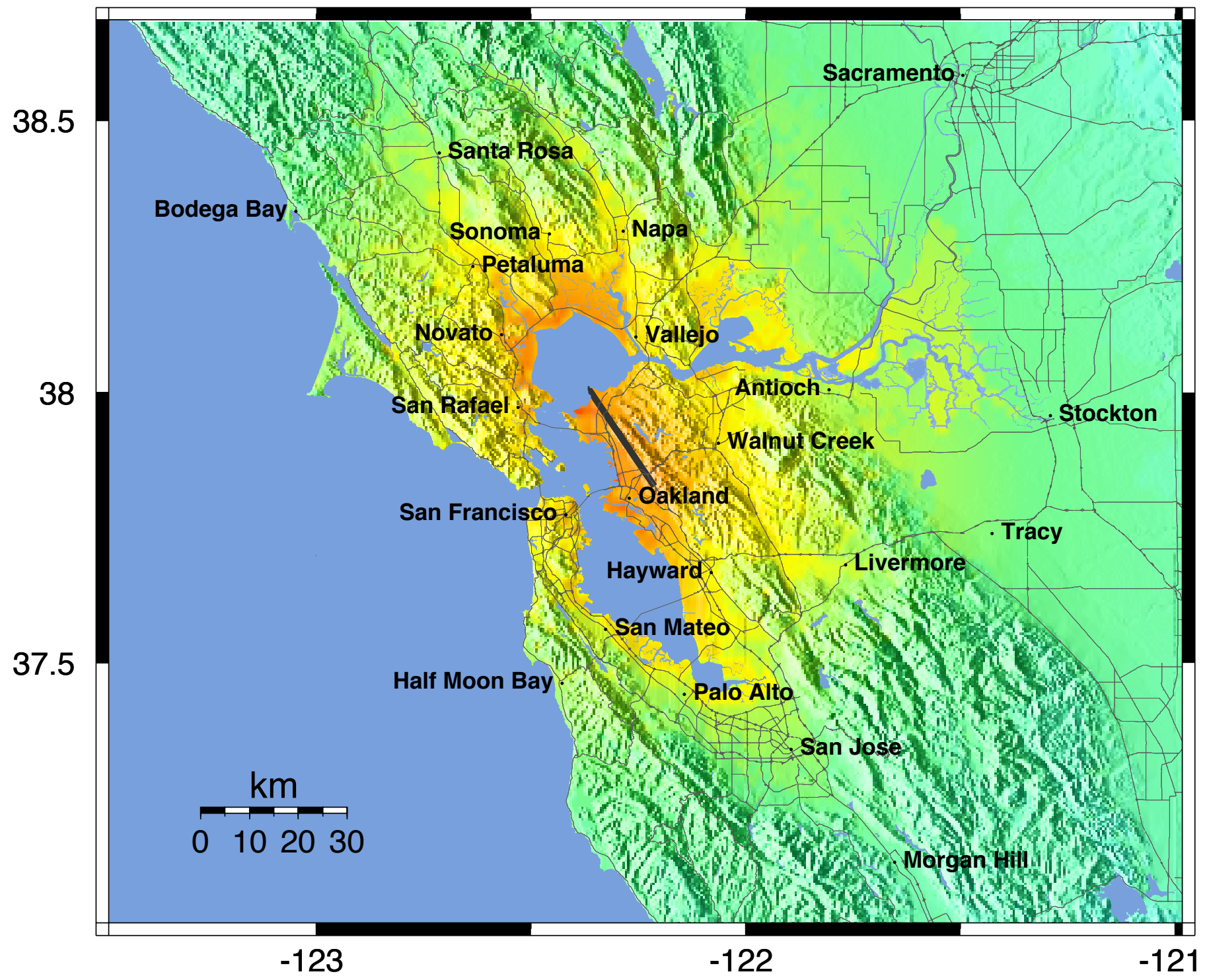

PLANNING SCENARIO ONLY -- PROCESSED: Tue Mar 11, 2003 01:34:01 PM PST

\begin{tabular}{|c|c|c|c|c|c|c|c|c|c|}
\hline $\begin{array}{c}\text { PERCEIVED } \\
\text { SHAKING }\end{array}$ & Not felt & Weak & Light & Moderate & Strong & Very strong & Severe & Violent & Extreme \\
\hline $\begin{array}{c}\text { POTENTIAL } \\
\text { DAMAGE }\end{array}$ & none & none & none & Very light & Light & Moderate & Moderate/Heavy & Heavy & Very Heavy \\
\hline PEAK ACC.(\%g) & $<.17$ & $.17-1.4$ & $1.4-3.9$ & $3.9-9.2$ & $9.2-18$ & $18-34$ & $34-65$ & $65-124$ & $>124$ \\
\hline PEAK VEL.(cm/s) & $<0.1$ & $0.1-1.1$ & $1.1-3.4$ & $3.4-8.1$ & $8.1-16$ & $16-31$ & $31-60$ & $60-116$ & $>116$ \\
\hline $\begin{array}{c}\text { INSTRUMENTAL } \\
\text { INTENSITY }\end{array}$ & $\mathbf{I}$ & $\mathbf{I I - I I I ~}$ & $\mathbf{I V}$ & $\mathbf{V}$ & $\mathbf{V I}$ & $\mathbf{V I I}$ & VIII & IX & $\mathbf{X}+$ \\
\hline
\end{tabular}

Figure 7.2d Scenario ShakeMap for rupture of the Northern Hayward segment in a M 6.49 event $(\mathrm{P}=0.12)$. 


\section{-- Earthquake Planning Scenario --}

\section{Rapid Instrumental Intensity Map for CLV_CN Scenario}

Scenario Date: Thu Mar 6, 2003 04:00:00 AM PST M 6.8 N37.57 W121.86 Depth: 0.0km

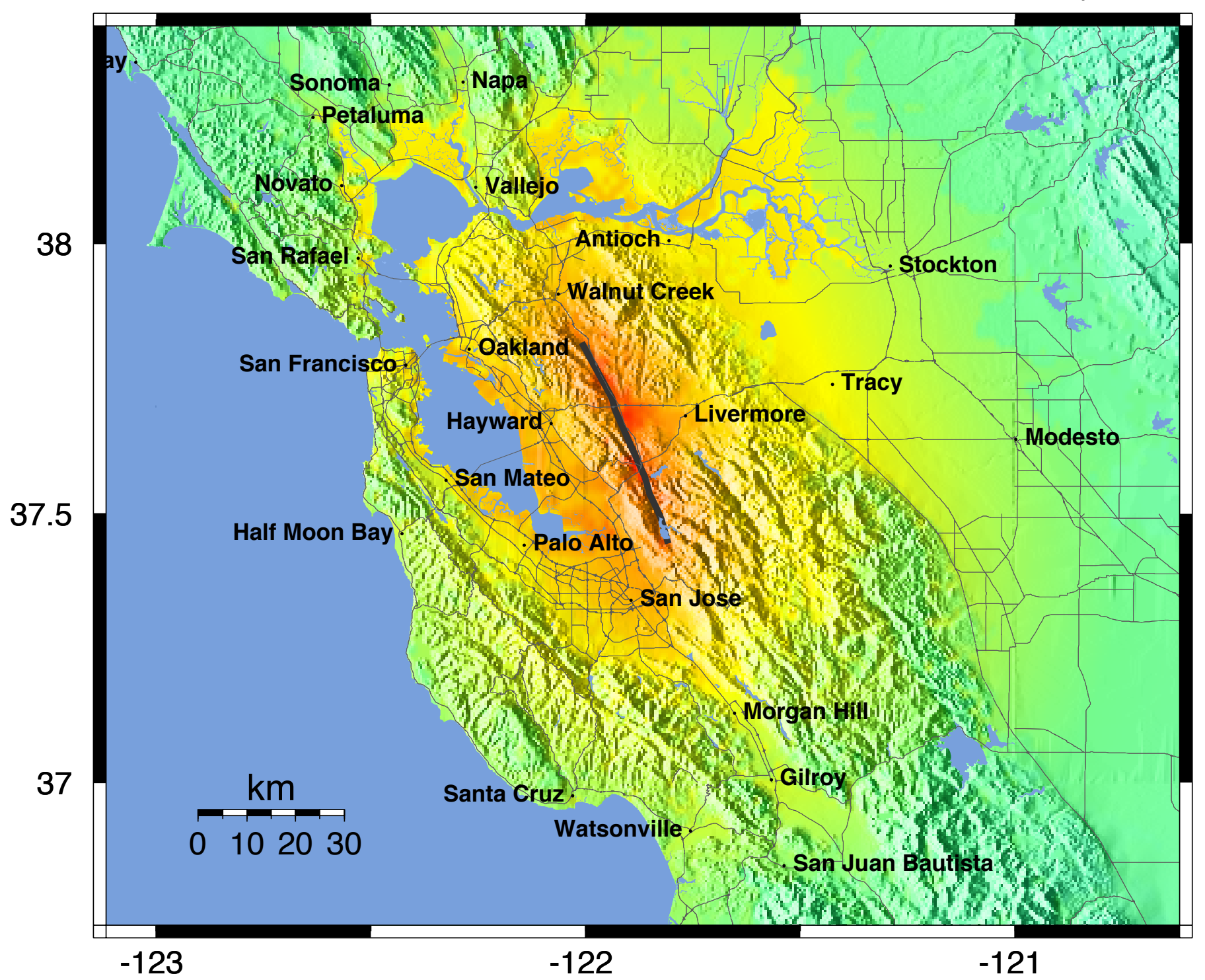

PLANNING SCENARIO ONLY -- PROCESSED: Thu Mar 6, 2003 02:39:55 PM PST

\begin{tabular}{|c|c|c|c|c|c|c|c|c|c|}
\hline $\begin{array}{c}\text { PERCEIVED } \\
\text { SHAKING }\end{array}$ & Not felt & Weak & Light & Moderate & Strong & Very strong & Severe & Violent & Extreme \\
\hline $\begin{array}{c}\text { POTENTIAL } \\
\text { DAMAGE }\end{array}$ & none & none & none & Very light & Light & Moderate & Moderate/Heavy & Heavy & Very Heavy \\
\hline PEAK ACC.(\%g) & $<.17$ & $.17-1.4$ & $1.4-3.9$ & $3.9-9.2$ & $9.2-18$ & $18-34$ & $34-65$ & $65-124$ & $>124$ \\
\hline PEAK VEL.(cm/s) & $<0.1$ & $0.1-1.1$ & $1.1-3.4$ & $3.4-8.1$ & $8.1-16$ & $16-31$ & $31-60$ & $60-116$ & $>116$ \\
\hline $\begin{array}{c}\text { INSTRUMENTAL } \\
\text { INTENSITY }\end{array}$ & $\mathbf{I}$ & $\mathbf{I I - I I I ~}$ & $\mathbf{I V}$ & $\mathbf{V}$ & $\mathbf{V I}$ & $\mathbf{V I I}$ & VIII & IX & $\mathbf{X}+$ \\
\hline
\end{tabular}

Figure 7.3a Scenario ShakeMap for rupture of the Northern Calaveras segment in a M 6.78 event $(\mathrm{P}=0.12)$. 
-- Earthquake Planning Scenario --

Rapid Instrumental Intensity Map for CGV_CON+GVS+GVN Scenario Scenario Date: Thu Mar 6, 2003 04:00:00 AM PST M 6.7 N38.06 W122.09 Depth: 0.0km

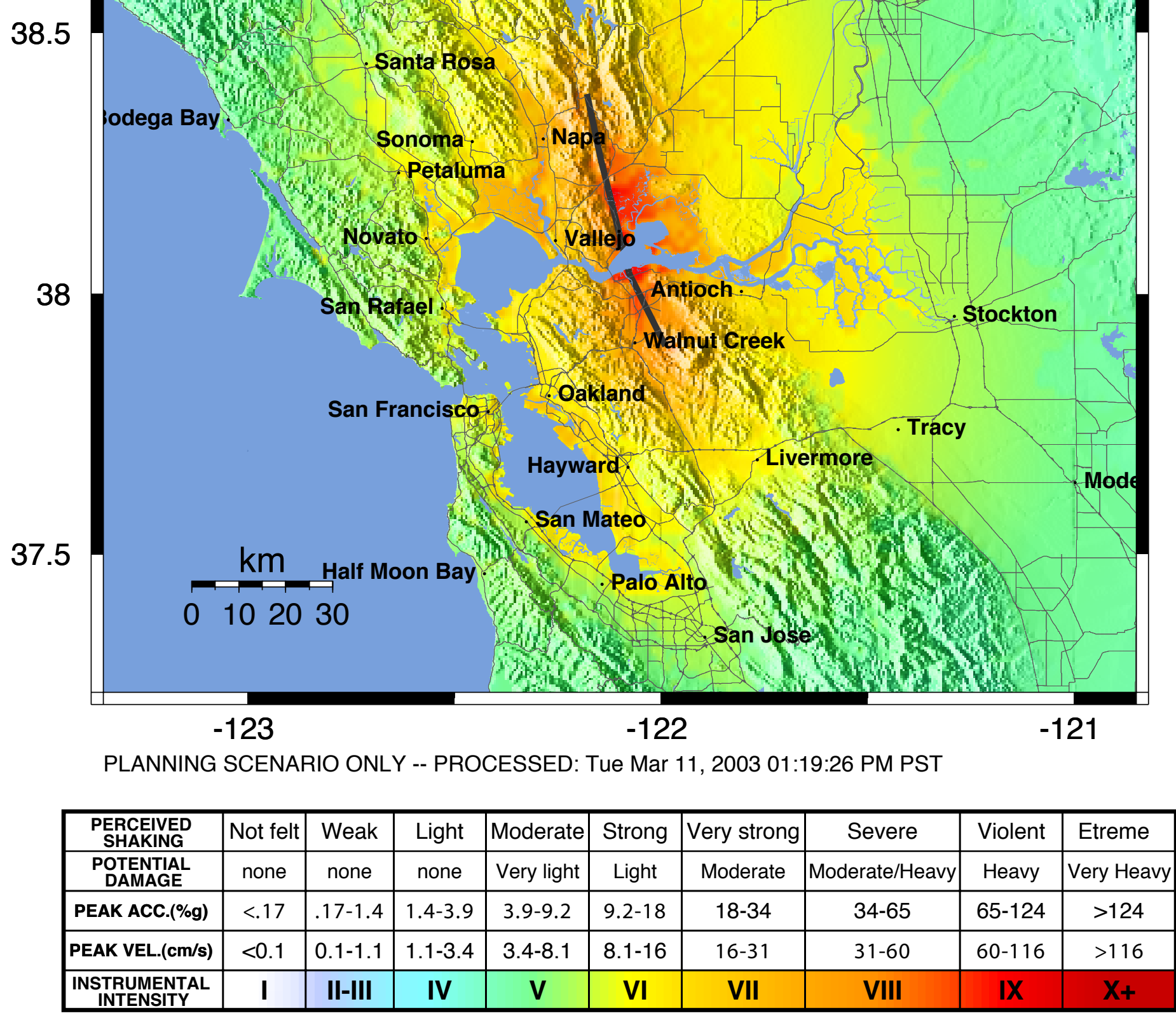

Figure 7.3b Scenario ShakeMap for rupture of the entire Concord - Green Valley in a M 6.71 ( $\mathrm{P}=0.06)$ event. 


\section{-- Earthquake Planning Scenario --}

\section{Rapid Instrumental Intensity Map for GNV_GS+GN Scenario}

Scenario Date: Thu Mar 6, 2003 04:00:00 AM PST M 6.9 N37.64 W121.64 Depth: 0.0km

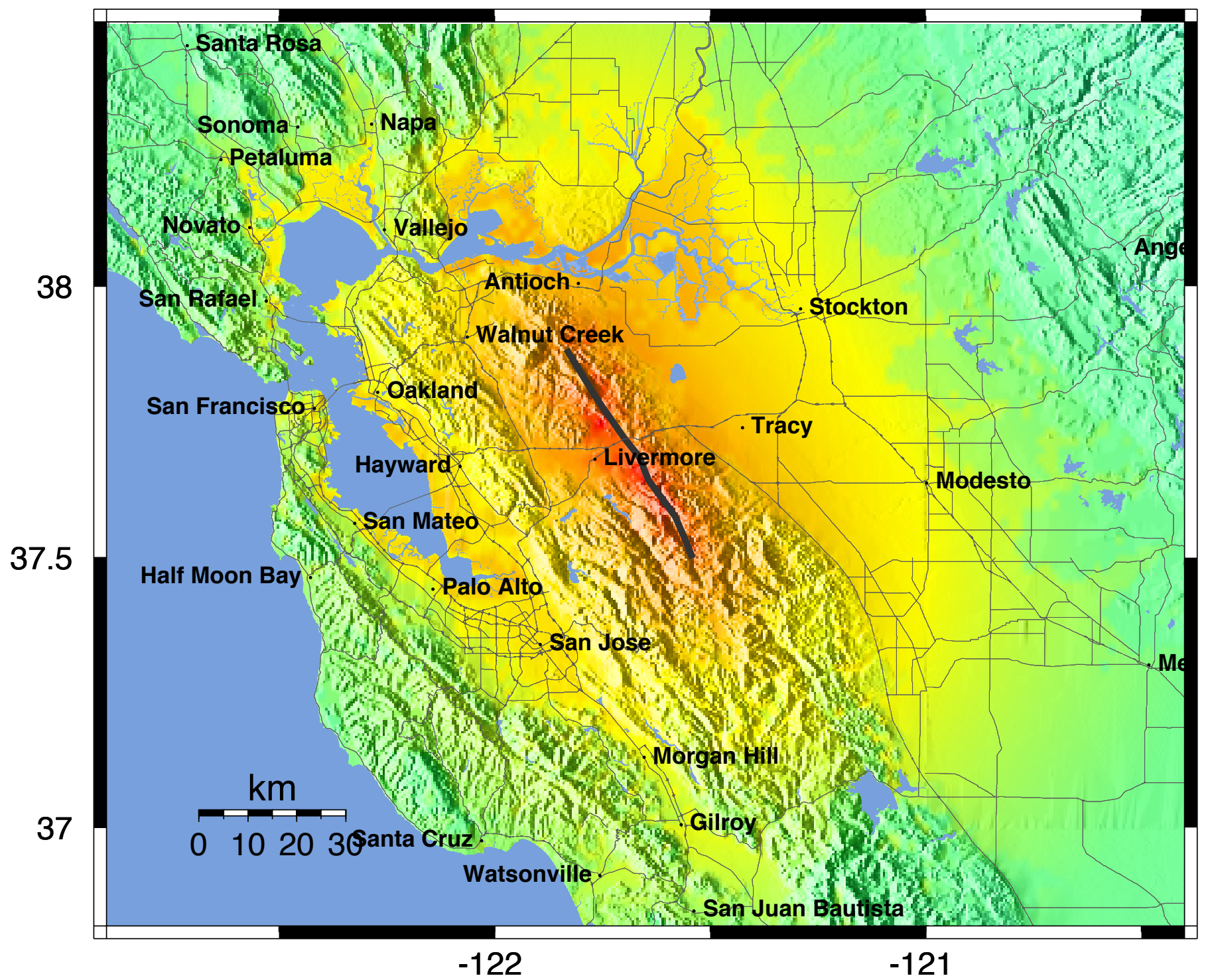

PLANNING SCENARIO ONLY -- PROCESSED: Wed Mar 12, 2003 09:08:37 AM PST

\begin{tabular}{|c|c|c|c|c|c|c|c|c|c|}
\hline $\begin{array}{c}\text { PERCEIVED } \\
\text { SHAKING }\end{array}$ & Not felt & Weak & Light & Moderate & Strong & Very strong & Severe & Violent & Etreme \\
\hline $\begin{array}{c}\text { POTENTIAL } \\
\text { DAMAGE }\end{array}$ & none & none & none & Very light & Light & Moderate & Moderate/Heavy & Heavy & Very Heavy \\
\hline PEAK ACC.(\%g) & $<.17$ & $.17-1.4$ & $1.4-3.9$ & $3.9-9.2$ & $9.2-18$ & $18-34$ & $34-65$ & $65-124$ & $>124$ \\
\hline PEAK VEL.(cm/s) & $<0.1$ & $0.1-1.1$ & $1.1-3.4$ & $3.4-8.1$ & $8.1-16$ & $16-31$ & $31-60$ & $60-116$ & $>116$ \\
\hline $\begin{array}{c}\text { INSTRUMENTAL } \\
\text { INTENSITY }\end{array}$ & $\mathbf{I}$ & $\mathbf{I I - I I I}$ & $\mathbf{I V}$ & $\mathbf{V}$ & $\mathbf{V I}$ & $\mathbf{V I I}$ & VIII & IX & $\mathbf{X}+$ \\
\hline
\end{tabular}

Figure 7.3c Scenario ShakeMap for rupture of the entire Greenville in a M 6.9 event $(\mathrm{P}=0.02)$. 


\section{-- Earthquake Planning Scenario --}

\section{Rapid Instrumental Intensity Map for MTD_MTD Scenario}

Scenario Date: Thu Mar 6, 2003 04:00:00 AM PST M 6.7 N37.79 W121.76 Depth: 0.0km

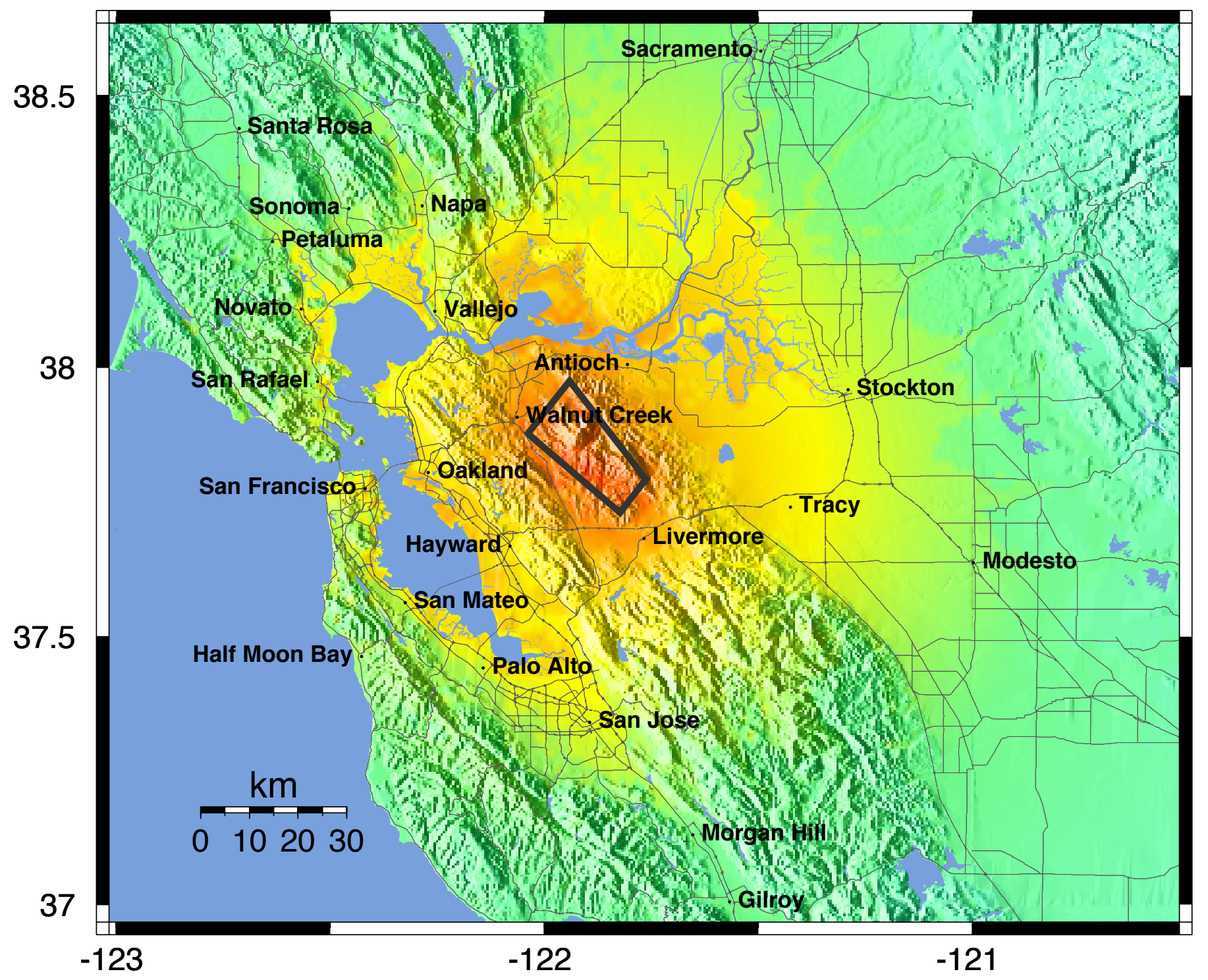

PLANNING SCENARIO ONLY -- PROCESSED: Fri Mar 7, 2003 01:33:52 PM PST

\begin{tabular}{|c|c|c|c|c|c|c|c|c|c|}
\hline $\begin{array}{l}\text { PERCEIVED } \\
\text { SHAKING }\end{array}$ & Not felt & Weak & Light & Moderate & Strong & ery strong & Seere & iolent & Etreme \\
\hline $\begin{array}{l}\text { POTENTIALL } \\
\text { DAMAGE }\end{array}$ & none & none & none & Very light & Light & Moderate & Moderate/Heavy & Heavy & Very Heavy \\
\hline PEAK ACC.(\%g) & $<.17$ & $.17-1.4$ & $1.4-3.9$ & 3.9-9.2 & $9.2-18$ & $18-34$ & $34-65$ & $65-124$ & $>124$ \\
\hline PEAK VEL.(cm/s) & $<0.1$ & $0.1-1.1$ & $1.1-3.4$ & $3.4-8.1$ & 8.1-16 & $16-31$ & $31-60$ & $60-116$ & $>116$ \\
\hline $\begin{array}{c}\text { INSTRUMENTAL } \\
\text { INTENSITY }\end{array}$ & I & II-III & IV & V & VI & VII & VIII & IX & $X+$ \\
\hline
\end{tabular}

Figure 7.3d Scenario ShakeMap for rupture of the Mt. Diablo blind thrust. 


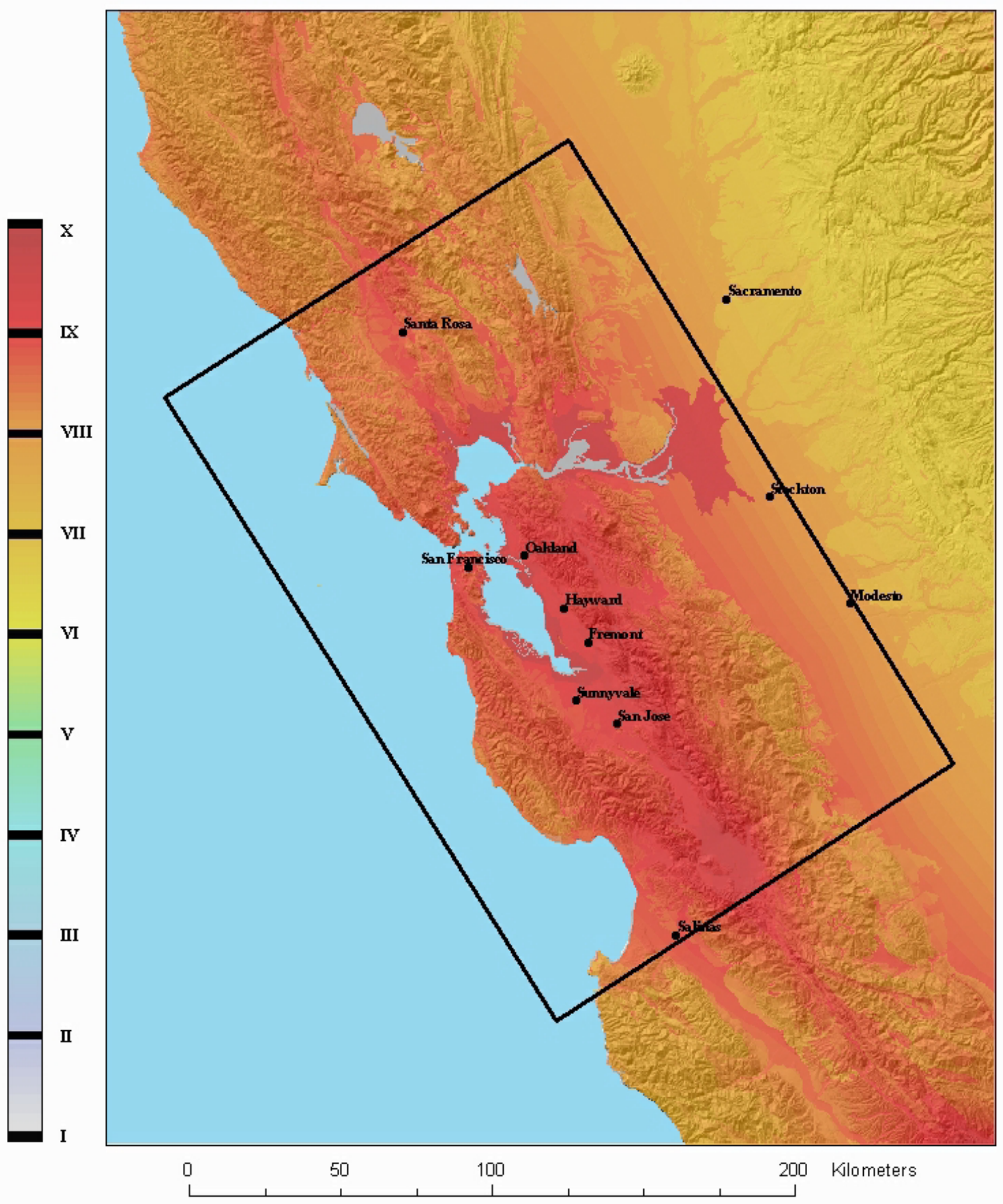

Figure 7.4a. Modified Mercalli intensity shaking levels for the SFBR with a $10 \%$ chance of exceedance in 30 years (time-independent). 


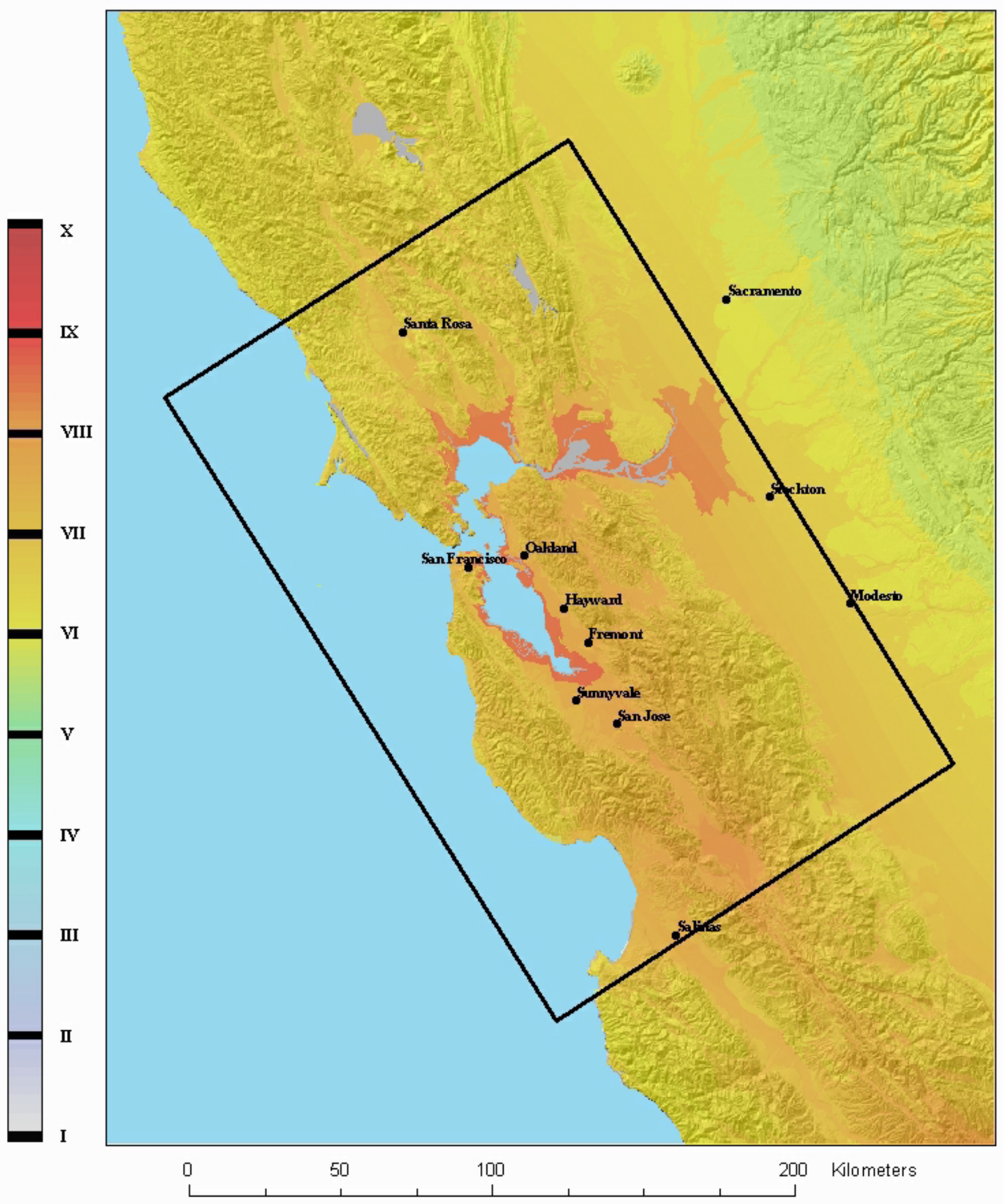

Figure 7.4b. Modified Mercalli intensity shaking levels for the SFBR with a $50 \%$ chance of exceedance in 30 years (time-independent). 


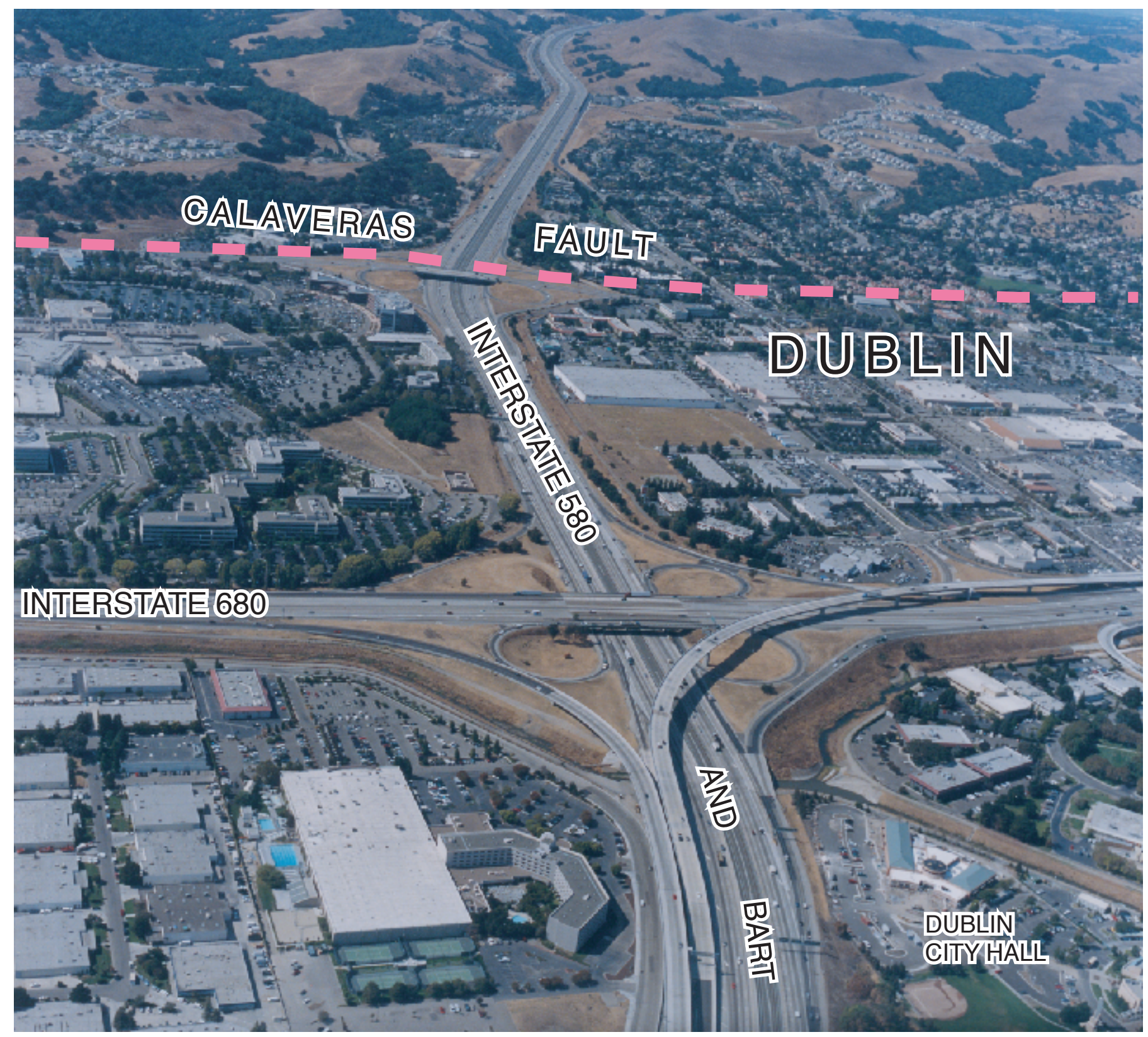

Figure 7.5 Aerial view of the recently (2002) completed Interstate 680-Interstate 580 interchange at Dublin, CA. Note the location of surface trace of the northern Calaveras fault, which crosses I 580 here, and I $68020 \mathrm{~km}$ to the south. All of the high-probability SFBR earthquake sources cross major transportation corridors. 


\section{Chapter 8. ReFlections AND FUTURE DIRECTIONS}

\section{Reflections on the Working Group process}

This analysis of earthquake probabilities in California continues a legacy dating back to 1983, a legacy consisting primarily of time-predictable models for single-segment ruptures. At the same time, it departs from the previous work in three significant ways: 1) in the development of the average, regional SFBR earthquake model in which multi-segment ruptures evolve for the characterized faults; 2) in the use of a suite of probability models, not just one, to develop the timedependent, 30-year earthquake probabilities; and 3) in the use of aggregated expert opinion to accommodate the range of differing scientific judgments, itself a source of significant uncertainty.

Developing new methods and models is the essential business of research science, but developing and using unvetted methods and models in a results-oriented, practical exercise such as this report will generally make for unanticipated problems that may take considerable time to resolve. Conversely, utilizing tried and true models, methods, and data will make for smoother and more efficient applications, but it may well lead to results that are out of date before they are out in print, given the present pace of earthquake science. In formulating research results for use in making public-policy decisions, it was incumbent upon WG99 and WG02 to strike a balance between these approaches.

While the SFBR earthquake model is straightforward in concept, with its origins in the decadesold ideas of characteristic earthquakes and fault-segmentation models, a number of difficult issues arose in implementing it. Such matters included the use of floating earthquakes of uncertain sizes in recognition of possible limitations of the fault-segmentation model; accommodating aseismic slip in the strain accumulation/strain release balances; developing new $\mathbf{M}-\log A$ relations upon recognizing that the Wells and Coppersmith (1994) relation underestimated $\mathbf{M}$ at large $A$; and in allowing for multi-segment ruptures, which provided several challenges involving expert opinion, relative rupture rates, and a separate moment-balancing calculation.

WG02 also expanded the range of probability models put to use in studies such as these. The BPT Model was new and unpublished when it was first put to use in this analysis, and while its use permitted incorporation of fault-interaction effects, first through clock corrections (WG99) and later with state-steps (this report), these advances presented significant and time-consuming computational challenges.

Stress changes arising from elastic-plate fault interactions were found to be insufficient to explain the 1906 stress shadow. In brief, stress changes recover too rapidly after 1906 to explain low rates of moderate-M earthquakes several decades later. What appears to be needed are fully time-dependent stress interactions involving the poorly constrained rheology of the lower crust and upper mantle beneath SFBR. In the absence of agreed-upon models for this phenomena, WG02 developed the Empirical Model, which employs the observed SFBR seismicity rates since 1906 as a proxy for the 1906 stress shadow. None of this transpired quickly and in fact involved 
a considerable expenditure of time, effort and controversy. But it has also made for the central difference between this report and its predecessor and for the central conclusion of this analysis: the limits of our knowledge of the extent and duration of the 1906 stress shadow are the essential limitation on the 30-year earthquake probabilities reported here.

The general principles underlying the use of diverse expert opinion have been discussed in Chapter 2, and its actual use has been described in Chapters 3, 4, and 5. Expert opinion in principle and expert opinion in practice, however, can be very different things. Even in the best of circumstances, which include a well-structured prospectus of how, where, when, and why expert opinion will be used, the process of actually exercising it is time-consuming and cumbersome. This "well-structured process" should also include feedback loops to the experts, with sufficient time for the experts to digest the consequences of their decisions.

WG02 sought out the views of many experts of diverse experiences and points of view and arranged for extensive interaction among them. Their expert opinions, finally expressed through voting, were applied in many instances, at all levels of importance to the results reported here. Due to the complexities noted above, our "well-structured process" developed over the course of our deliberations, and feedback on the consequences of decisions was uneven.

Because diverse expert opinion is itself a significant source of uncertainty in this analysis, we doubt that any future, comprehensive study of earthquake probabilities will be credible in the absence of sampling and quantifying the body and range of scientific judgments. If this is indeed the case, future studies of the scope of this one are well advised to think through in advance the processes by which they will employ differing scientific opinion and to make ample allowance for unanticipated problems that arise in the course of completing such studies.

The computer code developed by WG02 is a major product that allows the SFBR earthquake model and earthquake probabilities to be recalculated as new input values and branch weights become available. The code can easily be modified to accommodate new models, and can serve as a useful tool for exploring the sensitivity of results to the underlying models and input parameters. Given this flexibility, when should serious consideration be given to updating and replacing the results presented here? Incremental improvements in inputs (e.g., a refined slip rate or segmentation point) could be handled by re-running the WG02 code with modified input parameters or branch weights. However, our experience suggests that certain events may make it worthwhile to convene a new Working Group. These include:

- A sizeable earthquake on one of the characterized faults, or a background earthquake that significantly changes the stress state of characterized faults.

- New or improved data that significantly changes the calculated rate or magnitude of earthquakes on the characterized faults, in particular changes in the inferred rate of earthquakes on the San Andreas fault because of its dominating effect on the seismic moment budget and earthquake occurrence throughout the region.

- New results that increase understanding of the 1906 stress shadow.

- The development of a new probability model, or an evolution of opinion in the scientific community that would significantly change probability model weights. 


\section{Key questions for future research}

We have noted throughout this report that there is little about it that is not without uncertainty. The purpose of this chapter is to cast those things that most greatly influence the results in the form of questions to be addressed through research, noting those bodies of knowledge on which they depend and their attendant uncertainties. Critical goals of research in this field are to improve models for the occurrence, rate and probability of large earthquakes, and to better quantify the parameters needed to apply them to regions at risk.

The SFBR model balances strain energy accumulation against its release in all earthquakes and related phenomena, but not all earthquakes are equal in the accounting. The slip in one big earthquake equals that of many smaller ones, so a key aspect of the model is the manner in which big earthquakes are made. The segmentation models, the rupture models which specify the likelihood of multi-segment ruptures, the $\boldsymbol{M}$ - $\log$ A relations, and $\boldsymbol{M}$ for the 1906 event are all critical in defining the frequency of big earthquakes and their import in releasing the regional deformation available to make all of the earthquakes. Creep or aseismic slip is also crucial, particularly in the description of the Hayward fault.

The calculation of 30-year probabilities are based on the SFBR model, and also are critically dependent on our description of fault interactions, particularly the extent to which earthquake occurrence on faults in the SFBR in the next 30 years is controlled by the stress shadow of the 1906 event. The 30-year probabilities are also pivotally dependent on the variability of recurrence intervals of earthquakes on a fault segment, represented here by the coefficient of variation or aperiodicity, $\alpha$.

\section{Segmentation Models}

WG02's segmentation model was designed by committees of earth scientists expert in the workings of faults in general and SFBR faults in particular. There was considerable discussion in these groups about the existence and locations of fault segment end points -the consistent end points of rupture in significant earthquakes, Which end points are particularly strong? Which end points in the SFBR are clearly supported by geologic and geophysical observation? Which are not? How would removing these segments affect the model and the 30-year probabilities? WG02 included floating earthquakes of a particular $\mathbf{M}$ to account for unknown segmentation. Should floating earthquakes be part of future models? Or, is a continuous distribution of earthquake sizes, perhaps a Gutenberg-Richter distribution, more appropriate? Should future working groups consider a range of possible fault characterization approaches beyond the segmentation model?

\section{Multi-segment Ruptures}

How frequently earthquakes rupture through segment endpoints and grow into multi-segment (big) earthquakes is a crucial aspect of fault characterization. WG02's fault characterization committees based their assessments of the frequency of multi-segment ruptures on a collective subjective judgment (expert opinion) rather than on a specific analysis of resistance to failure. Future working groups would benefit from clarification of how earthquakes stop and which fault characteristics are particularly diagnostic of resistance to failure in big earthquakes. Does the apparent offset of the Hayward and Rodgers Creek faults beneath San Pablo Bay provide a barrier that is rarely broken in multi-segment earthquakes? Or, like the 1995 Kobe, Japan earthquake, does the fault trace offset 
concentrate stress and act as a nucleation point for multi-segment ruptures? What is the best way to assess the frequency of multi-segment ruptures on SFBR faults?

\section{M-logA Relations}

WG02 used a suite of empirical M-log relations to determine the magnitude of earthquakes from their areal dimensions. How fast does the average slip increase with area? WG02 struggled with the discrepancy between the available examples of big San Andreas fault system events (the 1857 earthquake in southern California and 1906 in northern California) and observations from big strikeslip earthquakes worldwide. Are earthquakes on the San Andreas fault system fundamentally different from their cousins worldwide? Or, are the 1906 and 1857 events extreme examples of the aleatory variability in the slip or rupture length of great strike-slip events? More specifically, should future working groups consider the low slip in 1906 as anomalous or representative of future comparable-length multi-segment ruptures? There is considerable aleatory uncertainty in the observations worldwide and great continental strike-slip earthquakes like 1906 and 1857 happen infrequently, so timely answers to these questions will not come from a data set supplemented by future great strikeslip earthquakes. Is the aleatory uncertainty normally distributed in $\mathbf{M}$ ? Or in $\mathbf{M}_{0}$ ?

\section{M for the 1906 Event}

If 1906 earthquake is treated as representative of comparable-length multi-segment ruptures, what $\mathbf{M}$ should be used for 1906 in constructing the long-term model? WG02 assumed M 7.8, but recognized that the uncertainty in this estimate corresponds to the slip in several smaller events. Thus, the estimates of 30-year probability of $\mathbf{M} \geq 6.7$ events depend on the value of $\mathbf{M}$ assumed for the 1906 event. Is the slip in the 1906 earthquake a repeat of earlier 4-segment ruptures of the San Andreas fault? What is the paleoseismic evidence for the occurrence of 1-, 2-, or 3-segment ruptures on the San Andreas fault? What is the paleoseismic evidence for multi-segment events on the HaywardRodgers Creek fault? Or on the other characterized faults?

\section{Creep or Aseismic Slip}

Recent satellite geodetic measurements suggest that a large part of segment HN may be creeping aseismically throughout the seismogenic zone. If true, the absence of locked patches would imply a diminished accumulation of elastic strain energy on this segment and a smaller likelihood that large earthquakes could nucleate there. Even if HN were freely creeping, however, locked patches to north and south could significantly retard slip on HN over the geologic rate, leading to substantial unreleased moment on that segment. Thus, even if failure of segment HN by itself were unlikely, HN might well rupture coseismically when earthquakes occurred on the segments to north or south in order to erase its slip deficit. Paleoseismic trenching of the HN segment at El Cerrito suggests that there have been at least four (and maybe seven or more) surface rupturing events in the past 2200 years, the last occurring between 1640 and 1776. Waldhauser and Ellsworth (2002) have inferred a locked patch on the HN segment based on the distribution of carefully located repeating earthquakes. It seems clear that an accurate assessment of the probability of large earthquakes on the HN segment depends on a much better understanding than we presently have of its creep behavior at depth and its reaction to earthquakes on adjacent segments.

How extensive is aseismic slip on SFBR faults at seismogenic depths? In particular, we need more and better GPS and INSAR data to resolve the extent to which creep is occurring at depth and the partition of slip on the different, closely spaced faults in the region. Is HN creeping at all 
depths? Or, is there sufficient accumulation of strain at depth on HN to generate $\mathbf{M} \geq 6.7$ earthquakes?

\section{Coefficient of Variation}

The variation of recurrence intervals of earthquakes on a fault segment is accounted for in the SFBR through the coefficient of variation $\alpha$. The uncertainty in $\alpha$ is an important source of uncertainty in our 30-year probabilities. Further evaluation of the appropriate range of $\alpha$ will be important to future working groups. What $\alpha$ should be used for segments like SAP that rupture alone and also as components of multi-segment ruptures? What data should be used to constrain $\alpha$ in these cases? How relevant are repeating sequences of small earthquakes on creeping segments to the behavior of large earthquakes on locked segments? Should $\alpha$ be estimated from SFBR data only, or should future working groups consider evidence from recurring earthquakes in other tectonic environments?

\section{Fault Interactions}

The stress shadow of the 1906 earthquake and uncertainty about its effects in the 2002-2031 period has been discussed at length in this report. We considered several probability models to represent the 1906 effects because no model available to us was completely satisfactory. In fact, WG02's recognition of the lack of any adequate model has stimulated the development of viscoelastic and rate-andstate models that promise to better represent the effects of the 1906 earthquake on future earthquake activity in the SFBR. A suite of such models needs to be developed, evaluated and made available for use by the next working group. In the following section we discuss the state—and promise_-of modeling efforts already underway.

The available data on post-seismic quienscence are tantalizing, but questions on their proper interpretation abound. For example, analyses of SFBR seismicity reveal regional quiescence of shorter duration followed the M6.8 earthquake in 1868, the M6.9 earthquake in 1989, and perhaps the M6.8 earthquake in 1838. Are there good analogs of these observations in other regions of the world? What do these quiescences tell us about the nature of stress shadows in general? Did the seismic quiescence after 1906 extend to smaller M? What is the relationship between spatial extent and duration of the quiescence and magnitude? Are the developing viscoelastic and rate-and state models discussed below consistent with these observations? The answers to these questions will bear directly on the uncertainties in future assessments of SFBR earthquake sources.

\section{Modeling fault interactions in a viscoelastic earth}

Deep post-earthquake afterslip and viscoelastic relaxation of the lower crust and upper mantle may act to redistribute stress into the seismogenic crust over time. Stress transfer within the elastic crust is static and immediate, whereas stress transferred by a large earthquake into the highertemperature lower crust and upper mantle is likely time dependent because strain occurs at depth by viscoelastic flow iresponse to a sudden stress change. Deep post-seismic stress readjustment may impact the seismogenic crust, and act to modify the coseismic static stress change. This process is known as stress diffusion, and appears to occur rapidly relative to the seismic cycle. For example, stress diffusion models were fit to geodetic measurements made after the 1999 M7.1 Hector Mine, California and 1999 M7.4 Izmit, Turkey earthquakes. Stress diffusion models have seen some success in explaining the Landers - Hector Mine earthquake pair, especially the 7-year delay between the two events. 
Post-1906 stress diffusion in the SFBR has been calculated using various finite-element (e.g., Kenner and Segall, 1999; Parsons, 2002a) and semi-analytic techniques (Pollitz, 2001), with all three studies predicting the effect of viscoelastic relaxation on the erosion rate and length of the 1906 stress shadow. The viscoelastic models generally predict lengthening of the 1906 stress shadow on faults sufficiently distant from the SAF. A comparison of the calculated post-1906 effects on the Hayward fault shows similar stress-shadow durations of 30-130 years (Kenner and Segall, 1999), 30-90 years (Pollitz, written comm.), and 37-74 years (Parsons, 2002a), depending on parameter choices and assumed deep fault geometry. If longer stress shadow durations are incorporated in probability calculations, then slightly lower probability values result. However, models that allow for a weak and mobile mantle produce a shortening of the 1906 stress shadow on faults located between the Calaveras and San Andreas faults. In addition, the viscoelastic models generally predict relatively faster reloading of the San Andreas fault itself. In both these cases, again depending on model parameters, the impact of viscoelastic relaxation would be to increase probability values on these faults.

Tectonic stressing rates must be calculated to estimate the duration of a stress shadow and to make clock-change estimates. Fault-stressing rates calculated with a finite element model were evaluated against numbers calculated using deep dislocation slip by Parsons (2002a). In the viscoelastic finite element model, tectonic stressing is distributed throughout the crust and upper mantle. In contrast, tectonic loading calculated with dislocations focuses nearly all plateboundary stress on faults, and comparably little in the surrounding crust. Thus calculation of tectonic stressing rates is model dependent, and higher rates are found on most Bay area faults with elastic dislocation models. Higher stressing rates cause shorter stress-shadow durations and slightly higher calculated earthquake probability.

So far, earthquake interactions have been viewed as 1) static stress changes that, when divided by the tectonic stressing rate, yield clock changes; 2) changes in state of the BPT model; or 3) coseismic static stress changes modified by time-dependent post-seismic stress changes. In addition to these possibilities, laboratory studies of rock friction show complex time- and ratedependent elastic behavior known as rate-and-state friction (e.g., Dieterich, 1978). A prediction emerges from rate-and-state theory that, following a sudden stress change, earthquake rates on affected faults change suddenly, and then obey an Omori-law return to background rates (Dieterich, 1994). If rate-and-state-dependent friction occurs in the Earth, then earthquake interactions should cause predictable rate changes that can be folded into probability calculations.

Dieterich and Kilgore (1996) formulated a method for incorporating rate-and-state transient functions into earthquake probability calculations. Studies show that globally, earthquake interactions cause marked $\mathbf{M} \geq 4.5$ earthquake rate increases followed by exponential decay with time. The technique has been used to calculate interaction earthquake probabilities in the Kobe, Japan region, in Turkey, and in the San Francisco Bay region.

Modeling and laboratory studies in combination with post-earthquake deformation and seismicity rate data should yield improvement in earthquake probability calculations where interactions from past large earthquakes are important. It will be necessary to gain confidence in model parameters, or at least to narrow the allowable range of values, to limit uncertainties in probability 
calculations introduced when more complex earthquake interaction calculations are made. In particular, advances in the rheologic character of the lithosphere, the deep configuration of faults, and rate/state parameters are needed. 


\section{REFERENCES}

Anderson, L.W., Anders, M.H., and Ostenaa, D.A., 1982, Late Quaternary faulting and seismic hazard potential eastern Diablo Range, California: California Division of Mines and Geology Special Publication, v. 62, p. 197-206.

Anderson, R.S., and Menking, K. M., 1994, The Quaternary marine terraces of Santa Cruz, California: evidence for coseismic uplift on two faults: Geological Society of America Bulletin, v. 106, no. 5, p. 649-664.

Andrews, D.J., Oppenheimer, D. H., and Lienkaemper, J. J., 1993, The Mission Link between the Hayward and Calaveras faults: Journal of Geophysical Research, v. 98, no. B7, p. 12,083-12,095.

Andrews, D.J., and Schwerer, E., 2000, Probability of rupture of multiple fault segments, , vol., no., pp..: Bulletin of the Seismological Society of America, v. 90, no. 6, p. 1498-1506.

Andrews, D.J., and Schwerer, E., 2000, Probability of rupture of multiple fault segments: Bulletin of the Seismological Society of America, v. 90, no. 6, p. 1498-1506.

Argus, D.F., and Gordon, R.G., 1991, Current Sierra Nevada- North American motion from very long baseline interferometry-implications for the kinematics of the western United States: Geology, v. 19, p. 1085-1088.

Argus, D.F., and Gordon, R.G., 2001, Present tectonic motion across the Coast Ranges and San Andreas fault system in central California: Geological Society of America Bulletin, v. 113, no. 12 , p. 1580-1592.

Bakun, W.H., 1980, Seismic activity on the southern Calaveras fault in central California: Seismological Society of America Bulletin, v. 70, no. 1181-1197.

Bakun, W.H., 1998, Modified Mercalli intensities for some recent California earthquakes and historic San Francisco Bay region earthquakes: U.S. Geological Survey Open-File Report 98-584, p. 175 pp.

Bakun, W.H., 1999, Seismic Activity of the San Francisco Bay Region: Bulletin Seismological Society of America, v. 89, p. 764-784.

Bakun, W.H., M.M. Clark, R.S. Cockerham, W. L. Ellsworth, A. G. Lindh, W. H. Prescott, A. F. Shakal, and P. Spudich (1984). The 1984 Morgan Hill, California, earthquake, Science 225, 288-291.

Bakun, W.H., King, G. C. P., and Cockerham, R. S., 1986, Seismic slip, aseismic slip, and the mechanics of repeating earthquakes on the Calaveras fault, California: Earthquake Source Mechanics, Geophysical Monograph 37, Am. Geophys. Union, p. 195-207.

Baldwin, J.N., and Lienkaemper, J.J., 1999, Paleoseismic investigations along the Green Valley fault, Solano County, California: U.S. Geol. Surv.

J.N. Baldwin, K.L. Knudsen, A. Lee, C.S. Prentice, R. Gross, 2001, Preliminary estimate of coseismic displacement of the penultimate earthquake on the Northern San Andreas Fault, Pt. Arena, California, in Proceedings of the 3rd Conference on Tectonic Problems of the San Andreas Fault System, September 6-8, 2000, Stanford University 15 pp. [http://pangea.stanford.edu/GP/sanandreas2000/Baldwin.pdf]

Bonilla, M.G., Lienkaemper, J. J., and Tinsley, J. C., 1980, Surface faulting near Livermore, 
California associated with the January 1980 earthquakes: U.S. Geological Survey Open-File Report 80-523, p. 32 p. and 1 pl.

Bonilla, M.G., and Lienkaemper, J.J., 1990, Visibility of fault strands in exploratory trenches and timing of rupture events: Geology, v. 18, no. 2, p. 153-156.

Boore, D.M., W.B. Joyner, and T.M. Fumal, Estimation of response spectra and peak accelerations from western North American earthquakes: a summary of recent work, Seism. Res. Lett., 66, 128-153, 1997.

Borcherdt, R.D., Estimates of site-dependent response spectra for design (methodology and justification), Earthquake Spectra, 10, 1964-1978, 1994.

Borchardt, G.S., David L; Wills, Chris J, 1999, Holocene slip rate of the Concord Fault at Galindo Creek in Concord, California: National Earthquake Hazards Program Final technical report, National Earthquake Hazards Program, U. S. Geological Survey, Library, Reston, VA, United States.

Borchardt, G., and Baldwin, J., 2001, Late Holocene behavior and seismogenic potential of the Concord-Green Valley fault system in Contra Costa and Solano counties, California: Calif. Geol. Surv. Bull., v. 210, p. 229-239.

Bortugno, E.J., McJunkin, R.D., and Wagner, D.L., 1992, Map showing recency of faulting, San Francisco-San Jose quadrangle, California: California Division of Mines and Geology Regional Geologic Map Series, Map 5A, Sheet 5, map scale 1:250,000.

Bowman, D.D., Ouillon, G., Sammis, C.G., Sornette, A., and Sornette, D., 1998, An observational test of the critical earthquake concept: Journal of Geophysical Research, B, Solid Earth and Planets, v. 103, no. 10, p. 24,359-24,372.

Bryant, W.A., Smith, D.P., and Hart, E.W., 1981, Sargent, San Andreas and Calaveras fault zone--evidence for recency in the Watsonville East, Chittenden and San Felipe quadrangles, California: California Division of Mines and Geology Open-File Report 81-7 SF (3 map sheets at 1:24,000 scale).

Bryant, W.A., 1985, Faults in the southern Monterey Bay area, Monterey County: California Division of Mines and Geology Fault Evaluation Report FER-167 [unpublished report, included in archive, staff, CDMG, 1990].

Budding, K.E., Schwartz, D.P., and Oppenheimer, D.H., 1991, Slip Rate, Earthquake Recurrence, and Seismological Potential of the Rodgers Creek fault zone, Northern California: Geophysical Research Letters, v. 18, p. 447-450.

Bufe, C.G., and Varnes, D.J., 1993, Predictive modelling of the seismic cycle of the greater San Francisco Bay region: Journal of Geophysical Research, B, Solid Earth and Planets, v. 98, p. 9871-9883.

Burgmann, R., Schmidt, D., Nadeau, R.M., d'Alessio, M., Fielding, E., Manaker, D., McEvilly, T.V., and Murray, M.H., 2000, Earthquake potential along the northern Hayward Fault, California: Science, v. 289, no. 5482, p. 1178-1182.

Castillo, D.A., and Ellsworth, W. L., 1993, Seismotectonics of the San Andreas fault system between Point Arena and Cape Mendocino in northern California: implications for the development and evolution of a young transform: Journal of Geophysical Research, v. 98, no. B4, p. 6543-6560. 
CDMG staff, 1990, Microfiche copies of Fault Evaluation Reports for the southern Coast Ranges: California Division of Mines and Geology Open-File Report 90-11, 4 p., 1 pl. and microfiche archive.

Chamberlin, T.C., 1890, The method of multiple working hypotheses: Science, v. 15, p. 92-97.

Clark, M.M., Harms, K.K., Lienkaemper, J.J., Harwood, D.S., Lajoie, K.R., Matti, J.C., Perkins, J.A., Rymer, M.J., Sarna-Wojcicki, A.M., Sharp, R.V., Sims, J.D., Tinsley, J.C. III, and Ziony, J.I., 1984, Preliminary slip-rate table and map of late-Quaternary faults of California: U.S. Geological Survey Open-File Report 84-106; 12 p., 5 plates, map scale 1:1,000,000.

Cockerham, R.S., Lester, F. W., and Ellsworth, W. L., 1980, A preliminary report on the Livermore Valley earthquake sequence January 24-February 26, 1980: U.S. Geological Survey Open-File Report 80-714; 54 p.

Cooper, A., 1973, Structure of the contintental shelf west of San Francisco, California: U.S. Geological Survey Open-File Report 73-1907; 65 p.

Coppersmith, K.J., 1979, Activity assessment of the Zayante-Vergeles fault, central San Andreas fault system, California, University of California, Santa Cruz, unpub. Ph.D. dissertation, $210 \mathrm{p}$.

Cornell, C.A., 1968, Engineering seismic risk analysis: Bulletin of the Seismological Society of America, v. 58, p. 1583-1606.

Cornell, C.A., and Winterstein, S.R., 1988, Temporal and magnitude dependence in earthquake recurrence models: Bulletin of the Seismological Society of America, v. 78, no. 4, p. 15221537.

Crane, R.C., 1995, Geology of the Mount Diablo region (abs.): AAPG Bulletin, v. 79, p. 582.

DeMets, C., Gordon, R.G., Argus, D.F., and Stein, S., 1994, Effects of recent revisions to the geomagnetic reversal of time scale on estimates of current plate motions: Geophysical Research Letters, v. 21, no. 20, p. 2191-2194.

DeMets, C., 1995, A reappraisal of seafloor spreading lineations in the Gulf of California: Implications for the transfer of Baja California to the Pacific plate and estimates of PacificNorth America motion: Geophysical Research Letters, v. 22, no. 24, p. 3545-3548.

DeMets, C., and Dixon, T.H., 1999, New kinematic models for Pacific-North America motion from 3 Ma to present; I, Evidence for steady motion and biases in the NUVEL-1A model: Geophysical Research Letters, v. 26, no. 13, p. 1921-1924.

Dietz, L., and Ellsworth, W.L., 1990, The October 17, 1989, Loma Prieta, California, earthquake and its aftershocks: geometry of the sequence from high-resolution locations: Geophys. Res. Letts., v. 17, p. 1417-1420.

Dietz, L.D., and Ellsworth, W.L., 1997, Aftershocks of the Loma Prieta earthquake and their tectonic implications, U. S. Geological Survey Professional Paper, p. D5-D47.

Dietz, L.D., and Ellsworth, W.L., 1997, Aftershocks of the Loma Prieta earthquake and their tectonic implications, U. S. Geological Survey Professional Paper, p. D5-D47.

Dixon, T.H., Robaudo, S., Lee, J., and Reheis, M.C., 1995, Constraints on present-day Basin and Range deformation from space geodesy: Tectonics, v. 14, p. 755-772.

Ellsworth, W.L., Lindh, A.G., Prescott, W.H., and Herd, D.G., 1981, The 1960 San Francisco earthquake and the seismic cycle, Maurice Ewing Series, AGU, p. 126-140. 
Ellsworth, W.L., Olson, J.A., Shijo, L.N., and Marks, S.M., 1982, Seismicity and active faults in the eastern San Francisco Bay region: California Division of Mines and Geology Special Publication, v. 62, p. 83-91.

Ellsworth, W.L., 1990, Earthquake history, 1769-1989, in The San Andreas fault system, California, U. S. Geological Survey Professional Paper, p. 153-187.

Ellsworth, W.L., 1995, Characteristic earthquakes and long-term earthquake forecasts: implications of central California seismicity, in Cheng, F.Y., and Sheu, M.S., eds., Urban Disaster Mitigation: the Role of Science and Technology, Elsevier, p. 1-14.

Ellsworth, W.L., Matthews, M.V., Nadeau, R.M., Nishenko, S.P., Reasenberg, P.A., and Simpson, R.W., 1999, A physically-based earthquake recurrence model for estimation of long-term earthquake probabilities: U. S. Geological Survey, OFR 99-522, 23 p.

Fassinger, P.W., Kirking, B., Perry, P.R., Smith, K., Wong, W., and Yang, C., 2001, Projections 2002 - Forecasts for the San Francisco Bay Area to the Year 2025, Association of Bay Area Governments, Oakland, CA, 285 p.

Feigl, K.L., Agnew, D. C., Bock, Y., Dong, D., Donnellan, A., Hager, B. H., Herring, T. A., Jackson, D. D., Jordan, T. H., King, R. W., Larsen, S., Larson, K. M., Murray, M. H., Shen, Z., and Webb, F. H., 1993, Space geodetic measurement of crustal deformation in central and southern California, 1984-1992: Journal of Geophysical Research, v. 98, no. B12, p. 21,677-21,712.

Field, E.H., Jackson, D.D., and Dolan, J.F., 1999, A Mutually Consistent Seismic-Hazard Source Model for Southern California: Bulletin of the Seismological Society of America, v. 89, p. 559-578.

Frankel, A., Mueller, C., Barnhard, T., Perkins, D., Leyendecker, E.V., Dickman, N. Hanson, S., and Hopper, M., 1996, National Seismic Hazard Maps: Documentation June 1996: U.S. Geological Survey Open-File Report 96-532, p. 44.

Frankel, A., Mueller, C., Barnhard, T., Perkins, D., Leyendecker, E.V., Dickman, N. Hanson, S., and Hopper, M., 1997, National 1996 Seismic Hazard Maps: U.S. Geological Survey OpenFile Report 97-131.

Fumal, T.E., Heingarther, G.F., and Schwartz, D.P., 1999, Timing and slip of large earthquakes on the San Andreas fault, Santa Cruz Mountains, California: Geol. Soc. Am. Abstracts with Programs, v. 31, no. 6, p. A-56.

Galehouse, J.S., 1990, Effect of the Loma Prieta earthquake on fault creep rates in the San Francisco Bay region: AGU 1989 fall meeting, late abstracts; Loma Prieta sessions [modified], v. 71, p. 288.

Galehouse, J.S., 1995, Theodolite measurements of creep rates on San Francisco Bay region faults: U.S. Geological Survey Open-File Report 95-210, p. 335-346.

Galehouse, J.S., 1998, Theodolite measurements of creep rates on San Francisco Bay region faults: National Earthquake Hazards Program Final technical report, National Earthquake Hazards Program, U. S. Geological Survey, Library, Reston, VA, United States.

Galehouse, J.S., and Lienkaemper, J.J., 2003, Inferences drawn from two decades of alinement array measurements of creep on faults in the San Francisco Bay region: Bull. Seism. Soc. Am. (in review), v. 93, p. (in review). 
Gilbert, G.K., 1886, The inculcation of scientific method by example, with an illustration drawn from the Quaternary geology of Utah: , v. 31, p. 284-299.

Gordon, R.G., and D. F. Argus, 1993, The San Andreas fault system in central California as the boundary between the Pacific and the Sierra Nevada-Great Valley microplate: kinematics from VLBI geodesy (abs.): Eos (American Geophysical Union, Transactions), v. 74, p. 64.

Greensfelder, R., 1968, Aftershocks of the Truckee, California, earthquake of September 12, 1966: Seismological Society of America Bulletin, v. 58, no. 5, p. 1607-1620.

Group, H.F.P., 1999, Timing of paleoearthquakes on the northern Hayward fault-preliminary evidence in El Cerrito, California: U.S. Geological Survey Open-File Report 99-318, 34 p.

Hall, N.T., Hunt, T. D., and Vaughan, P. R., 1994, Holocene behavior of the San Simeon fault zone, south-central coastal California: Geological Society of America Special Paper, v. 292, p. 167-189.

Hall, N.T., Wright, R. H., and Clahan, K. B., 1995, Final technical report, paleoseismic investigations of the San Andreas fault on the San Francisco Peninsula, California: USGSNEHRP contract report, \#14-08-0001-G2081, on file at U.S. Geological Survey, Reston, VA; 45 p., 26 figs., 2 tables, 27 plates.

Hall, N.T., Wright, R.H., and Clahan, K.B., 1999, Paleoseismic studies of the San Francisco peninsula segment of the San Andreas fault zone near Woodside, California: Journal of Geophysical Research, v. 104, no. B10, p. 23,215-23,236.

Hanks, T.C., and Kanamori, H., 1979, A moment-magnitude scale: Journal of Geophysical Research, v. 84, p. 2348-2350.

Hanks, T.C., and Krawinkler, H., 1991, The 1989 Loma Prieta, California, earthquake and its effects: Introduction to the special issue: Seismological Society of America Bulletin, v. 81, p. 1415-1423.

Hanks, T.C., 1997, Imperfect science: uncertainty, diversity, and experts: Eos (American Geophysical Union, Transactions), v. 78, p. 366-377.

Hanks, T.C., and Bakun, W.H., 2002, A bilinear source-scaling model for M-log A observations of continental earthquakes: Bulletin of the Seismological Society of America, v. 92, p. 1841-1846.

Hanson, K.L., and Lettis, W. R., 1994, Estimated Pleistocene slip rate for the San Simeon fault zone, south-central coastal California: Geological Society of America Special Paper, v. 292, p. 133-150.

Harms, K.K., Harden, J.W., and Clark, M.M., 1987, Use of quantified soil development to determine slip rates on the Paicines fault, northern California (abs.): Geological Society of America Abstracts with Programs, 83rd Meeting, Cordilleran Section, v. 19, no. 6, p. 387.

Harris, R.A., and Simpson, R.W., 1992, Changes in static stress on Southern California faults after the 1992 Landers earthquake: Nature, v. 360, no. 6401, p. 251-254.

Harris, R.A., and Day, S.M., 1995, Numerical simulations of earthquakes spontaneously propagating along complex faults [abs.]: International Union of Geodesy and Geophysicists Meeting, Abstract volume A, p. 369.

Harris, R.A., and Simpson, R.W., 1998, Suppression of large earthquakes by stress shadows: a comparison of Coulomb and rate-and-state failure: Journal of Geophysical Research, v. 103, 
p. $24,439-24,451$.

Hart, E.W., 1981, Recently active strands of the Greenville Fault, Alameda, Contra Costa, and Santa Clara counties, California: California Division of Mines and Geology Open-File Report 81-8, scale 1:24,000.

Hart, E.W., Bryant, W.A., Manson, M.W., and Kahle, J.E., 1986, Summary report, Fault evaluation program, 1984-1985, southern Coast Ranges region and other areas: California Division of Mines and Geology Open-File Report 86-3, 26 p., 1 plate, scale 1:500,000.

Hart, E.W., 1992, Recently active traces of the Rodgers Creek fault, Sonoma County, California: Calif. Div. Mines Geol Open-File Rep., v. 92-7, p. 18 pp.

Hartzell, S. H>, and T. H. Heaton (1986). Rupture history of the 1984 Morgan Hill, California earthquake from the inversion of strong motion records, Bull. Seism. Soc. Am. 76, 649-674.

Hayward Fault Paleoearthquake Group (Lienkaemper, J.J., Schwartz, D. P., Kelson, K. I., Lettis, W. R., Simpson, G. D., Southon, J.R., Wanket, J.A., Williams, P.L.), 1999, Timing of Paleoearthquakes on the Northern Hayward Fault -- Preliminary Evidence in El Cerrito, California: U.S. Geol. Surv. Open-File Rep., v. 99-318, p. 34.

Hedel, C.W., 1984, Maps showing geomorphic and geologic evidence for late Quaternary displacement along the Surprise Valley and associated faults, Modoc County, California: U.S. Geological Survey Miscellaneous Field Studies Map MF-1429, 2 sheets, scale $1: 62,500$.

Heingartner, G.F., and Schwartz, D. P., 1996, Paleoseismic evidence for large magnitude earthquakes along the San Andreas fault in the southern Santa Cruz mountains, California: Eos (American Geophysical Union, Transactions), v. 77, p. p. 462.

Herd, D.G., and Brabb, E.E., 1980, Faults at the General Electric test reactor site, Vallecitos Nuclear Center, Pleasanton, California: U.S. Geological Survey Administrative Report, 77 p.

Hill, D.P.E., Jerry P; Jones, Lucile M, 1990, Seismicity, 1980-86, in Wallace, R.E., ed., The San Andreas fault system, California, U. S. Geological Survey Professional Paper, P 1515, p. 115-151.

Hitchcock, C.S., Kelson, K. I., and Thompson, S. C., 1994, Geomorphic investigations of deformation along the northeastern margin of the Santa Cruz Mountains: U.S. Geological Survey Open-File Report 94-187; 51 p., 2 pl.

Jachens, R.C., and Zoback, M.L., 1999, The San Andreas fault in the San Francisco Bay Region, California: Structure and kinematics of a young plate boundary: International Geology Review, v. 41, p. 191-205.

Jackson, D.D., and Working Group on California Earthquake Probabilities, 1995, Seismic Hazards in Southern California: Probable Earthquakes, 1994 to 2024: Bulletin of the Seismological Society of America, v. 85, p. 379-439.

Jackson, D.D., and Kagan, Y.Y., 1999, Testable earthquake forecasts for 1999: Seismological Research Letters, v. 70, no. 4, p. 393-403.

Jaume, S.C., and Sykes, L.R., 1996, Evolution of moderate seismicity in the San Francisco Bay region, 1850 to 1993: Seismicity changes related to the occurrence of large and great earthquakes: Journal of Geophysical Research, v. 101, p. 765-789. 
Jeffreys, H., 1976, The Earth (sixth edition ed.), Cambridge University Press, 574 p.

Jennings, C.W., 1977, Geologic Map of California, 1:750,000: California Division of Mines and Geology, Geologic Data Map No.2.

Jennings, C.W., 1992, Preliminary fault activity map of California: California Division of Mines and Geology Open-File Report 92-3, scale 1:750,000.

Jennings, C.W., 1994, Fault activity map of California and adjacent areas with locations and ages of recent volcanic eruptions: California Division of Mines and Geology Data Map Series No. 6, 92 p., 2 plates, map scale 1:750,000.

Joyner, W.B., and D.M. Boore, Peak horizontal acceleration and velocity from strong-motion records including the records from the 1979 Imperial Valley, California, earthquake, Bull. Seism. Soc. Amer., 71, 2011-2038, 1981.

Kagan, Y.Y., and Knopoff, L., 1987, Random stress and earthquake statistics; time dependence: Geophys. J. R. Astr. Soc., v. 88, p. 723-731.

Kelson, K.I., Simpson, G.D., Lettis, W.R., and Haraden, C.C., 1996, Holocene slip rate and recurrence of the northern Calaveras fault at Leyden Creek, eastern San Francisco Bay region: Journal of Geophysical Research, v. 101, no. B3, p. 5961-5975.

Kelson, K.I., and others, 1998, Late Holocene slip rate and amounts of coseismic rupture along the central Calaveras fault, San Francisco Bay area, California: Final Technical Report submitted to the U.S. Geological Survey National Earthquake Hazard Reduction Program, Award Number 1434-HQ-97-GR-03151, 26 pp.

Kelson, K., 2001, Geologic characterization of the Calaveras fault as a potential seismic source, San Francisco Bay area, California: Calif. Geol. Surv. Bull., v. 210, p. 179-192.

Kenner, S., and Segall, P., 1999, Time-dependence of the stress shadowing effect and its relation to the structure of the lower crust: Geology, v. 27, no. 2, p. 119-122.

Kenner, S.J., and Segall, P., 2000, Postseismic deformation following the 1906 San Francisco earthquake: Journal of Geophysical Research B, Solid Earth and Planets, v. 105, no. 6, p. 13,195-13,209.

Knudsen, K.L., Witter, R.C., Garrison-Laney, C.E., Baldwin, J.N., and Carver, G.A., 1999, Evidence for earthquake-induced, rapid subsidence in estuarine sediment along northern fault: Final Technical Report, U.S. Geological Survey, Award 1434-HQ-97-GR-03009, $51 \mathrm{p}$.

Knudsen, K.L., Witter, R.C., Garrison-Laney, C.E., Baldwin, J.N., and Carver, G.A., 2002, Past earthquake-induced rapid subsidence along the northern San Andreas fault: A paleoseismological method for investigation strike-slip faults: Bull. Seism. Soc. Am., v. 92, p. 2612-2636.

Knuepfer, P.L., 1977, Geomorphic investigations of the Vaca and Antioch fault systems, Solano and Contra Costa Counties, California, Stanford University, Stanford, California, M.S. thesis, $53 \mathrm{p}$.

LaForge, R., and Lee, W. H. K., 1982, Seismicity and tectonics of the Ortigalita fault and southeast Diablo Range, California: California Division of Mines and Geology Special Publication, v. 62, p. 93-101.

Langridge, R.M.P., C S, 2000, Mid-Holocene slip rate on the San Andreas Fault near Fort Ross, 
California (abs.): Seismological Research Letters, v. 71, p. 228.

Lawson, A.C., 1908, The earthquake of 1868, in Lawson, A.C., ed., The California earthquake of April 18, 1906: Report of the State Earthquake Investigation Commission (Volume I): Carnegie Institution of Washington Publication, p. 434-448.

Lettis, W.R., 1982, Late Cenozoic stratigraphy and structure, central San Joaquin Valley, California: U.S. Geological Survey Open-File Report 82-526, p. 203 p., scale 1:500,000.

Lettis, W., 2001, Late Holocene behavior and seismogenic potential of the Hayward-RodgersCreek fault system in the San Francisco Bay area, California: Calif. Geol. Surv. Bulletin, v. 210, p. 167-178.

Lienkaemper, J.J., Pezzopane, S.K., Clark, M.M., and Rymer, M.J., 1987, Fault fractures formed in association with the 1986 Chalfant Valley, California, earthquake sequence: preliminary report: Seismological Society of America Bulletin, v. 77, no. 1, p. 297-305.

Lienkaemper, J.J., G. Borchardt, and M. Lisowski, 1991, Historic creep rate and potential for seismic slip along the Hayward fault, California: Journal of Geophysical Research, v. 96, no. B11, p. 18,261-18,283.

Lienkaemper, J.J., 1992, Map of recently active traces of the Hayward fault, Alameda and Contra Costa Counties, California: U.S. Geological Survey Miscellaneous Field Studies Map MF2196, map scale 1:24,000, p. 13.

Lienkaemper, J.J., Williams, P. L., Taylor, P., and Williams, K., 1995, New evidence of large surface-rupturing earthquakes along the northern Hayward fault zone [abstr.], in SEPM (Society of Economic Paleontologists and Mineralogists) Pacific Section, 70th Annual Meeting, San Francisco, California, SEPM, p. 38.

Lienkaemper, J.J., and Borchardt, G., 1996, Holocene slip rate of the Hayward fault at Union City, California: Journal of Geophysical Research, v. 101, no. B3, p. 6099-6108.

Lienkaemper, J.J., Galehouse, J.S., and Simpson, R.W., 1997, Creep response of the Hayward Fault to stress changes caused by the Loma Prieta earthquake: Science, v. 276, no. 5321, p. 2014-2016.

Lienkaemper, J.J., and Galehouse, J.S., 1998, New evidence doubles the seismic potential of the Hayward fault: Seismological Research Letters, v. 69, no. 6, p. 519-523.

Lienkaemper, J.J., and Williams, P.L., 1998, New evidence in north Oakland of minor ground rupture on the Hayward fault and major rupturing in prehistoric earthquakes: Geophysical Research Letters, v. 26, p. 1949-1952.

Lienkaemper, J.J., Schwartz, D. P., Kelson, K. I., Lettis, W. R., Simpson, G. D., Southon, J.R., Wanket, J.A., Williams, P.L., 1999, Timing of Paleoearthquakes on the Northern Hayward Fault -- Preliminary Evidence in El Cerrito, California: U.S. Geol. Surv. Open-File Rep., v. 99-318, p. 34.

Lienkaemper, J.J., Dawson, T. E., Personius, S. F., and Seitz, G.G., Reidy, L. M. and Schwartz, D. P., 2002, A record of large earthquakes on the southern Hayward fault for the past 500 years: Bull. Seism. Soc. Am., v. 92, no. 7, p. 2637-2658.

Lindh, A.G., 1983, Preliminary assessment of long-term probabilities for large earthquakes along selected segments of the San Andreas fault system in California: U.S. Geological Survey Open-File Report 83-63, 15 p. 
Lindh, A.G., 1988, Estimates of Long-Term Probabilities for Large Earthquakes Along Selected Fault Segments of the San Andreas Fault System in California, Earthquake Prediction -Present Status: Pune, India, Univ. of Poona, p. 189-200.

Lindh, A.G., and Oppenheimer, D.H., 1993, Probabilities of large earthquakes in the East Bay, Special Publication - California Division of Mines and Geology, p. 43.

Linker, M.F., and Rice, J.R., 1997, Models of postseismic deformation and stress transfer associated with the Loma Prieta earthquake, U. S. Geological Survey Professional Paper, Report: P 1550-D, p. D253-D275.

Lisowski, M., and Prescott, W. H., 1989, Strain accumulation near the Mendocino triple junction [abstr.]: Eos (American Geophysical Union, Transactions), v. 70, no. 43, p. 1332.

Lisowski, M., Prescott, W. H., Savage, J. C., and Johnston, M. J., 1990, Geodetic estimate of coseismic slip during the 1989 Loma Prieta, California, earthquake: Geophysical Research Letters, v. 17, no. 9, p. 1437-1440.

Liu, H., and D. V. Helmberger (1983). The near-source ground motion of the 6 August 1979 Coyote Lake, California, earthquake, Bull. Seism. Soc. Am. 73, 201-218.

Louderback, G.D., 1947, Central California earthquakes of the 1830's: Seismological Society of America Bulletin, v. 34, no. 1, p. 33-74.

Machette, M.N., Personius, S.F., and Nelson, A.R., 1992, Paleoseismology of the Wasatch fault zone: U.S. Geological Survey Professional Paper, v. 1500-A, p. 72 p.

McCarthy, J., Hart, P. E., and Oppenheimer, D., 1995, High-angle faulting in the western Sacramento delta region, Pittsburg, California, in SEPM (Society of Economic Paleontologists and Mineralogists) Pacific Section, 70th Annual Meeting, San Francisco, California, SEPM, p. 39.

McCrory, P.A., 1996, Evaluation of fault hazards, northern coastal California: U.S. Geological Survey Open-File Report 96-657, p. 87 p.

McCulloch, D.S., 1987, Regional geology and hydrocarbon potential of offshore central California, in D. W. Scholl, G., A., and Vedder, J. G., ed., Geology and resource potential of the continental margin of western North America and adjacent ocean basins_-Beaufort Sea to Baja California: Circum Pacific Council for Energy and Mineral Resources, Earth Science Series, p. 353-401.

McCulloch, D.S., and Greene, H.G., 1990, Geologic map of the central California continental margin, Map No. 5A (Geology), in Greene, H.G., and Kennedy, M.P., ed., California Division of Mines and Geology California Continental Margin Geologic Map Series, Area 5 of 7, map scale 1:250,000.

McNally, K.C., and Stakes, D. S., 1998, Implications of the San Gregorio fault zone seismicity for Monterey Bay Coastal Hazard Assessment: Eos (American Geophysical Union, Transactions), v. 79, p. 589.

Mendoza, C.H., S H, 1987, Inversion for slip distribution using teleseismic body waves; North Palm Springs and Borah Peak earthquakes (abstr.): Seism. Res. Letts., v. 58, p. 8.

Mendoza, C., and Hartzell, S.H., 1988 (87?), Aftershock patterns and main shock faulting: Bulletin of the Seismological Society of America, v. 78, no. 4, p. 1438-1449.

Mogi, K., 1982, Temporal variation of the precursory crustal deformation just prior to the 1944 , 
Tonankai earthquake: Zisin, v. 35, no. 1, p. 145-148.

Molnar, P., 1979, Earthquake recurrence intervals and plate tectonics: Bulletin of the Seismological Society of America, v. 69, no. 1, p. 115-133.

Mosier, J.B., 1977, Results of triangulation for earth movement study at California aqueductfault crossing sites: Section VI, north and south San Francisco Bay aqueducts, Suppl. No. 6, July 1977, Union and Veras sites.: U.S. Dept. Commerce, NOAA, National Geodetic Survey.

Murray, M.H., Marshall, G.A., Lisowski, M. and Stein, R.S., 1996, The 1992 M=7 Cape Mendocino, California earthquake: coseismic deformation at the south end of the Cascadian megathrust: Journal of Geophysical Research, v. 101, no. B8, p. 17,707-17,726.

NEHRP Recommended Provisions for Seismic Regulations for New Buildings and Other Structures, Building Seismic Safety Council, Washington, D.C., 33-35, 1997.

Niemi, T.M., and Hall, N. T., 1992, Late Holocene slip rate and recurrence of great earthquakes on the San Andreas fault in northern California: Geology, v. 20, no. 3, p. 196-198.

Niemi, T. M., and Zhang, H.; Generaux, S.; Fumal, T.; Seitz, G. G., 2002, A 2500-year record of earthquakes along the northern San Andreas Fault at Vedanta Marsh, Olema, California: Geological Society of America Cordilleran Section abstracts, Geological Society of America, Cordilleran Section, 98th annual meeting Abstracts with Programs, Geological Society of America, vol. 34, no. 5, p. 86.

Nishenko, S.P., and Buland, R., 1987, A Generic Recurrence Interval Distributiion for Earthquake Forecasting: , v. 77, p. 1382-1399.

Nolan, J.M., Zinn, E.N., and Weber, G.E., 1995, Paleoseismic study of the southern Sargent fault, Santa Clara and San Benito Counties California: U.S. Geological Survey NEHRP Final Technical Report 1434-94-G-2466, 23 p. [contract report on file at U.S. Geological Survey, Menlo Park, California].

Noller, J.S.S., J M; Lettis, W R, 1993, Preliminary maps showing Quaternary geology of the Solyo and Lone Tree Creek 7.5-minute quadrangles, California: U. S. Geological Survey, Open-File Report, OF 93-0224, 3 sheets.

Noller, J.S., and Lightfoot,, 1997, An archaeseismic approach and method for the study of active strike-slip faults: Geoarchaelogy, v. 12, p. p. 117-135.

Ogata, Y., 1999, Estimating the hazard of rupture using uncertain occurrence times of Paleoearthquakes: Journal of Geophysical Research, B, Solid Earth and Planets, v. 104, no. 8 , p. 17,995-18,014.

Oppenheimer, D.H., Bakun, W. H., and Lindh, A. G., 1990, Slip partitioning of the Calaveras fault, California, and prospects for future earthquakes: Journal of Geophysical Research, v. 95, no. B6, p. 8483-8498.

Oppenheimer, D.H., and MacGregor-Scott, N., 1992, The seismotectonics of the eastern San Francisco Bay region: California Division of Mines and Geology Special Publication, v. 113, p. 11-16.

Oppenheimer, D.H., and Lindh, A. G., 1993, The potential for earthquake rupture of the northern Calaveras fault: California Division of Mines and Geology Special Publication, v. 113, p. 233-240. 
Oppenheimer, D.H., Wong, I. G., and Klein, F. W., 1993, The seismicity of the Hayward fault, California: California Division of Mines and Geology Special Publication, v. 113, p. 91100.

Page, W.D., and Renne, P. R., 1994, ${ }^{40}$ AR- ${ }^{39}$ AR dating of Quaternary basalt, western Modoc Plateau, northeastern California: Implications to tectonics [abstr.]: U.S. Geological Survey Circular 1107 [Abstracts of the Eighth International Conference on Geochronology, Cosmochronology and Isotope Geology, Lanphere, M. A., Dalrymple, G. B., and Turrin, B. D. (eds.)], p. 240.

Parsons, T., 2002, Post-1906 stress recovery of the San Andreas fault system calculated from 3D finite element analysis: , v. in press.

Perkins, J.A., and Sims, J.D., 1988, Late Quaternary slip along Calaveras fault near Hollister, California: Eos (American Geophysical Union, Transactions), v. 69, no. 44, p. 1420.

Petersen, M.D., Bryant, W.A., Cramer, C.H., Cao, T., Reichle, M.S., Frankel, A.D., Lienkaemper, J.J., McCrory, P.A., and Schwartz, D.P., 1996, Probabilistic seismic hazard assessment for the state of California: Open-File Report - U. S. Geological Survey, v. OF 96-0706, p. 33.

Pezzopane, S.K., 1993, Active faults and earthquake ground motions in Oregon, University of Oregon, Ph. D. dissertation, 208 pp.

Phipps, S.P., 1992, Late Cenozoic tectonic wedging and blind thrusting beneath the Sacramento Valley and eastern Coast Ranges, Day 2: American Association of Petroleum Geologists. Pacific Section. Guidebook, v. 70, p. 63-84.

Pollitz, F.F., Burgmann, R., and Segall, P., 1998, Joint estimation of afterslip rate and postseismic relaxation following the 1989 Loma Prieta earthquake: J. Geophys. Res., v. 103, p. 26975-26992.

Prentice, C.S., 1989, Earthquake geology of the the northern San Andreas fault near Point Arena California, California Institute of Technology, Pasadena, unpub. Ph.D. dissertation, 252 p.

Prentice, C., Niemi, T. N., and Hall, N. T., 1991, Quaternary tectonics of the northern San Andreas fault, San Francisco Peninsula, Point Reyes, and Point Arena, California [field trip guide]: California Division of Mines and Geology Special Publication, v. 109, p. 25-34.

Prescott, W.H., and Burford, R. O., 1976, Slip on the Sargent fault: Seismological Society of America Bulletin, v. 66, no. 3, p. 1013-1016.

Prescott, W.H., Lisowski, M., and Savage, J.C., 1981, Geodetic Measurement of Crustal Deformation on the San Andreas, Hayward, and Calaveras Faults Near San Francisco, California: J. Geophys. Res., v. 86, p. 10853-10869.

Prescott, W.H., and M. Lisowski, 1983, Strain accumulation along the San Andreas fault system east of San Francisco Bay, California: Tectonophysics, v. 97, p. 41-56.

Prescott, W.H., King, N. E., and Gu, G. H., 1984, Preseismic, coseismic and postseismic deformation associated with the 1984 Morgan Hill, California, earthquake: California Division of Mines and Geology Special Publication, v. 68, p. 137-148.

Prescott, W.H., Savage, J.C., Svarc, J.L., and Manaker, David, 2001, Deformation across the Pacific-North America plate boundary near San Francisco, California: Journal of Geophysical Research, B, Solid Earth and Planets, v. 106, no. 4, p. 6673-6682. 
Reasenberg, P.A., and Simpson, R.W., 1992, Response of regional seismicity to the static stress change produced by the Loma Prieta earthquake: Science, v. 255, p. 1687-1690.

Reasenberg, P.A., Hanks, T.C., and Bakun, W.H., 2003, An empirical model for earthquake probabilities in the San Francisco Bay region, California, 2002-2031: v. to be submitted to .

Reid, H.F., 1910, The Mechanics of the Earthquake, The California earthquake of April 18, 1906: Report of the State Earthquake Investigation Commission: Publication No. 87, Carnegie Institution of Washington, v. II, $192 \mathrm{p}$.

Rikitake, T., 1974, Probability of Earthquake Occurrence as estimated from Crustal Strain: Tectonophysics, v. 23, p. 299-312.

Rogers, J.D., and Halliday, J. M., 1993, Exploring the Calaveras-Las Trampas fault junction in the Danville-San Ramon area: California Division of Mines and Geology Special Publication, v. 113, p. 261-270.

Rosenberg, L.I., and Clark, J. C., 1994, Final technical report, Quaternary faulting of the Greater Monterey area, California: USGS-NEHRP contract report, \#1434-94-G2443, on file at U.S. Geological Survey, Reston, VA.

Ross, S.L., Ryan, H. L., and Stevenson, A. J., 1998, San Gregorio fault zone studies offshore Half Moon Bay and Monterey Bay, CA: Eos (American Geophysical Union, Transactions), v. 79, p. 623.

Ryall, A., VanWormer, J. D., and Jones, A. E., 1968, Triggering of microearthquakes by earth tides, and other features of the Truckee, California, earthquake sequence of September, 1966: Seismological Society of America Bulletin, v. 58, no. 1, p. 215-248.

Rymer, M. J., and Ellsworth, W. L., 1990, The Coalinga, California, Earthquake of May 2, 1983: U. S. Geological Survey, Professional Paper 1487, 417 p.

Rymer, M.J., Kendrick, K.J., Lienkaemper, J.J., and Clark, M.M., 1990a, Surface rupture on the Nunez Fault during the Coalinga earthquake sequence: U.S. Geological Survey Professional Paper 1487, p. 299-318.

Rymer, M.J., Lienkaemper, J.J., and Brown, B., 1990b, Distribution and timing of slip along the Nuñez fault after June 11, 1983: U.S. Geological Survey Professional Paper 1487, p. 319334.

Savage, J.C., Prescott, W.H., Lisowski, M., and King, N., 1979, Geodolite measurements of deformation near Hollister, California, 1971-1978: Journal of Geophysical Research, v. 84, p. 7599-7615.

Savage, J.C., Lisowski, M., and Prescott, W.H., 1992, Strain accumulation across the Wasatch fault near Ogden, Utah: Journal of Geophysical Research, v. 97, no. B2, p. 2071-2083.

Savage, J.C., and Lisowski, M., 1993, Inferred depth of creep on the Hayward fault, central California: Journal of Geophysical Research, v. 98, no. B1, p. 787-793.

Savage, J.C., Lisowski, M., Svarc, J.L., and Gross, W.K., 1995, Strain accumulation across the Central Nevada Seismic Zone, 1973-1994: Journal of Geophysical Research, v. 100, no. B10, p. 20,257-20,269.

SCEC Phase II, 1994, Seismic Hazards in Southern California: Probable Earthquakes, 1994 to 2024 (Phase II): Southern California Earthquake Center, Report.

Schwartz, D.P., and Coppersmith, K.J., 1984, Fault behavior and characteristic earth-quakes: 
Examples from the Wasatch and San Andreas fault zones: , v. 89, p. 5681-5698.

Schwartz, D.P.P., D; Hecker, Suzanne; Okumura, Koji; Budding, Karin E; Powers, T J, 1992, The Rodgers Creek fault zone; fault behavior and earthquake potential: Calif. Div. Mines Geol., Spec. Pub., v. 113, p. 63.

Schwartz, D.P., Pantosti, D., Hecker, S., Okamura, K., Budding, K. E., and Powers, T., 1993, Late Holocene behavior and seismogenic potential of the Rodgers Creek fault zone, Sonoma County, California: California Division of Mines and Geology Special Publication, v. 113, p. 393-398.

Schwartz, D.P., Joyner,W.B., Stein, R.S., Brown, R.D., McGarr, A.F., Hickman, S.H., and Bakun, W.H., 1996, Review of seismic-hazard issues associated with the Auburn Dam project, Sierra Nevada foothills, California: U.S. Geological Survey Open-File Report 9611, p. $\sim 8$ p.

Schwartz, D.P., Pantosti, D., Okumura, K., Powers, T., and Hamilton, J., 1998, Paleoseismic investigations in the Santa Cruz Mountains: Implications for the recurrence of large magnitude earthquakes on the San Andreas Fault: Journal of Geophysical Research, v. 103, p. 17,985-18,001.

Schwartz, D.P., Seitz, G., Lienkaemper, J., Dawson, T., Hecker, S., Lettis, W., and Kelson, K, 2001, The Bay Area Earthquake Cycle: A paleoseismic perspective: Eos (American Geophysical Union, Transactions), v. 82 (47), p. Abstract S12F-07.

Segall, P., and Lisowski, M., 1990, Surface displacements in the 1906 San Francisco and 1989 Loma Prieta earthquakes: Science, v. 250, no. 4985, p. 1241-1244.

Seshadri, V., 1993, The inverse Gaussian distribution : a case study in exponential families: New York, Oxford: Clarendon Press, 256 p.

Shaw, J.H., Bischke, R., and Suppe, J., 1994, Relations between folding and faulting in the Loma Prieta epicentral zone: Strike-slip fault-bend folding: U.S. Geol. Surv. Prof. Paper, v. 1550F, p. F3-F21.

Shimazaki, K., and Nakata, T., 1980, Time-predictable recurrence model for large earthquakes: Geophysical Research Letters, v. 7, p. 279-282.

Sieh, K.E., and Jahns, R.H., 1984, Holocene activity of the San Andreas fault at Wallace Creek, California: Geological Society of America Bulletin, v. 95, p. 883-896.

Sieh, K., Stuiver, M., and Brillinger, D., 1989, A more precise chronology of earthquakes produced by the San Andreas Fault in Southern California: Journal of Geophysical Research, B, Solid Earth and Planets, v. 94, no. 1, p. 603-623.

Simpson, G.D., Lettis, W. R., and Kelson, K. I., 1993, Segmentation model for the northern Calaveras fault, Calaveras Reservoir to Walnut Creek: California Division of Mines and Geology Special Publication, v. 113, p. 253-259.

Simpson, G.D., and Lettis, W.R., 1994, Paleoseismic investigation of the northern Calaveras fault: U.S. Geological Survey Open-File Report 94-176, p. 660-661.

Simpson, G.D., Thompson, S.C., Noller, J.S., Lettis, W.R., and Williams, 1998, The northern San Gregorio fault zone: Evidence for the timing of late Holocene earthquakes near Seal Cove, California: Bulletin Seismological Society of America, v. 87, no. 5, p. 1158-1170.

Simpson, R.W., Lienkaemper, J.J., and Galehouse, J.S., 2001, Variations in creep rate along the 
Hayward Fault, California, interpreted as changes in depth of creep: Geophysical Research Letters, v. 28, no. 11, p. 2269-2272.

Sims, J.D., 1991, Distribution and rate of slip across the San Andreas transform boundary, Hollister area, central California: Geological Society of America Abstracts with Programs, 87th Meeting Cordilleran Section, v. 23, no. 2, p. 98.

Snyder, D.L., Wills, C. J., and Borchardt, G., 1995, Slip rate and earthquake recurrence on the Concord fault at Galindo Creek, Concord, California: USGS-NEHRP contract report, \#1434-94-G2483 [contract report on file at U.S. Geological Survey, Reston, VA, 37 p.].

Sowers, J.M., Noller, J. S., and Unruh, J. R., 1993, Quaternary deformation and blind-thrust faulting on the east flank of the Diablo range near Tracy, California: California Division of Mines and Geology Special Publication, v. 113, p. 377-383.

Stein, R.S., and Ekström, G., 1992, Seismicity and geometry of a 110-km-long blind thrust fault: 2. Synthesis of the 1982-1985 [Coalinga] California earthquake sequence: Journal of Geophysical Research, v. 97, no. B4, p. 4865-4883.

Stein, R.S., and Hanks, T.C., 1998, M=6 earthquakes in southern California during the twentieth century: no evidence for a seismicity or moment: Bulletin Seismological Society of America, v. 88, no. 645-652.

Steinbrugge, K.V., Bennett, J.H., Lagoria, H.J., Davis, J.F., Borchardt, G., and Toppozada. T.R., 1987, Earthquake Planning Scenario for a Magnitude 7.5 Earthquake on the Hayward Fault in the San Francisco Bay Area: C.D.M.G., Spec. Pub., California Division of Mines and Geology, Sacramento, CA, v. 78, 245 p.

Stover, C.W., and Coffman, J.L., 1993, Seismicity of the United States, 1568-1989 (revised): U. S. Geological Survey Professional Paper, Report 1527, 418 p.

Sykes, L.R., and Nishenko, S.P., 1984, Probabilities of occurrence of large plate rupturing earthquakes for the San Andreas, San Jacinto, and Imperial faults, California: Journal of Geophysical Research, v. 89, p. 5905-5927.

Thatcher, W., and Hanks, T.C., 1973, Source parameters of southern California earthquakes: Journal of Geophysical Research, v. 78, no. 35, p. 8547-8576.

Thatcher, W., Marshall, G., and Lisowski, M., 1997, Resolution of fault slip along the 470-kmlong rupture of the great 1906 San Francisco earthquake: Journal of Geophysical Research, v. 102, no. B3, p. 5353-5367.

Tocher, D., 1959, Creep on the San Andreas fault (California): Geological Society of America Bulletin, v. 70, no. 12, Part 2, p. 1753.

Toppozada, T.R., Borchardt, G., Hallstrom, C. L., and Youngs, L. G., 1993, Planning scenario for a major earthquake on the Hayward fault: California Division of Mines and Geology Special Publication, v. 113, p. 457-462.

Toppozada, T.R., and Borchardt, G., 1998, Re-evaluation of the 1836 "Hayward Fault" earthquake and the 1838 San Andreas Fault earthquake: Seismological Society of America Bulletin, v. 88, p. 140-159.

Toppozada, T., and Branum, D., 2001, Historical San Francisco Bay earthquakes and post-1989 quiescence (abstract): Seimological Research Letters, v. 72, no. 2, p. 227.

Toppozada T.R., B., G., Hallstrom, C.L., and Youngs. L.G.,, Planning Scenario for a Major 
Earthquake on the Rodgers Creek Fault in the Northern San Francisco Bay Area: Calif. Div. Mines \& Geol., Special Publication 112, California Division of Mines and Geology, Sacramento, CA, v. 112, 263 p.

Tuttle, M., and Sykes, L., 1993, Re-evaluation of the 1838, 1865, 1868, and 1890 earthquakes in the San Francisco Bay area: California Division of Mines and Geology Special Publication, v. 113, p. 81-89.

Unruh, J.R., and Moores, E. M., 1992, Quaternary blind thrusting in the southwestern Sacramento Valley, California: Tectonics, v. 11, no. 2, p. 192-203.

Unruh, J.R., Loewen, B. A., and Moores, E. M., 1995a, Progressive arcward contraction of a Mesozoic-Tertiary fore-arc basin, southwestern Sacramento Valley, California: Geological Society of America Bulletin, v. 107, no. 1, p. 38-53.

Unruh, J.R., Simpson, G. D., Hitchcock, C. S., and Lettis, W. R. [of W. R. Lettis and Associates], 1995b, Seismotectonic evaluation, Stony Gorge and East Park Dams, Orland Project, northern Coast Ranges, California: Draft report prepared for U.S. Bureau of Reclamation, $170 \mathrm{p}$.

Unruh, J., 2001, Seismic hazards associated with blind thrusts in the San Francisco Bay area: Calif. Geol. Surv. Bull., v. 210, p. 211-228.

Utsu, T., Aftershocks and earthquake statistics (IV): Journal of the Faculty of Science, Hokkaido University Series VII (Geophysics), v. 4, p. 1-42, 1972.

Utsu, T., Estimation of parameters for recurrence models of earthquakes: Bulletin of the Earthquake Research Institute, University of Tokyo, v. 59, p. 53-66, 1984.

Wakabayashi, J., and Smith, D. L., 1994, Evaluation of recurrence intervals, characteristic earthquakes, and slip rates associated with thrusting along the Coast Range-Central Valley geomorphic boundary, California: Seismological Society of America Bulletin, v. 84, no. 6, p. 1960-1970.

Wald, D.J., Heaton, S. H., and Helmberger, D. V., 1991, Rupture model of the 1989 Loma Prieta earthquake from the inversion of strong motion and broadband teleseismic data: Seismological Society of America Bulletin, v. 91, p. 1540-1572.

Wald, D.J., Quitoriano, V., Heaton, T.H., Kanamori, H., Scrivner, C.W., and Worden, C.B., 1999, TriNet "ShakeMaps": rapid generation of instrumental ground motion and intensity maps for earthquakes in southern California: Earthquake Spectra, v. 15, no. 3, p. 537-556.

Wald, D.J., Quitoriano, V., Heaton, T.H., and Kanamori, H., 1999, Relationships between peak ground acceleration, peak ground velocity and Modified Mercalli Intensity in California: Earthquake Spectra, v. 15, no. 3, p. 557-564.

Waldhauser, F., and Ellsworth, W.L., 2000, A double-difference earthquake location algorithm; method and application to the northern Hayward Fault, California: Bulletin of the Seismological Society of America, v. 90, no. 6, p. 1353-1368.

Walter, S.R., Oppenheimer, D.H., and Mandel, R.I., 1998, Seismicity Maps of the San Francisco and San Jose 1degree by 2degree Quadrangles, California for the period 1967-1993: U.S. Geol. Surv. Geologic Invest. Series, v. Map I-2580.

Ward, S.N., 1990, Pacific-North America Plate Motions_-New results from Very Long Baseline Interferometry: Journal of Geophysical Research, v. 95, no. B13, p. 21,965-21,981. 
Ward, S.N., 2000, San Francisco Bay Area earthquake simulations: a step toward a standard physical earthquake model: Bulletin of the Seismological Society of America, v. 90, p. 370386.

Weber, G.E., 1981, Geologic investigation of the marine terraces of the San Simeon region and Pleistocene activity on the San Simeon fault zone, San Luis Obispo County, California: USGS-NEHRP contract report, \#14-08-0001-18230, on file at U.S. Geological Survey, Reston, VA; 66 pp.

Weber, G.E., and Nolan, J. M., 1995, Determination of late Pleistocene-Holocene slip rates along the San Gregorio fault zone, San Mateo County, California: U.S. Geological Survey OpenFile Report 95-210, p. 805-807.

Wells, R.E., 1990, Paleomagnetic rotations and the Cenozoic tectonics of the Cascade Arc, Washington, Oregon, and California: Journal of Geophysical Research, v. 95, no. B12, p. 19,409-19,417.

Wells, D.L., and Coppersmith, K. J., 1994, New empirical relationships among magnitude, rupture length, rupture width, rupture area, and surface displacement: Seismological Society of America Bulletin, v. 84, no. 4, p. 974-1002.

Wesson, R.L., Bakun, W.H., Uhrhammer, R.A., Oppenheimer, D.H., and Perkins, D.M., 1999, Application of Bayesian inference to the association of earthquakes and faults in the San Francisco Bay Region: Seismological Research Letters, v. 70, no. 2, p. 270.

Wesson, R.L., Bakun, W.H., and Perkins, D.A., 2002, Associating Earthquakes with Faults in the San Francisco Bay Area using Bayesian Inference: preprint.

Williams, P.L., 1993, Geologic record of southern Hayward fault earthquakes: California Division of Mines and Geology Special Publication, v. 113, p. 171-179.

Williams, P.L., Anima, R. , Ingram, L., McCarthy, J., McEvilly, T. V., Nakata, T. , Okamura, M., and Shimazaki, K., 1997, Geometry and Holocene activity of the Pinole and southernmost Rodgers Creek faults, San Pablo Bay, California: Geological Society of America Bulletin [preprint, in review].

Williams, P.L., 1999, Strawberry Creek slip rate (Hayward fault slip rate constrains at Berkeley [CA]), in Contributions to Working Group on California Earthquake Probabilities May 28, 1999 Workshop, U.S. Geological Survey, Menlo Park, CA, U.S. Geological Survey, Menlo Park, CA (unpublished handout to participants), p. 4.

Wills, C.J., and Borchardt, G., 1993, Holocene slip rate and earthquake recurrence on the Honey Lake fault zone, northeastern California: Geology, v. 21, no. 9, p. 853-856.

Wong, I.G., and Hemphill-Haley, M.A., 1993, Seismicity and faulting near the Hayward and Mission faults: California Division of Mines and Geology Special Publication, v. 113, p. 207-215.

Wood, H.O., and Neumann, F., 1931, Modified Mercalli Intensity Scale of 1931, , .. , v. 21, p. 277-283.

Working Group on California Earthquake Probabilities, 1988, Probabilities of large earthquakes occurring in California on the San Andreas fault, U.S. Geological Survey Open-File Report, p. 62.

Working Group on California Earthquake Probabilities, 1990, Probabilities of large earthquakes 
in the San Francisco Bay Region, California, U.S. Geological Survey Circular, p. 51.

Working Group on California Earthquake Probabilities (Jackson, D. D.; Aki, K.; Cornell, C. A.; Dieterich, J, H.; Henyey, T. L.; Mahdyiar, M.; Schwartz, D.; Ward, S. N.),1995, Seismic hazards in southern California: probable earthquakes, 1994-2024: Bulletin Seismological Society of America, v. 85, p. 379-439.

Working Group on California Earthquake Probabilities, 1999, Earthquake probabilities in the San Francisco Bay Region: 2000-2030_A Summary of findings: U.S. Geological Survey Open-File Report 99-517, p. 55 p. [http://geopubs.wr.usgs.gov/open-file/of99-517/].

Working Group on Northern California Earthquake Potential, 1996, Database of potential sources for earthquakes larger than magnitude 6 in northern California: U.S. Geological Survey Open-File Report 96-705, p. 53 p. [http://quake.wr.usgs.gov:80/hazprep/NCEP/].

Wright, R.H., Hamilton, D. H., Hunt, T. D., Traubenik, M. L., and Shlemon, R. J., 1982 , Character and activity of the Greenville structural trend: California Division of Mines and Geology Special Publication, v. 62, p. 187-196.

Youngs, R.R.C., Kevin J, 1985, Implications of fault slip rates and earthquake recurrence models to probabilistic seismic hazard estimates: Bull. Seis. Soc. Amer., v. 75, p. 939-964.

Yu, E., and Segall, P., 1996, Slip in the 1868 Hayward earthquake from the analysis of historical triangulation data: Journal of Geophysical Research, v. 101, no. B7, p. 16,101-16,118.

Zoback, M.L., Jachens, R. C., and Olson, J. A., 1999, Abrupt along-strike change in tectonic style: San Andreas fault zone, San Francisco Peninsula: Journal of Geophysical Research, v. 104, p. 10719-10742. 